\title{
Investigation of the transverse and longitudinal moments at the transverse free end of deck slab cantilevers subjected to CHBDC truck loading
}

by

\author{
Hanieh Pourmand \\ Continuous Master's Degree in Architectural Engineering, \\ Islamic Azad University \\ Tehran, Iran, 2004
}

\begin{abstract}
A thesis
presented to Ryerson University

in partial fulfillment of the

requirement for the degree of

Master of Applied Science

in the program of Civil Engineering
\end{abstract}

Toronto, Ontario, Canada, 2017

CHanieh Pourmand 2017 


\section{AUTHOR'S DECLARATION}

I hereby declare that I am the sole author of this thesis. This is a true copy of the thesis, including any required final revisions, as accepted by my examiners.

I authorize Ryerson University to lend this document to other institutions or individuals for the purpose of scholarly research.

I further authorize Ryerson University to reproduce the document by photocopying or by other means, in total or part, at the request of other institutions or individuals for the purpose of scholarly research.

I understand that my thesis may be made electronically available to the public 


\title{
Investigation of the transverse and longitudinal moments at the transverse free end of deck slab cantilevers subjected to CHBDC truck loading
}

\author{
By \\ Hanieh Pourmand \\ Master of Applied Science \\ Civil Engineering, Ryerson University, 2017
}

\begin{abstract}
Clause 5.7.1.3 of the Canadian Highway Bridge Design Code (CHBDC) specifies an equation for the calculation of transverse moment intensity $\left(\mathrm{M}_{\mathrm{y}}\right)$ in the deck slab cantilever due to truck loading in a slab-on-girder bridge system. Also, it states that the transverse moment intensity shall be assumed $2 \mathrm{M}_{\mathrm{y}}$ for the locations within a distance equal to cantilever length of the transverse free end of the deck slab cantilever. However, CHBDC design values do not consider the effects of barrier length, variable thickness of the barrier wall and shape of the cantilever's edge stiffening on the response. In addition, the longitudinal moment on the deck slab cantilever due to truck loading is as yet unavailable. Thus, a parametric study was conducted, using the finite element modelling, to investigate the effect of these key parameters in the transverse and longitudinal moments at the region of the transverse free edge of deck slab cantilever. Based on the data generated from this parametric study, imperial equations for the transverse and longitudinal moments at the transverse end of the deck slab cantilever were deduced.
\end{abstract}




\section{ACKNOWLEGEMENT}

I would first like to take this opportunity to express my deepest gratitude and special thanks to my supervisor Dr. Sennah who has supported me throughout my thesis with his patience, knowledge, invaluable guidance, comments, and suggestions. It is with great excitement that I look forward to working with Dr. Sennah at the Ph.D. level.

I would also like to express my appreciation to my husband for the invaluable help, continuous support and encouragement he provides not just during my study, but all over my life.

Finally, the financial support from V-rod Canada Inc. and Ryerson University is greatly acknowledged. 


\section{TABLE OF CONTENTS}

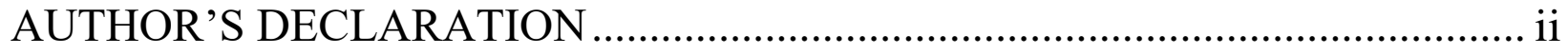

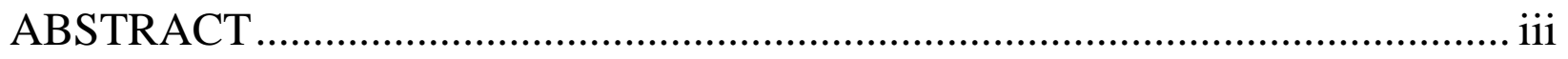

ACKNOWLEGEMENT ................................................................................... iv

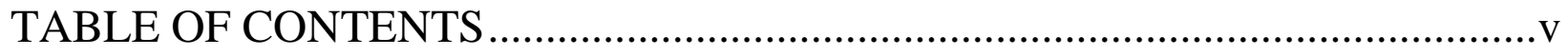

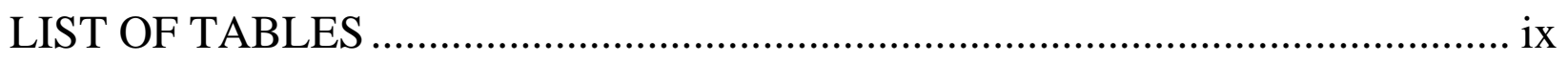

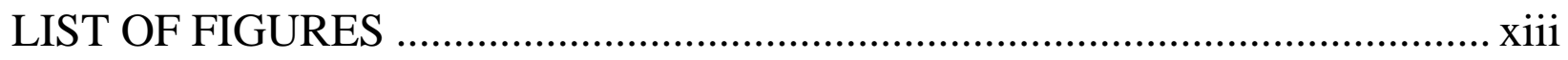

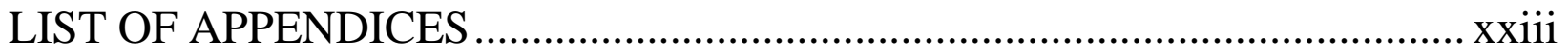

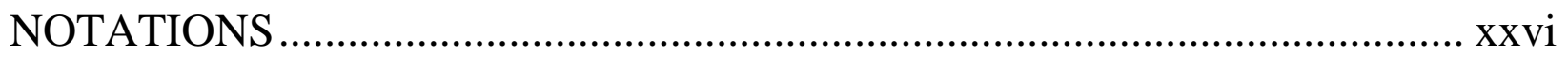

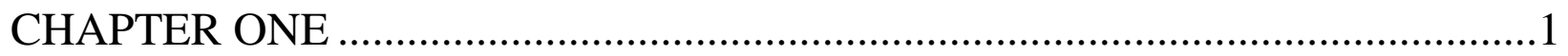

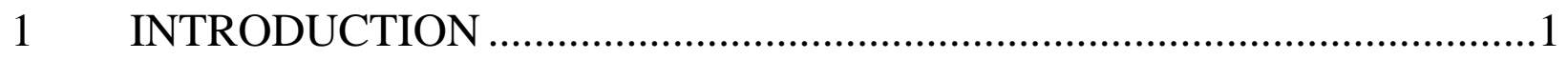

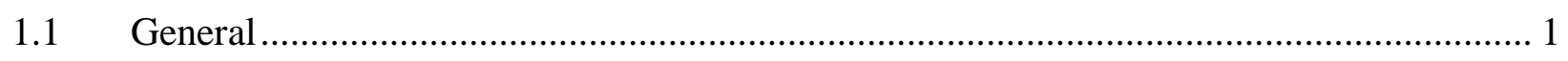

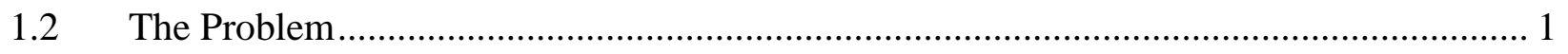

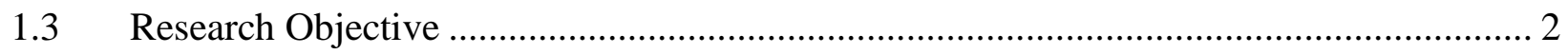

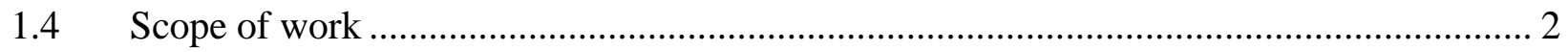

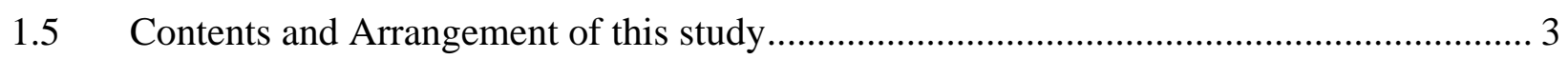

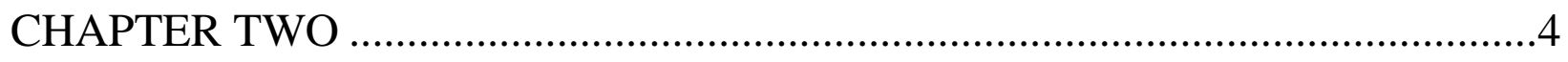

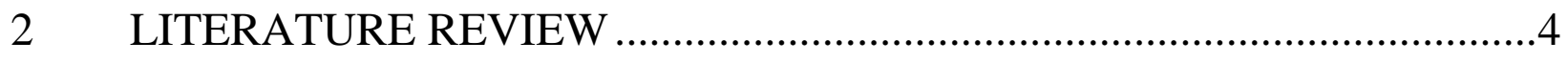

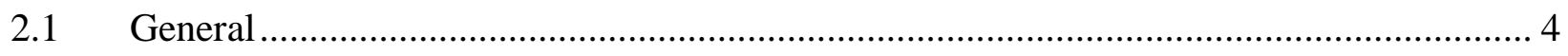

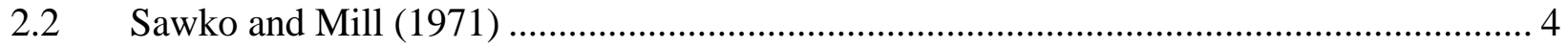

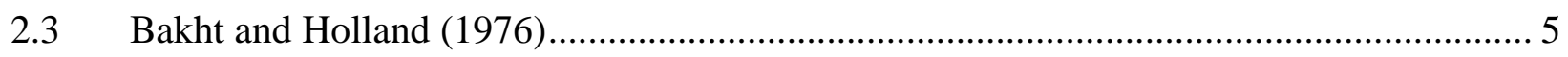

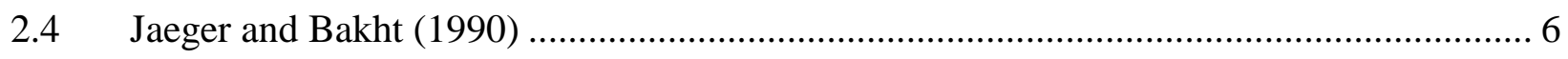

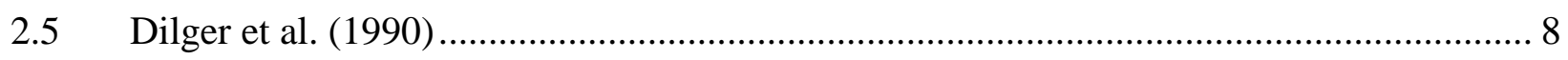

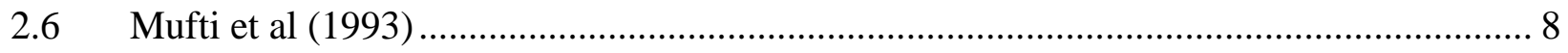




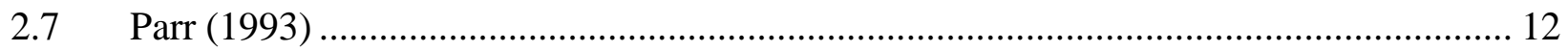

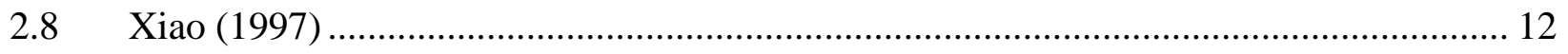

2.9 Canadian Highway Bridge Design Code Provision.......................................................... 12

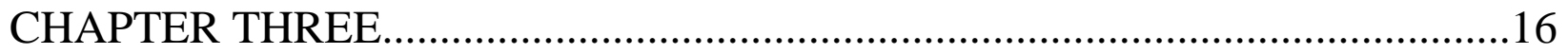

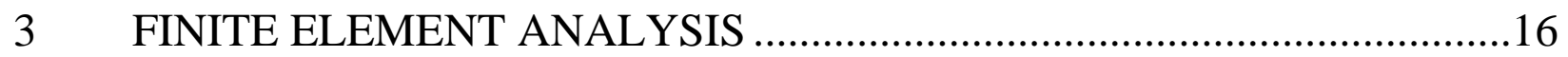

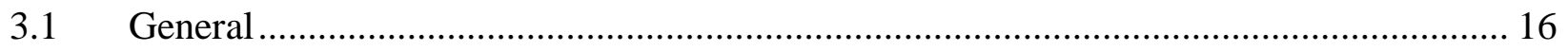

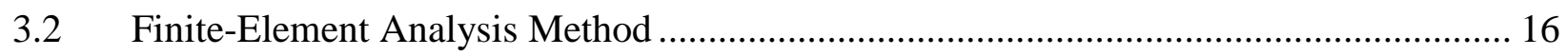

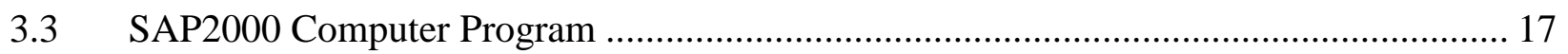

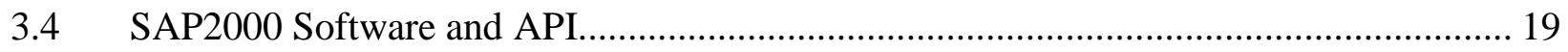

3.5 Finite Element Modelling of Deck Slab Overhang.......................................................... 20

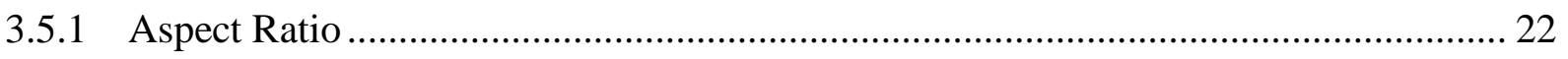

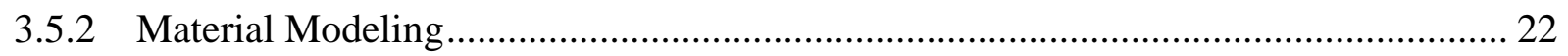

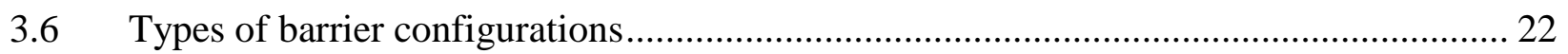

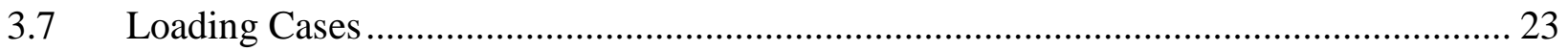

3.8 Dynamic Load Allowances ......................................................................................... 27

3.9 Sensitivity Study on Location of Maximum Transverse and Longitudinal Moment in the Cantilever Slab.................................................................................................. 27

3.10 Sensitivity study for Effect of Thickness of Barrier on the Response ............................. 37

3.10.1 Analysis of Transverse Moment ………………..................................................... 38

3.10.2 Analysis of Longitudinal Moment ............................................................................ 41

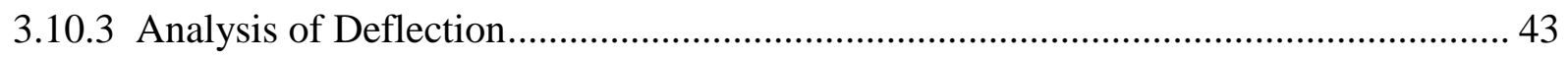

3.11 Sensitivity Study on Ratio of External Transverse Moment to Internal Transverse

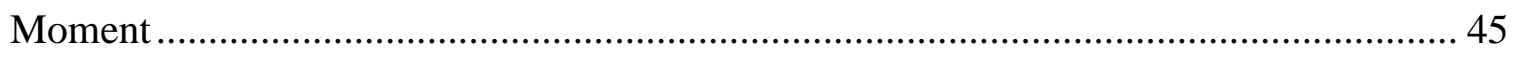

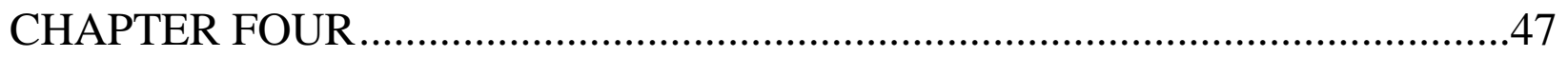

$4 \quad$ RESULTS FROM PARAMETRIC STUDY ….........................................47

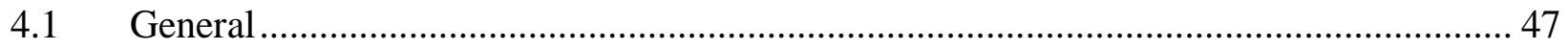

4.2 Cantilever-Barrier Arrangements for parametric study ................................................. 47 


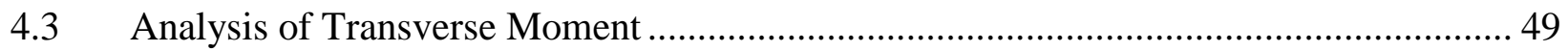

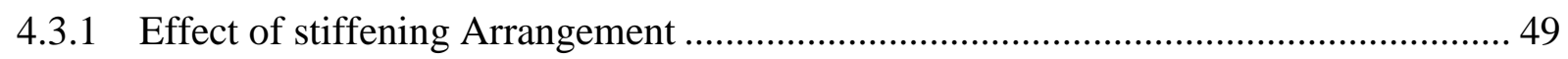

4.3.2 Effect of Barrier Length .......................................................................................... 49

4.3.3 Effect of slab thickness for various tapered slab thickness ratio ................................ 52

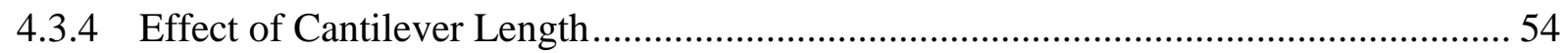

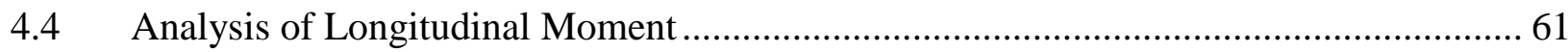

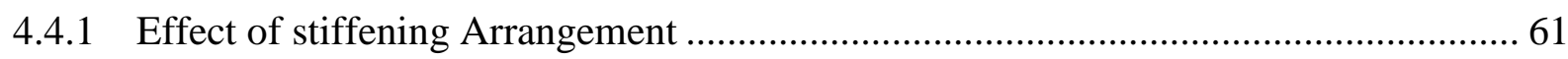

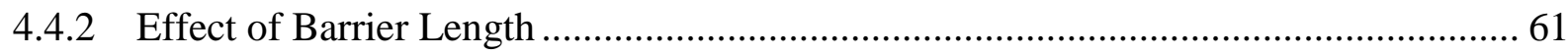

4.4.3 Effect of slab thickness for various thickness ratio..................................................... 64

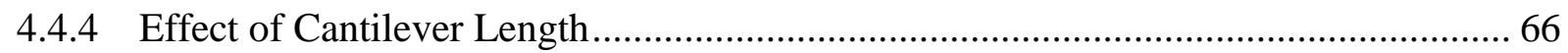

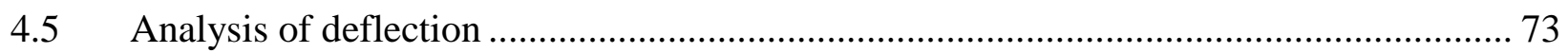

4.5.1 Effect of stiffening Arrangement …………………............................................ 73

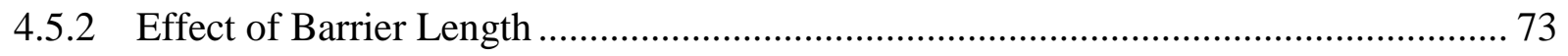

4.5.3 Effect of slab thickness for various thickness ratio..................................................... 76

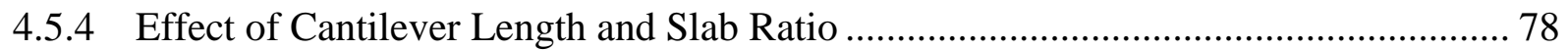

4.6 Results comparison with CHBDC and previous research's works.................................. 85

4.7 Comparison between results for external moments from this research with internal moments from Micovic results ............................................................................... 87

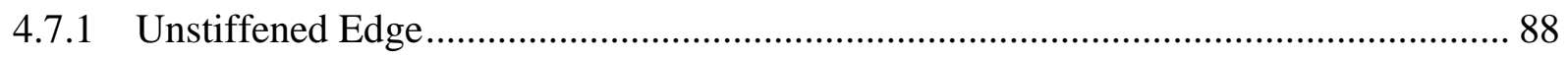

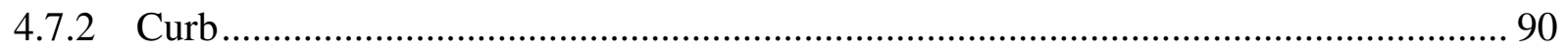

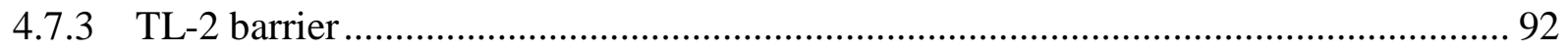

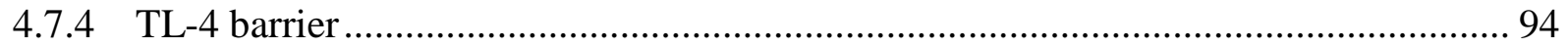

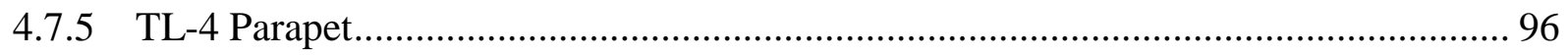

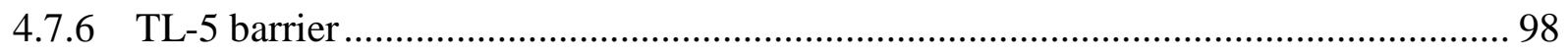

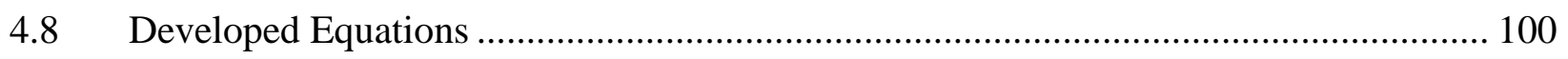

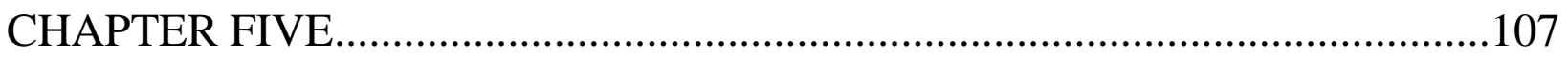




\section{CONCLUSIONS AND RECOMMENDATIONS FOR FUTURE}

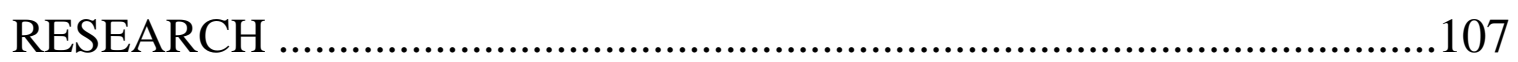

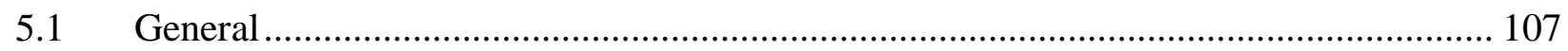

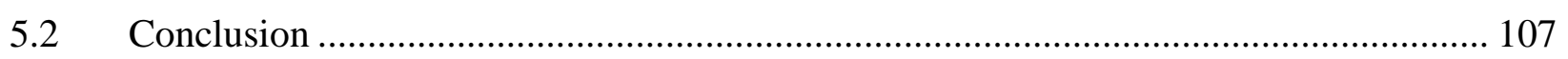

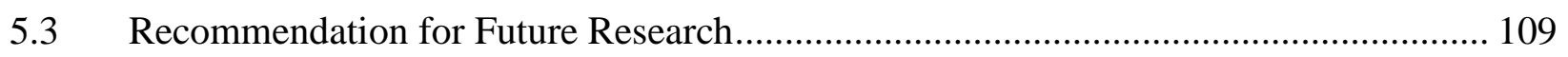

Appendix (A): Summary of Parametric Study .................................................110

Appendix (B): Sample Code of SAP2000 API ...................................................183

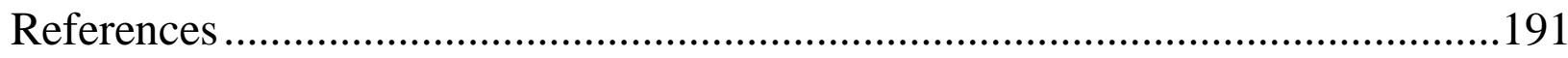




\section{LIST OF TABLES}

Table 2-1: Maximum cantilever moments due to CL-625 loading condition included dynamic

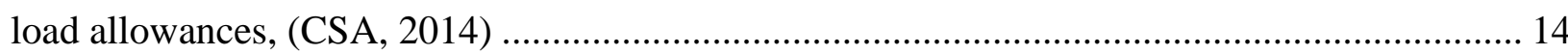

Table 3-1: Dynamic load allowance per CHBDC (2014) ....................................................... 27

Table 3-2: Range of Parameters considers for studying the effect of barrier thickness ................ 37

Table 3-3: Results of sensitivity study on external to internal moment ratio ................................ 46

Table 4-1: Range of parameters considered in this study ............................................................ 48

Table 4-2: Effect of stiffening arrangement on transverse moment ........................................... 49

Table 4-3: Effect of barrier length on transverse moment of slab cantilever with unstiffened edge

Table 4-4: Effect of barrier length on transverse moment for slab cantilever with a curb 50

Table 4-5: Effect of barrier length on transverse moment for slab cantilever with TL-2 barriers 50

Table 4-6: Effect of barrier length on transverse moment for slab cantilever with TL-4 barriers 51

Table 4-7: Effect of barrier length on transverse moment for slab cantilever with TL-4 parapet 51

Table 4-8: Effect of barrier length on transverse moment for slab cantilever with TL-5 barrier. 51

Table 4-9: Effect of slab thickness on transverse moment for slab cantilever with unstiffened

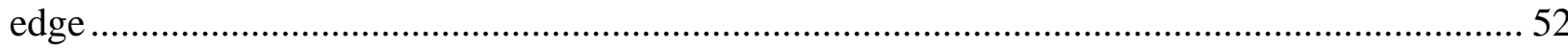

Table 4-10: Effect of slab thickness on transverse moment for slab cantilever with a curb ........ 52 
Table 4-11: Effect of slab thickness on transverse moment for slab cantilever with TL-2 barrier

Table 4-12: Effect of slab thickness on transverse moment for slab cantilever with TL-4 barrier

Table 4-13: Effect of slab thickness on transverse moment for slab cantilever with TL-4 parapet

Table 4-14: Effect of slab thickness on transverse moment for slab cantilever with TL-4 parapet

Table 4-15: Effect of stiffening arrangement on longitudinal moment

Table 4-16: Effect of barrier length on longitudinal moment for slab cantilever with unstiffened edge

Table 4-17: Effect of barrier length on longitudinal moment for slab cantilever with a curb ..... 62

Table 4-18: Effect of barrier length on longitudinal moment for slab cantilever with TL-2 barrier 62

Table 4-19: Effect of barrier length on longitudinal moment for slab cantilever with TL-4 barrier

Table 4-20: Effect of barrier length on longitudinal moment for slab cantilever with TL-4 parapet

Table 4-21: Effect of barrier length on longitudinal moment for slab cantilever with TL-5 barrier

Table 4-22: Effect of slab thickness on longitudinal moment for slab cantilever with unstiffened edge. 64 
Table 4-23: Effect of slab thickness on longitudinal moment for slab cantilever with a curb ..... 64

Table 4-24: Effect of slab thickness on longitudinal moment for slab cantilever with TL-2 barrier

Table 4-25: Effect of slab thickness on longitudinal moment for slab cantilever with TL-4 barrier 65

Table 4-26: Effect of slab thickness on longitudinal moment for slab cantilever with TL-4 parapet.......

Table 4-27: Effect of slab thickness on longitudinal moment for slab cantilever with TL-5 barrier 66

Table 4-28: Effect of stiffening arrangement on deflection 73

Table 4-29: Effect of barrier length on deflection for slab cantilever with unstiffened edge....... 74

Table 4-30: Effect of barrier length on deflection for slab cantilever with a curb 74

Table 4-31: Effect of barrier length on deflection for slab cantilever with TL-2 barrier 74

Table 4-32: Effect of barrier length on deflection for slab cantilever with TL-4 barrier 75

Table 4-33: Effect of barrier length on deflection for slab cantilever with TL-4 parapet 75

Table 4-34: Effect of barrier length on deflection for slab cantilever with TL-5 barrier 75

Table 4-35: Effect of slab thickness on deflection for slab cantilever with unstiffened edge ...... 76

Table 4-36: Effect of slab thickness on deflection for slab cantilever with a curb. 76

Table 4-37: Effect of slab thickness on deflection for slab cantilever with TL-2 barrier. 76 
Table 4-38: Effect of slab thickness on deflection for slab cantilever with TL-4 barrier.

Table 4-39: Effect of slab thickness on deflection for slab cantilever with TL-4 parapet........... 77

Table 4-40: Effect of slab thickness on deflection for slab cantilever with TL-5 barrier

Table 4-41: Maximum cantilever slab transverse moment $\left(\mathrm{M}_{\mathrm{y}}\right)$ due to unfactored CL- 625 truck wheel loads ( $\mathrm{I}_{\mathrm{D}}$ included) for slabs with unstiffened edge.

Table 4-42: Percentage difference between results from this research with CHDBC and Micovic's results.

Table 4-43: Empirical equations for transverse and longitudinal moments in deck slab cantilevers due to CL-625 truck loading... 101 


\section{LIST OF FIGURES}

Figure 2-1: Notation employed by Sawko and Mills. (Adopted from (Xiao, 1997)) 5

Figure 2-2: Values of A' for various thickness ratio (Adapted from Bakht and Holland, 1976) .... 6

Figure 2-3: Notation for deck slab overhang. (Adapted from (Jaeger \& Bakht, 1990)). 7

Figure 2-4: Partial cross section of bridge demonstrating bending moment reinforcement in deck slab overhang and internal panel of deck slab, (Adapted from Mufti et al, (1993)) ....................... 8

Figure 2-5: (a) Boundary condition assumption for internal deck slab. (b) Notation for cantilever slab and internal panel. (Adapted from Mufti et al, (1993)) ......................................................... 9

Figure 2-6: Evolution of various method; (adapted from Parr, (1993)) ……………………....... 11

Figure 2-7: Notation for cantilever slab (CSA, 2014) ............................................................. 14

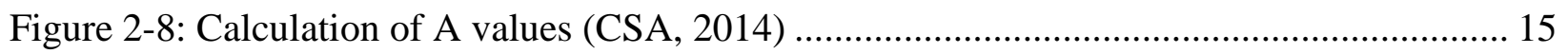

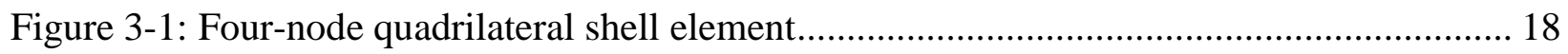

Figure 3-2: Internal moment sign convention at local coordinate of shell element...................... 19

Figure 3-3: Schematic diagram of the FEA modeling showing the centerline approach for modeling the edge-stiffened cantilever slab

Figure 3-4: Schematic Diagram showing varying thickness of the cantilever slab modeling ...... 21

Figure 3-5: Schematic diagram showing the tapered barrier wall with $50 \mathrm{~mm}$ length of finite elements of equal average width for each segment of the barrier height 
Figure 3-6: Barrier configurations considered in this study

Figure 3-7: (a) CL-W truck loading, (b) CL-W truck (CSA, 2014a) ...................................... 25

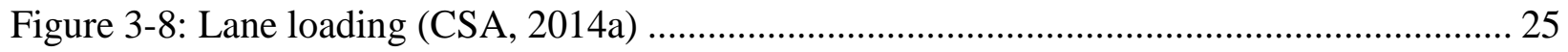

Figure 3-9: Location of the applied load beside the inner side of the barrier wall and the centreline of the FE modeling. 25

Figure 3-10: Plan views of the deck slab cantilever with different loading cases 26

Figure 3-11: Coordinate origin $(0,0)$ located at corner of transverse free end (where axel load applied) and longitudinal free edge of cantilever slab

Figure 3-12: Transverse moment versus barrier length due to axle 4 loading on unstiffened cantilever slab of $1.5 \mathrm{~m}$ length

Figure 3-13: Transverse moment versus barrier length due to axles 2 and 3 on the unstiffened cantilever slab of $1.5 \mathrm{~m}$ length

Figure 3-14: Transverse moment versus barrier length due to axles 1, 2, 3 and 4 on the unstiffened cantilever slab of $1.5 \mathrm{~m}$ length 30

Figure 3-15: Transverse moment versus barrier length due to full truck loading with 5 axles on the unstiffened cantilever slab of $1.5 \mathrm{~m}$ length

Figure 3-16: Longitudinal moment versus barrier length due to axle 4 on the unstiffened cantilever slab of $1.5 \mathrm{~m}$ length

Figure 3-17: Longitudinal moment versus barrier length due to axles 2 and 3 on the unstiffened cantilever slab of $1.5 \mathrm{~m}$ length 
Figure 3-18: Longitudinal moment versus barrier length due to axles 1, 2, 3 and 4 on the unstiffened cantilever slab of $1.5 \mathrm{~m}$ length

Figure 3-19: Longitudinal moment versus barrier length due to full truck loading with 5 axles on the unstiffened cantilever slab of $1.5 \mathrm{~m}$ length

Figure 3-20: Transverse moment versus barrier length due to axle 4 for the stiffened cantilever slab of $1.5 \mathrm{~m}$ length 33

Figure 3-21: Transverse moment versus barrier length due to axles 2 and 3 on the stiffened cantilever slab of $1.5 \mathrm{~m}$ length

Figure 3-22: Transverse moment versus barrier length due to axles 1, 2, 3 and 4 on stiffened cantilever slab of $1.5 \mathrm{~m}$ length 34

Figure 3-23: Transverse moment versus barrier length due to full truck loading with 5 axles on stiffened cantilever slab of $1.5 \mathrm{~m}$ length

Figure 3-24: Longitudinal moment versus barrier length due to axle 4 on stiffened cantilever slab of $1.5 \mathrm{~m}$ length 35

Figure 3-25: Longitudinal moment versus barrier length due to axles 2 and 3 on the stiffened cantilever slab of $1.5 \mathrm{~m}$ length

Figure 3-26: Longitudinal moment versus barrier length due to axles 1, 2, 3 and 4 on stiffened cantilever slab of $1.5 \mathrm{~m}$ length 36

Figure 3-27: Longitudinal moment versus barrier length due to full truck loading with 5 axles on stiffened cantilever slab of $1.5 \mathrm{~m}$ length 36

Figure 3-28: Notation used in Table 3-2 37 
Figure 3-29: Maximum transverse moment versus ratio of $\mathrm{I}_{\mathrm{B}} / \mathrm{I}_{\mathrm{S}}$ for slab cantilever with TL-2

barrier

Figure 3-30: Maximum transverse moment versus ratio of $\mathrm{I}_{\mathrm{B}} / \mathrm{I}_{\mathrm{S}}$ for slab cantilever with TL-4

barrier

Figure 3-31: Maximum transverse moment versus ratio of $\mathrm{I}_{\mathrm{B}} / \mathrm{I}_{\mathrm{S}}$ for slab cantilever with TL-4 parapet

Figure 3-32: Maximum transverse moment versus ratio of $\mathrm{I}_{\mathrm{B}} / \mathrm{I}_{\mathrm{S}}$ for slab cantilever with TL-5

barrier

Figure 3-33: Maximum longitudinal moment versus ratio of IB/IS for slab cantilever with TL-2

barrier 41

Figure 3-34: Maximum longitudinal moment versus ratio of IB/IS for slab cantilever with TL-4 barrier 41

Figure 3-35: Maximum longitudinal moment versus ratio of $\mathrm{I}_{\mathrm{B}} / \mathrm{I}_{\mathrm{S}}$ for slab cantilever with TL-4 parapet

Figure 3-36: Maximum longitudinal moment versus ratio of IB/IS for slab cantilever with TL-5

barrier 42

Figure 3-37: Maximum deflection versus ratio of $\mathrm{I}_{\mathrm{B}} / \mathrm{I}_{\mathrm{S}}$ for slab cantilever with TL-2 barrier ..... 43

Figure 3-38: Maximum deflection versus ratio of $\mathrm{I}_{\mathrm{B}} / \mathrm{I}_{\mathrm{S}}$ for slab cantilever with TL-4 barrier ..... 43

Figure 3-39: Maximum deflection versus ratio of $\mathrm{I}_{\mathrm{B}} / \mathrm{I}_{\mathrm{S}}$ for slab cantilever with TL-4 parapet .... 44

Figure 3-40: Maximum deflection versus ratio of $\mathrm{I}_{\mathrm{B}} / \mathrm{I}_{\mathrm{S}}$ for slab cantilever with TL-5 barrier ..... 44

Figure 4-1: (a) Notation used for the cantilever overhang (b) 3D viewing of cantilever slab...... 48 
Figure 4-2: Effect of cantilever length on transverse moment for slab cantilever with unstiffened edge 55

Figure 4-3: Effect of cantilever length on transverse moment for slab cantilever with a curb..... 55

Figure 4-4: Effect of cantilever length on transverse moment for slab cantilever with TL-2 barrier 56

Figure 4-5: Effect of cantilever length on transverse moment for slab cantilever with TL-4 barrier 56

Figure 4-6: Effect of cantilever length on transverse moment for slab cantilever with TL-4

parapet 57

Figure 4-7: Effect of cantilever length on transverse moment for slab cantilever with TL-5 barrier

Figure 4-8: Effect of tapered slab thickness ratio on transverse moment for slab cantilever with unstiffened edge $\left(\mathrm{L}_{b}=12 \mathrm{~m}, \mathrm{~L}_{\mathrm{c}}=1.5 \mathrm{~m}, \mathrm{t}_{1}=200 \mathrm{~mm}\right)$. 58

Figure 4-9: Effect of tapered slab thickness ratio on transverse moment for slab cantilever with a $\operatorname{curb}\left(\mathrm{L}_{\mathrm{b}}=12 \mathrm{~m}, \mathrm{~L}_{\mathrm{c}}=1.5 \mathrm{~m}, \mathrm{t}_{1}=200 \mathrm{~mm}\right)$....... 58

Figure 4-10: Effect of tapered slab thickness ratio on transverse moment for slab cantilever with TL-2 barriers $\left(\mathrm{L}_{\mathrm{b}}=12 \mathrm{~m}, \mathrm{~L}_{\mathrm{c}}=1.5 \mathrm{~m}, \mathrm{t}_{1}=200 \mathrm{~mm}\right)$. 59

Figure 4-11: Effect of tapered slab thickness ratio on transverse moment for slab cantilever with TL-4 barrier $\left(\mathrm{L}_{b}=12 \mathrm{~m}, \mathrm{~L}_{\mathrm{c}}=1.5 \mathrm{~m}, \mathrm{t}_{1}=200 \mathrm{~mm}\right)$ 59

Figure 4-12: Effect of tapered slab thickness ratio on transverse moment for slab cantilever with TL-4 parapet $\left(\mathrm{L}_{\mathrm{b}}=12 \mathrm{~m}, \mathrm{~L}_{\mathrm{c}}=1.5 \mathrm{~m}, \mathrm{t}_{1}=200 \mathrm{~mm}\right)$ 60 
Figure 4-13: Effect of tapered slab thickness ratio on transverse moment for slab cantilever with TL-5 barrier $\left(\mathrm{L}_{b}=12 \mathrm{~m}, \mathrm{~L}_{\mathrm{c}}=1.5 \mathrm{~m}, \mathrm{t}_{1}=200 \mathrm{~mm}\right)$ 60

Figure 4-14: Effect of cantilever length on longitudinal moment for slab cantilever with unstiffened edge

Figure 4-15: Effect of cantilever length on longitudinal moment for slab cantilever with a curb 67

Figure 4-16: Effect of cantilever length on longitudinal moment for slab cantilever with TL-2 barrier

Figure 4-17: Effect of cantilever length on longitudinal moment for slab cantilever with TL-4 barrier 68

Figure 4-18: Effect of cantilever length on longitudinal moment for slab cantilever with TL-4 parapet

Figure 4-19: Effect of cantilever length on longitudinal moment for slab cantilever with TL-5 barrier

Figure 4-20: Effect of tapered slab thickness ratio on longitudinal moment for slab cantilever with unstiffened edge $\left(\mathrm{L}_{\mathrm{b}}=12 \mathrm{~m}, \mathrm{~L}_{\mathrm{c}}=1.5 \mathrm{~m}, \mathrm{t}_{1}=200 \mathrm{~mm}\right)$.

Figure 4-21: Effect of tapered slab thickness ratio on longitudinal moment of slab cantilever with $\operatorname{a~curb}\left(\mathrm{L}_{b}=12 \mathrm{~m}, \mathrm{~L}_{\mathrm{c}}=1.5 \mathrm{~m}, \mathrm{t}_{1}=200 \mathrm{~mm}\right)$. 70

Figure 4-22: Effect of tapered slab thickness ratio on longitudinal moment for slab cantilever with TL-2 barrier $\left(\mathrm{L}_{\mathrm{b}}=12 \mathrm{~m}, \mathrm{~L}_{\mathrm{c}}=1.5 \mathrm{~m}, \mathrm{t}_{1}=200 \mathrm{~mm}\right)$

Figure 4-23: Effect of tapered slab thickness ratio on longitudinal moment for slab cantilever with TL-4 barrier $\left(\mathrm{L}_{\mathrm{b}}=12 \mathrm{~m}, \mathrm{~L}_{\mathrm{c}}=1.5 \mathrm{~m}, \mathrm{t}_{1}=200 \mathrm{~mm}\right)$ 71 
Figure 4-24: Effect of tapered slab thickness ratio on longitudinal moment for slab cantilever with TL-4 parapet $\left(\mathrm{L}_{b}=12 \mathrm{~m}, \mathrm{~L}_{\mathrm{c}}=1.5 \mathrm{~m}, \mathrm{t}_{1}=200 \mathrm{~mm}\right)$

Figure 4-25: Effect of slab ratio on longitudinal moment for slab cantilever with TL-5 barrier ( $\mathrm{L}_{b}$ $\left.=12 \mathrm{~m}, \mathrm{~L}_{\mathrm{c}}=1.5 \mathrm{~m}, \mathrm{t}_{1}=200 \mathrm{~mm}\right)$. 72

Figure 4-26: Effect of cantilever length on deflection for slab cantilever with unstiffened edge 78

Figure 4-27: Effect of cantilever length on deflection for slab cantilever with a curb 79

Figure 4-28: Effect of cantilever length on deflection for slab cantilever with TL-2 barrier. 79

Figure 4-29: Effect of cantilever length on deflection for slab cantilever with TL-4 barrier....... 80

Figure 4-30: Effect of cantilever length on deflection for slab cantilever with TL-4 parapet...... 80

Figure 4-31: Effect of cantilever length on deflection for slab cantilever with TL-5 barrier...... 81

Figure 4-32Effect of tapered slab thickness ratio on deflection for slab cantilever with unstiffened edge $\left(\mathrm{L}_{b}=12 \mathrm{~m}, \mathrm{~L}_{\mathrm{c}}=1.5 \mathrm{~m}, \mathrm{t}_{1}=200 \mathrm{~mm}\right)$.

Figure 4-33: Effect of tapered slab thickness ratio on deflection for slab cantilever with a curb $\left(\mathrm{L}_{\mathrm{b}}=12 \mathrm{~m}, \mathrm{~L}_{\mathrm{c}}=1.5 \mathrm{~m}, \mathrm{t}_{1}=200 \mathrm{~mm}\right.$ 82

Figure 4-34Effect of tapered slab thickness ratio on deflection for slab cantilever with TL-2 barrier $\left(\mathrm{L}_{\mathrm{b}}=12 \mathrm{~m}, \mathrm{~L}_{\mathrm{c}}=1.5 \mathrm{~m}, \mathrm{t}_{1}=200 \mathrm{~mm}\right)$.

Figure 4-35: Effect of tapered slab thickness ratio on deflection for slab cantilever with TL-4 $\operatorname{barrier}\left(\mathrm{L}_{\mathrm{b}}=12 \mathrm{~m}, \mathrm{~L}_{\mathrm{c}}=1.5 \mathrm{~m}, \mathrm{t}_{1}=200 \mathrm{~mm}\right)$ 83

Figure 4-36: Effect of tapered slab thickness ratio on deflection for slab cantilever with TL-4 parapet $\left(\mathrm{L}_{b}=12 \mathrm{~m}, \mathrm{~L}_{\mathrm{c}}=1.5 \mathrm{~m}, \mathrm{t}_{1}=200 \mathrm{~mm}\right)$. 83 
Figure 4-37: Effect of tapered slab thickness ratio on deflection for slab cantilever with TL-5 barrier $\left(\mathrm{L}_{\mathrm{b}}=12 \mathrm{~m}, \mathrm{~L}_{\mathrm{c}}=1.5 \mathrm{~m}, \mathrm{t}_{1}=200 \mathrm{~mm}\right)$ 84

Figure 4-38: Comparison between CHDBC moment and Micovic's results with those from the current study for slab cantilever with unstiffened edge and tapered slab thickness ratio of 1 .....86

Figure 4-39: Comparison between CHDBC moment and Micovic's results with those from the current study for slab cantilever with unstiffened edge and tapered slab thickness ratio of 0.7587

Figure 4-40: Comparison between CHDBC moment and Micovic's results with those from the current study for slab cantilever with unstiffened edge and tapered slab thickness ratio of $2 \ldots . .87$

Figure 4-41: Ratio on external moment obtained from the current study and internal moment obtained from Micovic's results for slab cantilever with unstiffened edge ( $\left.L_{c}=1 \mathrm{~m}\right)$ 88

Figure 4-42: Ratio on external moment obtained from the current study and internal moment obtained from Micovic's results for slab cantilever with unstiffened edge $\left(L_{c}=1.5 \mathrm{~m}\right)$ 88

Figure 4-43: Ratio on external moment obtained from the current study and internal moment obtained from Micovic's results for slab cantilever with unstiffened edge $\left(L_{c}=2 \mathrm{~m}\right)$

Figure 4-44: Ratio on external moment obtained from the current study and internal moment obtained from Micovic's results for slab cantilever with unstiffened edge $\left(L_{c}=2.5 \mathrm{~m}\right)$ 89

Figure 4-45: Ratio on external moment obtained from the current study and internal moment obtained from Micovic's results for slab cantilever with a curb $(\mathrm{Lc}=1 \mathrm{~m})$

Figure 4-46: Ratio on external moment obtained from the current study and internal moment obtained from Micovic's results for slab cantilever with a curb $\left(L_{c}=1.5 \mathrm{~m}\right)$ 90

Figure 4-47: Ratio on external moment obtained from the current study and internal moment obtained from Micovic's results for slab cantilever with a curb $\left(L_{c}=2 \mathrm{~m}\right)$ 
Figure 4-48: Ratio on external moment obtained from the current study and internal moment obtained from Micovic's results for slab cantilever with a curb $\left(L_{c}=2.5 \mathrm{~m}\right)$

Figure 4-49: Ratio on external moment obtained from the current study and internal moment obtained from Micovic's results for slab cantilever with TL-2 barrier $\left(L_{c}=1 \mathrm{~m}\right)$.....

Figure 4-50: Ratio on external moment obtained from the current study and internal moment obtained from Micovic's results for slab cantilever with TL-2 barrier $\left(\mathrm{L}_{\mathrm{c}}=1.5 \mathrm{~m}\right)$ 92

Figure 4-51: Ratio on external moment obtained from the current study and internal moment obtained from Micovic's results for slab cantilever with TL-2 barrier $\left(L_{c}=2 \mathrm{~m}\right)$ 93

Figure 4-52: Ratio on external moment obtained from the current study and internal moment obtained from Micovic's results for slab cantilever with TL-2 barrier ( $\left.\mathrm{L}_{c}=2.5 \mathrm{~m}\right)$ 93

Figure 4-53: Ratio on external moment obtained from the current study and internal moment obtained from Micovic's results for slab cantilever with TL-4 barrier $\left(L_{c}=1 \mathrm{~m}\right)$ 94

Figure 4-54: Ratio on external moment obtained from the current study and internal moment obtained from Micovic's results for slab cantilever with TL-4 barrier $\left(L_{c}=1.5 \mathrm{~m}\right)$..... 94

Figure 4-55: Ratio on external moment obtained from the current study and internal moment obtained from Micovic's results for slab cantilever with TL-4 barrier $\left(\mathrm{L}_{c}=2 \mathrm{~m}\right)$ 95

Figure 4-56: Ratio on external moment obtained from the current study and internal moment obtained from Micovic's results for slab cantilever with TL-4 barrier $\left(\mathrm{L}_{\mathrm{c}}=2.5 \mathrm{~m}\right)$. 95

Figure 4-57: Ratio on external moment obtained from the current study and internal moment obtained from Micovic's results for slab cantilever with TL-4 parapet $\left(\mathrm{L}_{\mathrm{c}}=1 \mathrm{~m}\right) \ldots \ldots \ldots \ldots \ldots \ldots . . \ldots 6$

Figure 4-58: Ratio on external moment obtained from the current study and internal moment obtained from Micovic's results for slab cantilever with TL-4 parapet ( Lc = $1.5 \mathrm{~m}$ ) 96 
Figure 4-59: Ratio on external moment obtained from the current study and internal moment obtained from Micovic's results for slab cantilever with TL-4 parapet $\left(\mathrm{L}_{\mathrm{c}}=2 \mathrm{~m}\right)$.

Figure 4-60: Ratio on external moment obtained from the current study and internal moment obtained from Micovic's results for slab cantilever with TL-4 parapet $\left(L_{c}=2.5 \mathrm{~m}\right)$

Figure 4-61: Ratio on external moment obtained from the current study and internal moment obtained from Micovic's results for slab cantilever with TL-5 barrier $\left(\mathrm{L}_{\mathrm{c}}=1 \mathrm{~m}\right)$. 98

Figure 4-62: Ratio on external moment obtained from the current study and internal moment obtained from Micovic's results for slab cantilever with TL-5 barrier $\left(L_{c}=1.5 \mathrm{~m}\right)$. 98

Figure 4-63: Ratio on external moment obtained from the current study and internal moment obtained from Micovic's results for slab cantilever with TL-5 barrier $\left(L_{c}=2 \mathrm{~m}\right)$. 99

Figure 4-64: Ratio on external moment obtained from the current study and internal moment obtained from Micovic's results for slab cantilever with TL-5 barrier $\left(L_{c}=2.5 \mathrm{~m}\right)$. 99

Figure 4-65: FE results versus developed equations for cantilever slab with TL-5 barrier 104

Figure 4-66: FE results versus developed equations for cantilever slab with TL-4 barrier 104

Figure 4-67: FE results versus developed equations for cantilever slab with TL-2 barrier 105

Figure 4-68: FE results versus developed equations for cantilever slab with TL-4 parapet....... 105

Figure 4-69: FE results versus developed equations for cantilever slab with curb 106

Figure 4-70: FE results versus developed equations for cantilever slab with unstiffened edge . 106 


\section{LIST OF APPENDICES}

Table A-1: Summary of Maximum deflection, Transverse Moment and Longitudinal Moment in Unstiffened Cantilevered Slab of Length $1 \mathrm{~m}$ 111

Table A-2: Summary of Maximum deflection, Transverse Moment and Longitudinal Moment in Unstiffened Cantilevered Slab of Length $1.5 \mathrm{~m}$ 114

Table A-3: Summary of Maximum deflection, Transverse Moment and Longitudinal Moment in Unstiffened Cantilevered Slab of Length $2 \mathrm{~m}$ 117

Table A-4: Summary of Maximum deflection, Transverse Moment and Longitudinal Moment in Unstiffened Cantilevered Slab of Length $2.5 \mathrm{~m}$ 120

Table A-5: Summary of Maximum deflection, Transverse Moment and Longitudinal Moment in Cantilevered Slab with Concrete Curb of Length $1 \mathrm{~m}$ 123

Table A-6: Summary of Maximum deflection, Transverse Moment and Longitudinal Moment in Cantilevered Slab with Concrete Curb of Length $1.5 \mathrm{~m}$ 126

Table A-7: Summary of Maximum deflection, Transverse Moment and Longitudinal Moment in Cantilevered Slab with Concrete Curb of Length $2 \mathrm{~m}$ 129

Table A-8: Summary of Maximum deflection, Transverse Moment and Longitudinal Moment in Cantilevered Slab with Concrete Curb of Length $2.5 \mathrm{~m}$ 132

Table A-9: Summary of Maximum deflection, Transverse Moment and Longitudinal Moment in Cantilevered Slab with Tl-2 Barrier of Length $1 \mathrm{~m}$ 135

Table A-10: Summary of Maximum deflection, Transverse Moment and Longitudinal Moment in Cantilevered Slab with Tl-2 Barrier of Length $1.5 \mathrm{~m}$ 138 
Table A-11: Summary of Maximum deflection, Transverse Moment and Longitudinal Moment in Cantilevered Slab with Tl-2 Barrier of Length $2 \mathrm{~m}$. 141

Table A-12: Summary of Maximum deflection, Transverse Moment and Longitudinal Moment in Cantilevered Slab with Tl-2 Barrier of Length $2.5 \mathrm{~m}$ 144

Table A-13: Summary of Maximum deflection, Transverse Moment and Longitudinal Moment in Cantilevered Slab with Tl-4 Barrier of Length $1 \mathrm{~m}$ 147

Table A-14: Summary of Maximum deflection, Transverse Moment and Longitudinal Moment in Cantilevered Slab with Tl-4 Barrier of Length $1.5 \mathrm{~m}$ 150

Table A-15: Summary of Maximum deflection, Transverse Moment and Longitudinal Moment in Cantilevered Slab with Tl-4 Barrier of Length $2 \mathrm{~m}$ 153

Table A-16: Summary of Maximum deflection, Transverse Moment and Longitudinal Moment in Cantilevered Slab with Tl-4 Barrier of Length $2.5 \mathrm{~m}$ 156

Table A-17: Summary of Maximum deflection, Transverse Moment and Longitudinal Moment in Cantilevered Slab with Tl-4 Parapet of Length $1 \mathrm{~m}$ 159

Table A-18: Summary of Maximum deflection, Transverse Moment and Longitudinal Moment in Cantilevered Slab with Tl-4 Parapet of Length $1.5 \mathrm{~m}$ 162

Table A-19: Summary of Maximum deflection, Transverse Moment and Longitudinal Moment in Cantilevered Slab with Tl-4 Parapet of Length $2 \mathrm{~m}$ 165

Table A-20: Summary of Maximum deflection, Transverse Moment and Longitudinal Moment in Cantilevered Slab with Tl-4 Parapet of Length $2.5 \mathrm{~m}$ 168

Table A-21: Summary of Maximum deflection, Transverse Moment and Longitudinal Moment in Cantilevered Slab with Tl-5 Barrier of Length $1 \mathrm{~m}$ 171 
Table A-22: Summary of Maximum deflection, Transverse Moment and Longitudinal Moment in Cantilevered Slab with Tl-5 Barrier of Length 1.5 m......................................................... 174

Table A-23: Summary of Maximum deflection, Transverse Moment and Longitudinal Moment

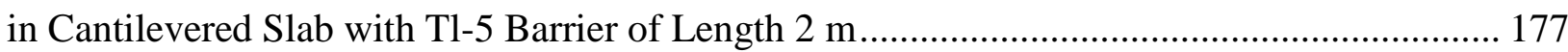

Table A-24: Summary of Maximum deflection, Transverse Moment and Longitudinal Moment in Cantilevered Slab with Tl-5 Barrier of Length 2.5 m........................................................... 180 


\section{NOTATIONS}

A

$A^{\prime}$

$B$

$B^{\prime}$

$b$

$b_{\text {base }}$

C

CHBDC

E

$E_{c}$

$f^{\prime}{ }_{c}$

FEA

$I_{B}$

$I_{S}$

$L_{b}$

$L_{c}$

$M_{x}$

$M_{y}$

$S$

$S_{p}$
Coefficient obtained from graphical design charts to compute transverse moment intensity, $M_{y}$

(CSA 2014)

Coefficient obtained from graphical design charts to compute transverse moment intensity, $M_{y}$

(Bakht and Jaeger, 1985)

Coefficients based on different ratios of $S / S_{c}$ for values of $t_{1} / t_{2}$ to determine $M_{y}$ (Mufti et al., 1993)

Coefficient obtained from graphical design charts to compute transverse moment intensity, $M_{y}$

(Bakht and Jaeger, 1985)

Barrier wall thickness

Barrier wall base width

Transverse distance of load from supported edge of cantilever slab (CSA 2014); lowercase in previous studies

Canadian Highway Bridge Design Code

Young's modulus; modulus of elasticity

Modulus of elasticity of concrete

Compressive strength of concrete

Finite Element Analysis

Moment of inertia of barrier wall

Moment of inertia of slab

Length of barrier

Length of cantilever deck slab

Longitudinal moment

Transverse moment

Centre-to-centre spacing of longitudinal girders

Transverse distance of the free edge to the supported edge of cantilever slabs (CSA 2014) 
Slab thickness at the free end of the cantilever

Slab thickness at the root of the cantilever

Thickness of slab

Slab thickness ratio, $t_{2} / t_{1}$

$X$ coordinate of point evaluated on a cantilever slab (CHBDC 2014)

$Y$ coordinate of a point evaluated on a cantilever slab (CHBDC 2014) 


\section{CHAPTER ONE 1 INTRODUCTION}

\subsection{General}

The deck slab cantilever extends in the bridge's transverse direction from exterior girder in a slabon-girder bridge system, perpendicular to the direction of traffic. While the deck slab overhang adds aesthetical value, it also proves to be an economical solution due to reducing the deck slab width between longitudinal girders. Additionally, the cantilever overhang is typically designed to vary in height, with it cross-section tapering to a smaller value at its free edge. Extensive research was conducted over the years to analyze cantilever slabs in a simplified appreciable loss. Majority of these simplified methods are based on calculating the transverse moment due to applying wheel loads on the internal portion of cantilever slabs, however, this research focuses on investing the structural response of cantilever overhang due to applying truck loading near the transverse free end of the slab (i.e. construction joint) and developing imperial equation for transverse and longitudinal moments based on the obtained results.

\subsection{The Problem}

The intensity of the transverse negative moment $\left(\mathrm{M}_{\mathrm{y}}\right)$ at the interior location of the deck slab cantilever can be determined as stipulated in Clause 5.7.1.3 of the Canadian Highway Bridge Design Code, CHBDC, (CSA, 2014a) using moment equation or in table format. Nevertheless, the task of determining transverse moment at the location of bridge expansion joints, or within a distance equal the slab cantilever length, $S_{\mathrm{P}}$, of the transverse free edge, was simplified in the CHBDC by assuming the design moment in this region as $2 \mathrm{M}_{\mathrm{y}}$. However, the downside of this Clause can be summarized as follows:

1- It does not consider the effect of increasing length of barrier.

2- The equation is limited to either unstiffened deck slab cantilever edge or stiffened edge with Jersey barrier, while CHBDC specifies barrier shapes, namely: TL-5, TL-4, TL-2 and TL-1. 
These barrier shapes have different cross-section area and flexural stiffened based on the associated design loads due to vehicle impact and traffic volume in the bridge.

3- CHBDC does not refer to the longitudinal moment in the deck slab cantilever at the interior locations or near the transverse free end of the cantilever slab.

As a result, a practical-design-oriented parametric study was carried out in this research, using the commercially available SAP2000 finite element software, on more than 2400 deck slab cantilevers to study the peak intensity of transverse and longitudinal moment, as well as the deflection resulted from the applied wheel loads at the region of their free end (i.e. where the bridge expansion joint exists).

\subsection{Research Objective}

The aims of this research are as follows:

1- Conduct a practical-design-oriented parametric study, using the 3D finite element modeling, of the cantilever deck slabs in the slab-on-girder bridge system to investigate their behavior when subjected to truck loading conditions at the region of their free end.

2- Perform a comparison between obtained results for external moments and the corresponding results for internal moment obtained from CHBDC and Micovic (2016) to investigate the accuracy of the simplified method of analysis specified in CHBDC at free end.

3- Develop equations to calculate the external transverse and longitudinal moment based on the studied geometries and truck configuration.

\subsection{Scope of work}

The scope of this research comprises of carrying out a literature review of previous research work, textbooks, design codes and standards of practice associated with unstiffened as well as stiffened edge of the cantilever deck slab subjected to truck loading.

Moreover, the study includes a series of sensitivity studies conducted to investigate the accuracy of obtained data from SAP2000 software, location of peak intensity of transverse and longitudinal moment, the effect of barrier thickness, and the loading case that produces the maximum moment 
intensity. Next, a parametric study was conducted, using SAP2000 software, on cantilever overhangs subject to CHBDC truck loading at its free transverse end to investigate the effect of different parameters on the response. The key parameters considered in this study include cantilever length, barrier length, slab thickness, slab tapered thickness ratio and end-stiffening configurations. Then, a comparison between the generated data and corresponding data from CHBDC and Micovic's research work was conducted to scrutinize the accuracy of the ratio of 2 for the external-to-internal moments stated in CHBDC. Finally, a set of more reliable equations for the transverse and longitudinal moments at the free end of the deck slab cantilever was deduced.

\subsection{Contents and Arrangement of this study}

In this study, Chapter 1 is an introductory Chapter which sheds light on the research's problem, scope and its main goals. Chapter 2 describes the simplified methods utilized for determining the moment intensity in the deck slab cantilever as well as reviews previous research works and methods provided in CHBDC. Chapter 3 explains the concept of the finite element method and SAP2000 software utilized in the modeling and analyzing of the deck slab cantilever, loading cases, and sensitivity studies conducted to examine the approach of modelling. Chapter 4 demonstrates the results of the parametric study conducted on the cantilever deck slab, and the comparison of the generated data with CHBDC and Micovic's research work. Also, it presents the developed equations to determine the resulting moment. Chapter 5 summarize the findings of this study, outlines conclusions and presents recommendations for future research. 


\section{CHAPTER TWO}

\section{LITERATURE REVIEW}

\subsection{General}

A lot of study has been conducted over time on figuring out the intensity of bending moment due to wheel loads on bridge cantilever overhang to produce a user-friendly method that can be adopted instead of applying more rigorous methods. Generally, these simplified methods are based on assumption of 'isolating the deck slab overhang from the internal slab panels of the bridge on fixed supports retrained from any movement and rotation. As it the comparisons between the results from simplified methods with rigorous methods such as FE Analysis shows, the percentage error is insignificant. In addition, $\mathrm{X}$ direction refers to the direction of traffic flow and parallel to the root of cantilever and $\mathrm{Y}$ direction is perpendicular to bridge girders; as a result, $\mathrm{M}_{\mathrm{y}}$ indicated the traverse moment. Also, the slab materials presumed homogeneous and isotropic. In this chapters, the practices on developing simplified expressions for determining transverse moment due a concentrated load on cantilever slab is reviewed, and the way how Canadian Highway Bridge Design Code (2014) are based on these investigations is clarified.

\subsection{Sawko and Mill (1971)}

Sawko and Mill (1971) presented a manual method for calculating hogging moment $\left(\mathrm{M}_{\mathrm{y}}\right)$ due to a concentrated load (P) on an isotropic deck slab overhang with uniform thickness. The relationship they suggested, included hyperbolic function ( $\cosh )$, and is in the form of:

$$
M_{y}=-\frac{P A^{\prime}}{\pi}\left[\frac{1}{\cosh A^{\prime}\left(\frac{y}{a} / \frac{c}{a}\right)}\right]
$$


Where $\mathrm{A}^{\prime}$ is a function of the location of the load $(\mathrm{P})$ to the fixed edge. The negative sign shows that the top fiber is under tension. Other components are described in Figure 1.1. However, this method only can be applied for determining the bending moment at unyielding supports at the root of cantilever overhang, therefore designers were not able to use this expression for calculating the moment all over cantilever slab.

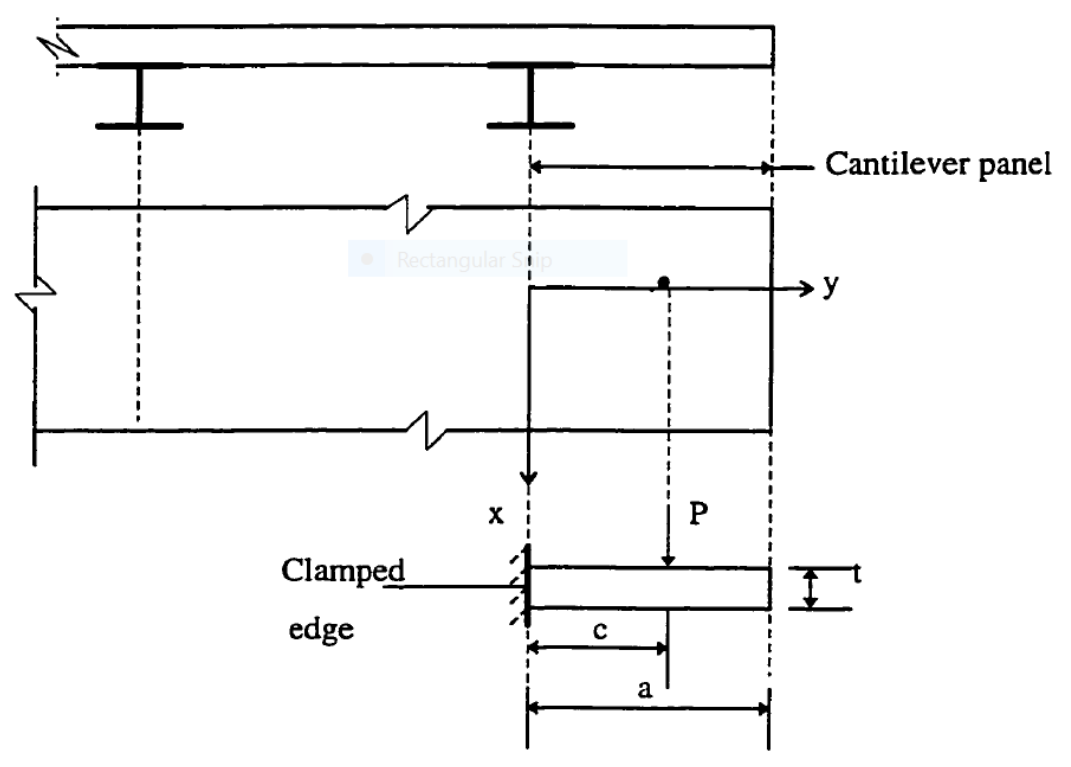

Figure 2-1: Notation employed by Sawko and Mills. (Adopted from (Xiao, 1997))

\subsection{Bakht and Holland (1976)}

Since, the equation developed by Sawko and Mills (1971) is only restricted for determining the bending moment along the root of the cantilever overhang with uniform thickness, Bakht and Holland (1976) developed a semi-graphical solution based on the assumption of an elastic cantilever overhang with isotropic material. This simplified solution for cantilever slab with concentrated loads presented results similar to classical method; however, it can be applied for calculating moment intensity all over the deck slab overhangs with linearly varying thickness. The formula is in the form of: 


$$
M_{y}=-\frac{P A^{\prime}}{\pi}\left[\frac{1}{\cosh \frac{A^{\prime} x}{(c-y)}}\right]
$$

Where $\mathrm{P}$ is the intensity of applied load. Coefficient $\mathrm{A}^{\prime}$ is function relative to the position of the load $(\mathrm{P})$ with respect to the root of cantilever slab and it depends on: the thickness ratio $\operatorname{tr}=\mathrm{t} 2 / \mathrm{t} 1$, $c_{r}=c / a$ and $y_{r}=y / r . A^{\prime}$ can be found through graphical charts (Figure 2-2).

Bakht (1981) demonstrated that above equation by Bakht and Holland (1976) cannot be applied to the edge-stiffened deck overhangs with finite length. As can be seen on Figure 2-2. the charts Bakht and Holland (1976) produced is restricted to the variation of $\mathrm{A}^{\prime}$ for unstiffened cantilever slabs; nevertheless, Bakht (1981) prepared charts for edge-stiffened cantilever overhangs.
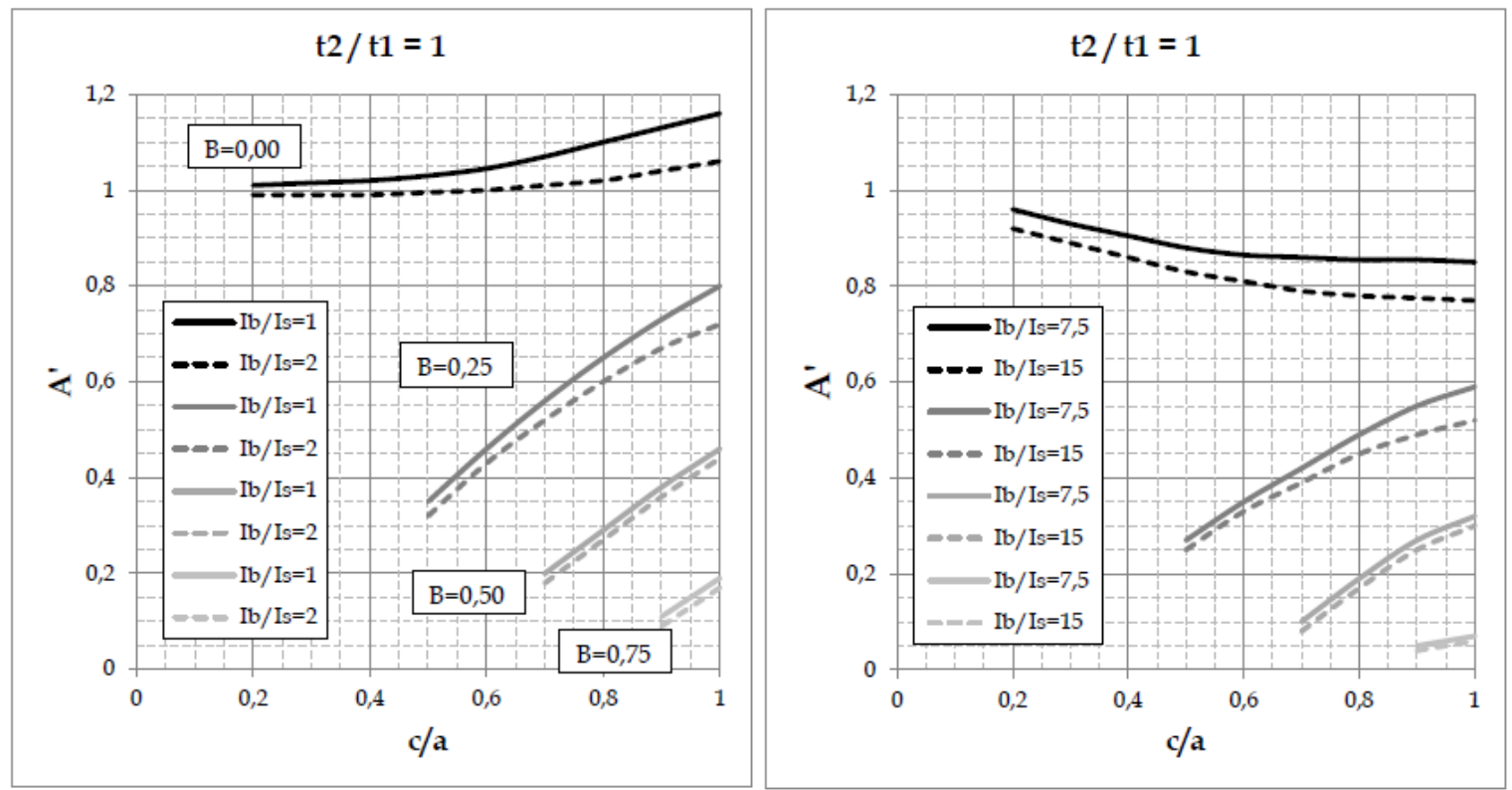

Figure 2-2: Values of $A^{\prime}$ for various thickness ratio (Adapted from Bakht and Holland, 1976)

\subsection{Jaeger and Bakht (1990)}

Surprisingly, in spite of the fact that the results given by Bakht and Holland (1976) were confirmed by other rigorous methods, such as Finite Element Analysis, the hyperbolic function (cosh) of the 
previous method was extracted empirically; as a result, Jaeger and Bakht (1990) replaced the relationship by an algebraic function from linear elastic solution which is easier to apply than former expression. In this method, $\mathrm{M}_{\mathrm{y}}$ can be calculated as below:

$$
M_{y}=\frac{2 P}{\pi} \frac{A^{\prime}}{2} \frac{(c-y)^{4}}{\left\{(c-y)^{2}+\left(\frac{A^{\prime}}{2} x\right)^{2}\right\}^{2}}
$$

Where $\mathrm{P}$ is magnitude of applied load. $\mathrm{c}$ is the distance between applied load and root od cantilever slab. Other notation shown on Figure 2-3. For the concentrated load at the tip of the cantilever overhang where $\mathrm{c}=\mathrm{s}$, this formula becomes:

$$
M_{y}=\frac{2 P}{\pi} D^{\prime} \frac{(s-y)^{4}}{\left\{(s-y)^{2}+\left(D^{\prime} x\right)^{2}\right\}^{2}}
$$

Where $D^{\prime}=\frac{A^{\prime}}{2}$ and s is distance between root and tip of cantilever overhang.

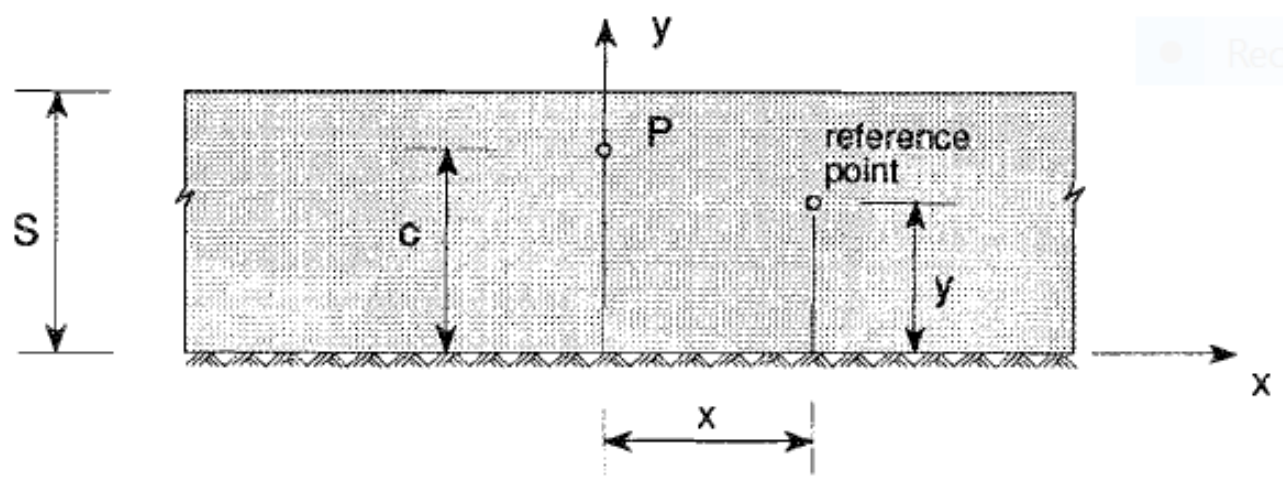

Figure 2-3: Notation for deck slab overhang. (Adapted from (Jaeger \& Bakht, 1990))

Even though, this method seems to be user friendly and appealing to engineers and designers, the maximum moment magnitude which determined by this method is exaggerated from real value. Since this method, is based on assumption of fully fixity at the clamped edge of the cantilever slab. 


\subsection{Dilger et al. (1990)}

Dilger et al. (1990) evaluated the assumption of unyielding supports at the root of cantilever slab. For this purpose, they used FE Analysis, and modeled the cantilever slab as a separate part. They proved that the maximum hogging moment for the rather thin and deep webs was $40 \%$ higher than the real value, if it is calculated based on the assumption of full fixity at the root of cantilever slab. However, it is interesting to note that a flexible restrain produced smaller hogging moment at the clamped edge, especially for short cantilever slab span, and loads near to supports.

Dilger el al (1990) applied the same equations that Bakht and his coworkers used, but they introduced a new value for $B$ which is $A^{\prime} / 2$. Coefficient $B$ is the function of $t_{r}, c_{r}, y_{r}$ and a new parameter $S_{r}=S / S_{c} . S_{r}$ is the ratio of internal slab to cantilever slab. In addition, they added a stiffness factor. All of previously discussed methods including Dilger et al (1990) measures of bending moment in cantilever overhang, and do not give any information on the intensity of hogging moment in the first internal panel.

\subsection{Mufti et al (1993)}

As noted above, the methods developed by Bakht and Holland (1976), and Dilger et al. (1990) can be used only for determining moment in the cantilever slab, not the first internal panel. Nevertheless, Mufti et al. (1993) proposed a simplified method for determining the intensity of hogging moment in the first internal panel due to a concentrated load on the deck slab overhang.

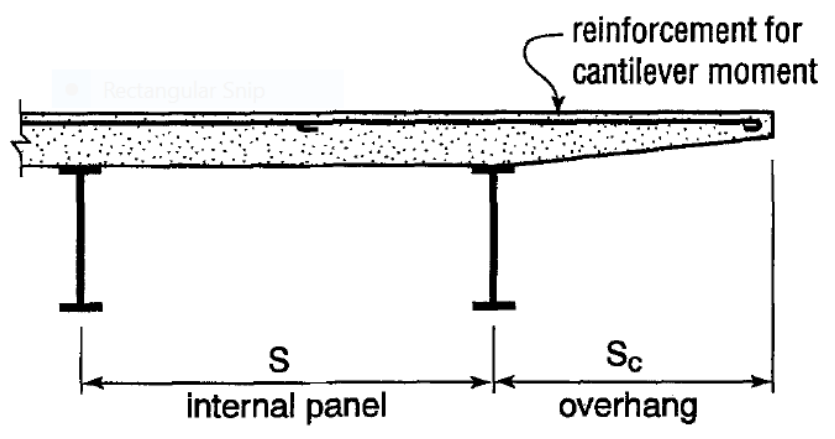

Figure 2-4: Partial cross section of bridge demonstrating bending moment reinforcement in deck slab overhang and internal panel of deck slab, (Adapted from Mufti et al, (1993)) 
Mufti et al (1993) solved the problem based of some simplification. For instance, they reached to the point that, the girders can be supposed to be non-deflecting; furthermore, it can be assumed that the deck slab is simply supported over the girder close to external girder.

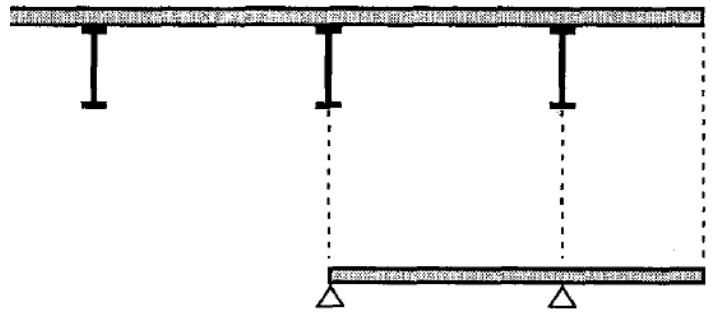

(a)

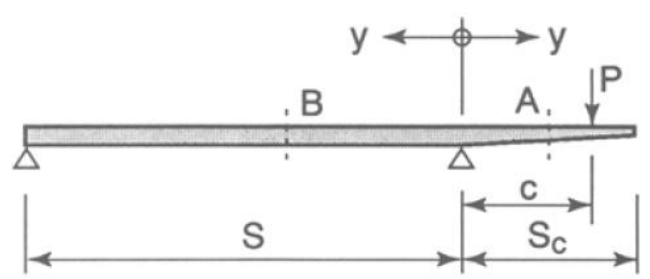

(b)

Figure 2-5: (a) Boundary condition assumption for internal deck slab. (b) Notation for cantilever slab and internal panel. (Adapted from Mufti et al, (1993))

Based on such these simplification, Mufti et al (1993) proposed two equations for finding the magnitude of the bending moment in both cantilever overhang and first internal panel as follows:

$$
\begin{aligned}
& M_{y c}=-\frac{2 P B_{c}}{\pi}\left[\frac{\left(c-y_{c}\right)^{4}}{\left[\left(c-y_{c}\right)^{2}+\left(B_{c} x\right)^{2}\right]^{2}}\right] \\
& M_{y i}=-\frac{2 P B_{i}}{\pi}\left[\frac{c^{4}\left(S-y_{i}\right)^{4}}{\left[c^{2}\left(S-y_{i}\right)^{2}+S^{2}\left(B_{i} x\right)^{2}\right]^{2}}\right]
\end{aligned}
$$

Equation 2-5 is for finding hogging moment intensity in the cantilever slab and equation 2-6 is for calculation of transverse moment in the internal panel due to the concentrated load applied on cantilever slab. Value of $B_{c}$ and $B_{i}$ can be found through tabulated tables Mufti et al (1993) prepared. Figure 2-5(b) demonstrated the notation used in above relationships. It is interesting to note that, Mufti et al (1993) proved that variation the peak intensity of transverse moment $\mathrm{M}_{\mathrm{y}}$ 
cannot turn into linear relationship, even for larger value of $S_{c} / S$, unlike the common postulate of linear variation the peak intensity of $\mathrm{M}_{\mathrm{y}}$.

Sylvain Parr (1993) demonstrated the development of deck slab overhang from Sawko and Mills (1971) to Mufti et al (1993) shown in Figure 2-7. 


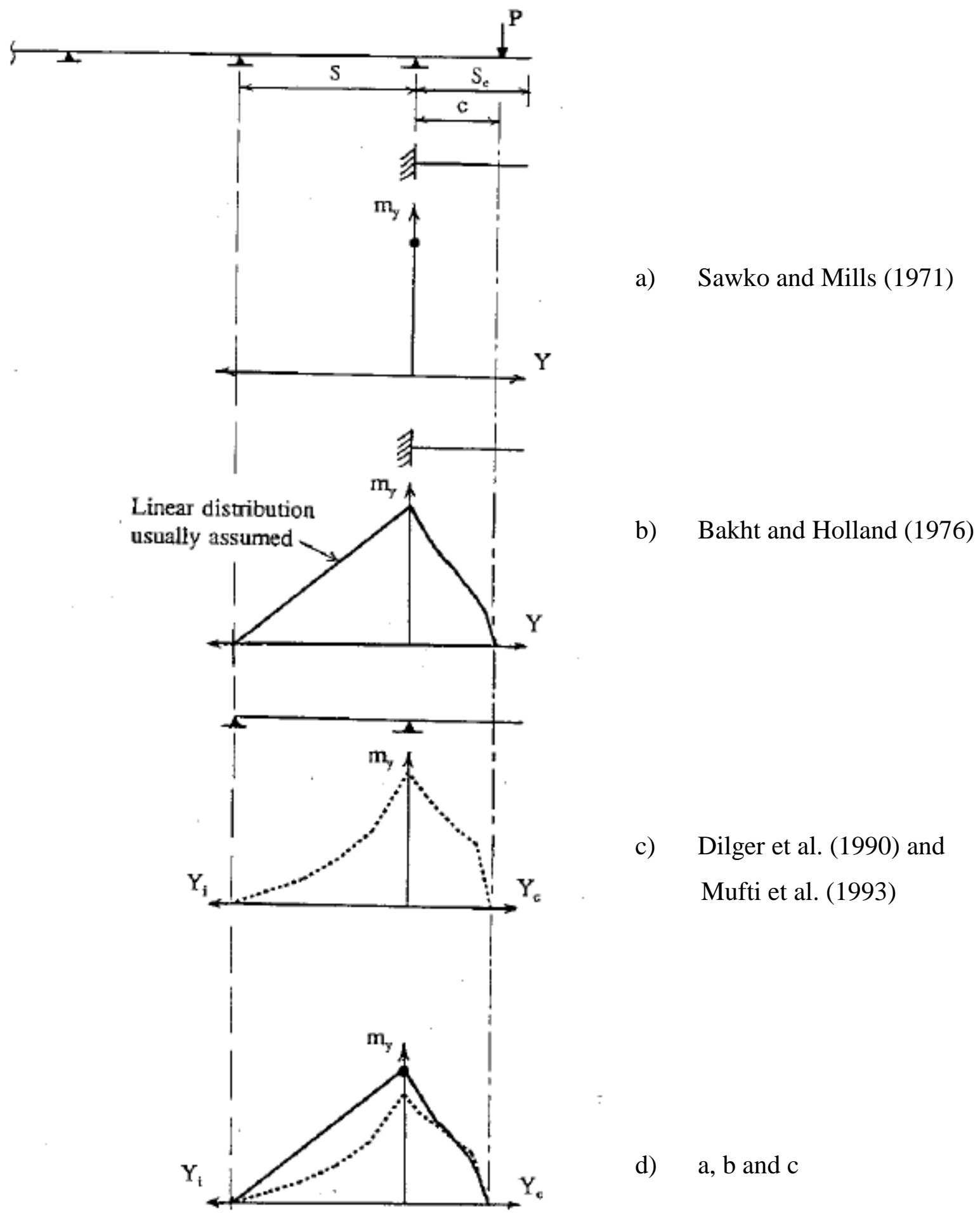

Figure 2-6: Evolution of various method; (adapted from Parr, (1993)) 


\subsection{Parr (1993)}

A computer program named ANCAS which developed by Parr (1993), was built on the simplified method by Mufti et al (1993). This program designed for determining transverse moment intensities of the cantilever portion and first internal panel of slab-on-girders bridges due to OHBDC or the CS-W truck loads on the deck slab overhang. The purpose of this program was to facilitate the calculations proposed by simplified methods which discussed in this chapter. ANCAS is acronym derived from Analysis of Cantilever Slabs, and is written in FORTAN 77.

Later, Parr (1993) extended ANCAS to ANDECAS which is an acronym for Analysis and Design of Cantilever Slabs which is written with the same computer language (FORTAN 77). ANDECAS employed the same procedure used by ANCAS; however, it included design capabilities, such as, ability to find design moments, and specify the required steel area corresponding to the design moments for each section. This program is limited to the analysis and design of cantilever overhangs without edge-stiffening; nonetheless, Parr (1993) pointed out in his thesis that, the program could be used for cantilevers with stiffened edges, provided that new tables of coefficient A would be developed.

\subsection{Xiao (1997)}

Xiao (1997) worked on improving program ANDECAS developed by Parr (1993). The program expanded by Xiao (1997) named ANDECS4 which can be used for edge-stiffening deck slab as well. In this program, the maximum moment intensity was calculated by a close-form solution versus the time-consuming iterative process employed by ANDECAS. Also, ANDECAS4 included user defined truck load function, in order to be used worldwide. Also, it abled to calculate the moment intensities for a fully clamped cantilever as well as design the tensile reinforcement made of fiber reinforced polymer.

\subsection{Canadian Highway Bridge Design Code Provision}

The CHBDC provision for determining on transverse moment $\left(\mathrm{M}_{\mathrm{y}}\right)$ due to a concentrated load on deck slab overhang is built on the discussed methods in this chapter such as, Bakht and Holland (1976), Dilger et al (1990) and Mufti et al (1993). The expression, which adopted in the second 
edition of the OHBDC (MTO 1983) for finding the bending moment in cantilever overhang due to a concentrated load is as a form of:

$$
M_{y}=-\frac{P A^{\prime}}{\pi}\left[\frac{1}{\cosh \frac{A^{\prime} x}{(c-y)}}\right]
$$

However, as discussed previously, Jaeger and Bakht (1990) proposed a more attractive and easier to apply algebraic relationship than the above equation; thus, the equation including the hyperbolic function has been replaced with algebraic equation in the latest version of CHBDC (2014). In addition, $\mathrm{A}^{\prime}$ in the former formula has been changed to $2 \mathrm{~A}$ to be in consistency with Jaeger and Bakht (1990) and other publication. As per clause 5.7.1.3 of CHBDC (2014) the magnitude of traverse moment $\mathrm{M}_{\mathrm{y}}$ for a cantilever overhand with a uniform or varying thickness ratio can be found through the expression as followed:

$$
M_{y}=\frac{2 P A}{\pi\left[1+\left(\frac{A x}{c-y}\right)^{2}\right]^{2}}
$$

Where, $\mathrm{P}$ is magnitude of concentrated load on cantilever, $\mathrm{A}$ is a coefficient can be found through graphical charts (Figure), and depends on factors such as thickness ratio, and ratio of distance of load (p) to the root of cantilever slab and cantilever span length; other notation demonstrated on the Figure 2-8.

Another option specified by in clause 5.7.1.3 of the CHBDC (2014) for determining the transverse moment intensity due to the CL-625 Truck., is to obtain the corresponding value from Table 5.15 provided in this clause. The table can be used for both stiffened and unstiffened edge.

Additionally, as it can be observed, the methods discussed in this chapter from Bakht and Holland (1976) to Mufti et al (1993) can be used only when the load are far from cantilever free edge. Bakht et al (1979) presented a simplified method for the case when the loads apply near the 
transverse free edge of cantilever slab, however this method was tedious to apply, since it needed another set of coefficients. For this reason, CHBCD (2014) makes the task of designers easer, by proposing that the bending moment at the cantilever part within a distance of $\mathrm{S}_{\mathrm{p}}$ from the transverse free edge of cantilever slab should be taken twice the calculate moments $\left(\mathrm{M}_{\mathrm{y}}\right)$ for which the rest of cantilever overhang is designed. However, this part of CHBDC (2014) is subject of investigation for this research, and in next chapters some studies for validity of this part.

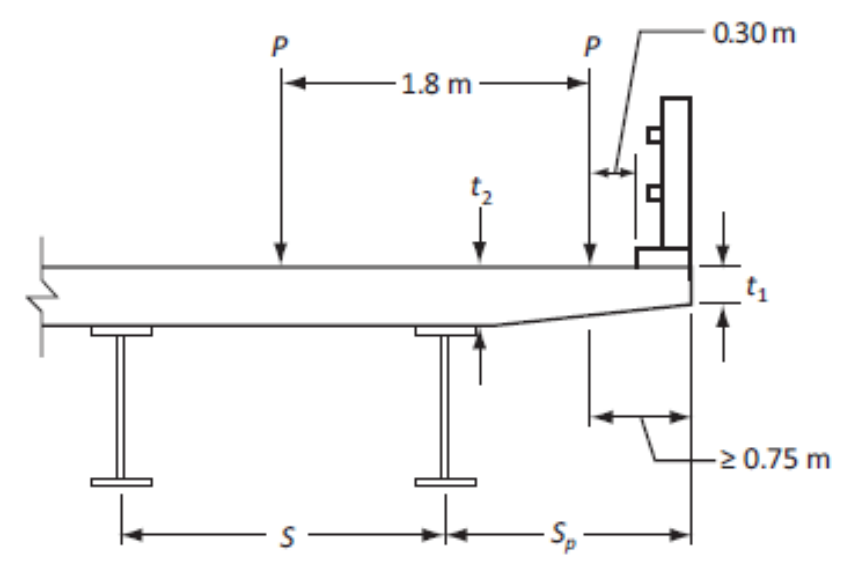

Figure 2-7: Notation for cantilever slab (CSA, 2014)

Table 2-1: Maximum cantilever moments due to CL-625 loading condition included dynamic load allowances, (CSA, 2014)

\begin{tabular}{|c|c|c|c|c|c|c|}
\hline & \multicolumn{3}{|c|}{ Unstiffened edge } & \multicolumn{3}{|c|}{$\begin{array}{l}\text { Edge stiffened with New Jersey } \\
\text { barrier }\end{array}$} \\
\hline & \multicolumn{3}{|c|}{ Maximum $\mathrm{M}_{\mathrm{y}}, \mathrm{kN} . \mathrm{m} / \mathrm{m}$} & \multicolumn{3}{|c|}{ Maximum $\mathrm{M}_{\mathrm{y}}, \mathrm{kN} . \mathrm{m} / \mathrm{m}$} \\
\hline $\mathrm{S}_{\mathrm{p}}, \mathrm{m}$ & $\mathrm{r}_{\mathrm{t}}=1.00$ & $\mathrm{r}_{\mathrm{t}}=0.75$ & $\mathrm{r}_{\mathrm{t}}=0.5$ & $\mathrm{r}_{\mathrm{t}}=1.00$ & $\mathrm{r}_{\mathrm{t}}=0.75$ & $\mathrm{r}_{\mathrm{t}}=0.5$ \\
\hline 1.00 & 41 & 43 & 44 & 37 & 41 & 45 \\
\hline 1.50 & 43 & 47 & 51 & 34 & 37 & 41 \\
\hline 2.00 & 53 & 57 & 60 & 35 & 39 & 43 \\
\hline 2.50 & 60 & 65 & 70 & 37 & 40 & 43 \\
\hline 3.00 & 92 & 99 & 107 & 70 & 74 & 77 \\
\hline
\end{tabular}

Note: Value obtained for $\mathrm{y}=0, \mathrm{C}=\mathrm{S}_{\mathrm{p}}-0.75$ 


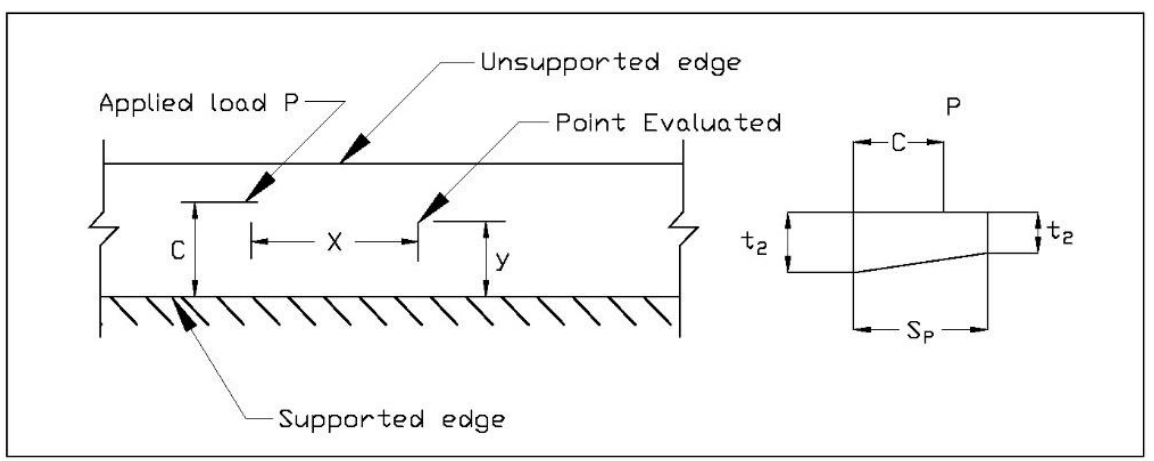

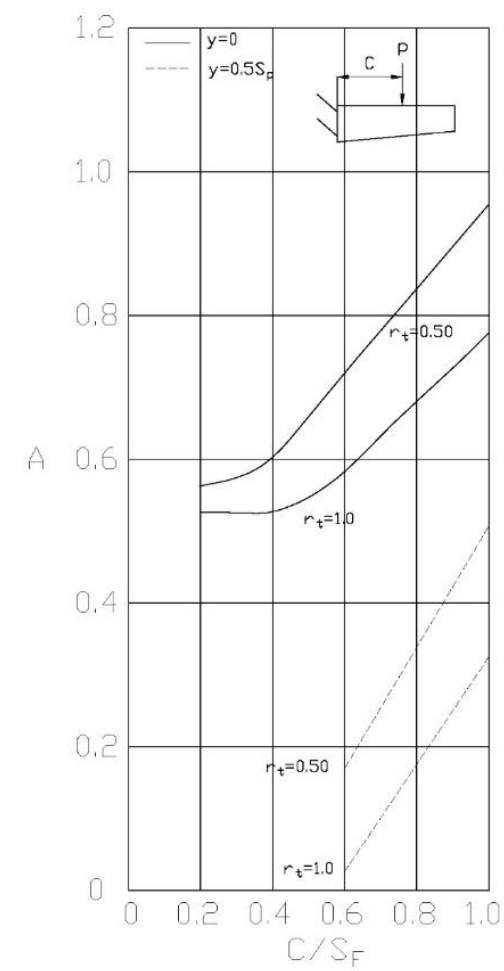

a) Slab without edge stiffening

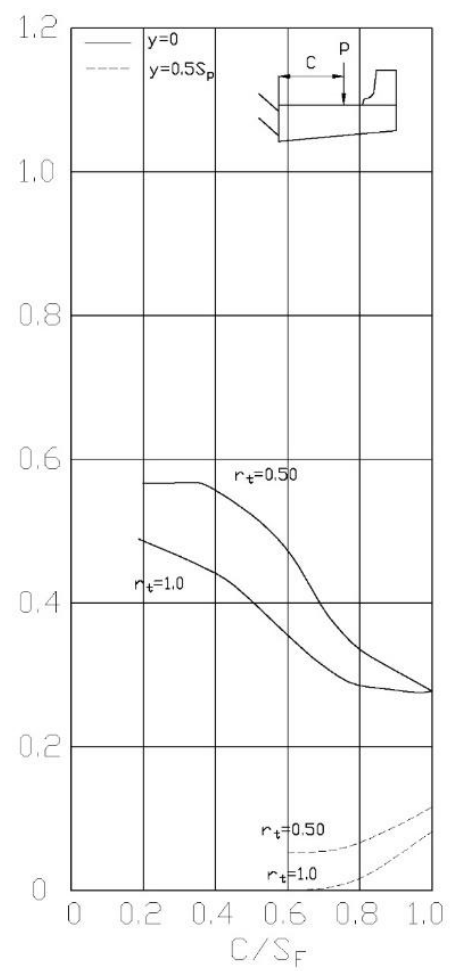

b) Slab with edge stiffening

Figure 2-8: Calculation of A values (CSA, 2014) 


\section{CHAPTER THREE \\ 3 FINITE ELEMENT ANALYSIS}

\subsection{General}

The Finite Element Method (FEM) is a computerized method based on numerical technique. Complicated problems can be solved by this method, to generate valid results in comparison with experimental discovery. For that reason, the finite element analysis method is vastly used by code writers and designers. Also, the finite element analysis is a suggested method by CHBDC in accordance with Clause 5.9.1. FEM can solve problems by dividing the body into finite elements with associated nodes which are similar to original system. These elements can be summarized as follows:

1- One dimensional elements or linear elements;

2- Two dimensional elements, such as triangular or quadrilaterals;

3- Three dimensional elements; and

4- Simple axisymmetric triangular and quadrilateral elements used for axisymmetric problems.

Finite element analysis involves obtaining element stiffness matrix relating the nodal vector displacement to nodal allied forces by various methods, namely: a) direct equilibrium or stiffness method, and b) work or energy method. Nowadays, there are well-known and reliable finite element analysis software in the market, among them: SAP2000, ETABS and ABAQUS software. SAP2000 software (CSI, 2015) is a reliable software that can be widely used for solving day-today problems to complex models. SAP2000 software version 17 was employed in this research to execute the sensitivity and parametric studies on structural behaviour of deck slab overhangs. The variables which are taken into account in this study includes barrier length, cantilever length, slab thickness, tapered slab thickness ratio and diverse types of edge stiffening for cantilever slabs.

\subsection{Finite-Element Analysis Method}

As mentioned earlier, FEM is a numerical method for solving a wide range of problems from engineering field to mathematical physics. It can be used for structure analysis, heat transfer, fluid 
flow, mass transport, and electromagnetic potential. In addition, problems which consist of complicated geometries, loading and material properties which is not solvable by analytical solution involving partial differential equations, can be solved by the FEM. The finite element method involves taking some steps to solve problems. The first step is discretizing a whole model to smaller parts, called finite elements, to produce equivalent system of smaller bodies, which interconnected at points called nodes. In the finite element method, the element types, the kinds of loads to be applied, and type of boundary conditions or supports are specified by the users. However, other steps are executed by the computer automatically. The next step is selecting a displacement function. Linear, quadratic, and cubic polynomials are vastly employed because of simplicity. Then, the strain/displacement or stress/strain relationship is defined to derive an equation for each finite element. Then, the element stiffness matrix and equations relating nodal forces to nodal displacement are extracted by applying force equilibrium conditions for an element along with force/deformation relationships. Lastly, the global stiffness matrix can be produced from combining basic element's matrix, using methods, such as direct stiffness method in form of:

$$
[P]=[K][U]
$$

Where $\mathrm{P}$ is the node load vector, $\mathrm{K}$ is the global stiffness matrix and $\mathrm{U}$ is the nodal displacement vector. As it can be seen, this matrix demonstrates the relationship between nodal force and displacement. It is interesting to note that the finite element analysis can be used to solve both elastic and inelastic problem. For the elastic problem, the solution is straightforward and can be directly gained by applying load. However, for non-linear problems, the analysis involves a different numerical method and materials non-linearity.

\subsection{SAP2000 Computer Program}

SAP2000 is one of the most reliable software which used for finite element analysis. This software is famous worldwide for its ability to solve a wide range of problems including static or dynamic problems, and linear or nonlinear analysis. SAP2000 finite element library includes six element types, namely: frame element, shell element, plane element, solid element, Nllink element and Asolid element. The type of element which was utilized in this study to simulate the cantilever slab and barrier wall is the shell element shown in Figure 3-1 and its thickness defined as the slab thickness or barrier thickness. In addition, the next step after selecting the type of elements is to 
understand the sign conversion presented by SAP2000 manual for shell element internal forces, stresses and moments. Figure 3-2 shows the sign convention for positive internal moment. Also, it is noted that these shell element internal moments are moments per unit length acting on the mid-surface of the shell elements.

For the purpose of investigating the accuracy of intensity and direction of obtained moments from SAP2000 software, a sensitivity study was conducted by applying a unit load per meter of the cantilever slab and comparing the generated results for transverse and longitudinal moment, as well as defection, to exact solution. According to this study, M22 and M11, depicted in Figure 32 , were taken as transverse and longitudinal moments in all analysis, respectively.

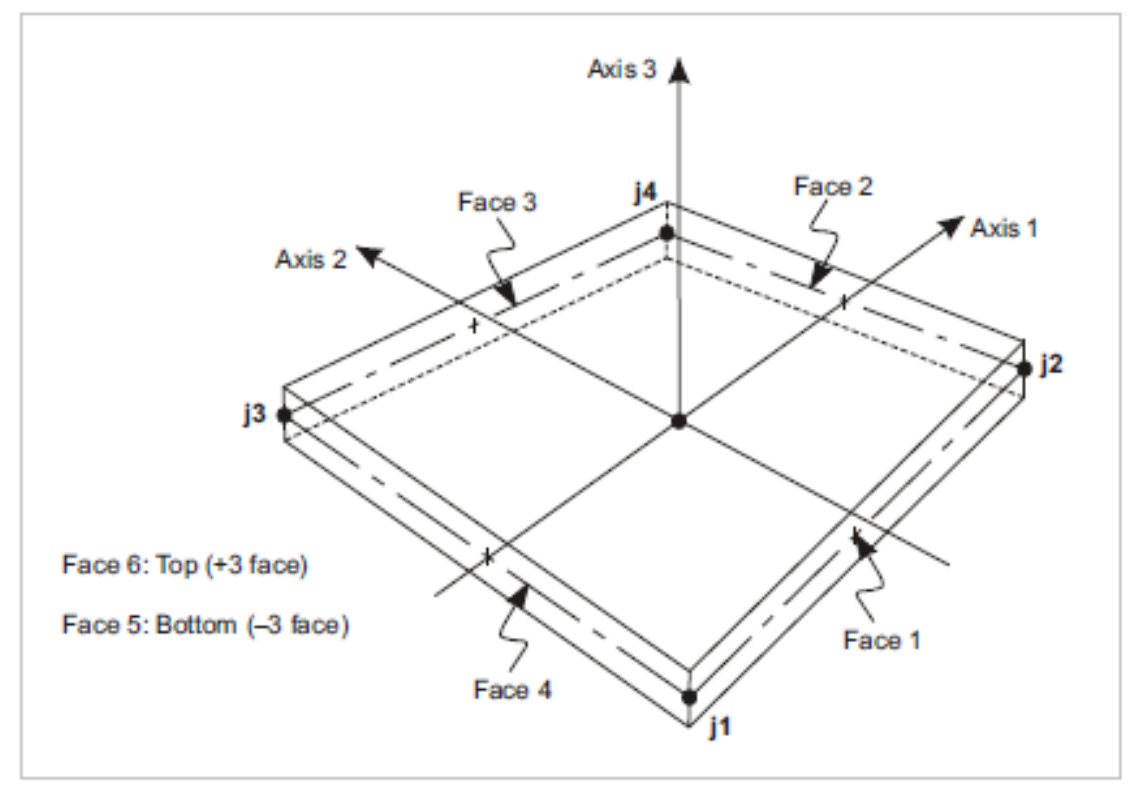

Figure 3-1: Four-node quadrilateral shell element (https://wiki.csiamerica.com/display/kb/Shell, n.d.) 


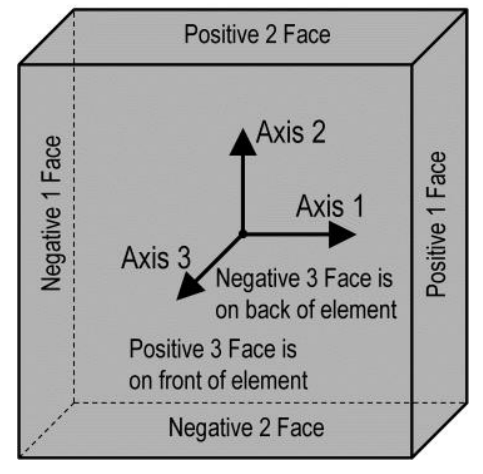

(a)

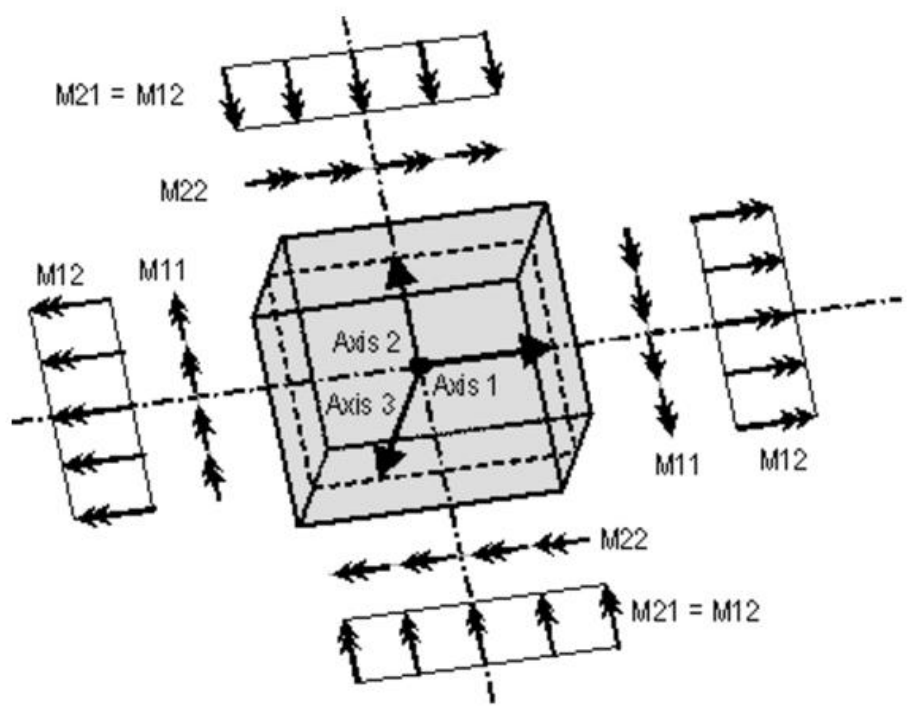

(b)

Figure 3-2: Internal moment sign convention at local coordinate of shell element

\subsection{SAP2000 Software and API}

In this study, SAP2000 software version 17, which is a powerful tool for the finite element analysis is employed in combination with Application Programming Interface (API). API is created to enable users to create a spreadsheet, plugin, or third-party-application, and is compatible with most major programming languages. API is used in this research to analysis more than 2400 computerized modeling and to automate the process required to acquire customized analysis and results with providing a path for two-way exchange of model information with Microsoft excel which includes Visual Basic Application (VPA).

It is good to note that, this tool plays a key role in this study, otherwise the process of collecting data from specified nodes from modelling could be time-consuming and rigorous task. The VPA codes can be written in Microsoft Excel to find transverse and longitudinal moments as well as deflection for various cantilever-barrier configurations with changing parameters. The sample codes, which used in this study presented in Appendix B. 


\subsection{Finite Element Modelling of Deck Slab Overhang}

In this study, over 2400 finite element modeling were created by SAP2000 software for the purpose of sensitivity and parametric studies. Similar to the approach used to develop the simplified methods explained in the literature review Chapter, the cantilever deck slabs was created by isolating it from the rest of the bridge deck slab on the slab-on-girder bridge system and restraining its end at the centre of the exterior girder against rotations and movements along the cantilever root. Thin shell element with six degrees of freedom at nodes was employed to model the cantilever slab and the cast-in-place concrete barriers. Also, centerline approach was used for modeling the deck slab and barrier wall, considering rigid joint between them. Figure 3-3 depicts a schematic diagram of the finite element modelling of the barrier-deck slab cantilever system using the centreline approach with the thickness of each element extruded to obtain surface stresses and contour lines if required.

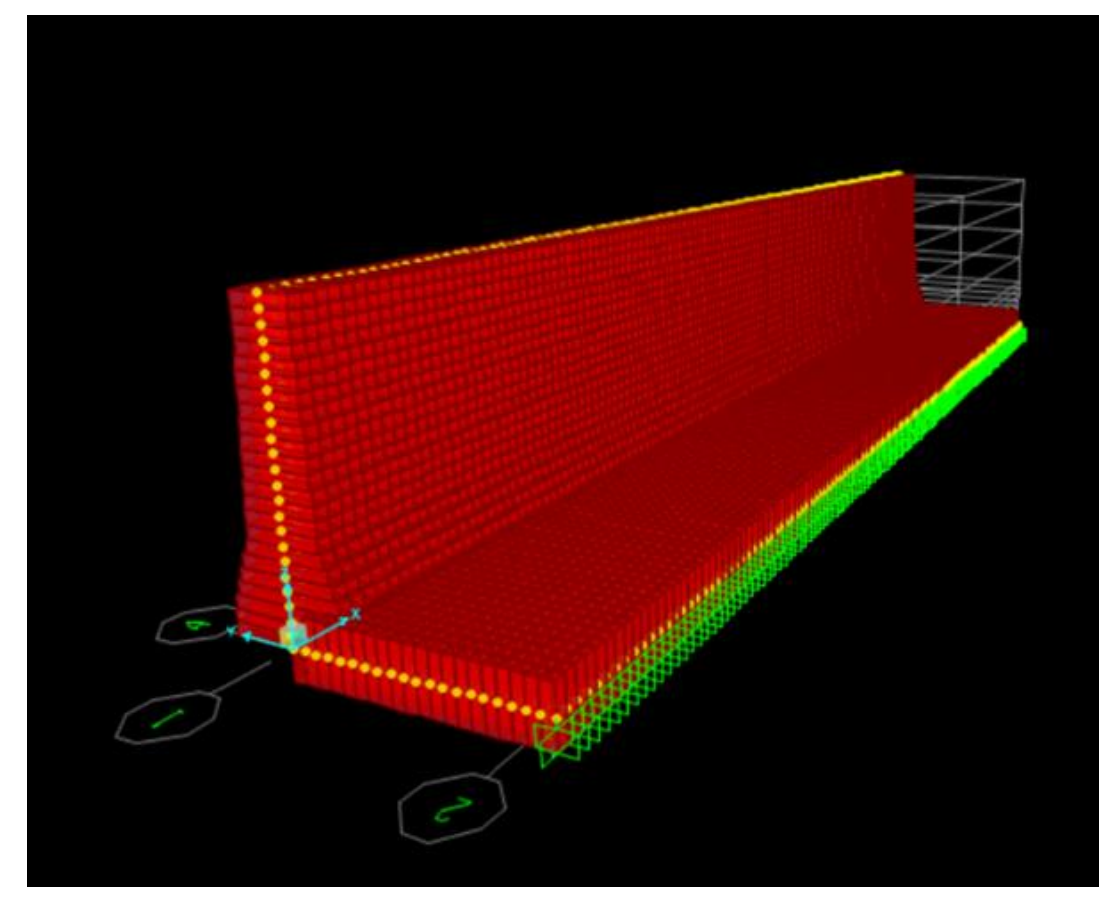

Figure 3-3: Schematic diagram of the FEA modeling showing the centerline approach for modeling the edge-stiffened cantilever slab 
With respect to number of elements used in the modeling, 50x50 mm element size was utilized and element thickness equal to either the thickness of the barrier wall or the deck slab cantilever. For the deck slab with constant thickness, the thickness of shell element was considered as thickness of the deck slab, while for tapered deck slab, the slab was divided into five areas through its length to simulate the body of a linear varying cantilever overhang as shown in Figure 3-4. Average thickness of these areas was considered as the thickness of the shell elements. The same approach is used for creating tapered barriers. Therefore, for each $50 \mathrm{~mm}$ segment of the barrier wall along the height, an average wall thickness was assigned as the thickness of shell element through the barrier to replicate the cross sectional variation of tapered wall as shown in Figure 35.

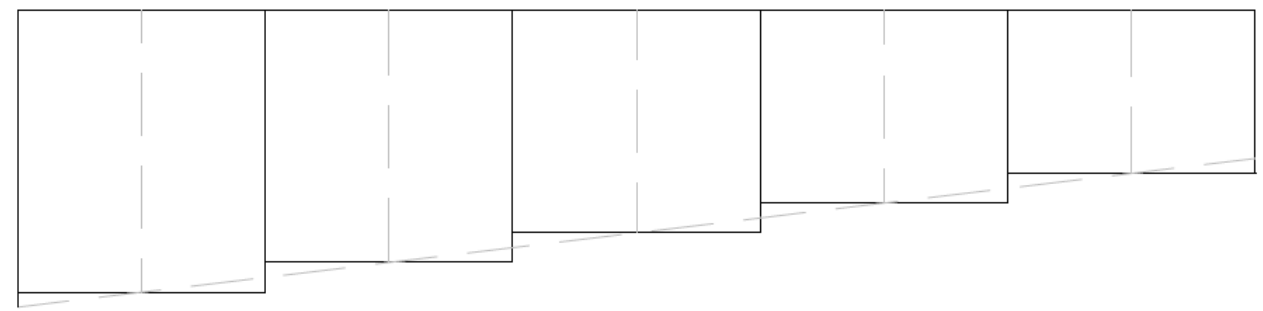

Figure 3-4: Schematic Diagram showing varying thickness of the cantilever slab modeling

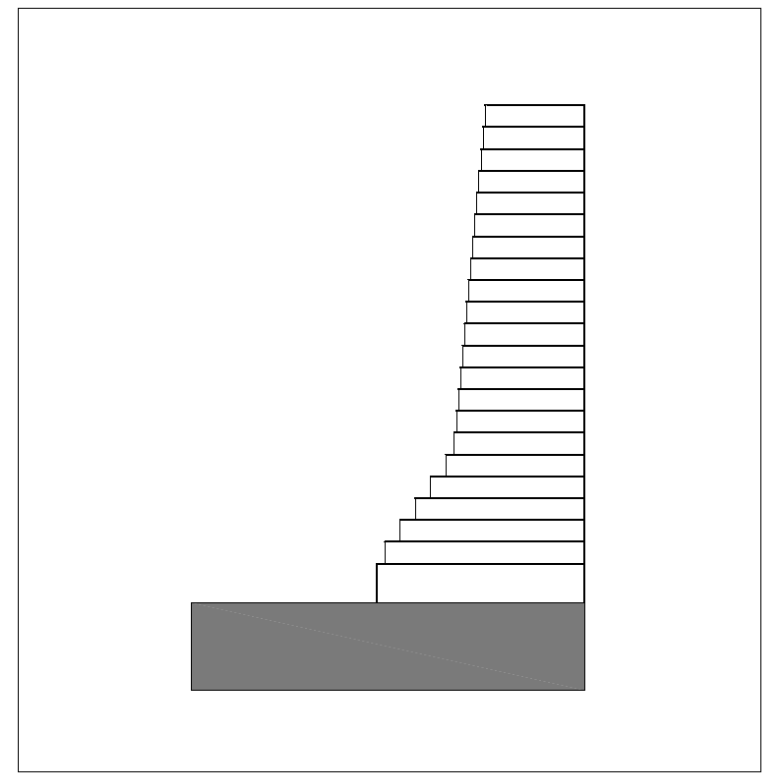

Figure 3-5: Schematic diagram showing the tapered barrier wall with $50 \mathrm{~mm}$ length of finite elements of equal average width for each segment of the barrier height 


\subsubsection{Aspect Ratio}

In general, the ratio of the longest dimension to the shortest dimension of a quadrilateral element is called aspect ratio. According to the literature review, the inaccuracy of the solution increases by rising the aspect ratio (Logan, 2012). This demonstrates that the results are expected to be close to exact solution for the elements with smaller aspect ratio, ideally close to 1 . Consequently, as explained earlier, the $50 \times 50 \mathrm{~mm}$ finite elements with aspect ratio of 1 were used to simulate cantilever overhang and barrier wall. However, in some areas like the base of tapered barriers, this number increased to a maximum of 1.1.

\subsubsection{Material Modeling}

Material properties for the barrier wall and the deck slab cantilever were employed in this study are defined as linear elastic and isotropic. The material is defined in SAP2000 software and a unique name was assigned to it. Also, mesh reinforcement was not considered for the modeling. The defined material properties utilized for cantilever slab and barriers by SAP2000 software are as follows:

$>$ Compressive strength of concrete $\left(\mathrm{f}_{\mathrm{c}}^{\prime}\right)$ was taken as $30 \mathrm{MPa}$

$>$ The specific weight of concrete $\left(\gamma_{c}\right)$ was assumed as $24 \mathrm{kN} / \mathrm{m}^{3}$

$>$ The modulus of elasticity of concrete $\left(\mathrm{E}_{\mathrm{c}}\right)$ was determined through following formula:

$$
E c=4500 \sqrt{f_{c}^{\prime}}
$$

Poisson's ratio $(v)$ was considered as 0.2

\subsection{Types of barrier configurations}

Figure 3-6 illustrates the different geometric shapes of barriers with their denoted names. 


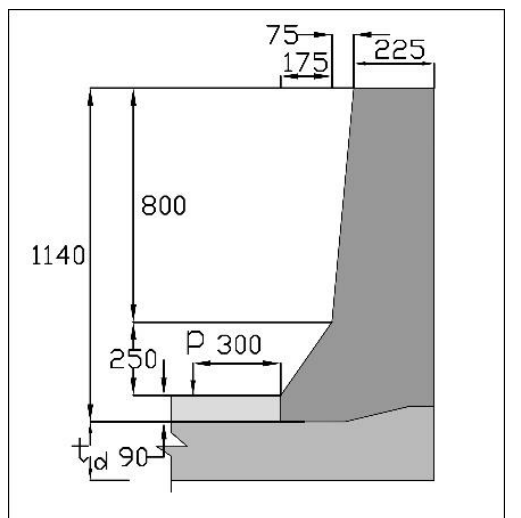

(a) TL-5 Barrier

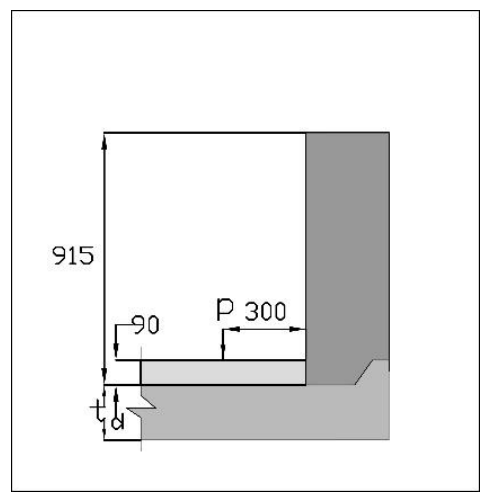

(d) TL-4 Parapet

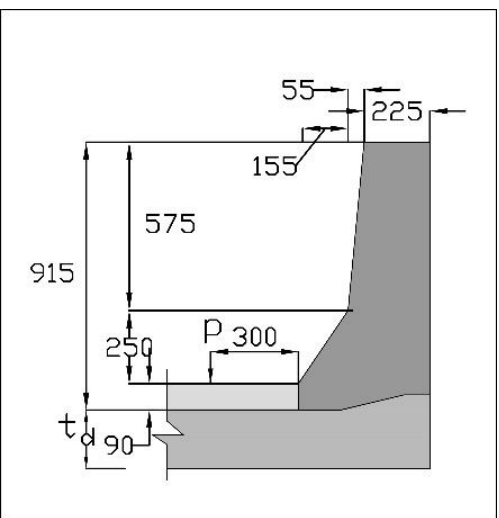

(b) TL-4 Barrier

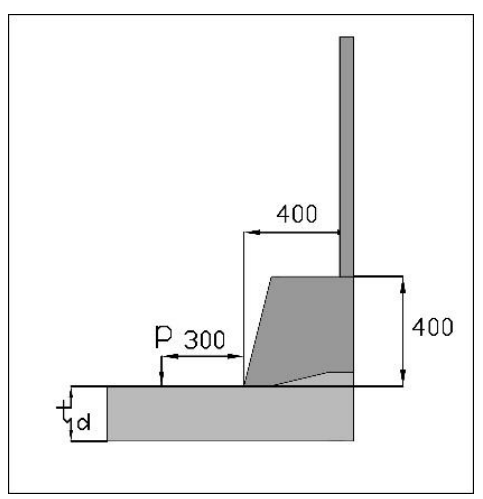

(e) Curb

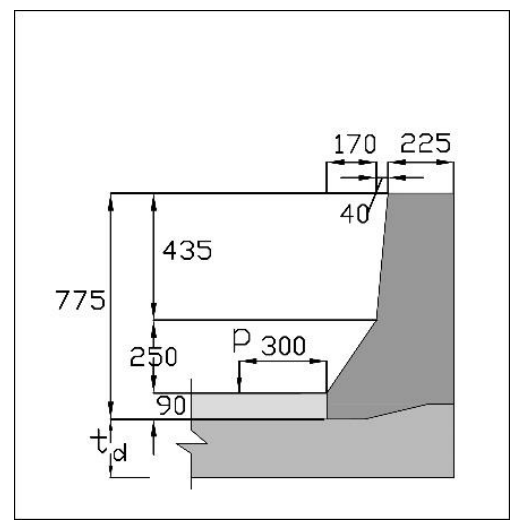

(c) TL-2 Barrier

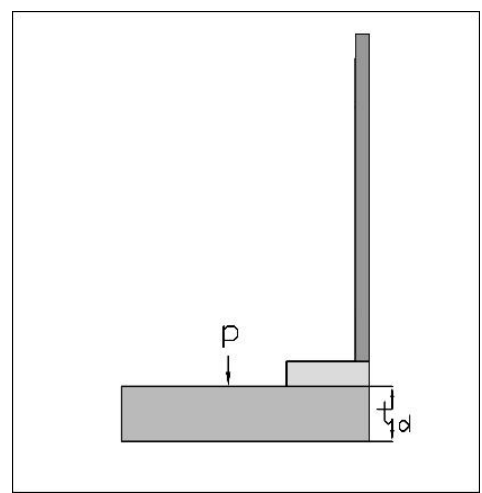

(f) Unstiffened Edge

Figure 3-6: Barrier configurations considered in this study

\subsection{Loading Cases}

In this study, CL-625 truck load was applied near the free edge of deck slab overhang $300 \mathrm{~mm}$ away from the inner (traffic) side of the barrier, curb or parapet as depicted in Figure 3-6. CHBDC defines two types of CL-W loading as follows:

1) CL-W truck which is the idealized five-axle truck as shown in Figure 3-7. W is shown in Figure 3-7(a) represents the gross load of CL-W truck in kilo-Newton, while Figure3-7 (b) demonstrates the wheel spacing, weight distribution, and clearance envelope of the CL-W truck.

2) CL-W lane load which is defined as per clause 3.8.3.1.3 of CHBDC and consists of a CL-W truck with each axel reduced to $80 \%$ of the original value and superimposed within a uniformly distributed load of 9 kN/m over $3.0 \mathrm{~m}$ wide as shown in Figure 3-8. 
In this study, CL-625 axel load was applied at region of the transverse free end of the cantilever slab. Instead of applying point loads, a physical footprint of $600 \times 250 \mathrm{~mm}$ utilized for each axel was considered in the modelling. The magnitude of the load of each axel was then divided by the footprint area to calculate area pressure of the footprint in mega-pascal. In addition, the edge of axel footprint was applied at the distance $300 \mathrm{~mm}$ away from the inner (traffic) side of the barrier wall as depicted in Figure 3-9. Moreover, the loading cases which used in this research are demonstrated in Figure 3-10. These loading cases are meant to determine the greatest moment at the fixed end of the deck slab cantilever, given the change in axle loadings, spacing of axles, number of axles to be considered and the corresponding dynamic load allowance.

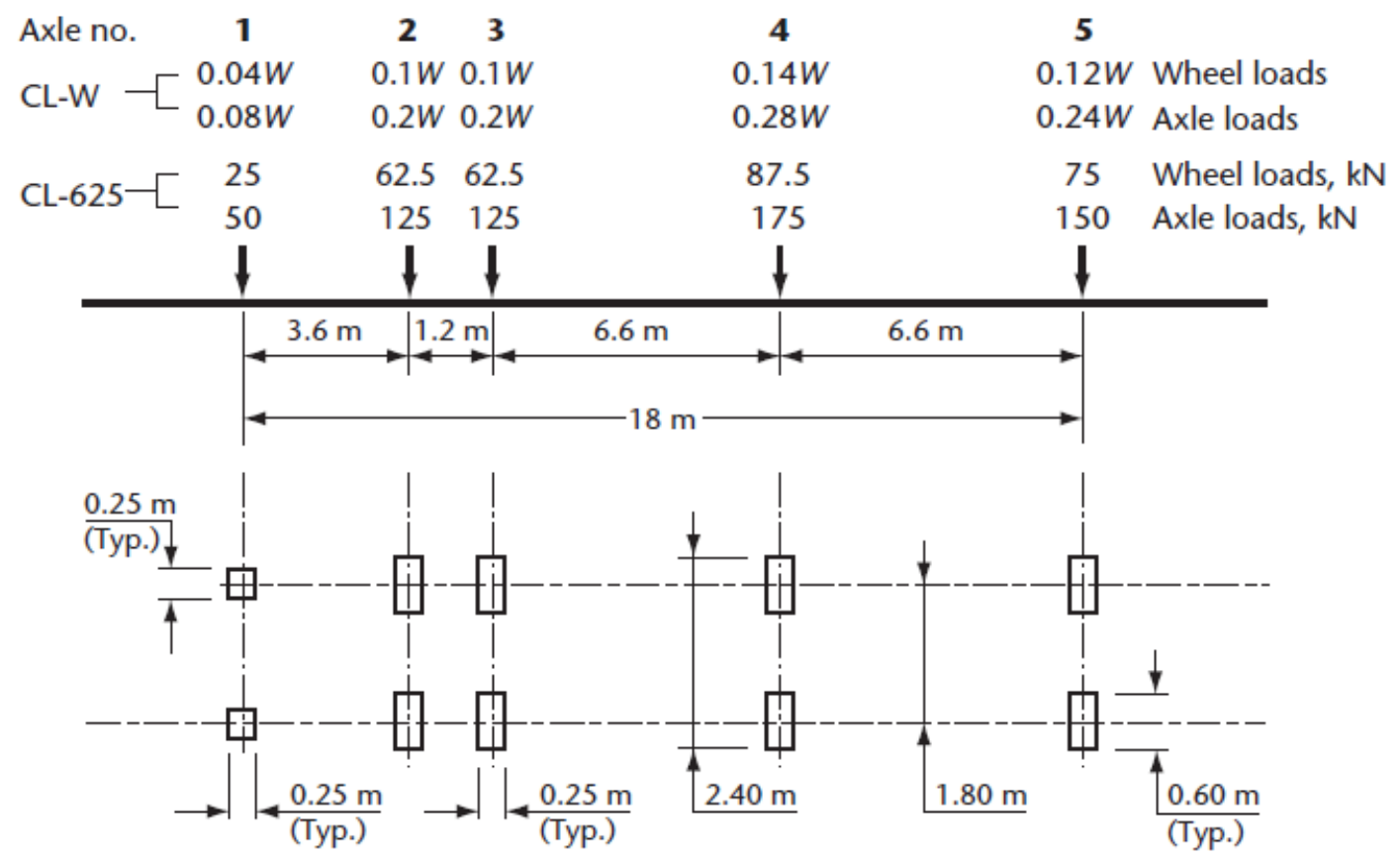

(a) 


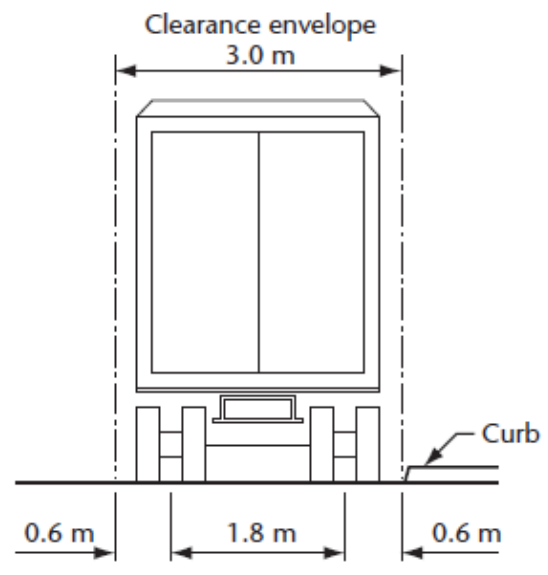

(b)

Figure 3-7: (a) CL-W truck loading, (b) CL-W truck (CSA, 2014a)

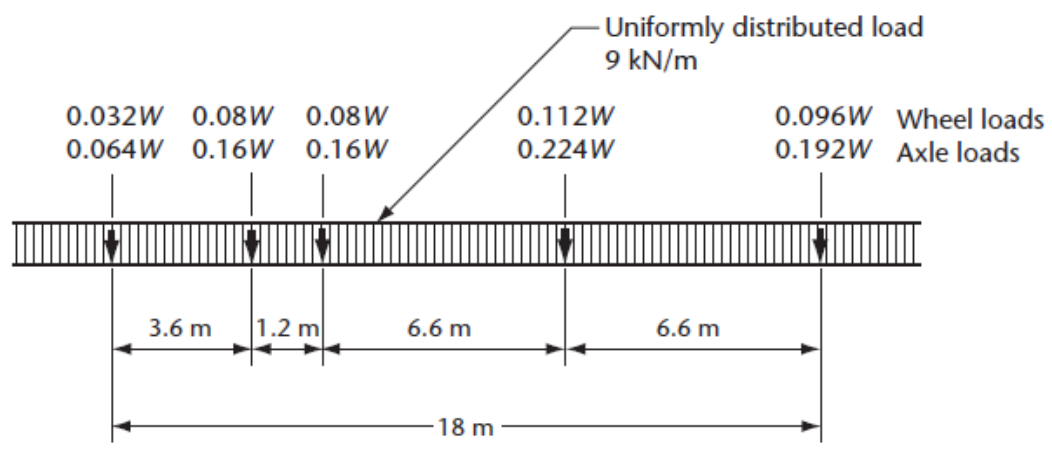

Figure 3-8: Lane loading (CSA, 2014a)

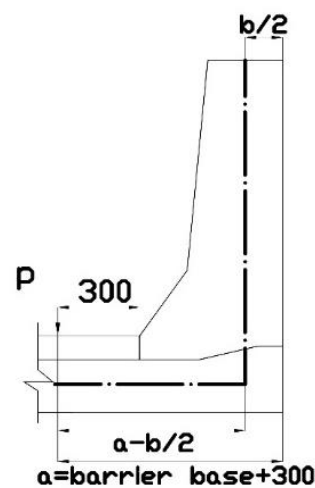

Figure 3-9: Location of the applied load beside the inner side of the barrier wall and the centreline of the FE modeling 
As it can be seen from Figure 3-10, only loading cases with one wheel applied, since maximum cantilever length $\left(\mathrm{L}_{c}\right)$ investigated in this study was $2.5 \mathrm{~mm}$. As a result, there was no enough space to fit loading cases with two wheels.

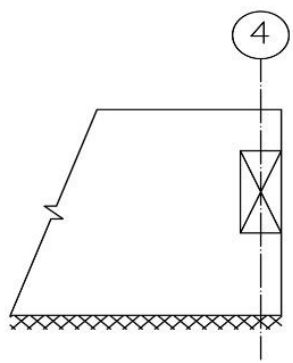

(a) Cantilever slab with truck axle 4

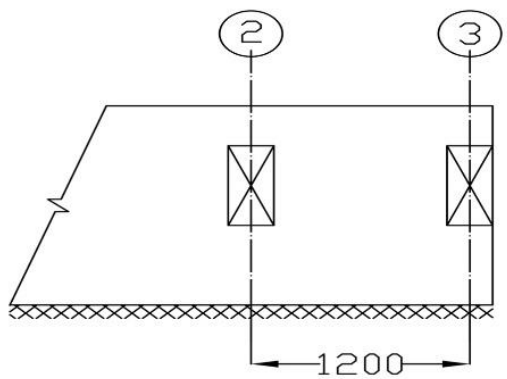

(b) Cantilever slab with truck axles 2 and 3

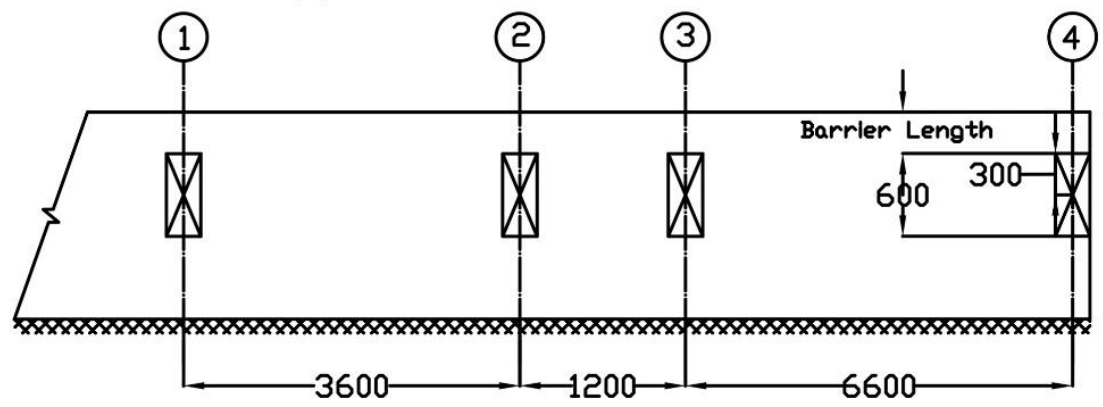

(c) Cantilever slab with truck axles $1,2,3$ and 4

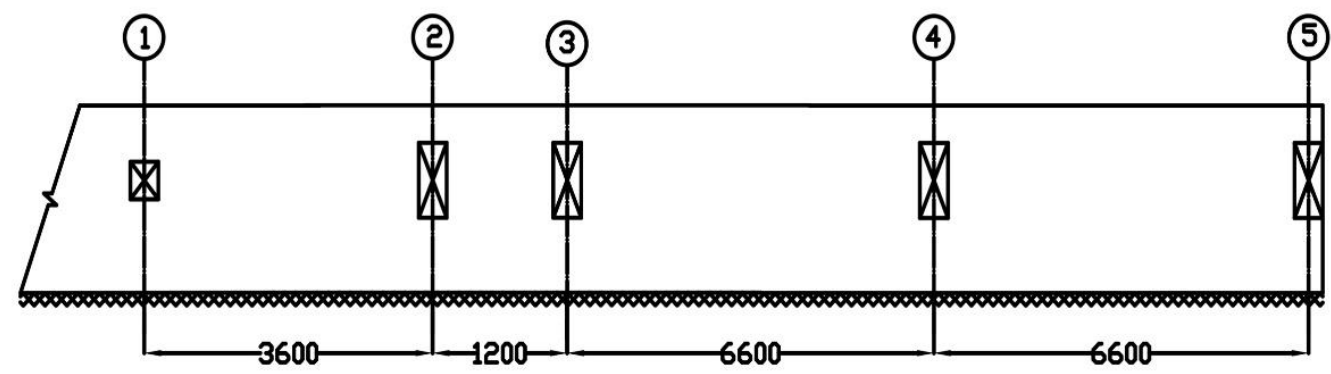

(d) Cantilever slab with full truck loading

Figure 3-10: Plan views of the deck slab cantilever with different loading cases 


\subsection{Dynamic Load Allowances}

Table 3-1 shows the dynamic load allowances $\left(I_{D}\right)$ specified by CHBDC. By applying the dynamic load allowance for each loading case, the load applied to the cantilever slab can be calculated as follows:

$$
\text { Wheel load }=\mathrm{P}\left(1+\mathrm{I}_{\mathrm{D}}\right)
$$

Table 3-1: Dynamic load allowance per CHBDC (2014)

\begin{tabular}{lccccc}
\hline & One axel & Two axels & Three axels & Four axels & Five axels \\
\hline Dynamic Load Allowance, ID & 0.4 & 0.3 & 0.25 & 0.25 & 0.25 \\
\hline
\end{tabular}

\subsection{Sensitivity Study on Location of Maximum Transverse and Longitudinal Moment in the Cantilever Slab}

This study was carried out to investigate the location of maximum transverse and longitudinal moment due to CL-625 loading conditions near the transverse free end of the deck slab cantilever. The calculated moment herein is taken as the average moment values from the $1 \mathrm{~m}$ strip at the location of maximum moment for each loading case. This greatest average may be calculated from the following, as an example:

$500 \mathrm{~mm}$ from each side of maximum moment if the distance from the maximum moment value is greater than $500 \mathrm{~mm}$ from the free end of the cantilever slab.

$>400 \mathrm{~mm}$ from one side of the location of maximum moment and $600 \mathrm{~mm}$ from other side (i.e. one side may be greater in length than the other side, measured from maximum moment location).

$>$ All the $1000 \mathrm{~mm}$ is from one side of the greatest moment value, if it is at the free end.

Another aim of this investigation was to find out which loading case amongst the cases shown in Figure 3-10 produces the greatest transverse and longitudinal moment. This study was conducted on two types of cantilever slab, namely: unstiffened cantilever overhang, and cantilever slab stiffened with TL-4 parapet. The barrier length $\left(\mathrm{L}_{b}\right)$ and the cantilever length $\left(\mathrm{L}_{c}\right)$ were considered 
as $20 \mathrm{~m}$ and $1.5 \mathrm{~m}$, respectively. A constant slab thickness of $200 \mathrm{~mm}$ was assumed (i.e. $\mathrm{t}_{\mathrm{r}}=1$ ). Separate SAP2000 files were created for each loading case. The coordinate origin was placed at free longitudinal edge of cantilever slab so the fixed edge at the root is $1.5 \mathrm{~m}$ from origin in vertical direction as shown in Figure 3-11.

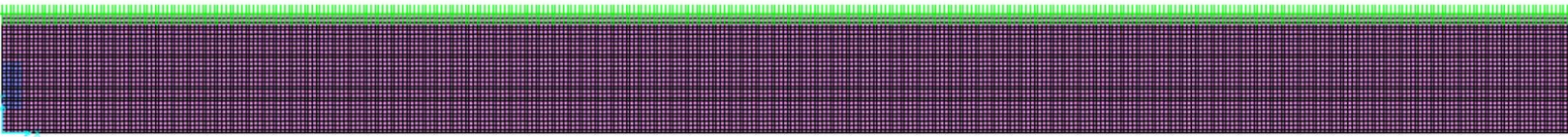

Figure 3-11: Coordinate origin $(0,0)$ located at corner of transverse free end (where axel load applied) and longitudinal free edge of cantilever slab

The developed FE models were analysed, and the results were recorded for both transverse and longitudinal moments in both transverse and longitudinal direction in excel spreadsheet with the help of API application. Then, 3D plot was created by SigmaPlot software version 13.0 from the generated date from modelling.

As it can be seen thorough the 3D graphs presented in in Figures 3-12 through 3-27, axel 4 with the first loading case in Figure 3-10 produced the maximum transverse and longitudinal moments for both unstiffened cantilever slab and edge-stiffened deck slab overhang with TL-4 parapet. In addition, the maximum moment in both transverse and longitudinal direction occurred at the cantilever slab's fixed edge near the transverse free end where the axel load applied.

Figures 3-12 through 3-15 illustrate the transverse moment intensity in $\mathrm{kN} . \mathrm{m} / \mathrm{m}$ due to different loading case for the unstiffened cantilever slab. Transverse moment was plotted in $\mathrm{Z}$ axis versus cantilever length in $\mathrm{X}$ axis, and barrier length in $\mathrm{Y}$ direction. Also, Figures 3-16 through 3-19 show the longitudinal moment intensity for the same cantilever slab configuration. Figures 3-20 through 3-23 and Figures 3-24 through 3-27 demonstrate the transverse and longitudinal moment, respectively, for the cantilever slab stiffened with PL-4 parapet. 


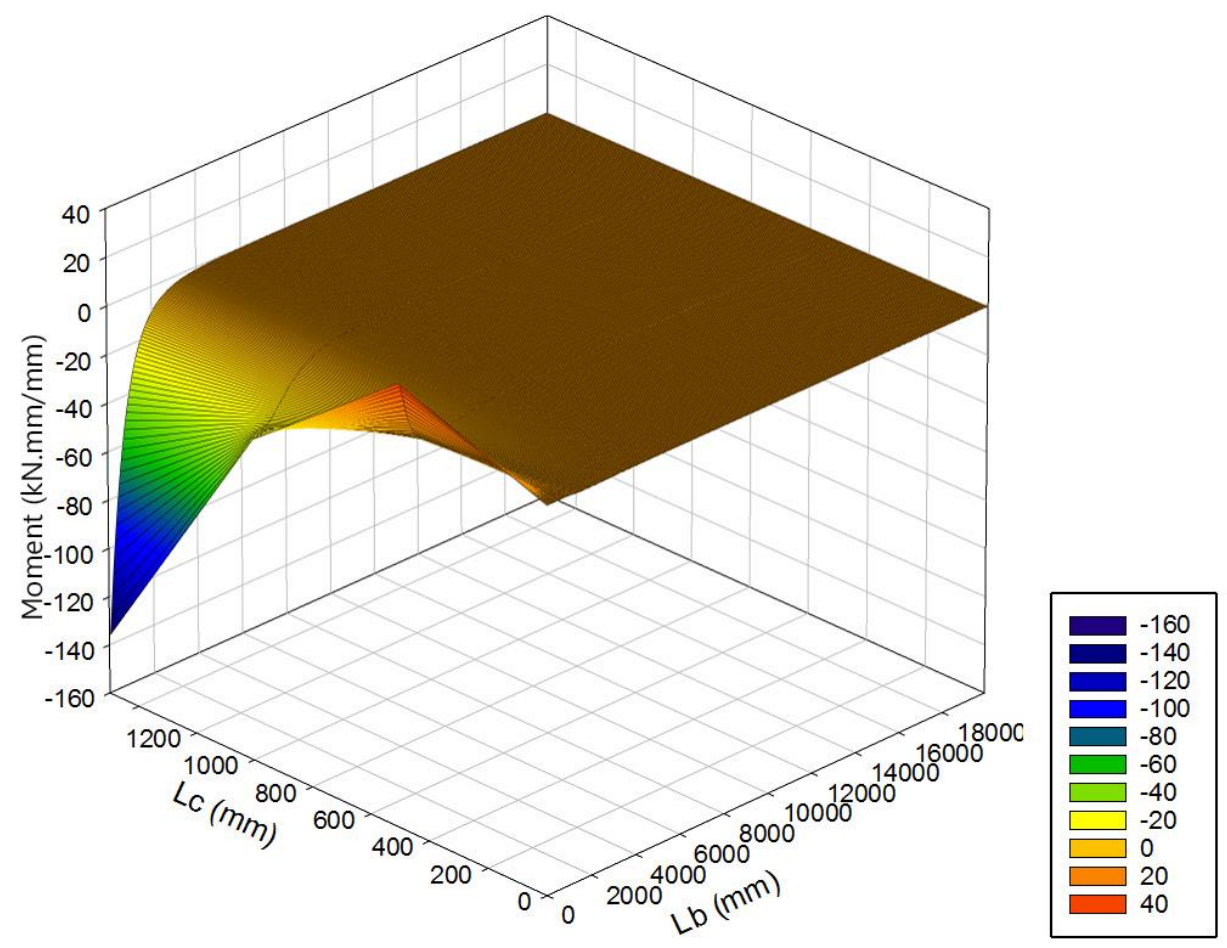

Figure 3-12: Transverse moment versus barrier length due to axle 4 loading on unstiffened cantilever slab of $1.5 \mathrm{~m}$ length
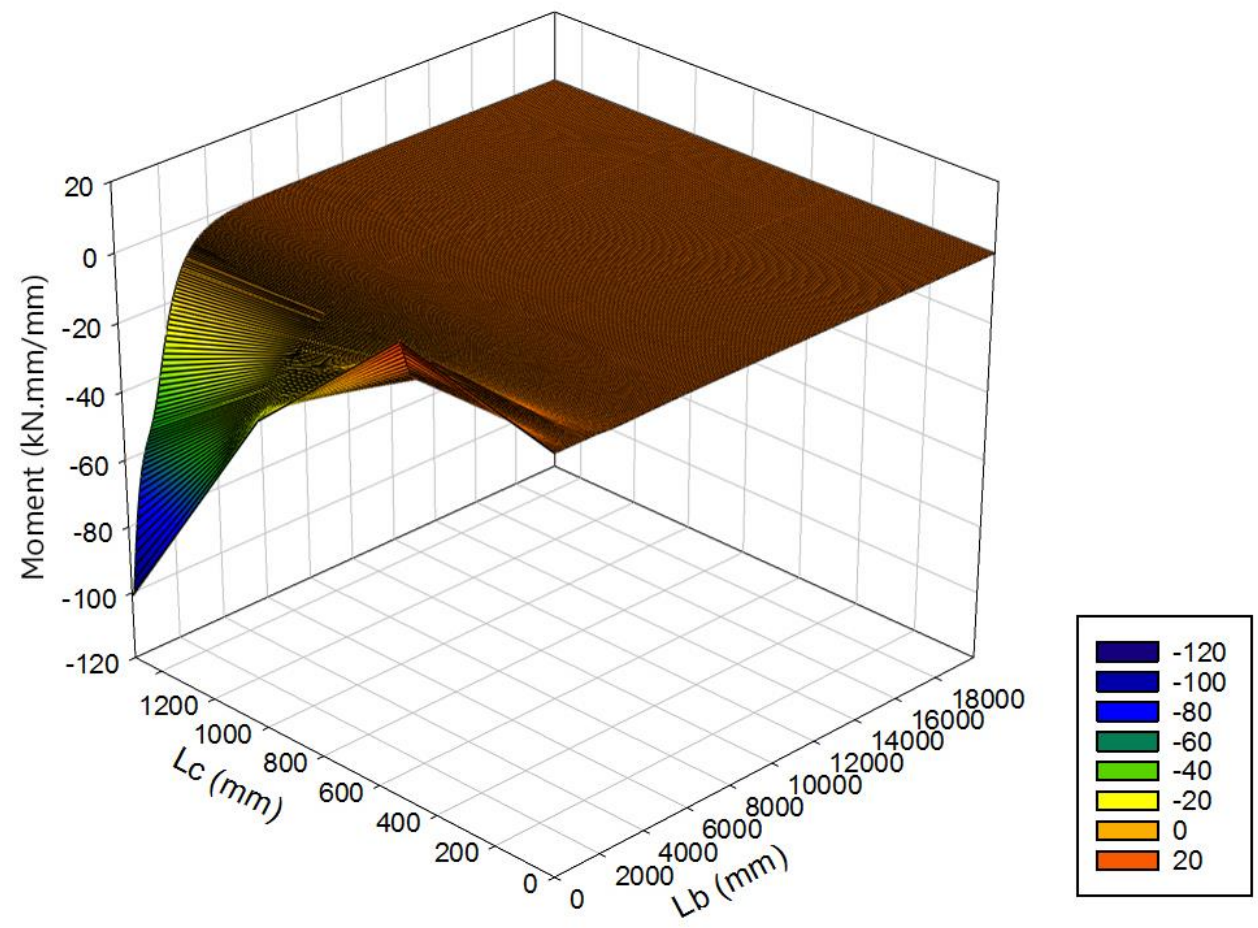

Figure 3-13: Transverse moment versus barrier length due to axles 2 and 3 on the unstiffened cantilever slab of $1.5 \mathrm{~m}$ length 


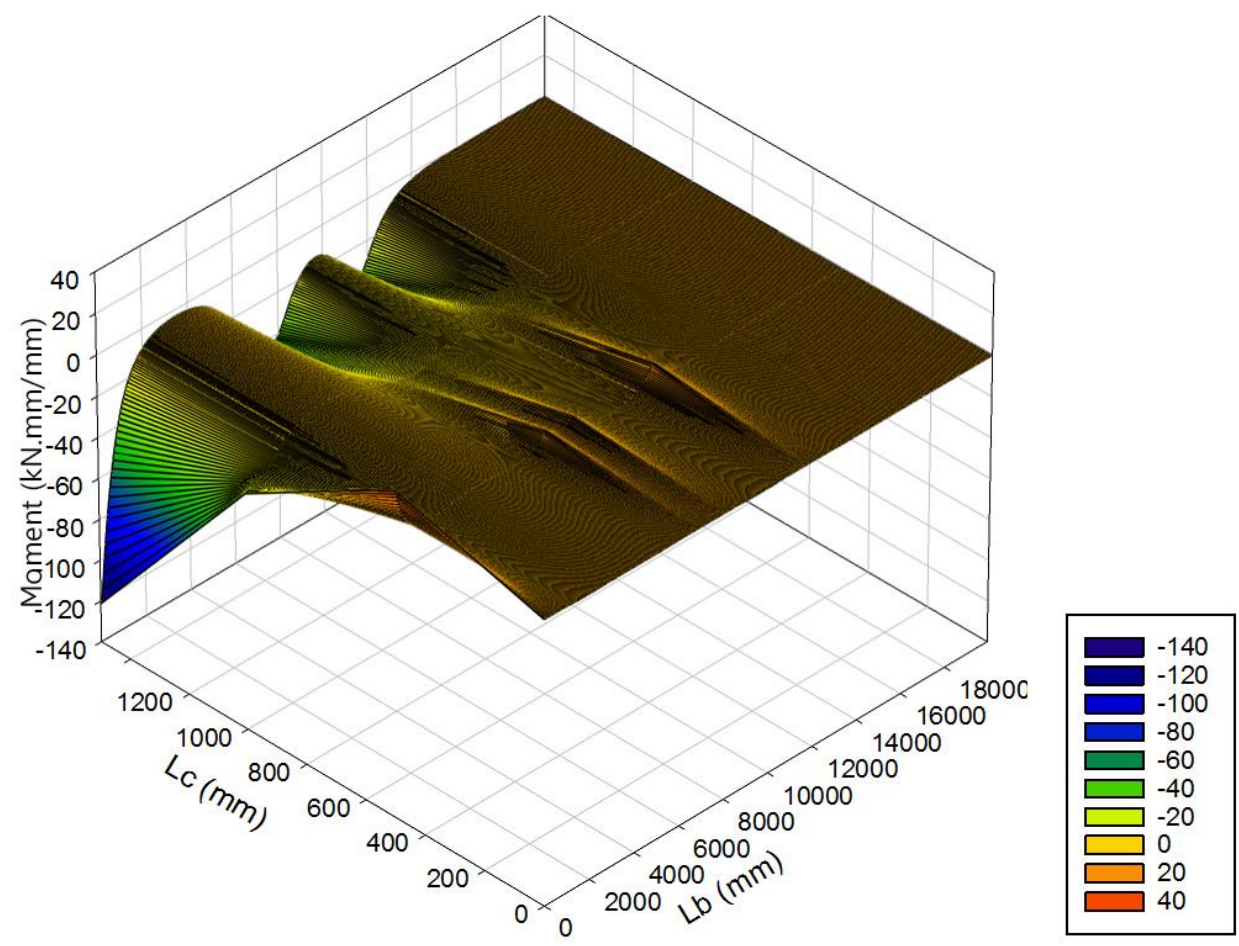

Figure 3-14: Transverse moment versus barrier length due to axles 1, 2, 3 and 4 on the unstiffened cantilever slab of $1.5 \mathrm{~m}$ length

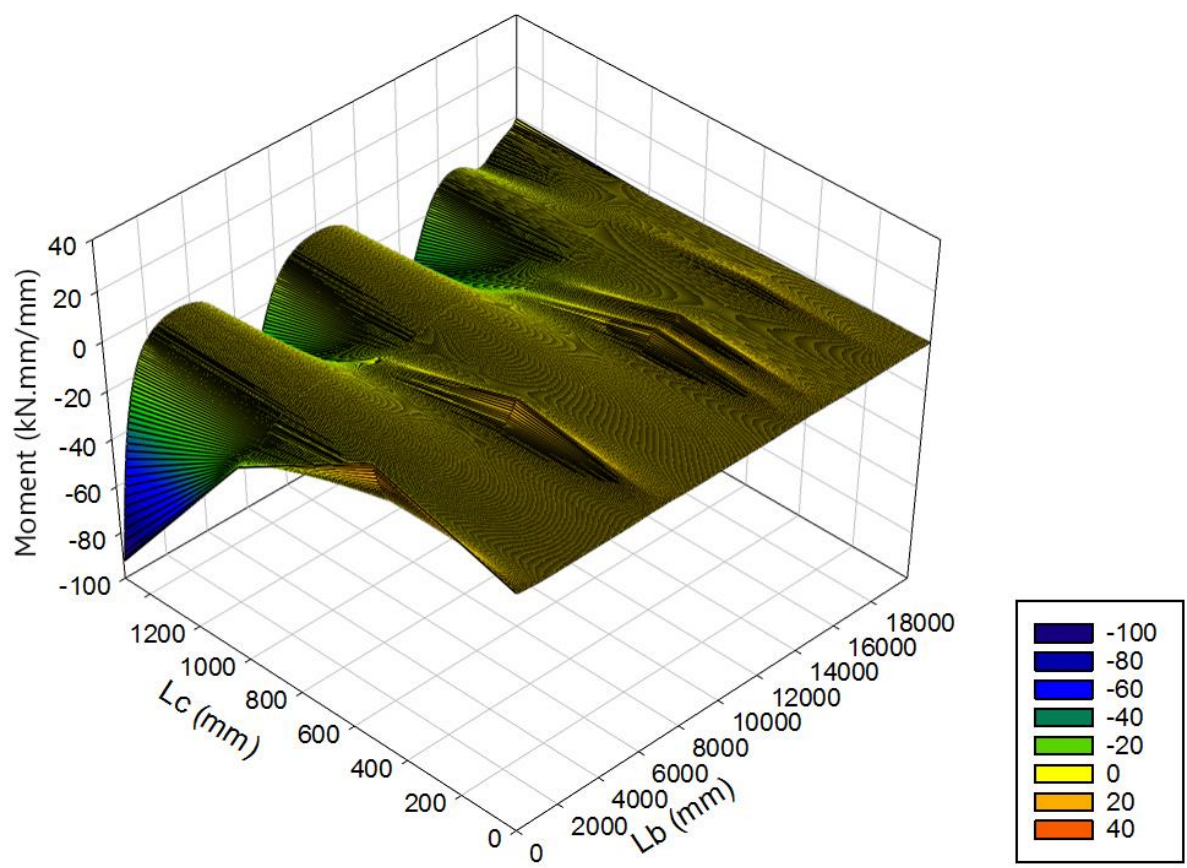

Figure 3-15: Transverse moment versus barrier length due to full truck loading with 5 axles on the unstiffened cantilever slab of $1.5 \mathrm{~m}$ length 

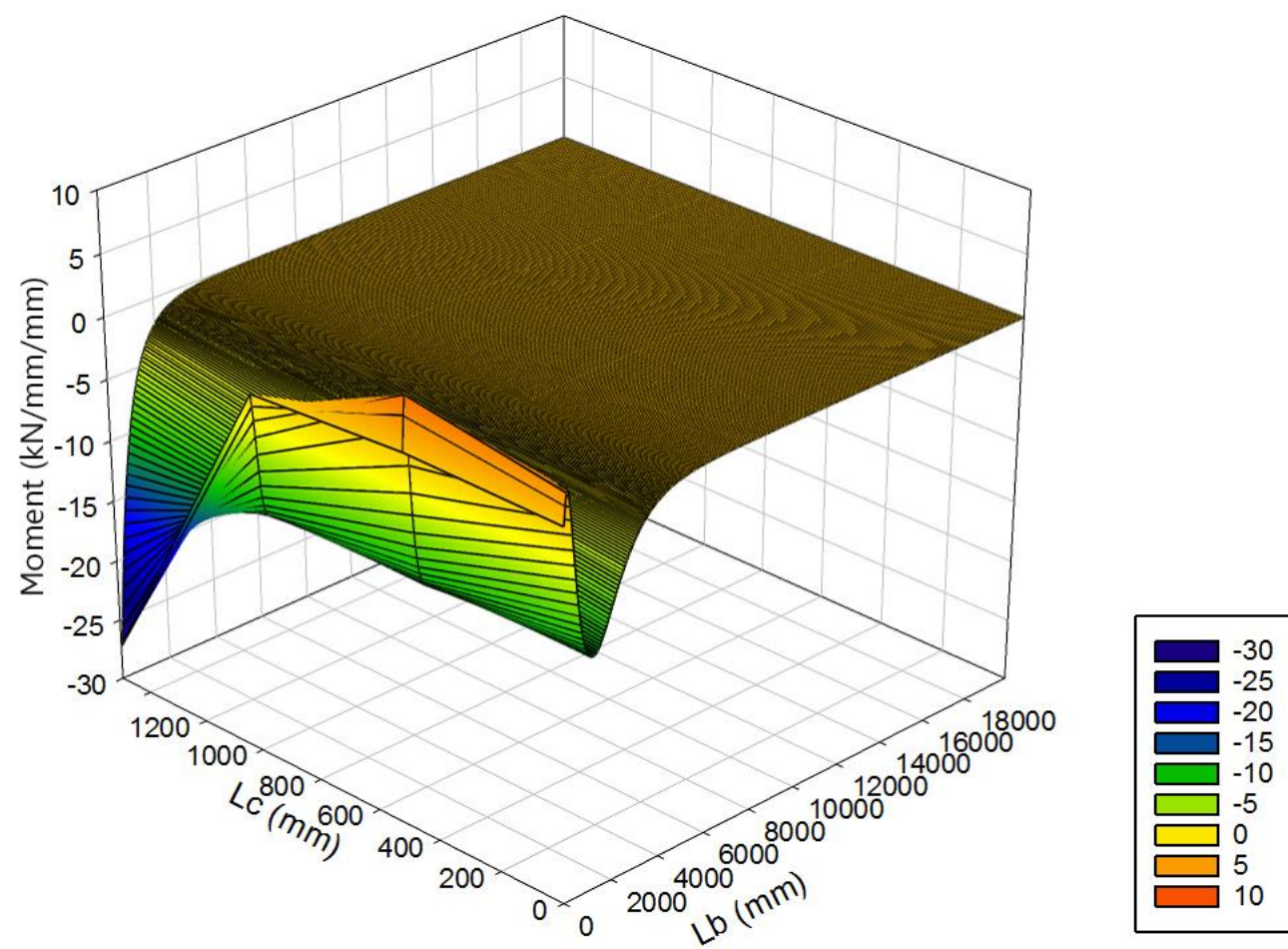

Figure 3-16: Longitudinal moment versus barrier length due to axle 4 on the unstiffened cantilever slab of $1.5 \mathrm{~m}$ length
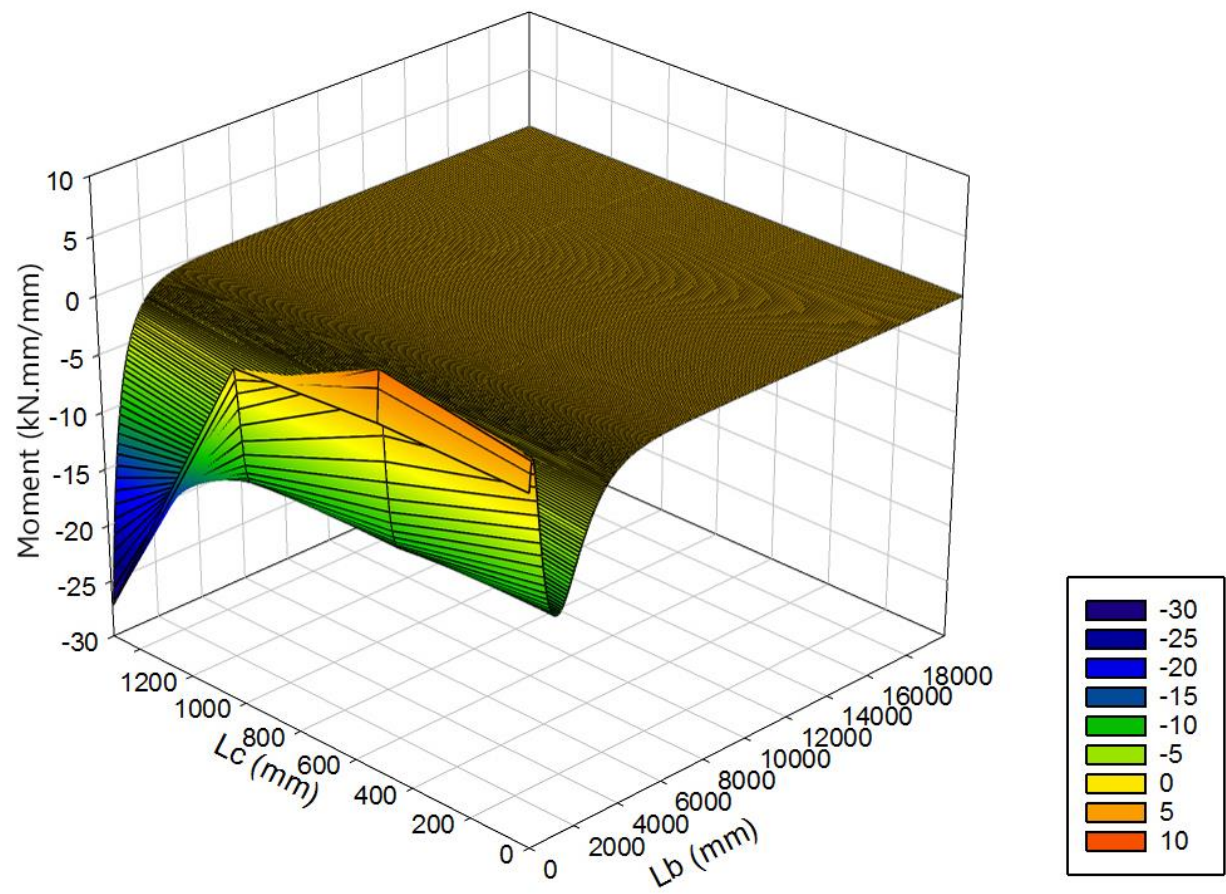

Figure 3-17: Longitudinal moment versus barrier length due to axles 2 and 3 on the unstiffened cantilever slab of $1.5 \mathrm{~m}$ length 


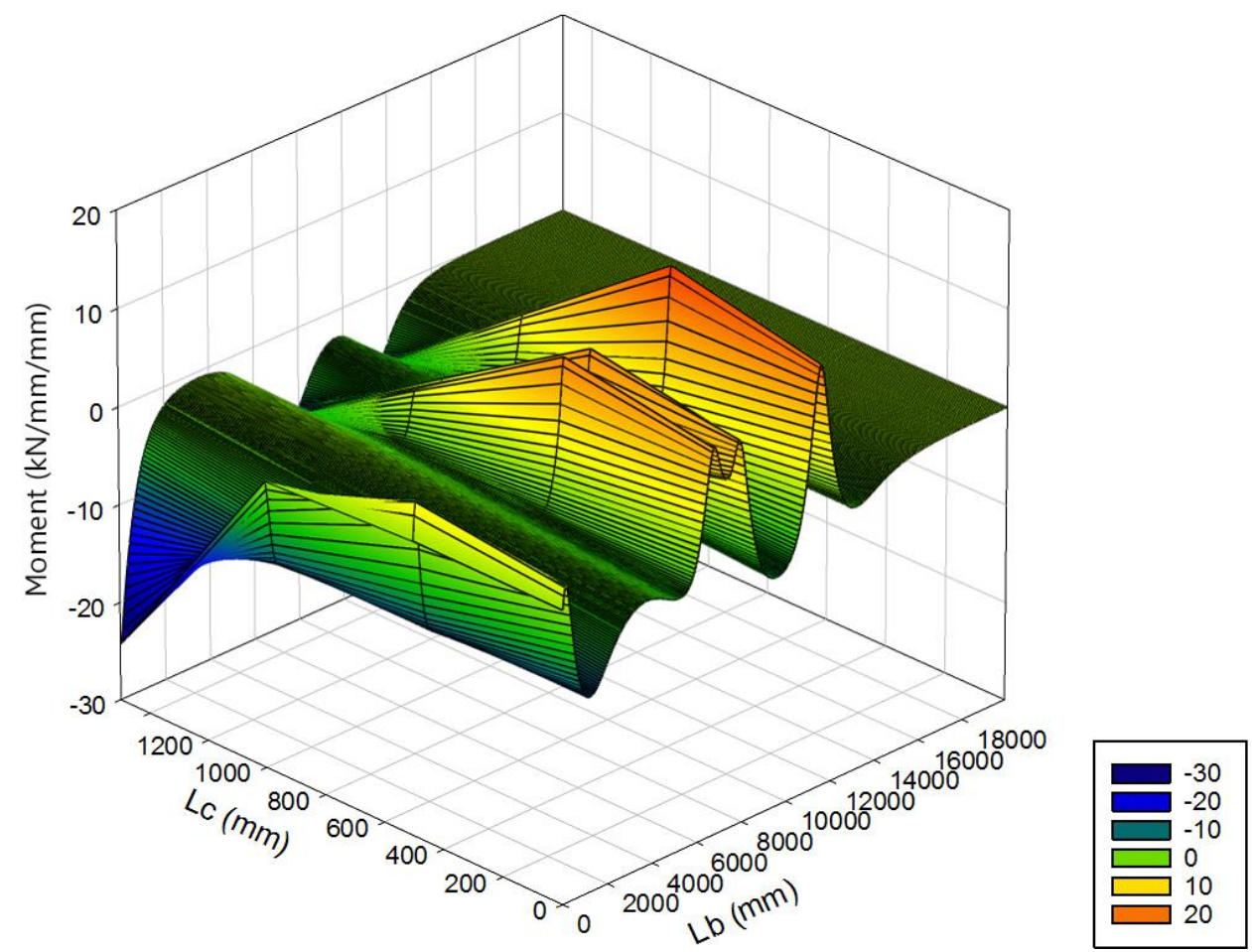

Figure 3-18: Longitudinal moment versus barrier length due to axles 1, 2, 3 and 4 on the unstiffened cantilever slab of $1.5 \mathrm{~m}$ length

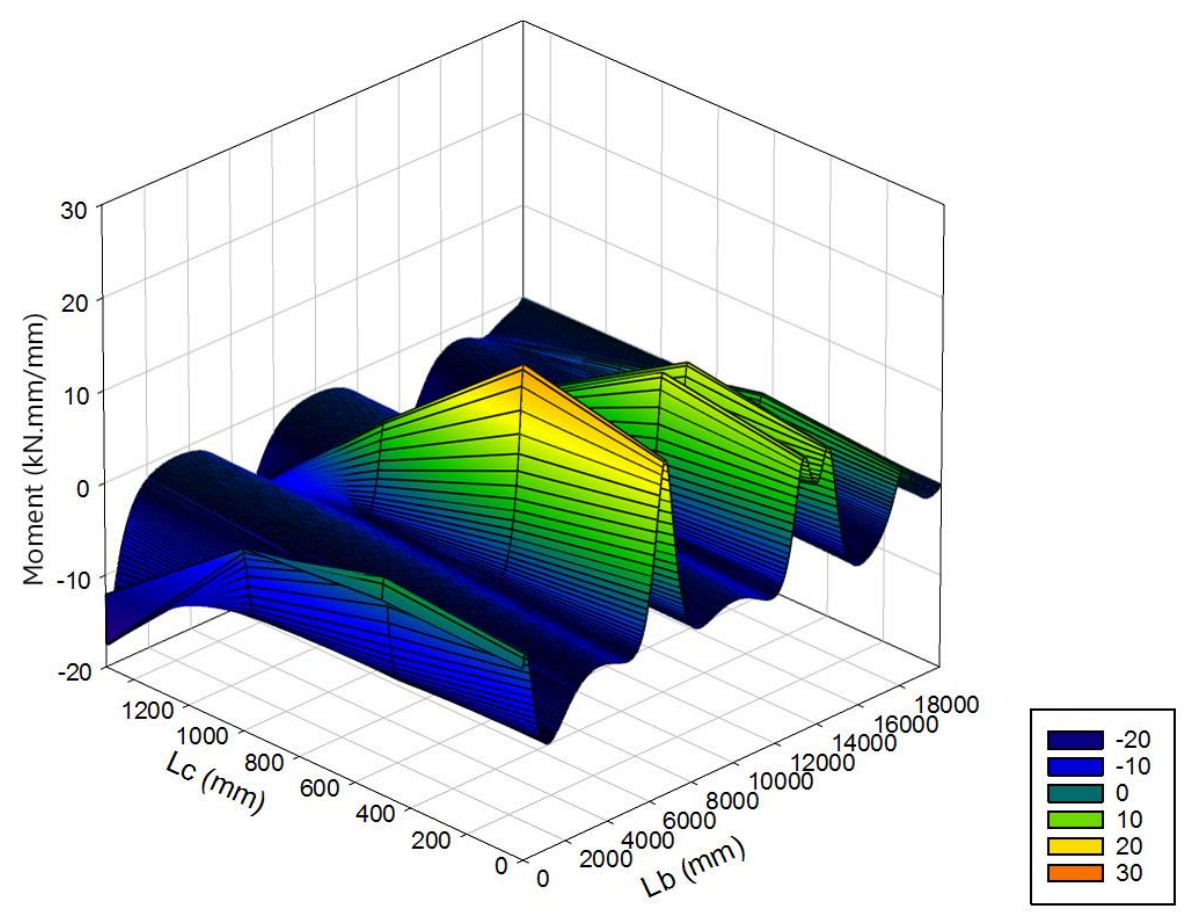

Figure 3-19: Longitudinal moment versus barrier length due to full truck loading with 5 axles on the unstiffened cantilever slab of $1.5 \mathrm{~m}$ length 


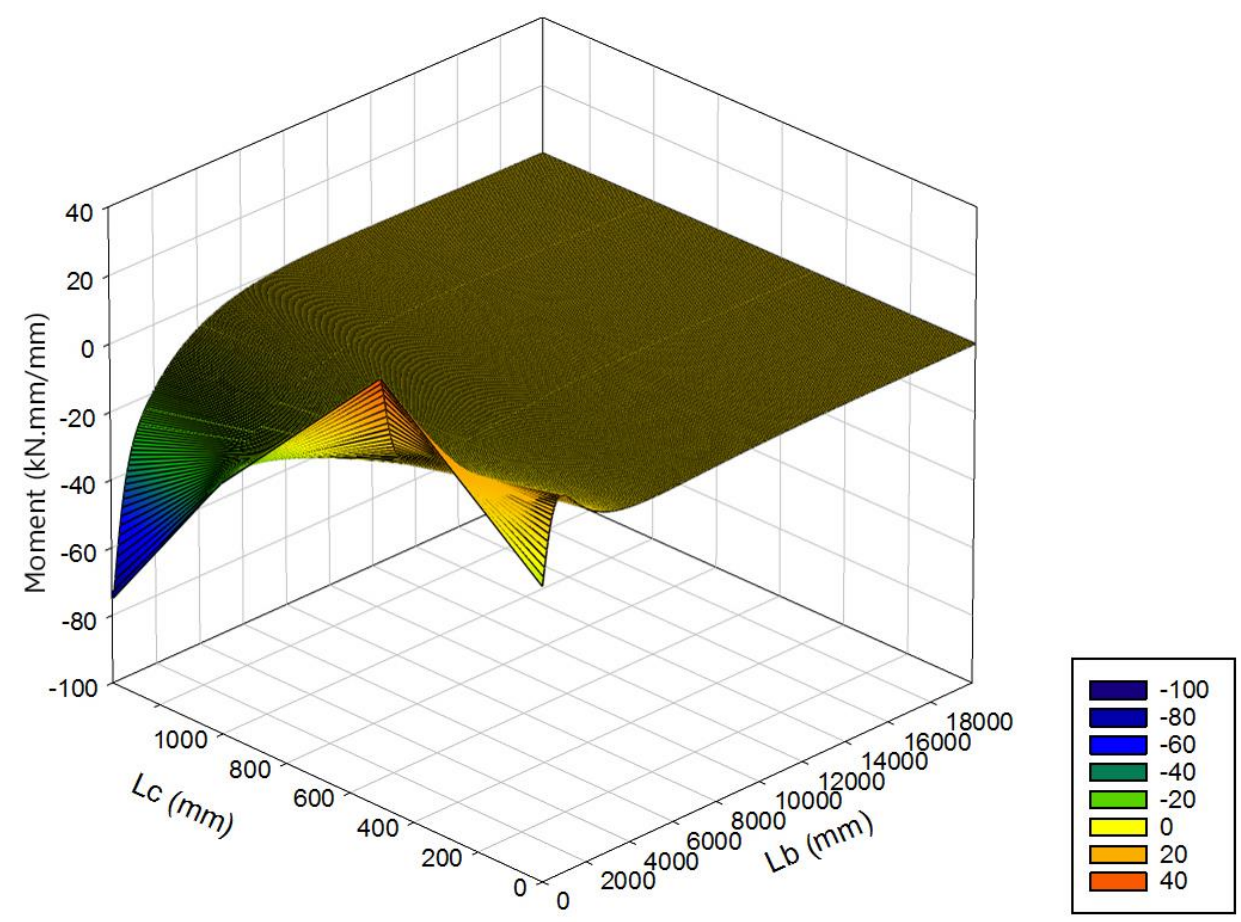

Figure 3-20: Transverse moment versus barrier length due to axle 4 for the stiffened cantilever slab of $1.5 \mathrm{~m}$ length

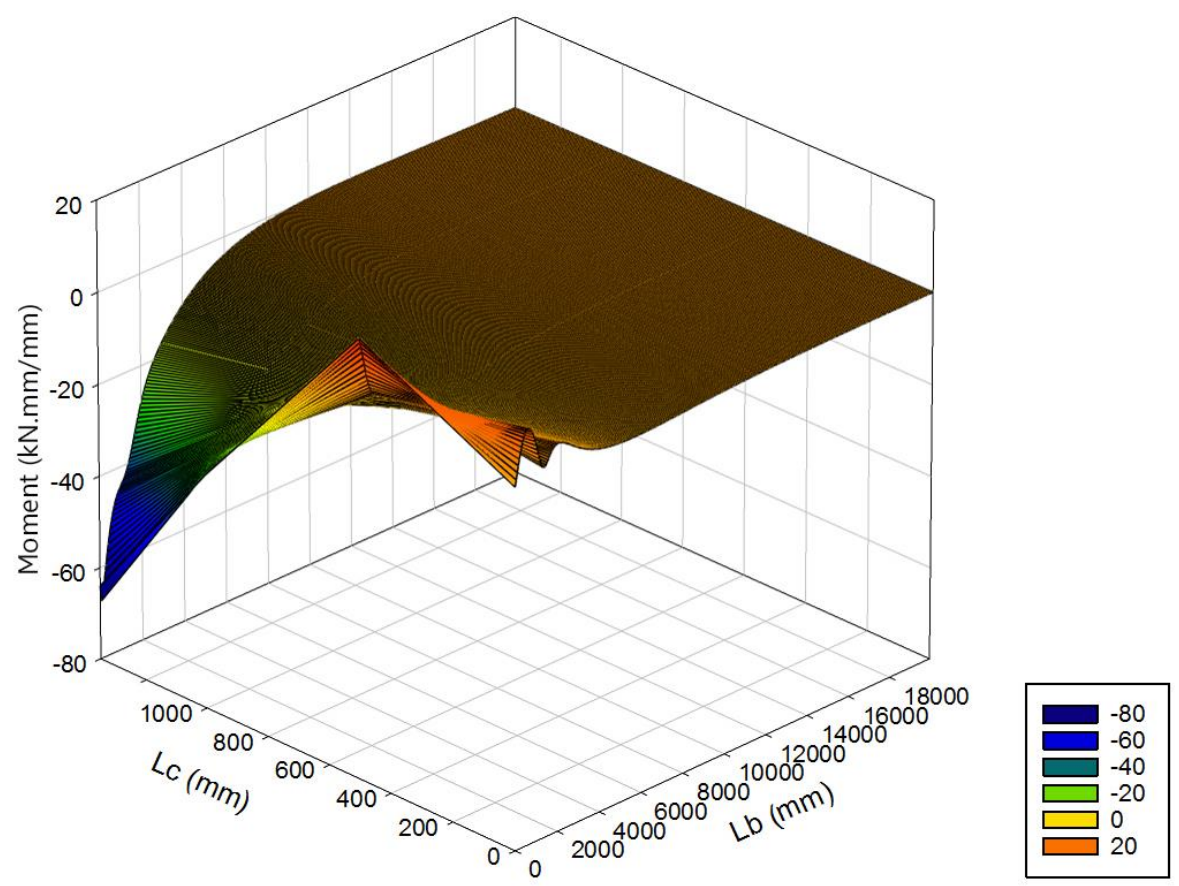

Figure 3-21: Transverse moment versus barrier length due to axles 2 and 3 on the stiffened cantilever slab of $1.5 \mathrm{~m}$ length 


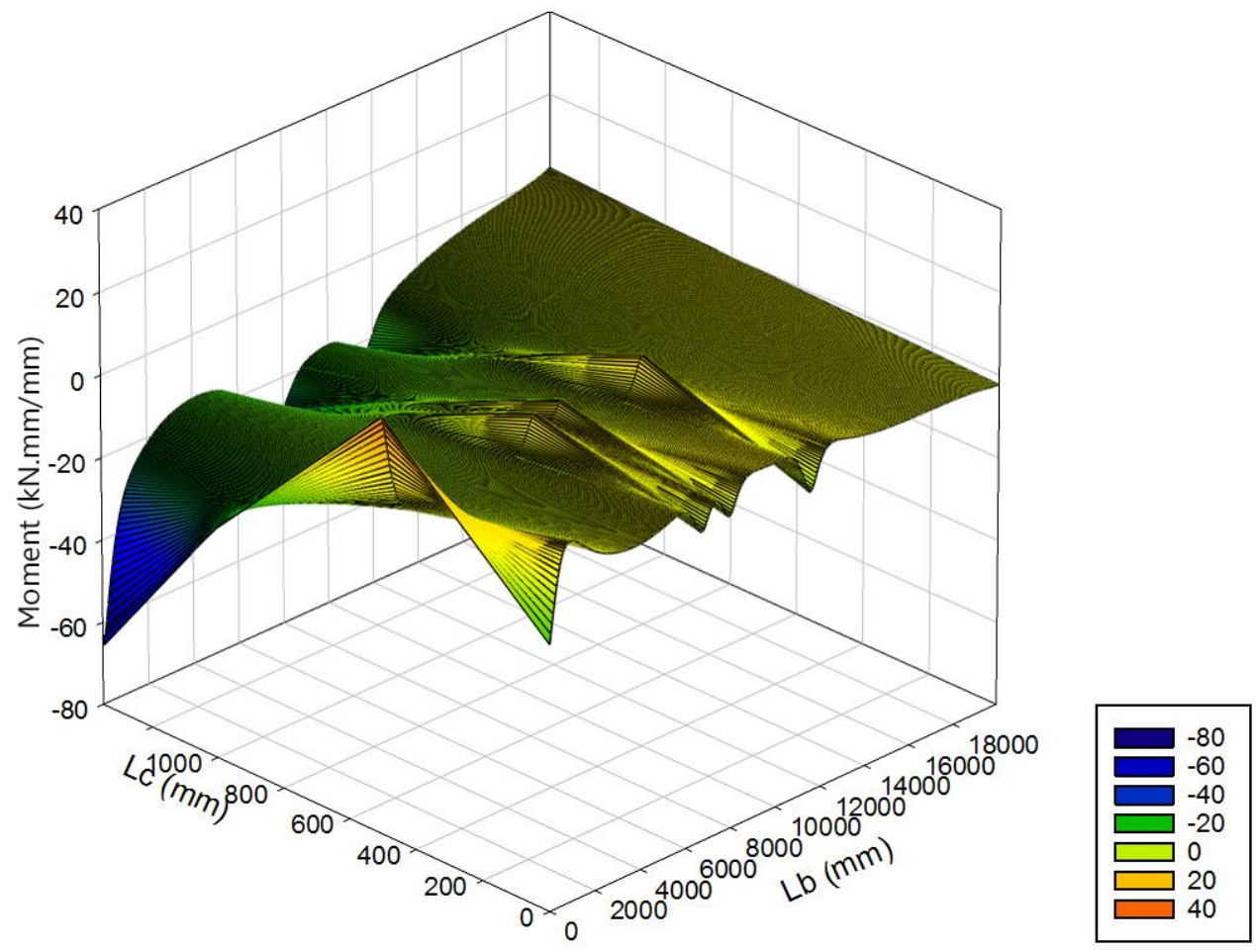

Figure 3-22: Transverse moment versus barrier length due to axles 1, 2, 3 and 4 on stiffened cantilever slab of $1.5 \mathrm{~m}$ length

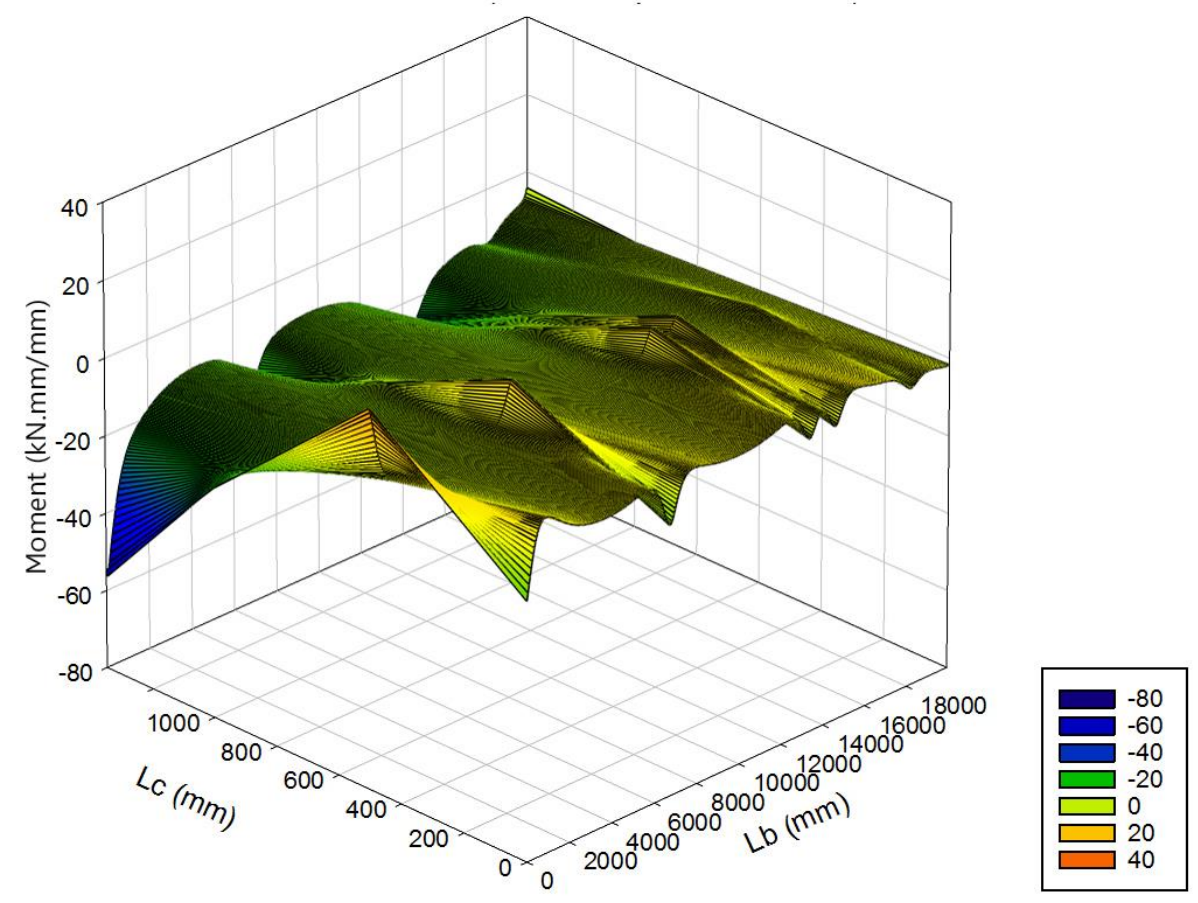

Figure 3-23: Transverse moment versus barrier length due to full truck loading with 5 axles on stiffened cantilever slab of $1.5 \mathrm{~m}$ length 


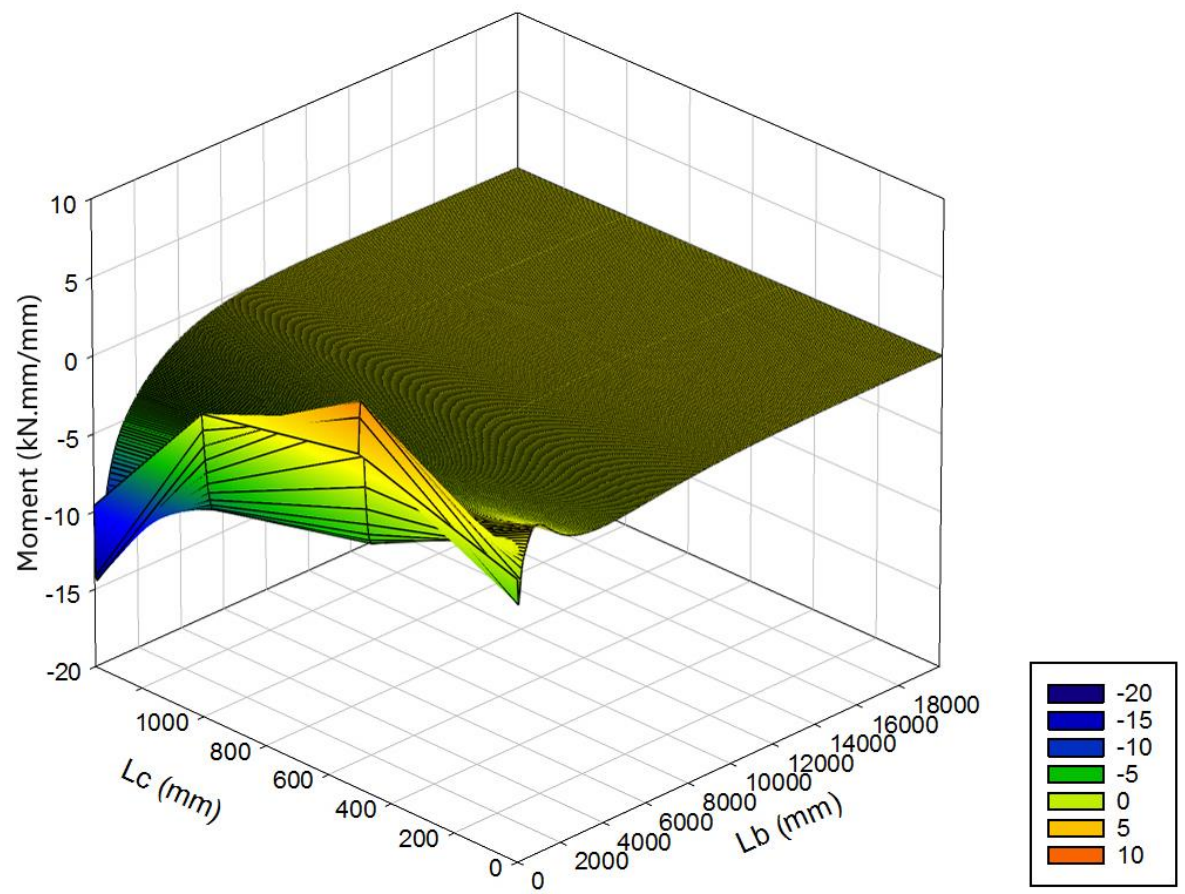

Figure 3-24: Longitudinal moment versus barrier length due to axle 4 on stiffened cantilever slab of $1.5 \mathrm{~m}$ length

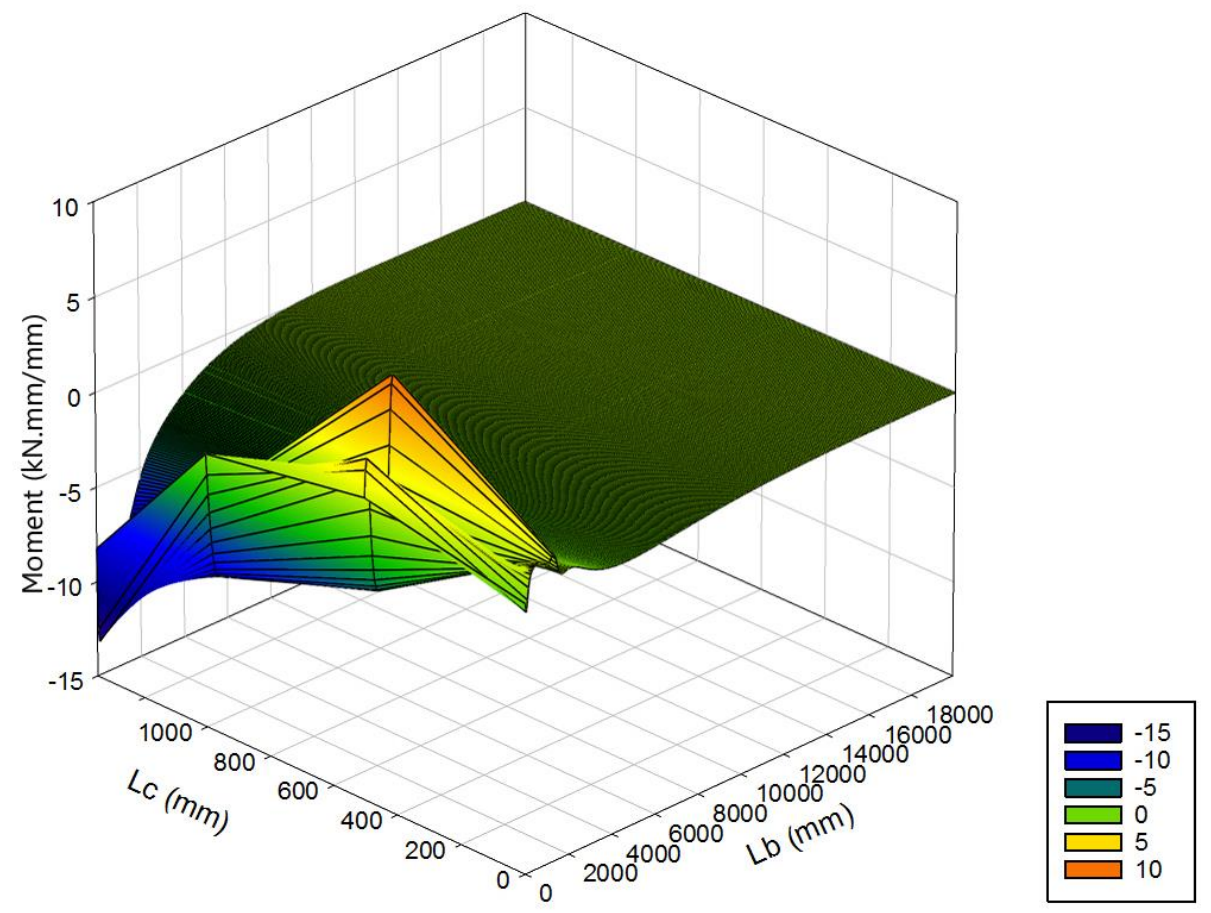

Figure 3-25: Longitudinal moment versus barrier length due to axles 2 and 3 on the stiffened cantilever slab of $1.5 \mathrm{~m}$ length 


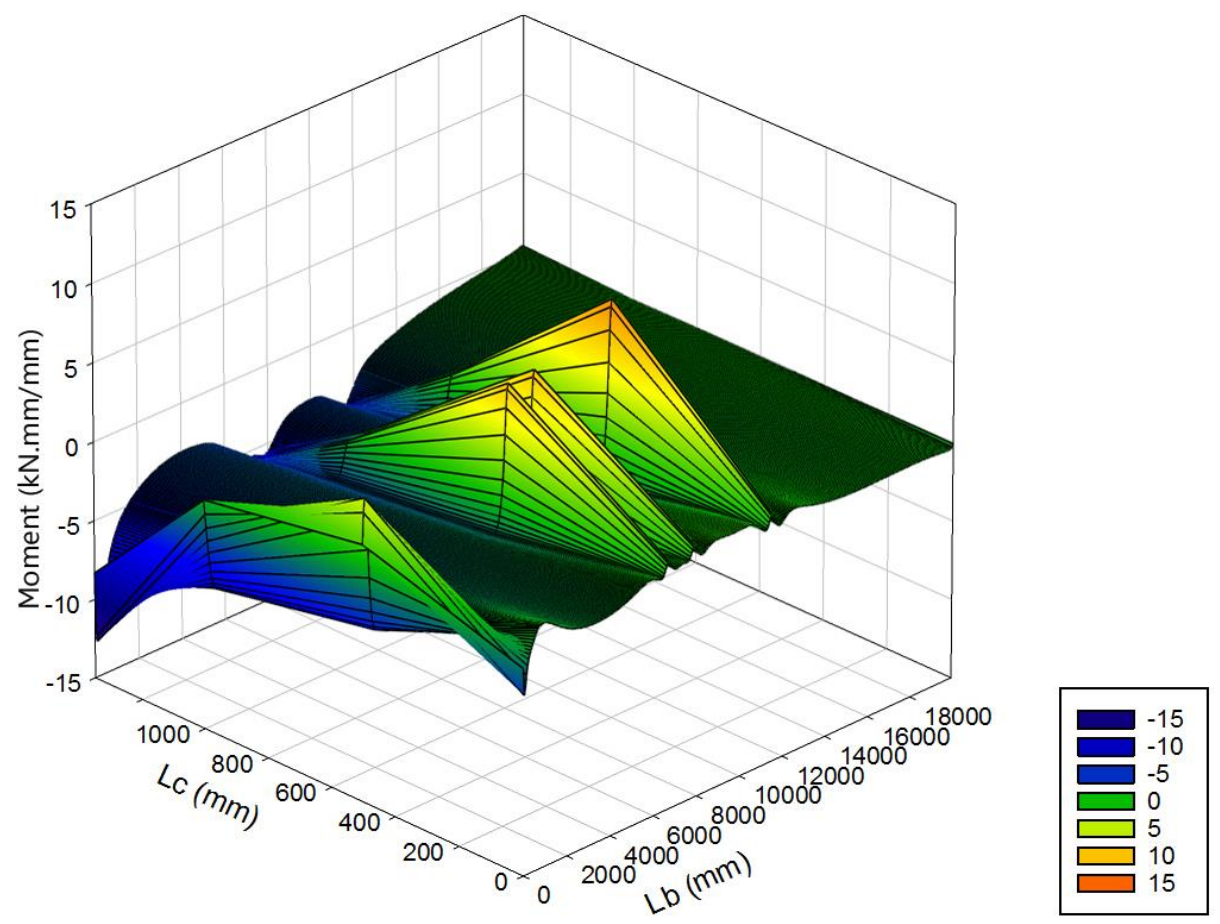

Figure 3-26: Longitudinal moment versus barrier length due to axles 1, 2, 3 and 4 on stiffened cantilever slab of $1.5 \mathrm{~m}$ length

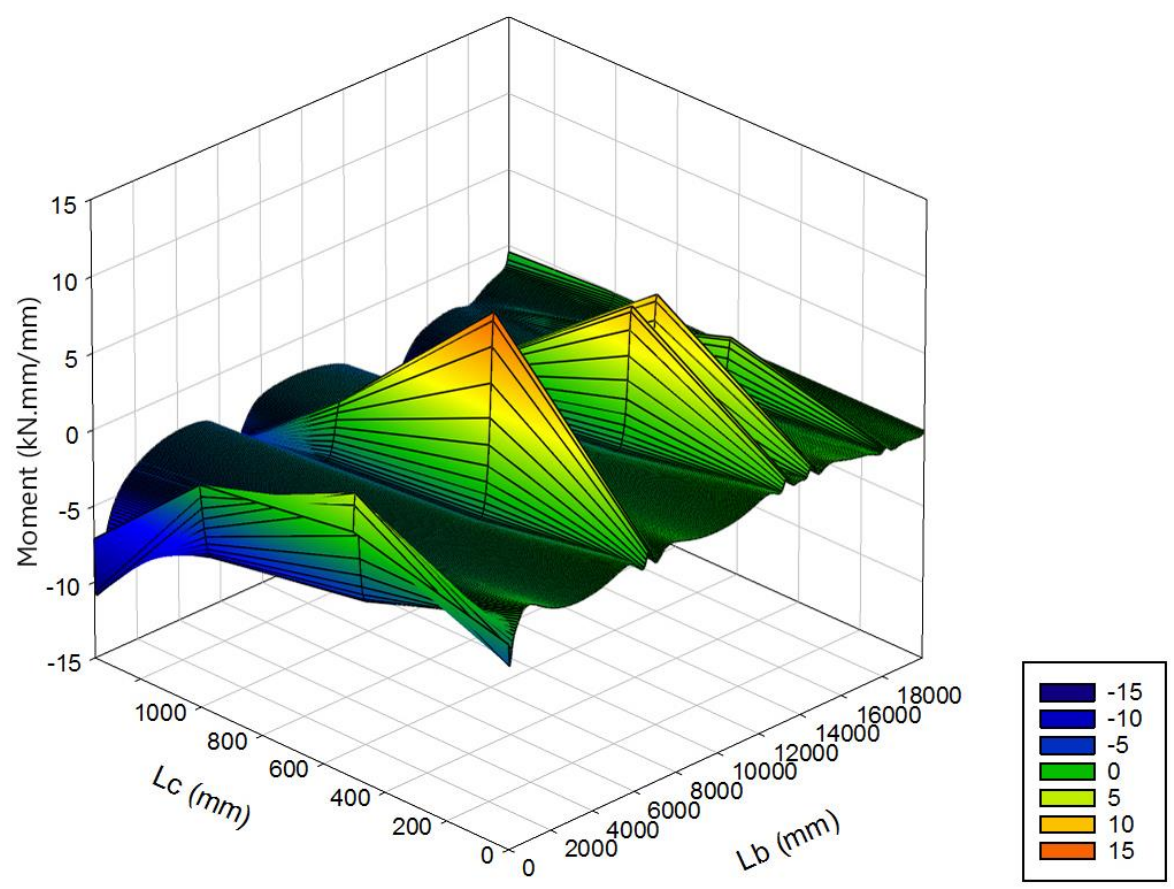

Figure 3-27: Longitudinal moment versus barrier length due to full truck loading with 5 axles on stiffened cantilever slab of $1.5 \mathrm{~m}$ length 


\subsection{Sensitivity study for Effect of Thickness of Barrier on the Response}

Another sensitivity study was conducted to evaluate the effect of both constant and tapered barrier thickness on maximum transverse moment, longitudinal moment and deflection. The types of barriers considered in this study include TL-2, TL-4 barrier, TL4 parapet, and TL-5 barrier. Dimensional parameters considered for the purpose of this investigation are demonstrated in Table 3-2 with notations shown in Figure 3-28.

Table 3-2: Range of Parameters considers for studying the effect of barrier thickness

\begin{tabular}{lcccccc}
\hline \hline & $\mathrm{L}_{\mathrm{c}}(\mathrm{m})$ & $\mathrm{L}_{\mathrm{b}}(\mathrm{m})$ & $\mathrm{t}_{1}(\mathrm{~mm})$ & $\mathrm{t}_{2} / \mathrm{t}_{1}$ & $\mathrm{~b}(\mathrm{~mm})$ & $\mathrm{H}(\mathrm{mm})$ \\
\hline \hline TL-2 & $1.5,2.5$ & 6,12 & 250 & 1 & $200,225,250$ & 775 \\
\hline TL-4 & $1.5,2.5$ & 6,12 & 250 & 1 & $200,225,250$ & 915 \\
(Barrier) & & & & & & \\
\hline TL-4 & $1.5,2.5$ & 6,12 & 250 & 1 & $250,300,350$ & 915 \\
(Parapet) & & & & & & \\
\hline TL-5 & $1.5,2.5$ & 6,12 & 250 & 1 & $200,225,250$ & 1140 \\
\hline
\end{tabular}

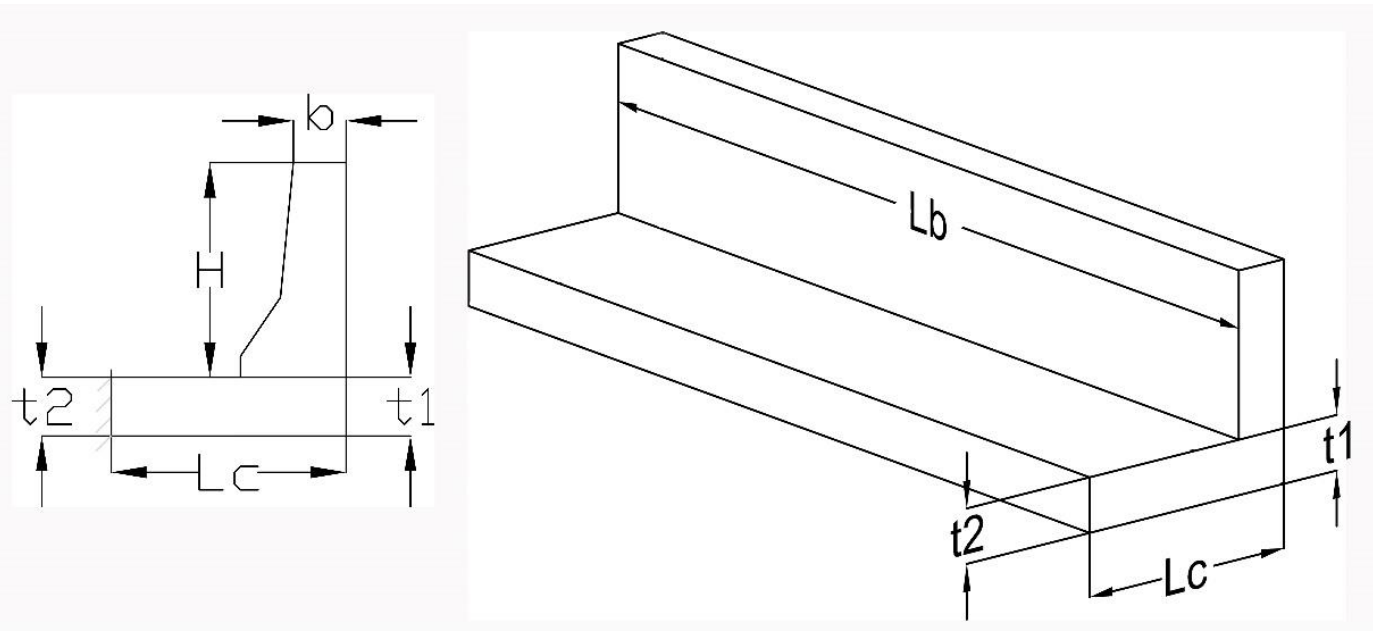

Figure 3-28: Notation used in Table 3-2 
First, the finite element modeling of the cantilever deck slabs with varied parameters and edge stiffening configuration were created by SAP2000 software. Maximum transverse moment, maximum longitudinal moment and, maximum deflection were calculated by the method of $1 \mathrm{~m}$ strip which explained previously. Then, these numbers were plotted versus the ratio of second moment of inertia of barrier wall $\left(I_{B}\right)$ to second moment of inertia of the cantilever slab ( $\left.I_{S}\right)$ on separate graphs for different edge stiffening arrangement. For tapered barrier, $\mathrm{I}_{\mathrm{B}}$ can be calculated through finding the moment of inertia for composite areas using the parallel - axis theorem. Is can be simply determined as follows:

$$
I_{s}=\frac{\left(L_{c}-b_{\text {base }}\right) * t_{1}{ }^{3}}{12}
$$

Where $L_{c}$ is cantilever length, $b_{\text {base }}$ is barrier wall thickness at the barrier-deck junction, and $t_{1}$ is cantilever slab thickness as shown in Figure 3-28.

\subsubsection{Analysis of Transverse Moment}

Figures 3-19 through 3-22 present the plots of maximum transverse moment against $\mathrm{I}_{\mathrm{B}} / \mathrm{I}_{\mathrm{S}}$ for a cantilever slab with changing parameter for $\mathrm{L}_{c}$ and $\mathrm{L}_{b}$, and various edge-stiffening configuration which were considered in this study. As it can be observed, increase in barrier thickness does not have a significant effect on the magnitude of maximum transverse moment. For instance, for a cantilever slab with TL-4 parapet with cantilever length of $1.5 \mathrm{~m}$ and barrier length of $12 \mathrm{~m}$, the negative transverse moment decreased by $8.16 \%$ (from $67.7 \mathrm{kN} . \mathrm{m} / \mathrm{m}$ to $62.17 \mathrm{kN} . \mathrm{m} / \mathrm{m}$ ) when $\mathrm{I}_{\mathrm{B}} / \mathrm{I}_{\mathrm{S}}$ changes from 20 to 30 . For the cantilever slab with other types of barrier, this percentage difference was around $5 \%$. 


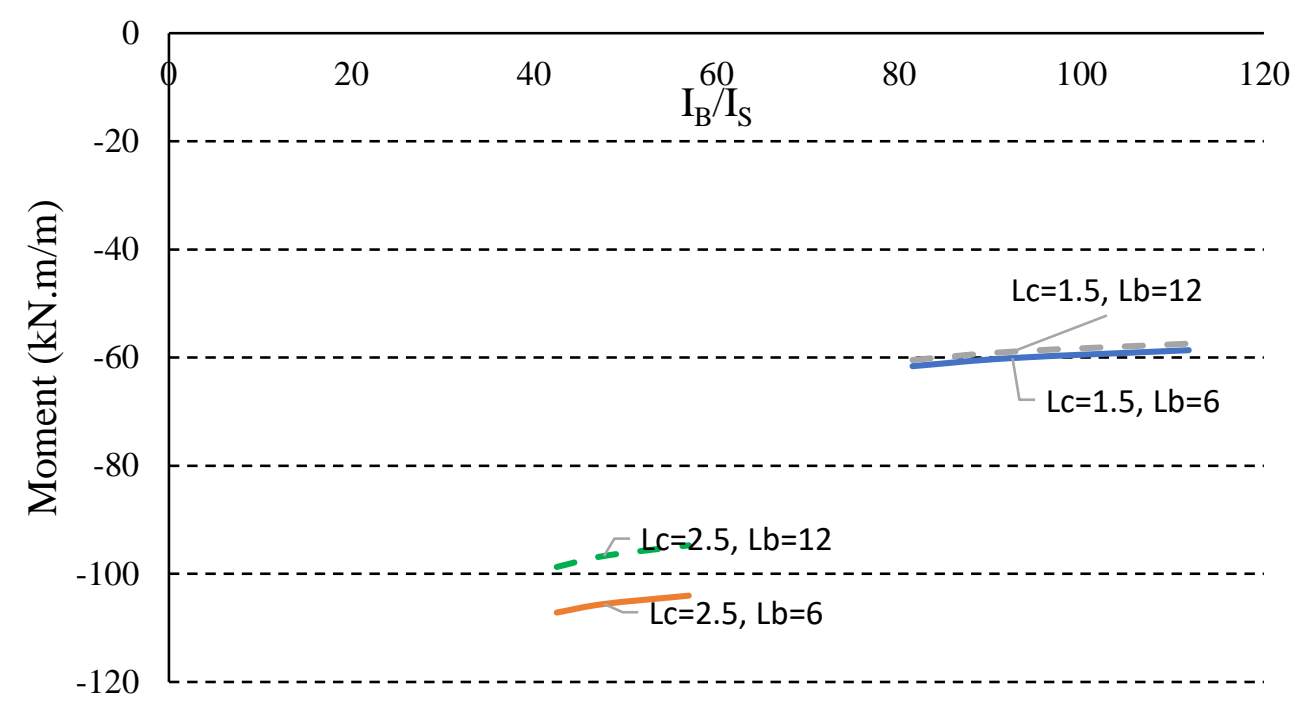

Figure 3-29: Maximum transverse moment versus ratio of $\mathrm{I}_{\mathrm{B}} / \mathrm{I}_{\mathrm{S}}$ for slab cantilever with TL-2 barrier

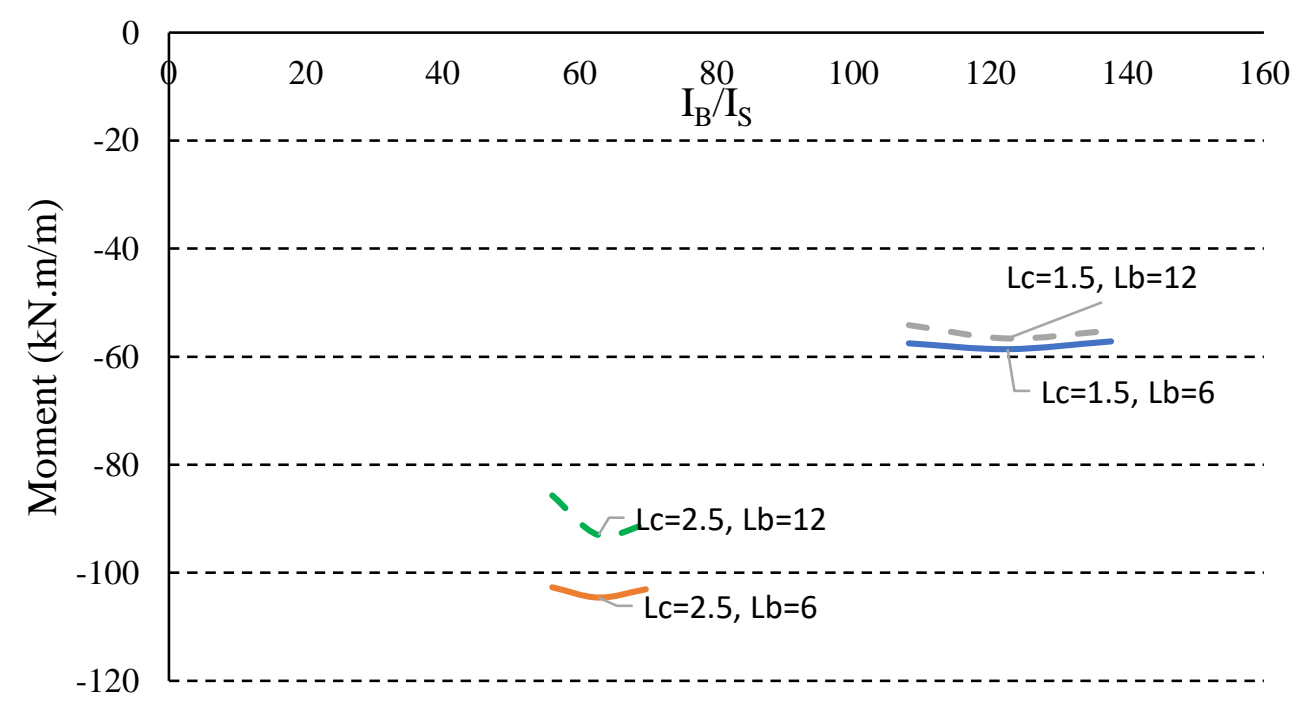

Figure 3-30: Maximum transverse moment versus ratio of $\mathrm{I}_{\mathrm{B}} / \mathrm{I}_{\mathrm{S}}$ for slab cantilever with TL-4 barrier 


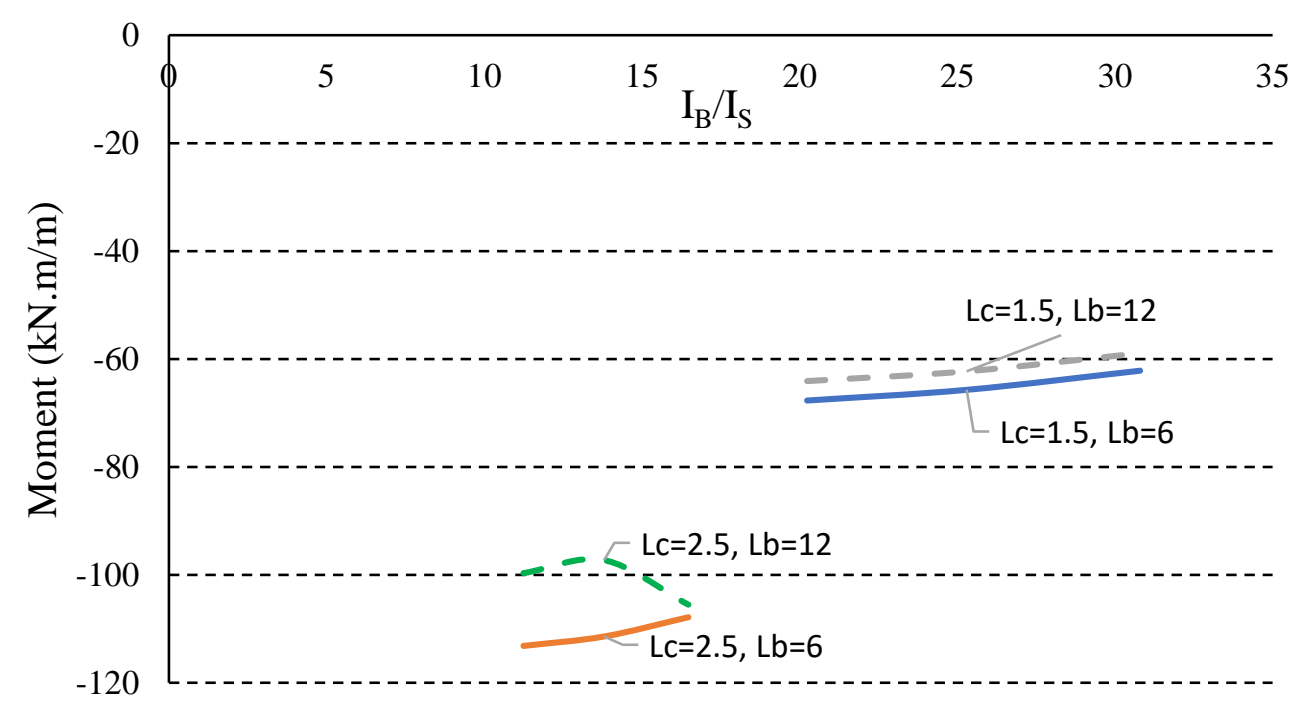

Figure 3-31: Maximum transverse moment versus ratio of $\mathrm{I}_{\mathrm{B}} / \mathrm{I}_{\mathrm{S}}$ for slab cantilever with TL-4 parapet

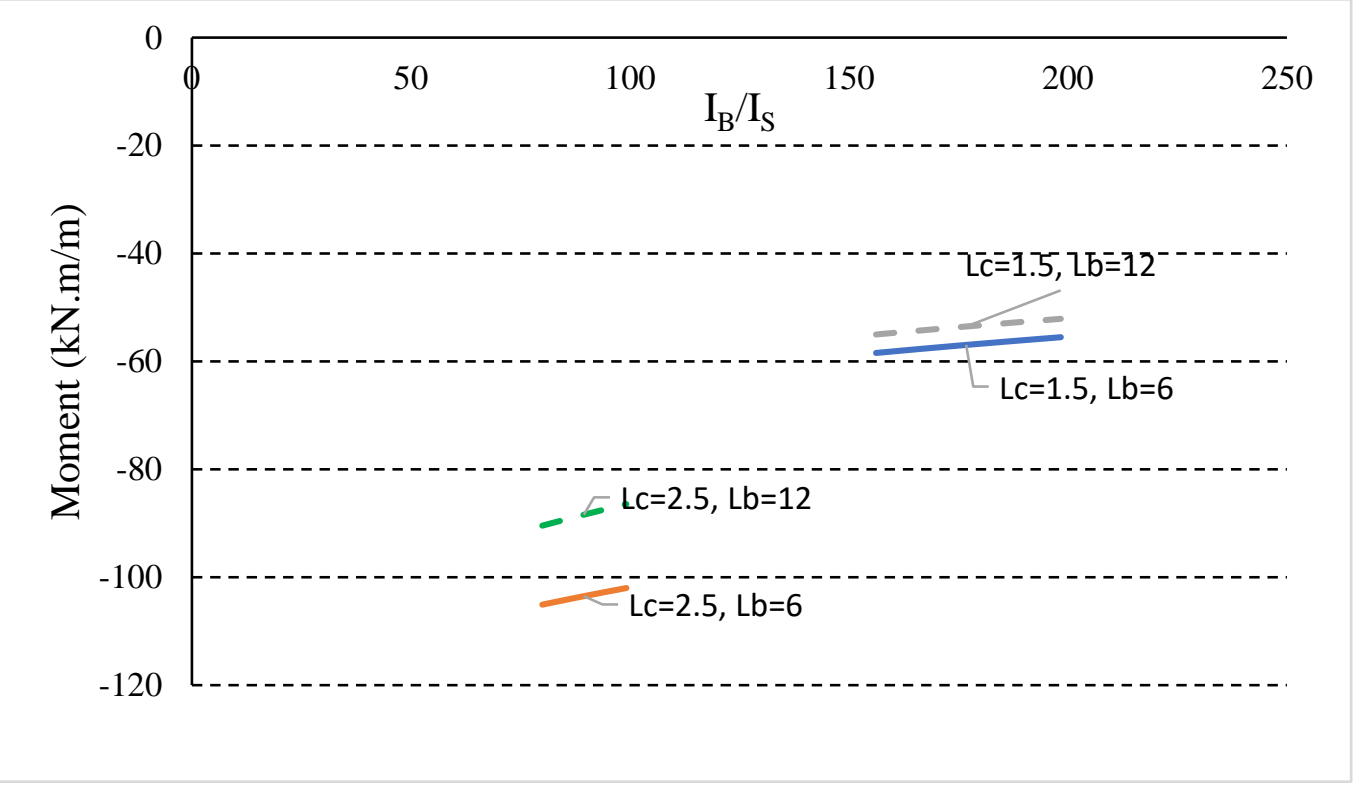

Figure 3-32: Maximum transverse moment versus ratio of $\mathrm{I}_{\mathrm{B}} / \mathrm{I}_{\mathrm{S}}$ for slab cantilever with TL-5 barrier 


\subsubsection{Analysis of Longitudinal Moment}

Figures 3-23 through 3-26 demonstrate the plot of maximum longitudinal moment versus $\mathrm{I}_{\mathrm{B}} / \mathrm{I}_{\mathrm{S}}$ for a cantilever slab with variable $\mathrm{L}_{c}$ and $\mathrm{L}_{b}$ and different barrier shapes. It can be observed that the magnitude of longitudinal moment is very low in comparison with transverse moment. Also, one may observe that the change in the amount of longitudinal moment with the change of $I_{B} / I_{S}$ is more pronounced for cantilever length of $2.5 \mathrm{~m}$ than for cantilever length of $1.5 \mathrm{~m}$.

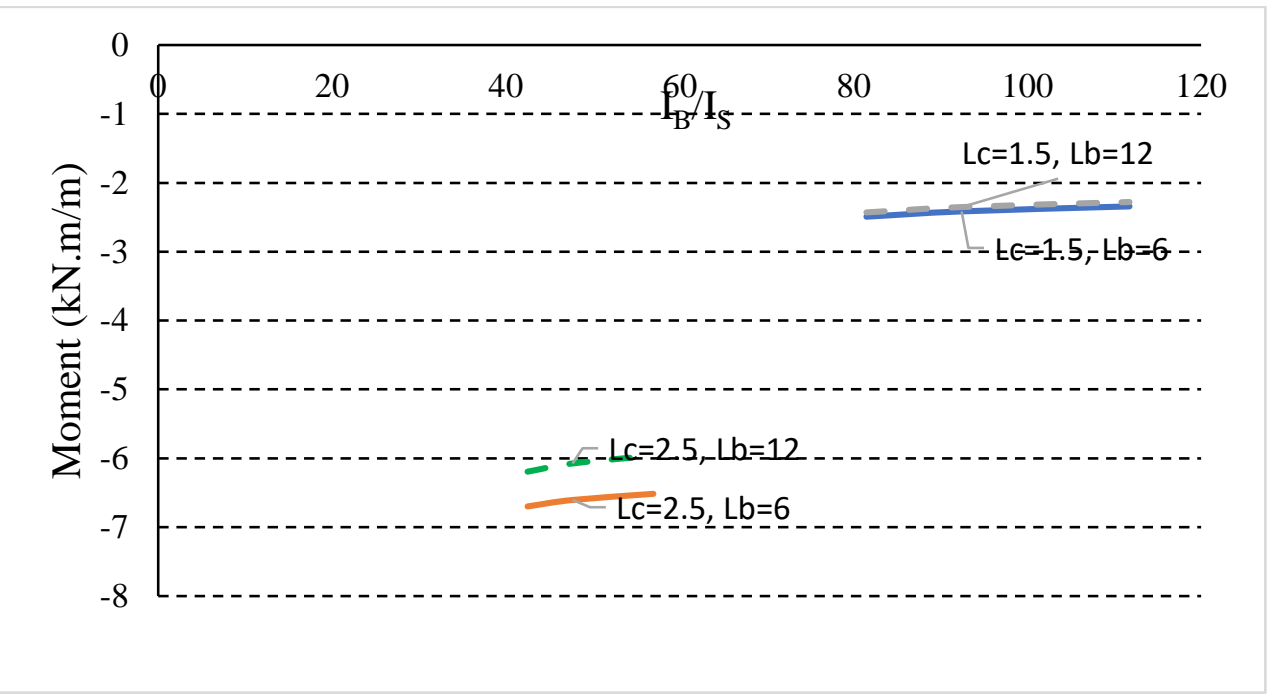

Figure 3-33: Maximum longitudinal moment versus ratio of IB/IS for slab cantilever with TL-2 barrier

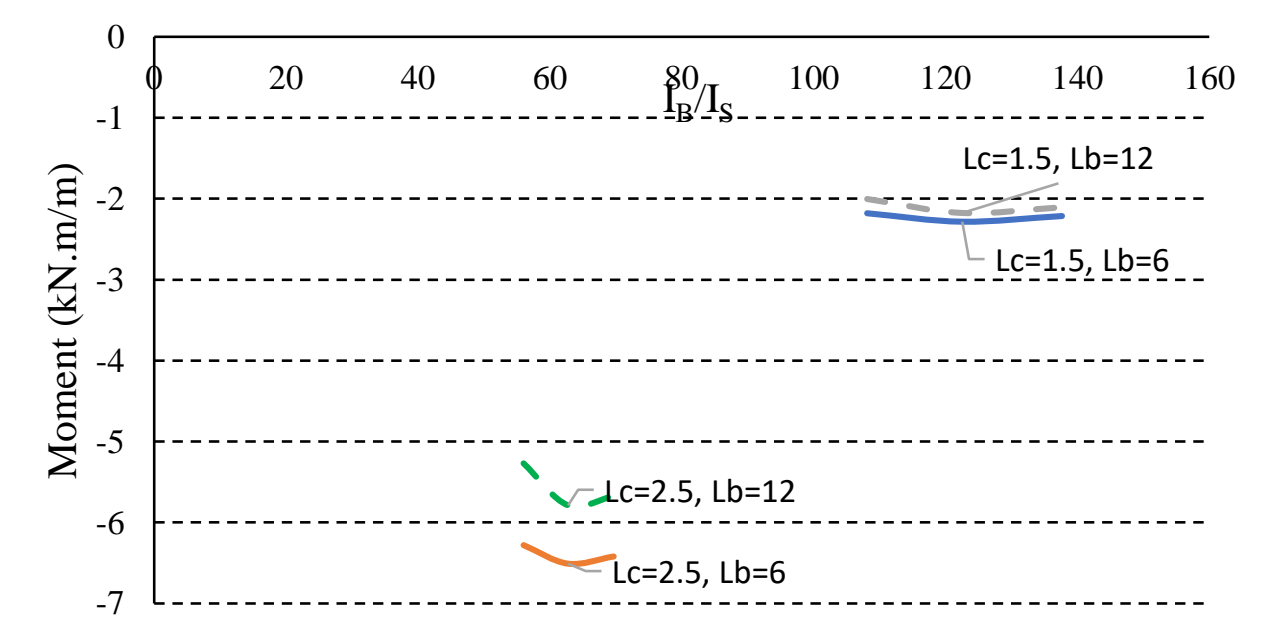

Figure 3-34: Maximum longitudinal moment versus ratio of IB/IS for slab cantilever with TL-4 barrier 


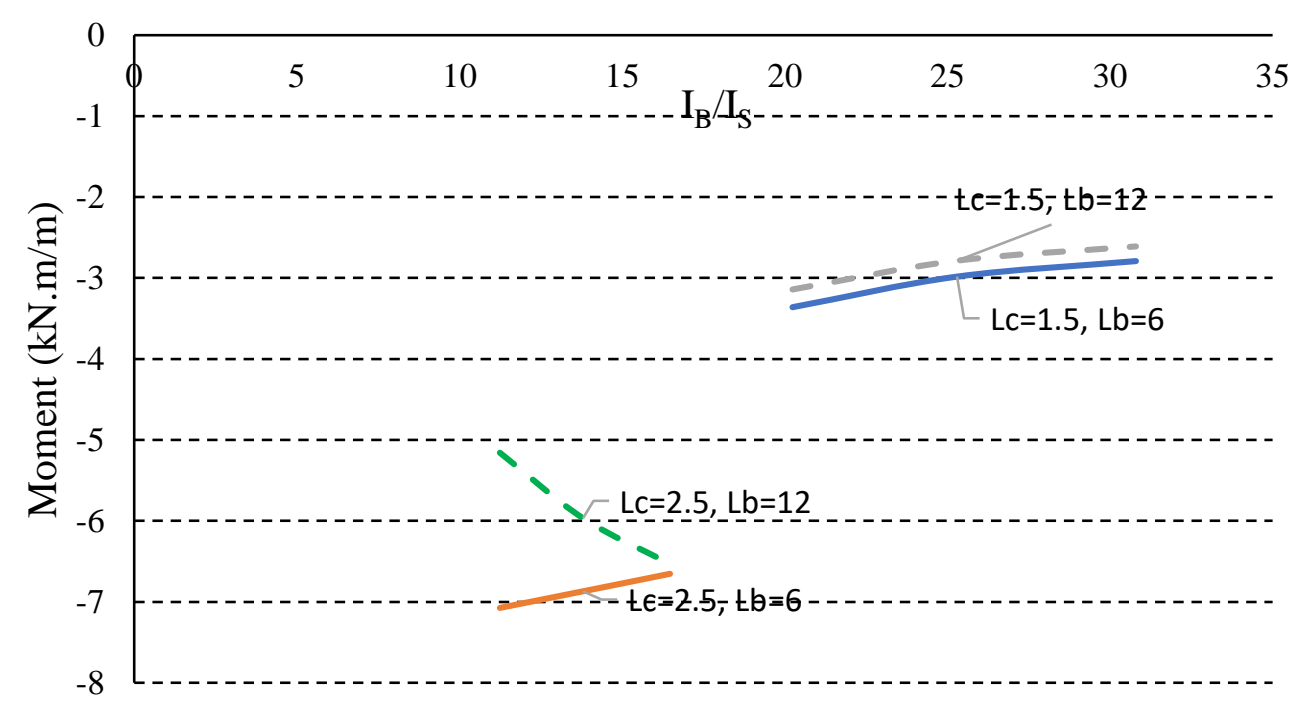

Figure 3-35: Maximum longitudinal moment versus ratio of $\mathrm{I}_{\mathrm{B}} / \mathrm{I}_{\mathrm{S}}$ for slab cantilever with TL-4 parapet

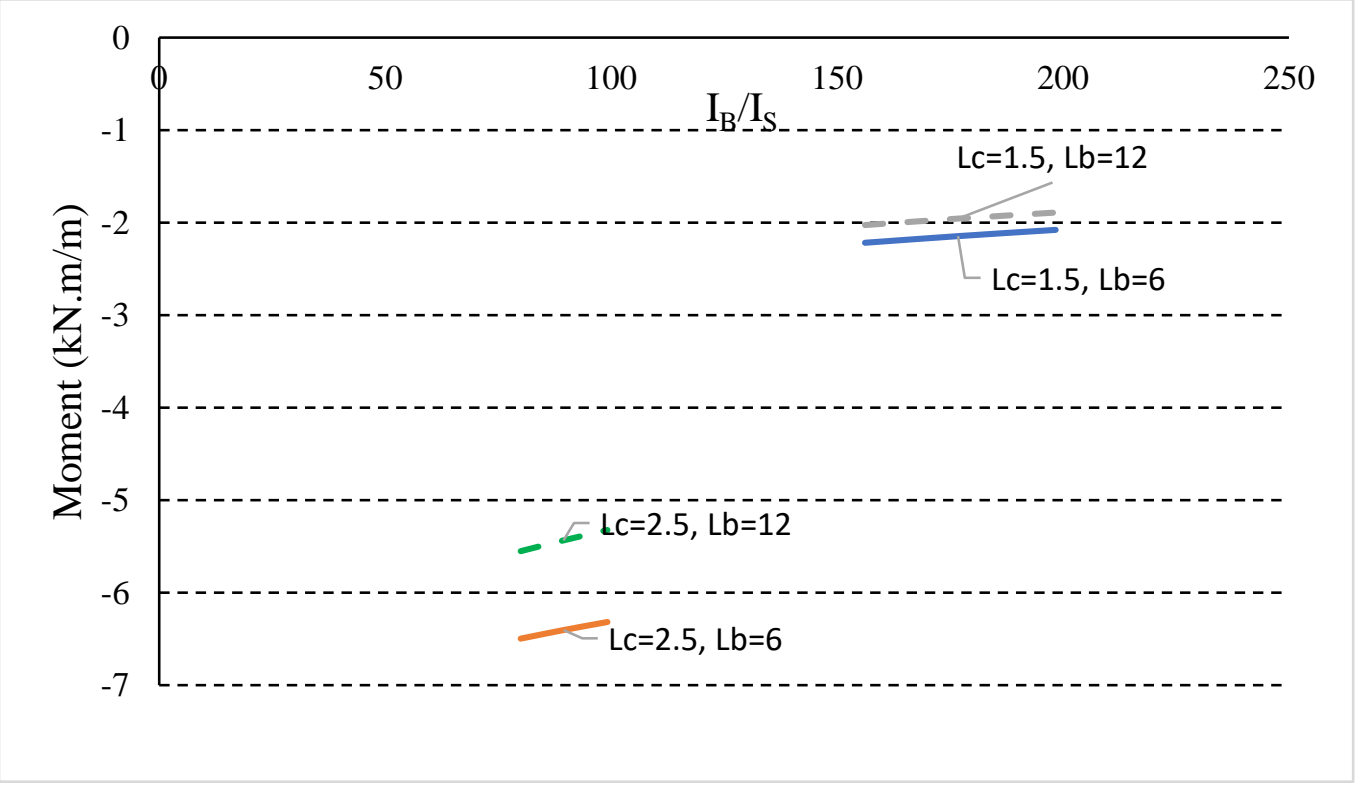

Figure 3-36: Maximum longitudinal moment versus ratio of IB/IS for slab cantilever with TL-5 barrier 


\subsubsection{Analysis of Deflection}

Figures 3-23 through 3-26 demonstrate the plot of maximum deflection of the deck slab cantilever versus $\mathrm{I}_{\mathrm{B}} / \mathrm{IS}_{\mathrm{S}}$ with variable $\mathrm{L}_{\mathrm{c}}$ and $\mathrm{L}_{\mathrm{b}}$ and different barrier shapes. Similar trend to the change of longitudinal moment with $\mathrm{I}_{\mathrm{B}} / \mathrm{I}_{\mathrm{S}}$ is observed. In general, the maximum deflection in some cases for $2.5 \mathrm{~m}$ cantilever length changed by around $10 \%$ as a result of changing barrier wall thickness.

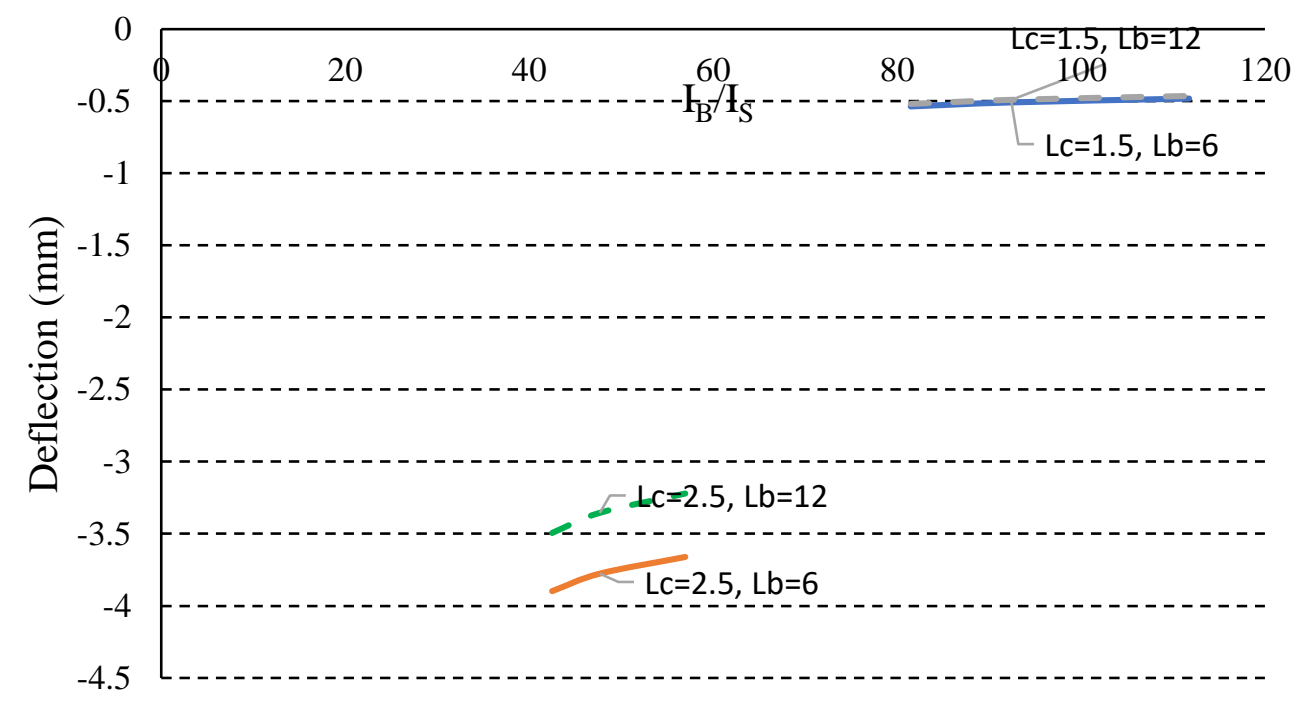

Figure 3-37: Maximum deflection versus ratio of $\mathrm{I}_{\mathrm{B}} / \mathrm{I}_{\mathrm{S}}$ for slab cantilever with TL-2 barrier

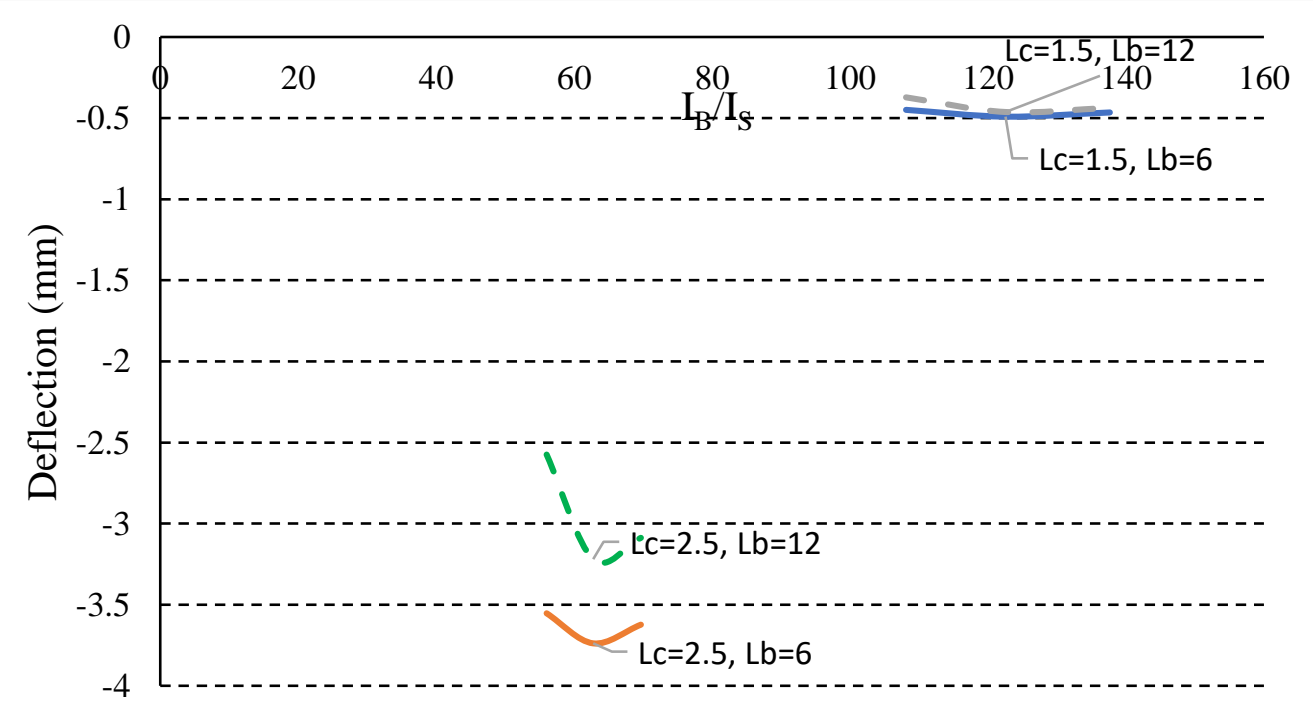

Figure 3-38: Maximum deflection versus ratio of $\mathrm{I}_{\mathrm{B}} / \mathrm{I}_{\mathrm{S}}$ for slab cantilever with TL-4 barrier 


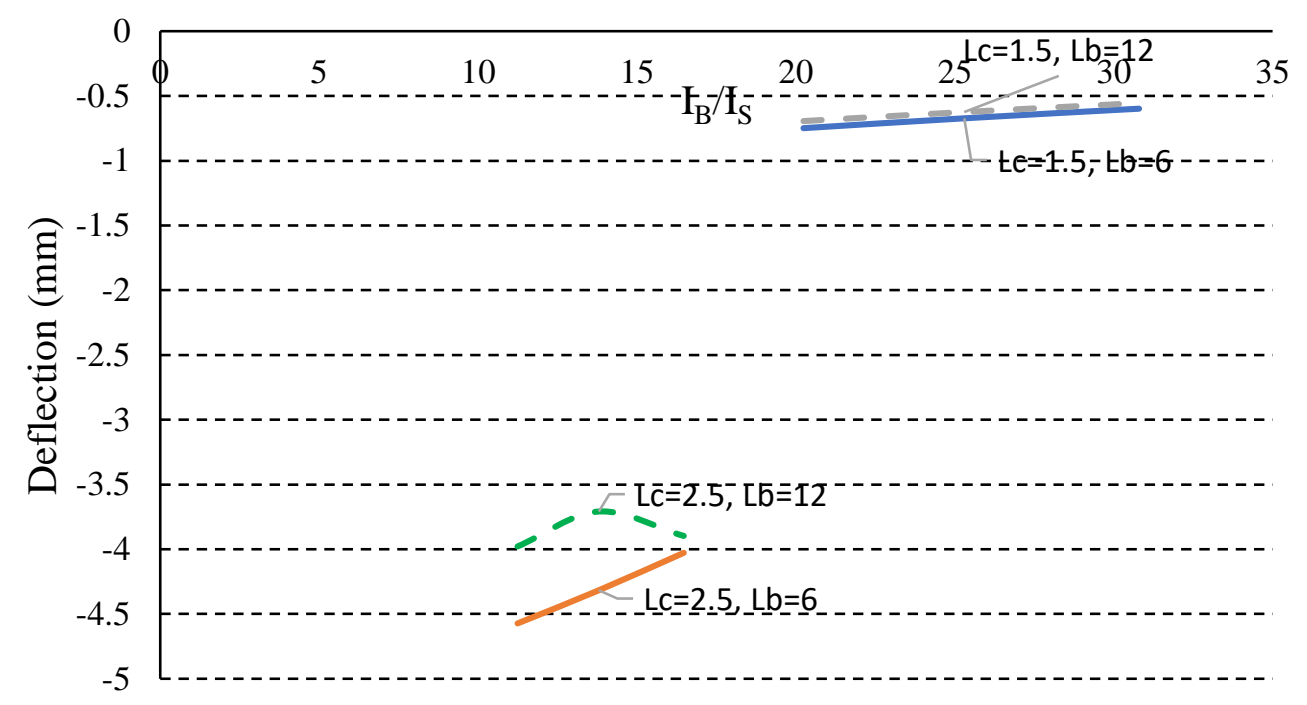

Figure 3-39: Maximum deflection versus ratio of $\mathrm{I}_{\mathrm{B}} / \mathrm{I}_{\mathrm{S}}$ for slab cantilever with TL-4 parapet

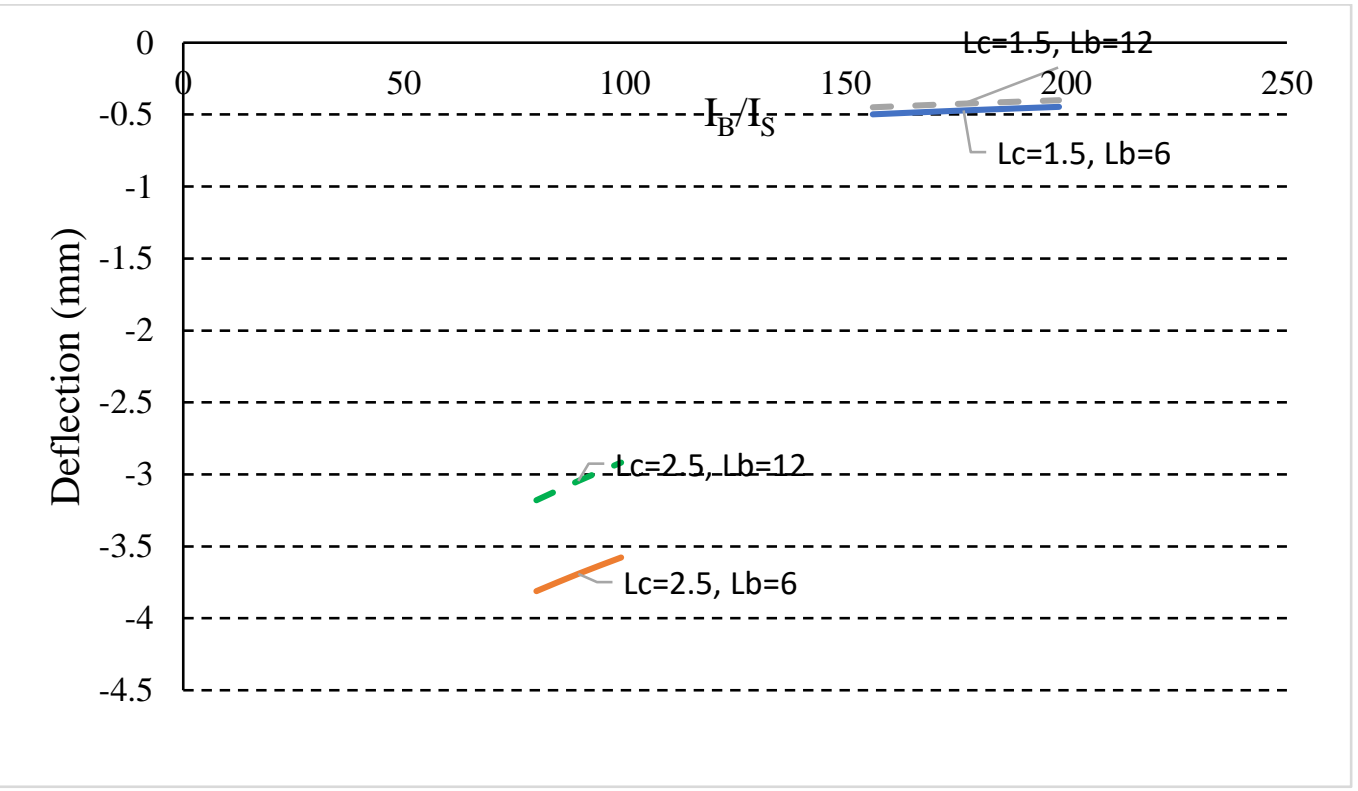

Figure 3-40: Maximum deflection versus ratio of $\mathrm{I}_{\mathrm{B}} / \mathrm{I}_{\mathrm{S}}$ for slab cantilever with TL-5 barrier 


\subsection{Sensitivity Study on Ratio of External Transverse Moment to Internal Transverse Moment}

As described in literature review, according to CHBDC Clause 5.7.1.3, designers shall take the transverse moment intensity in the region of the free end of the deck slab cantilever as double of $M_{y}$. In the case, the wheel loads apply at the distance $S_{p}$ equal to the cantilever length from the free end of the cantilever slab. This sensitivity study was conducted to scrutinize whether the ratio of external moment (i.e. the moment due to applying load near the free end of the cantilever overhang) to the internal moment (i.e. the moment due to applied truck loading to the internal portion of cantilever slab) remains under 2 or exceed this number.

For this purpose, unstiffened cantilever slabs with barrier length of $20 \mathrm{~m}$, slab thickness of 200 $\mathrm{mm}$, and the tapered slab thickness ratio of 1 was created by SAP2000 software. The cantilever lengths considered in this sensitivity study were taken as $1,1.5,2$, and $2.5 \mathrm{~m}$. Also, the four loading cases shown in Figure 3-10 were applied near the free end of the cantilever slab to determine the external moments. To obtained the internal transverse moment, the same loading cases shown in Figure 3-10 were applied to the internal portion of deck slab cantilever.

Table 3-2 summarizes the results obtained from the FE modelling in the form of the external and internal transverse moments as well as the ratio between then as $\mathrm{M}_{\mathrm{y}}\left(\right.$ Ext.) to $\mathrm{M}_{\mathrm{y}}(\mathrm{Int}$.). It should be noted that the maximum moment ratio is obtained based on the largest moment intensity obtained from the four loading cases shown in Figure 3-10. Results shown that the external/internal transverse moment ratios are 1.47, 1.901 .94 and 1.97 for deck slab cantilever lengths of $1,1.5,2$ and $2.5 \mathrm{~m}$, respectively. All these values are less than 2 which makes CHBDC specified value conservative for all cased considered in this sensitivity study. One may also observe that this moment ratio increases with increase in deck slab cantilever length. Moreover, it can be observed that loading case with axle 4 provides the greatest transverse moment for cantilever length of 1 and $1.5 \mathrm{~m}$. However, the loading case with the first four axles provide the greatest transverse moment at interior location for cantilever lengths of 2 and $2.5 \mathrm{~m}$. On the other hand, loading case with axle 4 and loading case with axles 2 and 3 provide the greatest transverse moment at exterior location for cantilever lengths of 2 and $2.5 \mathrm{~m}$, respectively. 
Table 3-3: Results of sensitivity study on external to internal moment ratio

\begin{tabular}{|c|c|c|c|c|c|c|c|}
\hline \multicolumn{8}{|c|}{ Unstiffened Cantilever Slab } \\
\hline $\begin{array}{l}\mathrm{L}_{\mathrm{c}} \\
(\mathrm{mm})\end{array}$ & $\begin{array}{l}\text { Load } \\
\text { case }\end{array}$ & $\begin{array}{c}\mathrm{M}_{\mathrm{y}} \text { (Int.) } \\
(\mathrm{kN} \cdot \mathrm{m} / \mathrm{m})\end{array}$ & $\begin{array}{l}\mathrm{M}_{\mathrm{y}}(\text { Ext.) } \\
(\mathrm{kN} \cdot \mathrm{m} / \mathrm{m})\end{array}$ & $\begin{array}{c}\mathrm{M}_{\mathrm{y}}(\text { Ext. }) / \\
\mathrm{M}_{\mathrm{y}} \text { (Int.) }\end{array}$ & $\begin{array}{c}\mathrm{M}_{\mathrm{x}} \text { (Int.) } \\
(\mathrm{kN} \cdot \mathrm{m} / \mathrm{m})\end{array}$ & $\begin{array}{c}\mathrm{M}_{\mathrm{x}}(\text { Ext. }) \\
(\mathrm{kN} \cdot \mathrm{m} / \mathrm{m})\end{array}$ & $\begin{array}{l}\mathrm{M}_{\mathrm{x}}(\text { Ext. }) / \\
\mathrm{Mx} \text { (Int.) }\end{array}$ \\
\hline \multirow{4}{*}{1000} & Axle 4 & -30.98 & -45.48 & 1.47 & 7.81 & -2.20 & 0.28 \\
\hline & Axle 2,3 & -24.28 & -38.20 & & 4.19 & -1.50 & \\
\hline & $\begin{array}{l}\text { Axle } \\
1,2,3,4\end{array}$ & -23.47 & -40.56 & & 6.97 & -1.61 & \\
\hline & $\begin{array}{l}\text { Axle } \\
1,2,3,4 \\
5\end{array}$ & -27.66 & -34.80 & & 6.97 & -1.68 & \\
\hline \multirow{4}{*}{1500} & Axle 4 & -43.63 & -83.07 & 1.90 & 18.58 & -4.17 & 0.22 \\
\hline & Axle 2,3 & -41.39 & -77.47 & & 10.31 & -3.11 & \\
\hline & $\begin{array}{l}\text { Axle } \\
1,2,3,4\end{array}$ & -42.44 & -74.14 & & 16.55 & -3.21 & \\
\hline & $\begin{array}{l}\text { Axle } \\
1,2,3,4, \\
5\end{array}$ & -39.07 & -63.65 & & 16.51 & -3.19 & \\
\hline \multirow{4}{*}{2000} & Axle 4 & -48.25 & -105.75 & 1.94 & 25.86 & -5.35 & 0.21 \\
\hline & Axle 2,3 & -51.99 & -105.25 & & 16.17 & -4.38 & \\
\hline & $\begin{array}{l}\text { Axle } \\
1,2,3,4\end{array}$ & -54.57 & -94.73 & & 22.83 & -4.19 & \\
\hline & $\begin{array}{l}\text { Axle } \\
1,2,3,4 \\
5\end{array}$ & -43.69 & -81.36 & & 22.49 & -4.09 & \\
\hline \multirow{4}{*}{2500} & Axle 4 & -50.74 & -120.64 & 1.97 & 31.54 & -5.87 & 0.19 \\
\hline & Axle 2,3 & -58.69 & -125.45 & & 21.84 & -5.14 & \\
\hline & $\begin{array}{l}\text { Axle } \\
1,2,3,4\end{array}$ & -63.71 & -108.95 & & 27.24 & -4.61 & \\
\hline & $\begin{array}{l}\text { Axle } \\
1,2,3,4, \\
5\end{array}$ & -47.95 & -93.62 & & 26.81 & -4.47 & \\
\hline
\end{tabular}




\section{CHAPTER FOUR}

\section{RESULTS FROM PARAMETRIC STUDY}

\subsection{General}

Structural response of the cantilever deck slab was analyzed using finite-element-modeling. A parametric study performed on 2400 cantilever overhang prototypes to investigate the transverse and longitudinal moment, and deflection. The cantilever slabs were analyzed using SAP2000 software to evaluate their structural response when subjected to CHBDC (2014) CL-625 near their transverse free edge. The main parameters considered in this study included:

$>$ The type of edge stiffening

$>$ The slab thickness and thickness ratio

$>$ The length of cantilever slab in transverse direction $\left(\mathrm{L}_{\mathrm{c}}\right)$

$>$ The length of barrier $\left(\mathrm{L}_{\mathrm{b}}\right)$

Moreover, a comparison between the obtained results from finite-element modeling and corresponding results from the simplified method of analysis of cantilever slab stated in CHBDC (2014) including Table 5.15 from CHBDC (2014) is conducted. Also, the acquired results from this parametric study was compared to the corresponding results from the previous study which done by Micovic (2016). Micovic (2016) investigated the structural response of cantilever deck slab due to applying Canadian Highway Bridge Design truck loading (CL-625) on the internal portion of the cantilever overhang.

\subsection{Cantilever-Barrier Arrangements for parametric study}

As mentioned earlier, variable geometric conditions were considered to investigate the effect of these parameters on structural response of the cantilever deck slab included transverse and longitudinal moment intensity and deflection, when the cantilever deck slab is subjected to CHBDC truck loading near its transverse free end. Also, Table 4-1 presents the range of key parameters considered in this study, while Figure 4-1 demonstrates the notation used for cantilever slab in Table 4-1. 


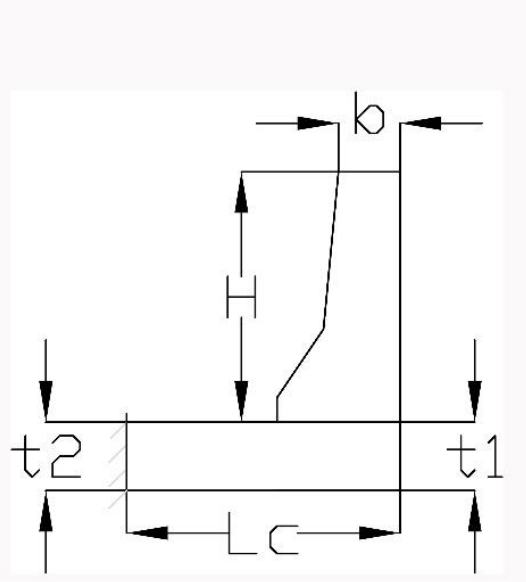

(a)

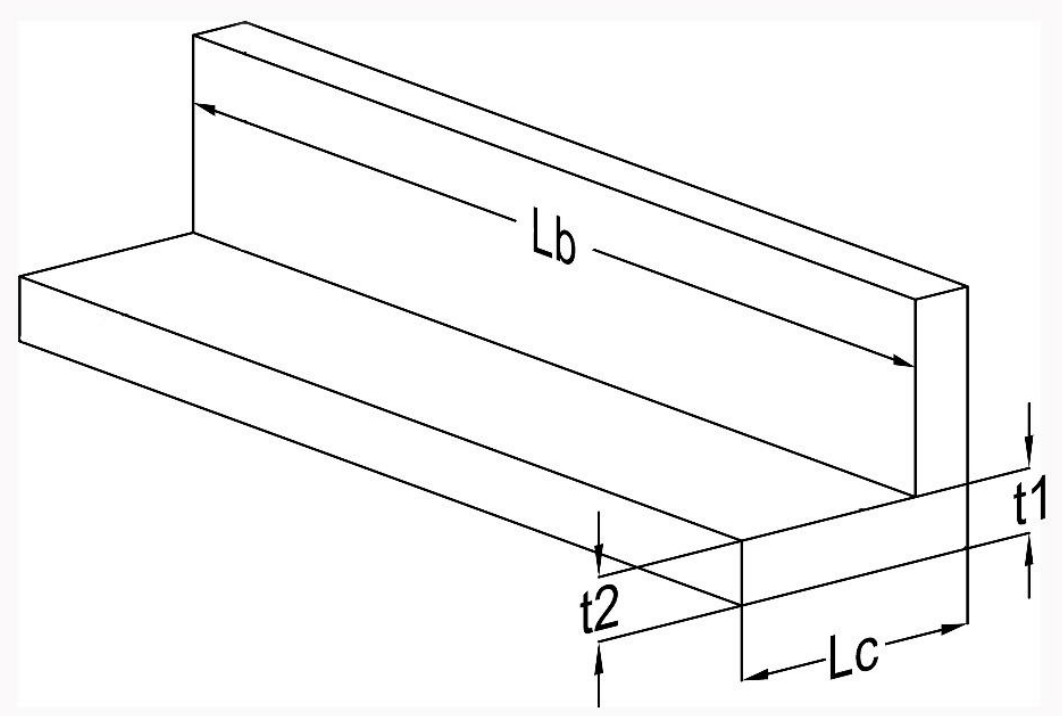

(b)

Figure 4-1: (a) Notation used for the cantilever overhang (b) 3D viewing of cantilever slab

Table 4-1: Range of parameters considered in this study

\begin{tabular}{|c|c|c|c|c|c|c|}
\hline & $\mathbf{L}_{c}(\mathrm{~m})$ & $\mathbf{L}_{b}(\mathrm{~m})$ & $\mathbf{t}_{1}(\mathrm{~mm})$ & $\mathbf{t}_{2} / \mathrm{t}_{1}$ & $\begin{array}{c}\mathbf{b} \\
(\mathrm{mm})\end{array}$ & $\begin{array}{c}\mathrm{H} \\
(\mathrm{mm})\end{array}$ \\
\hline TL-5 & $1,1.5,2,2.5$ & $\begin{array}{c}5,6,8 \\
10,12\end{array}$ & $\begin{array}{c}200,225, \\
250,300, \\
350\end{array}$ & $1,1.2,1.5,2$ & 225 & 1140 \\
\hline TL-4 (Barrier) & $1,1.5,2,2.5$ & $\begin{array}{c}5,6,8 \\
10,12\end{array}$ & $\begin{array}{c}200,225, \\
250,300, \\
350\end{array}$ & $1,1.2,1.5,2$ & 225 & 915 \\
\hline TL-4 (Parapet) & $1,1.5,2,2.5$ & $\begin{array}{c}5,6,8 \\
10,12\end{array}$ & $\begin{array}{c}200,225, \\
250,300, \\
350\end{array}$ & $1,1.2,1.5,2$ & 300 & 915 \\
\hline TL-2 & $1,1.5,2,2.5$ & $\begin{array}{c}5,6,8 \\
10,12\end{array}$ & $\begin{array}{c}200,225, \\
250,300, \\
350\end{array}$ & $1,1.2,1.5,2$ & 225 & 775 \\
\hline Curb & $1,1.5,2,2.5$ & $\begin{array}{c}5,6,8 \\
10,12\end{array}$ & $\begin{array}{c}200,225, \\
250,300, \\
350\end{array}$ & $1,1.2,1.5,2$ & 300 & 400 \\
\hline Unstiffened & $1,1.5,2,2.5$ & $\begin{array}{c}5,6,8 \\
10,12\end{array}$ & $\begin{array}{c}200,225, \\
250,300, \\
350\end{array}$ & $1,1.2,1.5,2$ & N/A & N/A \\
\hline
\end{tabular}




\subsection{Analysis of Transverse Moment}

This section presents the effect of different geometry conditions on the maximum transverse moment intensity in deck slab cantilever. These parameters included edge stiffening configuration, slab thickness, tapered slab thickness ratio, cantilever length and barrier length.

\subsubsection{Effect of stiffening Arrangement}

Table 4-2 presented the applied transverse moment in the deck slab cantilever with unstiffened edge, followed by the percentage change in this moment with the inclusion of stiffened edge of different types. It can be observed that edge stiffening arrangement reduces the intensity of maximum transverse moment significantly when compared to that for slab cantilevers with unstiffened slab, as expected.

Table 4-2: Effect of stiffening arrangement on transverse moment

\begin{tabular}{lcrrrr}
\hline Unstiffened & Curb & TL-2 barrier & TL-4 barrier & TL-5 barrier & TL-4 parapet \\
\hline-83.07 kN.m & $-16.29 \%$ & $-30.07 \%$ & $-31.84 \%$ & $-35.56 \%$ & $-50.27 \%$ \\
\hline $\begin{array}{l}\text { Maximum transverse moment for } \mathrm{L}_{\mathrm{c}}=1.5 \mathrm{~m}, \mathrm{~L}_{\mathrm{b}}=12 \mathrm{~m} \text { slab thickness }\left(\mathrm{t}_{1}\right)=250 \mathrm{~mm}, \\
\text { slab ratio }\left(\mathrm{t}_{2} / \mathrm{t}_{1}=1\right)\end{array}$ & & &
\end{tabular}

\subsubsection{Effect of Barrier Length}

Tables 4-3 through 4-8 demonstrate the effect of barrier length on maximum transverse moment of the deck slab cantilever with different edge stiffening conditions. One may observe that the slab deck cantilever with unstiffened edge maintained almost the same transverse moment with increase of barrier length from 5 to $12 \mathrm{~m}$ as depicted in Table 4-3. However, for slab cantilevers with stiffened edge, the applied transverse moment decreases with increase in barrier length. However, the effect of barrier length is significantly decreasing with the increase in in the size of the barrier at the stiffened edge. For example, the maximum moment decreases by $7.86 \%, 17.55 \%$, $20.49 \%, 21.93 \%$ and $23.93 \%$ for cantilever slabs with curb, TL-2 barrier, TL-4 barrier, TL-4 parapet and TL-5 barrier, respectively. 
Table 4-3: Effect of barrier length on transverse moment of slab cantilever with unstiffened edge

\begin{tabular}{lccccc}
\hline \hline & $\mathrm{L}_{b}=\mathbf{5} \mathrm{m}$ & $\mathrm{L}_{b}=6 \mathrm{~m}$ & $\mathrm{~L}_{b}=\mathbf{8} \mathrm{m}$ & $\mathrm{L}_{b}=10 \mathrm{~m}$ & $\mathrm{~L}_{b}=12 \mathrm{~m}$ \\
\hline \hline $\mathrm{L}_{c}=\mathbf{1} \mathbf{m}$ & -45.48 & $0.00 \%$ & $0.00 \%$ & $0.00 \%$ & $0.00 \%$ \\
\hline $\mathrm{L}_{c}=\mathbf{1 . 5} \mathbf{m}$ & -83.08 & $-0.01 \%$ & $-0.01 \%$ & $-0.01 \%$ & $-0.01 \%$ \\
\hline $\mathrm{L}_{c}=\mathbf{2} \mathbf{m}$ & -105.90 & $-0.12 \%$ & $-0.14 \%$ & $-0.15 \%$ & $-0.15 \%$ \\
\hline $\mathrm{L}_{c}=\mathbf{2 . 5} \mathbf{m}$ & -126.77 & $-0.75 \%$ & $-1.02 \%$ & $-1.04 \%$ & $-1.04 \%$
\end{tabular}

Maximum transverse moment in kN.m for slab thickness $\left(\mathrm{t}_{1}\right)=200 \mathrm{~mm}$, slab ratio $\left(\mathrm{t}_{2} / \mathrm{t}_{1}\right)=1$.

Table 4-4: Effect of barrier length on transverse moment for slab cantilever with a curb

\begin{tabular}{|c|c|c|c|c|c|}
\hline & $L_{b}=5 \mathrm{~m}$ & $L_{b}=6 \mathrm{~m}$ & $\mathrm{~L}_{b}=8 \mathrm{~m}$ & $L_{b}=10 \mathrm{~m}$ & $L_{b}=12 \mathrm{~m}$ \\
\hline $\mathrm{L}_{\mathrm{c}}=1 \mathrm{~m}$ & -31.77 & $-0.15 \%$ & $-0.20 \%$ & $-0.21 \%$ & $-0.21 \%$ \\
\hline $\mathrm{L}_{\mathrm{c}}=1.5 \mathrm{~m}$ & -66.97 & $-0.92 \%$ & $-1.39 \%$ & $-1.46 \%$ & $-1.46 \%$ \\
\hline $\mathrm{L}_{\mathrm{c}}=2 \mathrm{~m}$ & -88.96 & $-2.18 \%$ & $-3.69 \%$ & $-4.00 \%$ & $-4.06 \%$ \\
\hline $\mathrm{L}_{\mathrm{c}}=2.5 \mathrm{~m}$ & -114.29 & $-3.54 \%$ & $-6.70 \%$ & $-7.62 \%$ & $-7.86 \%$ \\
\hline
\end{tabular}

Maximum transverse moment in kN.m for slab thickness $\left(\mathrm{t}_{1}\right)=200 \mathrm{~mm}$, slab ratio $\left(\mathrm{t}_{2} / \mathrm{t}_{1}\right)=1$.

Table 4-5: Effect of barrier length on transverse moment for slab cantilever with TL-2 barriers

\begin{tabular}{|c|c|c|c|c|c|}
\hline & $\mathrm{L}_{\mathrm{b}}=5 \mathrm{~m}$ & $\mathrm{~L}_{\mathrm{b}}=6 \mathrm{~m}$ & $L_{b}=8 m$ & $\mathrm{~L}_{b}=10 \mathrm{~m}$ & $L_{b}=12 \mathrm{~m}$ \\
\hline $\mathrm{L}_{\mathrm{c}}=1 \mathrm{~m}$ & -24.68 & $-0.98 \%$ & $-1.52 \%$ & $-1.60 \%$ & $-1.61 \%$ \\
\hline $\mathrm{L}_{\mathrm{c}}=1.5 \mathrm{~m}$ & -58.82 & $-3.11 \%$ & $-5.80 \%$ & $-6.54 \%$ & $-6.72 \%$ \\
\hline $\mathrm{L}_{\mathrm{c}}=2 \mathrm{~m}$ & -81.38 & $-4.88 \%$ & $-10.13 \%$ & $-12.20 \%$ & $-12.95 \%$ \\
\hline $\mathrm{L}_{\mathrm{c}}=2.5 \mathrm{~m}$ & -108.82 & $-5.46 \%$ & $-12.37 \%$ & $-15.88 \%$ & $-17.55 \%$ \\
\hline
\end{tabular}

Maximum transverse moment in kN.m for slab thickness $\left(\mathrm{t}_{1}\right)=200 \mathrm{~mm}$, slab ratio $\left(\mathrm{t}_{2} / \mathrm{t}_{1}\right)=1$. 
Table 4-6: Effect of barrier length on transverse moment for slab cantilever with TL-4 barriers

\begin{tabular}{lccccc}
\hline \hline & $\mathrm{L}_{b}=\mathbf{5} \mathrm{m}$ & $\mathrm{L}_{b}=\mathbf{6} \mathrm{m}$ & $\mathrm{L}_{b}=\mathbf{8} \mathrm{m}$ & $\mathrm{L}_{b}=10 \mathrm{~m}$ & $\mathrm{~L}_{b}=12 \mathrm{~m}$ \\
\hline \hline $\mathrm{L}_{c}=\mathbf{1} \mathbf{m}$ & -24.22 & $-1.49 \%$ & $-2.49 \%$ & $-2.68 \%$ & $-2.71 \%$ \\
\hline $\mathrm{L}_{c}=\mathbf{1 . 5} \mathrm{m}$ & -57.97 & $-3.85 \%$ & $-7.65 \%$ & $-8.96 \%$ & $-9.38 \%$ \\
\hline $\mathrm{L}_{c}=\mathbf{2} \mathbf{m}$ & -80.57 & $-5.53 \%$ & $-12.02 \%$ & $-15.01 \%$ & $-16.33 \%$ \\
\hline $\mathrm{L}_{c}=\mathbf{2 . 5} \mathrm{m}$ & -108.46 & $-5.83 \%$ & $-13.65 \%$ & $-18.08 \%$ & $-20.49 \%$
\end{tabular}

Maximum transverse moment in kN.m for slab thickness $\left(\mathrm{t}_{1}\right)=200 \mathrm{~mm}$, slab ratio $\left(\mathrm{t}_{2} / \mathrm{t}_{1}\right)=1$.

Table 4-7: Effect of barrier length on transverse moment for slab cantilever with TL-4 parapet

\begin{tabular}{lccccc}
\hline \hline & $\mathbf{L}_{b}=\mathbf{5}$ & $\mathbf{L}_{b}=\mathbf{6}$ & $\mathbf{L}_{b}=\mathbf{8}$ & $\mathbf{L}_{b}=10$ & $\mathbf{L}_{b}=\mathbf{1 2}$ \\
\hline \hline $\mathbf{L}_{c}=\mathbf{1} \mathbf{m}$ & -36.19 & $-2.21 \%$ & $-3.89 \%$ & $-4.27 \%$ & $-4.35 \%$ \\
\hline $\mathbf{L}_{c}=\mathbf{1 . 5} \mathbf{m}$ & -43.10 & $-4.70 \%$ & $-9.70 \%$ & $-12.46 \%$ & $-12.46 \%$ \\
\hline $\mathbf{L}_{c}=\mathbf{2} \mathbf{m}$ & -85.96 & $-6.08 \%$ & $-13.50 \%$ & $-17.28 \%$ & $-19.16 \%$ \\
\hline $\mathbf{L}_{c}=\mathbf{2 . 5} \mathbf{m}$ & -115.44 & $-6.01 \%$ & $-14.16 \%$ & $-19.03 \%$ & $-21.93 \%$
\end{tabular}

Maximum transverse moment in kN.m for slab thickness $\left(\mathrm{t}_{1}\right)=200 \mathrm{~mm}$, slab ratio $\left(\mathrm{t}_{2} / \mathrm{t}_{1}\right)=1$.

Table 4-8: Effect of barrier length on transverse moment for slab cantilever with TL-5 barrier

\begin{tabular}{lccccc}
\hline \hline & $\mathbf{L}_{b}=\mathbf{5}$ & $\mathbf{L}_{b}=\mathbf{6}$ & $\mathbf{L}_{b}=\mathbf{8}$ & $\mathbf{L}_{b}=10$ & $\mathbf{L}_{b}=\mathbf{1 2}$ \\
\hline \hline $\mathbf{L}_{c}=\mathbf{1} \mathbf{m}$ & -23.72 & $-2.25 \%$ & $-4.13 \%$ & $-4.65 \%$ & $-4.78 \%$ \\
\hline $\mathbf{L}_{c}=\mathbf{1 . 5} \mathbf{m}$ & -57.10 & $-4.70 \%$ & $-9.97 \%$ & $-12.27 \%$ & $-13.22 \%$ \\
\hline $\mathbf{L}_{c}=\mathbf{2} \mathbf{m}$ & -79.78 & $-6.22 \%$ & $-14.13 \%$ & $-18.35 \%$ & $-20.58 \%$ \\
\hline $\mathbf{L}_{c}=\mathbf{2 . 5} \mathbf{m}$ & -108.08 & $-6.21 \%$ & $-15.03 \%$ & $-20.53 \%$ & $-23.93 \%$
\end{tabular}

Maximum transverse moment in kN.m for slab thickness $\left(\mathrm{t}_{1}\right)=200 \mathrm{~mm}$, slab ratio $\left(\mathrm{t}_{2} / \mathrm{t}_{1}\right)=1$. 


\subsubsection{Effect of slab thickness for various tapered slab thickness ratio}

Tables 4-9 through 4-14 demonstrate the effect of slab thickness for various tapered slab thickness ratio on maximum transverse moment of the deck slab cantilever. One may observe that the slab deck cantilever with unstiffened edge maintained almost the same transverse moment with increase of slab thickness from 200 to $350 \mathrm{~mm}$ as depicted in Table 4-9. On the other hand, for slab cantilevers with stiffened edge, the applied transverse moment increases with increase in slab thickness. For example, the maximum moment increases by $11.24 \%, 17.05 \%, 18.62 \%, 22.97 \%$ and $20.04 \%$ for cantilever slabs with curb, TL-2 barrier, TL-4 barrier, TL-4 parapet and TL-5 barrier, respectively. However, the rate of increase in this moment with the increase in slab thickness is significantly decreasing with the increase in in the tapered slab thickness ratio at the stiffened edge. The above observations are presented later in graphical format in Figures 4-8 through 4-13.

Table 4-9: Effect of slab thickness on transverse moment for slab cantilever with unstiffened edge

\begin{tabular}{lccccc}
\hline \hline & $\begin{array}{c}\mathbf{t}_{\mathbf{1}}=\mathbf{2 0 0} \\
(\mathbf{m m})\end{array}$ & $\begin{array}{c}\mathbf{t}_{\mathbf{1}}=\mathbf{2 2 5} \\
(\mathbf{m m})\end{array}$ & $\begin{array}{c}\mathbf{t}_{\mathbf{1}}=\mathbf{2 5 0} \\
(\mathbf{m m})\end{array}$ & $\begin{array}{c}\mathbf{t}_{\mathbf{1}}=\mathbf{3 0 0} \\
(\mathbf{m m})\end{array}$ & $\begin{array}{c}\mathbf{t}_{\mathbf{1}}=\mathbf{3 5 0} \\
(\mathbf{m m})\end{array}$ \\
\hline \hline $\mathbf{t}_{\mathbf{r}}=\mathbf{1}$ & -83.07 & $0.00 \%$ & $0.00 \%$ & $0.00 \%$ & $0.00 \%$ \\
\hline $\mathbf{t}_{\mathbf{r}}=\mathbf{1 . 2}$ & -85.99 & $0.00 \%$ & $0.00 \%$ & $0.00 \%$ & $0.00 \%$ \\
\hline $\mathbf{t}_{\mathbf{r}}=\mathbf{1 . 5}$ & -89.07 & $0.00 \%$ & $0.00 \%$ & $0.00 \%$ & $0.00 \%$ \\
\hline $\mathbf{t}_{\mathbf{r}}=\mathbf{2 . 0}$ & -92.32 & $0.00 \%$ & $0.00 \%$ & $0.00 \%$ & $0.00 \%$
\end{tabular}

Maximum transverse moment in kN.m for $\mathrm{L}_{b}=12 \mathrm{~m}, \mathrm{~L}_{\mathrm{c}}=2 \mathrm{~m}$.

Table 4-10: Effect of slab thickness on transverse moment for slab cantilever with a curb

\begin{tabular}{lccccc}
\hline \hline & $\begin{array}{c}\mathbf{t}_{\mathbf{1}}=\mathbf{2 0 0} \\
(\mathbf{m m})\end{array}$ & $\begin{array}{c}\mathbf{t}_{\mathbf{1}}=\mathbf{2 2 5} \\
(\mathbf{m m})\end{array}$ & $\begin{array}{c}\mathbf{t}_{\mathbf{1}}=\mathbf{2 5 0} \\
(\mathbf{m m})\end{array}$ & $\begin{array}{c}\mathbf{t}_{\mathbf{1}}=\mathbf{3 0 0} \\
(\mathbf{m m})\end{array}$ & $\begin{array}{c}\mathbf{t}_{\mathbf{1}}=\mathbf{3 5 0} \\
(\mathbf{m m})\end{array}$ \\
\hline \hline $\mathbf{t}_{\mathbf{r}}=\mathbf{1}$ & -65.99 & $2.98 \%$ & $5.37 \%$ & $8.89 \%$ & $11.24 \%$ \\
\hline $\mathbf{t}_{\mathbf{r}}=\mathbf{1 . 2}$ & -70.00 & $2.52 \%$ & $4.51 \%$ & $7.37 \%$ & $9.24 \%$ \\
\hline $\mathbf{t}_{\mathbf{r}}=\mathbf{1 . 5}$ & -74.46 & $1.99 \%$ & $3.53 \%$ & $5.70 \%$ & $7.08 \%$ \\
\hline $\mathbf{t}_{\mathbf{r}}=\mathbf{2 . 0}$ & -79.32 & $1.40 \%$ & $2.46 \%$ & $3.90 \%$ & $4.78 \%$ \\
\hline
\end{tabular}

Maximum transverse moment in kN.m for $\mathrm{L}_{b}=12 \mathrm{~m}, \mathrm{~L}_{\mathrm{c}}=1.5 \mathrm{~m}$. 
Table 4-11: Effect of slab thickness on transverse moment for slab cantilever with TL-2 barrier

\begin{tabular}{lccccc}
\hline \hline & $\begin{array}{c}\mathbf{t}_{\mathbf{1}}=\mathbf{2 0 0} \\
(\mathbf{m m})\end{array}$ & $\begin{array}{c}\mathbf{t}_{\mathbf{1}}=\mathbf{2 2 5} \\
(\mathbf{m m})\end{array}$ & $\begin{array}{c}\mathbf{t}_{\mathbf{1}}=\mathbf{2 5 0} \\
(\mathbf{m m})\end{array}$ & $\begin{array}{c}\mathbf{t}_{\mathbf{1}}=\mathbf{3 0 0} \\
(\mathbf{m m})\end{array}$ & $\begin{array}{c}\mathbf{t}_{\mathbf{1}}=\mathbf{3 5 0} \\
(\mathbf{m m})\end{array}$ \\
\hline \hline $\mathbf{t}_{\mathbf{r}}=\mathbf{1}$ & -54.87 & $3.94 \%$ & $7.36 \%$ & $12.89 \%$ & $17.05 \%$ \\
\hline $\mathbf{t}_{\mathbf{r}}=\mathbf{1 . 2}$ & -59.68 & $3.55 \%$ & $6.58 \%$ & $11.40 \%$ & $15.04 \%$ \\
\hline $\mathbf{t}_{\mathbf{r}}=\mathbf{1 . 5}$ & -64.46 & $3.03 \%$ & $5.56 \%$ & $9.48 \%$ & $12.27 \%$ \\
\hline $\mathbf{t}_{\mathbf{r}}=\mathbf{2 . 0}$ & -70.07 & $2.37 \%$ & $4.29 \%$ & $7.16 \%$ & $9.12 \%$
\end{tabular}

Maximum transverse moment in kN.m for $\mathrm{L}_{b}=12 \mathrm{~m}, \mathrm{~L}_{\mathrm{c}}=1.5 \mathrm{~m}$.

Table 4-12: Effect of slab thickness on transverse moment for slab cantilever with TL-4 barrier

\begin{tabular}{lccccc}
\hline \hline & $\begin{array}{c}\mathbf{t}_{1}=\mathbf{2 0 0} \\
(\mathbf{m m})\end{array}$ & $\begin{array}{c}\mathbf{t}_{\mathbf{1}}=\mathbf{2 2 5} \\
(\mathbf{m m})\end{array}$ & $\begin{array}{c}\mathbf{t}_{\mathbf{1}}=\mathbf{2 5 0} \\
(\mathbf{m m})\end{array}$ & $\begin{array}{c}\mathbf{t}_{\mathbf{1}}=\mathbf{3 0 0} \\
(\mathbf{m m})\end{array}$ & $\begin{array}{c}\mathbf{t}_{\mathbf{1}}=\mathbf{3 5 0} \\
(\mathbf{m m})\end{array}$ \\
\hline \hline $\mathbf{t}_{\mathbf{r}}=\mathbf{1}$ & -52.53 & $4.13 \%$ & $7.79 \%$ & $13.88 \%$ & $18.62 \%$ \\
\hline $\mathbf{t}_{\mathbf{r}}=\mathbf{1 . 2}$ & -57.28 & $3.79 \%$ & $7.10 \%$ & $12.50 \%$ & $16.62 \%$ \\
\hline $\mathbf{t}_{\mathbf{r}}=\mathbf{1 . 5}$ & -62.15 & $3.30 \%$ & $6.14 \%$ & $10.64 \%$ & $13.97 \%$ \\
\hline $\mathbf{t r}_{\mathbf{r}}=\mathbf{2 . 0}$ & -67.98 & $2.67 \%$ & $4.90 \%$ & $8.31 \%$ & $10.72 \%$
\end{tabular}

Maximum transverse moment in kN.m for $\mathrm{L}_{b}=12 \mathrm{~m}, \mathrm{~L}_{\mathrm{c}}=1.5 \mathrm{~m}$.

Table 4-13: Effect of slab thickness on transverse moment for slab cantilever with TL-4 parapet

\begin{tabular}{lccccc}
\hline \hline & $\begin{array}{c}\mathbf{t}_{\mathbf{1}}=\mathbf{2 0 0} \\
(\mathbf{m m})\end{array}$ & $\begin{array}{c}\mathbf{t}_{\mathbf{1}}=\mathbf{2 2 5} \\
(\mathbf{m m})\end{array}$ & $\begin{array}{c}\mathbf{t}_{\mathbf{1}}=\mathbf{2 5 0} \\
(\mathbf{m m})\end{array}$ & $\begin{array}{c}\mathbf{t}_{\mathbf{1}}=\mathbf{3 0 0} \\
(\mathbf{m m})\end{array}$ & $\begin{array}{c}\mathbf{t}_{\mathbf{1}}=\mathbf{3 5 0} \\
(\mathbf{m m})\end{array}$ \\
\hline \hline $\mathbf{t}_{\mathbf{r}}=\mathbf{1}$ & -37.73 & $5.02 \%$ & $9.49 \%$ & $17.01 \%$ & $22.97 \%$ \\
\hline $\mathbf{t}_{\mathbf{r}}=\mathbf{1 . 2}$ & -61.66 & $4.65 \%$ & $8.73 \%$ & $15.47 \%$ & $20.69 \%$ \\
\hline $\mathbf{t}_{\mathbf{r}}=\mathbf{1 . 5}$ & -67.54 & $4.14 \%$ & $7.71 \%$ & $13.47 \%$ & $17.80 \%$ \\
\hline $\mathbf{t}_{\mathbf{r}}=\mathbf{2 . 0}$ & -74.90 & $3.44 \%$ & $6.33 \%$ & $10.83 \%$ & $14.07 \%$ \\
\hline Maximum transverse moment in $\mathrm{kN} . \mathrm{m}$ for $\mathrm{L}_{\mathrm{b}}=12 \mathrm{~m}, \mathrm{~L}_{\mathrm{c}}=1.5 \mathrm{~m}$.
\end{tabular}


Table 4-14: Effect of slab thickness on transverse moment for slab cantilever with TL-4 parapet

\begin{tabular}{lccccc}
\hline \hline & $\begin{array}{c}\mathbf{t}_{\mathbf{1}}=\mathbf{2 0 0} \\
(\mathbf{m m})\end{array}$ & $\begin{array}{c}\mathbf{t}_{\mathbf{1}}=\mathbf{2 2 5} \\
(\mathbf{m m})\end{array}$ & $\begin{array}{c}\mathbf{t}_{\mathbf{1}}=\mathbf{2 5 0} \\
(\mathbf{m m})\end{array}$ & $\begin{array}{c}\mathbf{t}_{\mathbf{1}}=\mathbf{3 0 0} \\
(\mathbf{m m})\end{array}$ & $\begin{array}{c}\mathbf{t}_{\mathbf{1}}=\mathbf{3 5 0} \\
(\mathbf{m m})\end{array}$ \\
\hline \hline $\mathbf{t}_{\mathbf{r}}=\mathbf{1}$ & -49.55 & $4.21 \%$ & $8.04 \%$ & $14.65 \%$ & $20.04 \%$ \\
\hline $\mathbf{t}_{\mathbf{r}}=\mathbf{1 . 2}$ & -54.14 & $3.96 \%$ & $7.52 \%$ & $13.55 \%$ & $18.37 \%$ \\
\hline $\mathbf{t}_{\mathbf{r}}=\mathbf{1 . 5}$ & -59.00 & $3.57 \%$ & $6.72 \%$ & $11.93 \%$ & $15.96 \%$ \\
\hline $\mathbf{t}_{\mathbf{r}}=\mathbf{2 . 0}$ & -65.02 & $3.02 \%$ & $5.60 \%$ & $9.74 \%$ & $12.80 \%$ \\
\hline \multicolumn{4}{l}{ Maximum transverse moment in $\mathrm{kN} . \mathrm{m}$ for $\mathrm{L}_{\mathrm{b}}=12 \mathrm{~m}, \mathrm{~L}_{\mathrm{c}}=1.5 \mathrm{~m}}$.
\end{tabular}

\subsubsection{Effect of Cantilever Length}

Figures 4-2 through 4-7 demonstrate the effect of increasing the cantilever length on maximum transverse moment induced by truck loading close to the transverse free edge of cantilever slab with $12 \mathrm{~m}$ barrier length, constant slab thickness of $200 \mathrm{~mm}$, and varied cantilever length of $1 \mathrm{~m}$, $1.5 \mathrm{~m}, 2 \mathrm{~m}$, and $2.5 \mathrm{~m}$. The obtained results for maximum transverse moment plotted on vertical axis versus the barrier length in meters on $\mathrm{X}$ axis for all types of edge-stiffening arrangement considered in parametric study. As it can be observed that the increase in cantilever length increases the induced moment intensity. Also, with increase in cantilever length, the presence of transverse moment extends farther into the slab cantilever longitudinal length. 


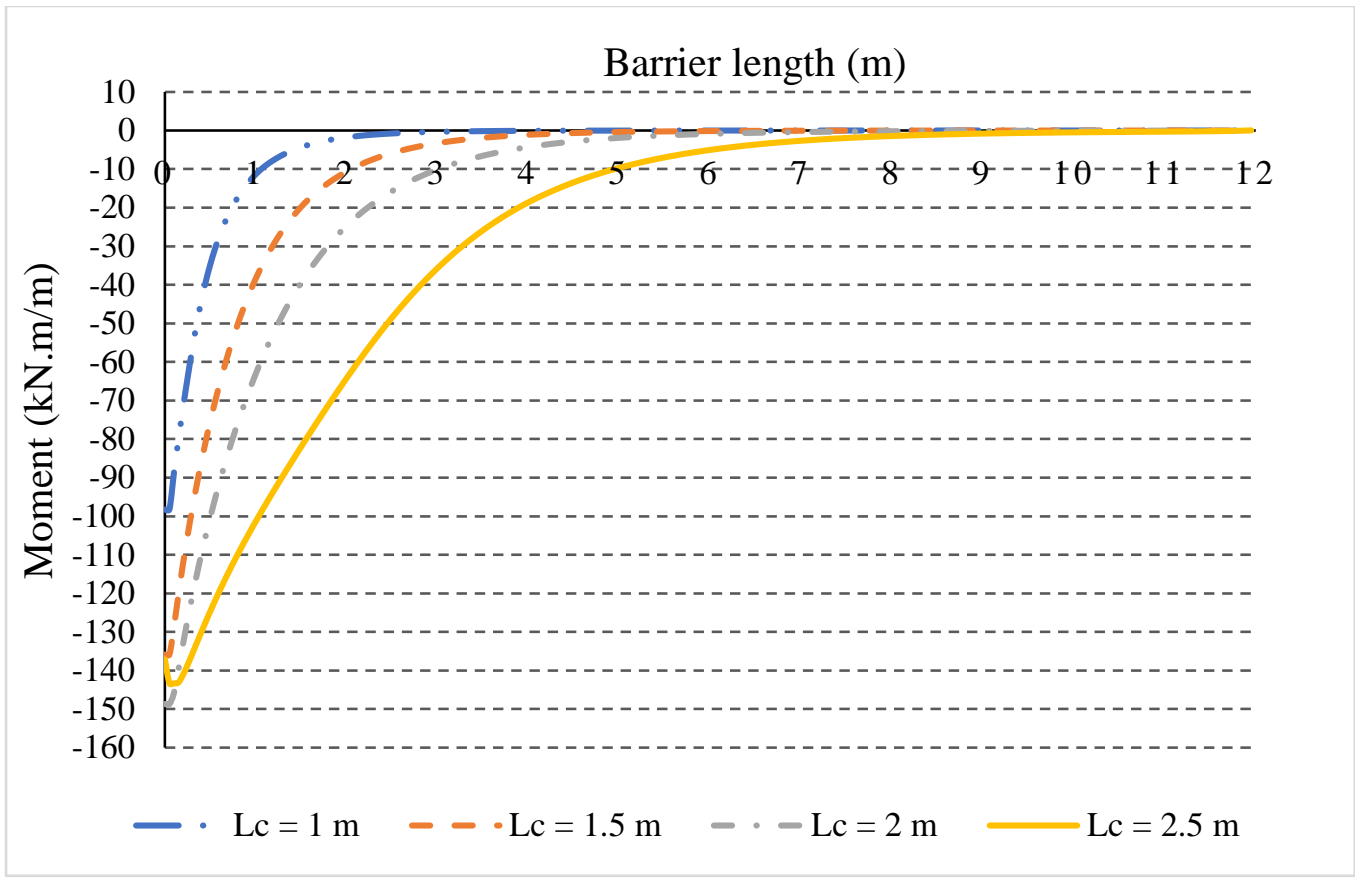

Figure 4-2: Effect of cantilever length on transverse moment for slab cantilever with unstiffened edge

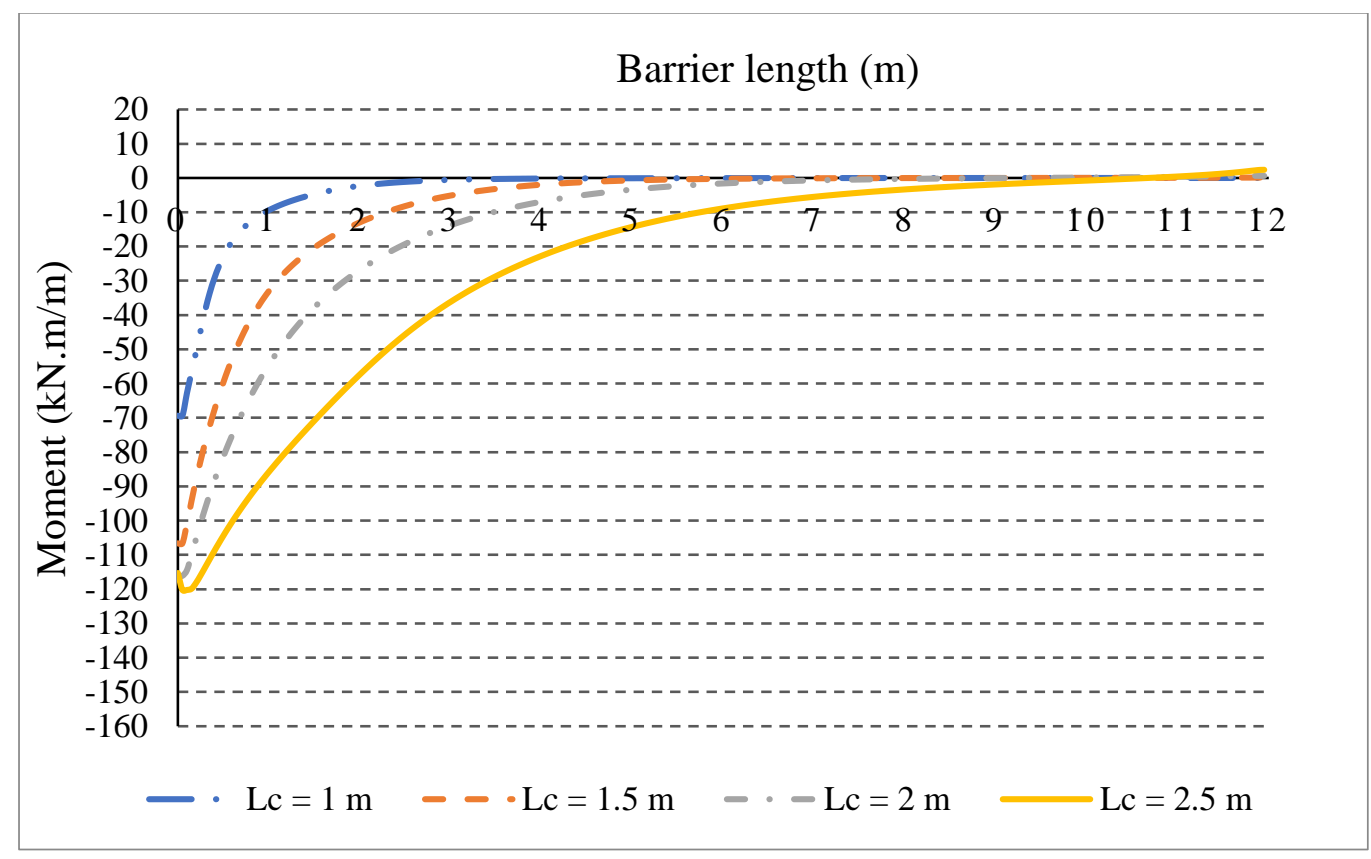

Figure 4-3: Effect of cantilever length on transverse moment for slab cantilever with a curb 


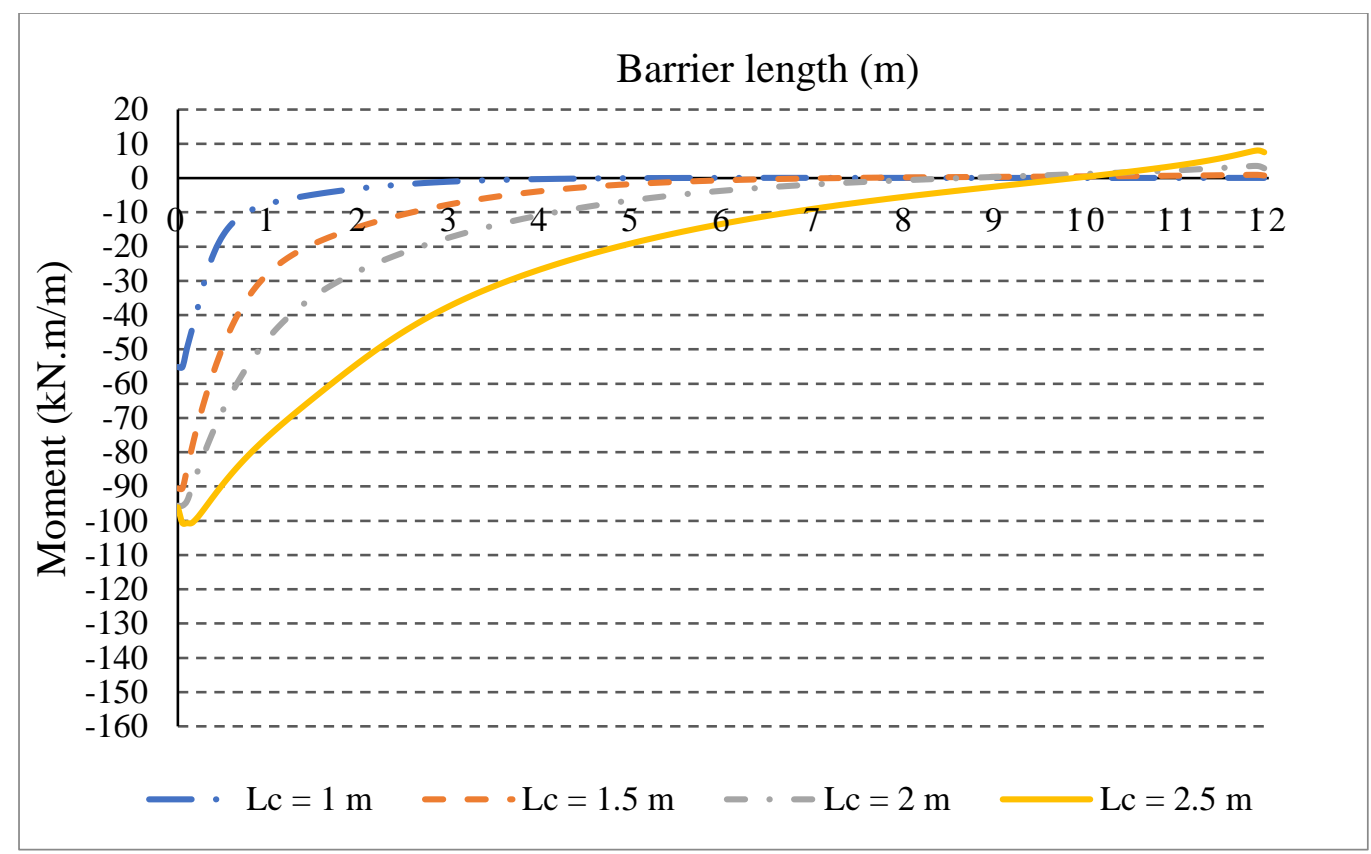

Figure 4-4: Effect of cantilever length on transverse moment for slab cantilever with TL-2 barrier

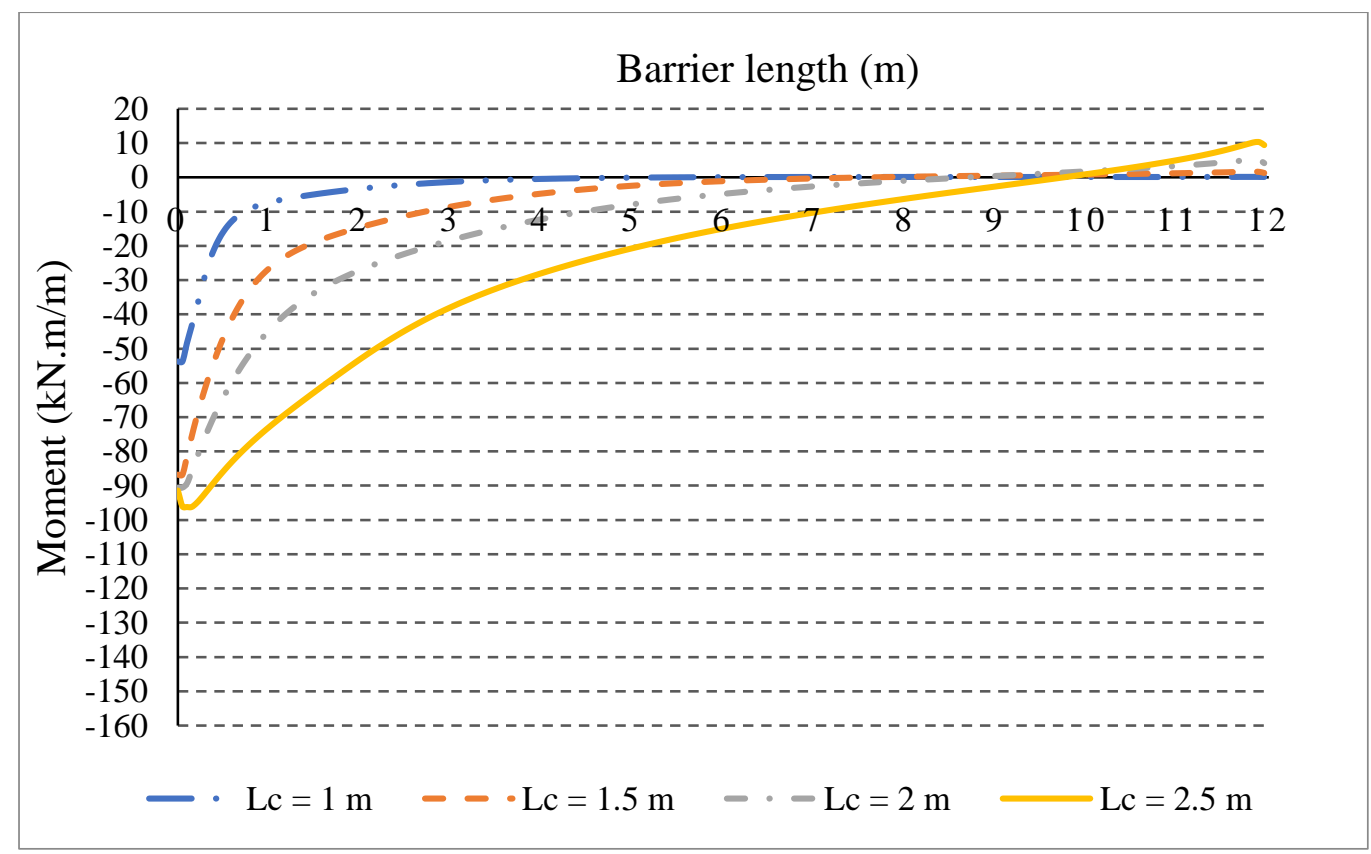

Figure 4-5: Effect of cantilever length on transverse moment for slab cantilever with TL-4 barrier 


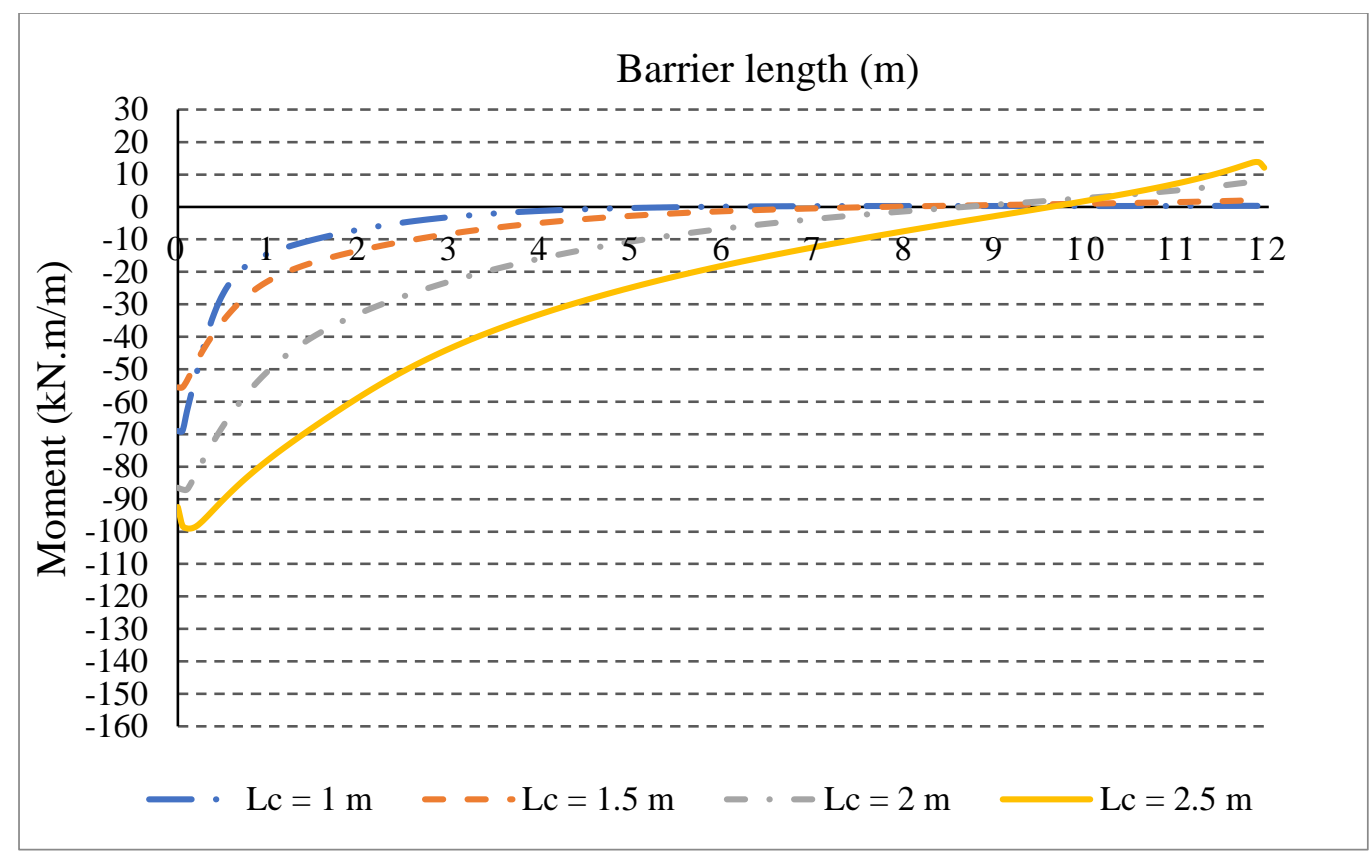

Figure 4-6: Effect of cantilever length on transverse moment for slab cantilever with TL-4 parapet

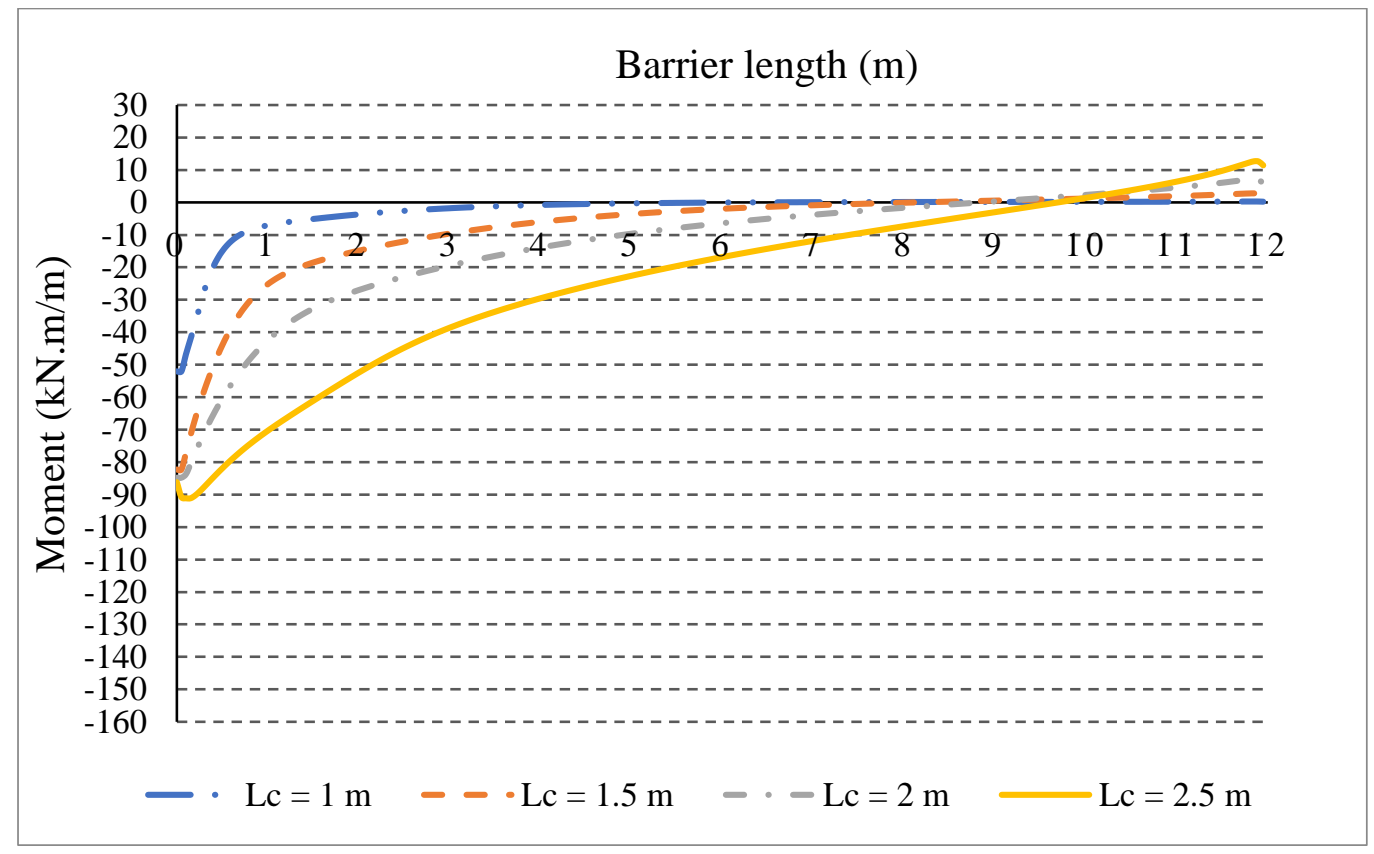

Figure 4-7: Effect of cantilever length on transverse moment for slab cantilever with TL-5 barrier 


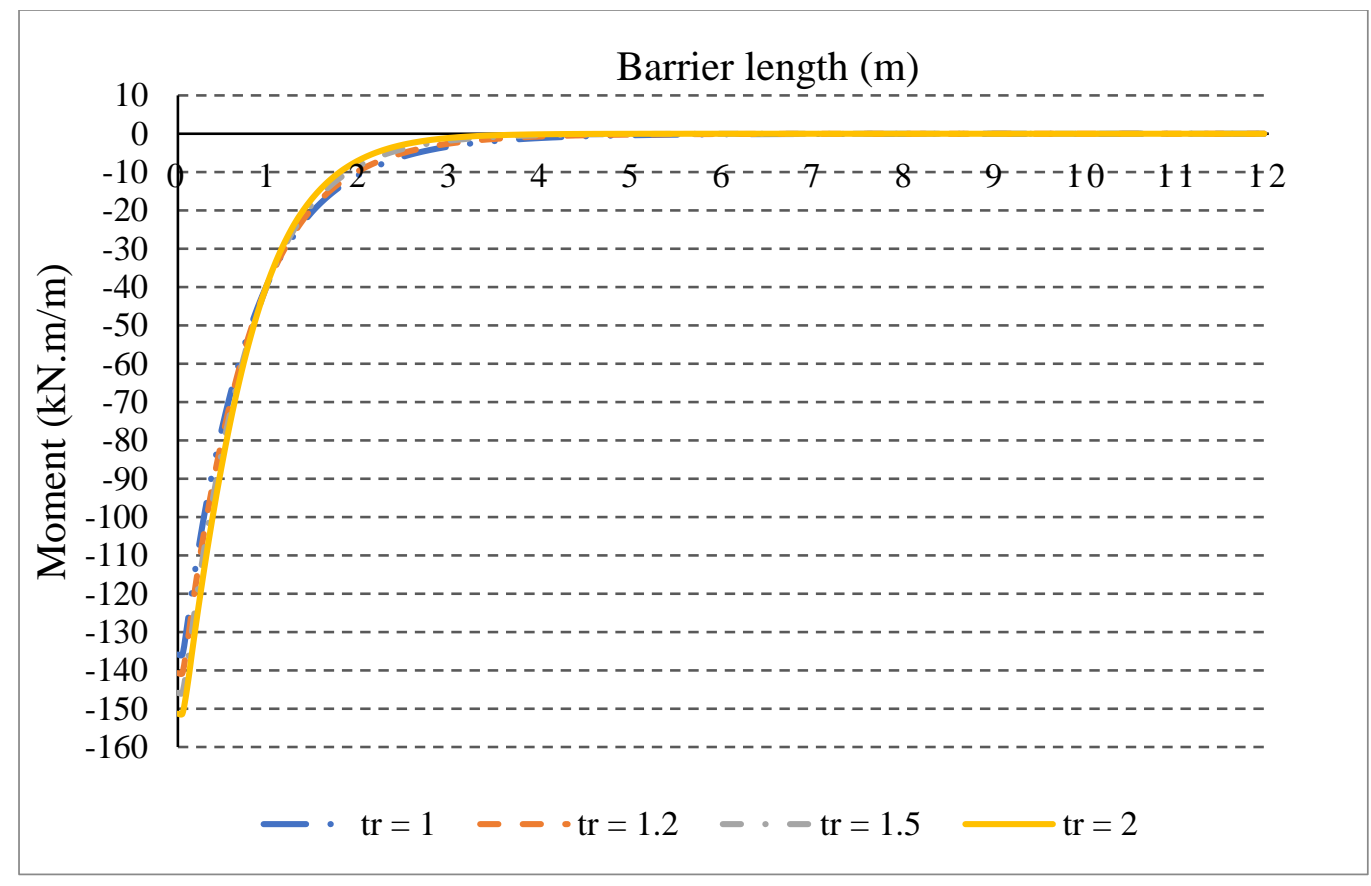

Figure 4-8: Effect of tapered slab thickness ratio on transverse moment for slab cantilever with unstiffened edge $\left(\mathrm{L}_{b}=12 \mathrm{~m}, \mathrm{~L}_{\mathrm{c}}=1.5 \mathrm{~m}, \mathrm{t}_{1}=200 \mathrm{~mm}\right)$

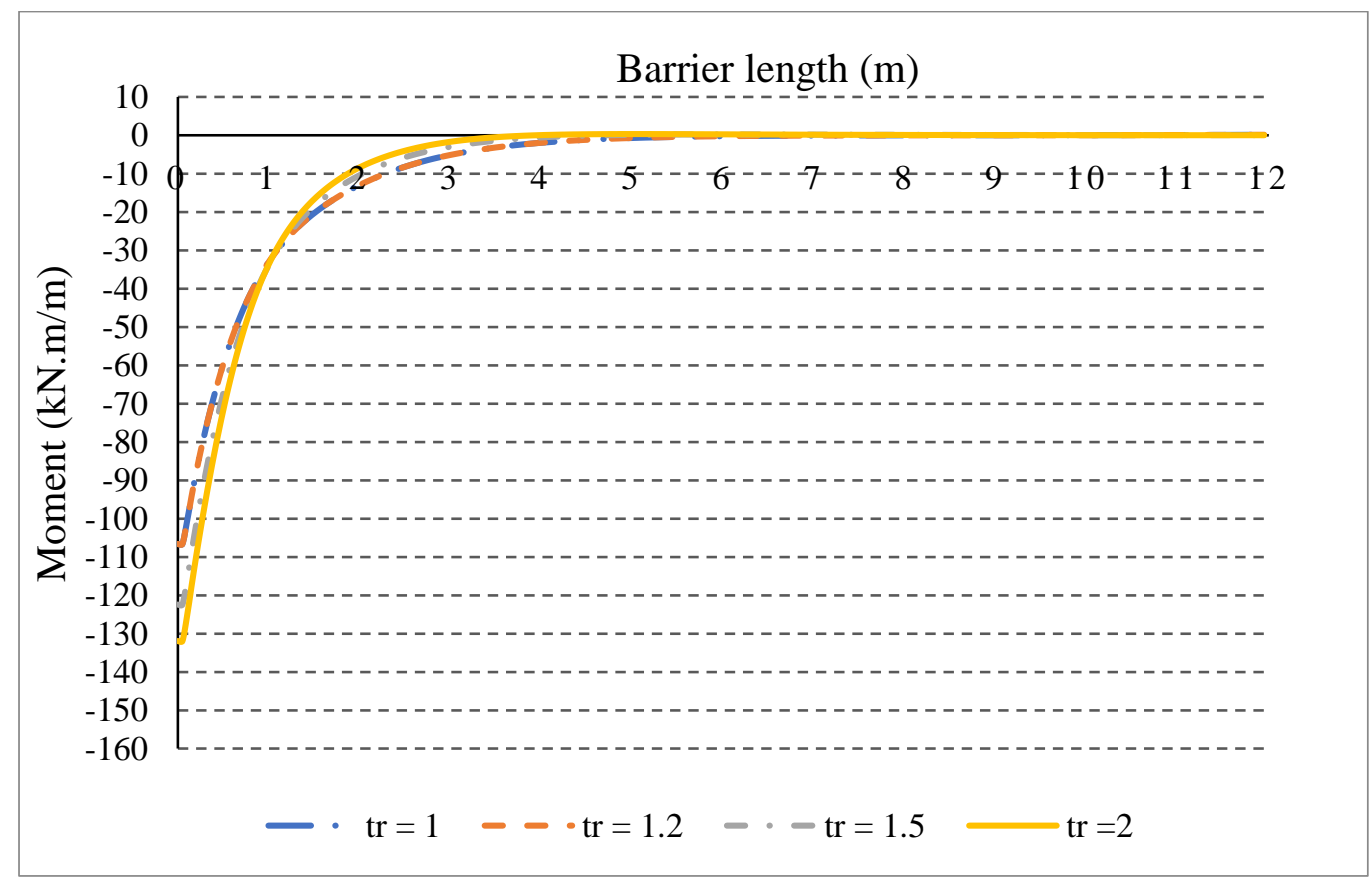

Figure 4-9: Effect of tapered slab thickness ratio on transverse moment for slab cantilever with a $\operatorname{curb}\left(\mathrm{L}_{b}=12 \mathrm{~m}, \mathrm{~L}_{\mathrm{c}}=1.5 \mathrm{~m}, \mathrm{t}_{1}=200 \mathrm{~mm}\right)$ 


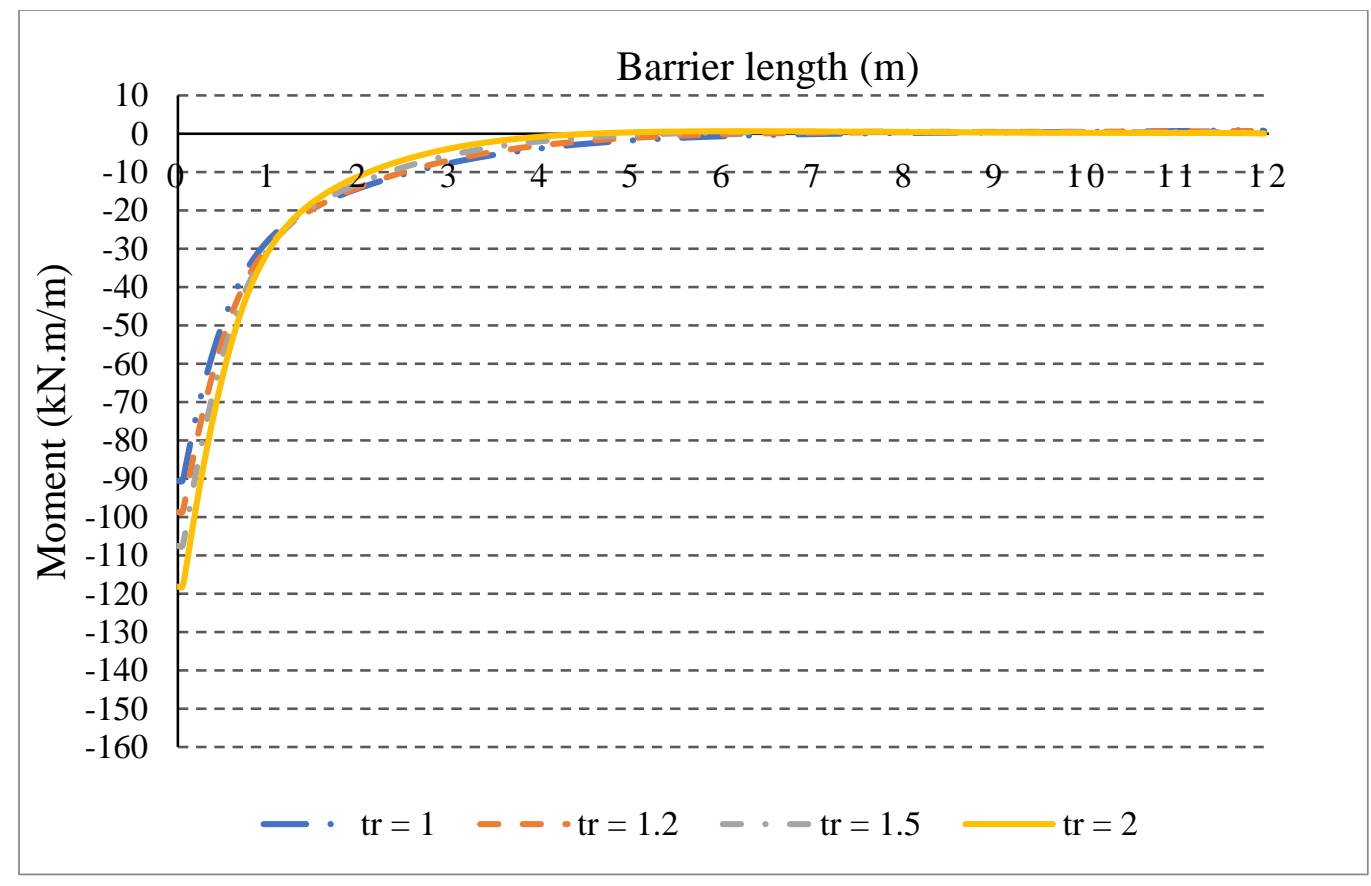

Figure 4-10: Effect of tapered slab thickness ratio on transverse moment for slab cantilever with TL-2 barriers $\left(\mathrm{L}_{b}=12 \mathrm{~m}, \mathrm{~L}_{\mathrm{c}}=1.5 \mathrm{~m}, \mathrm{t}_{1}=200 \mathrm{~mm}\right)$

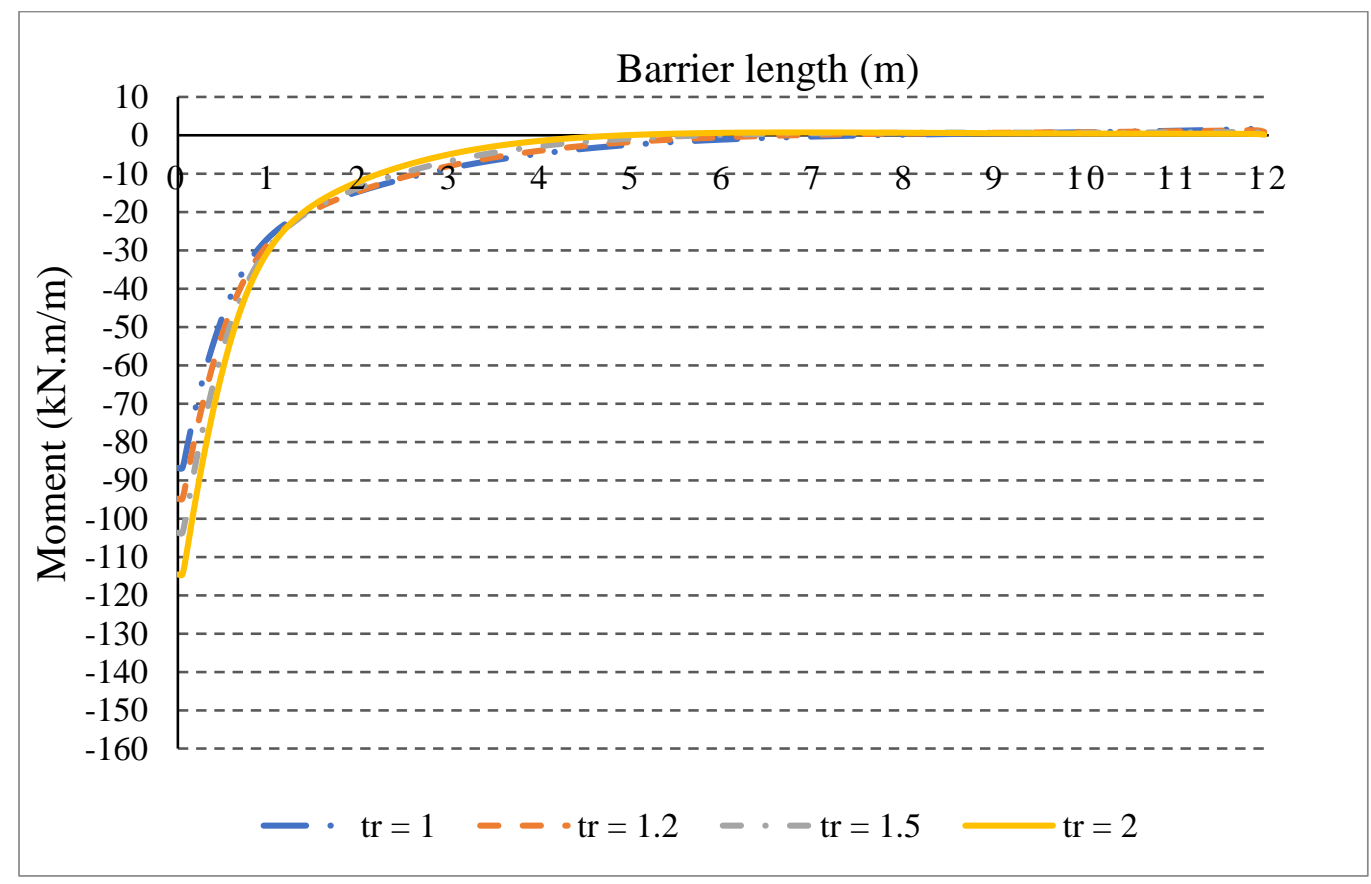

Figure 4-11: Effect of tapered slab thickness ratio on transverse moment for slab cantilever with TL-4 barrier $\left(\mathrm{L}_{b}=12 \mathrm{~m}, \mathrm{~L}_{\mathrm{c}}=1.5 \mathrm{~m}, \mathrm{t}_{1}=200 \mathrm{~mm}\right)$ 


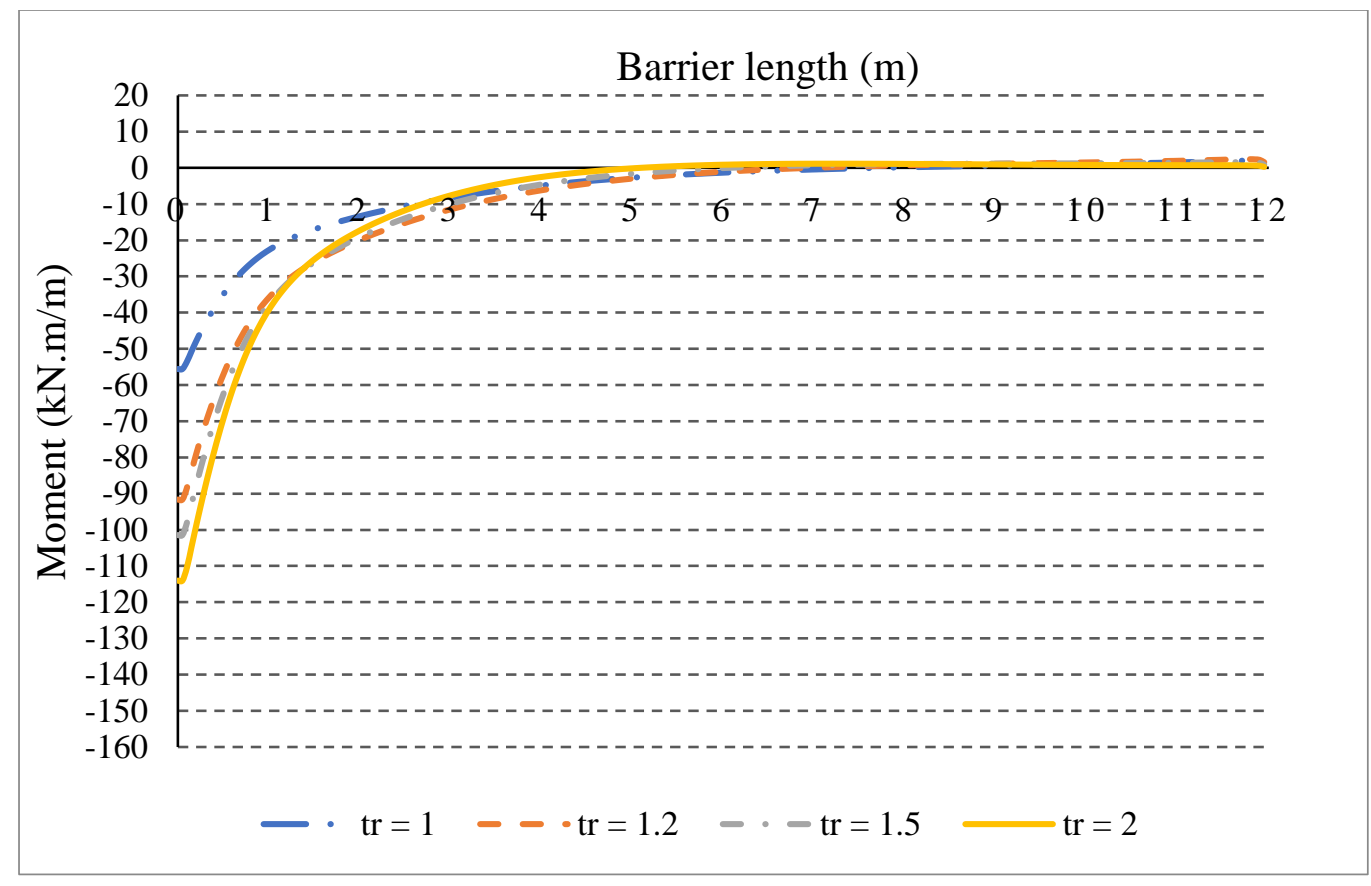

Figure 4-12: Effect of tapered slab thickness ratio on transverse moment for slab cantilever with TL-4 parapet $\left(\mathrm{L}_{b}=12 \mathrm{~m}, \mathrm{~L}_{\mathrm{c}}=1.5 \mathrm{~m}, \mathrm{t}_{1}=200 \mathrm{~mm}\right)$

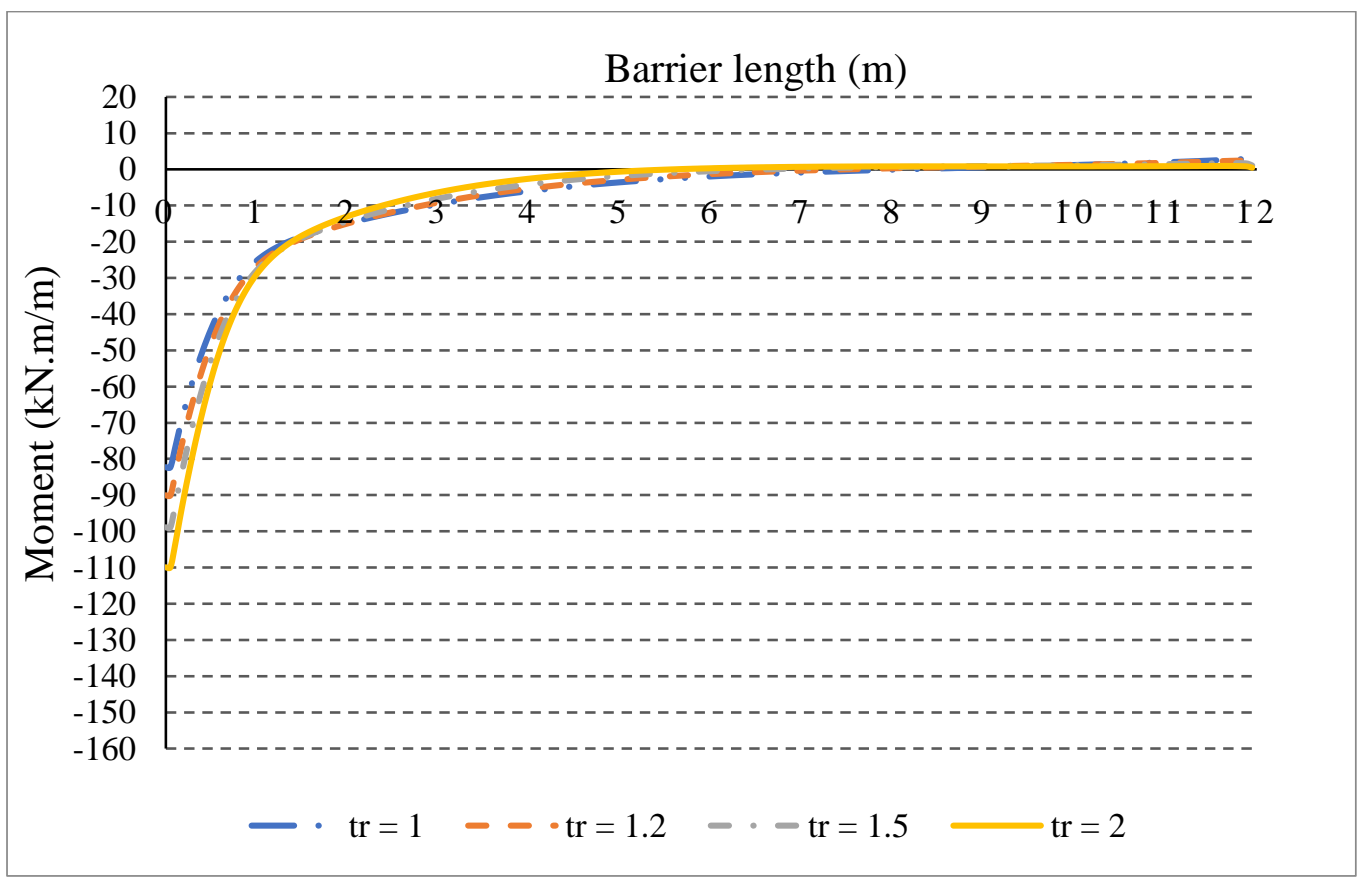

Figure 4-13: Effect of tapered slab thickness ratio on transverse moment for slab cantilever with TL-5 barrier $\left(\mathrm{L}_{\mathrm{b}}=12 \mathrm{~m}, \mathrm{~L}_{\mathrm{c}}=1.5 \mathrm{~m}, \mathrm{t}_{1}=200 \mathrm{~mm}\right)$ 


\subsection{Analysis of Longitudinal Moment}

Similar to Section 4.3 in this thesis, this section provides information on the effect of key parameters considered in parametric study on the longitudinal moment intensity due to wheel loads near the transverse free edge of the cantilever deck slab. Results show that the intensity of negative longitudinal moment is very small in comparison with the hogging moment created in the transverse direction.

\subsubsection{Effect of stiffening Arrangement}

Table 4-15 presented the applied longitudinal moment in the deck slab cantilever with unstiffened edge, followed by the percentage change in this moment with the inclusion of stiffened edge of different types. It can be observed that edge stiffening arrangement reduces the intensity of maximum longitudinal moment significantly when compared to that for slab cantilevers with unstiffened slab, as expected.

Table 4-15: Effect of stiffening arrangement on longitudinal moment

\begin{tabular}{cccccc}
\hline Unstiffened & Curb & TL-2 barrier & TL-4 Barrier & TL-5 barrier & TL-4 Parapet \\
\hline-4.96 kN.m & $-33.47 \%$ & $-52.62 \%$ & $-56.05 \%$ & $-60.48 \%$ & $-62.70 \%$
\end{tabular}

Maximum transverse moment for $\mathrm{L}_{\mathrm{c}}=1.5 \mathrm{~m}, \mathrm{~L}_{\mathrm{b}}=12 \mathrm{~m}$, slab thickness $\left(\mathrm{t}_{1}\right)=250 \mathrm{~mm}$, tapered slab thickness ratio $\left(\mathrm{t}_{2} / \mathrm{t}_{1}\right)=1$.

\subsubsection{Effect of Barrier Length}

Tables 4-16 through 4-21 demonstrate the effect of barrier length on maximum longitudinal moment of the deck slab cantilever with different edge stiffening conditions. One may observe that the slab deck cantilever with unstiffened edge maintained almost the same longitudinal moment with increase of barrier length from 5 to $12 \mathrm{~m}$ as depicted in Table 4-16. However, for slab cantilevers with stiffened edge, the applied longitudinal moment decreases with increase in barrier length. However, the effect of barrier length is significantly decreasing with the increase in in the size of the barrier at the stiffened edge. For example, the maximum moment decreases by $6.33 \%, 17.46 \%, 20.94 \%, 22.78 \%$ and $24.95 \%$ for cantilever slabs with curb, TL-2 barrier, TL-4 barrier, TL-4 parapet and TL-5 barrier, respectively. 
Table 4-16: Effect of barrier length on longitudinal moment for slab cantilever with unstiffened edge

\begin{tabular}{lccccc}
\hline \hline & $\mathbf{L}_{b}=\mathbf{5} \mathbf{m}$ & $\mathbf{L}_{b}=\mathbf{6} \mathbf{m}$ & $\mathbf{L}_{b}=\mathbf{8} \mathbf{m}$ & $\mathbf{L}_{b}=10 \mathrm{~m}$ & $\mathbf{L}_{b}=12 \mathrm{~m}$ \\
\hline \hline $\mathrm{L}_{c}=\mathbf{1} \mathbf{m}$ & -1.73 & $0.00 \%$ & $0.00 \%$ & $0.00 \%$ & $0.00 \%$ \\
\hline $\mathrm{L}_{c}=\mathbf{1 . 5} \mathbf{m}$ & -4.96 & $0.00 \%$ & $0.00 \%$ & $0.00 \%$ & $0.00 \%$ \\
\hline $\mathbf{L}_{c}=\mathbf{2} \mathbf{m}$ & -7.99 & $-0.02 \%$ & $-0.02 \%$ & $-0.02 \%$ & $-0.02 \%$ \\
\hline $\mathbf{L}_{c}=\mathbf{2 . 5} \mathbf{m}$ & -8.12 & $-0.20 \%$ & $-0.23 \%$ & $-0.23 \%$ & $-0.23 \%$
\end{tabular}

Maximum longitudinal moment in kN.m for slab thickness $\left(\mathrm{t}_{1}\right)=200 \mathrm{~mm}$, slab ratio $\left(\mathrm{t}_{2} / \mathrm{t}_{1}\right)=1$.

Table 4-17: Effect of barrier length on longitudinal moment for slab cantilever with a curb

\begin{tabular}{llllll}
\hline \hline & $\mathbf{L}_{b}=\mathbf{5} \mathbf{m}$ & $\mathbf{L}_{b}=\mathbf{6} \mathbf{m}$ & $\mathbf{L}_{b}=\mathbf{8} \mathbf{m}$ & $\mathbf{L}_{b}=\mathbf{1 0} \mathbf{m}$ & $\mathbf{L}_{b}=\mathbf{1 2} \mathbf{~ m}$ \\
\hline \hline $\mathbf{L}_{c}=\mathbf{1} \mathbf{~ m}$ & -1.21 & $-0.17 \%$ & $-0.23 \%$ & $-0.23 \%$ & $-0.23 \%$ \\
\hline $\mathbf{L}_{c}=\mathbf{1 . 5} \mathbf{m}$ & -2.99 & $-0.98 \%$ & $-1.44 \%$ & $-1.50 \%$ & $-1.51 \%$ \\
\hline $\mathbf{L}_{c}=\mathbf{2} \mathbf{m}$ & -5.90 & $-1.84 \%$ & $-3.02 \%$ & $-3.23 \%$ & $-3.27 \%$ \\
\hline $\mathbf{L}_{c}=\mathbf{2 . 5} \mathbf{m}$ & -7.13 & $-2.97 \%$ & $-5.50 \%$ & $-6.17 \%$ & $-6.33 \%$
\end{tabular}

Maximum longitudinal moment in kN.m for slab thickness $\left(t_{1}\right)=200 \mathrm{~mm}$, slab ratio $\left(\mathrm{t}_{2} / \mathrm{t}_{1}\right)=1$.

Table 4-18: Effect of barrier length on longitudinal moment for slab cantilever with TL-2 barrier

\begin{tabular}{lccccc}
\hline \hline & $\mathbf{L}_{b}=\mathbf{5} \mathbf{m}$ & $\mathbf{L}_{b}=\mathbf{6} \mathrm{m}$ & $\mathbf{L}_{b}=\mathbf{8} \mathrm{m}$ & $\mathbf{L}_{b}=10 \mathrm{~m}$ & $\mathbf{L}_{b}=12 \mathrm{~m}$ \\
\hline \hline $\mathbf{L}_{c}=\mathbf{1} \mathbf{m}$ & -0.88 & $-0.97 \%$ & $-1.52 \%$ & $-1.60 \%$ & $-1.61 \%$ \\
\hline $\mathbf{L}_{c}=\mathbf{1 . 5} \mathbf{m}$ & -2.24 & $-4.56 \%$ & $-8.25 \%$ & $-9.21 \%$ & $-9.44 \%$ \\
\hline $\mathbf{L}_{c}=\mathbf{2} \mathbf{m}$ & -5.09 & $-5.16 \%$ & $-10.38 \%$ & $-12.31 \%$ & $-12.97 \%$ \\
\hline $\mathbf{L}_{c}=\mathbf{2 . 5} \mathbf{m}$ & -6.72 & $-5.55 \%$ & $-12.50 \%$ & $-15.91 \%$ & $-17.46 \%$
\end{tabular}

Maximum longitudinal moment in kN.m for slab thickness $\left(\mathrm{t}_{1}\right)=200 \mathrm{~mm}$, slab ratio $\left(\mathrm{t}_{2} / \mathrm{t}_{1}\right)=1$. 
Table 4-19: Effect of barrier length on longitudinal moment for slab cantilever with TL-4 barrier

\begin{tabular}{lccccc}
\hline \hline & $\mathbf{L}_{b}=\mathbf{5}$ & $\mathbf{L}_{b}=\mathbf{6}$ & $\mathbf{L}_{b}=\mathbf{8}$ & $\mathbf{L}_{b}=\mathbf{1 0}$ & $\mathbf{L}_{b}=\mathbf{1 2}$ \\
\hline \hline $\mathbf{L}_{c}=\mathbf{1}$ & -0.86 & $-1.36 \%$ & $-2.25 \%$ & $-2.43 \%$ & $-2.47 \%$ \\
\hline $\mathbf{L}_{c}=\mathbf{1 . 5}$ & -2.16 & $-5.88 \%$ & $-11.36 \%$ & $-13.15 \%$ & $-13.70 \%$ \\
\hline $\mathbf{L}_{c}=\mathbf{2}$ & -5.00 & $-6.00 \%$ & $-12.65 \%$ & $-15.54 \%$ & $-16.75 \%$ \\
\hline $\mathbf{L}_{c}=\mathbf{2 . 5}$ & -6.68 & $-6.06 \%$ & $-14.14 \%$ & $-18.59 \%$ & $-20.94 \%$
\end{tabular}

Maximum longitudinal moment in kN.m for slab thickness $\left(\mathrm{t}_{1}\right)=200 \mathrm{~mm}$, slab ratio $\left(\mathrm{t}_{2} / \mathrm{t}_{1}\right)=1$.

Table 4-20: Effect of barrier length on longitudinal moment for slab cantilever with TL-4 parapet

\begin{tabular}{lccccc}
\hline \hline & $\mathbf{L}_{b}=\mathbf{5} \mathbf{m}$ & $\mathbf{L}_{b}=\mathbf{6} \mathbf{m}$ & $\mathbf{L}_{b}=\mathbf{8} \mathbf{m}$ & $\mathbf{L}_{b}=\mathbf{1 0} \mathbf{m}$ & $\mathbf{L}_{b}=\mathbf{1 2} \mathbf{m}$ \\
\hline \hline $\mathbf{L}_{c}=\mathbf{1} \mathbf{m}$ & -1.39 & $-2.34 \%$ & $-4.10 \%$ & $-4.51 \%$ & $-4.59 \%$ \\
\hline $\mathbf{L}_{c}=\mathbf{1 . 5} \mathbf{m}$ & -1.87 & $-6.44 \%$ & $-12.96 \%$ & $-15.46 \%$ & $-16.35 \%$ \\
\hline $\mathbf{L}_{c}=\mathbf{2} \mathbf{m}$ & -5.45 & $-6.55 \%$ & $-14.20 \%$ & $-17.92 \%$ & $-19.71 \%$ \\
\hline $\mathbf{L}_{c}=\mathbf{2 . 5} \mathbf{m}$ & -7.04 & $-6.25 \%$ & $-14.79 \%$ & $-19.83 \%$ & $-22.78 \%$
\end{tabular}

Maximum longitudinal moment in kN.m for slab thickness $\left(\mathrm{t}_{1}\right)=200 \mathrm{~mm}$, slab ratio $\left(\mathrm{t}_{2} / \mathrm{t}_{1}\right)=1$.

Table 4-21: Effect of barrier length on longitudinal moment for slab cantilever with TL-5 barrier

\begin{tabular}{lccccc}
\hline \hline & $\mathbf{L}_{b}=\mathbf{5} \mathbf{m}$ & $\mathbf{L}_{b}=\mathbf{6} \mathbf{m}$ & $\mathbf{L}_{b}=\mathbf{8} \mathbf{m}$ & $\mathbf{L}_{b}=10 \mathrm{~m}$ & $\mathbf{L}_{b}=\mathbf{1 2} \mathbf{m}$ \\
\hline \hline $\mathbf{L}_{c}=\mathbf{1} \mathbf{m}$ & -0.85 & $-1.81 \%$ & $-3.37 \%$ & $-3.82 \%$ & $-3.94 \%$ \\
\hline $\mathbf{L}_{c}=\mathbf{1 . 5} \mathbf{m}$ & -2.09 & $-7.43 \%$ & $-15.33 \%$ & $-18.60 \%$ & $-19.91 \%$ \\
\hline $\mathbf{L}_{c}=\mathbf{2} \mathbf{m}$ & -4.91 & $-6.90 \%$ & $-15.15 \%$ & $-19.34 \%$ & $-21.47 \%$ \\
\hline $\mathbf{L}_{c}=\mathbf{2 . 5} \mathbf{m}$ & -6.64 & $-6.59 \%$ & $-15.89 \%$ & $-21.54 \%$ & $-24.95 \%$
\end{tabular}

Maximum longitudinal moment in kN.m for slab thickness $\left(\mathrm{t}_{1}\right)=200 \mathrm{~mm}$, slab ratio $\left(\mathrm{t}_{2} / \mathrm{t}_{1}\right)=1$. 


\subsubsection{Effect of slab thickness for various thickness ratio}

Tables 4-22 through 4-14 demonstrate the effect of slab thickness for various tapered slab thickness ratio on maximum longitudinal moment of the deck slab cantilever. One may observe that the slab deck cantilever with unstiffened edge maintained almost the same longitudinal moment with increase of slab thickness from 200 to $350 \mathrm{~mm}$ m as depicted in Table 4-22. On the other hand, for slab cantilevers with stiffened edge, the applied transverse moment increases with increase in slab thickness. The above observations are presented later in graphical format in Figures 4-20 through 4-25.

Table 4-22: Effect of slab thickness on longitudinal moment for slab cantilever with unstiffened edge

\begin{tabular}{lccccc}
\hline \hline & $\begin{array}{c}\mathbf{t}_{\mathbf{1}}=\mathbf{2 0 0} \\
(\mathbf{m m})\end{array}$ & $\begin{array}{c}\mathbf{t}_{\mathbf{1}}=\mathbf{2 2 5} \\
(\mathbf{m m})\end{array}$ & $\begin{array}{c}\mathbf{t}_{\mathbf{1}}=\mathbf{2 5 0} \\
(\mathbf{m m})\end{array}$ & $\begin{array}{c}\mathbf{t}_{\mathbf{1}}=\mathbf{3 0 0} \\
(\mathbf{m m})\end{array}$ & $\begin{array}{c}\mathbf{t}_{\mathbf{1}}=\mathbf{3 5 0} \\
(\mathbf{m m})\end{array}$ \\
\hline \hline $\mathbf{t}_{\mathbf{r}=\mathbf{1}}$ & -4.96 & $0.00 \%$ & $0.00 \%$ & $0.00 \%$ & $0.00 \%$ \\
\hline $\mathbf{t}_{\mathbf{r}}=\mathbf{1 . 2}$ & -5.16 & $0.00 \%$ & $0.00 \%$ & $0.00 \%$ & $0.00 \%$ \\
\hline $\mathbf{t}_{\mathbf{r}}=\mathbf{1 . 5}$ & -5.38 & $0.00 \%$ & $0.00 \%$ & $0.00 \%$ & $0.00 \%$ \\
\hline $\mathbf{t}_{\mathbf{r}}=\mathbf{2 . 0}$ & -5.62 & $0.00 \%$ & $0.00 \%$ & $0.00 \%$ & $0.00 \%$ \\
\hline \multicolumn{4}{l}{ Maximum longitudinal moment in $\mathrm{kN} . \mathrm{m}$ for $\mathrm{L}_{b}=12 \mathrm{~m}, \mathrm{~L}_{\mathrm{c}}=2 \mathrm{~m}}$.
\end{tabular}

Table 4-23: Effect of slab thickness on longitudinal moment for slab cantilever with a curb

\begin{tabular}{lccccc}
\hline \hline & $\begin{array}{c}\mathbf{t}_{\mathbf{1}}=\mathbf{2 0 0} \\
(\mathbf{m m})\end{array}$ & $\begin{array}{c}\mathbf{t}_{\mathbf{1}}=\mathbf{2 2 5} \\
(\mathbf{m m})\end{array}$ & $\begin{array}{c}\mathbf{t}_{\mathbf{1}}=\mathbf{2 5 0} \\
(\mathbf{m m})\end{array}$ & $\begin{array}{c}\mathbf{t}_{\mathbf{1}}=\mathbf{3 0 0} \\
(\mathbf{m m})\end{array}$ & $\begin{array}{c}\mathbf{t}_{\mathbf{1}}=\mathbf{3 5 0} \\
(\mathbf{m m})\end{array}$ \\
\hline \hline $\mathbf{t}_{\mathbf{r}}=\mathbf{1}$ & -2.94 & $6.57 \%$ & $12.24 \%$ & $21.06 \%$ & $27.29 \%$ \\
\hline $\mathbf{t}_{\mathbf{r}}=\mathbf{1 . 2}$ & -3.28 & $5.51 \%$ & $10.11 \%$ & $17.10 \%$ & $21.88 \%$ \\
\hline $\mathbf{t}_{\mathbf{r}}=\mathbf{1 . 5}$ & -3.67 & $4.32 \%$ & $7.82 \%$ & $12.95 \%$ & $16.34 \%$ \\
\hline $\mathbf{t}_{\mathbf{r}}=\mathbf{2 . 0}$ & -4.12 & $3.04 \%$ & $5.41 \%$ & $8.73 \%$ & $10.83 \%$ \\
\hline
\end{tabular}

Maximum longitudinal moment in kN.m for $\mathrm{L}_{\mathrm{b}}=12 \mathrm{~m}, \mathrm{~L}_{\mathrm{c}}=1.5 \mathrm{~m}$. 
Table 4-24: Effect of slab thickness on longitudinal moment for slab cantilever with TL-2 barrier

\begin{tabular}{lccccc}
\hline \hline & $\begin{array}{c}\mathbf{t}_{\mathbf{1}}=\mathbf{2 0 0} \\
(\mathbf{m m})\end{array}$ & $\begin{array}{c}\mathbf{t}_{\mathbf{1}}=\mathbf{2 2 5} \\
(\mathbf{m m})\end{array}$ & $\begin{array}{c}\mathbf{t}_{\mathbf{1}}=\mathbf{2 5 0} \\
(\mathbf{m m})\end{array}$ & $\begin{array}{c}\mathbf{t}_{\mathbf{1}}=\mathbf{3 0 0} \\
(\mathbf{m m})\end{array}$ & $\begin{array}{c}\mathbf{t}_{\mathbf{1}}=\mathbf{3 5 0} \\
(\mathbf{m m})\end{array}$ \\
\hline \hline $\mathbf{t}_{\mathbf{r}}=\mathbf{1}$ & -2.03 & $8.20 \%$ & $15.79 \%$ & $29.20 \%$ & $40.16 \%$ \\
\hline $\mathbf{t}_{\mathbf{r}}=\mathbf{1 . 2}$ & -2.38 & $7.10 \%$ & $13.56 \%$ & $24.57 \%$ & $33.73 \%$ \\
\hline $\mathbf{t}_{\mathbf{r}}=\mathbf{1 . 5}$ & -2.78 & $5.80 \%$ & $10.94 \%$ & $19.45 \%$ & $26.03 \%$ \\
\hline $\mathbf{t}_{\mathbf{r}}=\mathbf{2 . 0}$ & -3.26 & $4.50 \%$ & $8.37 \%$ & $14.58 \%$ & $19.08 \%$
\end{tabular}

Maximum longitudinal moment in kN.m for $\mathrm{L}_{\mathrm{b}}=12 \mathrm{~m}, \mathrm{~L}_{\mathrm{c}}=1.5 \mathrm{~m}$.

Table 4-25: Effect of slab thickness on longitudinal moment for slab cantilever with TL-4 barrier

\begin{tabular}{lccccc}
\hline \hline & $\mathbf{t}_{\mathbf{1}}=\mathbf{2 0 0}$ & $\mathbf{t}_{\mathbf{1}}=\mathbf{2 2 5}$ & $\mathbf{t}_{\mathbf{1}}=\mathbf{2 5 0}$ & $\mathbf{t}_{\mathbf{1}}=\mathbf{3 0 0}$ & $\mathbf{t}_{\mathbf{1}}=\mathbf{3 5 0}$ \\
& $(\mathbf{m m})$ & $(\mathbf{m m})$ & $(\mathbf{m m})$ & $(\mathbf{m m})$ & $(\mathbf{m m})$ \\
\hline \hline $\mathbf{t}_{\mathbf{r}}=\mathbf{1}$ & -1.87 & $8.53 \%$ & $16.53 \%$ & $-84.19 \%$ & $-89.30 \%$ \\
\hline $\mathbf{t}_{\mathbf{r}}=\mathbf{1 . 2}$ & -2.21 & $7.35 \%$ & $14.24 \%$ & $-90.53 \%$ & $-93.64 \%$ \\
\hline $\mathbf{t}_{\mathbf{r}}=\mathbf{1 . 5}$ & -2.61 & $6.18 \%$ & $11.77 \%$ & $-95.01 \%$ & $-96.67 \%$ \\
\hline $\mathbf{t}_{\mathbf{r}}=\mathbf{2 . 0}$ & -3.10 & $4.80 \%$ & $9.10 \%$ & $-97.80 \%$ & $-98.55 \%$ \\
\hline
\end{tabular}

Maximum longitudinal moment in kN.m for $\mathrm{L}_{b}=12 \mathrm{~m}, \mathrm{~L}_{\mathrm{c}}=1.5 \mathrm{~m}$.

Table 4-26: Effect of slab thickness on longitudinal moment for slab cantilever with TL-4 parapet

\begin{tabular}{lccccc}
\hline & $\begin{array}{c}\mathbf{t}_{\mathbf{1}}=\mathbf{2 0 0} \\
(\mathbf{m m})\end{array}$ & $\begin{array}{c}\mathbf{t}_{\mathbf{1}}=\mathbf{2 2 5} \\
(\mathbf{m m})\end{array}$ & $\begin{array}{c}\mathbf{t}_{\mathbf{1}}=\mathbf{2 5 0} \\
(\mathbf{m m})\end{array}$ & $\begin{array}{c}\mathbf{t}_{\mathbf{1}}=\mathbf{3 0 0} \\
(\mathbf{m m})\end{array}$ & $\begin{array}{c}\mathbf{t}_{\mathbf{1}}=\mathbf{3 5 0} \\
(\mathbf{m m})\end{array}$ \\
\hline \hline $\mathbf{t}_{\mathbf{r}}=\mathbf{1}$ & -1.56 & $9.36 \%$ & $18.12 \%$ & $33.89 \%$ & $47.32 \%$ \\
\hline $\mathbf{t}_{\mathbf{r}}=\mathbf{1 . 2}$ & -2.73 & $8.31 \%$ & $15.97 \%$ & $29.48 \%$ & $40.66 \%$ \\
\hline $\mathbf{t}_{\mathbf{r}}=\mathbf{1 . 5}$ & -3.20 & $7.16 \%$ & $13.63 \%$ & $24.83 \%$ & $33.80 \%$ \\
\hline $\mathbf{t}_{\mathbf{r}}=\mathbf{2 . 0}$ & -3.81 & $5.87 \%$ & $11.02 \%$ & $19.46 \%$ & $25.89 \%$ \\
\hline \multicolumn{4}{l}{ Maximum longitudinal moment in $\mathrm{kN} . \mathrm{m}$ for $\mathrm{L}_{\mathrm{b}}=12 \mathrm{~m}, \mathrm{~L}_{\mathrm{c}}=1.5 \mathrm{~m}}$.
\end{tabular}


Table 4-27: Effect of slab thickness on longitudinal moment for slab cantilever with TL-5 barrier

\begin{tabular}{lccccc}
\hline \hline & $\begin{array}{c}\mathbf{t}_{\mathbf{1}}=\mathbf{2 0 0} \\
(\mathbf{m m})\end{array}$ & $\begin{array}{c}\mathbf{t}_{\mathbf{1}}=\mathbf{2 2 5} \\
(\mathbf{m m})\end{array}$ & $\begin{array}{c}\mathbf{t}_{\mathbf{1}}=\mathbf{2 5 0} \\
(\mathbf{m m})\end{array}$ & $\begin{array}{c}\mathbf{t}_{\mathbf{1}}=\mathbf{3 0 0} \\
(\mathbf{m m})\end{array}$ & $\begin{array}{c}\mathbf{t}_{\mathbf{1}}=\mathbf{3 5 0} \\
(\mathbf{m m})\end{array}$ \\
\hline \hline $\mathbf{t}_{\mathbf{r}=\mathbf{1}}$ & -1.67 & $8.72 \%$ & $17.07 \%$ & $32.52 \%$ & $46.32 \%$ \\
\hline $\mathbf{t}_{\mathbf{r}}=\mathbf{1 . 2}$ & -2.00 & $7.61 \%$ & $14.81 \%$ & $28.02 \%$ & $39.44 \%$ \\
\hline $\mathbf{t}_{\mathbf{r}}=\mathbf{1 . 5}$ & -2.39 & $6.49 \%$ & $12.56 \%$ & $23.26 \%$ & $32.13 \%$ \\
\hline $\mathbf{t}_{\mathbf{r}}=\mathbf{2 . 0}$ & -2.90 & $5.23 \%$ & $9.95 \%$ & $18.07 \%$ & $24.54 \%$ \\
\hline Maximum longitudinal moment $\mathrm{f}$ in $\mathrm{kN} . \mathrm{m}$ or $\mathrm{L}_{\mathrm{b}}=12 \mathrm{~m}, \mathrm{~L}_{\mathrm{c}}=1.5 \mathrm{~m}$.
\end{tabular}

\subsubsection{Effect of Cantilever Length}

Figures 4-14 through 4-19 demonstrate the effect of increasing the cantilever length on maximum longitudinal induced by truck loading close to the transverse free edge of cantilever slab with 12 $\mathrm{m}$ barrier length, constant slab thickness of $200 \mathrm{~mm}$, and varied cantilever length of $1 \mathrm{~m}, 1.5 \mathrm{~m}, 2$ $\mathrm{m}$, and $2.5 \mathrm{~m}$. The obtained results for maximum longitudinal moment plotted on vertical axis versus the barrier length in meters on $\mathrm{X}$ axis for all types of edge-stiffening arrangement considered in parametric study. As it can be observed that the increase in cantilever length increases the induced moment intensity. Also, with increase in cantilever length, the presence of longitudinal moment extends farther into the slab cantilever longitudinal length. 


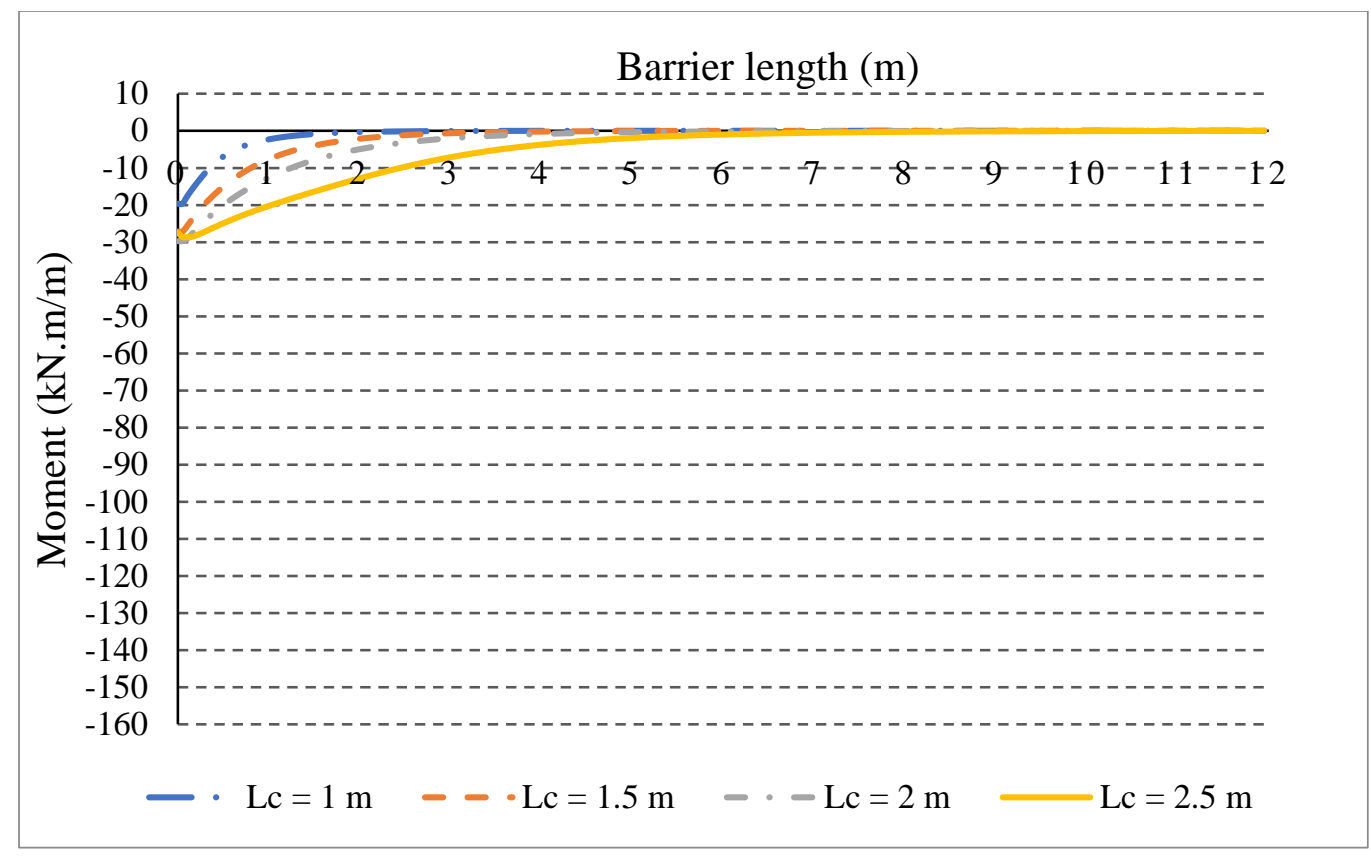

Figure 4-14: Effect of cantilever length on longitudinal moment for slab cantilever with unstiffened edge

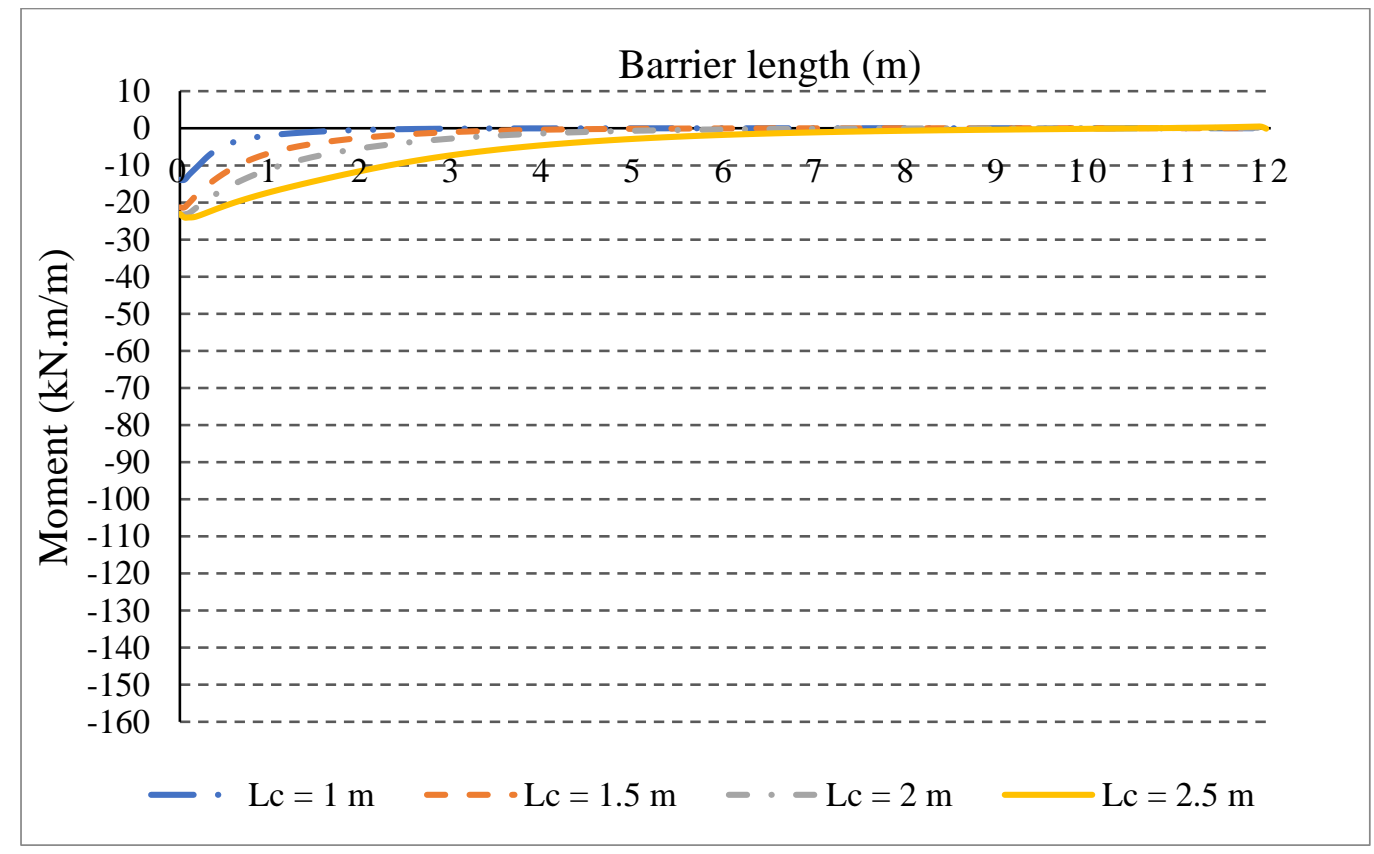

Figure 4-15: Effect of cantilever length on longitudinal moment for slab cantilever with a curb 


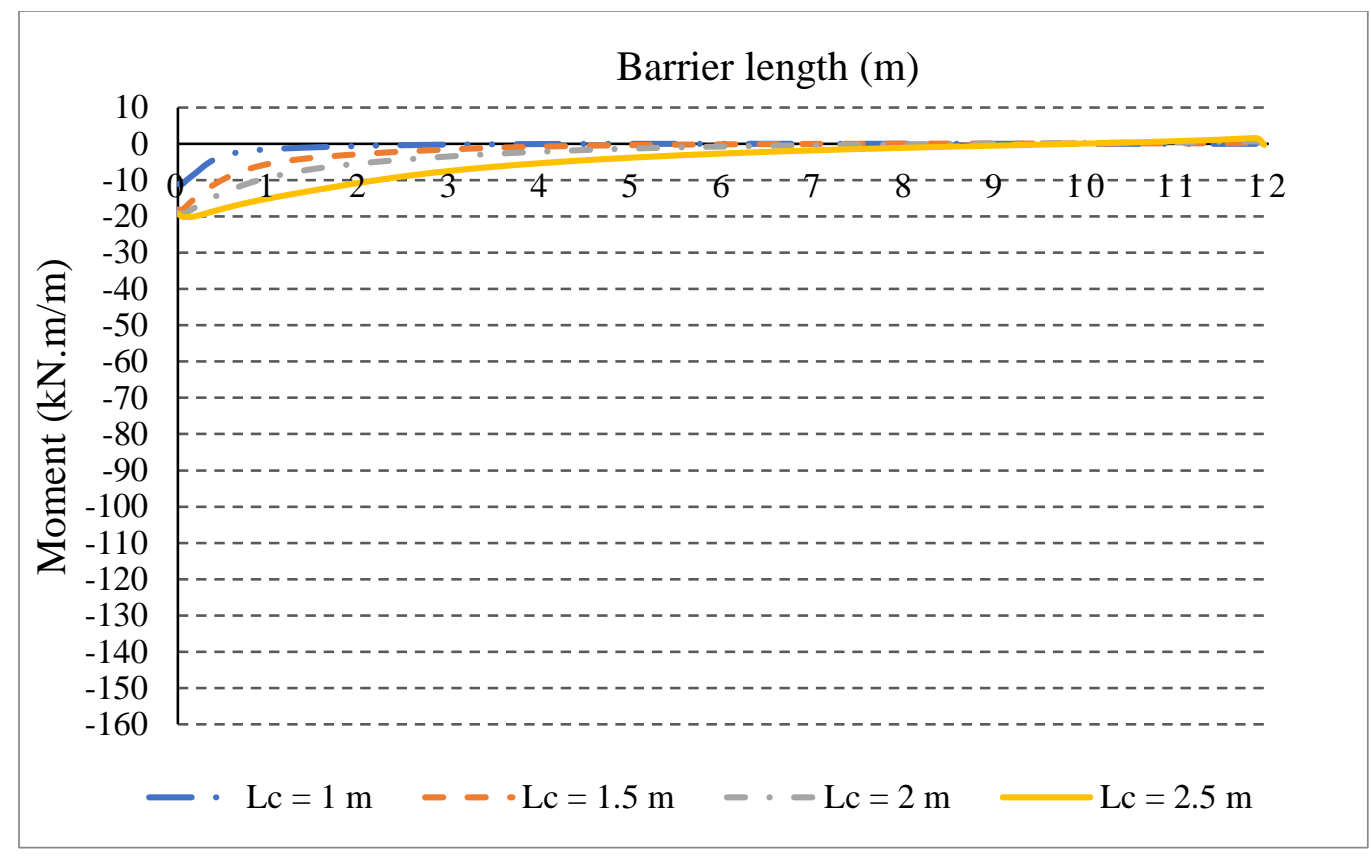

Figure 4-16: Effect of cantilever length on longitudinal moment for slab cantilever with TL-2 barrier

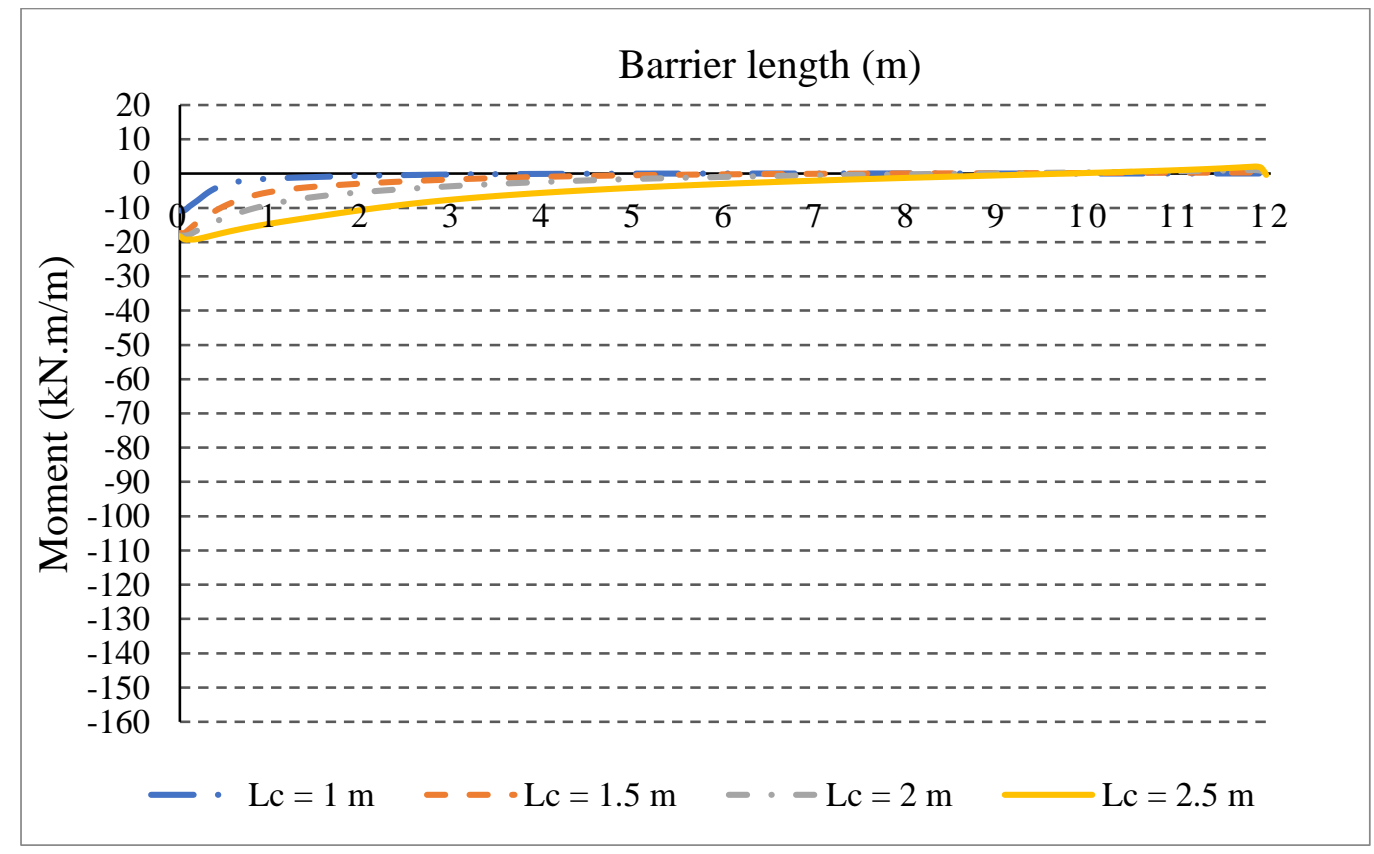

Figure 4-17: Effect of cantilever length on longitudinal moment for slab cantilever with TL-4 barrier 


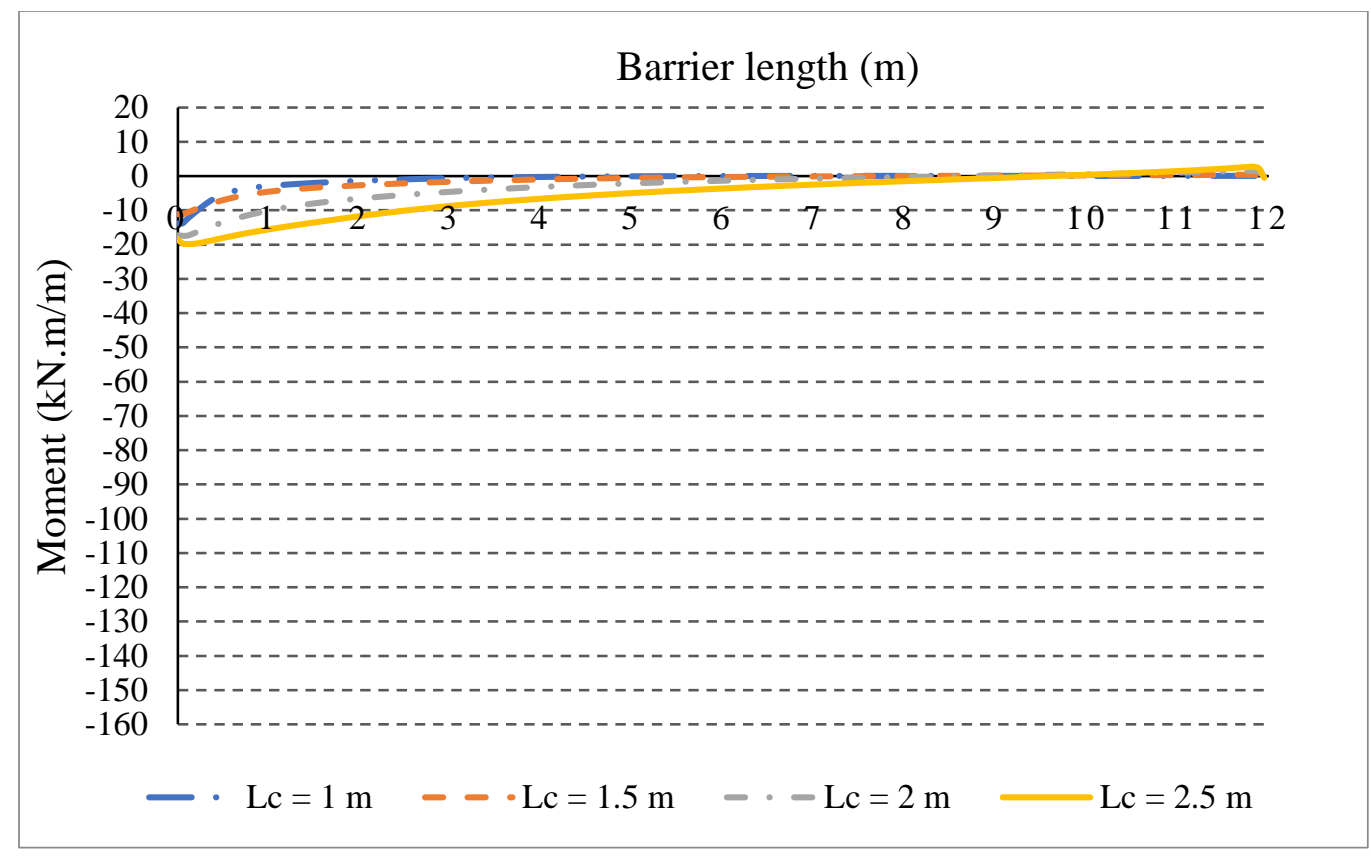

Figure 4-18: Effect of cantilever length on longitudinal moment for slab cantilever with TL-4 parapet

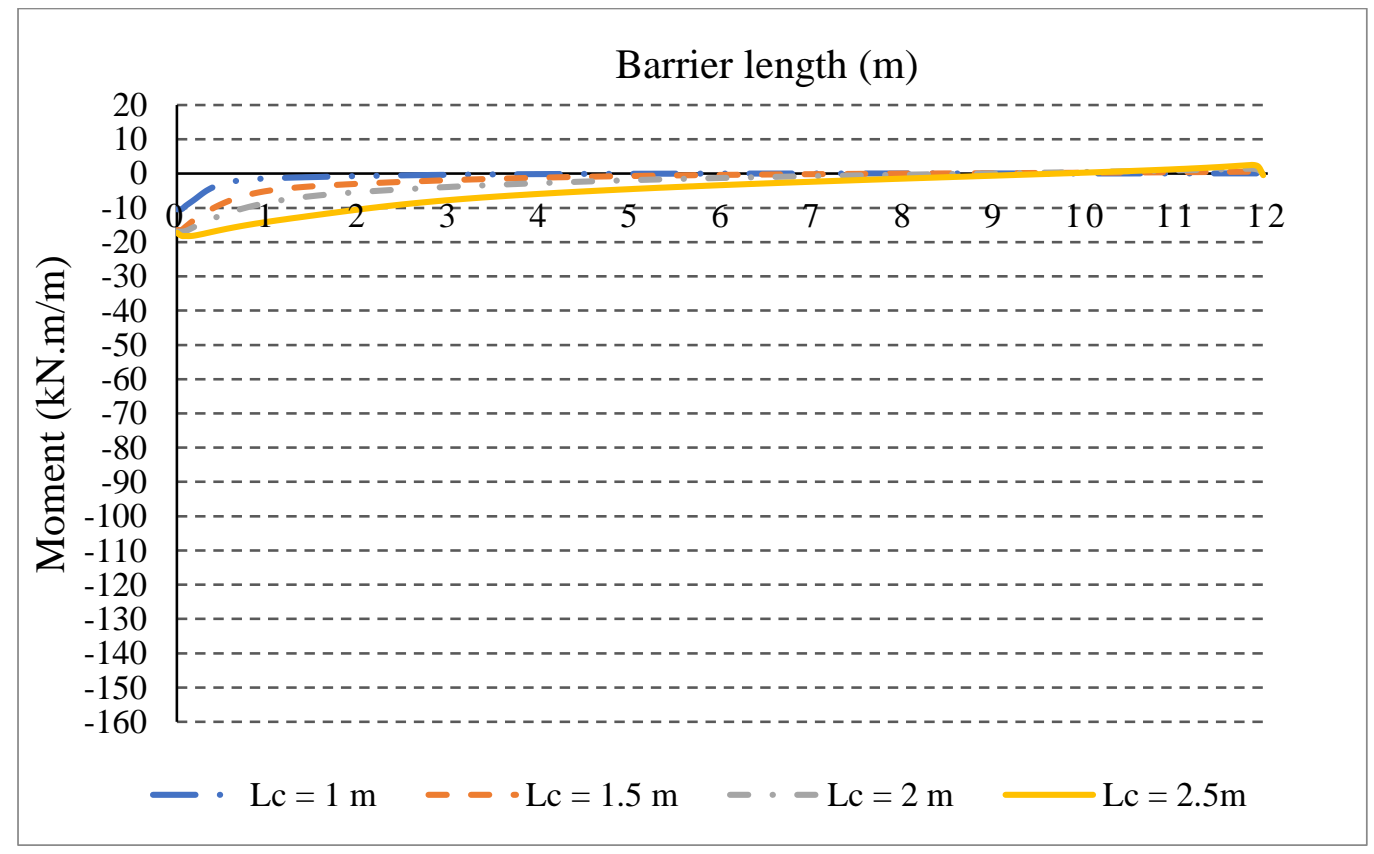

Figure 4-19: Effect of cantilever length on longitudinal moment for slab cantilever with TL-5 barrier 


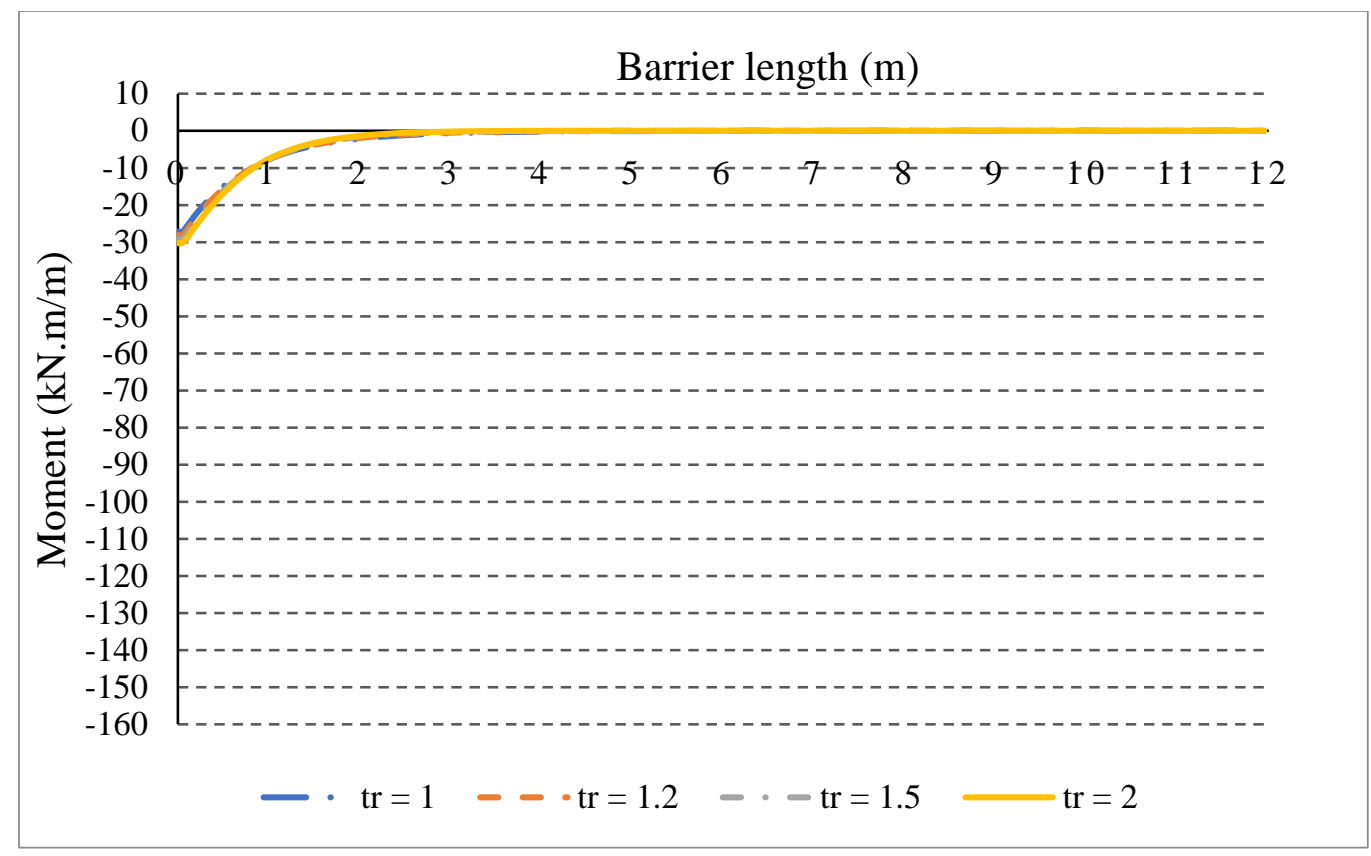

Figure 4-20: Effect of tapered slab thickness ratio on longitudinal moment for slab cantilever with unstiffened edge $\left(\mathrm{L}_{b}=12 \mathrm{~m}, \mathrm{~L}_{\mathrm{c}}=1.5 \mathrm{~m}, \mathrm{t}_{1}=200 \mathrm{~mm}\right)$

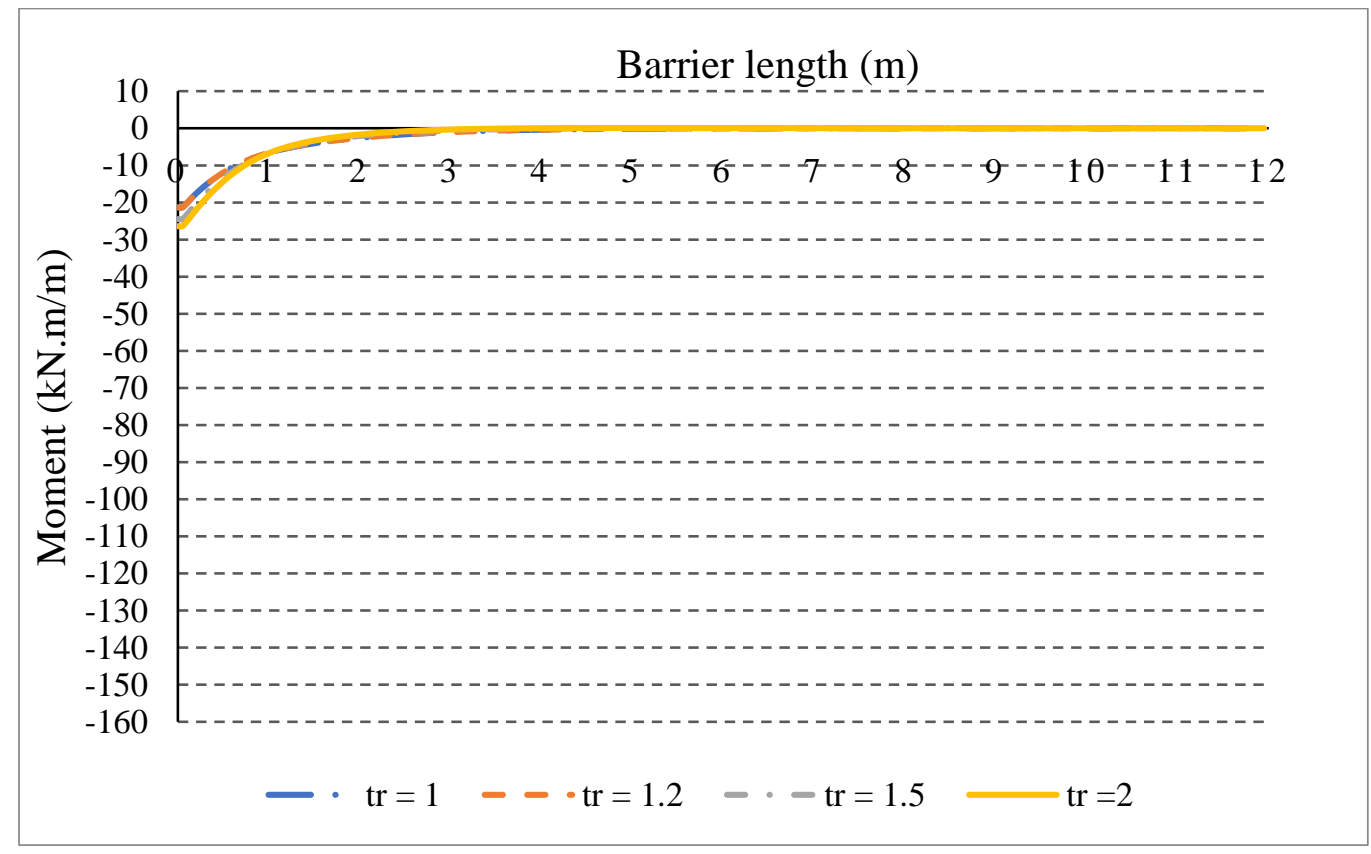

Figure 4-21: Effect of tapered slab thickness ratio on longitudinal moment of slab cantilever with a curb $\left(\mathrm{L}_{\mathrm{b}}=12 \mathrm{~m}, \mathrm{~L}_{\mathrm{c}}=1.5 \mathrm{~m}, \mathrm{t}_{1}=200 \mathrm{~mm}\right)$ 


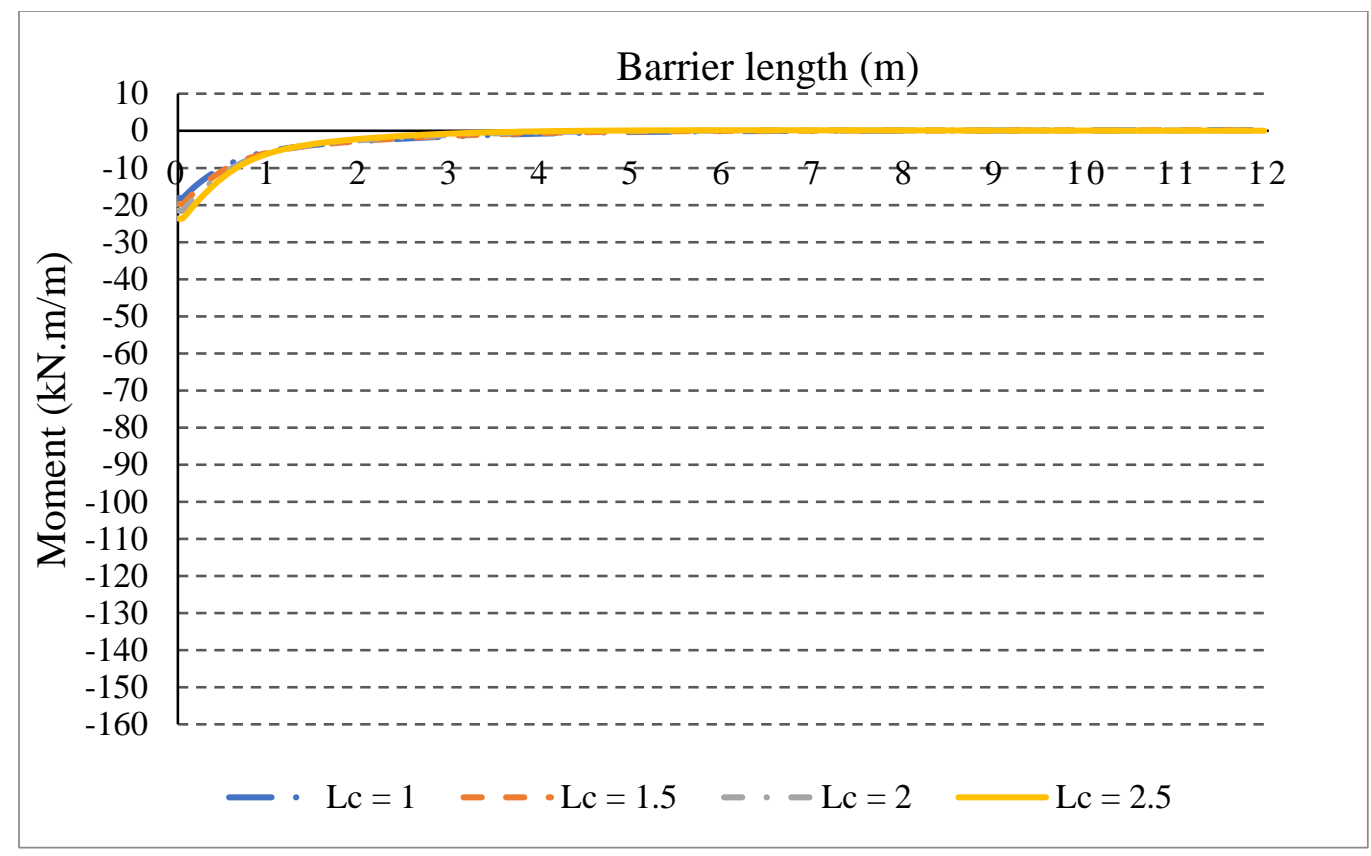

Figure 4-22: Effect of tapered slab thickness ratio on longitudinal moment for slab cantilever with TL-2 barrier $\left(\mathrm{L}_{b}=12 \mathrm{~m}, \mathrm{~L}_{\mathrm{c}}=1.5 \mathrm{~m}, \mathrm{t}_{1}=200 \mathrm{~mm}\right)$

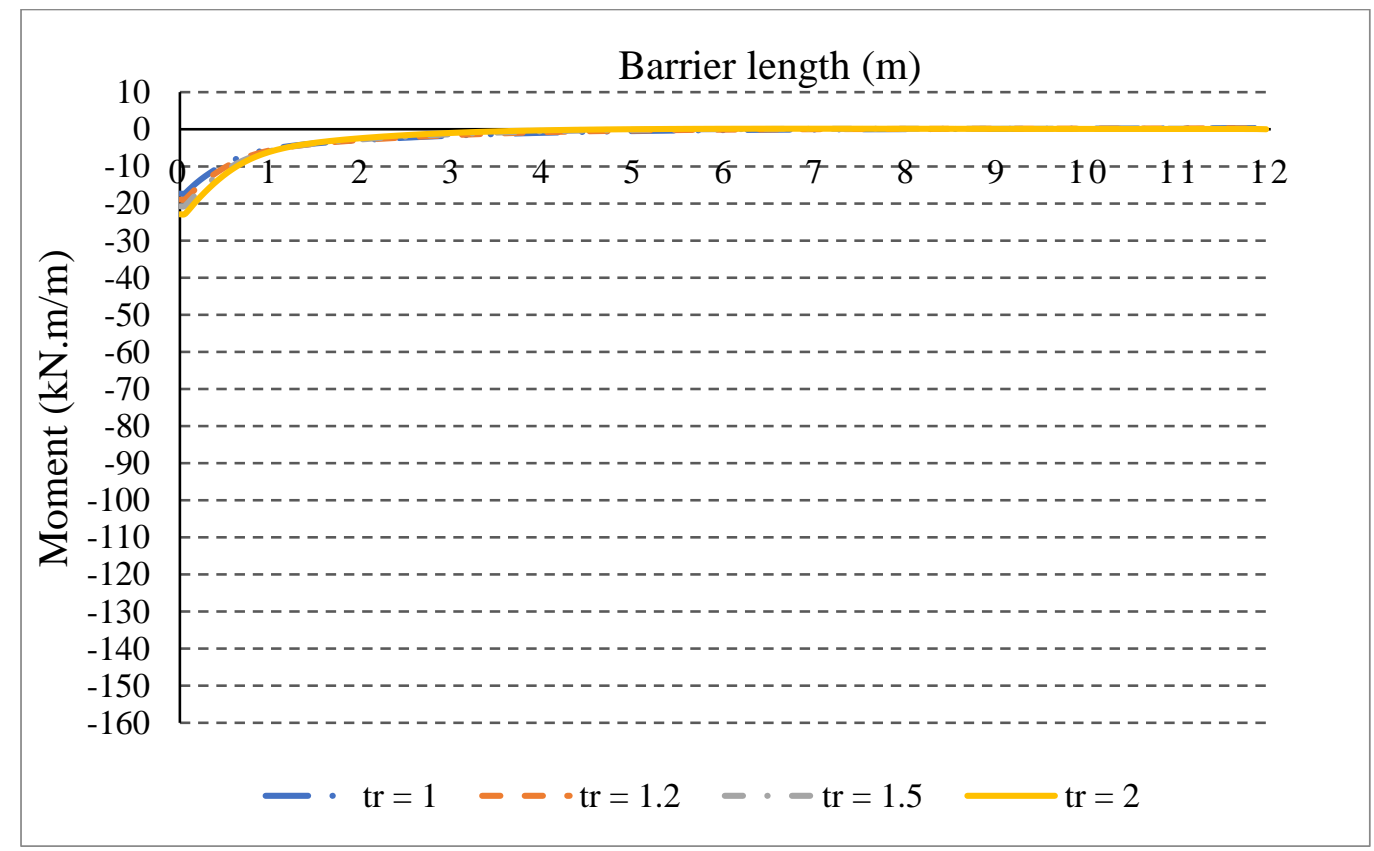

Figure 4-23: Effect of tapered slab thickness ratio on longitudinal moment for slab cantilever with TL-4 barrier $\left(\mathrm{L}_{b}=12 \mathrm{~m}, \mathrm{~L}_{\mathrm{c}}=1.5 \mathrm{~m}, \mathrm{t}_{1}=200 \mathrm{~mm}\right)$ 


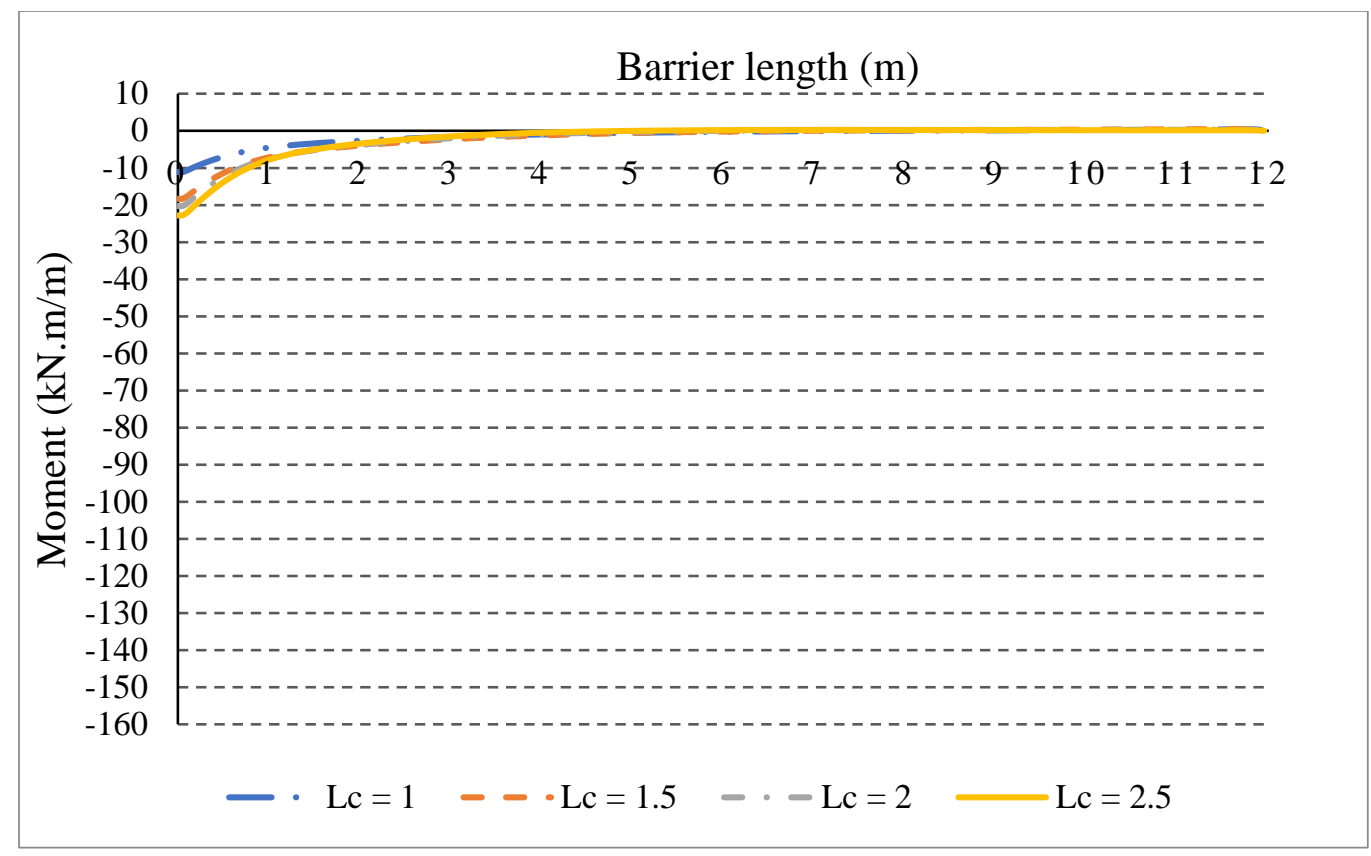

Figure 4-24: Effect of tapered slab thickness ratio on longitudinal moment for slab cantilever with TL-4 parapet $\left(\mathrm{L}_{b}=12 \mathrm{~m}, \mathrm{~L}_{c}=1.5 \mathrm{~m}, \mathrm{t}_{1}=200 \mathrm{~mm}\right)$

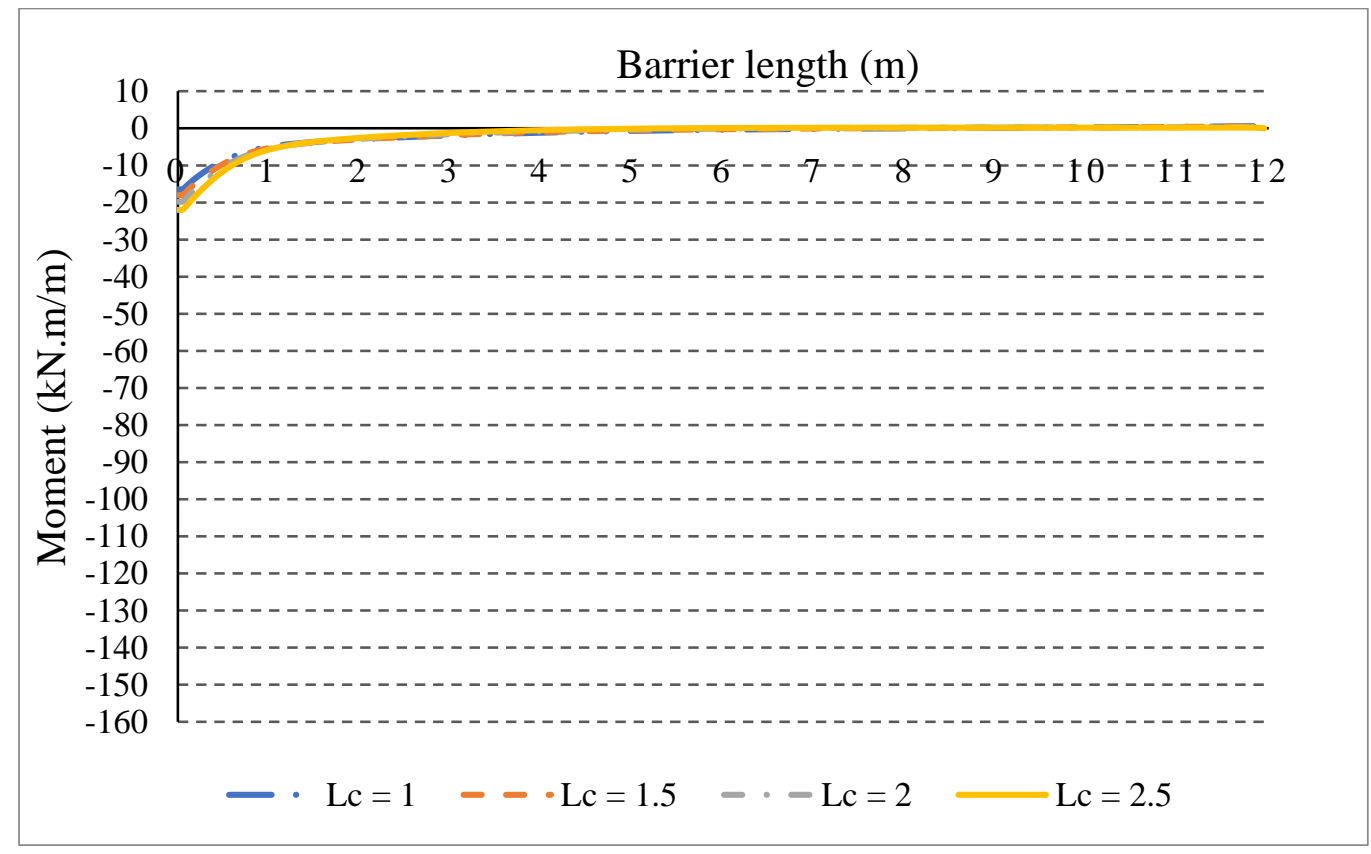

Figure 4-25: Effect of slab ratio on longitudinal moment for slab cantilever with TL-5 barrier ( $\mathrm{L}_{b}$ $=12 \mathrm{~m}, \mathrm{~L}_{\mathrm{c}}=1.5 \mathrm{~m}, \mathrm{t}_{1}=200 \mathrm{~mm}$ ) 


\subsection{Analysis of deflection}

Similar to analysis of transverse and longitudinal moments, a serious of tables and graphs are presented in this section to demonstrate the effect of key variables on the induced deflection.

\subsubsection{Effect of stiffening Arrangement}

Table 4-28 presented the maximum deflection of the deck slab cantilever with unstiffened edge, followed by the percentage change in this deflection value with the inclusion of stiffened edge of different types. It can be observed that edge stiffening arrangement reduces the intensity of maximum deflection significantly when compared to that for slab cantilevers with unstiffened slab, as expected.

Table 4-28: Effect of stiffening arrangement on deflection

\begin{tabular}{cccccc}
\hline Unstiffened & Curb & TL-2 barrier & TL-4 Barrier & TL-5 barrier & TL-4 Parapet \\
\hline-2 & $-68.00 \%$ & $-75.50 \%$ & $-77.00 \%$ & $-79.00 \%$ & $-79.50 \%$
\end{tabular}

Maximum deflection $(\mathrm{mm})$ for $\mathrm{L}_{\mathrm{c}}=1.5 \mathrm{~m}, \mathrm{~L}_{\mathrm{b}}=12 \mathrm{~m}$ slab thickness $\left(\mathrm{t}_{1}\right)=250 \mathrm{~mm}$, slab ratio $\left(\mathrm{t}_{2} / \mathrm{t}_{1}\right)=1$.

\subsubsection{Effect of Barrier Length}

Tables 4-29 through 4-34 demonstrate the effect of barrier length on maximum deflection of the deck slab cantilever with different edge stiffening conditions. One may observe that the slab deck cantilever with unstiffened edge maintained almost the same deflection with increase of barrier length from 5 to $12 \mathrm{~m}$ as depicted in Table 4-29. On the other hand, for slab cantilevers with stiffened edge, the maximum deflection decreases with increase in barrier length. However, the effect of barrier length is significantly increasing with the increase in in the size of the barrier at the stiffened edge. 
Table 4-29: Effect of barrier length on deflection for slab cantilever with unstiffened edge

\begin{tabular}{llllll}
\hline \hline & $\mathbf{L}_{b}=\mathbf{5} \mathbf{m}$ & $\mathbf{L}_{b}=\mathbf{6} \mathbf{m}$ & $\mathbf{L}_{b}=\mathbf{8} \mathbf{m}$ & $\mathbf{L}_{b}=10 \mathrm{~m}$ & $\mathbf{L}_{b}=12 \mathrm{~m}$ \\
\hline \hline $\mathrm{L}_{c}=\mathbf{1} \mathbf{m}$ & -0.41 & $0.00 \%$ & $0.00 \%$ & $0.00 \%$ & $0.00 \%$ \\
\hline $\mathrm{L}_{c}=\mathbf{1 . 5} \mathbf{m}$ & -2.01 & $-0.03 \%$ & $-0.04 \%$ & $-0.04 \%$ & $-0.04 \%$ \\
\hline $\mathrm{L}_{c}=\mathbf{2} \mathbf{m}$ & -5.01 & $-0.30 \%$ & $-0.38 \%$ & $-0.38 \%$ & $-0.38 \%$ \\
\hline $\mathbf{L}_{c}=\mathbf{2 . 5} \mathbf{m}$ & -10.85 & $-1.53 \%$ & $-2.19 \%$ & $-2.25 \%$ & $-2.25 \%$
\end{tabular}

Maximum deflection $(\mathrm{mm})$ for slab thickness $\left(\mathrm{t}_{1}\right)=200 \mathrm{~mm}$, slab ratio $\left(\mathrm{t}_{2} / \mathrm{t}_{1}\right)=1$.

Table 4-30: Effect of barrier length on deflection for slab cantilever with a curb

\begin{tabular}{llllll}
\hline \hline & $\mathbf{L}_{b}=\mathbf{5} \mathbf{m}$ & $\mathbf{L}_{b}=\mathbf{6} \mathbf{m}$ & $\mathbf{L}_{b}=\mathbf{8} \mathbf{m}$ & $\mathbf{L}_{b}=\mathbf{1 0} \mathbf{m}$ & $\mathbf{L}_{b}=\mathbf{1 2} \mathbf{~ m}$ \\
\hline \hline $\mathbf{L}_{c}=\mathbf{1} \mathbf{~ m}$ & -0.18 & $-0.41 \%$ & $-0.57 \%$ & $-0.58 \%$ & $-0.59 \%$ \\
\hline $\mathbf{L}_{c}=\mathbf{1 . 5} \mathbf{m}$ & -1.17 & $-1.74 \%$ & $-2.93 \%$ & $-2.93 \%$ & $-2.93 \%$ \\
\hline $\mathbf{L}_{c}=\mathbf{2} \mathbf{m}$ & -1.14 & $183.85 \%$ & $176.46 \%$ & $174.79 \%$ & $174.43 \%$ \\
\hline $\mathbf{L}_{c}=\mathbf{2 . 5} \mathbf{m}$ & -8.21 & $-5.50 \%$ & $-10.38 \%$ & $-11.88 \%$ & $-12.32 \%$
\end{tabular}

Maximum deflection $(\mathrm{mm})$ for slab thickness $\left(\mathrm{t}_{1}\right)=200$, slab ratio $\left(\mathrm{t}_{2} / \mathrm{t}_{1}\right)=1$.

Table 4-31: Effect of barrier length on deflection for slab cantilever with TL-2 barrier

\begin{tabular}{llllll}
\hline \hline & $\mathbf{L}_{b}=\mathbf{5} \mathbf{m}$ & $\mathbf{L}_{b}=\mathbf{6} \mathrm{m}$ & $\mathbf{L}_{b}=\mathbf{8} \mathrm{m}$ & $\mathbf{L}_{b}=10 \mathrm{~m}$ & $\mathbf{L}_{b}=12 \mathrm{~m}$ \\
\hline \hline $\mathbf{L}_{c}=\mathbf{1} \mathbf{m}$ & -0.12 & $-2.37 \%$ & $-3.77 \%$ & $-3.99 \%$ & $-4.02 \%$ \\
\hline $\mathbf{L}_{c}=\mathbf{1 . 5} \mathbf{m}$ & -0.95 & $-5.21 \%$ & $-9.83 \%$ & $-11.19 \%$ & $-11.56 \%$ \\
\hline $\mathbf{L}_{c}=\mathbf{2} \mathbf{m}$ & -2.94 & $-6.85 \%$ & $-14.12 \%$ & $-17.08 \%$ & $-18.21 \%$ \\
\hline $\mathbf{L}_{c}=\mathbf{2 . 5} \mathbf{m}$ & -7.65 & $-7.72 \%$ & $-16.67 \%$ & $-21.03 \%$ & $-23.12 \%$
\end{tabular}

Maximum deflection $(\mathrm{mm})$ for slab thickness $\left(\mathrm{t}_{1}\right)=200$, slab ratio $\left(\mathrm{t}_{2} / \mathrm{t}_{1}\right)=1$. 
Table 4-32: Effect of barrier length on deflection for slab cantilever with TL-4 barrier

\begin{tabular}{lccccc}
\hline \hline & $\mathbf{L}_{b}=\mathbf{5} \mathbf{m}$ & $\mathbf{L}_{b}=\mathbf{6} \mathbf{m}$ & $\mathbf{L}_{b}=\mathbf{8} \mathbf{m}$ & $\mathbf{L}_{b}=10 \mathrm{~m}$ & $\mathbf{L}_{b}=\mathbf{1 2} \mathbf{m}$ \\
\hline \hline $\mathbf{L}_{c}=\mathbf{1} \mathbf{m}$ & -0.12 & $-3.43 \%$ & $-5.85 \%$ & $-6.35 \%$ & $-6.45 \%$ \\
\hline $\mathbf{L}_{c}=\mathbf{1 . 5} \mathbf{m}$ & -0.93 & $-6.24 \%$ & $-12.47 \%$ & $-14.74 \%$ & $-15.51 \%$ \\
\hline $\mathbf{L}_{c}=\mathbf{2} \mathbf{m}$ & -2.91 & $-7.56 \%$ & $-16.23 \%$ & $-20.28 \%$ & $-22.14 \%$ \\
\hline $\mathbf{L}_{c}=\mathbf{2 . 5} \mathbf{m}$ & -7.62 & $-8.08 \%$ & $-17.88 \%$ & $-23.11 \%$ & $-25.94 \%$
\end{tabular}

Maximum deflection $(\mathrm{mm})$ for slab thickness $\left(\mathrm{t}_{1}\right)=200$, slab ratio $\left(\mathrm{t}_{2} / \mathrm{t}_{1}\right)=1$.

Table 4-33: Effect of barrier length on deflection for slab cantilever with TL-4 parapet

\begin{tabular}{lccccc}
\hline \hline & $\mathbf{L}_{b}=\mathbf{5}$ & $\mathbf{L}_{b}=\mathbf{6}$ & $\mathbf{L}_{b}=\mathbf{8}$ & $\mathbf{L}_{b}=\mathbf{1 0}$ & $\mathbf{L}_{b}=\mathbf{1 2}$ \\
\hline \hline $\mathbf{L}_{c}=\mathbf{1}$ & -0.23 & $-3.65 \%$ & $-6.55 \%$ & $-7.27 \%$ & $-7.42 \%$ \\
\hline $\mathbf{L}_{\mathbf{c}=\mathbf{1 . 5}}$ & -0.84 & $-6.05 \%$ & $-12.55 \%$ & $-15.29 \%$ & $-16.38 \%$ \\
\hline $\mathbf{L}_{c}=\mathbf{2}$ & -3.52 & $-7.14 \%$ & $-15.59 \%$ & $-19.95 \%$ & $-22.21 \%$ \\
\hline $\mathbf{L}_{\mathbf{c}}=\mathbf{2 . 5}$ & -8.70 & $-7.59 \%$ & $-16.78 \%$ & $-21.91 \%$ & $-24.95 \%$ \\
\hline \multicolumn{4}{l}{ Maximum deflection $(\mathrm{mm})$ for slab thickness $\left(\mathrm{t}_{1}\right)=200$, slab ratio $\left(\mathrm{t}_{2} / \mathrm{t}_{1}=1\right)$}
\end{tabular}

Table 4-34: Effect of barrier length on deflection for slab cantilever with TL-5 barrier

\begin{tabular}{|c|c|c|c|c|c|}
\hline & $\mathrm{L}_{b}=5 \mathrm{~m}$ & $\mathrm{~L}_{b}=6 \mathrm{~m}$ & $\mathrm{~L}_{b}=8 \mathrm{~m}$ & $\mathrm{~L}_{\mathrm{b}}=10 \mathrm{~m}$ & $\mathrm{~L}_{b}=12 \mathrm{~m}$ \\
\hline $\mathrm{L}_{\mathrm{c}}=1 \mathrm{~m}$ & -0.11 & $-5.03 \%$ & $-9.41 \%$ & $-10.69 \%$ & $-11.03 \%$ \\
\hline $\mathrm{L}_{\mathrm{c}}=1.5 \mathrm{~m}$ & -0.91 & $-7.46 \%$ & $-15.83 \%$ & $-19.61 \%$ & $-21.27 \%$ \\
\hline $\mathrm{L}_{\mathrm{c}}=2 \mathrm{~m}$ & -2.88 & $-8.37 \%$ & $-18.65 \%$ & $-24.14 \%$ & $-27.13 \%$ \\
\hline$L_{c}=2.5 \mathrm{~m}$ & -7.58 & $-8.51 \%$ & $-19.29 \%$ & $-25.53 \%$ & $-29.33 \%$ \\
\hline
\end{tabular}




\subsubsection{Effect of slab thickness for various thickness ratio}

Table 4-35: Effect of slab thickness on deflection for slab cantilever with unstiffened edge

\begin{tabular}{lccccc}
\hline \hline & $\begin{array}{c}\mathbf{t}_{\mathbf{1}}=\mathbf{2 0 0} \\
(\mathbf{m m})\end{array}$ & $\begin{array}{c}\mathbf{t}_{\mathbf{1}}=\mathbf{2 2 5} \\
(\mathbf{m m})\end{array}$ & $\begin{array}{c}\mathbf{t}_{\mathbf{1}}=\mathbf{2 5 0} \\
(\mathbf{m m})\end{array}$ & $\begin{array}{c}\mathbf{t}_{\mathbf{1}}=\mathbf{3 0 0} \\
(\mathbf{m m})\end{array}$ & $\begin{array}{c}\mathbf{t}_{\mathbf{1}}=\mathbf{3 5 0} \\
(\mathbf{m m})\end{array}$ \\
\hline \hline $\mathbf{t}_{\mathbf{r}}=\mathbf{1}$ & -2.01 & $-29.77 \%$ & $-48.80 \%$ & $-70.37 \%$ & $-81.34 \%$ \\
\hline $\mathbf{t}_{\mathbf{r}}=\mathbf{1 . 2}$ & -1.36 & $-29.77 \%$ & $-48.80 \%$ & $-70.37 \%$ & $-81.34 \%$ \\
\hline $\mathbf{t}_{\mathbf{r}}=\mathbf{1 . 5}$ & -0.83 & $-29.77 \%$ & $-48.80 \%$ & $-70.37 \%$ & $-70.37 \%$ \\
\hline $\mathbf{t}_{\mathbf{r}}=\mathbf{2 . 0}$ & -0.42 & $-29.77 \%$ & $-48.80 \%$ & $-70.37 \%$ & $-81.34 \%$
\end{tabular}

Maximum deflection $(\mathrm{mm})$ for $\mathrm{L}_{b}=12 \mathrm{~m}, \mathrm{~L}_{\mathrm{c}}=2 \mathrm{~m}$ for TL-5 barrier shape

Table 4-36: Effect of slab thickness on deflection for slab cantilever with a curb

\begin{tabular}{lccccc}
\hline \hline & $\begin{array}{c}\mathbf{t}_{1}=\mathbf{2 0 0} \\
(\mathbf{m m})\end{array}$ & $\begin{array}{c}\mathbf{t}_{\mathbf{1}}=\mathbf{2 2 5} \\
(\mathbf{m m})\end{array}$ & $\begin{array}{c}\mathbf{t}_{\mathbf{1}}=\mathbf{2 5 0} \\
(\mathbf{m m})\end{array}$ & $\begin{array}{c}\mathbf{t}_{\mathbf{1}}=\mathbf{3 0 0} \\
(\mathbf{m m})\end{array}$ & $\begin{array}{c}\mathbf{t}_{\mathbf{1}}=\mathbf{3 5 0} \\
(\mathbf{m m})\end{array}$ \\
\hline \hline $\mathbf{t}_{\mathbf{r}}=\mathbf{1}$ & -1.14 & $-25.91 \%$ & $-43.65 \%$ & $-65.32 \%$ & $-77.26 \%$ \\
\hline $\mathbf{t}_{\mathbf{r}}=\mathbf{1 . 2}$ & -0.79 & $-26.37 \%$ & $-44.29 \%$ & $-65.99 \%$ & $-77.83 \%$ \\
\hline $\mathbf{t}_{\mathbf{r}}=\mathbf{1 . 5}$ & -0.50 & $-26.90 \%$ & $-45.03 \%$ & $-66.76 \%$ & $-78.47 \%$ \\
\hline $\mathbf{t}_{\mathbf{r}}=\mathbf{2 . 0}$ & -0.26 & $-27.54 \%$ & $-45.90 \%$ & $-67.63 \%$ & $-79.19 \%$ \\
\hline
\end{tabular}

Maximum deflection $(\mathrm{mm})$ for $\mathrm{L}_{b}=12 \mathrm{~m}, \mathrm{~L}_{\mathrm{c}}=1.5 \mathrm{~m}$

Table 4-37: Effect of slab thickness on deflection for slab cantilever with TL-2 barrier

\begin{tabular}{lccccc}
\hline \hline & $\begin{array}{c}\mathbf{t}_{1}=\mathbf{2 0 0} \\
(\mathbf{m m})\end{array}$ & $\begin{array}{c}\mathbf{t}_{\mathbf{1}}=\mathbf{2 2 5} \\
(\mathbf{m m})\end{array}$ & $\begin{array}{c}\mathbf{t}_{\mathbf{1}}=\mathbf{2 5 0} \\
(\mathbf{m m})\end{array}$ & $\begin{array}{c}\mathbf{t}_{\mathbf{1}}=\mathbf{3 0 0} \\
(\mathbf{m m})\end{array}$ & $\begin{array}{c}\mathbf{t}_{\mathbf{1}}=\mathbf{3 5 0} \\
(\mathbf{m m})\end{array}$ \\
\hline \hline $\mathbf{t}_{\mathbf{r}}=\mathbf{1}$ & -0.84 & $-24.58 \%$ & $-41.68 \%$ & $-63.04 \%$ & $-75.17 \%$ \\
\hline $\mathbf{t}_{\mathbf{r}}=\mathbf{1 . 2}$ & -0.60 & $-24.99 \%$ & $-42.28 \%$ & $-63.74 \%$ & $-75.41 \%$ \\
\hline $\mathbf{t}_{\mathbf{r}}=\mathbf{1 . 5}$ & -0.38 & $-25.52 \%$ & $-43.05 \%$ & $-64.60 \%$ & $-76.58 \%$ \\
\hline $\mathbf{t}_{\mathbf{r}}=\mathbf{2 . 0}$ & -0.21 & $-26.22 \%$ & $-44.05 \%$ & $-65.69 \%$ & $-77.54 \%$
\end{tabular}

Maximum deflection $(\mathrm{mm})$ for $\mathrm{L}_{b}=12 \mathrm{~m}, \mathrm{~L}_{\mathrm{c}}=1.5 \mathrm{~m}$ 
Table 4-38: Effect of slab thickness on deflection for slab cantilever with TL-4 barrier

\begin{tabular}{lccccc}
\hline \hline & $\begin{array}{c}\mathbf{t}_{1}=\mathbf{2 0 0} \\
(\mathbf{m m})\end{array}$ & $\begin{array}{c}\mathbf{t}_{1}=\mathbf{2 2 5} \\
(\mathbf{m m})\end{array}$ & $\begin{array}{c}\mathbf{t}_{\mathbf{1}}=\mathbf{2 5 0} \\
(\mathbf{m m})\end{array}$ & $\begin{array}{c}\mathbf{t}_{1}=\mathbf{3 0 0} \\
(\mathbf{m m})\end{array}$ & $\begin{array}{c}\mathbf{t}_{\mathbf{1}}=\mathbf{3 5 0} \\
(\mathbf{m m})\end{array}$ \\
\hline \hline $\mathbf{t}_{\mathbf{r}}=\mathbf{1}$ & -0.79 & $-24.32 \%$ & $-41.26 \%$ & $-62.50 \%$ & $-74.63 \%$ \\
\hline $\mathbf{t}_{\mathbf{r}}=\mathbf{1 . 2}$ & -0.57 & $-24.68 \%$ & $-41.79 \%$ & $-63.14 \%$ & $-75.22 \%$ \\
\hline $\mathbf{t}_{\mathbf{r}}=\mathbf{1 . 5}$ & -0.36 & $-25.15 \%$ & $-42.50 \%$ & $-63.95 \%$ & $-75.98 \%$ \\
\hline $\mathbf{t}_{\mathbf{r}}=\mathbf{2 . 0}$ & -0.20 & $-25.81 \%$ & $-43.46 \%$ & $-65.03 \%$ & $-76.95 \%$
\end{tabular}

Maximum deflection (mm) for $\mathrm{L}_{b}=12 \mathrm{~m}, \mathrm{~L}_{\mathrm{c}}=1.5 \mathrm{~m}$

Table 4-39: Effect of slab thickness on deflection for slab cantilever with TL-4 parapet

\begin{tabular}{lccccc}
\hline \hline & $\begin{array}{c}\mathbf{t}_{\mathbf{1}}=\mathbf{2 0 0} \\
(\mathbf{m m})\end{array}$ & $\begin{array}{c}\mathbf{t}_{\mathbf{1}}=\mathbf{2 2 5} \\
(\mathbf{m m})\end{array}$ & $\begin{array}{c}\mathbf{t}_{\mathbf{1}}=\mathbf{2 5 0} \\
(\mathbf{m m})\end{array}$ & $\begin{array}{c}\mathbf{t}_{\mathbf{1}}=\mathbf{3 0 0} \\
(\mathbf{m m})\end{array}$ & $\begin{array}{c}\mathbf{t}_{\mathbf{1}}=\mathbf{3 5 0} \\
(\mathbf{m m})\end{array}$ \\
\hline \hline $\mathbf{t}_{\mathbf{r}}=\mathbf{1}$ & -0.70 & $-24.33 \%$ & $-41.25 \%$ & $-62.46 \%$ & $-74.57 \%$ \\
\hline $\mathbf{t}_{\mathbf{r}}=\mathbf{1 . 2}$ & -0.75 & $-24.63 \%$ & $-41.71 \%$ & $-63.01 \%$ & $-75.10 \%$ \\
\hline $\mathbf{t}_{\mathbf{r}}=\mathbf{1 . 5}$ & -0.49 & $-25.05 \%$ & $-42.33 \%$ & $-63.75 \%$ & $-75.79 \%$ \\
\hline $\mathbf{t}_{\mathbf{r}}=\mathbf{2 . 0}$ & -0.27 & $-25.66 \%$ & $-43.23 \%$ & $-64.79 \%$ & $-76.74 \%$ \\
\hline \multicolumn{4}{l}{ Maximum deflection $(\mathrm{mm})$ for $\mathrm{L}_{\mathrm{b}}=12 \mathrm{~m}, \mathrm{~L}_{\mathrm{c}}=1.5 \mathrm{~m}$} &
\end{tabular}

Table 4-40: Effect of slab thickness on deflection for slab cantilever with TL-5 barrier

\begin{tabular}{lccccc}
\hline \hline & $\begin{array}{c}\mathbf{t}_{\mathbf{1}}=\mathbf{2 0 0} \\
(\mathbf{m m})\end{array}$ & $\begin{array}{c}\mathbf{t}_{\mathbf{1}}=\mathbf{2 2 5} \\
(\mathbf{m m})\end{array}$ & $\begin{array}{c}\mathbf{t}_{\mathbf{1}}=\mathbf{2 5 0} \\
(\mathbf{m m})\end{array}$ & $\begin{array}{c}\mathbf{t}_{\mathbf{1}}=\mathbf{3 0 0} \\
(\mathbf{m m})\end{array}$ & $\begin{array}{c}\mathbf{t}_{\mathbf{1}}=\mathbf{3 5 0} \\
(\mathbf{m m})\end{array}$ \\
\hline \hline $\mathbf{t}_{\mathbf{r}}=\mathbf{1}$ & -0.72 & $-24.16 \%$ & $-40.96 \%$ & $-62.02 \%$ & $-74.09 \%$ \\
\hline $\mathbf{t}_{\mathbf{r}}=\mathbf{1 . 2}$ & -0.52 & $-24.41 \%$ & $-41.34 \%$ & $-62.50 \%$ & $-74.56 \%$ \\
\hline $\mathbf{t}_{\mathbf{r}}=\mathbf{1 . 5}$ & -0.33 & $-24.77 \%$ & $-41.89 \%$ & $-63.17 \%$ & $-75.20 \%$ \\
\hline $\mathbf{t}_{\mathbf{r}}=\mathbf{2 . 0}$ & -0.18 & $-25.31 \%$ & $-42.70 \%$ & $-64.14 \%$ & $-76.11 \%$ \\
\hline \multicolumn{7}{l}{ Maximum deflection $(\mathrm{mm})$ for $\mathrm{L}_{\mathrm{b}}=12 \mathrm{~m}, \mathrm{~L}_{\mathrm{c}}=1.5 \mathrm{~m}$} &
\end{tabular}




\subsubsection{Effect of Cantilever Length and Slab Ratio}

From the graphs illustrated in Figure 4-26 to Figure 4-31, it is obvious that cantilever length increase is one of main contributors on increasing deflection. This result is anticipated, since like cantilever beam subjected to force at its free end, larger cantilever length can lead to deflection increase.

Graphs in the Figure 4-32 to Figure 4-37 shows the deflection due to wheel loads at the free transverse edge of cantilever slab decreased as slab ratio increased. This result can be anticipated as increasing section rigidity cause reduction in deflection.

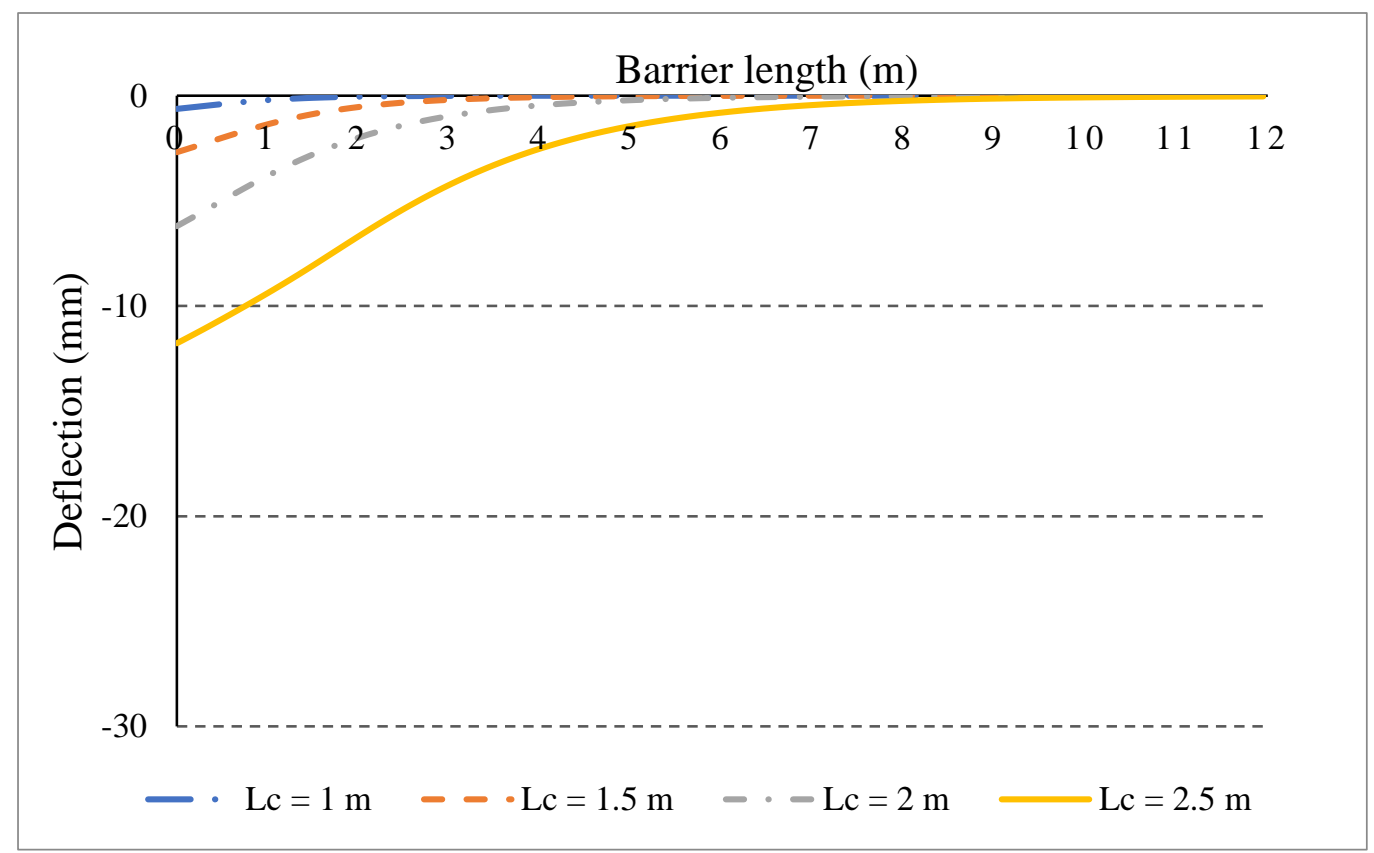

Figure 4-26: Effect of cantilever length on deflection for slab cantilever with unstiffened edge 


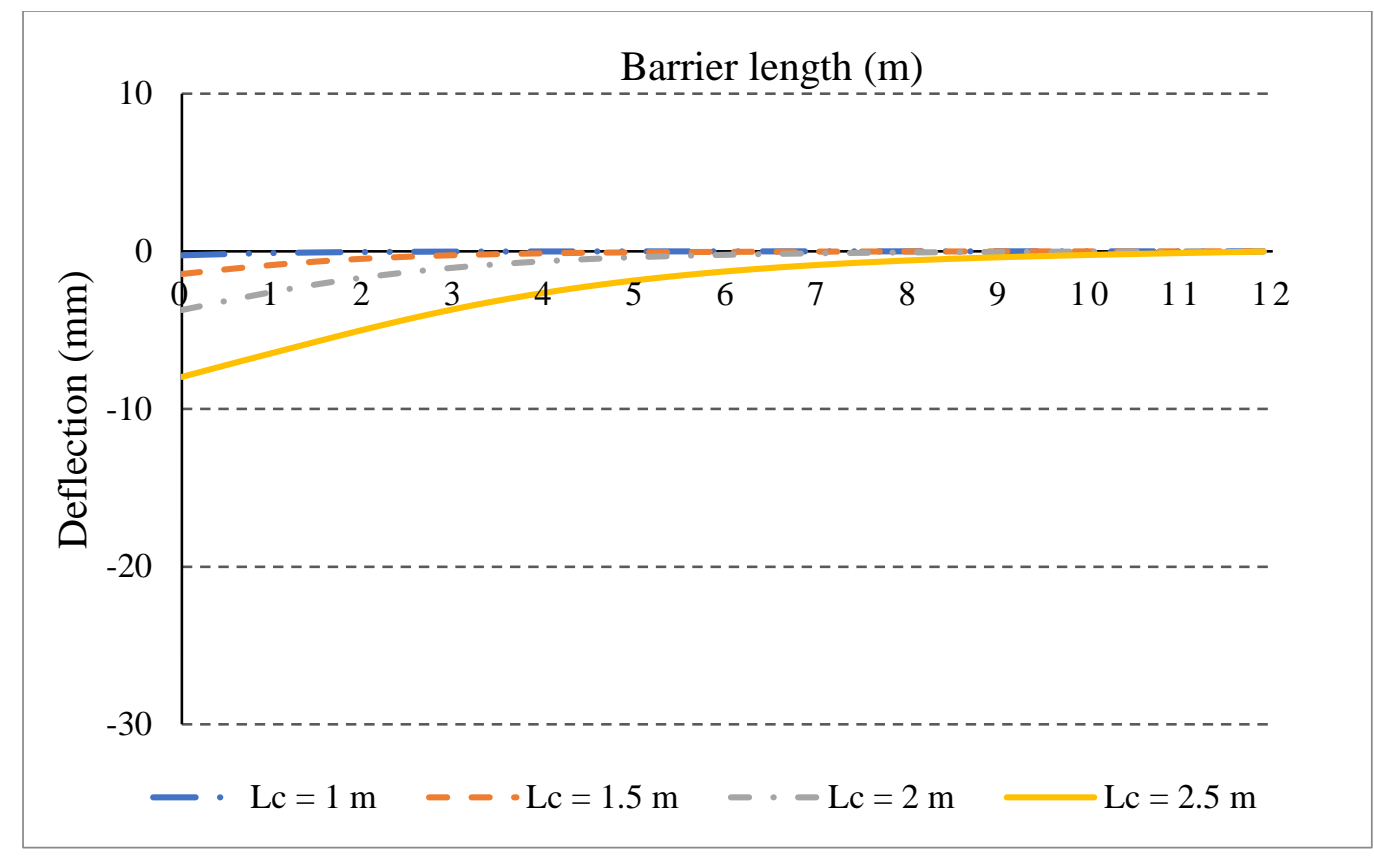

Figure 4-27: Effect of cantilever length on deflection for slab cantilever with a curb

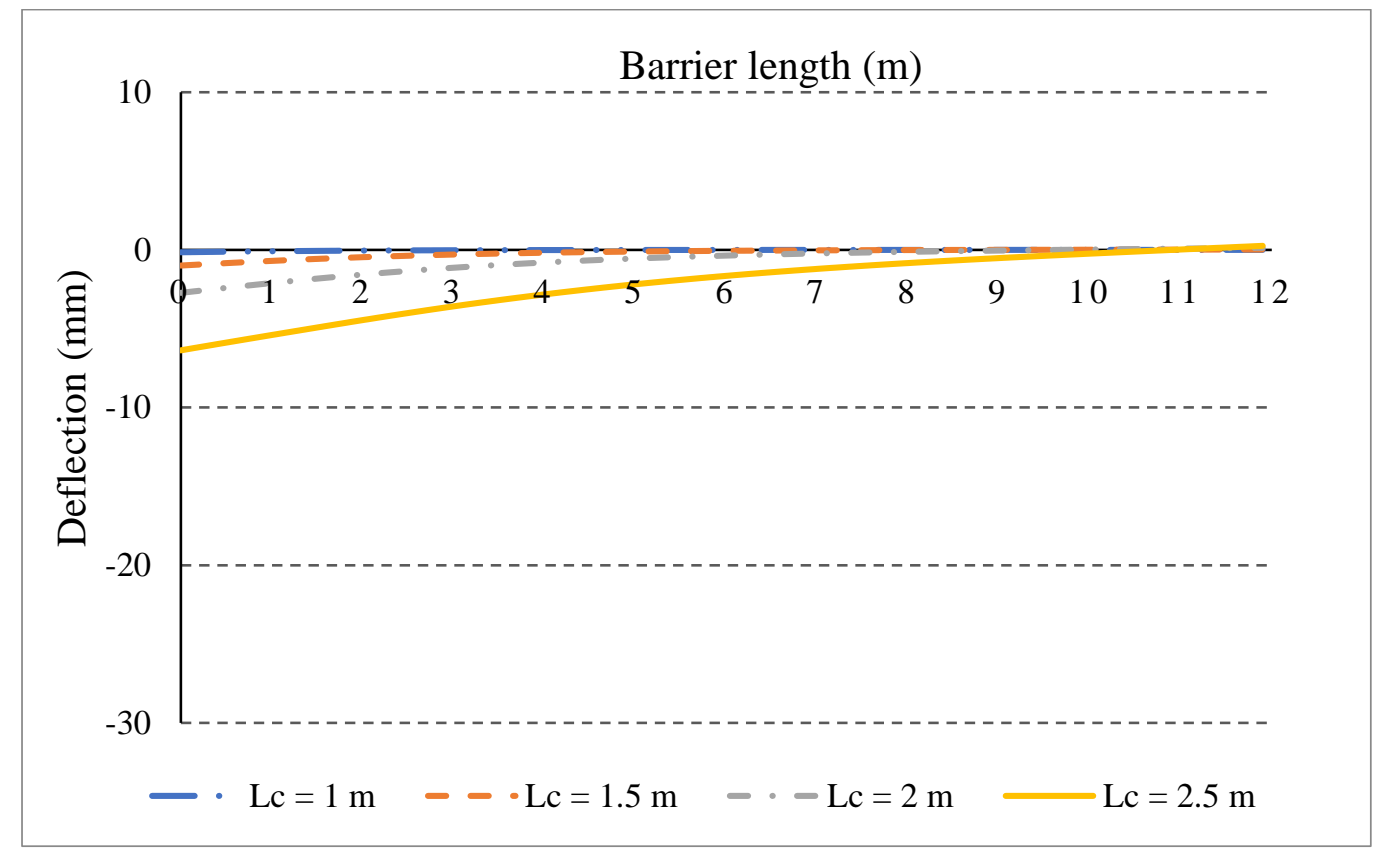

Figure 4-28: Effect of cantilever length on deflection for slab cantilever with TL-2 barrier 


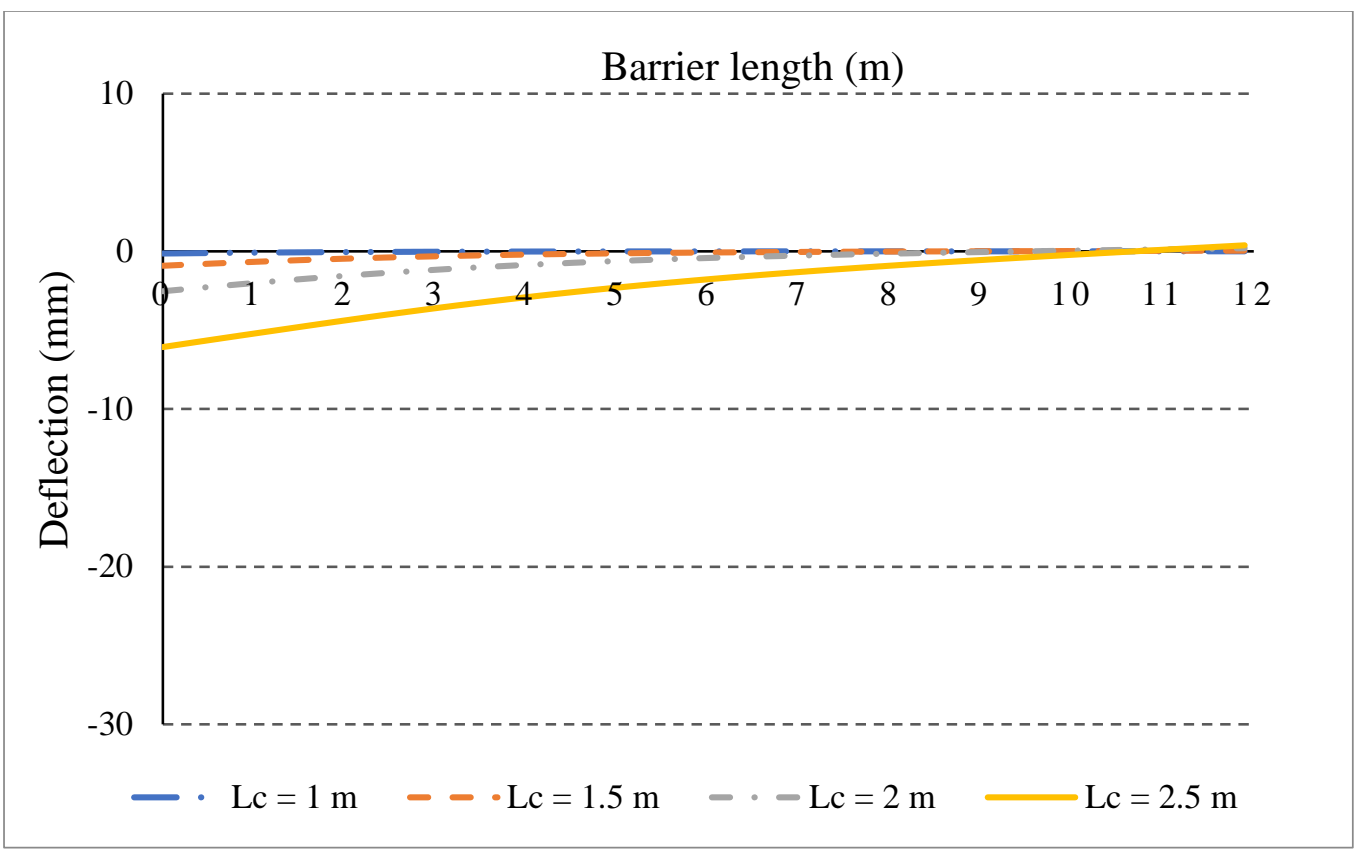

Figure 4-29: Effect of cantilever length on deflection for slab cantilever with TL-4 barrier

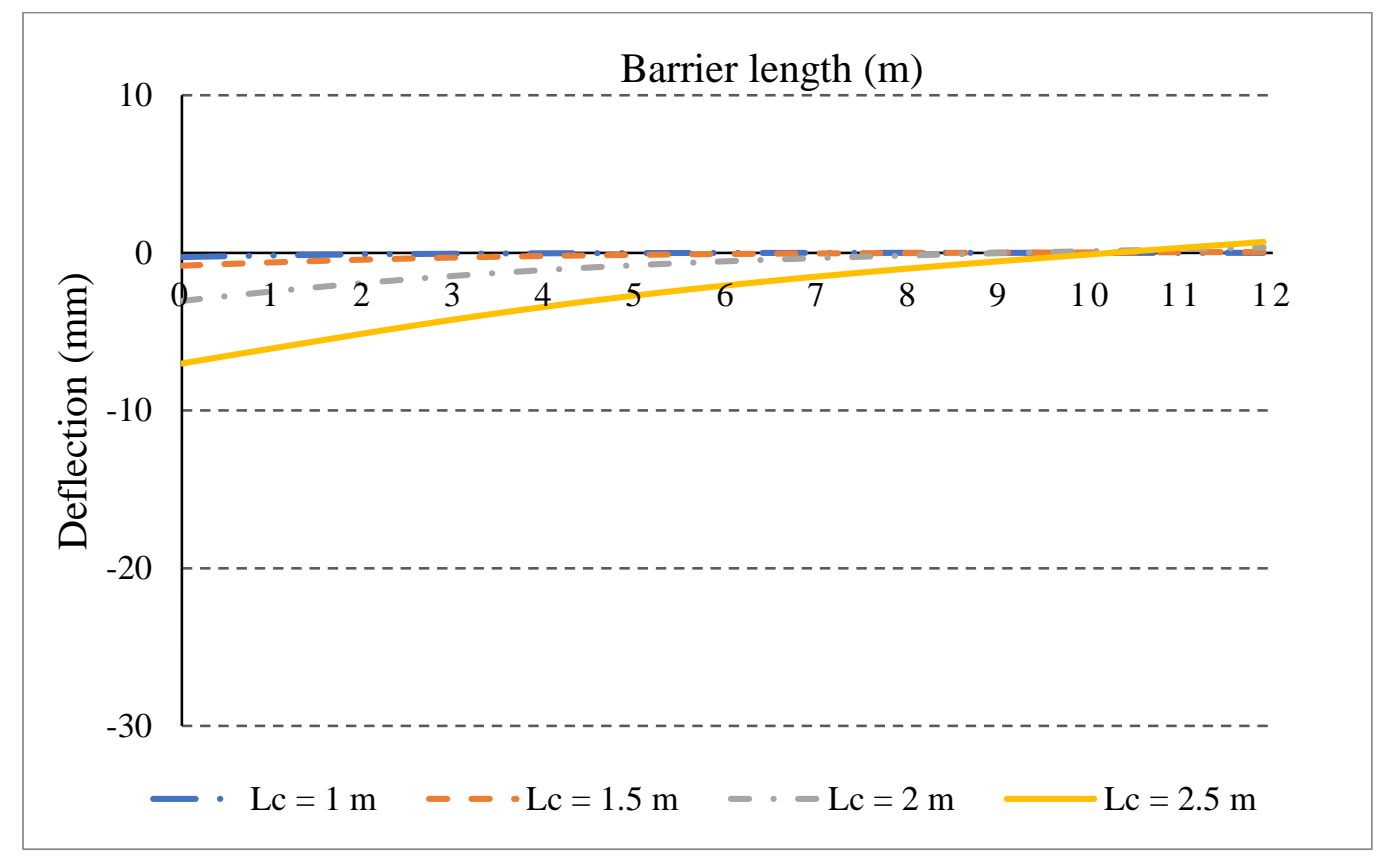

Figure 4-30: Effect of cantilever length on deflection for slab cantilever with TL-4 parapet 


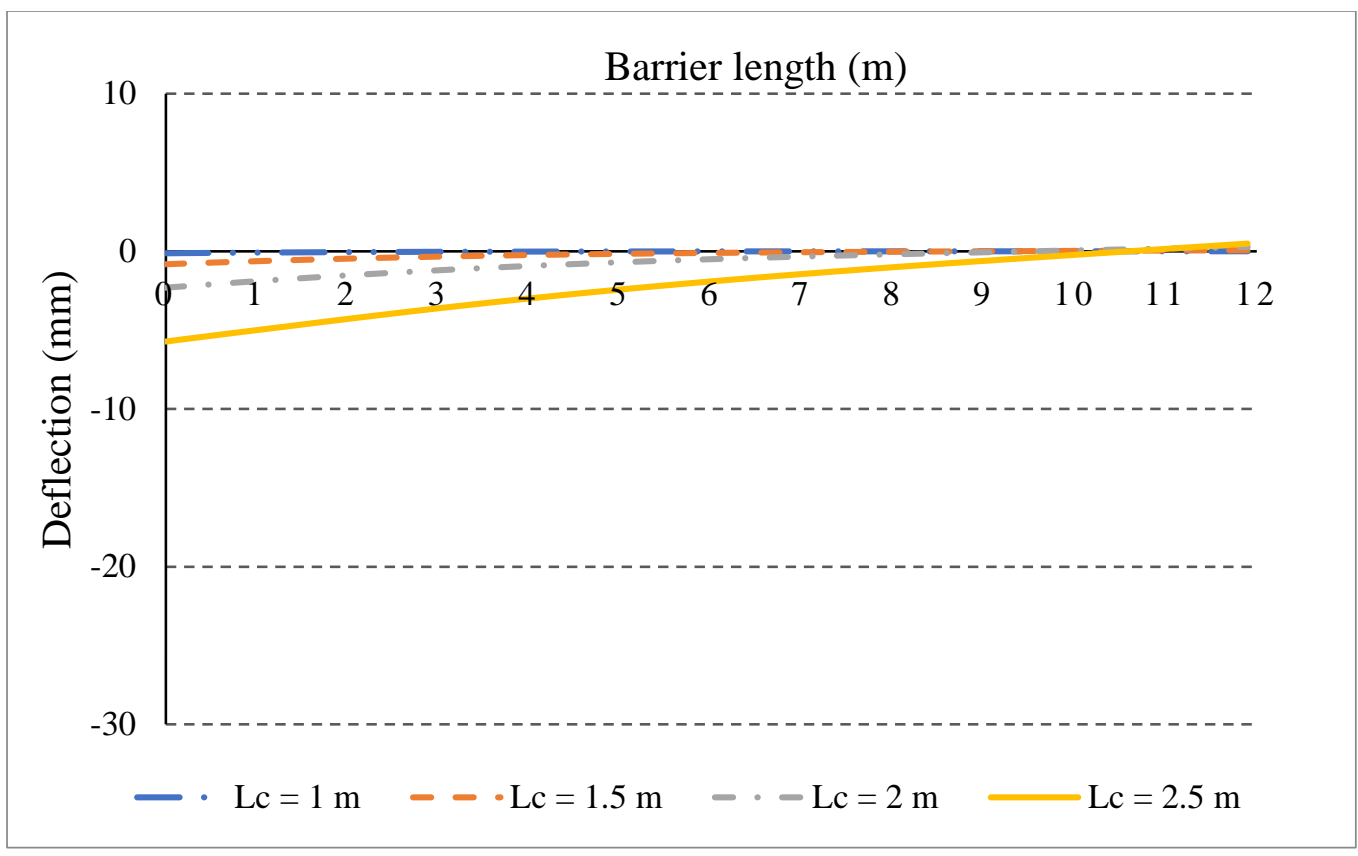

Figure 4-31: Effect of cantilever length on deflection for slab cantilever with TL-5 barrier

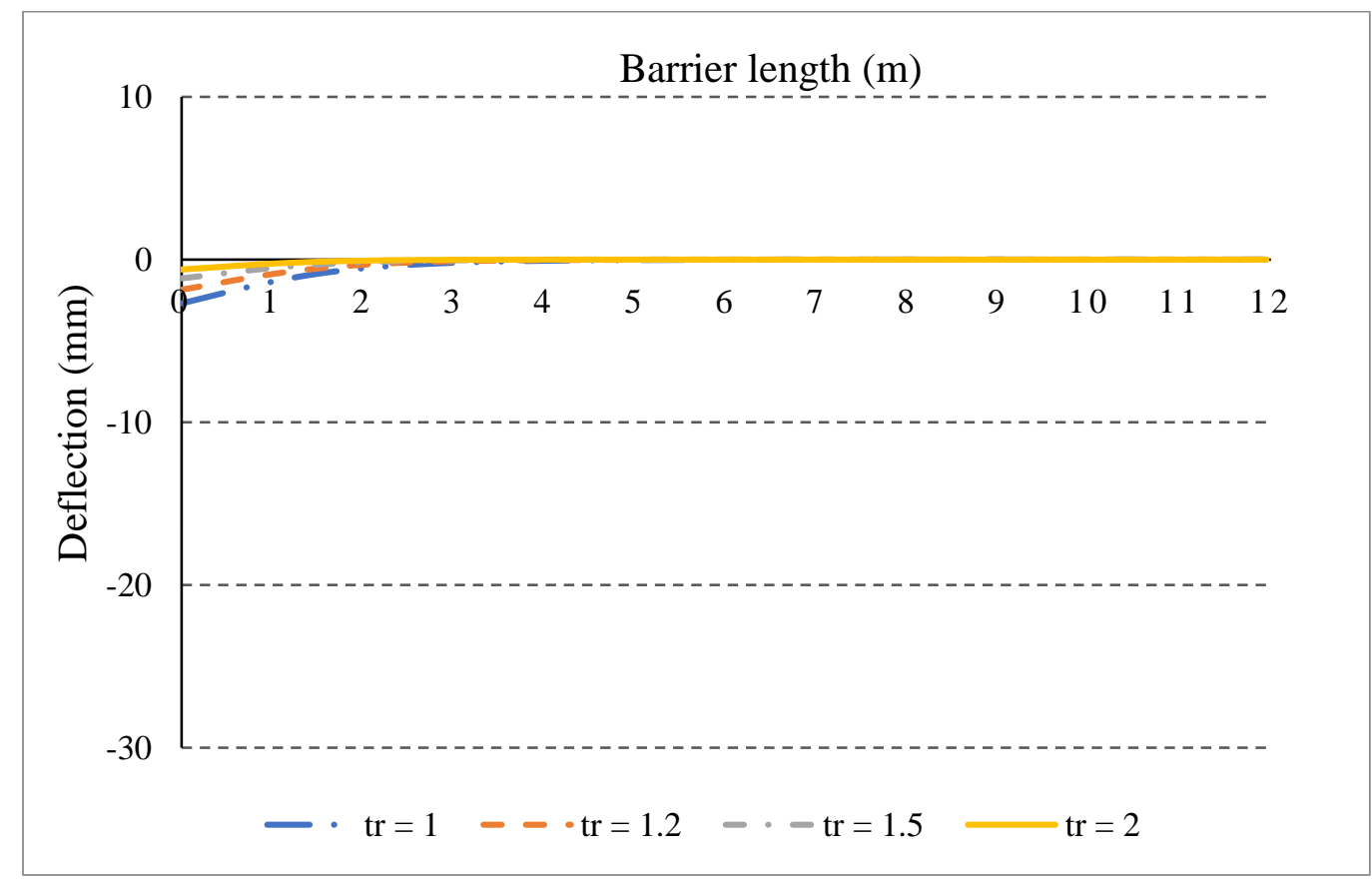

Figure 4-32Effect of tapered slab thickness ratio on deflection for slab cantilever with unstiffened edge $\left(\mathrm{L}_{b}=12 \mathrm{~m}, \mathrm{~L}_{\mathrm{c}}=1.5 \mathrm{~m}, \mathrm{t}_{1}=200 \mathrm{~mm}\right)$ 


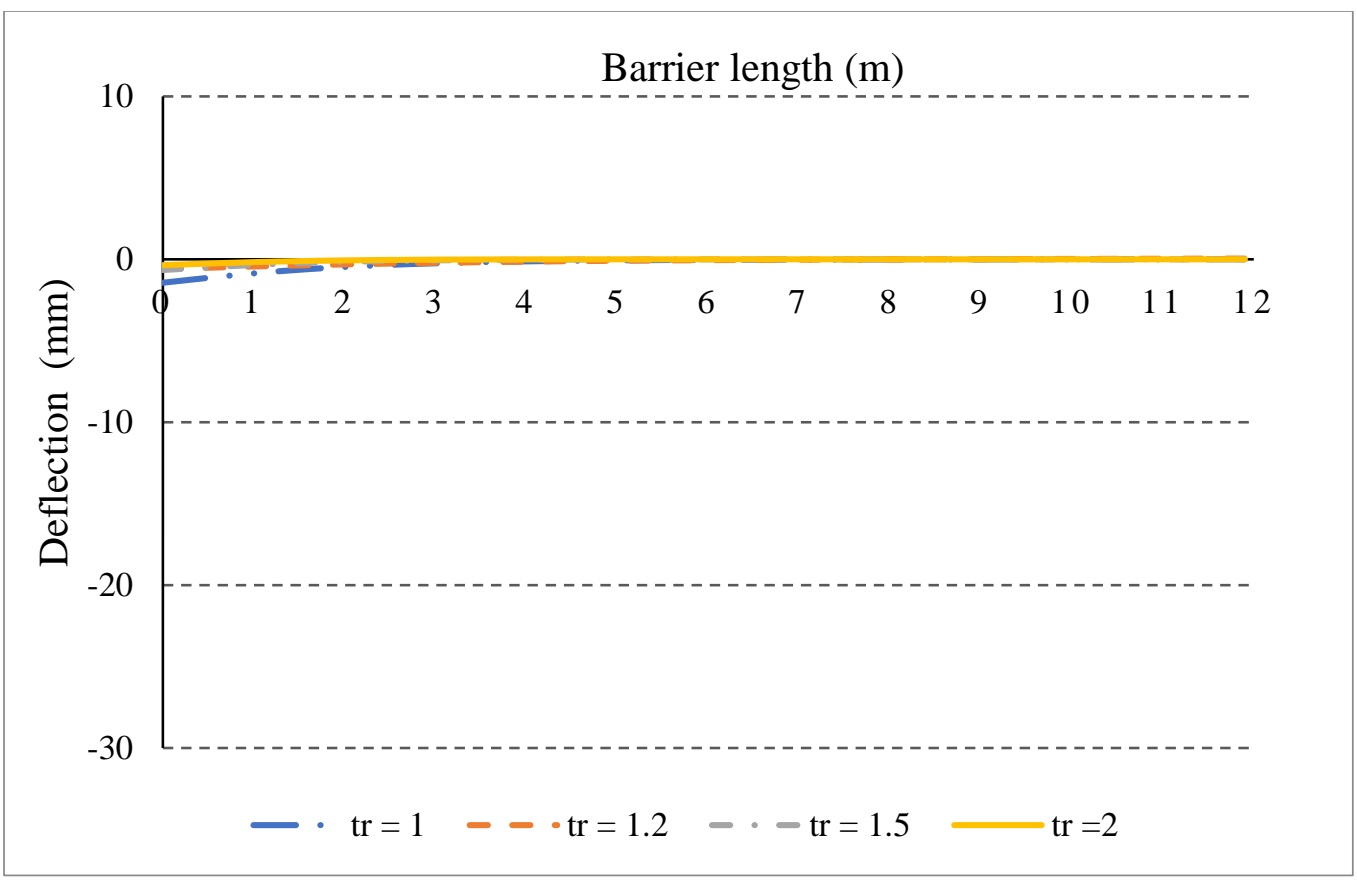

Figure 4-33: Effect of tapered slab thickness ratio on deflection for slab cantilever with a curb $\left(\mathrm{L}_{\mathrm{b}}=12 \mathrm{~m}, \mathrm{~L}_{\mathrm{c}}=1.5 \mathrm{~m}, \mathrm{t}_{1}=200 \mathrm{~mm}\right.$

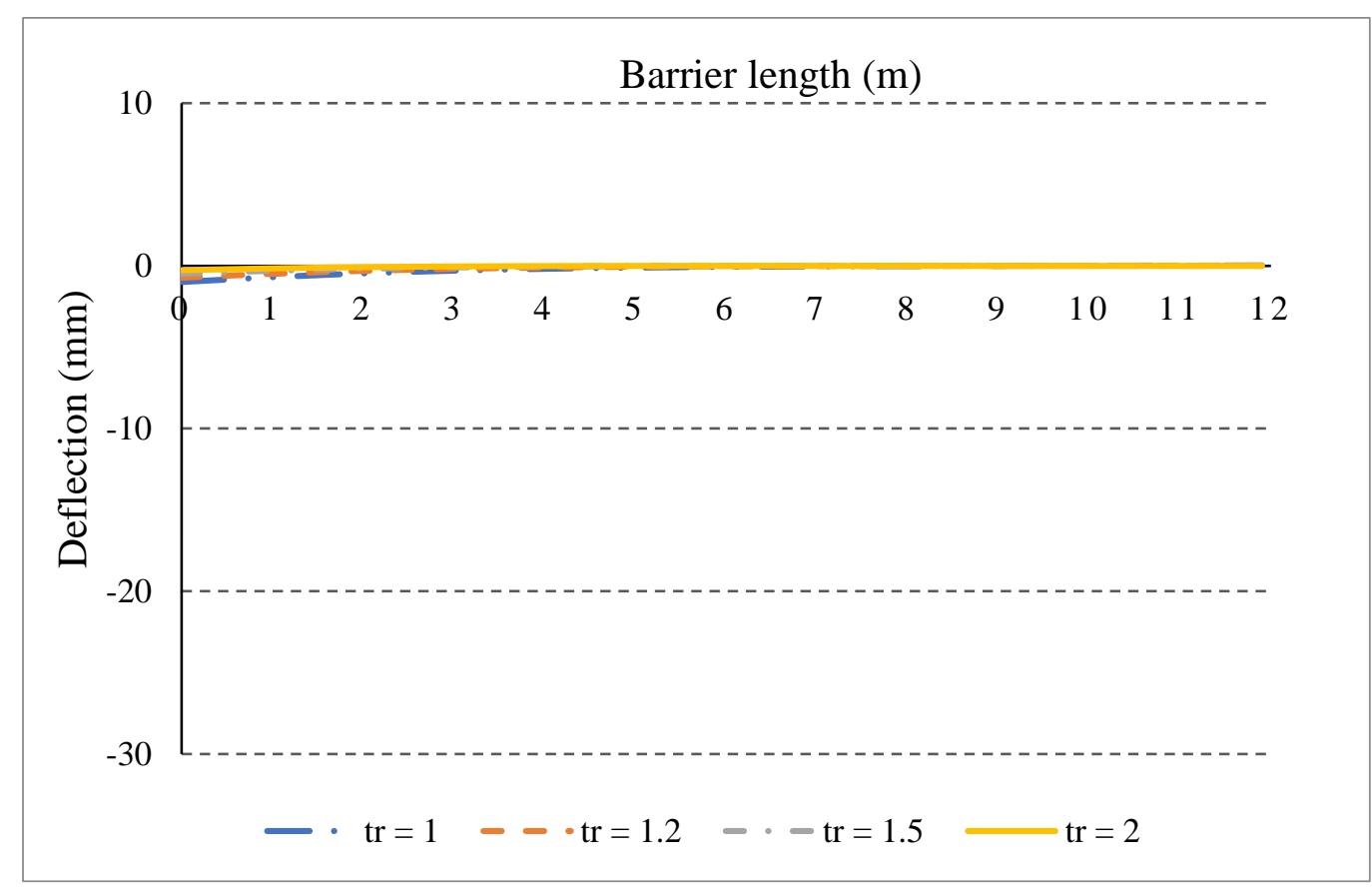

Figure 4-34Effect of tapered slab thickness ratio on deflection for slab cantilever with TL-2 $\operatorname{barrier}\left(\mathrm{L}_{\mathrm{b}}=12 \mathrm{~m}, \mathrm{~L}_{\mathrm{c}}=1.5 \mathrm{~m}, \mathrm{t}_{1}=200 \mathrm{~mm}\right)$ 


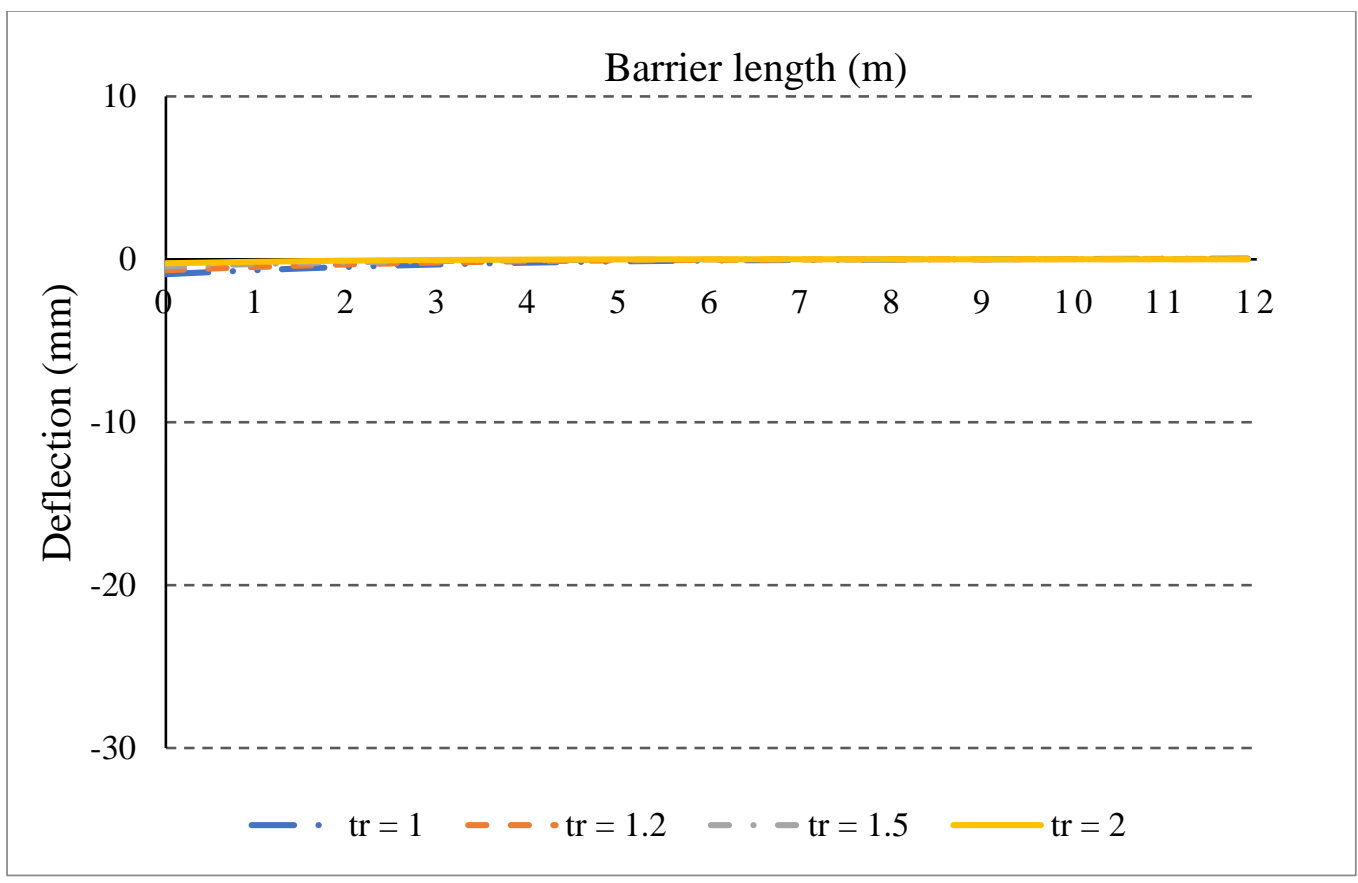

Figure 4-35: Effect of tapered slab thickness ratio on deflection for slab cantilever with TL-4 barrier $\left(\mathrm{L}_{b}=12 \mathrm{~m}, \mathrm{~L}_{\mathrm{c}}=1.5 \mathrm{~m}, \mathrm{t}_{1}=200 \mathrm{~mm}\right)$

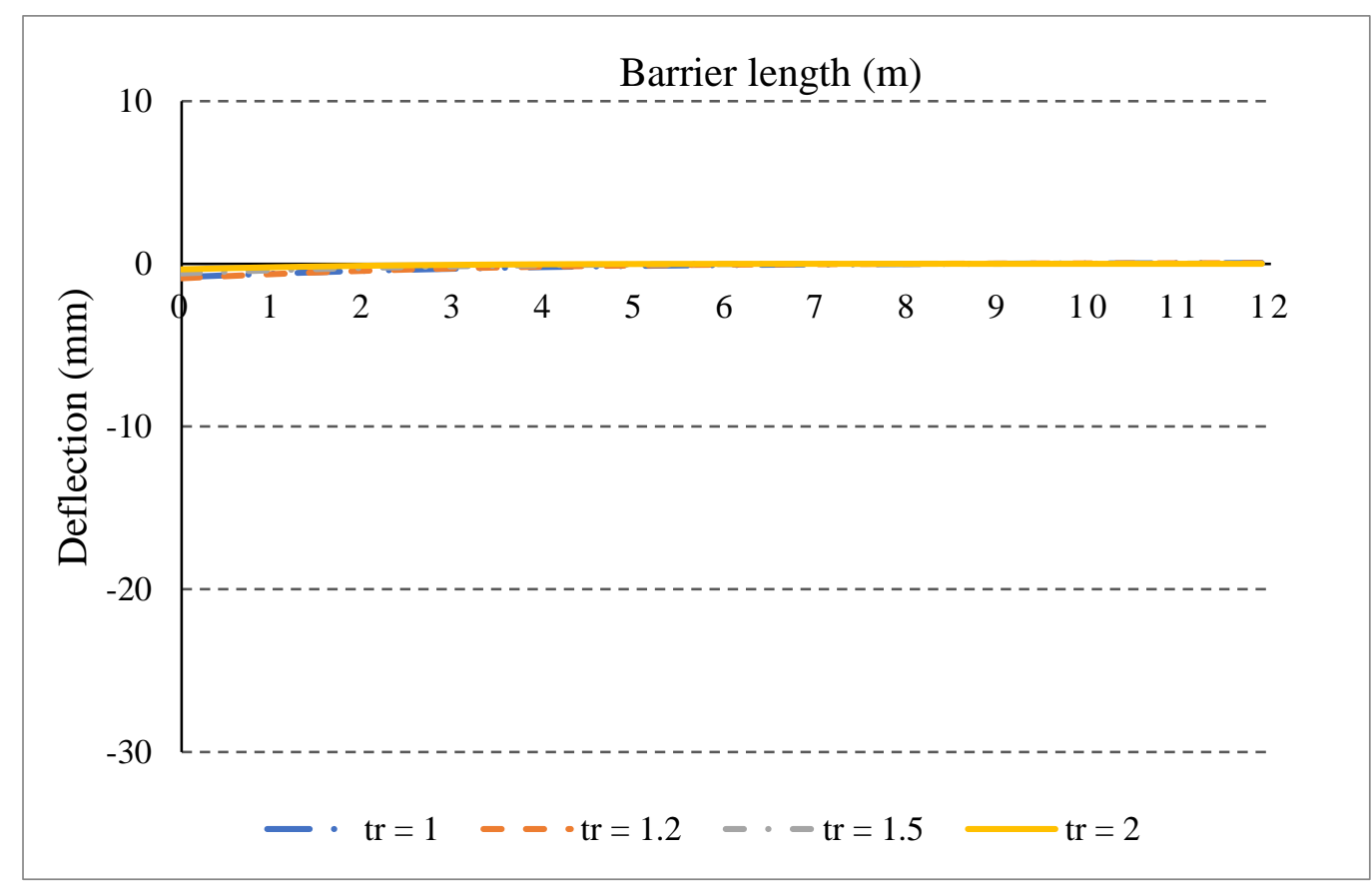

Figure 4-36: Effect of tapered slab thickness ratio on deflection for slab cantilever with TL-4 parapet $\left(\mathrm{L}_{\mathrm{b}}=12 \mathrm{~m}, \mathrm{~L}_{\mathrm{c}}=1.5 \mathrm{~m}, \mathrm{t}_{1}=200 \mathrm{~mm}\right)$ 


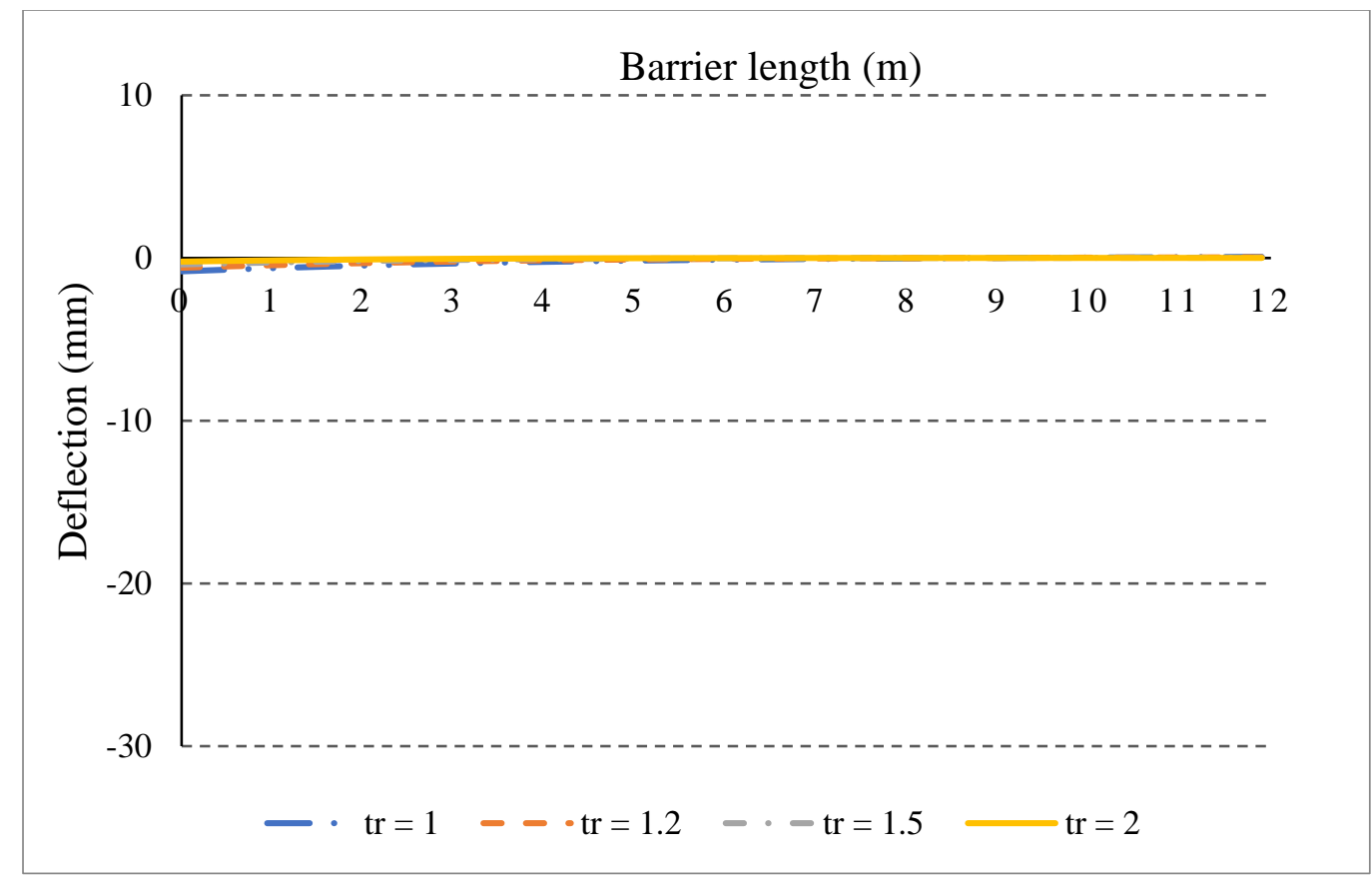

Figure 4-37: Effect of tapered slab thickness ratio on deflection for slab cantilever with TL-5 barrier $\left(\mathrm{L}_{b}=12 \mathrm{~m}, \mathrm{~L}_{\mathrm{c}}=1.5 \mathrm{~m}, \mathrm{t}_{1}=200 \mathrm{~mm}\right)$ 


\subsection{Results comparison with CHBDC and previous research's works}

Tables 4-41 and 4-42 show the comparison between results obtained from the parametric study with the corresponding results from Table 5.15 in CHBDC of 2014. Also, these tables compare the obtained results with corresponding results from Micovic (2016) for internal moment intensity. Since Clause 5.7.1.3 of CHBDC specifies that the external moment in transverse direction should be taken as twice times of the calculated internal moment, the acquired results from CHBDC and Micovic are multiplied by 2 to compare them with results taken from this research. The results are also presented in graphical format in Figures 4-38 through 4-40. One may observe that the results from the current study for the transverse moment intensity at the free end of the deck slab cantilever is almost identical to those specified in CHBDC for deck slab cantilever more than $1.5 \mathrm{~m}$. However, the specified values in CHBDC are significantly greater than those obtained from the current study for cantilever lengths between 1 and $1.5 \mathrm{~m}$.

Table 4-41: Maximum cantilever slab transverse moment $\left(\mathrm{M}_{\mathrm{y}}\right)$ due to unfactored CL- 625 truck wheel loads ( $I_{D}$ included) for slabs with unstiffened edge

\begin{tabular}{cccccccccc}
\hline \hline & \multicolumn{3}{c}{ CHDBC (kN) } & \multicolumn{3}{c}{ Micovic (2016) Results (kN) } & \multicolumn{2}{c}{ Current Results (kN) } \\
\hline \hline $\mathrm{S}_{\mathrm{p}, \mathrm{m}}$ & $\mathrm{r}_{\mathrm{t}}=1$ & $\mathrm{r}_{\mathrm{t}}=0.75$ & $\mathrm{r}_{\mathrm{t}}=2$ & $\mathrm{r}_{\mathrm{t}}=1$ & $\mathrm{r}_{\mathrm{t}}=0.75$ & $\mathrm{r}_{\mathrm{t}}=2$ & $\mathrm{r}_{\mathrm{t}}=1$ & $\mathrm{r}_{\mathrm{t}}=0.75$ & $\mathrm{r}_{\mathrm{t}}=2$ \\
\hline 1.00 & 82.00 & 86.00 & 88.00 & 51.22 & 58.66 & 56.70 & 45.48 & 47.03 & 48.56 \\
\hline 1.50 & 86.00 & 94.00 & 102.00 & 73.94 & 78.25 & 83.88 & 83.07 & 87.53 & 92.32 \\
\hline 2.00 & 106.00 & 114.00 & 120.00 & 89.56 & 95.12 & 102.48 & 105.75 & 112.51 & 119.95 \\
\hline 2.50 & 120.00 & 130.00 & 140.00 & 113.60 & 119.31 & 126.93 & 125.45 & 133.27 & 140.59 \\
\hline
\end{tabular}

Table 4-42: Percentage difference between results from this research with CHDBC and Micovic's results

\begin{tabular}{cccccc}
\hline \hline \multicolumn{2}{c}{ \% Diff. with CHDBC } & \multicolumn{2}{c}{ \% Diff. with Micovic's results } \\
\hline \hline $\mathrm{r}_{\mathrm{t}}=1$ & $\mathrm{r}_{\mathrm{t}}=0.75$ & $\mathrm{r}_{\mathrm{t}}=2$ & $\mathrm{r}_{\mathrm{t}}=1$ & $\mathrm{r}_{\mathrm{t}}=0.75$ & $\mathrm{r}_{\mathrm{t}}=2$ \\
\hline \hline$-44.54 \%$ & $-45.32 \%$ & $-44.82 \%$ & $-11.21 \%$ & $-19.83 \%$ & $-14.36 \%$ \\
$-3.41 \%$ & $-6.89 \%$ & $-9.49 \%$ & $12.35 \%$ & $11.85 \%$ & $10.06 \%$ \\
$-0.24 \%$ & $-1.31 \%$ & $-0.04 \%$ & $18.08 \%$ & $18.28 \%$ & $17.05 \%$ \\
$4.54 \%$ & $2.52 \%$ & $0.42 \%$ & $10.43 \%$ & $11.70 \%$ & $10.76 \%$ \\
\hline \hline
\end{tabular}




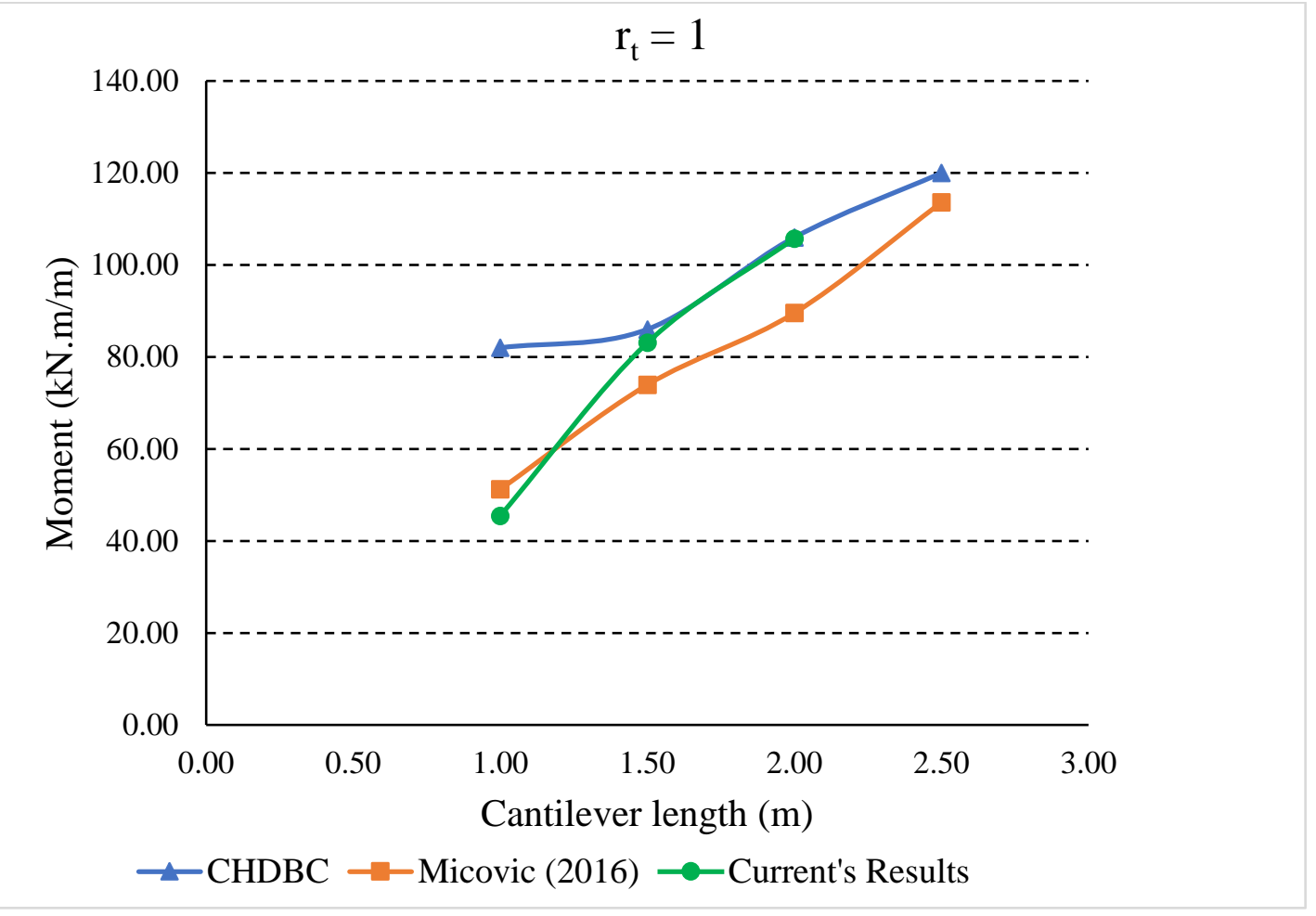

Figure 4-38: Comparison between CHDBC moment and Micovic's results with those from the current study for slab cantilever with unstiffened edge and tapered slab thickness ratio of 1

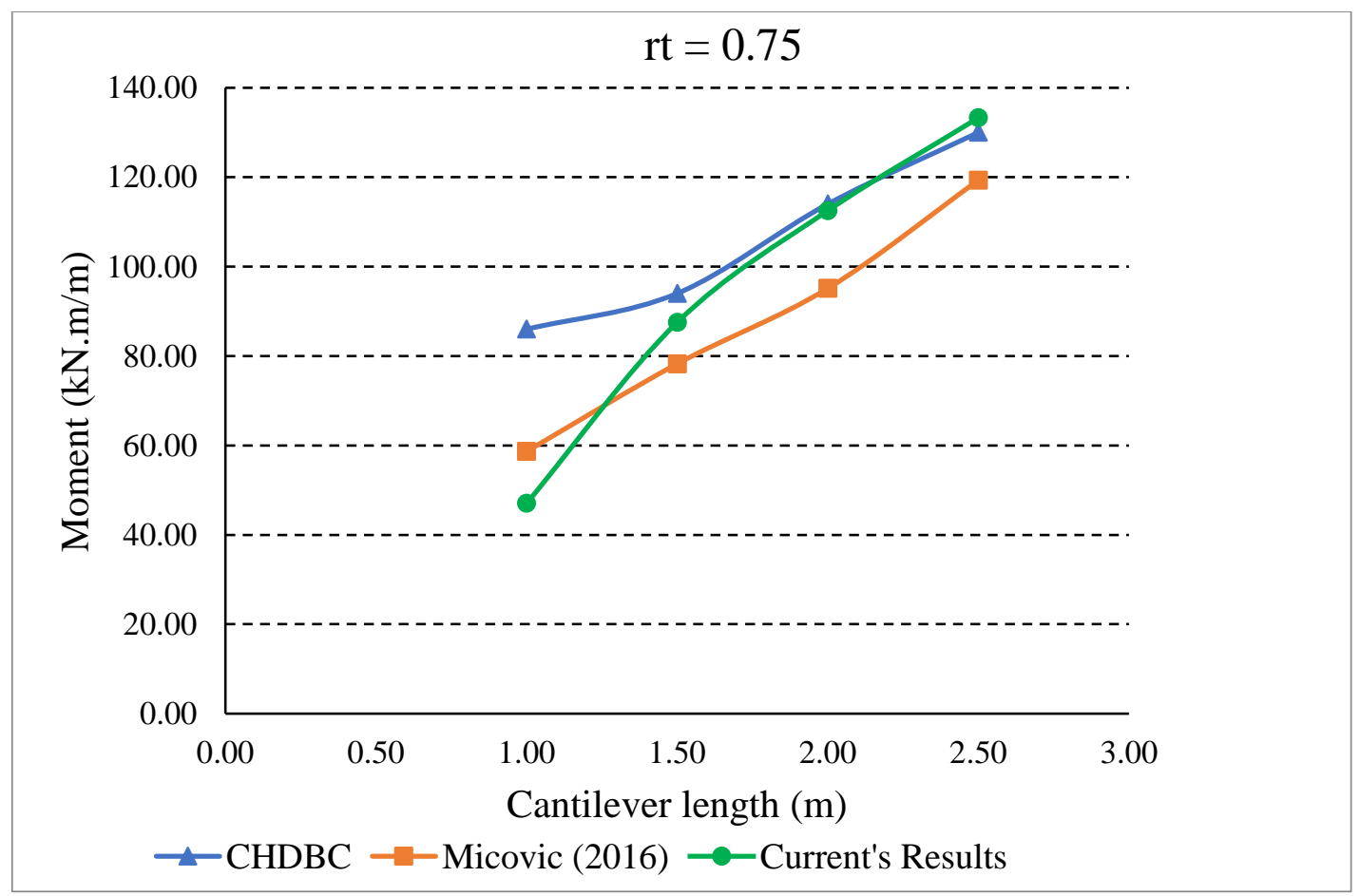


Figure 4-39: Comparison between CHDBC moment and Micovic's results with those from the current study for slab cantilever with unstiffened edge and tapered slab thickness ratio of 0.75

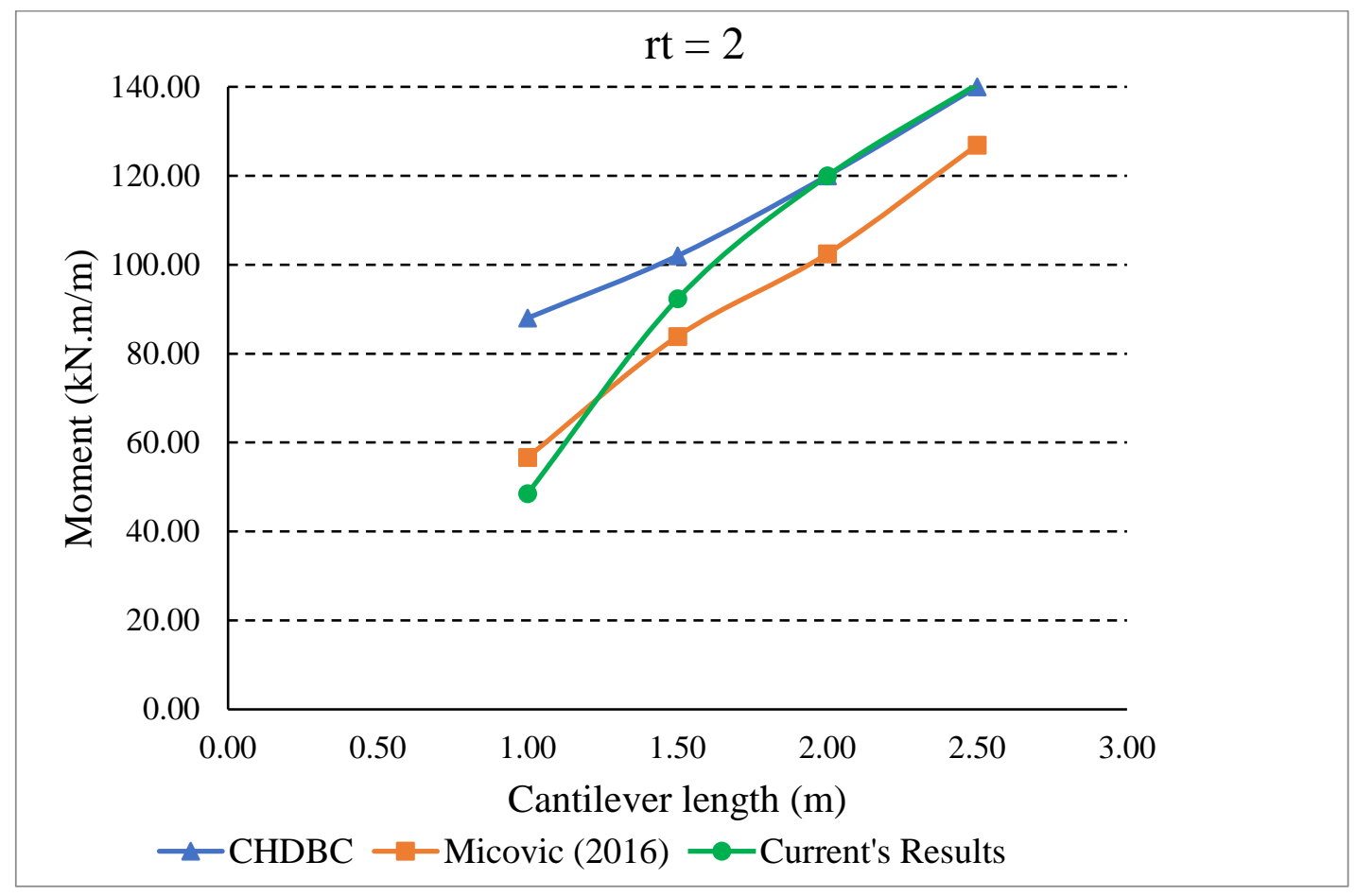

Figure 4-40: Comparison between CHDBC moment and Micovic's results with those from the current study for slab cantilever with unstiffened edge and tapered slab thickness ratio of 2

\subsection{Comparison between results for external moments from this research with internal moments from Micovic results}

This part of the study investigated the ratio of calculated external moment from this study to the corresponding internal moment obtained from Micovic (2016) by producing graphs illustrated in Figure 4-41 to Figure 4-64. The ratio of external moment to internal moment are plotted in Y axis against the barrier length in $\mathrm{X}$ axis. The graphs were created for all cantilever lengths and types of edge stiffening barriers considered in this study. Also, the line for $\mathrm{M}_{\mathrm{Ex}} / \mathrm{M}_{\text {Int }}=2$ was added to the graphs as stated by Clause 5.7.1.3 of CHBDC. As it can be observed from the graphs, the comparison between the obtained external moment and internal moment from finite element analysis shows that the ratio of $\mathrm{M}_{\text {Ext }} / \mathrm{M}_{\text {Int }}$ is below 2 for cantilever length equal to $1 \mathrm{~m}$. On the other hand, for cantilever length equal to, or greater than, $1.5 \mathrm{~m}$, this moment ratio exceeded 2. 


\subsubsection{Unstiffened Edge}

Figure 4-42 to Figure 4-45 shows the ratio of external moment to internal moment for the unstiffened slab with variable barrier length and cantilever length

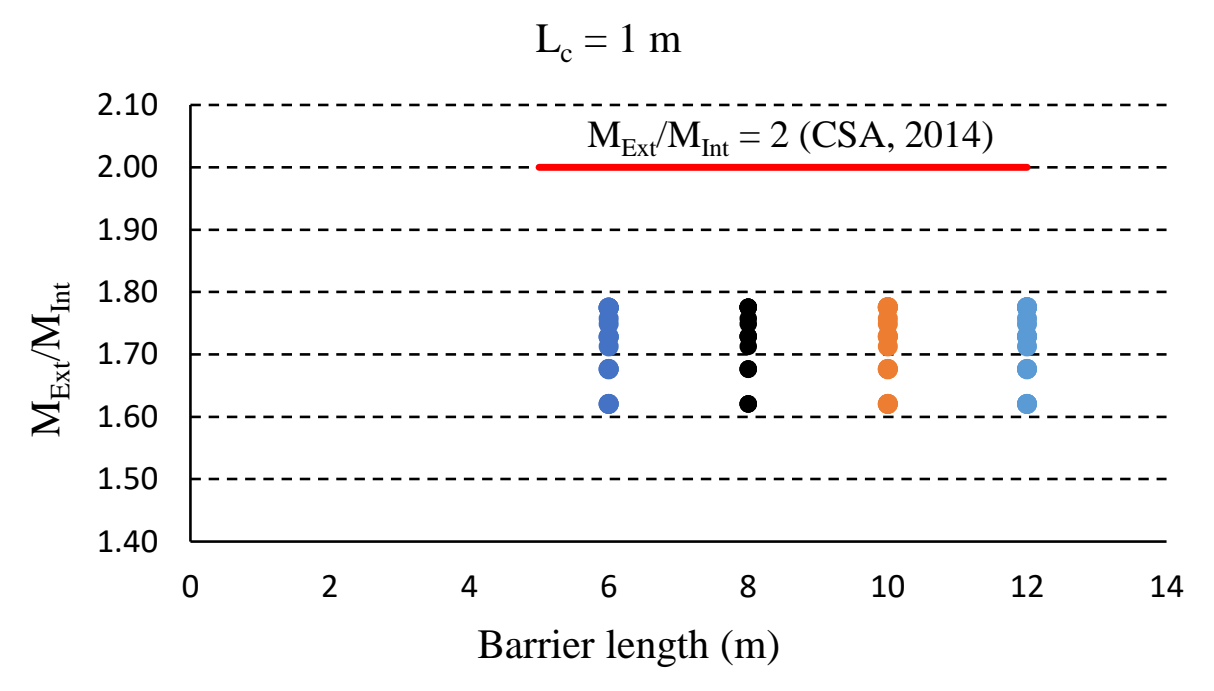

Figure 4-41: Ratio on external moment obtained from the current study and internal moment obtained from Micovic's results for slab cantilever with unstiffened edge ( $\left.L_{c}=1 \mathrm{~m}\right)$

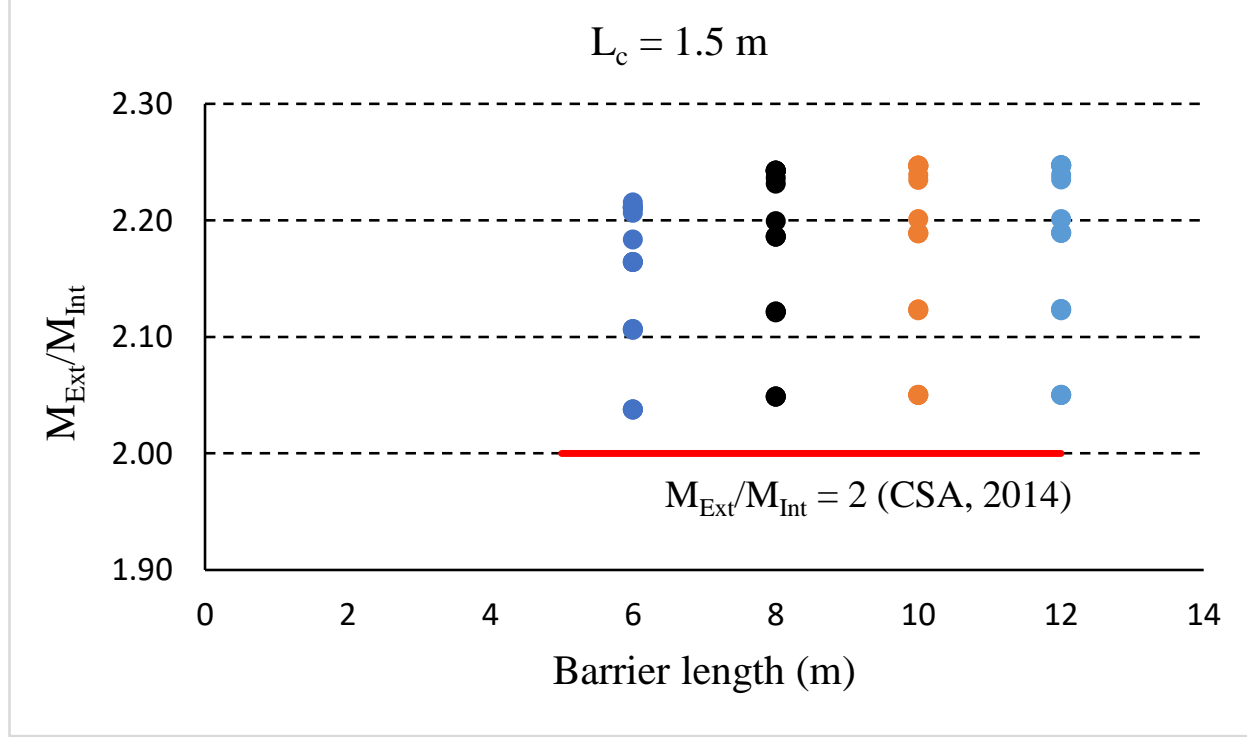

Figure 4-42: Ratio on external moment obtained from the current study and internal moment obtained from Micovic's results for slab cantilever with unstiffened edge $\left(L_{c}=1.5 \mathrm{~m}\right)$ 


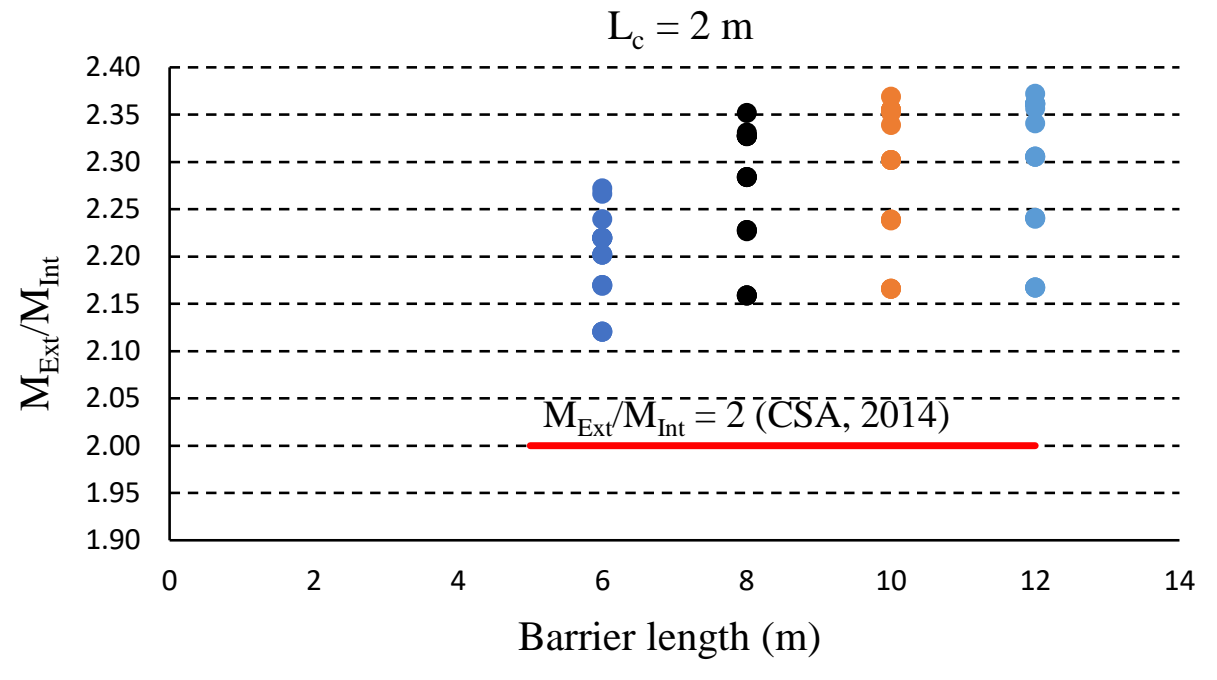

Figure 4-43: Ratio on external moment obtained from the current study and internal moment obtained from Micovic's results for slab cantilever with unstiffened edge $\left(L_{c}=2 \mathrm{~m}\right)$

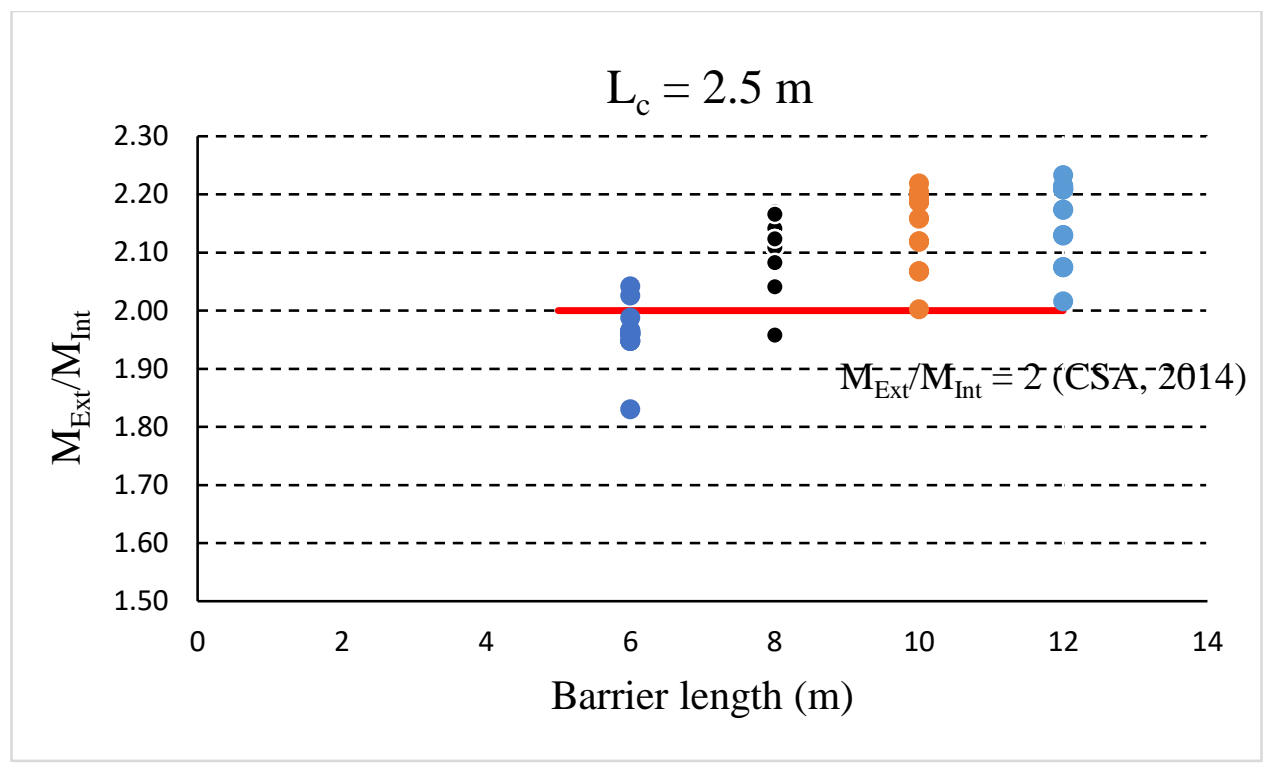

Figure 4-44: Ratio on external moment obtained from the current study and internal moment obtained from Micovic's results for slab cantilever with unstiffened edge $\left(L_{c}=2.5 \mathrm{~m}\right)$ 


\subsubsection{Curb}

Figure 4-46 to Figure 4-49 shows the ratio of external moment to internal moment for the cantilever slab stiffed with curb with variable barrier length and cantilever length.

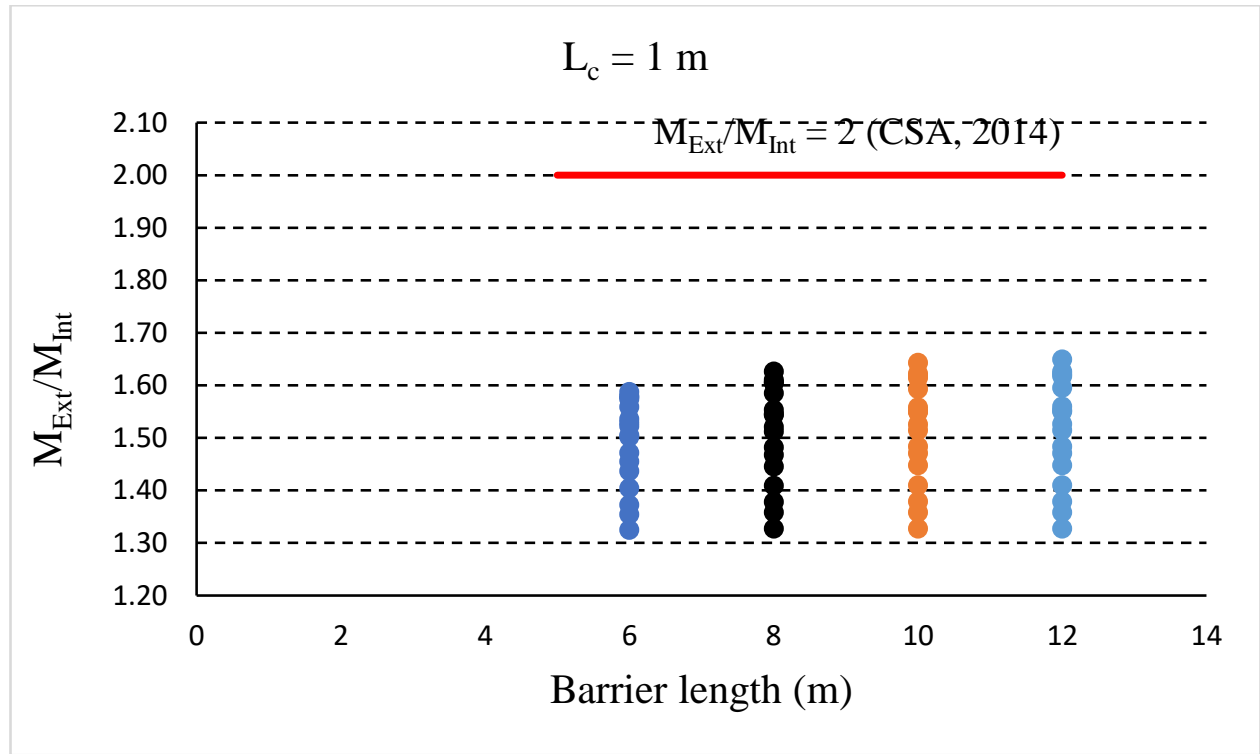

Figure 4-45: Ratio on external moment obtained from the current study and internal moment obtained from Micovic's results for slab cantilever with a curb $(\mathrm{Lc}=1 \mathrm{~m})$

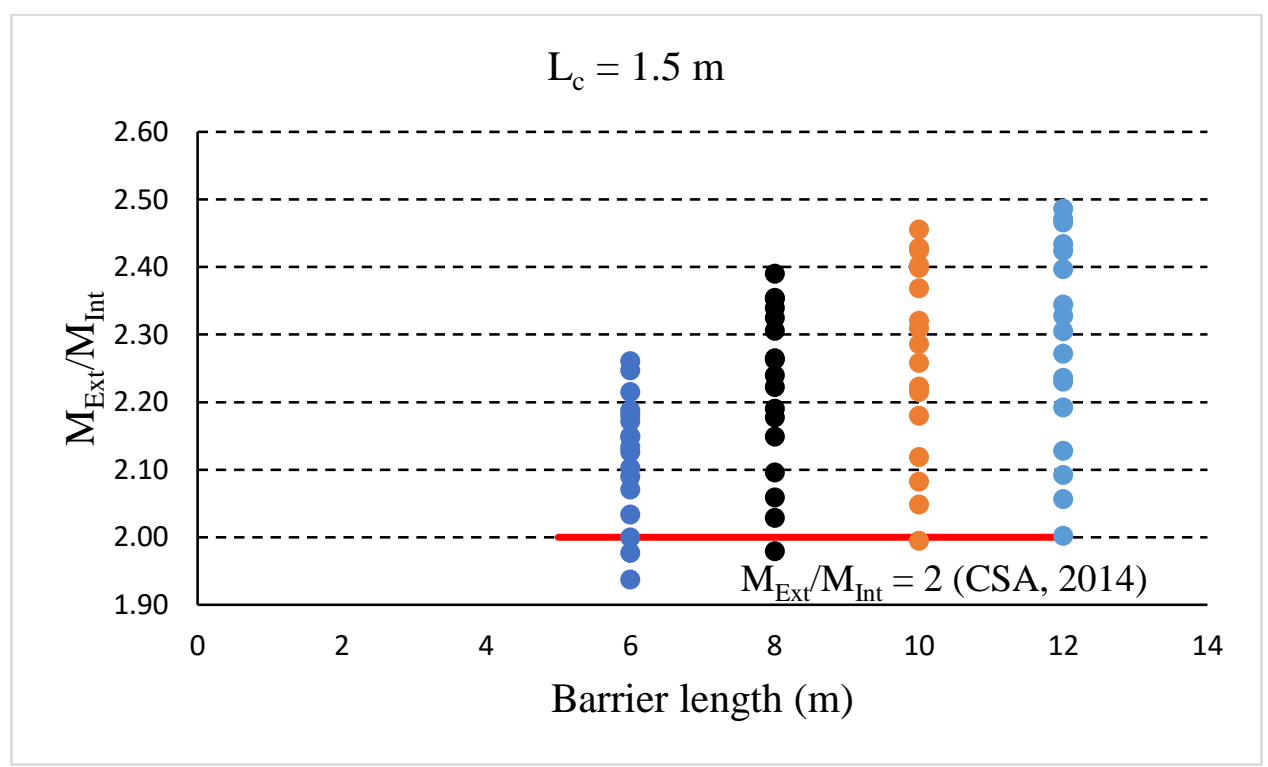

Figure 4-46: Ratio on external moment obtained from the current study and internal moment obtained from Micovic's results for slab cantilever with a curb $\left(L_{c}=1.5 \mathrm{~m}\right)$ 


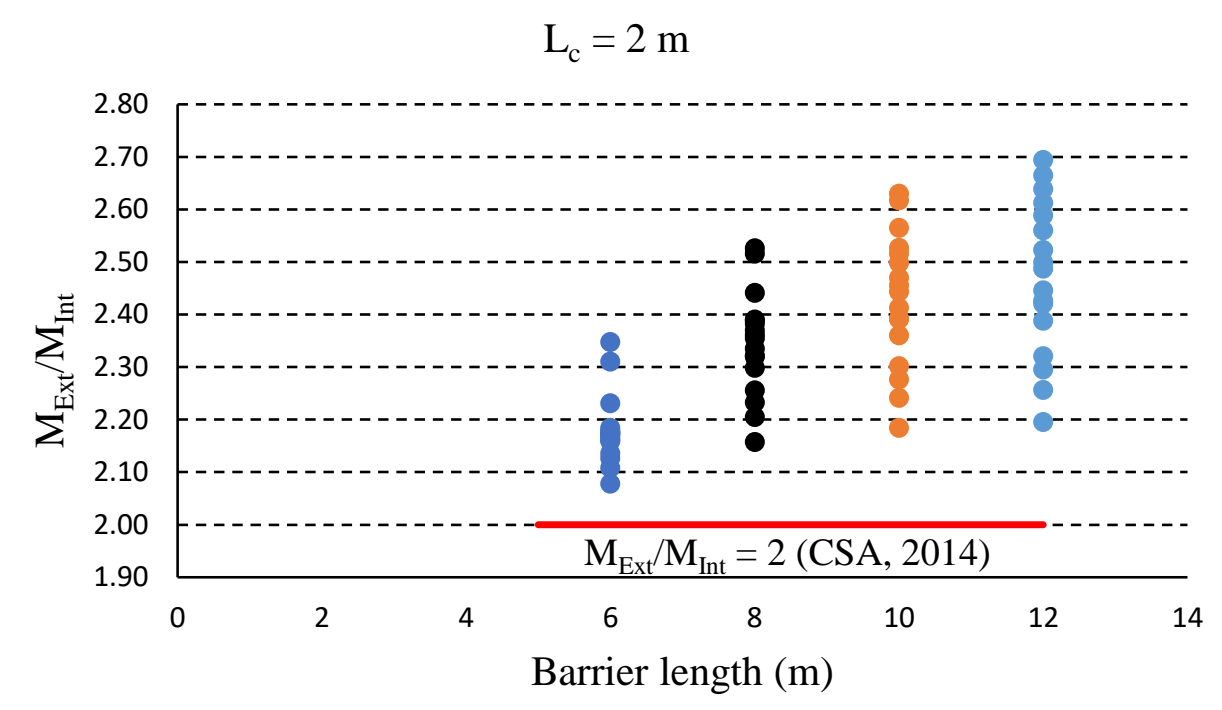

Figure 4-47: Ratio on external moment obtained from the current study and internal moment obtained from Micovic's results for slab cantilever with a curb $\left(L_{c}=2 \mathrm{~m}\right)$

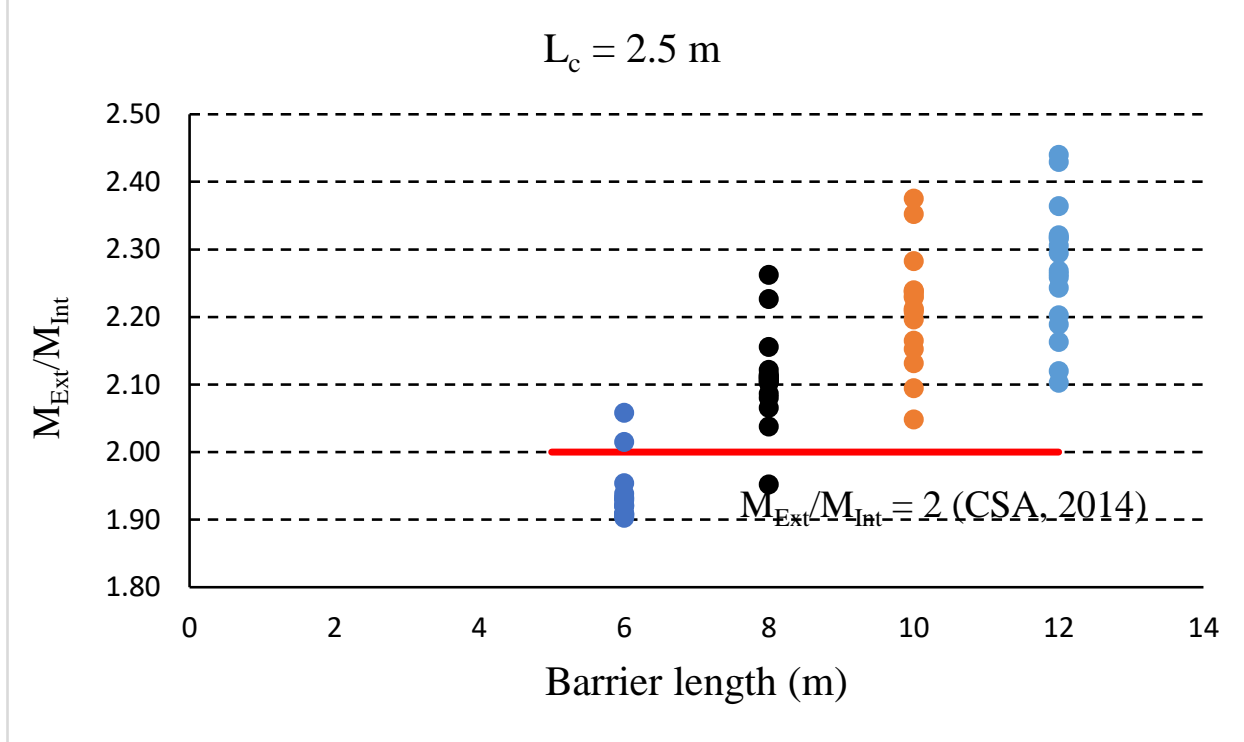

Figure 4-48: Ratio on external moment obtained from the current study and internal moment obtained from Micovic's results for slab cantilever with a curb $\left(\mathrm{L}_{\mathrm{c}}=2.5 \mathrm{~m}\right)$ 


\subsubsection{TL-2 barrier}

Figure 4-50 to Figure 4-53 shows the ratio of external moment to internal moment for the cantilever slab stiffed with TL-2 barrier with variable barrier length and cantilever length.

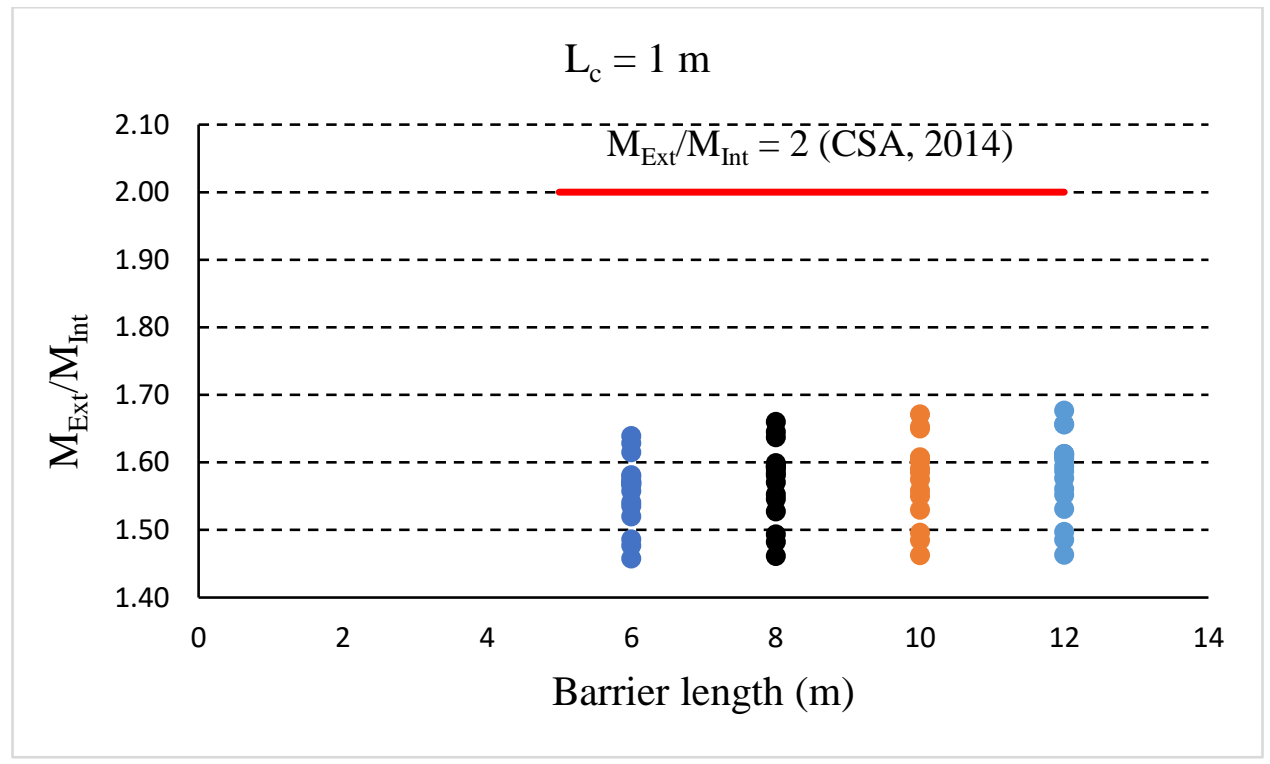

Figure 4-49: Ratio on external moment obtained from the current study and internal moment obtained from Micovic's results for slab cantilever with TL-2 barrier $\left(\mathrm{L}_{c}=1 \mathrm{~m}\right)$

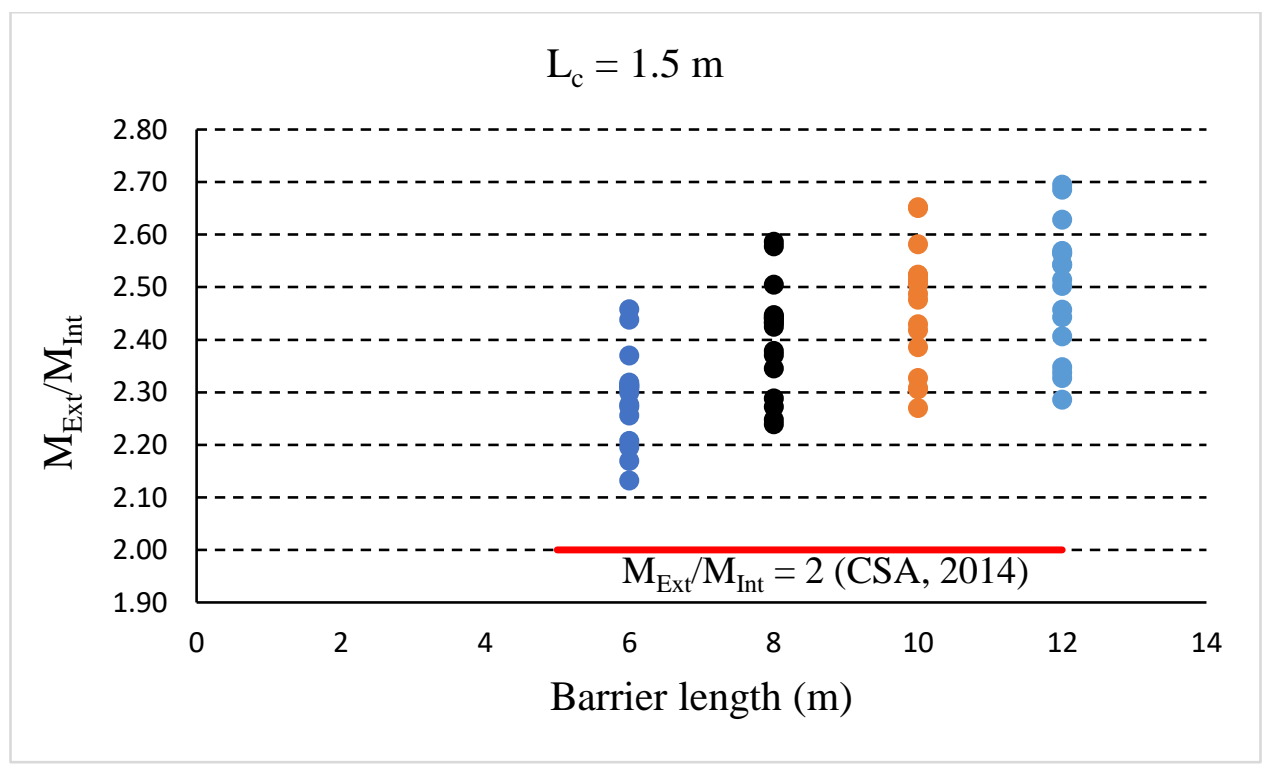

Figure 4-50: Ratio on external moment obtained from the current study and internal moment obtained from Micovic's results for slab cantilever with TL-2 barrier $\left(\mathrm{L}_{c}=1.5 \mathrm{~m}\right)$ 


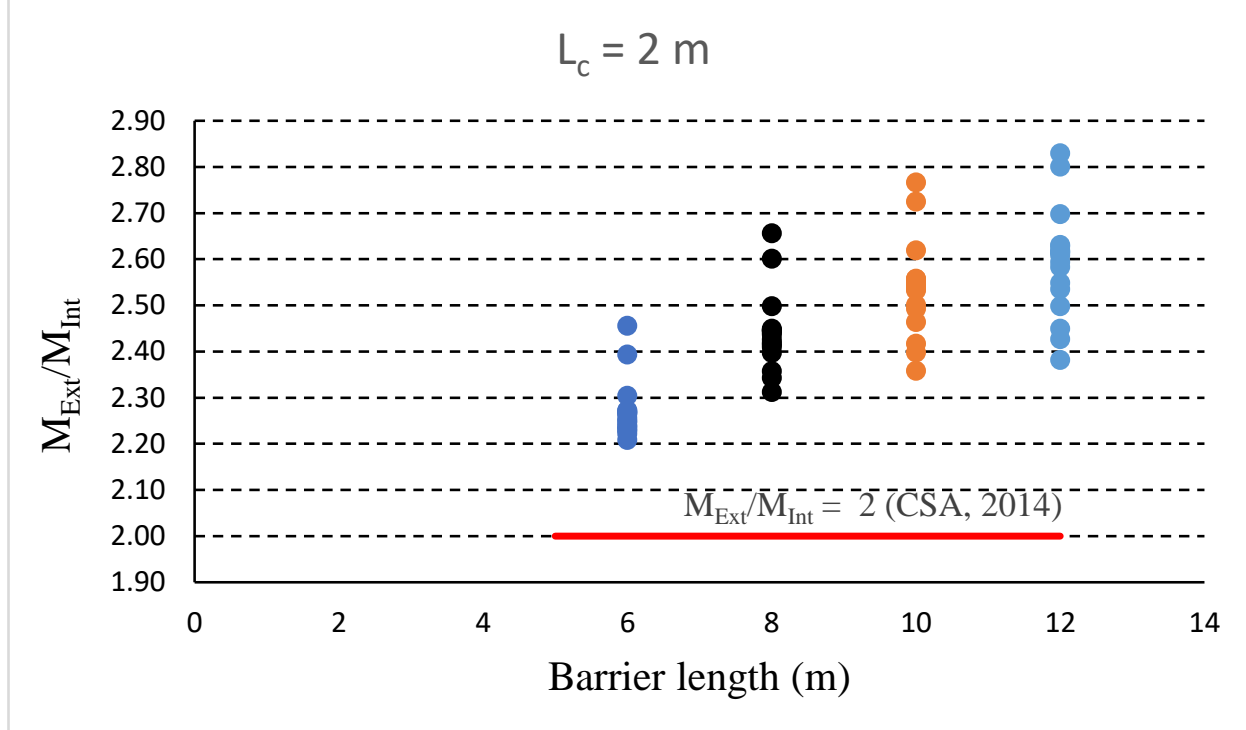

Figure 4-51: Ratio on external moment obtained from the current study and internal moment obtained from Micovic's results for slab cantilever with TL-2 barrier $\left(L_{c}=2 \mathrm{~m}\right)$

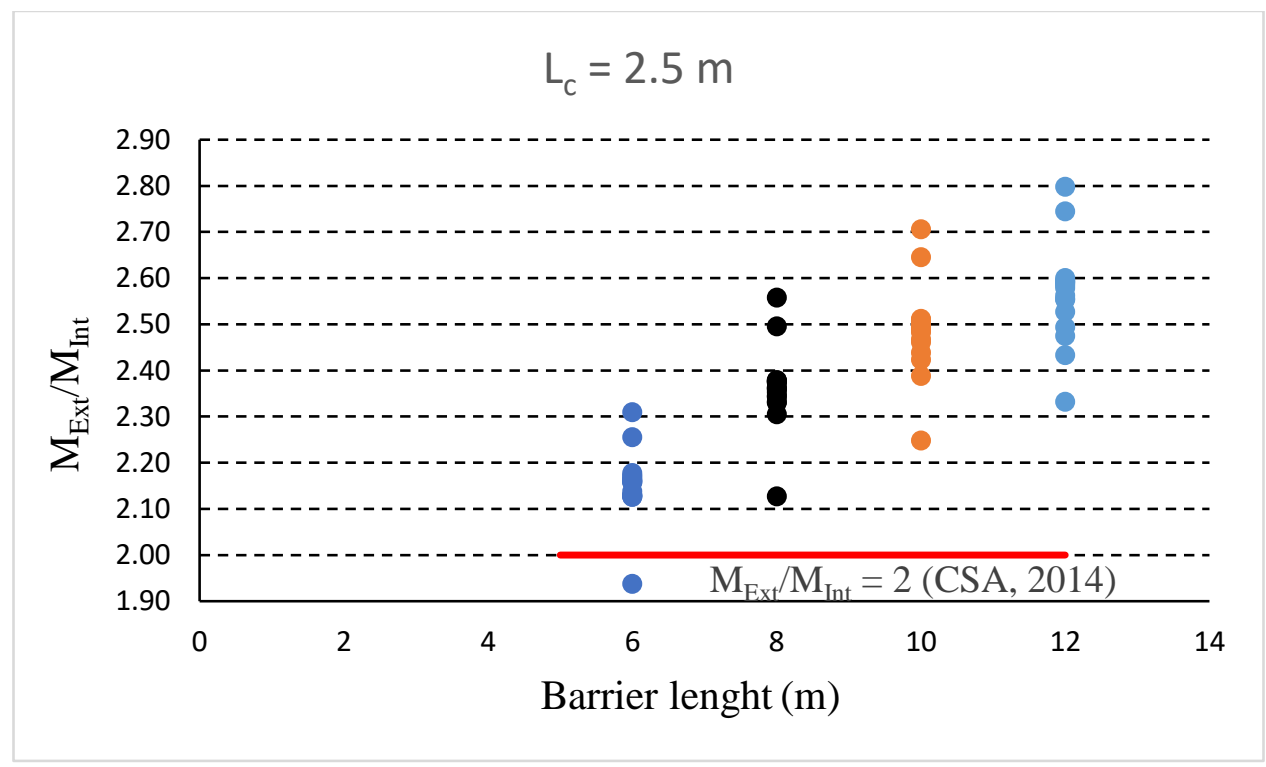

Figure 4-52: Ratio on external moment obtained from the current study and internal moment obtained from Micovic's results for slab cantilever with TL-2 barrier ( $\left.\mathrm{L}_{c}=2.5 \mathrm{~m}\right)$ 


\subsubsection{TL-4 barrier}

Figure 4-54 to Figure 4-57 shows the ratio of external moment to internal moment for the cantilever slab stiffed with TL-4 barrier with variable barrier length and cantilever length.

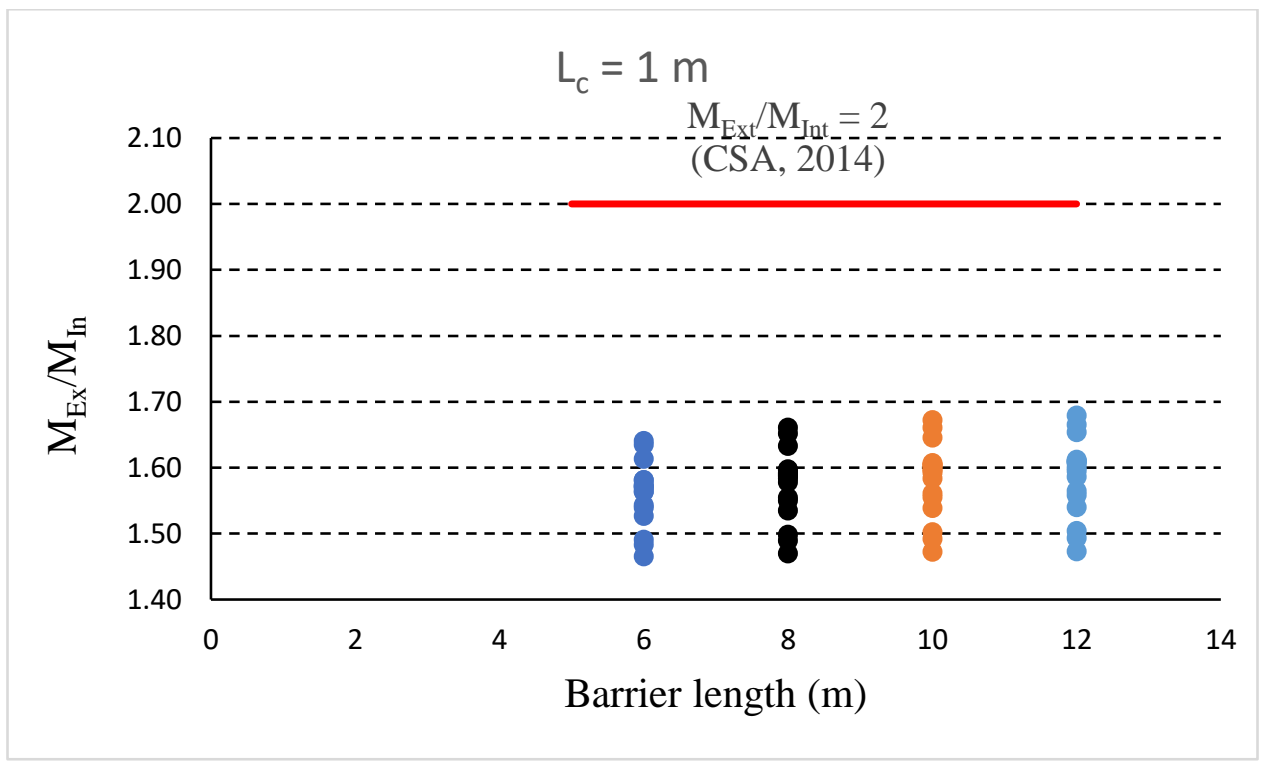

Figure 4-53: Ratio on external moment obtained from the current study and internal moment obtained from Micovic's results for slab cantilever with TL-4 barrier $\left(\mathrm{L}_{\mathrm{c}}=1 \mathrm{~m}\right)$

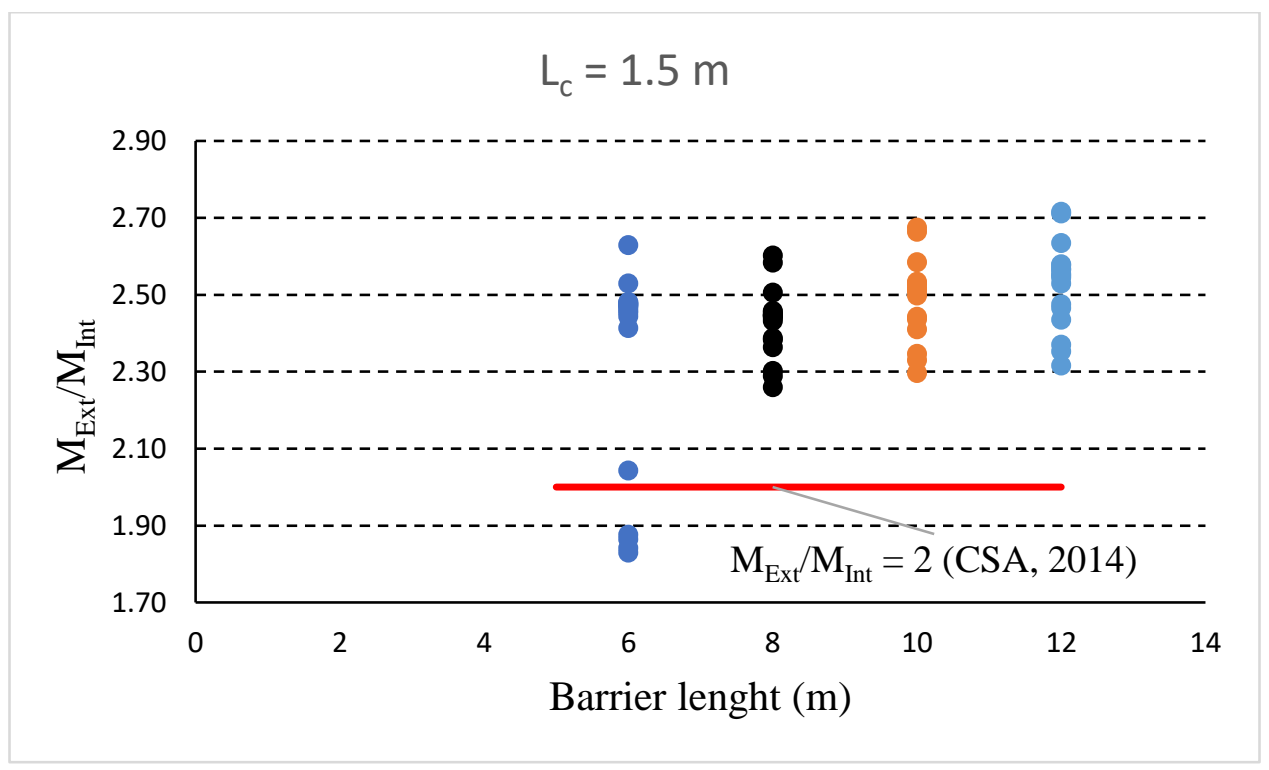

Figure 4-54: Ratio on external moment obtained from the current study and internal moment obtained from Micovic's results for slab cantilever with TL-4 barrier $\left(\mathrm{L}_{\mathrm{c}}=1.5 \mathrm{~m}\right)$ 


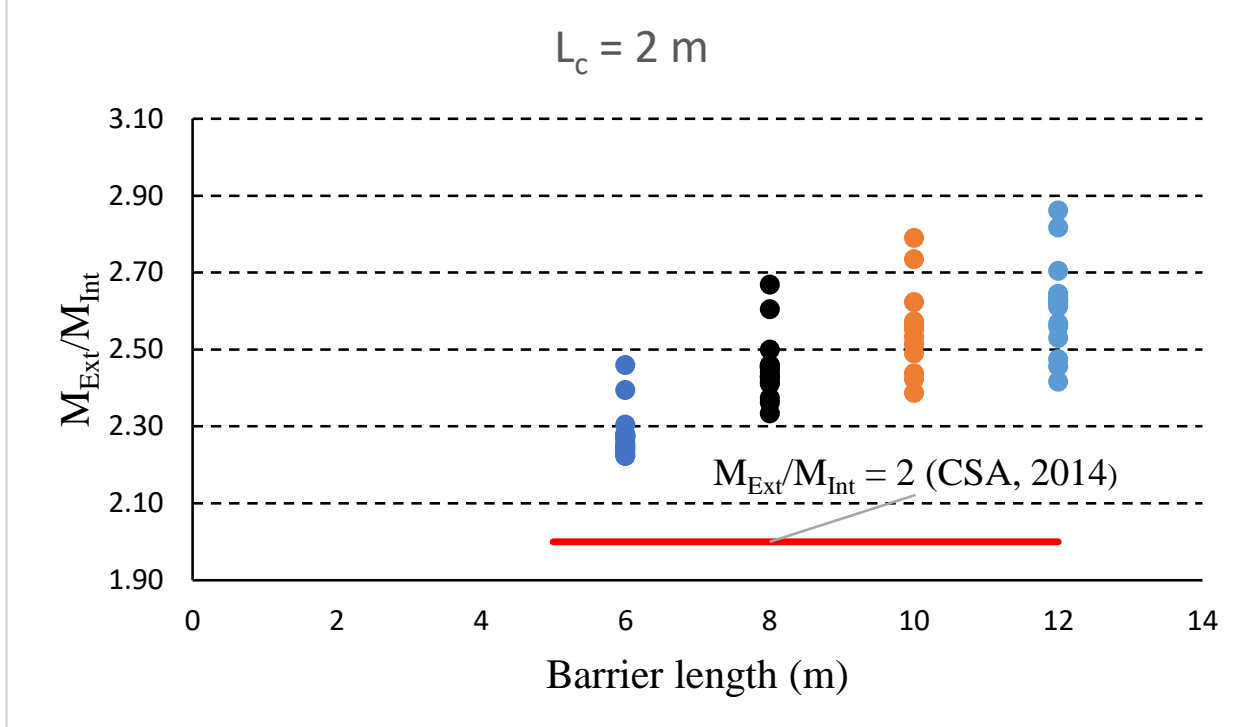

Figure 4-55: Ratio on external moment obtained from the current study and internal moment obtained from Micovic's results for slab cantilever with TL-4 barrier $\left(L_{c}=2 \mathrm{~m}\right.$ )

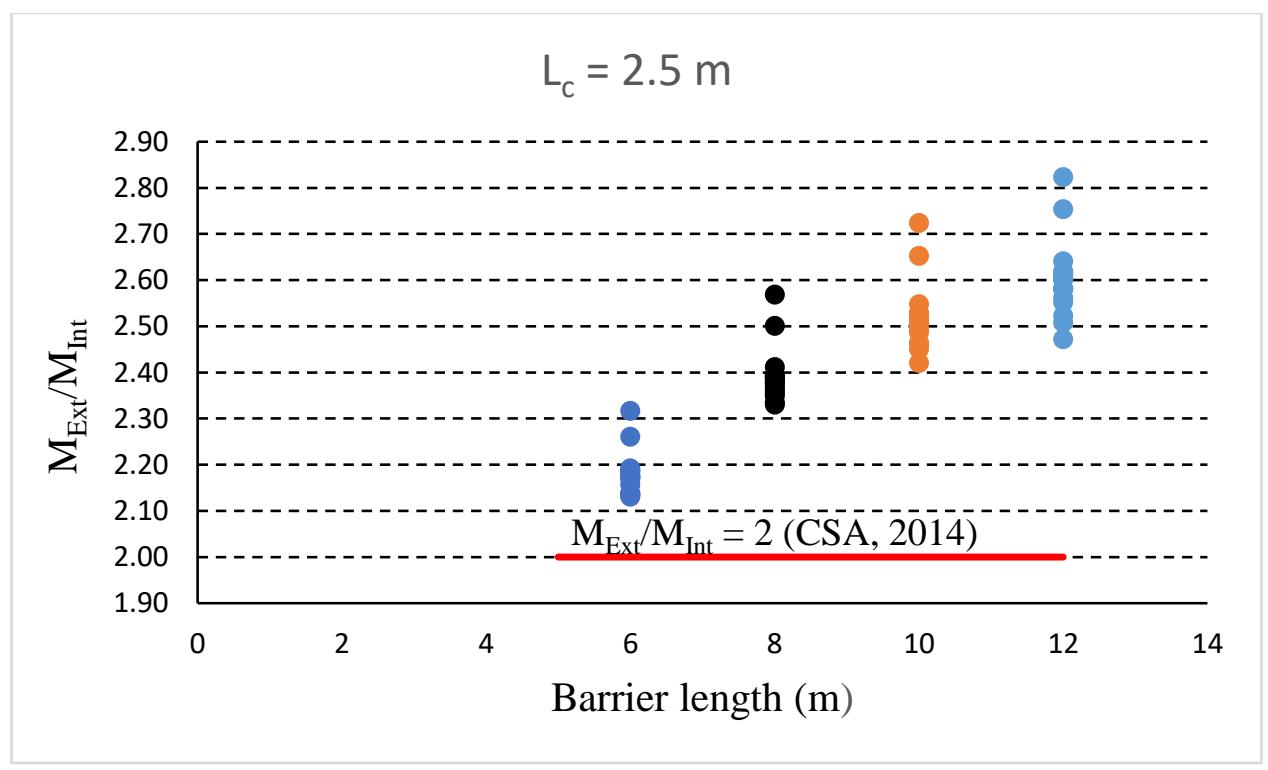

Figure 4-56: Ratio on external moment obtained from the current study and internal moment obtained from Micovic's results for slab cantilever with TL-4 barrier $\left(\mathrm{L}_{\mathrm{c}}=2.5 \mathrm{~m}\right)$ 


\subsubsection{TL-4 Parapet}

Figures 4-57 through 4-60 show the ratio of external moment to internal moment for the cantilever slab with TL-4 parapet considering variable barrier length and cantilever length.

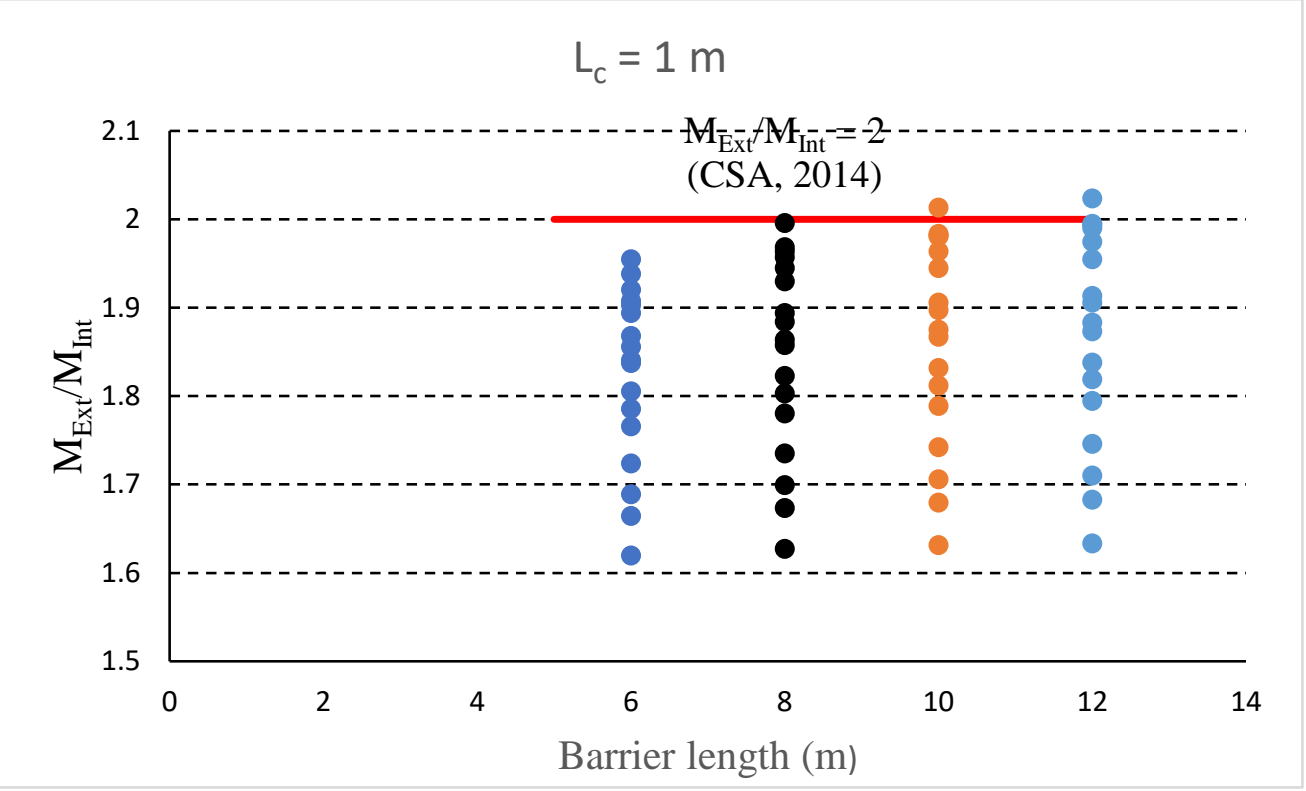

Figure 4-57: Ratio on external moment obtained from the current study and internal moment obtained from Micovic's results for slab cantilever with TL-4 parapet $\left(\mathrm{L}_{c}=1 \mathrm{~m}\right.$ )

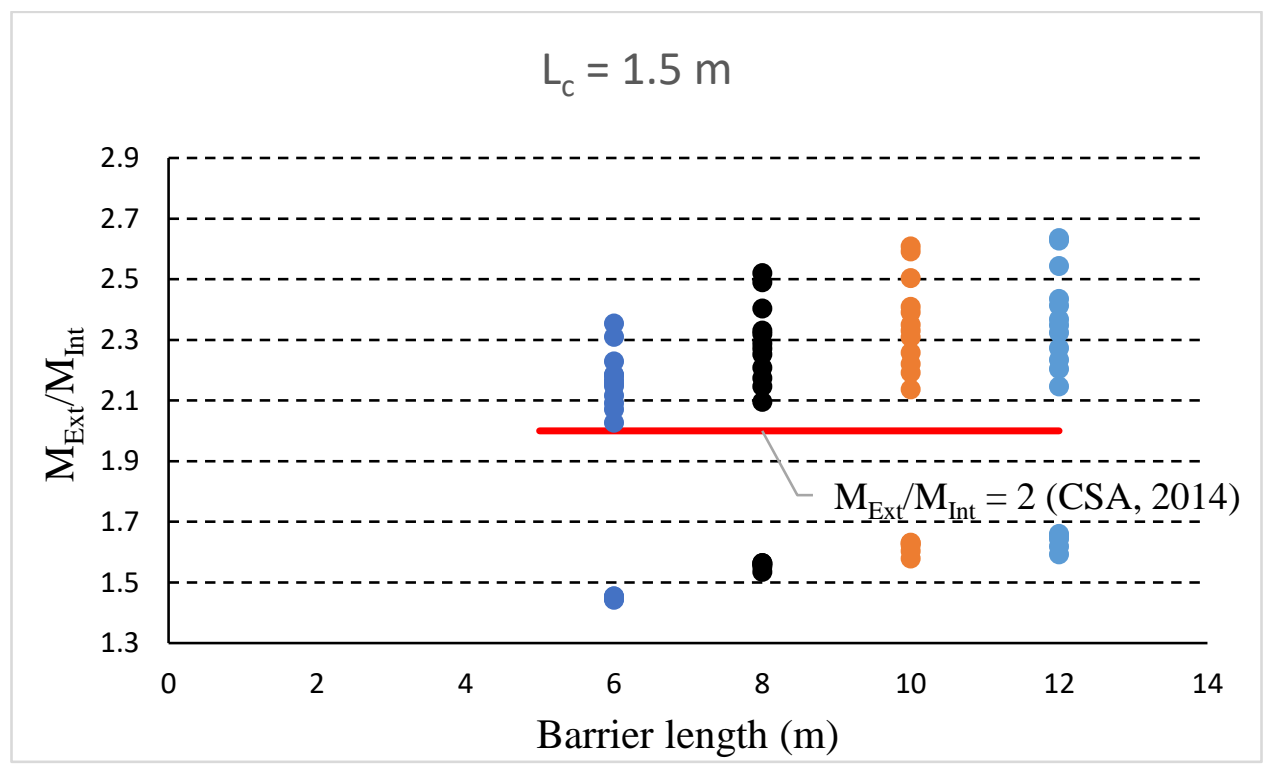

Figure 4-58: Ratio on external moment obtained from the current study and internal moment obtained from Micovic's results for slab cantilever with TL-4 parapet ( $\mathrm{Lc}=1.5 \mathrm{~m}$ ) 


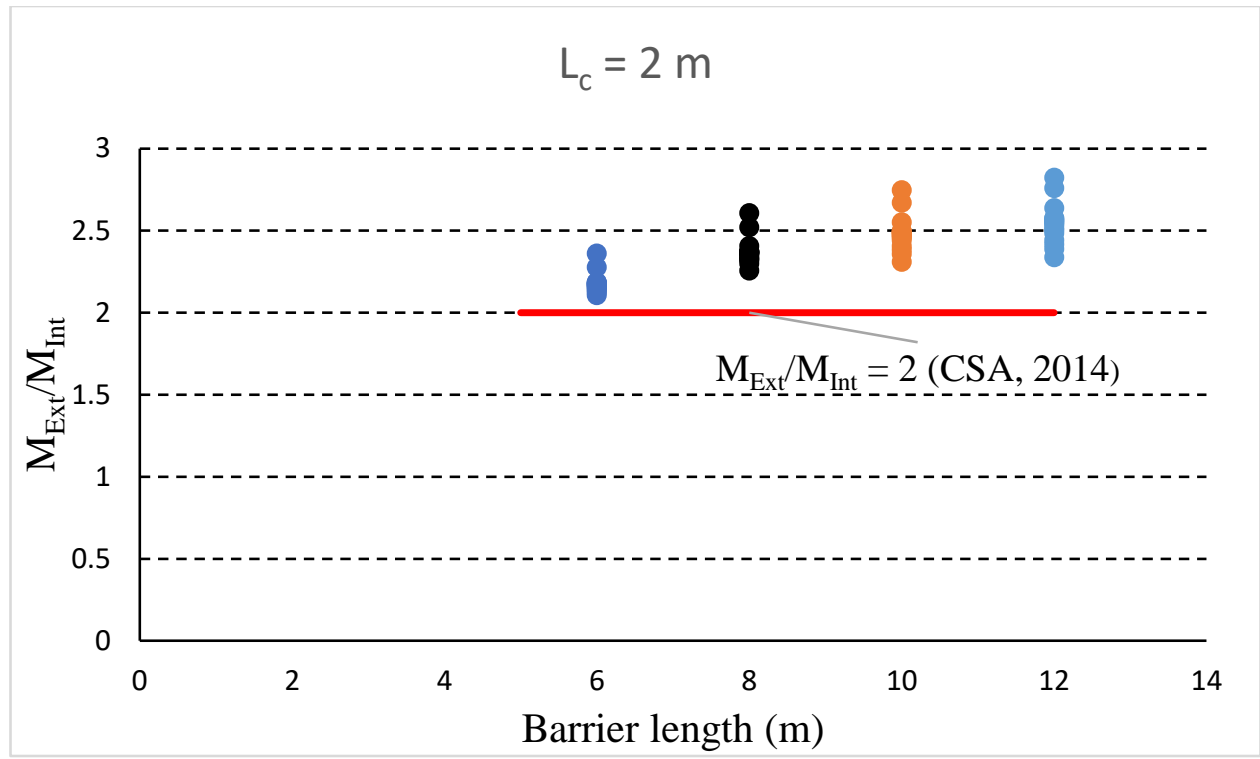

Figure 4-59: Ratio on external moment obtained from the current study and internal moment obtained from Micovic's results for slab cantilever with TL-4 parapet $\left(\mathrm{L}_{c}=2 \mathrm{~m}\right)$

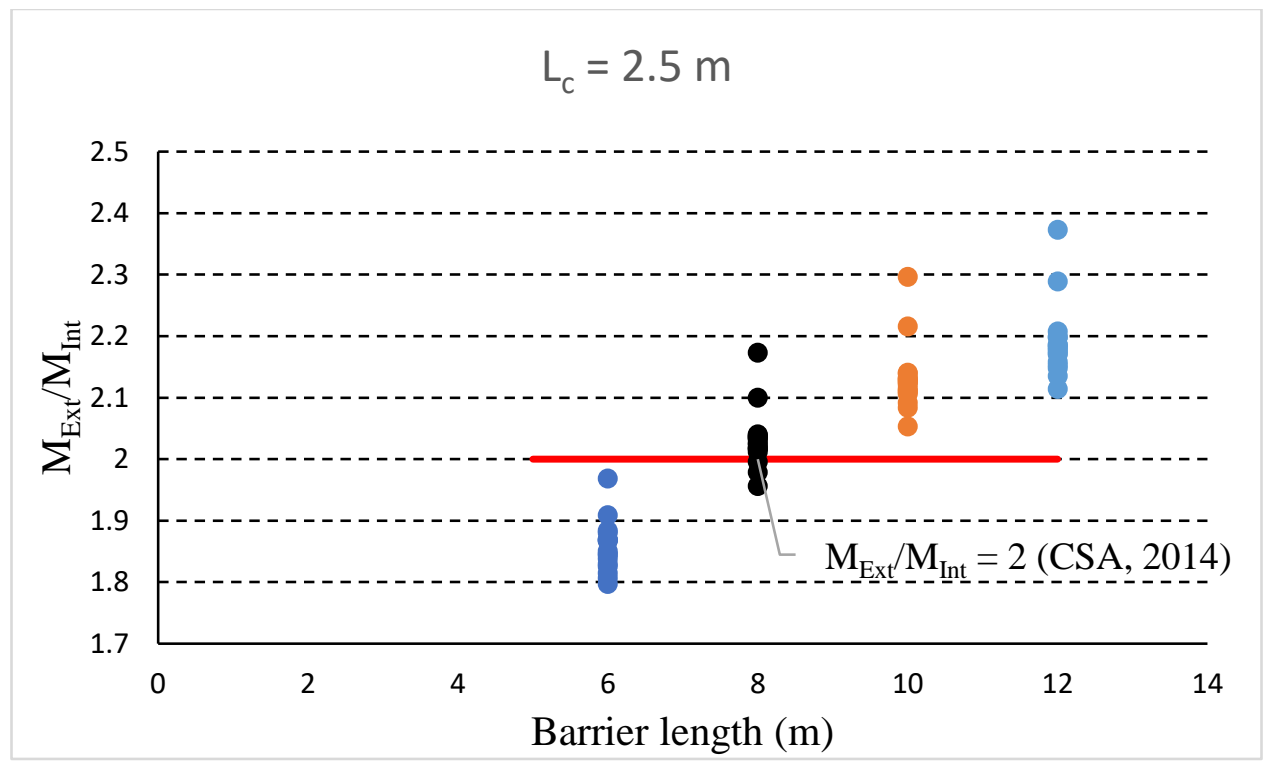

Figure 4-60: Ratio on external moment obtained from the current study and internal moment obtained from Micovic's results for slab cantilever with TL-4 parapet $\left(\mathrm{L}_{c}=2.5 \mathrm{~m}\right)$ 


\subsubsection{TL-5 barrier}

Figure 4-62 to Figure 4-65 shows the ratio of external moment to internal moment for the cantilever slab stiffed with TL-5 barrier with variable barrier length and cantilever length.

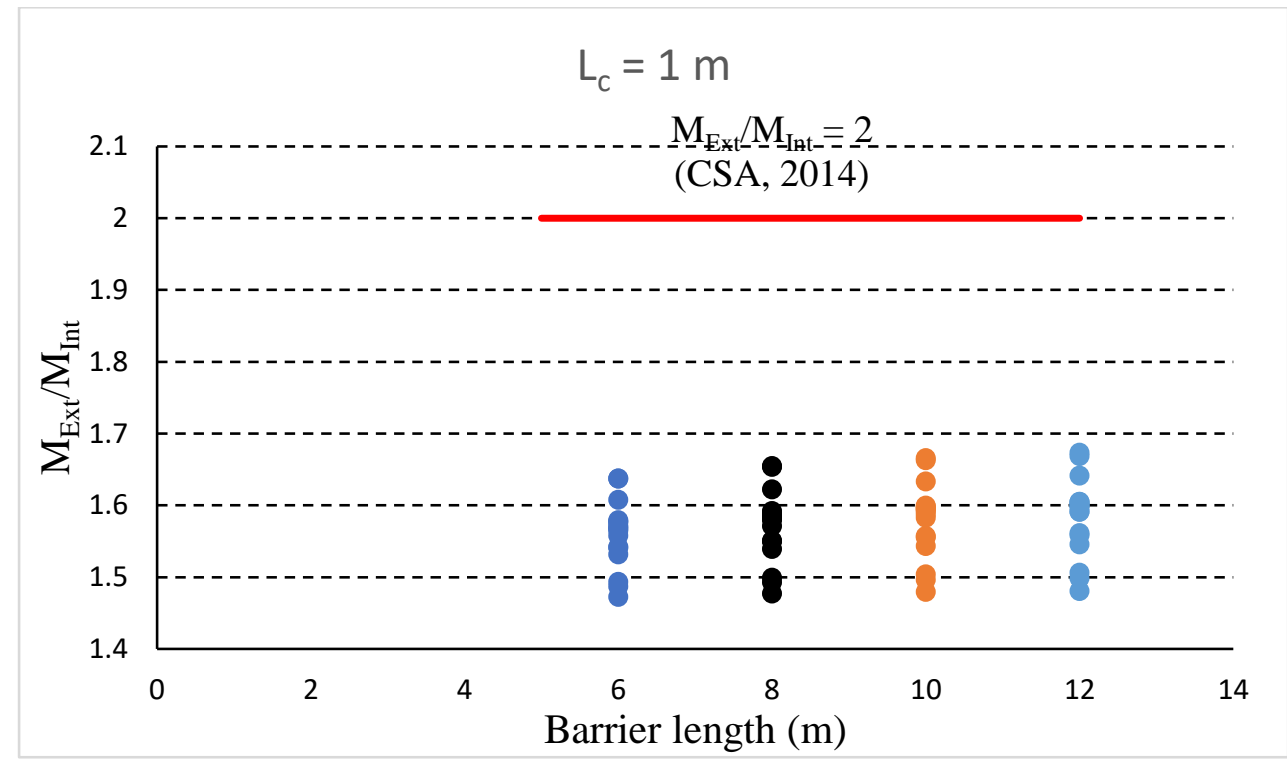

Figure 4-61: Ratio on external moment obtained from the current study and internal moment obtained from Micovic's results for slab cantilever with TL-5 barrier $\left(\mathrm{L}_{\mathrm{c}}=1 \mathrm{~m}\right)$

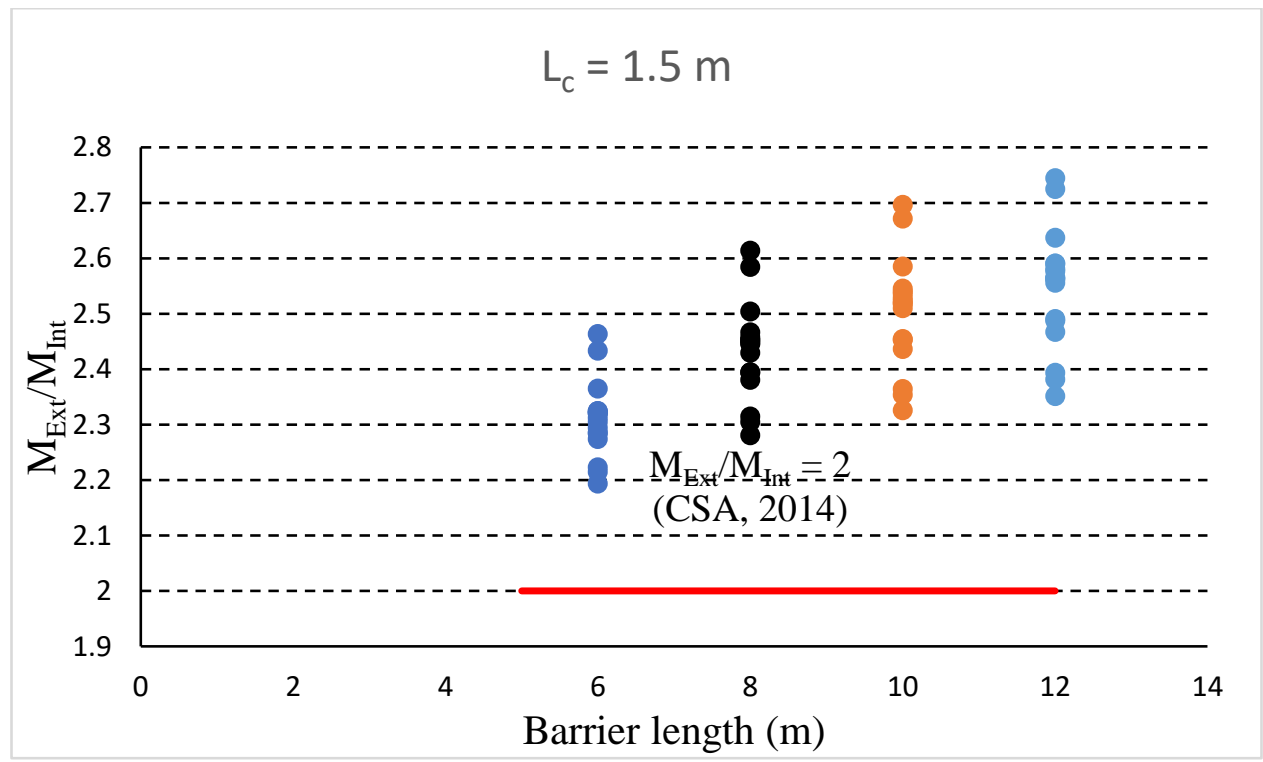

Figure 4-62: Ratio on external moment obtained from the current study and internal moment obtained from Micovic's results for slab cantilever with TL-5 barrier $\left(\mathrm{L}_{c}=1.5 \mathrm{~m}\right)$ 


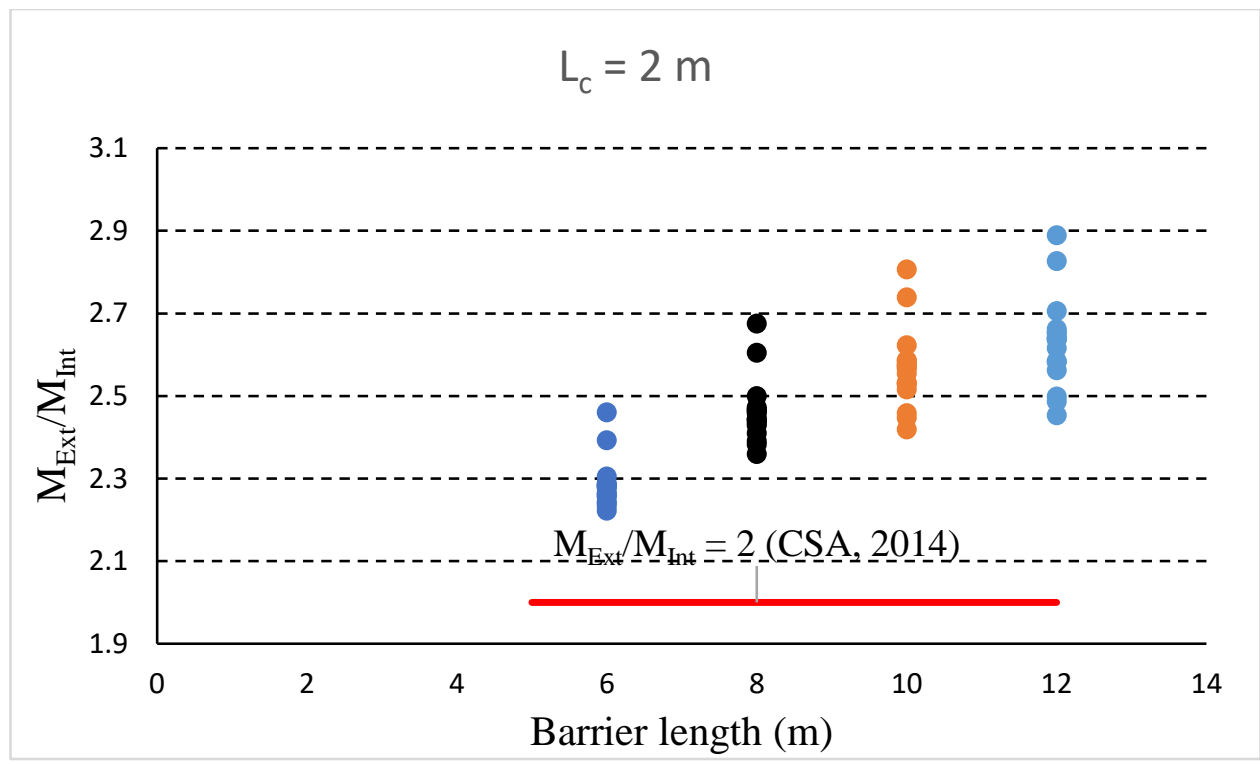

Figure 4-63: Ratio on external moment obtained from the current study and internal moment obtained from Micovic's results for slab cantilever with TL-5 barrier $\left(L_{c}=2 \mathrm{~m}\right)$

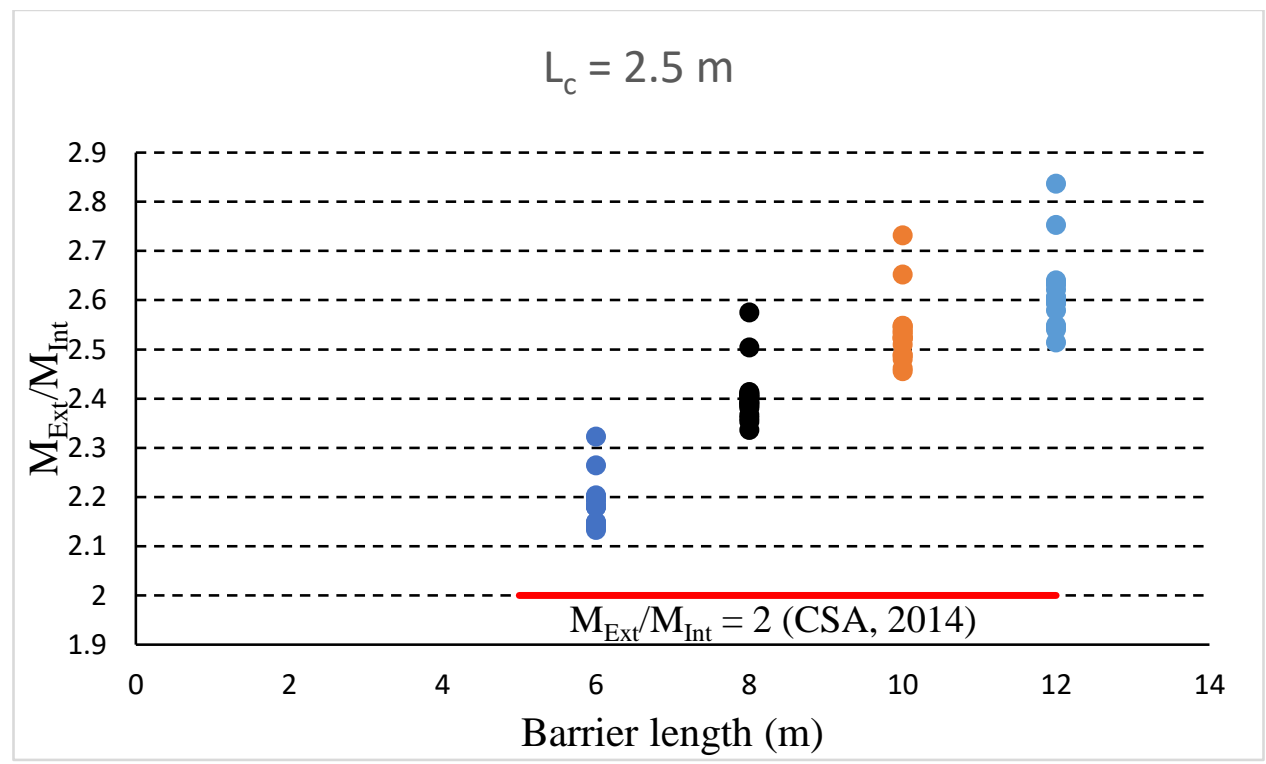

Figure 4-64: Ratio on external moment obtained from the current study and internal moment obtained from Micovic's results for slab cantilever with TL-5 barrier $\left(\mathrm{L}_{\mathrm{c}}=2.5 \mathrm{~m}\right)$ 


\subsection{Developed Equations}

Base on the data obtained from the parametric study, empirical equations ware developed for various cantilever-barrier configuration. These equations developed for both transverse moment $\left(\mathrm{M}_{\mathrm{y}}\right)$ and longitudinal moment $\left(\mathrm{M}_{\mathrm{x}}\right)$. For the unstiffened cantilever slab, two variables, namely: cantilever length $\left(\mathrm{L}_{\mathrm{c}}\right)$ and tapered slab thickness ratio, were considered for developing equations, While, the equations for end stiffened cantilever slab were developed created considering four variables, namely: cantilever length, barrier length, slab thickness and tapered slab thickness ratio. Table 4-43 demonstrates the developed equations for determining the transverse and longitudinal moment intensity for different cantilever-barrier configurations considered in this study. In addition, these equations can be applied to the parameter ranges considered in this research. The coefficients of these equations were calculated utilizing least square regression line method embedded in Microsoft Excel software. Figure 4-65 shows the accuracy of the equations by comparing the results from finite element analysis with the developed equations. It should be noted that the barrier length was not considered in these equations since the form of the equation used in the regression analysis led to a power of zero for the barrier length, $\mathrm{L}_{\mathrm{c}}$. It is recommended to propose other equation format so that the barrier length can be included in the equation. 
Table 4-43: Empirical equations for transverse and longitudinal moments in deck slab cantilevers due to CL-625 truck loading

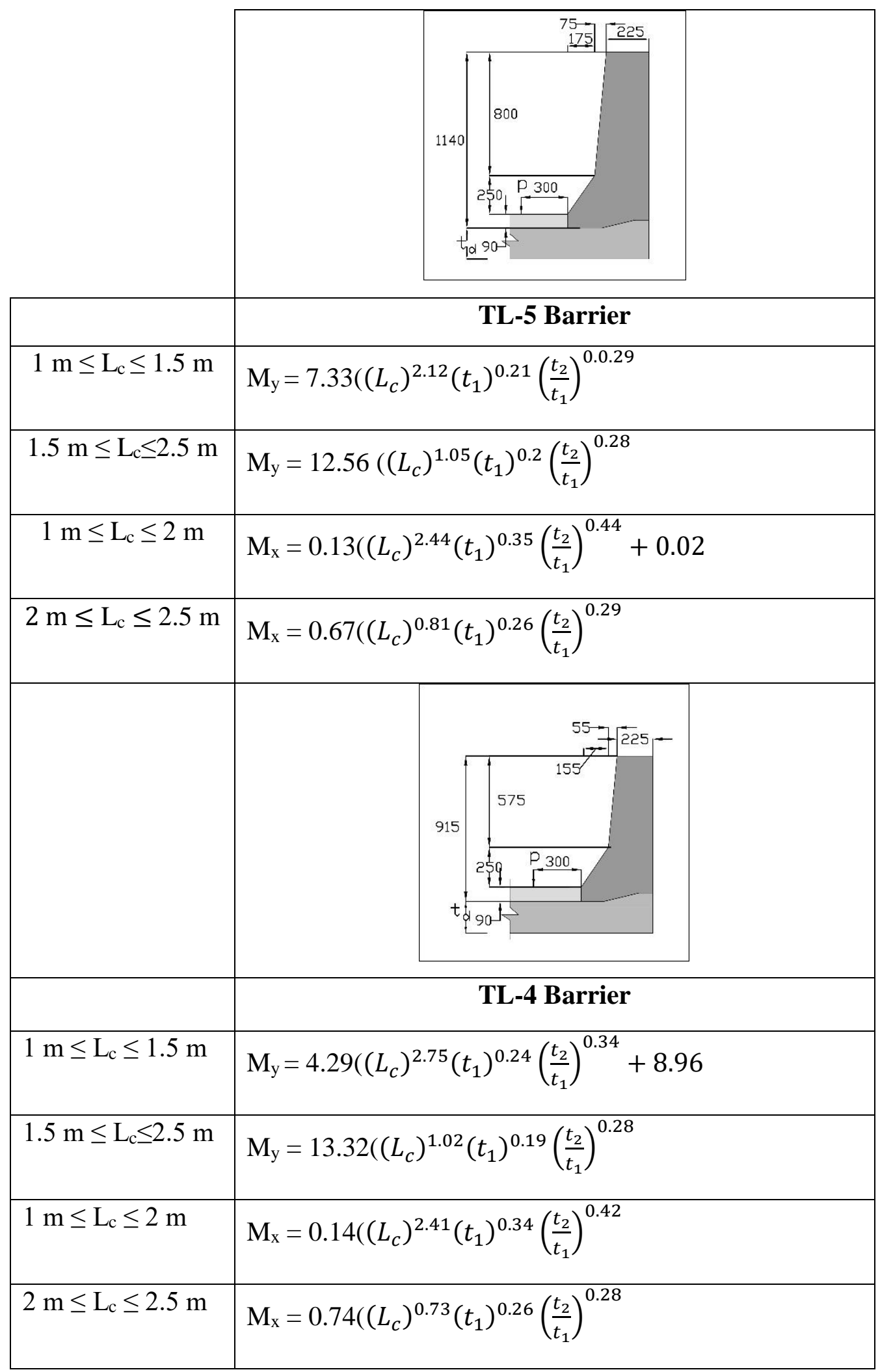




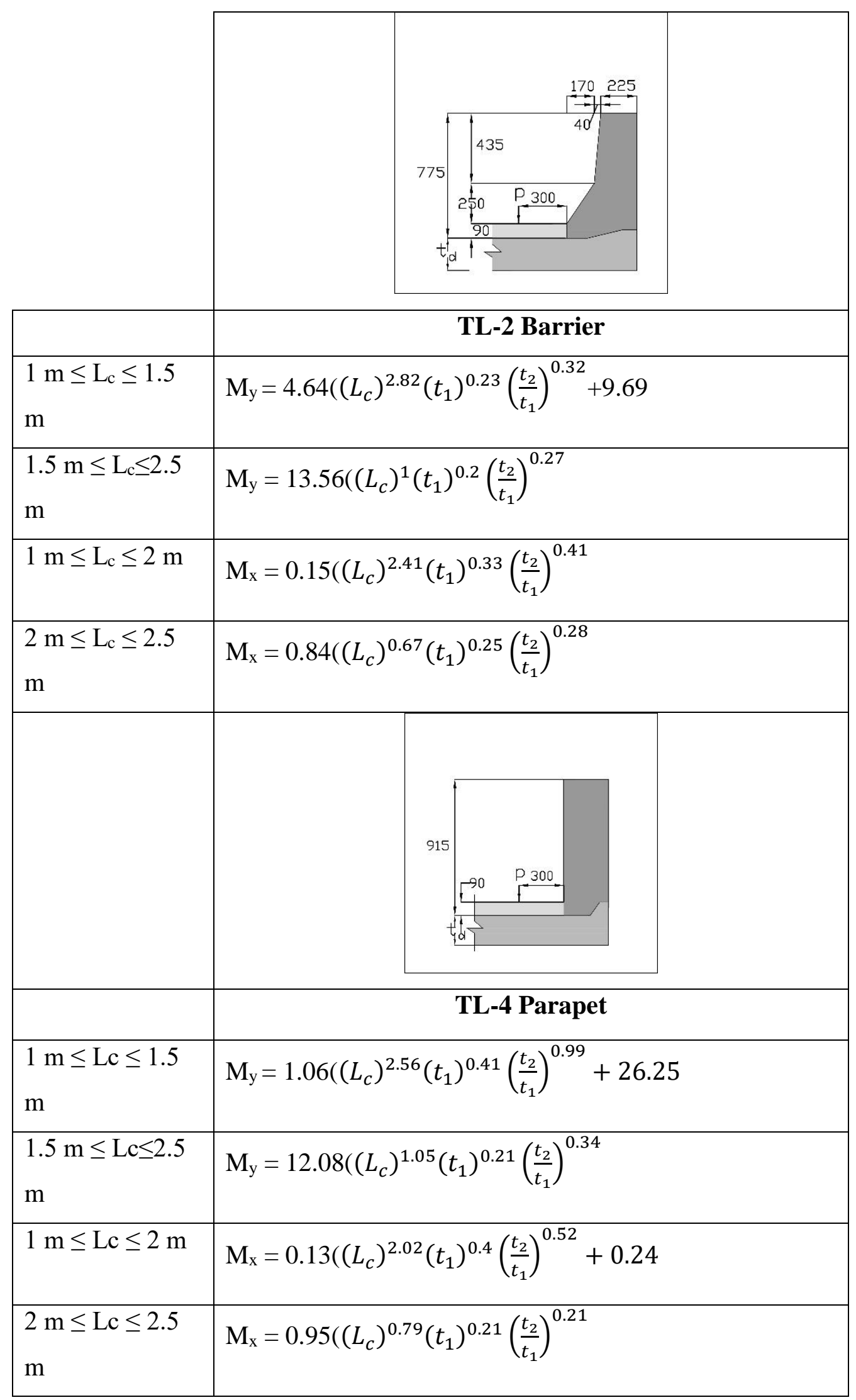




\begin{tabular}{|c|c|}
\hline & Curb \\
\hline $\begin{array}{l}1 \mathrm{~m} \leq \mathrm{Lc} \leq 1.5 \\
\mathrm{~m}\end{array}$ & $\mathrm{M}_{\mathrm{y}}=19.04\left(\left(L_{c}\right)^{1.91}\left(t_{1}\right)^{0.1}\left(\frac{t_{2}}{t_{1}}\right)^{0.2}\right.$ \\
\hline $\begin{array}{l}1.5 \mathrm{~m} \leq \mathrm{Lc} \leq 2.5 \\
\mathrm{~m}\end{array}$ & $\mathrm{M}_{\mathrm{y}}=24.34\left(\left(L_{c}\right)^{0.93}\left(t_{1}\right)^{0.12}\left(\frac{t_{2}}{t_{1}}\right)^{0.22}\right.$ \\
\hline $1 \mathrm{~m} \leq \mathrm{Lc} \leq 2 \mathrm{~m}$ & $\mathrm{M}_{\mathrm{x}}=0.38\left(\left(L_{c}\right)^{2.17}\left(t_{1}\right)^{0.23}\left(\frac{t_{2}}{t_{1}}\right)^{0.31}\right.$ \\
\hline $\begin{array}{l}2 \mathrm{~m} \leq \mathrm{Lc} \leq 2.5 \\
\mathrm{~m}\end{array}$ & $\mathrm{M}_{\mathrm{x}}=1.93\left(\left(L_{c}\right)^{0.37}\left(t_{1}\right)^{0.17}\left(\frac{t_{2}}{t_{1}}\right)^{0.21}\right.$ \\
\hline & Unstiffened Edge \\
\hline $1 \leq \mathrm{L}_{\mathrm{c}}<1.5$ & $\mathrm{M}_{\mathrm{y}}=21.42\left(\left(L_{c}\right)^{2.51}\left(\frac{t_{2}}{t_{1}}\right)^{0.2}+24.16\right.$ \\
\hline $1.5 \leq \mathrm{L}_{\mathrm{c}}<2.5$ & $\mathrm{M}_{\mathrm{y}}=48.02\left(\left(L_{c}\right)^{0.94}\left(\frac{t_{2}}{t_{1}}\right)^{0.18}+13.9\right.$ \\
\hline $1 \leq \mathrm{L}_{\mathrm{c}} \leq 1.5$ & $\mathrm{M}_{\mathrm{x}}=1.78\left(\left(L_{c}\right)^{2.53}\left(\frac{t_{2}}{t_{1}}\right)^{0.19}\right.$ \\
\hline $2<\mathrm{L}_{\mathrm{c}} \leq 2.5$ & $\mathrm{M}_{\mathrm{x}}=5.65\left(\left(L_{c}\right)^{0.51}\left(\frac{t_{2}}{t_{1}}\right)^{0.14}\right.$ \\
\hline
\end{tabular}




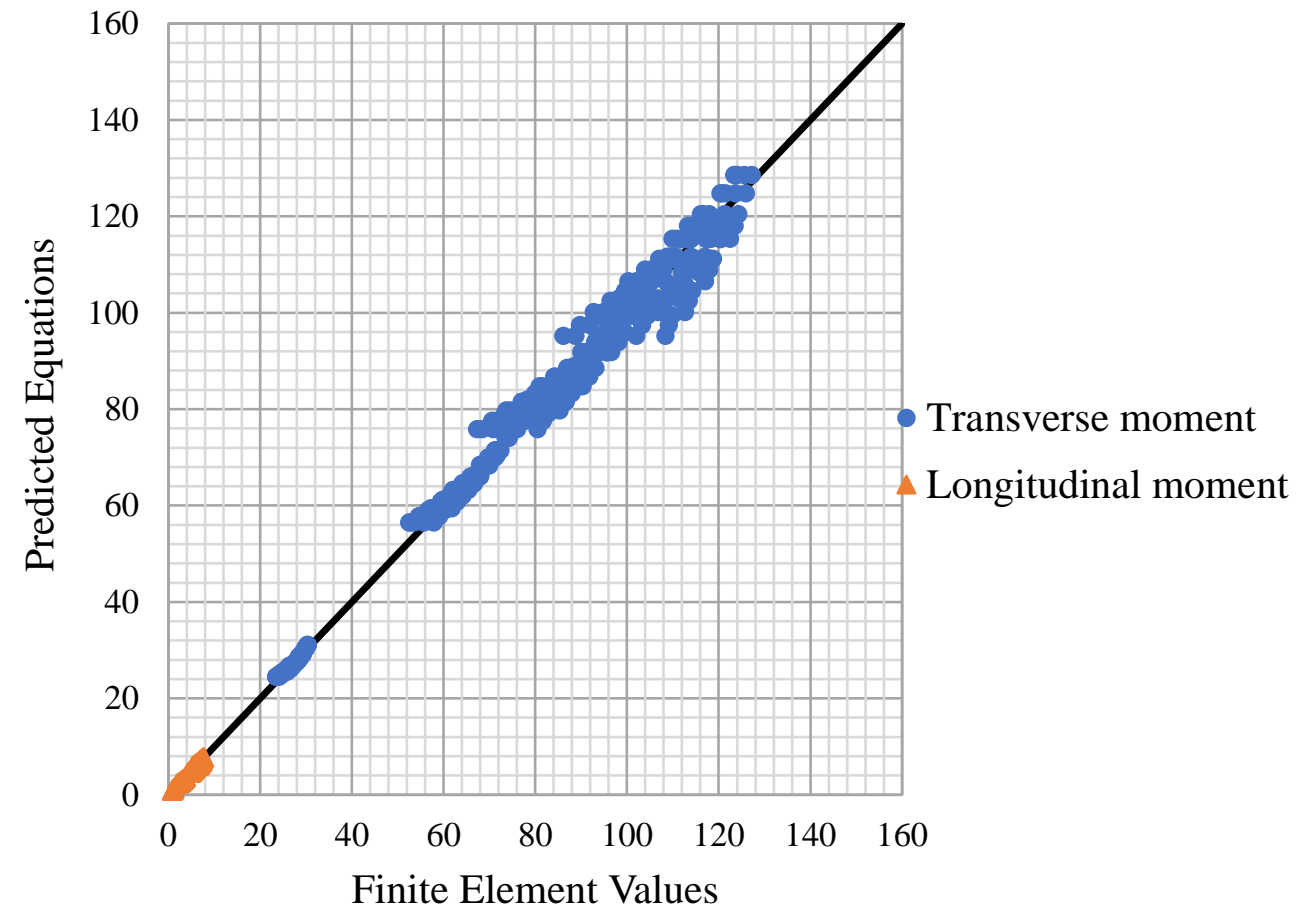

Figure 4-65: FE results versus developed equations for cantilever slab with TL-5 barrier

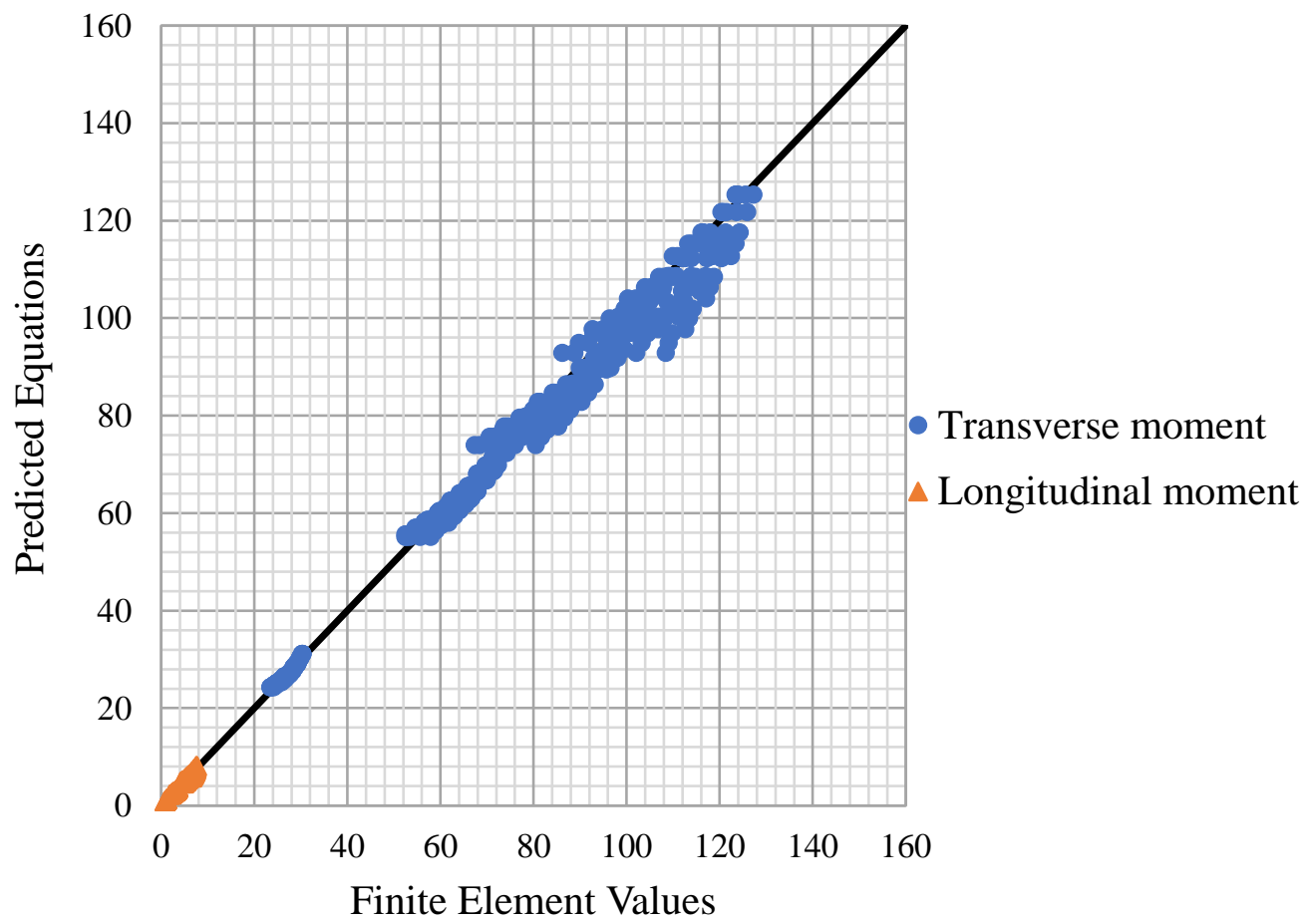

Figure 4-66: FE results versus developed equations for cantilever slab with TL-4 barrier 


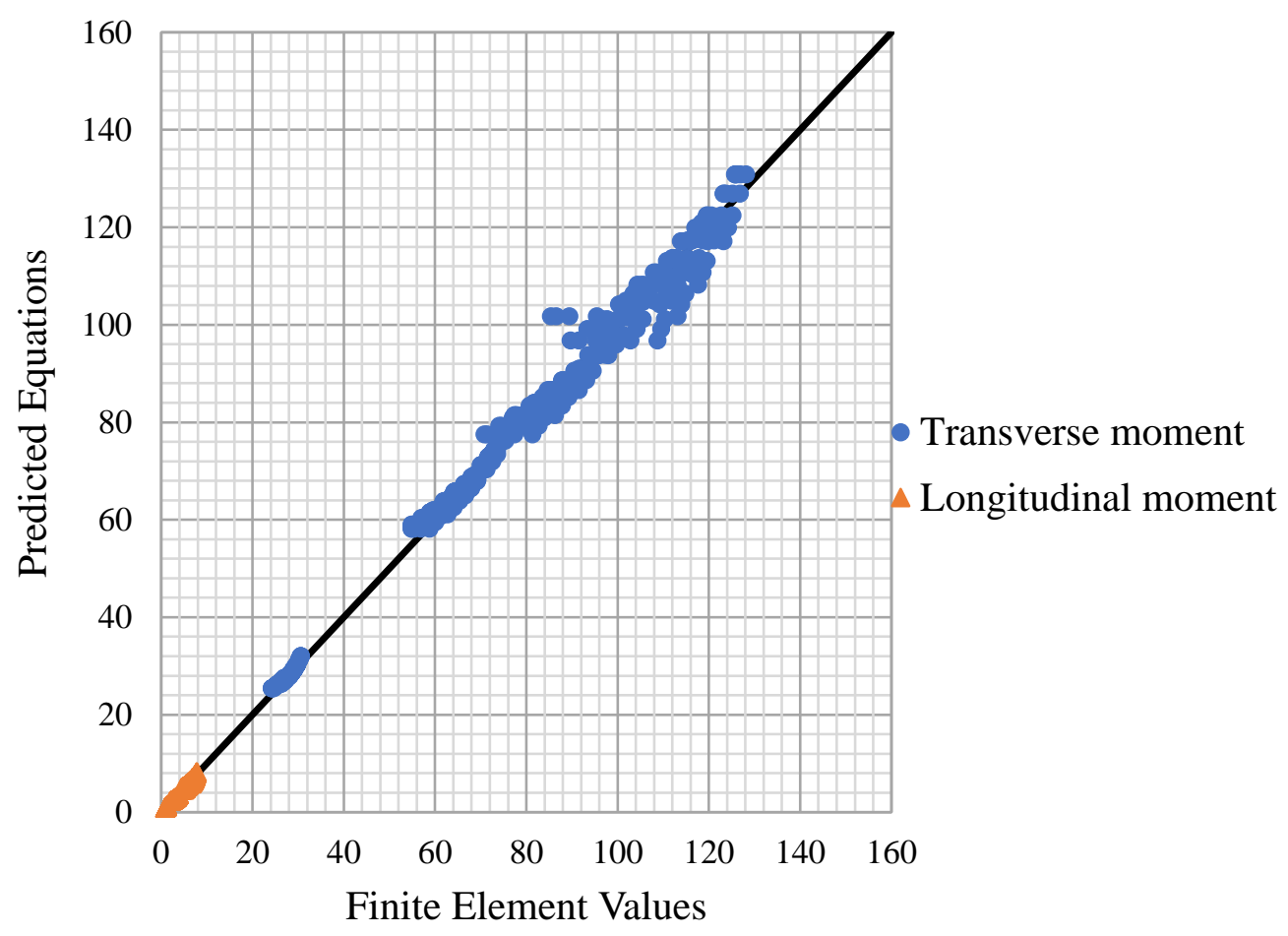

Figure 4-67: FE results versus developed equations for cantilever slab with TL-2 barrier

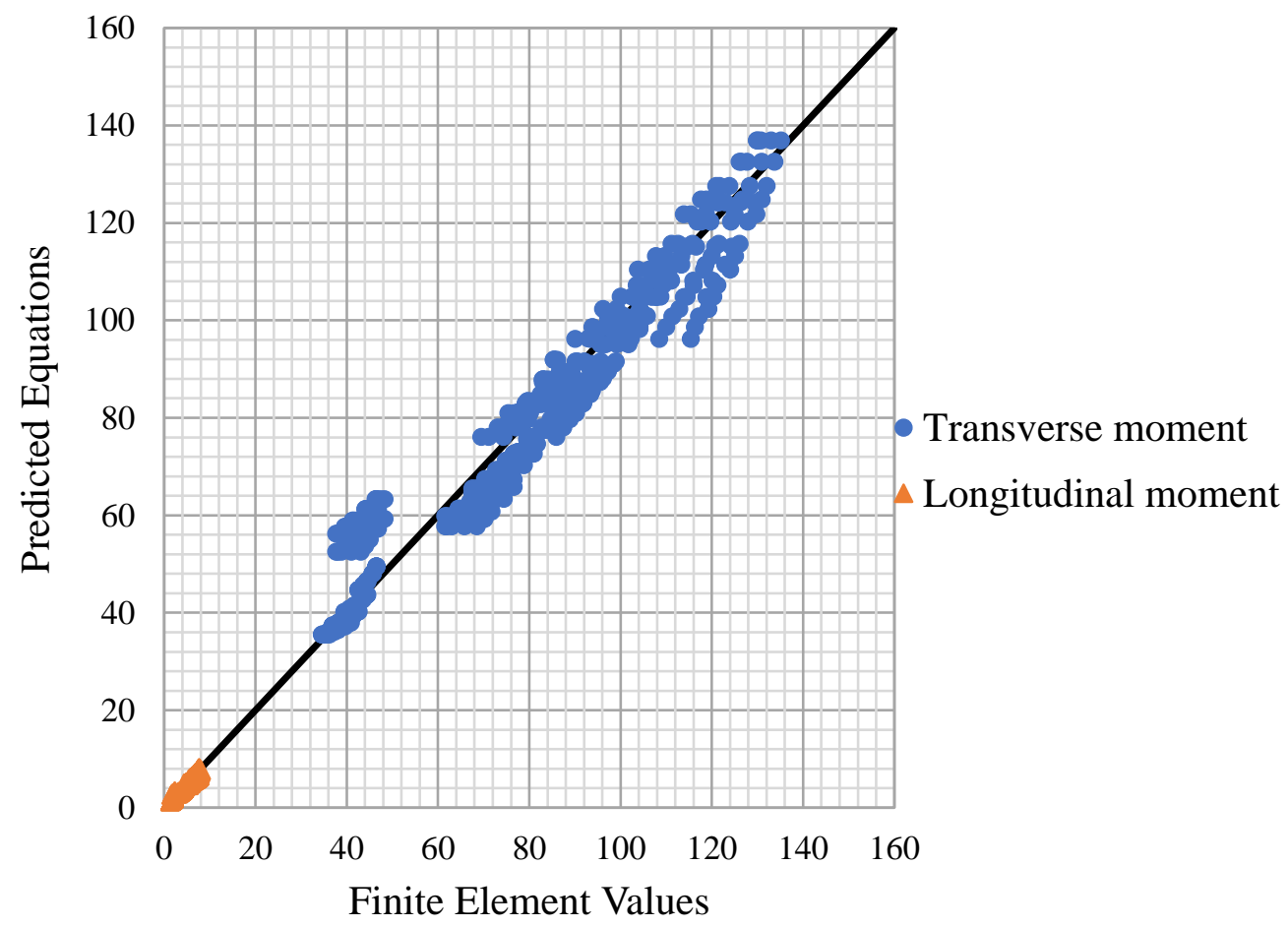

Figure 4-68: FE results versus developed equations for cantilever slab with TL-4 parapet 


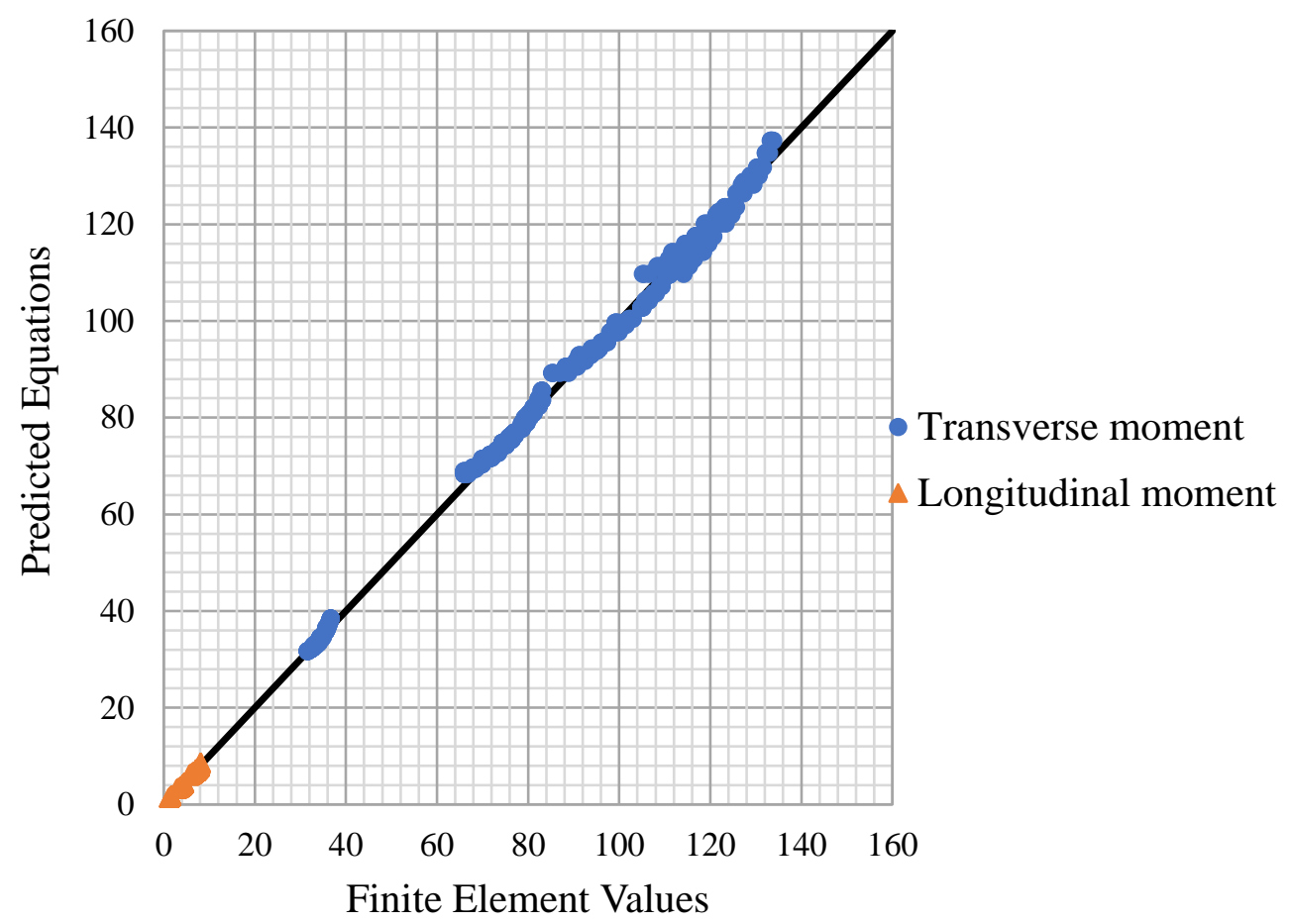

Figure 4-69: FE results versus developed equations for cantilever slab with curb

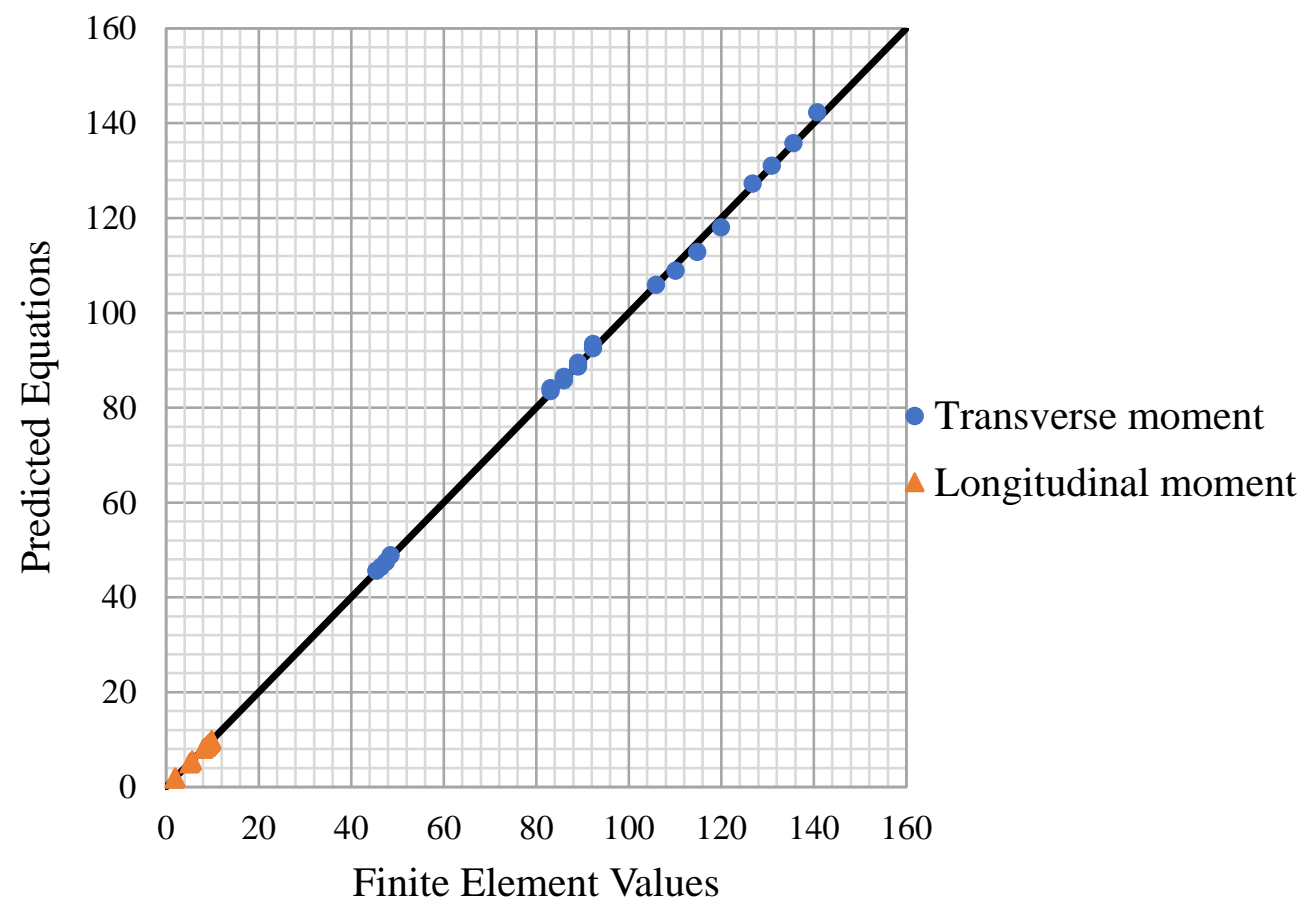

Figure 4-70: FE results versus developed equations for cantilever slab with unstiffened edge 


\section{CHAPTER FIVE}

\section{CONCLUSIONS AND RECOMMENDATIONS FOR FUTURE RESEARCH}

\subsection{General}

Clause 5.7.1.3 of the Canadian Highway Bridge Design Code of 2014 proposed an equation for the calculation of the transverse moment in deck slab cantilever due to truck loading at middle portion of cantilever overhang, in addition, it states at the location within the distance of equal to the cantilever of transverse free edge of the slab, the transverse moment intensity shall be assumed twice times the transverse moment obtained from the above mention equation. However, it does not consider the effect of length of barrier wall and slab thickness. In addition, the amount of the longitudinal moment in the deck slab cantilever is as yet unavailable. As a result, a practical parametric study was conducted utilizing the finite-element software SAP2000 to investigate the structural response of the cantilever overhang, when subjected to truck load at its free edge. The key parameters considered in this study included, barrier length, cantilever length, slab thickness, tapered slab thickness ratio, different end stiffening arrangements.

\subsection{Conclusion}

Based on the results from parametric study, the following conclusions would be drawn as follows:

1. The maximum moment intensity due to applying CHBDC truck loading for both unstiffened and stiffened edge slabs occurs at the root of cantilever slab (i.e. fixed edge) near the transverse free edge (i.e. where load applied).

2. The maximum moment intensity in both transverse and longitudinal direction induced by axel 4 which is the heaviest axel of CL-625 truck, although for the cantilever length of 2.5 $\mathrm{m}$, two axels (axels 2,3 ) produce the maximum moment intensity in both direction.

3. The moment in the longitudinal direction is very small when compared with transverse direction. 
4. End stiffening barrier plays a key role in reducing both the transverse and longitudinal moments.

5. Increasing barrier length does not have effect on moment intensity created in the unstiffened slab. Thus, the moment intensity obtained from this study can be directly compared with the corresponding value in the CHBDC of 2014 for unstiffened slab, since the effect of the barrier length is not considered by CHBDC. However, the trend is different for edge-stiffened slabs. The increase in barrier length reduces the transverse moment intensity up to $24 \%$ when TL-5 barrier applied.

6. The peak value of the moment does not change by increasing the slab thickness for unstiffened slabs, nonetheless, the value increased when end stiffened barriers considered, and the rate of change is higher for the slabs with constant thickness. Similarly, increasing the slab tapered slab thickness ratio has similar effect on increasing the moment intensity.

7. Increasing cantilever length resulted in increasing the moment intensity.

8. The comparison of obtained results with corresponding results from CHBDC for the unstiffened slab demonstrates that CHBDC overestimates the results for cantilever length of $1 \mathrm{~m}$ by almost $45 \%$.

9. The calculated ratio of external moments generated from this research to corresponding internal moments obtained from Micovic (2016) using finite elements method shows that this ratio in some cases exceeds 2 , especially for cantilever length of equal or over $1.5 \mathrm{~m}$. As a result, it can be said that the CHBDC underestimates the external moment by taking it as the twice value of the internal moment $\left(\mathrm{M}_{\mathrm{y}}\right)$.

10. The empirical equations were developed based on data generated from the parametric study to best fit the data. The developed equation includes few key parameters including cantilever length, barrier length, slab thickness and tapered slab thickness ratio. It should be noted that the barrier length was not considered in these equations since the form of the equation used in the regression analysis led to a power of zero for the barrier length, Lc. It is recommended to propose other equation format so that the barrier length can be included in the equation. 


\subsection{Recommendation for Future Research}

$>$ Study the moment intensity in deck slab cantilever due to AASHTO-LRFD truck loading conditions.

$>$ Revisit the developed equations in this thesis to include the effect of the barrier length in the response.

$>$ Develop equations for the maximum deflection due to CHBDC truck load at free edge of cantilever slab. 


\section{Appendix (A): $\quad$ Summary of Parametric Study}


Table A-1: Summary of Maximum deflection, Transverse Moment and Longitudinal Moment in Unstiffened Cantilevered Slab of Length $1 \mathrm{~m}$

\begin{tabular}{|c|c|c|c|c|c|c|}
\hline \multicolumn{7}{|c|}{ Cantilever length: $1.0 \mathrm{~m}$} \\
\hline \multirow{2}{*}{$\begin{array}{c}\text { Barrier length } \\
\text { (m) }\end{array}$} & \multicolumn{2}{|c|}{ S Slab thickness } & \multirow[t]{2}{*}{$\mathbf{t}_{2} / \mathbf{t}_{1}$} & \multirow{2}{*}{$\begin{array}{c}\Delta \\
(\mathbf{m m})\end{array}$} & \multirow{2}{*}{$\begin{array}{c}M_{\mathbf{y}} \\
(\mathbf{k N} \cdot \mathbf{m m} / \mathbf{m m})\end{array}$} & \multirow{2}{*}{$\begin{array}{c}\mathbf{M}_{\mathbf{x}} \\
(\mathbf{k N} \cdot \mathbf{m m} / \mathbf{m m})\end{array}$} \\
\hline & $\mathbf{t}_{1}(\mathbf{m m})$ & $\mathbf{t}_{2}(\mathbf{m m})$ & & & & \\
\hline \multirow{20}{*}{5} & 200 & 200 & 1 & -0.41 & -45.48 & -1.73 \\
\hline & & 240 & 1.2 & -0.27 & -46.51 & -1.83 \\
\hline & & 300 & 1.5 & -0.16 & -47.54 & -1.93 \\
\hline & & 400 & 2 & -0.08 & -48.56 & -2.06 \\
\hline & 225 & 225 & 1 & -0.28 & -45.48 & -1.73 \\
\hline & & 270 & 1.2 & -0.19 & -46.51 & -1.83 \\
\hline & & 337.5 & 1.5 & -0.11 & -47.54 & -1.93 \\
\hline & & 450 & 2 & -0.05 & -48.56 & -2.06 \\
\hline & 250 & 250 & 1 & -0.21 & -45.48 & -1.73 \\
\hline & & 300 & 1.2 & -0.14 & -46.51 & -1.83 \\
\hline & & 375 & 1.5 & -0.08 & -47.54 & -1.93 \\
\hline & & 500 & 2 & -0.04 & -48.56 & -2.06 \\
\hline & 300 & 300 & 1 & -0.12 & -45.48 & -1.73 \\
\hline & & 360 & 1.2 & -0.08 & -46.51 & -1.83 \\
\hline & & 450 & 1.5 & -0.05 & -47.54 & -1.93 \\
\hline & & 600 & 2 & -0.02 & -48.56 & -2.06 \\
\hline & 350 & 350 & 1 & -0.08 & -45.48 & -1.73 \\
\hline & & 420 & 1.2 & -0.05 & -46.51 & -1.83 \\
\hline & & 525 & 1.5 & -0.03 & -47.54 & -1.93 \\
\hline & & 700 & 2 & -0.01 & -48.56 & -2.06 \\
\hline \multirow{20}{*}{6} & 200 & 200 & 1 & -0.41 & -45.48 & -1.73 \\
\hline & & 240 & 1.2 & -0.27 & -46.51 & -1.83 \\
\hline & & 300 & 1.5 & -0.16 & -47.54 & -1.93 \\
\hline & & 400 & 2 & -0.08 & -48.56 & -2.06 \\
\hline & 225 & 225 & 1 & -0.28 & -45.48 & -1.73 \\
\hline & & 270 & 1.2 & -0.19 & -46.51 & -1.83 \\
\hline & & 337.5 & 1.5 & -0.11 & -47.54 & -1.93 \\
\hline & & 450 & 2 & -0.05 & -48.56 & -2.06 \\
\hline & 250 & 250 & 1 & -0.21 & -45.48 & -1.73 \\
\hline & & 300 & 1.2 & -0.14 & -46.51 & -1.83 \\
\hline & & 375 & 1.5 & -0.08 & -47.54 & -1.93 \\
\hline & & 500 & 2 & -0.04 & -48.56 & -2.06 \\
\hline & 300 & 300 & 1 & -0.12 & -45.48 & -1.73 \\
\hline & & 360 & 1.2 & -0.08 & -46.51 & -1.83 \\
\hline & & 450 & 1.5 & -0.05 & -47.54 & -1.93 \\
\hline & & 600 & 2 & -0.02 & -48.56 & -2.06 \\
\hline & 350 & 350 & 1 & -0.08 & -45.48 & -1.73 \\
\hline & & 420 & 1.2 & -0.05 & -46.51 & -1.83 \\
\hline & & 525 & 1.5 & -0.03 & -47.54 & -1.93 \\
\hline & & 700 & 2 & -0.01 & -48.56 & -2.06 \\
\hline
\end{tabular}




\begin{tabular}{|c|c|c|c|c|c|c|}
\hline \multicolumn{7}{|c|}{ Cantilever length: $1.0 \mathrm{~m}$} \\
\hline \multirow{2}{*}{$\begin{array}{l}\text { Barrier length } \\
(\mathrm{m})\end{array}$} & \multicolumn{2}{|c|}{ Slab thickness } & \multirow[t]{2}{*}{$\mathbf{t}_{2} / \mathbf{t}_{1}$} & \multirow{2}{*}{$\underset{(\mathbf{m m})}{\Delta}$} & \multirow{2}{*}{$\begin{array}{c}\mathbf{M}_{\mathbf{y}} \\
(\mathbf{k N} \cdot \mathbf{m m} / \mathbf{m m})\end{array}$} & \multirow{2}{*}{$\begin{array}{c}\mathbf{M}_{\mathbf{x}} \\
(\mathbf{k N} \cdot \mathbf{m m} / \mathbf{m m})\end{array}$} \\
\hline & $\mathbf{t}_{\mathbf{1}}(\mathbf{m m})$ & $\mathbf{t}_{2}(\mathbf{m m})$ & & & & \\
\hline \multirow{20}{*}{8} & 200 & 200 & 1 & -0.41 & -45.48 & -1.73 \\
\hline & & 240 & 1.2 & -0.27 & -46.51 & -1.83 \\
\hline & & 300 & 1.5 & -0.16 & -47.54 & -1.93 \\
\hline & & 400 & 2 & -0.08 & -48.56 & -2.06 \\
\hline & 225 & 225 & 1 & -0.28 & -45.48 & -1.73 \\
\hline & & 270 & 1.2 & -0.19 & -46.51 & -1.83 \\
\hline & & 337.5 & 1.5 & -0.11 & -47.54 & -1.93 \\
\hline & & 450 & 2 & -0.05 & -48.56 & -2.06 \\
\hline & 250 & 250 & 1 & -0.21 & -45.48 & -1.73 \\
\hline & & 300 & 1.2 & -0.14 & -46.51 & -1.83 \\
\hline & & 375 & 1.5 & -0.08 & -47.54 & -1.93 \\
\hline & & 500 & 2 & -0.04 & -48.56 & -2.06 \\
\hline & 300 & 300 & 1 & -0.12 & -45.48 & -1.73 \\
\hline & & 360 & 1.2 & -0.08 & -46.51 & -1.83 \\
\hline & & 450 & 1.5 & -0.05 & -47.54 & -1.93 \\
\hline & & 600 & 2 & $\begin{array}{l}-0.02 \\
\end{array}$ & -48.56 & -2.06 \\
\hline & 350 & 350 & 1 & -0.08 & -45.48 & -1.73 \\
\hline & & 420 & 1.2 & -0.05 & -46.51 & -1.83 \\
\hline & & 525 & 1.5 & -0.03 & -47.54 & -1.93 \\
\hline & & 700 & 2 & -0.01 & -48.56 & -2.06 \\
\hline \multirow{20}{*}{10} & 200 & 200 & 1 & -0.41 & -45.48 & -1.73 \\
\hline & & 240 & 1.2 & -0.27 & -46.51 & -1.83 \\
\hline & & 300 & 1.5 & -0.16 & -47.54 & -1.93 \\
\hline & & 400 & 2 & $\begin{array}{l}-0.08 \\
\end{array}$ & -48.56 & -2.06 \\
\hline & 225 & 225 & 1 & -0.28 & -45.48 & -1.73 \\
\hline & & 270 & 1.2 & -0.19 & -46.51 & -1.83 \\
\hline & & 337.5 & 1.5 & -0.11 & -47.54 & -1.93 \\
\hline & & 450 & 2 & -0.05 & -48.56 & -2.06 \\
\hline & 250 & 250 & 1 & -0.21 & -45.48 & -1.73 \\
\hline & & 300 & 1.2 & -0.14 & -46.51 & -1.83 \\
\hline & & 375 & 1.5 & -0.08 & -47.54 & -1.93 \\
\hline & & 500 & 2 & -0.04 & -48.56 & -2.06 \\
\hline & 300 & 300 & 1 & -0.12 & -45.48 & -1.73 \\
\hline & & 360 & 1.2 & -0.08 & -46.51 & -1.83 \\
\hline & & 450 & 1.5 & -0.05 & -47.54 & -1.93 \\
\hline & & 600 & 2 & -0.02 & -48.56 & -2.06 \\
\hline & 350 & 350 & 1 & -0.08 & -45.48 & -1.73 \\
\hline & & 420 & 1.2 & -0.05 & -46.51 & -1.83 \\
\hline & & 525 & 1.5 & -0.03 & -47.54 & -1.93 \\
\hline & & 700 & 2 & -0.01 & -48.56 & -2.06 \\
\hline
\end{tabular}




\begin{tabular}{|c|c|c|c|c|c|c|}
\hline \multicolumn{7}{|c|}{ Cantilever length: $1.0 \mathrm{~m}$} \\
\hline \multirow{2}{*}{$\begin{array}{c}\text { Barrier length } \\
(\mathrm{m})\end{array}$} & \multicolumn{2}{|c|}{ Slab thickness } & \multirow[t]{2}{*}{$\overline{\mathbf{t}_{2} / \mathbf{t}_{1}}$} & \multirow{2}{*}{$\begin{array}{c}\boldsymbol{\Delta} \\
(\mathbf{m m})\end{array}$} & \multirow{2}{*}{$\begin{array}{c}\mathbf{M}_{\mathbf{y}} \\
(\mathbf{k N} \cdot \mathbf{m m} / \mathbf{m m})\end{array}$} & \multirow{2}{*}{$\begin{array}{c}\mathbf{M}_{\mathbf{x}} \\
(\mathbf{k N} \cdot \mathbf{m m} / \mathbf{m m})\end{array}$} \\
\hline & $\mathbf{t}_{\mathbf{1}}(\mathbf{m m})$ & $\mathbf{t}_{2}(\mathrm{~mm})$ & & & & \\
\hline \multirow{20}{*}{12} & 200 & 200 & 1 & -0.41 & -45.48 & -1.73 \\
\hline & & 240 & 1.2 & -0.27 & -46.51 & -1.83 \\
\hline & & 300 & 1.5 & -0.16 & -47.54 & -1.93 \\
\hline & & 400 & 2 & -0.08 & -48.56 & -2.06 \\
\hline & 225 & 225 & 1 & -0.28 & -45.48 & -1.73 \\
\hline & & 270 & 1.2 & -0.19 & -46.51 & -1.83 \\
\hline & & 337.5 & 1.5 & -0.11 & -47.54 & -1.93 \\
\hline & & 450 & 2 & -0.05 & -48.56 & -2.06 \\
\hline & 250 & 250 & 1 & -0.21 & -45.48 & -1.73 \\
\hline & & 300 & 1.2 & -0.14 & -46.51 & -1.83 \\
\hline & & 375 & 1.5 & -0.08 & -47.54 & -1.93 \\
\hline & & 500 & 2 & -0.04 & -48.56 & -2.06 \\
\hline & 300 & 300 & 1 & -0.12 & -45.48 & -1.73 \\
\hline & & 360 & 1.2 & -0.08 & -46.51 & -1.83 \\
\hline & & 450 & 1.5 & -0.05 & -47.54 & -1.93 \\
\hline & & 600 & 2 & -0.02 & -48.56 & -2.06 \\
\hline & 350 & 350 & 1 & -0.08 & -45.48 & -1.73 \\
\hline & & 420 & 1.2 & -0.05 & -46.51 & -1.83 \\
\hline & & 525 & 1.5 & -0.03 & -47.54 & -1.93 \\
\hline & & 700 & 2 & -0.01 & -48.56 & -2.06 \\
\hline
\end{tabular}


Table A-2: Summary of Maximum deflection, Transverse Moment and Longitudinal Moment in Unstiffened Cantilevered Slab of Length 1.5m

\begin{tabular}{|c|c|c|c|c|c|c|}
\hline \multicolumn{7}{|c|}{ Cantilever length: $1.5 \mathrm{~m}$} \\
\hline \multirow{2}{*}{$\begin{array}{c}\text { Barrier length } \\
\text { (m) }\end{array}$} & \multicolumn{2}{|c|}{ Slab thickness } & \multirow{3}{*}{$\begin{array}{c}\mathbf{t}_{2} / \mathbf{t}_{\mathbf{1}} \\
\\
1 \\
1\end{array}$} & \multirow{3}{*}{$\begin{array}{c}\begin{array}{c}\Delta \\
(\mathbf{m m})\end{array} \\
-2.01 \\
\end{array}$} & \multirow{3}{*}{$\begin{array}{c}\mathbf{M}_{\mathbf{y}} \\
(\mathbf{k N} \cdot \mathbf{m m} / \mathbf{m m}) \\
-83.08 \\
\end{array}$} & \multirow{3}{*}{ 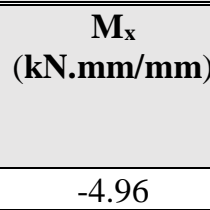 } \\
\hline & $\mathbf{t}_{\mathbf{1}}(\mathbf{m m})$ & $\mathbf{t}_{2}(\mathrm{~mm})$ & & & & \\
\hline \multirow{20}{*}{5} & 200 & 200 & & & & \\
\hline & & 240 & 1.2 & -1.36 & -85.99 & -5.16 \\
\hline & & 300 & 1.5 & -0.83 & -89.08 & \begin{tabular}{|l|}
-5.38 \\
\end{tabular} \\
\hline & & 400 & 2 & -0.42 & -92.32 & -5.62 \\
\hline & 225 & 225 & 1 & -1.41 & -83.08 & -4.96 \\
\hline & & 270 & 1.2 & -0.96 & -85.99 & -5.16 \\
\hline & & 337.5 & 1.5 & -0.58 & -89.08 & -5.38 \\
\hline & & 450 & 2 & -0.30 & -92.32 & -5.62 \\
\hline & 250 & 250 & 1 & -1.03 & -83.08 & -4.96 \\
\hline & & 300 & 1.2 & -0.70 & -85.99 & -5.16 \\
\hline & & 375 & 1.5 & -0.42 & -89.08 & -5.38 \\
\hline & & 500 & 2 & -0.22 & -92.32 & -5.62 \\
\hline & 300 & 300 & 1 & -0.60 & -83.08 & -4.96 \\
\hline & & 360 & 1.2 & -0.40 & -85.99 & -5.16 \\
\hline & & 450 & 1.5 & -0.25 & -89.08 & -5.38 \\
\hline & & 600 & 2 & -0.13 & -92.32 & -5.62 \\
\hline & 350 & 350 & 1 & -0.38 & -83.08 & -4.96 \\
\hline & & 420 & 1.2 & -0.25 & -85.99 & -5.16 \\
\hline & & 525 & 1.5 & -0.25 & -89.08 & -5.38 \\
\hline & & 700 & 2 & -0.08 & -92.32 & -5.62 \\
\hline \multirow{20}{*}{6} & 200 & 200 & 1 & -2.01 & -83.08 & -4.96 \\
\hline & & 240 & 1.2 & -1.36 & -85.99 & -5.16 \\
\hline & & 300 & 1.5 & -0.83 & -89.07 & -5.38 \\
\hline & & 400 & 2 & -0.42 & -92.32 & -5.62 \\
\hline & 225 & 225 & 1 & -1.41 & -83.08 & -4.96 \\
\hline & & 270 & 1.2 & -0.96 & -85.99 & -5.16 \\
\hline & & 337.5 & 1.5 & -0.58 & -89.07 & -5.38 \\
\hline & & 450 & 2 & -0.30 & -92.32 & -5.62 \\
\hline & 250 & 250 & 1 & -1.03 & -83.08 & -4.96 \\
\hline & & 300 & 1.2 & -0.70 & -85.99 & -5.16 \\
\hline & & 375 & 1.5 & -0.42 & -89.07 & -5.38 \\
\hline & & 500 & 2 & -0.22 & -92.32 & -5.62 \\
\hline & 300 & 300 & 1 & -0.60 & -83.08 & -4.96 \\
\hline & & 360 & 1.2 & -0.40 & -85.99 & -5.16 \\
\hline & & 450 & 1.5 & -0.25 & -89.07 & -5.38 \\
\hline & & 600 & 2 & -0.13 & -92.32 & -5.62 \\
\hline & 350 & 350 & 1 & -0.37 & -83.08 & -4.96 \\
\hline & & 420 & 1.2 & -0.25 & -85.99 & -5.16 \\
\hline & & 525 & 1.5 & -0.25 & -89.07 & $\begin{array}{l}-5.38 \\
\end{array}$ \\
\hline & & 700 & 2 & -0.08 & -92.32 & -5.62 \\
\hline
\end{tabular}




\begin{tabular}{|c|c|c|c|c|c|c|}
\hline \multicolumn{7}{|c|}{ "Cantilever length: $1.5 \mathrm{~m}$} \\
\hline \multirow{2}{*}{$\begin{array}{l}\text { Barrier length } \\
(\mathrm{m})\end{array}$} & \multicolumn{2}{|c|}{ Slab thickness } & \multirow[t]{2}{*}{$\mathbf{t}_{2} / \mathbf{t}_{1}$} & \multirow{2}{*}{$\begin{array}{c}\Delta \\
(\mathbf{m m})\end{array}$} & \multirow{2}{*}{$\begin{array}{c}\mathbf{M}_{\mathbf{y}} \\
(\mathbf{k N} \cdot \mathbf{m m} / \mathbf{m m})\end{array}$} & \multirow{2}{*}{$\begin{array}{c}\mathbf{M}_{\mathbf{x}} \\
(\mathbf{k N} \cdot \mathbf{m m} / \mathbf{m m})\end{array}$} \\
\hline & $\mathbf{t}_{\mathbf{1}}(\mathbf{m m})$ & $\mathbf{t}_{2}(\mathbf{m m})$ & & & & \\
\hline \multirow{20}{*}{8} & 200 & 200 & 1 & -2.01 & -83.07 & -4.96 \\
\hline & & 240 & 1.2 & -1.36 & -85.99 & -5.16 \\
\hline & & 300 & 1.5 & -0.83 & -89.07 & -5.38 \\
\hline & & 400 & 2 & -0.42 & -92.32 & -5.62 \\
\hline & 225 & 225 & 1 & -1.41 & -83.07 & -4.96 \\
\hline & & 270 & 1.2 & -0.96 & -85.99 & -5.16 \\
\hline & & 337.5 & 1.5 & -0.58 & -89.07 & -5.38 \\
\hline & & 450 & 2 & -0.30 & -92.32 & -5.62 \\
\hline & 250 & 250 & 1 & -1.03 & -83.07 & -4.96 \\
\hline & & 300 & 1.2 & -0.70 & -85.99 & -5.16 \\
\hline & & 375 & 1.5 & -0.42 & -89.07 & -5.38 \\
\hline & & 500 & 2 & -0.22 & -92.32 & -5.62 \\
\hline & 300 & 300 & 1 & -0.60 & -83.07 & -4.96 \\
\hline & & 360 & 1.2 & -0.40 & -85.99 & -5.16 \\
\hline & & 450 & 1.5 & -0.25 & -89.07 & -5.38 \\
\hline & & 600 & 2 & -0.13 & -92.32 & -5.62 \\
\hline & 350 & 350 & 1 & -0.37 & -83.07 & -4.96 \\
\hline & & 420 & 1.2 & -0.25 & -85.99 & -5.16 \\
\hline & & 525 & 1.5 & -0.25 & -89.07 & -5.38 \\
\hline & & 700 & 2 & -0.08 & -92.32 & -5.62 \\
\hline \multirow{20}{*}{10} & 200 & 200 & 1 & -2.01 & -83.07 & -4.96 \\
\hline & & 240 & 1.2 & -1.36 & -85.99 & -5.16 \\
\hline & & 300 & 1.5 & -0.83 & -89.07 & -5.38 \\
\hline & & 400 & 2 & -0.42 & -92.32 & -5.62 \\
\hline & 225 & 225 & 1 & -1.41 & -83.07 & -4.96 \\
\hline & & 270 & 1.2 & -0.96 & -85.99 & -5.16 \\
\hline & & 337.5 & 1.5 & -0.58 & -89.07 & -5.38 \\
\hline & & 450 & 2 & -0.30 & -92.32 & -5.62 \\
\hline & 250 & 250 & 1 & -1.03 & -83.07 & -4.96 \\
\hline & & 300 & 1.2 & -0.70 & -85.99 & -5.16 \\
\hline & & 375 & 1.5 & -0.42 & -89.07 & -5.38 \\
\hline & & 500 & 2 & -0.22 & -92.32 & -5.62 \\
\hline & 300 & 300 & 1 & -0.60 & -83.07 & -4.96 \\
\hline & & 360 & 1.2 & -0.40 & -85.99 & -5.16 \\
\hline & & 450 & 1.5 & -0.25 & -89.07 & -5.38 \\
\hline & & 600 & 2 & -0.13 & -92.32 & $\begin{array}{l}-5.62 \\
\end{array}$ \\
\hline & 350 & 350 & 1 & -0.37 & -83.07 & -4.96 \\
\hline & & 420 & 1.2 & -0.25 & -85.99 & -5.16 \\
\hline & & 525 & 1.5 & -0.25 & -89.07 & -5.38 \\
\hline & & 700 & 2 & -0.08 & -92.32 & -5.62 \\
\hline
\end{tabular}




\begin{tabular}{|c|c|c|c|c|c|c|}
\hline \multicolumn{7}{|c|}{ Cantilever length: $1.5 \mathrm{~m}$} \\
\hline \multirow{2}{*}{$\begin{array}{c}\text { Barrier length } \\
(\mathbf{m})\end{array}$} & \multicolumn{2}{|c|}{ Slab thickness } & \multirow{3}{*}{$\begin{array}{c}\mathbf{t}_{2} / \mathbf{t}_{1} \\
\\
1\end{array}$} & \multirow{3}{*}{$\begin{array}{c}\begin{array}{c}\Delta \\
(\mathbf{m m})\end{array} \\
-2.01\end{array}$} & \multirow{3}{*}{ 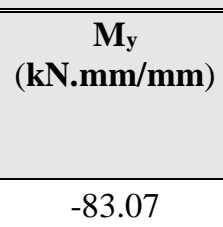 } & \multirow{3}{*}{$\begin{array}{c}\begin{array}{c}\mathbf{M}_{\mathbf{x}} \\
(\mathbf{k N} \cdot \mathbf{m m} / \mathbf{m m})\end{array} \\
-4.96\end{array}$} \\
\hline & $\overline{\mathbf{t}_{\mathbf{1}}(\mathbf{m m})}$ & $\overline{\mathbf{t}_{2}(\mathbf{m m})}$ & & & & \\
\hline \multirow{20}{*}{12} & 200 & 200 & & & & \\
\hline & & 240 & 1.2 & -1.36 & -85.99 & -5.16 \\
\hline & & 300 & 1.5 & -0.83 & -89.07 & -5.38 \\
\hline & & 400 & 2 & -0.42 & -92.32 & -5.62 \\
\hline & 225 & 225 & 1 & -1.41 & -83.07 & -4.96 \\
\hline & & 270 & 1.2 & -0.96 & -85.99 & -5.16 \\
\hline & & 337.5 & 1.5 & -0.58 & -89.07 & -5.38 \\
\hline & & 450 & 2 & -0.30 & -92.32 & -5.62 \\
\hline & 250 & 250 & 1 & -1.03 & -83.07 & -4.96 \\
\hline & & 300 & 1.2 & -0.70 & -85.99 & -5.16 \\
\hline & & 375 & 1.5 & -0.42 & -89.07 & -5.38 \\
\hline & & 500 & 2 & -0.22 & -92.32 & -5.62 \\
\hline & 300 & 300 & 1 & -0.60 & -83.07 & -4.96 \\
\hline & & 360 & 1.2 & -0.40 & -85.99 & -5.16 \\
\hline & & 450 & 1.5 & -0.25 & -89.07 & -5.38 \\
\hline & & 600 & 2 & -0.13 & -92.32 & -5.62 \\
\hline & 350 & 350 & 1 & -0.37 & -83.07 & -4.96 \\
\hline & & 420 & 1.2 & -0.25 & -85.99 & -5.16 \\
\hline & & 525 & 1.5 & -0.25 & -89.07 & -5.38 \\
\hline & & 700 & 2 & -0.08 & -92.32 & -5.62 \\
\hline
\end{tabular}


Table A-3: Summary of Maximum deflection, Transverse Moment and Longitudinal Moment in Unstiffened Cantilevered Slab of Length 2m

\begin{tabular}{|c|c|c|c|c|c|c|}
\hline \multicolumn{7}{|c|}{ Cantilever length: 2 m } \\
\hline \multirow{2}{*}{$\begin{array}{c}\text { Barrier length } \\
(\mathrm{m})\end{array}$} & \multicolumn{2}{|c|}{ Slab thickness } & \multirow{3}{*}{$\begin{array}{c}\mathbf{t}_{\mathbf{2}} / \mathbf{t}_{\mathbf{1}} \\
\\
1\end{array}$} & \multirow{3}{*}{$\begin{array}{c}\begin{array}{c}\Delta \\
(\mathbf{m m})\end{array} \\
-5.01 \\
\end{array}$} & \multirow{3}{*}{$\begin{array}{c}\begin{array}{c}\mathbf{M}_{\mathbf{y}} \\
(\mathbf{k N} \cdot \mathbf{m m} / \mathbf{m m})\end{array} \\
-105.90 \\
\end{array}$} & \multirow{3}{*}{ 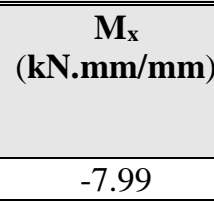 } \\
\hline & $\mathbf{t}_{\mathbf{1}}(\mathbf{m m})$ & $\mathrm{t}_{2}(\mathrm{~mm})$ & & & & \\
\hline \multirow{20}{*}{5} & 200 & 200 & & & & \\
\hline & & 240 & 1.2 & -3.45 & -110.17 & -8.27 \\
\hline & & 300 & 1.5 & -2.14 & -114.85 & -8.57 \\
\hline & & 400 & 2 & -1.13 & -119.95 & -8.89 \\
\hline & 225 & 225 & 1 & -3.52 & -105.90 & -7.99 \\
\hline & & 270 & 1.2 & -2.42 & -110.17 & -8.27 \\
\hline & & 337.5 & 1.5 & -1.51 & -114.85 & -8.57 \\
\hline & & 450 & 2 & -0.79 & -119.95 & -8.89 \\
\hline & 250 & 250 & 1 & -2.57 & -105.90 & -7.99 \\
\hline & & 300 & 1.2 & -1.77 & -110.17 & -8.27 \\
\hline & & 375 & 1.5 & -1.10 & -114.85 & -8.57 \\
\hline & & 500 & 2 & -0.58 & -119.95 & -8.89 \\
\hline & 300 & 300 & 1 & -1.49 & -105.90 & -7.99 \\
\hline & & 360 & 1.2 & -1.02 & -110.17 & -8.27 \\
\hline & & 450 & 1.5 & -0.64 & -114.85 & -8.57 \\
\hline & & 600 & 2 & -0.33 & -119.95 & -8.89 \\
\hline & 350 & 350 & 1 & -0.94 & -105.90 & -7.99 \\
\hline & & 420 & 1.2 & -0.64 & -110.17 & -8.27 \\
\hline & & 525 & 1.5 & -0.40 & -114.85 & -8.57 \\
\hline & & 700 & 2 & -0.21 & -119.95 & -8.89 \\
\hline \multirow{20}{*}{6} & 200 & 200 & 1 & -5.00 & -105.78 & -7.99 \\
\hline & & 240 & 1.2 & -3.44 & -110.11 & -8.27 \\
\hline & & 300 & 1.5 & -2.14 & -114.82 & -8.57 \\
\hline & & 400 & 2 & -1.13 & -119.95 & -8.89 \\
\hline & 225 & 225 & 1 & -3.51 & -105.78 & $\begin{array}{l}-7.99 \\
\end{array}$ \\
\hline & & 270 & 1.2 & -2.42 & -110.11 & -8.27 \\
\hline & & 337.5 & 1.5 & -1.50 & -114.82 & -8.57 \\
\hline & & 450 & 2 & -0.79 & -119.95 & -8.89 \\
\hline & 250 & 250 & 1 & -2.56 & -105.78 & -7.99 \\
\hline & & 300 & 1.2 & -1.76 & -110.11 & -8.27 \\
\hline & & 375 & 1.5 & -1.10 & -114.82 & -8.57 \\
\hline & & 500 & 2 & -0.58 & -119.95 & -8.89 \\
\hline & 300 & 300 & 1 & -1.48 & -105.78 & -7.99 \\
\hline & & 360 & 1.2 & -1.02 & -110.11 & -8.27 \\
\hline & & 450 & 1.5 & -0.63 & -114.82 & -8.57 \\
\hline & & 600 & 2 & -0.33 & -119.95 & -8.89 \\
\hline & 350 & 350 & 1 & -0.93 & -105.78 & -7.99 \\
\hline & & 420 & 1.2 & -0.64 & -110.11 & -8.27 \\
\hline & & 525 & 1.5 & -0.40 & -114.82 & -8.57 \\
\hline & & 700 & 2 & -0.21 & -119.95 & -8.89 \\
\hline
\end{tabular}


Cantilever length: $\mathbf{2}$ m

\begin{tabular}{|c|c|c|c|c|c|c|}
\hline \multirow{2}{*}{$\begin{array}{l}\text { Barrier length } \\
(\mathrm{m})\end{array}$} & \multicolumn{2}{|c|}{ Slab thickness } & \multirow{3}{*}{$\begin{array}{c}\mathbf{t}_{\mathbf{2}} / \mathbf{t}_{\mathbf{1}} \\
\\
1\end{array}$} & \multirow{3}{*}{$\begin{array}{c}\begin{array}{c}\Delta \\
(\mathbf{m m})\end{array} \\
-5.00 \\
\end{array}$} & \multirow{3}{*}{$\begin{array}{c}\begin{array}{c}\mathbf{M}_{\mathbf{y}} \\
(\mathbf{k N . m m} / \mathbf{m m})\end{array} \\
-105.75 \\
\end{array}$} & \multirow{3}{*}{ 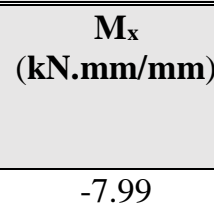 } \\
\hline & $\mathbf{t}_{1}(\mathbf{m m})$ & $\mathrm{t}_{2}(\mathrm{~mm})$ & & & & \\
\hline \multirow{20}{*}{8} & 200 & 200 & & & & \\
\hline & & 240 & 1.2 & -3.44 & -110.09 & -8.27 \\
\hline & & 300 & 1.5 & -2.14 & -114.82 & -8.57 \\
\hline & & 400 & 2 & -1.13 & -119.95 & -8.89 \\
\hline & 225 & 225 & 1 & -3.51 & -105.75 & -7.99 \\
\hline & & 270 & 1.2 & -2.42 & -110.09 & -8.27 \\
\hline & & 337.5 & 1.5 & -1.50 & -114.82 & -8.57 \\
\hline & & 450 & 2 & -0.79 & -119.95 & -8.89 \\
\hline & 250 & 250 & 1 & -2.56 & -105.75 & -7.99 \\
\hline & & 300 & 1.2 & -1.76 & -110.09 & -8.27 \\
\hline & & 375 & 1.5 & -1.10 & -114.82 & -8.57 \\
\hline & & 500 & 2 & -0.58 & -119.95 & -8.89 \\
\hline & 300 & 300 & 1 & -1.48 & -105.75 & -7.99 \\
\hline & & 360 & 1.2 & -1.02 & -110.09 & -8.27 \\
\hline & & 450 & 1.5 & -0.63 & -114.82 & -8.57 \\
\hline & & 600 & 2 & -0.33 & -119.95 & -8.89 \\
\hline & 350 & 350 & 1 & -0.93 & -105.75 & -7.99 \\
\hline & & 420 & 1.2 & -0.64 & -110.09 & -8.27 \\
\hline & & 525 & 1.5 & -0.40 & -114.82 & -8.57 \\
\hline & & 700 & 2 & -0.21 & -119.95 & -8.89 \\
\hline \multirow{20}{*}{10} & 200 & 200 & 1 & -5.00 & -105.75 & -7.99 \\
\hline & & 240 & 1.2 & -3.44 & -110.09 & -8.27 \\
\hline & & 300 & 1.5 & -2.14 & -114.82 & -8.57 \\
\hline & & 400 & 2 & -1.13 & -119.95 & -8.89 \\
\hline & 225 & 225 & 1 & -3.51 & -105.75 & -7.99 \\
\hline & & 270 & 1.2 & -2.42 & -110.09 & -8.27 \\
\hline & & 337.5 & 1.5 & -1.50 & -114.82 & -8.57 \\
\hline & & 450 & 2 & -0.79 & -119.95 & -8.89 \\
\hline & 250 & 250 & 1 & -2.56 & -105.75 & $\begin{array}{l}-7.99 \\
\end{array}$ \\
\hline & & 300 & 1.2 & -1.76 & -110.09 & -8.27 \\
\hline & & 375 & 1.5 & -1.10 & -114.82 & -8.57 \\
\hline & & 500 & 2 & -0.58 & -119.95 & -8.89 \\
\hline & 300 & 300 & 1 & -1.48 & -105.75 & $\begin{array}{l}-7.99 \\
\end{array}$ \\
\hline & & 360 & 1.2 & -1.02 & -110.09 & -8.27 \\
\hline & & 450 & 1.5 & -0.63 & -114.82 & -8.57 \\
\hline & & 600 & 2 & -0.33 & -119.95 & -8.89 \\
\hline & 350 & 350 & 1 & -0.93 & -105.75 & -7.99 \\
\hline & & 420 & 1.2 & -0.64 & -110.09 & -8.27 \\
\hline & & 525 & 1.5 & -0.40 & -114.82 & -8.57 \\
\hline & & 700 & 2 & -0.21 & -119.95 & -8.89 \\
\hline
\end{tabular}




\begin{tabular}{|c|c|c|c|c|c|c|}
\hline \multicolumn{7}{|c|}{ Cantilever length: $2 \mathrm{~m}$} \\
\hline \multirow{2}{*}{$\begin{array}{c}\text { Barrier length } \\
(\mathrm{m})\end{array}$} & \multicolumn{2}{|c|}{ Slab thickness } & \multirow{3}{*}{$\begin{array}{c}\mathbf{t}_{2} / \mathbf{t}_{1} \\
\\
1\end{array}$} & \multirow{3}{*}{$\begin{array}{c}\begin{array}{c}\Delta \\
(\mathbf{m m})\end{array} \\
-5.00\end{array}$} & \multirow{3}{*}{$\begin{array}{c}\mathbf{M}_{\mathbf{y}} \\
(\mathbf{k N} \cdot \mathbf{m m} / \mathbf{m m}) \\
-105.75\end{array}$} & \multirow{3}{*}{$\begin{array}{c}\mathbf{M}_{\mathbf{x}} \\
(\mathbf{k N} \cdot \mathbf{m m} / \mathbf{m m}) \\
-7.99\end{array}$} \\
\hline & $\mathbf{t}_{1}(\mathbf{m m})$ & $\mathbf{t}_{2}(\mathrm{~mm})$ & & & & \\
\hline \multirow{20}{*}{12} & 200 & 200 & & & & \\
\hline & & 240 & 1.2 & -3.44 & -110.09 & -8.27 \\
\hline & & 300 & 1.5 & -2.14 & -114.82 & -8.57 \\
\hline & & 400 & 2 & -1.13 & -119.95 & -8.89 \\
\hline & 225 & 225 & 1 & -3.51 & -105.75 & -7.99 \\
\hline & & 270 & 1.2 & -2.42 & -110.09 & -8.27 \\
\hline & & 337.5 & 1.5 & -1.50 & -114.82 & -8.57 \\
\hline & & 450 & 2 & -0.79 & -119.95 & -8.89 \\
\hline & 250 & 250 & 1 & -2.56 & -105.75 & -7.99 \\
\hline & & 300 & 1.2 & -1.76 & -110.09 & -8.27 \\
\hline & & 375 & 1.5 & -1.10 & -114.82 & -8.57 \\
\hline & & 500 & 2 & -0.58 & -119.95 & -8.89 \\
\hline & 300 & 300 & 1 & -1.48 & -105.75 & -7.99 \\
\hline & & 360 & 1.2 & -1.02 & -110.09 & -8.27 \\
\hline & & 450 & 1.5 & -0.63 & -114.82 & -8.57 \\
\hline & & 600 & 2 & -0.33 & -119.95 & -8.89 \\
\hline & 350 & 350 & 1 & -0.93 & -105.75 & -7.99 \\
\hline & & 420 & 1.2 & -0.64 & -110.09 & -8.27 \\
\hline & & 525 & 1.5 & -0.40 & -114.82 & -8.57 \\
\hline & & 700 & 2 & -0.21 & -119.95 & -8.89 \\
\hline
\end{tabular}


Table A-4: Summary of Maximum deflection, Transverse Moment and Longitudinal Moment in Unstiffened Cantilevered Slab of Length $2.5 \mathrm{~m}$

\begin{tabular}{|c|c|c|c|c|c|c|}
\hline \multicolumn{7}{|c|}{ Cantilever length: $2.5 \mathrm{~m}$} \\
\hline \multirow{2}{*}{$\begin{array}{l}\text { Barrier length } \\
(\mathrm{m})\end{array}$} & \multicolumn{2}{|c|}{ Slab thickness } & \multirow[t]{2}{*}{$\mathbf{t}_{2} / \mathbf{t}_{1}$} & \multirow{2}{*}{$\underset{(\mathbf{m m})}{\Delta}$} & \multirow{2}{*}{$\begin{array}{c}\mathbf{M}_{\mathbf{y}} \\
(\mathbf{k N} \cdot \mathbf{m m} / \mathbf{m m})\end{array}$} & \multirow{2}{*}{$\begin{array}{c}\mathbf{M}_{\mathbf{x}} \\
(\mathbf{k N} \cdot \mathbf{m m} / \mathbf{m m})\end{array}$} \\
\hline & $\mathbf{t}_{\mathbf{1}}(\mathbf{m m})$ & $\mathbf{t}_{2}(\mathbf{m m})$ & & & & \\
\hline \multirow{20}{*}{5} & 200 & 200 & 1 & -10.85 & -126.77 & -8.12 \\
\hline & & 240 & 1.2 & -7.43 & -130.94 & -8.27 \\
\hline & & 300 & 1.5 & $\begin{array}{l}-4.61 \\
\end{array}$ & -135.60 & -8.41 \\
\hline & & 400 & 2 & -2.44 & -140.78 & -8.52 \\
\hline & 225 & 225 & 1 & $\begin{array}{l}-7.62 \\
\end{array}$ & -126.77 & -8.12 \\
\hline & & 270 & 1.2 & -5.22 & -130.94 & -8.27 \\
\hline & & 337.5 & 1.5 & -3.24 & -135.60 & -8.41 \\
\hline & & 450 & 2 & -1.71 & -140.78 & -8.52 \\
\hline & 250 & 250 & 1 & -5.55 & -126.77 & -8.12 \\
\hline & & 300 & 1.2 & -3.80 & -130.94 & -8.27 \\
\hline & & 375 & 1.5 & -2.36 & -135.60 & -8.41 \\
\hline & & 500 & 2 & -1.25 & -140.78 & -8.52 \\
\hline & 300 & 300 & 1 & -3.21 & -126.77 & -8.12 \\
\hline & & 360 & 1.2 & -2.20 & -130.94 & -8.27 \\
\hline & & 450 & 1.5 & -1.37 & -135.60 & -8.41 \\
\hline & & 600 & 2 & -0.72 & -140.78 & -8.52 \\
\hline & 350 & 350 & 1 & -2.02 & -126.77 & -8.12 \\
\hline & & 420 & 1.2 & -1.39 & -130.94 & -8.27 \\
\hline & & 525 & 1.5 & -0.86 & -135.60 & -8.41 \\
\hline & & 700 & 2 & -0.45 & -140.78 & -8.52 \\
\hline \multirow{20}{*}{6} & 200 & 200 & 1 & -10.68 & -125.83 & -8.10 \\
\hline & & 240 & 1.2 & -7.36 & -130.31 & -8.26 \\
\hline & & 300 & 1.5 & -4.59 & -135.24 & -8.41 \\
\hline & & 400 & 2 & -2.43 & -140.61 & -8.52 \\
\hline & 225 & 225 & 1 & -7.50 & -125.83 & -8.10 \\
\hline & & 270 & 1.2 & -5.17 & -130.31 & -8.26 \\
\hline & & 337.5 & 1.5 & -3.22 & -135.24 & -8.41 \\
\hline & & 450 & 2 & -1.71 & -140.61 & -8.52 \\
\hline & 250 & 250 & 1 & -5.47 & -125.83 & -8.10 \\
\hline & & 300 & 1.2 & -3.77 & -130.31 & -8.26 \\
\hline & & 375 & 1.5 & -2.35 & -135.24 & -8.41 \\
\hline & & 500 & 2 & -1.24 & -140.61 & -8.52 \\
\hline & 300 & 300 & 1 & -3.17 & -125.83 & -8.10 \\
\hline & & 360 & 1.2 & -2.18 & -130.31 & -8.26 \\
\hline & & 450 & 1.5 & -1.36 & -135.24 & -8.41 \\
\hline & & 600 & 2 & -0.72 & -140.61 & -8.52 \\
\hline & 350 & 350 & 1 & -1.99 & -125.83 & -8.10 \\
\hline & & 420 & 1.2 & -1.37 & -130.31 & -8.26 \\
\hline & & 525 & 1.5 & -0.86 & -135.24 & -8.41 \\
\hline & & 700 & 2 & -0.45 & -140.61 & -8.52 \\
\hline
\end{tabular}


Cantilever length: $2.5 \mathrm{~m}$

\begin{tabular}{|c|c|c|c|c|c|c|}
\hline \multirow{2}{*}{$\begin{array}{l}\text { Barrier length } \\
(\mathbf{m})\end{array}$} & \multicolumn{2}{|c|}{ Slab thickness } & \multirow[t]{2}{*}{$\mathbf{t}_{2} / \mathbf{t}_{1}$} & \multirow{2}{*}{$\begin{array}{c}\Delta \\
(\mathbf{m m})\end{array}$} & \multirow{2}{*}{$\begin{array}{c}\mathbf{M}_{\mathbf{y}} \\
(\mathbf{k N} \cdot \mathbf{m m} / \mathbf{m m})\end{array}$} & \multirow{2}{*}{$\begin{array}{c}\mathbf{M}_{\mathbf{x}} \\
(\mathbf{k N} \cdot \mathbf{m m} / \mathbf{m m})\end{array}$} \\
\hline & $\mathbf{t}_{1}(\mathbf{m m})$ & $\mathbf{t}_{2}(\mathrm{~mm})$ & & & & \\
\hline \multirow{20}{*}{8} & 200 & 200 & 1 & -10.61 & -125.48 & -8.10 \\
\hline & & 240 & 1.2 & $\begin{array}{l}-7.33 \\
\end{array}$ & -130.12 & -8.26 \\
\hline & & 300 & 1.5 & -4.58 & -135.16 & -8.41 \\
\hline & & 400 & 2 & -2.43 & -140.59 & -8.52 \\
\hline & 225 & 225 & 1 & -7.45 & -125.48 & -8.10 \\
\hline & & 270 & 1.2 & -5.15 & -130.12 & -8.26 \\
\hline & & 337.5 & 1.5 & -3.22 & -135.16 & -8.41 \\
\hline & & 450 & 2 & -1.71 & -140.59 & -8.52 \\
\hline & 250 & 250 & 1 & -5.43 & -125.48 & -8.10 \\
\hline & & 300 & 1.2 & -3.75 & -130.12 & -8.26 \\
\hline & & 375 & 1.5 & -2.34 & -135.16 & -8.41 \\
\hline & & 500 & 2 & -1.24 & -140.59 & -8.52 \\
\hline & 300 & 300 & 1 & -3.14 & -125.48 & -8.10 \\
\hline & & 360 & 1.2 & -2.17 & -130.12 & -8.26 \\
\hline & & 450 & 1.5 & -1.36 & -135.16 & -8.41 \\
\hline & & 600 & 2 & -0.72 & -140.59 & -8.52 \\
\hline & 350 & 350 & 1 & -1.98 & -125.48 & -8.10 \\
\hline & & 420 & 1.2 & -1.37 & -130.12 & -8.26 \\
\hline & & 525 & 1.5 & -0.85 & -135.16 & -8.41 \\
\hline & & 700 & 2 & -0.45 & -140.59 & -8.52 \\
\hline \multirow{20}{*}{10} & 200 & 200 & 1 & -10.61 & -125.46 & -8.10 \\
\hline & & 240 & 1.2 & -7.33 & -130.11 & -8.26 \\
\hline & & 300 & 1.5 & -4.58 & -135.15 & -8.41 \\
\hline & & 400 & 2 & -2.43 & -140.59 & -8.52 \\
\hline & 225 & 225 & 1 & -7.45 & -125.46 & -8.10 \\
\hline & & 270 & 1.2 & -5.15 & -130.11 & -8.26 \\
\hline & & 337.5 & 1.5 & -3.22 & -135.15 & -8.41 \\
\hline & & 450 & 2 & -1.71 & -140.59 & -8.52 \\
\hline & 250 & 250 & 1 & -5.43 & -125.46 & -8.10 \\
\hline & & 300 & 1.2 & -3.75 & -130.11 & -8.26 \\
\hline & & 375 & 1.5 & -2.34 & -135.15 & -8.41 \\
\hline & & 500 & 2 & -1.24 & -140.59 & -8.52 \\
\hline & 300 & 300 & 1 & -3.14 & -125.46 & -8.10 \\
\hline & & 360 & 1.2 & -2.17 & -130.11 & -8.26 \\
\hline & & 450 & 1.5 & -1.36 & -135.15 & -8.41 \\
\hline & & 600 & 2 & -0.72 & -140.59 & -8.52 \\
\hline & 350 & 350 & 1 & -1.98 & -125.46 & -8.10 \\
\hline & & 420 & 1.2 & -1.37 & -130.11 & -8.26 \\
\hline & & 525 & 1.5 & -0.85 & -135.15 & -8.41 \\
\hline & & 700 & 2 & -0.45 & -140.59 & -8.52 \\
\hline
\end{tabular}




\begin{tabular}{|c|c|c|c|c|c|c|}
\hline \multicolumn{7}{|c|}{ Cantilever length: $2.5 \mathrm{~m}$} \\
\hline \multirow{2}{*}{$\begin{array}{c}\text { Barrier length } \\
(\mathrm{m})\end{array}$} & \multicolumn{2}{|c|}{ Slab thickness } & \multirow{3}{*}{$\begin{array}{c}\mathbf{t}_{2} / \mathbf{t}_{1} \\
\\
1\end{array}$} & \multirow{3}{*}{$\begin{array}{c}\begin{array}{c}\Delta \\
(\mathbf{m m})\end{array} \\
-10.60\end{array}$} & \multirow{3}{*}{$\begin{array}{c}\mathbf{M}_{\mathbf{y}} \\
(\mathbf{k N} \cdot \mathbf{m m} / \mathbf{m m}) \\
-125.45\end{array}$} & \multirow{3}{*}{ 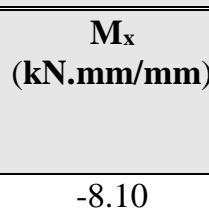 } \\
\hline & $\mathbf{t}_{1}(\mathbf{m m})$ & $\mathbf{t}_{2}(\mathrm{~mm})$ & & & & \\
\hline \multirow{20}{*}{12} & 200 & 200 & & & & \\
\hline & & 240 & 1.2 & -7.33 & -130.11 & -8.26 \\
\hline & & 300 & 1.5 & -4.58 & -135.15 & -8.41 \\
\hline & & 400 & 2 & -2.43 & -140.59 & -8.52 \\
\hline & 225 & 225 & 1 & -7.45 & -125.45 & -8.10 \\
\hline & & 270 & 1.2 & -5.15 & -130.11 & -8.26 \\
\hline & & 337.5 & 1.5 & -3.22 & -135.15 & -8.41 \\
\hline & & 450 & 2 & -1.71 & -140.59 & -8.52 \\
\hline & 250 & 250 & 1 & -5.43 & -125.45 & -8.10 \\
\hline & & 300 & 1.2 & -3.75 & -130.11 & -8.26 \\
\hline & & 375 & 1.5 & -2.34 & -135.15 & -8.41 \\
\hline & & 500 & 2 & -1.24 & -140.59 & -8.52 \\
\hline & 300 & 300 & 1 & -3.14 & -125.45 & -8.10 \\
\hline & & 360 & 1.2 & -2.17 & -130.11 & -8.26 \\
\hline & & 450 & 1.5 & -1.36 & -135.15 & -8.41 \\
\hline & & 600 & 2 & -0.72 & -140.59 & -8.52 \\
\hline & 350 & 350 & 1 & -1.98 & -125.45 & -8.10 \\
\hline & & 420 & 1.2 & -1.37 & -130.11 & -8.26 \\
\hline & & 525 & 1.5 & -0.85 & -135.15 & -8.41 \\
\hline & & 700 & 2 & -0.45 & -140.59 & -8.52 \\
\hline
\end{tabular}


Table A-5: Summary of Maximum deflection, Transverse Moment and Longitudinal Moment in Cantilevered Slab with Concrete Curb of Length 1m

\begin{tabular}{|c|c|c|c|c|c|c|}
\hline \multicolumn{7}{|c|}{ Cantilever length: $1 \mathrm{~m}$} \\
\hline \multirow{2}{*}{$\begin{array}{l}\text { Barrier length } \\
(\mathbf{m})\end{array}$} & \multicolumn{2}{|c|}{ Slab thickness } & \multirow{3}{*}{$\begin{array}{c}\mathbf{t}_{2} / \mathbf{t}_{1} \\
\\
1 \\
\end{array}$} & \multirow{3}{*}{$\begin{array}{c}\begin{array}{c}\Delta \\
(\mathbf{m m})\end{array} \\
-0.18 \\
\end{array}$} & \multirow{3}{*}{ 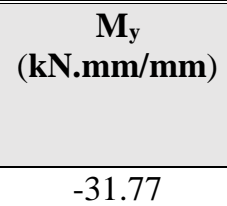 } & \multirow{3}{*}{$\begin{array}{c}\begin{array}{c}\mathbf{M}_{\mathbf{x}} \\
(\mathbf{k N} \cdot \mathbf{m m} / \mathbf{m m}\end{array} \\
-1.21\end{array}$} \\
\hline & $\mathbf{t}_{1}(\mathbf{m m})$ & $\mathbf{t}_{2}(\mathrm{~mm})$ & & & & \\
\hline \multirow{20}{*}{5} & 200 & 200 & & & & \\
\hline & & 240 & 1.2 & -0.12 & -33.05 & -1.33 \\
\hline & & 300 & 1.5 & -0.07 & -34.41 & -1.46 \\
\hline & & 400 & 2 & -0.04 & -35.79 & -1.61 \\
\hline & 225 & 225 & 1 & $\begin{array}{l}-0.13 \\
\end{array}$ & -32.39 & -1.26 \\
\hline & & 270 & 1.2 & -0.09 & -33.59 & -1.37 \\
\hline & & 337.5 & 1.5 & -0.05 & -34.84 & -1.49 \\
\hline & & 450 & 2 & -0.03 & -36.08 & -1.63 \\
\hline & 250 & 250 & 1 & -0.10 & -32.89 & -1.29 \\
\hline & & 300 & 1.2 & -0.07 & -34.02 & -1.40 \\
\hline & & 375 & 1.5 & -0.04 & -35.17 & -1.52 \\
\hline & & 500 & 2 & -0.02 & -36.31 & -1.65 \\
\hline & 300 & 300 & 1 & -0.06 & -33.63 & -1.35 \\
\hline & & 360 & 1.2 & -0.04 & -34.63 & -1.45 \\
\hline & & 450 & 1.5 & -0.02 & -35.64 & -1.56 \\
\hline & & 600 & 2 & -0.01 & -36.61 & -1.68 \\
\hline & 350 & 350 & 1 & -0.04 & -34.13 & -1.39 \\
\hline & & 420 & 1.2 & -0.03 & -35.04 & -1.48 \\
\hline & & 525 & 1.5 & -0.02 & -35.93 & -1.58 \\
\hline & & 700 & 2 & -0.01 & -36.79 & -1.70 \\
\hline \multirow{20}{*}{6} & 200 & 200 & 1 & -0.18 & -31.72 & -1.21 \\
\hline & & 240 & 1.2 & -0.12 & -33.02 & -1.32 \\
\hline & & 300 & 1.5 & -0.07 & -34.40 & -1.46 \\
\hline & & 400 & 2 & $\begin{array}{l}-0.04 \\
\end{array}$ & -35.78 & -1.61 \\
\hline & 225 & 225 & 1 & -0.13 & -32.36 & -1.25 \\
\hline & & 270 & 1.2 & -0.09 & -33.57 & -1.37 \\
\hline & & 337.5 & 1.5 & -0.05 & -34.83 & -1.49 \\
\hline & & 450 & 2 & -0.03 & -36.08 & -1.63 \\
\hline & 250 & 250 & 1 & -0.10 & -32.87 & -1.29 \\
\hline & & 300 & 1.2 & -0.07 & -34.01 & -1.40 \\
\hline & & 375 & 1.5 & -0.04 & -35.17 & -1.52 \\
\hline & & 500 & 2 & -0.02 & -36.31 & -1.65 \\
\hline & 300 & 300 & 1 & -0.06 & -33.62 & -1.35 \\
\hline & & 360 & 1.2 & -0.04 & -34.63 & -1.45 \\
\hline & & 450 & 1.5 & -0.02 & -35.64 & -1.56 \\
\hline & & 600 & 2 & -0.01 & -36.61 & -1.68 \\
\hline & 350 & 350 & 1 & -0.04 & -34.13 & -1.39 \\
\hline & & 420 & 1.2 & -0.03 & -35.03 & -1.48 \\
\hline & & 525 & 1.5 & -0.02 & -35.93 & -1.58 \\
\hline & & 700 & 2 & -0.01 & -36.79 & -1.70 \\
\hline
\end{tabular}


Cantilever length: $1 \mathrm{~m}$

\begin{tabular}{|c|c|c|c|c|c|c|}
\hline \multirow{2}{*}{$\begin{array}{l}\text { Barrier length } \\
(\mathbf{m})\end{array}$} & \multicolumn{2}{|c|}{ Slab thickness } & \multirow{3}{*}{$\begin{array}{c}\mathbf{t}_{\mathbf{2}} / \mathbf{t}_{\mathbf{1}} \\
\\
1\end{array}$} & \multirow{3}{*}{$\begin{array}{c}\begin{array}{c}\Delta \\
(\mathbf{m m})\end{array} \\
-0.18 \\
\end{array}$} & \multirow{3}{*}{$\begin{array}{c}\mathbf{M}_{\mathbf{y}} \\
(\mathbf{k N . m m} / \mathbf{m m}) \\
-31.70\end{array}$} & \multirow{3}{*}{ 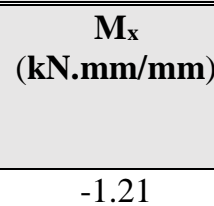 } \\
\hline & $\mathbf{t}_{1}(\mathbf{m m})$ & $\mathbf{t}_{2}(\mathrm{~mm})$ & & & & \\
\hline \multirow{20}{*}{8} & 200 & 200 & & & & \\
\hline & & 240 & 1.2 & -0.12 & -33.02 & -1.32 \\
\hline & & 300 & 1.5 & -0.07 & -34.39 & -1.46 \\
\hline & & 400 & 2 & -0.04 & -35.78 & -1.61 \\
\hline & 225 & 225 & 1 & -0.13 & -32.35 & -1.25 \\
\hline & & 270 & 1.2 & -0.09 & -33.57 & -1.37 \\
\hline & & 337.5 & 1.5 & -0.05 & -34.83 & -1.49 \\
\hline & & 450 & 2 & -0.03 & -36.08 & -1.63 \\
\hline & 250 & 250 & 1 & -0.10 & -32.87 & -1.29 \\
\hline & & 300 & 1.2 & -0.07 & -34.00 & -1.40 \\
\hline & & 375 & 1.5 & -0.04 & -35.17 & -1.52 \\
\hline & & 500 & 2 & -0.02 & -36.31 & -1.65 \\
\hline & 300 & 300 & 1 & -0.06 & -33.62 & -1.35 \\
\hline & & 360 & 1.2 & -0.04 & -34.63 & -1.45 \\
\hline & & 450 & 1.5 & -0.02 & -35.64 & -1.56 \\
\hline & & 600 & 2 & $\begin{array}{l}-0.01 \\
\end{array}$ & -36.61 & -1.68 \\
\hline & 350 & 350 & 1 & -0.04 & -34.13 & -1.39 \\
\hline & & 420 & 1.2 & $\begin{array}{l}-0.03 \\
\end{array}$ & -35.03 & -1.48 \\
\hline & & 525 & 1.5 & -0.02 & -35.93 & -1.58 \\
\hline & & 700 & 2 & -0.01 & -36.79 & -1.70 \\
\hline \multirow{20}{*}{10} & 200 & 200 & 1 & -0.18 & -31.70 & -1.21 \\
\hline & & 240 & 1.2 & -0.12 & -33.01 & -1.32 \\
\hline & & 300 & 1.5 & -0.07 & -34.39 & -1.46 \\
\hline & & 400 & 2 & -0.04 & -35.78 & -1.61 \\
\hline & 225 & 225 & 1 & -0.13 & -32.35 & -1.25 \\
\hline & & 270 & 1.2 & -0.09 & -33.57 & -1.37 \\
\hline & & 337.5 & 1.5 & -0.05 & -34.83 & $\begin{array}{l}-1.49 \\
\end{array}$ \\
\hline & & 450 & 2 & -0.03 & -36.08 & -1.63 \\
\hline & 250 & 250 & 1 & -0.10 & -32.87 & -1.29 \\
\hline & & 300 & 1.2 & $\begin{array}{l}-0.07 \\
\end{array}$ & -34.00 & -1.40 \\
\hline & & 375 & 1.5 & -0.04 & -35.17 & -1.52 \\
\hline & & 500 & 2 & -0.02 & -36.31 & -1.65 \\
\hline & 300 & 300 & 1 & -0.06 & -33.62 & -1.35 \\
\hline & & 360 & 1.2 & -0.04 & -34.63 & -1.45 \\
\hline & & 450 & 1.5 & -0.02 & -35.64 & -1.56 \\
\hline & & 600 & 2 & $\begin{array}{l}-0.01 \\
\end{array}$ & -36.61 & $\begin{array}{l}-1.68 \\
\end{array}$ \\
\hline & 350 & 350 & 1 & -0.04 & -34.13 & -1.39 \\
\hline & & 420 & 1.2 & -0.03 & -35.03 & -1.48 \\
\hline & & 525 & 1.5 & $\begin{array}{l}-0.02 \\
\end{array}$ & -35.93 & -1.58 \\
\hline & & 700 & 2 & -0.01 & -36.79 & -1.70 \\
\hline
\end{tabular}




\begin{tabular}{|c|c|c|c|c|c|c|}
\hline \multicolumn{7}{|c|}{ Cantilever length: 1 m } \\
\hline \multirow{2}{*}{$\begin{array}{c}\text { Barrier length } \\
(\mathrm{m})\end{array}$} & \multicolumn{2}{|c|}{ Slab thickness } & \multirow[t]{2}{*}{$\overline{t_{2} / \mathbf{t}_{1}}$} & \multirow{2}{*}{$\begin{array}{c}\boldsymbol{\Delta} \\
(\mathbf{m m})\end{array}$} & \multirow{2}{*}{$\begin{array}{c}\mathbf{M}_{\mathbf{y}} \\
(\mathbf{k N} \cdot \mathbf{m m} / \mathbf{m m})\end{array}$} & \multirow{2}{*}{$\begin{array}{c}\mathbf{M}_{\mathbf{x}} \\
(\mathbf{k N} \cdot \mathbf{m m} / \mathbf{m m})\end{array}$} \\
\hline & $\mathbf{t}_{\mathbf{1}}(\mathbf{m m})$ & $\mathbf{t}_{2}(\mathrm{~mm})$ & & & & \\
\hline \multirow{20}{*}{12} & 200 & 200 & 1 & -0.18 & -31.70 & -1.21 \\
\hline & & 240 & 1.2 & -0.12 & -33.01 & -1.32 \\
\hline & & 300 & 1.5 & -0.07 & -34.39 & -1.46 \\
\hline & & 400 & 2 & -0.04 & -35.78 & -1.61 \\
\hline & 225 & 225 & 1 & -0.13 & -32.35 & -1.25 \\
\hline & & 270 & 1.2 & -0.09 & -33.57 & -1.37 \\
\hline & & 337.5 & 1.5 & -0.05 & -34.83 & -1.49 \\
\hline & & 450 & 2 & -0.03 & -36.08 & -1.63 \\
\hline & 250 & 250 & 1 & -0.10 & -32.87 & -1.29 \\
\hline & & 300 & 1.2 & -0.07 & -34.00 & -1.40 \\
\hline & & 375 & 1.5 & -0.04 & -35.17 & -1.52 \\
\hline & & 500 & 2 & -0.02 & -36.31 & -1.65 \\
\hline & 300 & 300 & 1 & -0.06 & -33.62 & -1.35 \\
\hline & & 360 & 1.2 & -0.04 & -34.63 & -1.45 \\
\hline & & 450 & 1.5 & -0.02 & -35.64 & -1.56 \\
\hline & & 600 & 2 & -0.01 & -36.61 & $\begin{array}{l}-1.68 \\
\end{array}$ \\
\hline & 350 & 350 & 1 & -0.04 & -34.13 & -1.39 \\
\hline & & 420 & 1.2 & -0.03 & -35.03 & -1.48 \\
\hline & & 525 & 1.5 & -0.02 & -35.93 & -1.58 \\
\hline & & 700 & 2 & -0.01 & -36.79 & -1.70 \\
\hline
\end{tabular}


Table A-6: Summary of Maximum deflection, Transverse Moment and Longitudinal Moment in Cantilevered Slab with Concrete Curb of Length 1.5 m

\begin{tabular}{|c|c|c|c|c|c|c|}
\hline \multicolumn{7}{|c|}{ Cantilever length: $1.5 \mathrm{~m}$} \\
\hline \multirow{2}{*}{$\begin{array}{l}\text { Barrier length } \\
(\mathrm{m})\end{array}$} & \multicolumn{2}{|c|}{ Slab thickness } & \multirow[t]{2}{*}{$\mathbf{t}_{2} / \mathbf{t}_{1}$} & \multirow{2}{*}{$\begin{array}{c}\Delta \\
(\mathbf{m m})\end{array}$} & \multirow{2}{*}{$\begin{array}{c}\mathbf{M}_{\mathbf{y}} \\
(\mathbf{k N} \cdot \mathbf{m m} / \mathbf{m m})\end{array}$} & \multirow{2}{*}{$\begin{array}{c}\mathbf{M}_{\mathbf{x}} \\
(\mathbf{k N} \cdot \mathbf{m m} / \mathbf{m m})\end{array}$} \\
\hline & $\mathbf{t}_{\mathbf{1}}(\mathbf{m m})$ & $\mathbf{t}_{2}(\mathrm{~mm})$ & & & & \\
\hline \multirow{20}{*}{5} & 200 & 200 & 1 & -1.17 & -66.97 & -2.99 \\
\hline & & 240 & 1.2 & -0.81 & -70.63 & -3.31 \\
\hline & & 300 & 1.5 & -0.50 & -74.81 & -3.69 \\
\hline & & 400 & 2 & -0.26 & -79.47 & -4.13 \\
\hline & 225 & 225 & 1 & -0.86 & -68.61 & -3.17 \\
\hline & & 270 & 1.2 & -0.59 & -72.17 & -3.48 \\
\hline & & 337.5 & 1.5 & -0.36 & -76.16 & -3.84 \\
\hline & & 450 & 2 & -0.19 & -80.53 & -4.25 \\
\hline & 250 & 250 & 1 & -0.65 & -69.99 & -3.32 \\
\hline & & 300 & 1.2 & -0.44 & -73.44 & -3.62 \\
\hline & & 375 & 1.5 & -0.27 & -77.24 & -3.97 \\
\hline & & 500 & 2 & -0.14 & -81.34 & -4.35 \\
\hline & 300 & 300 & 1 & -0.40 & -72.09 & -3.57 \\
\hline & & 360 & 1.2 & -0.27 & -75.31 & -3.85 \\
\hline & & 450 & 1.5 & -0.17 & -78.78 & -4.15 \\
\hline & & 600 & 2 & -0.08 & -82.45 & -4.48 \\
\hline & 350 & 350 & 1 & -0.26 & -73.54 & -3.75 \\
\hline & & 420 & 1.2 & -0.18 & -76.55 & -4.00 \\
\hline & & 525 & 1.5 & -0.11 & -79.77 & -4.28 \\
\hline & & 700 & 2 & -0.05 & -83.13 & -4.57 \\
\hline \multirow{20}{*}{6} & 200 & 200 & 1 & -1.15 & -66.36 & -2.96 \\
\hline & & 240 & 1.2 & -0.80 & -70.22 & -3.29 \\
\hline & & 300 & 1.5 & -0.50 & -74.57 & -3.68 \\
\hline & & 400 & 2 & -0.26 & -79.37 & -4.13 \\
\hline & 225 & 225 & 1 & -0.85 & -68.19 & -3.15 \\
\hline & & 270 & 1.2 & -0.59 & -71.90 & -3.47 \\
\hline & & 337.5 & 1.5 & -0.36 & -76.01 & -3.84 \\
\hline & & 450 & 2 & -0.19 & -80.46 & -4.25 \\
\hline & 250 & 250 & 1 & -0.65 & -69.69 & -3.31 \\
\hline & & 300 & 1.2 & -0.44 & -73.25 & -3.62 \\
\hline & & 375 & 1.5 & -0.27 & -77.14 & -3.96 \\
\hline & & 500 & 2 & -0.14 & -81.29 & -4.35 \\
\hline & 300 & 300 & 1 & -0.40 & -71.93 & -3.56 \\
\hline & & 360 & 1.2 & -0.27 & -75.21 & -3.84 \\
\hline & & 450 & 1.5 & -0.16 & -78.73 & -4.15 \\
\hline & & 600 & 2 & -0.08 & -82.42 & -4.48 \\
\hline & 350 & 350 & 1 & -0.26 & -73.45 & -3.75 \\
\hline & & 420 & 1.2 & -0.18 & -76.50 & -4.00 \\
\hline & & 525 & 1.5 & -0.11 & -79.74 & -4.27 \\
\hline & & 700 & 2 & -0.05 & -83.12 & -4.57 \\
\hline
\end{tabular}


Cantilever length: $1.5 \mathrm{~m}$

\begin{tabular}{|c|c|c|c|c|c|c|}
\hline \multirow{2}{*}{$\begin{array}{l}\text { Barrier length } \\
\text { (m) }\end{array}$} & \multicolumn{2}{|c|}{ Slab thickness } & \multirow[t]{2}{*}{$\mathbf{t}_{2} / \mathbf{t}_{1}$} & \multirow{2}{*}{$\underset{(\mathbf{m m})}{\Delta}$} & \multirow{2}{*}{$\begin{array}{c}\mathbf{M}_{\mathbf{y}} \\
(\mathbf{k N} \cdot \mathbf{m m} / \mathbf{m m})\end{array}$} & \multirow{2}{*}{$\begin{array}{c}\mathbf{M}_{\mathbf{x}} \\
(\mathbf{k N} \cdot \mathbf{m m} / \mathbf{m m})\end{array}$} \\
\hline & $\mathbf{t}_{1}(\mathrm{~mm})$ & $\mathbf{t}_{2}(\mathrm{~mm})$ & & & & \\
\hline \multirow{20}{*}{8} & 200 & 200 & 1 & -1.14 & -66.04 & -2.94 \\
\hline & & 240 & 1.2 & -0.79 & -70.03 & -3.28 \\
\hline & & 300 & 1.5 & -0.50 & -74.47 & -3.67 \\
\hline & & 400 & 2 & -0.26 & -79.33 & -4.12 \\
\hline & 225 & 225 & 1 & -0.85 & -67.99 & -3.14 \\
\hline & & 270 & 1.2 & -0.58 & -71.78 & -3.46 \\
\hline & & 337.5 & 1.5 & -0.36 & -75.95 & -3.83 \\
\hline & & 450 & 2 & -0.19 & -80.44 & -4.25 \\
\hline & 250 & 250 & 1 & -0.64 & -69.56 & -3.30 \\
\hline & & 300 & 1.2 & -0.44 & -73.17 & -3.61 \\
\hline & & 375 & 1.5 & -0.27 & -77.10 & -3.96 \\
\hline & & 500 & 2 & -0.14 & -81.27 & -4.35 \\
\hline & 300 & 300 & 1 & -0.40 & -71.87 & -3.56 \\
\hline & & 360 & 1.2 & -0.27 & -75.17 & -3.84 \\
\hline & & 450 & 1.5 & -0.16 & -78.71 & -4.15 \\
\hline & & 600 & 2 & -0.08 & -82.42 & -4.48 \\
\hline & 350 & 350 & 1 & -0.26 & -73.41 & -3.74 \\
\hline & & 420 & 1.2 & -0.18 & -76.48 & -4.00 \\
\hline & & 525 & 1.5 & -0.11 & -79.73 & -4.27 \\
\hline & & 700 & 2 & -0.05 & -83.12 & -4.57 \\
\hline \multirow{20}{*}{10} & 200 & 200 & 1 & -1.14 & -66.00 & -2.94 \\
\hline & & 240 & 1.2 & -0.79 & -70.01 & -3.28 \\
\hline & & 300 & 1.5 & -0.50 & -74.46 & -3.67 \\
\hline & & 400 & 2 & -0.26 & -79.32 & -4.12 \\
\hline & 225 & 225 & 1 & -0.85 & -67.96 & -3.14 \\
\hline & & 270 & 1.2 & -0.58 & -71.77 & -3.46 \\
\hline & & 337.5 & 1.5 & -0.36 & -75.94 & -3.83 \\
\hline & & 450 & 2 & -0.19 & -80.43 & -4.25 \\
\hline & 250 & 250 & 1 & -0.64 & -69.54 & -3.30 \\
\hline & & 300 & 1.2 & -0.44 & -73.16 & -3.61 \\
\hline & & 375 & 1.5 & -0.27 & -77.09 & -3.96 \\
\hline & & 500 & 2 & -0.14 & -81.27 & -4.35 \\
\hline & 300 & 300 & 1 & -0.40 & -71.86 & -3.56 \\
\hline & & 360 & 1.2 & -0.27 & -75.17 & -3.84 \\
\hline & & 450 & 1.5 & -0.16 & -78.71 & -4.15 \\
\hline & & 600 & 2 & -0.08 & -82.41 & -4.48 \\
\hline & 350 & 350 & 1 & -0.26 & -73.41 & -3.74 \\
\hline & & 420 & 1.2 & -0.18 & -76.48 & -4.00 \\
\hline & & 525 & 1.5 & -0.11 & -79.73 & -4.27 \\
\hline & & 700 & 2 & -0.05 & -83.12 & -4.57 \\
\hline
\end{tabular}




\begin{tabular}{|c|c|c|c|c|c|c|}
\hline \multicolumn{7}{|c|}{ "Cantilever length: $1.5 \mathrm{~m}$} \\
\hline \multirow{2}{*}{$\begin{array}{l}\text { Barrier length } \\
(\mathrm{m})\end{array}$} & \multicolumn{2}{|c|}{ Slab thickness } & \multirow[t]{2}{*}{$\overline{t_{2} / t_{1}}$} & \multirow{2}{*}{$\begin{array}{c}\Delta \\
(\mathbf{m m})\end{array}$} & \multirow{2}{*}{$\begin{array}{c}\mathbf{M}_{\mathbf{y}} \\
(\mathbf{k N} \cdot \mathbf{m m} / \mathbf{m m})\end{array}$} & \multirow{2}{*}{$\begin{array}{c}\mathbf{M}_{\mathbf{x}} \\
(\mathbf{k N} \cdot \mathbf{m m} / \mathbf{m m})\end{array}$} \\
\hline & $\mathbf{t}_{\mathbf{1}}(\mathbf{m m})$ & $\mathbf{t}_{2}(\mathrm{~mm})$ & & & & \\
\hline \multirow{20}{*}{12} & 200 & 200 & 1 & -1.14 & -65.99 & -2.94 \\
\hline & & 240 & 1.2 & -0.79 & -70.00 & -3.28 \\
\hline & & 300 & 1.5 & -0.50 & -74.46 & -3.67 \\
\hline & & 400 & 2 & -0.26 & -79.32 & -4.12 \\
\hline & 225 & 225 & 1 & -0.85 & -67.96 & -3.14 \\
\hline & & 270 & 1.2 & -0.58 & -71.77 & -3.46 \\
\hline & & 337.5 & 1.5 & -0.36 & -75.94 & -3.83 \\
\hline & & 450 & 2 & -0.19 & -80.43 & -4.25 \\
\hline & 250 & 250 & 1 & -0.64 & -69.54 & -3.30 \\
\hline & & 300 & 1.2 & -0.44 & -73.16 & -3.61 \\
\hline & & 375 & 1.5 & -0.27 & -77.09 & -3.96 \\
\hline & & 500 & 2 & -0.14 & -81.27 & -4.35 \\
\hline & 300 & 300 & 1 & -0.40 & -71.86 & -3.56 \\
\hline & & 360 & 1.2 & -0.27 & -75.17 & -3.84 \\
\hline & & 450 & 1.5 & -0.16 & -78.70 & -4.15 \\
\hline & & 600 & 2 & -0.08 & -82.41 & -4.48 \\
\hline & 350 & 350 & 1 & -0.26 & -73.41 & -3.74 \\
\hline & & 420 & 1.2 & -0.18 & -76.48 & -4.00 \\
\hline & & 525 & 1.5 & -0.11 & -79.73 & -4.27 \\
\hline & & 700 & 2 & -0.05 & -83.12 & -4.57 \\
\hline
\end{tabular}


Table A-7: Summary of Maximum deflection, Transverse Moment and Longitudinal Moment in Cantilevered Slab with Concrete Curb of Length 2 m

\begin{tabular}{|c|c|c|c|c|c|c|}
\hline \multicolumn{7}{|c|}{ Cantilever length: $2 \mathrm{~m}$} \\
\hline \multirow{2}{*}{$\begin{array}{c}\text { Barrier length } \\
(\mathrm{m})\end{array}$} & \multicolumn{2}{|c|}{ Slab thickness } & \multirow[t]{2}{*}{$\mathbf{t}_{2} / \mathrm{t}_{1}$} & \multirow{2}{*}{$\begin{array}{c}\boldsymbol{\Delta} \\
(\mathbf{m m})\end{array}$} & \multirow{2}{*}{$\begin{array}{c}\mathbf{M}_{\mathbf{y}} \\
(\mathbf{k N} \cdot \mathbf{m m} / \mathbf{m m})\end{array}$} & \multirow{2}{*}{$\begin{array}{c}\mathbf{M}_{\mathbf{x}} \\
(\mathbf{k N} \cdot \mathbf{m m} / \mathbf{m m})\end{array}$} \\
\hline & $\mathbf{t}_{1}(\mathbf{m m})$ & $\mathbf{t}_{2}(\mathbf{m m})$ & & & & \\
\hline \multirow{20}{*}{5} & 200 & 200 & 1 & -3.36 & -88.96 & -5.90 \\
\hline & & 240 & 1.2 & -2.32 & -93.85 & -6.32 \\
\hline & & 300 & 1.5 & -1.45 & -99.69 & -6.82 \\
\hline & & 400 & 2 & -0.78 & -106.64 & -7.41 \\
\hline & 225 & 225 & 1 & -2.44 & -90.90 & -6.14 \\
\hline & & 270 & 1.2 & -1.68 & -95.80 & -6.55 \\
\hline & & 337.5 & 1.5 & -1.05 & -101.54 & -7.03 \\
\hline & & 450 & 2 & -0.56 & -108.22 & -7.59 \\
\hline & 250 & 250 & 1 & -1.83 & -92.60 & -6.35 \\
\hline & & 300 & 1.2 & -1.26 & -97.45 & -6.75 \\
\hline & & 375 & 1.5 & -0.79 & -103.06 & -7.21 \\
\hline & & 500 & 2 & -0.42 & -109.46 & -7.74 \\
\hline & 300 & 300 & 1 & -1.11 & -95.29 & -6.68 \\
\hline & & 360 & 1.2 & -0.76 & -99.98 & -7.06 \\
\hline & & 450 & 1.5 & -0.47 & -105.29 & -7.48 \\
\hline & & 600 & 2 & -0.25 & -111.20 & -7.95 \\
\hline & 350 & 350 & 1 & -0.72 & -97.20 & -6.92 \\
\hline & & 420 & 1.2 & -0.76 & -99.98 & -7.06 \\
\hline & & 525 & 1.5 & -0.31 & -106.76 & -7.66 \\
\hline & & 700 & 2 & -0.16 & -112.30 & -8.08 \\
\hline \multirow{20}{*}{6} & 200 & 200 & 1 & -3.24 & -87.02 & -5.80 \\
\hline & & 240 & 1.2 & -2.26 & -92.41 & -6.24 \\
\hline & & 300 & 1.5 & $\begin{array}{l}-1.43 \\
\end{array}$ & -98.74 & -6.77 \\
\hline & & 400 & 2 & -0.77 & -106.14 & -7.38 \\
\hline & 225 & 225 & 1 & \begin{tabular}{|l|}
-2.38 \\
\end{tabular} & -89.44 & -6.06 \\
\hline & & 270 & 1.2 & -1.65 & -94.75 & -6.50 \\
\hline & & 337.5 & 1.5 & -1.04 & -100.88 & $\begin{array}{l}-7.00 \\
\end{array}$ \\
\hline & & 450 & 2 & -0.56 & -107.89 & -7.58 \\
\hline & 250 & 250 & 1 & $\begin{array}{l}-1.79 \\
\end{array}$ & -91.49 & -6.29 \\
\hline & & 300 & 1.2 & -1.25 & -96.68 & -6.71 \\
\hline & & 375 & 1.5 & -0.78 & -102.59 & $\begin{array}{l}-7.19 \\
\end{array}$ \\
\hline & & 500 & 2 & $\begin{array}{l}-0.42 \\
\end{array}$ & -109.23 & $\begin{array}{l}-7.73 \\
\end{array}$ \\
\hline & 300 & 300 & 1 & -1.10 & -94.61 & -6.65 \\
\hline & & 360 & 1.2 & -0.76 & -99.54 & -7.04 \\
\hline & & 450 & 1.5 & -0.47 & -105.03 & -7.47 \\
\hline & & 600 & 2 & -0.25 & -111.08 & -7.94 \\
\hline & 350 & 350 & 1 & -0.72 & -96.76 & -6.90 \\
\hline & & 420 & 1.2 & -0.76 & -99.54 & -7.04 \\
\hline & & 525 & 1.5 & -0.31 & -106.61 & -7.65 \\
\hline & & 700 & 2 & -0.16 & -112.23 & -8.08 \\
\hline
\end{tabular}




\begin{tabular}{|c|c|c|c|c|c|c|}
\hline \multicolumn{7}{|c|}{ Cantilever length: $2 \mathrm{~m}$} \\
\hline \multirow{2}{*}{$\begin{array}{c}\text { Barrier length } \\
(\mathrm{m})\end{array}$} & \multicolumn{2}{|c|}{ Slab thickness } & \multirow[t]{2}{*}{$\overline{t_{2} / \mathbf{t}_{1}}$} & \multirow{2}{*}{$\begin{array}{c}\boldsymbol{\Delta} \\
(\mathbf{m m})\end{array}$} & \multirow{2}{*}{$\begin{array}{c}\mathbf{M}_{\mathbf{y}} \\
(\mathbf{k N} \cdot \mathbf{m m} / \mathbf{m m})\end{array}$} & \multirow{2}{*}{$\begin{array}{c}\mathbf{M}_{\mathbf{x}} \\
(\mathbf{k N} \cdot \mathbf{m m} / \mathbf{m m})\end{array}$} \\
\hline & $\mathbf{t}_{\mathbf{1}}(\mathbf{m m})$ & $\mathbf{t}_{2}(\mathrm{~mm})$ & & & & \\
\hline \multirow{20}{*}{8} & 200 & 200 & 1 & -3.16 & -85.67 & -5.73 \\
\hline & & 240 & 1.2 & -2.22 & -91.49 & -6.20 \\
\hline & & 300 & 1.5 & -1.42 & -98.20 & -6.74 \\
\hline & & 400 & 2 & -0.77 & -105.89 & -7.37 \\
\hline & 225 & 225 & 1 & -2.33 & -88.52 & -6.02 \\
\hline & & 270 & 1.2 & -1.64 & -94.14 & -6.47 \\
\hline & & 337.5 & 1.5 & -1.04 & -100.53 & -6.98 \\
\hline & & 450 & 2 & -0.56 & -107.73 & -7.57 \\
\hline & 250 & 250 & 1 & -1.77 & -90.84 & -6.26 \\
\hline & & 300 & 1.2 & -1.24 & -96.26 & -6.69 \\
\hline & & 375 & 1.5 & -0.78 & -102.35 & -7.18 \\
\hline & & 500 & 2 & -0.42 & -109.12 & -7.72 \\
\hline & 300 & 300 & 1 & -1.09 & -94.27 & -6.63 \\
\hline & & 360 & 1.2 & -0.75 & -99.32 & -7.03 \\
\hline & & 450 & 1.5 & -0.47 & -104.91 & -7.46 \\
\hline & & 600 & 2 & -0.25 & -111.03 & -7.94 \\
\hline & 350 & 350 & 1 & -0.71 & -96.56 & -6.90 \\
\hline & & 420 & 1.2 & -0.75 & -99.32 & -7.03 \\
\hline & & 525 & 1.5 & -0.31 & -106.54 & -7.65 \\
\hline & & 700 & 2 & -0.16 & -112.21 & -8.08 \\
\hline \multirow{19}{*}{10} & 200 & 200 & 1 & -3.14 & -85.40 & -5.71 \\
\hline & & 240 & 1.2 & -2.21 & -91.32 & -6.19 \\
\hline & & 300 & 1.5 & -1.41 & -98.11 & -6.74 \\
\hline & & 400 & 2 & -0.77 & -105.85 & -7.37 \\
\hline & 225 & 225 & 1 & -2.33 & -88.35 & -6.01 \\
\hline & & 270 & 1.2 & -1.63 & -94.04 & -6.46 \\
\hline & & 337.5 & 1.5 & -1.04 & -100.48 & -6.98 \\
\hline & & 450 & 2 & -0.56 & -107.71 & -7.57 \\
\hline & 250 & 250 & 1 & -1.77 & -90.73 & -6.25 \\
\hline & & 300 & 1.2 & -1.24 & -96.19 & -6.69 \\
\hline & & 375 & 1.5 & -0.78 & -102.32 & -7.18 \\
\hline & & 500 & 2 & -0.42 & -109.11 & -7.72 \\
\hline & 300 & 300 & 1 & -1.09 & -94.21 & -6.63 \\
\hline & & 360 & 1.2 & -0.75 & -99.29 & -7.03 \\
\hline & & 450 & 1.5 & -0.47 & -104.90 & -7.46 \\
\hline & & 600 & 2 & -0.25 & -111.03 & -7.94 \\
\hline & 350 & 350 & 1 & -0.71 & -96.53 & -6.89 \\
\hline & & 420 & 1.2 & -0.75 & -99.29 & -7.03 \\
\hline & & 525 & 1.5 & -0.31 & -106.54 & -7.65 \\
\hline
\end{tabular}




\begin{tabular}{|l|l|l|l|l|l|l|}
\hline & 700 & 2 & -0.16 & -112.20 & -8.08 \\
\hline \hline
\end{tabular}

\begin{tabular}{|c|c|c|c|c|c|c|}
\hline \multirow{2}{*}{$\begin{array}{l}\text { Barrier length } \\
(\mathrm{m})\end{array}$} & \multicolumn{2}{|c|}{ Slab thickness } & \multirow[t]{2}{*}{$\overline{t_{2} / \mathbf{t}_{1}}$} & \multirow{2}{*}{$\begin{array}{c}\Delta \\
(\mathbf{m m})\end{array}$} & \multirow{2}{*}{$\begin{array}{c}\mathbf{M}_{\mathbf{y}} \\
(\mathbf{k N} \cdot \mathbf{m m} / \mathbf{m m})\end{array}$} & \multirow{2}{*}{$\begin{array}{c}\mathbf{M}_{\mathbf{x}} \\
(\mathrm{kN} \cdot \mathbf{m m} / \mathbf{m m})\end{array}$} \\
\hline & $\mathbf{t}_{1}(\mathrm{~mm})$ & $\mathbf{t}_{2}(\mathrm{~mm})$ & & & & \\
\hline \multirow{20}{*}{12} & 200 & 200 & 1 & -3.14 & -85.34 & -5.71 \\
\hline & & 240 & 1.2 & -2.21 & -91.29 & -6.19 \\
\hline & & 300 & 1.5 & -1.41 & -98.10 & -6.74 \\
\hline & & 400 & 2 & -0.77 & -105.85 & -7.37 \\
\hline & 225 & 225 & 1 & -2.32 & -88.31 & -6.01 \\
\hline & & 270 & 1.2 & -1.63 & -94.02 & -6.46 \\
\hline & & 337.5 & 1.5 & -1.04 & -100.47 & -6.98 \\
\hline & & 450 & 2 & -0.56 & -107.70 & -7.57 \\
\hline & 250 & 250 & 1 & -1.77 & -90.71 & -6.25 \\
\hline & & 300 & 1.2 & -1.23 & -96.18 & -6.69 \\
\hline & & 375 & 1.5 & -0.78 & -102.31 & -7.18 \\
\hline & & 500 & 2 & -0.42 & -109.11 & -7.72 \\
\hline & 300 & 300 & 1 & -1.09 & -94.20 & -6.63 \\
\hline & & 360 & 1.2 & -0.75 & -99.28 & -7.03 \\
\hline & & 450 & 1.5 & -0.47 & -104.89 & -7.46 \\
\hline & & 600 & 2 & -0.25 & -111.02 & -7.94 \\
\hline & 350 & 350 & 1 & -0.71 & -96.52 & -6.89 \\
\hline & & 420 & 1.2 & -0.75 & -99.28 & -7.03 \\
\hline & & 525 & 1.5 & -0.31 & -106.53 & -7.65 \\
\hline & & 700 & 2 & -0.16 & -112.20 & -8.08 \\
\hline
\end{tabular}


Table A-8: Summary of Maximum deflection, Transverse Moment and Longitudinal Moment in Cantilevered Slab with Concrete Curb of Length $2.5 \mathrm{~m}$

\begin{tabular}{|c|c|c|c|c|c|c|}
\hline \multicolumn{7}{|c|}{ Cantilever length: $2.5 \mathrm{~m}$} \\
\hline \multirow{2}{*}{$\begin{array}{c}\text { Barrier length } \\
(\mathrm{m})\end{array}$} & \multicolumn{2}{|c|}{ Slab thickness } & \multirow[t]{2}{*}{$\mathbf{t}_{2} / \mathbf{t}_{1}$} & \multirow{2}{*}{$\begin{array}{c}\boldsymbol{\Delta} \\
(\mathbf{m m})\end{array}$} & \multirow{2}{*}{$\begin{array}{c}\mathbf{M}_{\mathbf{y}} \\
(\mathbf{k N} \cdot \mathbf{m m} / \mathbf{m m})\end{array}$} & \multirow{2}{*}{$\begin{array}{c}\mathbf{M}_{\mathbf{x}} \\
(\mathbf{k N} \cdot \mathbf{m m} / \mathbf{m m})\end{array}$} \\
\hline & $\mathbf{t}_{1}(\mathbf{m m})$ & $\mathrm{t}_{2}(\mathrm{~mm})$ & & & & \\
\hline \multirow{20}{*}{5} & 200 & 200 & 1 & -8.21 & -114.29 & -7.13 \\
\hline & & 240 & 1.2 & -5.59 & -118.49 & -7.37 \\
\hline & & 300 & 1.5 & -3.45 & -123.52 & $\begin{array}{l}-7.62 \\
\end{array}$ \\
\hline & & 400 & 2 & -1.82 & -129.60 & -7.89 \\
\hline & 225 & 225 & 1 & -5.87 & -115.46 & -7.26 \\
\hline & & 270 & 1.2 & -4.00 & -119.72 & -7.49 \\
\hline & & 337.5 & 1.5 & -2.48 & -124.76 & -7.73 \\
\hline & & 450 & 2 & -1.31 & -130.74 & -7.98 \\
\hline & 250 & 250 & 1 & -4.35 & -116.52 & -7.36 \\
\hline & & 300 & 1.2 & -2.97 & -120.80 & -7.59 \\
\hline & & 375 & 1.5 & -1.84 & -125.81 & -7.82 \\
\hline & & 500 & 2 & -0.97 & -131.68 & -8.04 \\
\hline & 300 & 300 & 1 & -2.59 & -118.27 & -7.53 \\
\hline & & 360 & 1.2 & -1.77 & -122.51 & -7.74 \\
\hline & & 450 & 1.5 & -1.09 & -127.42 & -7.95 \\
\hline & & 600 & 2 & -0.57 & -133.04 & -8.14 \\
\hline & 350 & 350 & 1 & -1.66 & -119.55 & -7.65 \\
\hline & & 420 & 1.2 & -1.13 & -123.74 & $\begin{array}{l}-7.84 \\
\end{array}$ \\
\hline & & 525 & 1.5 & -0.70 & -128.52 & -8.03 \\
\hline & & 700 & 2 & -0.37 & -133.93 & -8.19 \\
\hline \multirow{20}{*}{6} & 200 & 200 & 1 & -7.76 & -110.24 & $\begin{array}{l}-6.92 \\
\end{array}$ \\
\hline & & 240 & 1.2 & -5.34 & -115.23 & -7.21 \\
\hline & & 300 & 1.5 & -3.35 & -121.15 & -7.51 \\
\hline & & 400 & 2 & $\begin{array}{l}-1.79 \\
\end{array}$ & -128.16 & \begin{tabular}{|l|}
-7.83 \\
\end{tabular} \\
\hline & 225 & 225 & 1 & -5.60 & -112.08 & $\begin{array}{l}-7.09 \\
\end{array}$ \\
\hline & & 270 & 1.2 & -3.86 & -117.07 & $\begin{array}{l}-7.37 \\
\end{array}$ \\
\hline & & 337.5 & 1.5 & -2.41 & -122.90 & -7.65 \\
\hline & & 450 & 2 & -1.29 & -129.67 & -7.94 \\
\hline & 250 & 250 & 1 & -4.18 & -113.68 & -7.23 \\
\hline & & 300 & 1.2 & -2.88 & -118.63 & $\begin{array}{l}-7.50 \\
\end{array}$ \\
\hline & & 375 & 1.5 & -1.80 & -124.34 & -7.76 \\
\hline & & 500 & 2 & -0.96 & -130.86 & -8.02 \\
\hline & 300 & 300 & 1 & -2.51 & -116.17 & -7.45 \\
\hline & & 360 & 1.2 & -1.73 & -120.98 & $\begin{array}{l}-7.69 \\
\end{array}$ \\
\hline & & 450 & 1.5 & -1.08 & -126.43 & $\begin{array}{l}-7.92 \\
\end{array}$ \\
\hline & & 600 & 2 & -0.57 & -132.52 & -8.12 \\
\hline & 350 & 350 & 1 & -1.62 & -117.91 & $\begin{array}{l}-7.59 \\
\end{array}$ \\
\hline & & 420 & 1.2 & -1.12 & -122.57 & -7.81 \\
\hline & & 525 & 1.5 & $\begin{array}{l}-0.69 \\
\end{array}$ & -127.80 & -8.01 \\
\hline & & 700 & 2 & -0.37 & -133.56 & $\begin{array}{l}-8.18 \\
\end{array}$ \\
\hline
\end{tabular}




\begin{tabular}{|c|c|c|c|c|c|c|}
\hline \multicolumn{7}{|c|}{ "Cantilever length: $2.5 \mathrm{~m}$} \\
\hline \multirow{2}{*}{$\begin{array}{c}\text { Barrier length } \\
(\mathrm{m})\end{array}$} & \multicolumn{2}{|c|}{ Slab thickness } & \multirow[t]{2}{*}{$\overline{\mathbf{t}_{2} / \mathbf{t}_{1}}$} & \multirow{2}{*}{$\begin{array}{c}\boldsymbol{\Delta} \\
(\mathbf{m m})\end{array}$} & \multirow{2}{*}{$\begin{array}{c}\mathbf{M}_{\mathbf{y}} \\
(\mathbf{k N} \cdot \mathbf{m m} / \mathbf{m m})\end{array}$} & \multirow{2}{*}{$\begin{array}{c}\mathbf{M}_{\mathbf{x}} \\
(\mathbf{k N} \cdot \mathbf{m m} / \mathbf{m m})\end{array}$} \\
\hline & $\mathbf{t}_{1}(\mathrm{~mm})$ & $t_{2}(\mathrm{~mm})$ & & & & \\
\hline \multirow{20}{*}{8} & 200 & 200 & 1 & -7.36 & -106.63 & -6.74 \\
\hline & & 240 & 1.2 & -5.14 & -112.54 & -7.08 \\
\hline & & 300 & 1.5 & -3.27 & -119.39 & -7.43 \\
\hline & & 400 & 2 & -1.77 & -127.24 & -7.79 \\
\hline & 225 & 225 & 1 & -5.38 & -109.36 & -6.96 \\
\hline & & 270 & 1.2 & -3.75 & -115.12 & -7.28 \\
\hline & & 337.5 & 1.5 & -2.37 & -121.68 & -7.60 \\
\hline & & 450 & 2 & -1.28 & -129.06 & -7.91 \\
\hline & 250 & 250 & 1 & -4.05 & -111.59 & -7.14 \\
\hline & & 300 & 1.2 & -2.82 & -117.17 & -7.44 \\
\hline & & 375 & 1.5 & -1.78 & -123.45 & -7.73 \\
\hline & & 500 & 2 & -0.95 & -130.43 & -8.00 \\
\hline & 300 & 300 & 1 & -2.46 & -114.87 & -7.40 \\
\hline & & 360 & 1.2 & -1.71 & -120.12 & -7.66 \\
\hline & & 450 & 1.5 & -1.07 & -125.93 & -7.90 \\
\hline & & 600 & 2 & -0.57 & -132.29 & -8.11 \\
\hline & 350 & 350 & 1 & -1.60 & -117.02 & -7.57 \\
\hline & & 420 & 1.2 & -1.11 & -122.01 & $\begin{array}{l}-7.79 \\
\end{array}$ \\
\hline & & 525 & 1.5 & -0.69 & -127.49 & -8.00 \\
\hline & & 700 & 2 & -0.37 & -133.43 & -8.18 \\
\hline \multirow{20}{*}{10} & 200 & 200 & 1 & -7.23 & -105.58 & -6.69 \\
\hline & & 240 & 1.2 & -5.09 & -111.85 & -7.05 \\
\hline & & 300 & 1.5 & -3.25 & -119.00 & -7.42 \\
\hline & & 400 & 2 & -1.77 & -127.06 & -7.78 \\
\hline & 225 & 225 & 1 & -5.32 & -108.66 & -6.93 \\
\hline & & 270 & 1.2 & -3.73 & -114.67 & -7.26 \\
\hline & & 337.5 & 1.5 & -2.37 & -121.43 & $\begin{array}{l}-7.59 \\
\end{array}$ \\
\hline & & 450 & 2 & -1.28 & -128.95 & -7.91 \\
\hline & 250 & 250 & 1 & -4.02 & -111.11 & -7.13 \\
\hline & & 300 & 1.2 & -2.81 & -116.87 & -7.43 \\
\hline & & 375 & 1.5 & -1.77 & -123.29 & -7.72 \\
\hline & & 500 & 2 & -0.95 & -130.36 & -8.00 \\
\hline & 300 & 300 & 1 & -2.45 & -114.62 & $\begin{array}{l}-7.39 \\
\end{array}$ \\
\hline & & 360 & 1.2 & -1.70 & -119.97 & -7.65 \\
\hline & & 450 & 1.5 & -1.07 & -125.85 & -7.90 \\
\hline & & 600 & 2 & -0.57 & -132.26 & -8.11 \\
\hline & 350 & 350 & 1 & -1.60 & -116.88 & -7.56 \\
\hline & & 420 & 1.2 & -1.10 & -121.93 & -7.79 \\
\hline & & 525 & 1.5 & -0.69 & -127.45 & -8.00 \\
\hline & & 700 & 2 & -0.36 & -133.41 & -8.18 \\
\hline
\end{tabular}




\begin{tabular}{|c|c|c|c|c|c|c|}
\hline \multicolumn{7}{|c|}{ Cantilever length: $2.5 \mathrm{~m}$} \\
\hline \multirow{2}{*}{$\begin{array}{c}\text { Barrier length } \\
(\mathrm{m})\end{array}$} & \multicolumn{2}{|c|}{ Slab thickness } & \multirow[t]{2}{*}{$\overline{\mathbf{t}_{2} / \mathbf{t}_{1}}$} & \multirow{2}{*}{$\begin{array}{c}\boldsymbol{\Delta} \\
(\mathbf{m m})\end{array}$} & \multirow{2}{*}{$\begin{array}{c}\mathbf{M}_{\mathbf{y}} \\
(\mathbf{k N} / \mathbf{m m} . \mathbf{m m})\end{array}$} & \multirow{2}{*}{$\begin{array}{c}\mathbf{M}_{\mathbf{x}} \\
(\mathbf{k N} \cdot \mathbf{m m} / \mathbf{m m})\end{array}$} \\
\hline & $\mathbf{t}_{\mathbf{1}}(\mathbf{m m})$ & $t_{2}(\mathrm{~mm})$ & & & & \\
\hline \multirow{20}{*}{12} & 200 & 200 & 1 & -7.20 & -105.30 & -6.68 \\
\hline & & 240 & 1.2 & -5.08 & -111.68 & -7.04 \\
\hline & & 300 & 1.5 & -3.24 & -118.91 & -7.41 \\
\hline & & 400 & 2 & -1.76 & -127.03 & $\begin{array}{l}-7.78 \\
\end{array}$ \\
\hline & 225 & 225 & 1 & -5.30 & -108.48 & -6.93 \\
\hline & & 270 & 1.2 & -3.72 & -114.56 & -7.26 \\
\hline & & 337.5 & 1.5 & -2.36 & -121.37 & -7.59 \\
\hline & & 450 & 2 & -1.28 & -128.93 & -7.91 \\
\hline & 250 & 250 & 1 & -4.01 & -111.00 & -7.12 \\
\hline & & 300 & 1.2 & -2.80 & -116.80 & -7.42 \\
\hline & & 375 & 1.5 & -1.77 & -123.25 & -7.72 \\
\hline & & 500 & 2 & -0.95 & -130.35 & -8.00 \\
\hline & 300 & 300 & 1 & -2.45 & -114.57 & -7.39 \\
\hline & & 360 & 1.2 & -1.70 & -119.94 & -7.65 \\
\hline & & 450 & 1.5 & -1.07 & -125.84 & -7.90 \\
\hline & & 600 & 2 & -0.57 & -132.25 & -8.11 \\
\hline & 350 & 350 & 1 & -1.60 & -116.86 & -7.56 \\
\hline & & 420 & 1.2 & -1.10 & -121.92 & -7.79 \\
\hline & & 525 & 1.5 & -0.69 & -127.44 & -8.00 \\
\hline & & 700 & 2 & -0.36 & -133.41 & -8.18 \\
\hline
\end{tabular}


Table A-9: Summary of Maximum deflection, Transverse Moment and Longitudinal Moment in Cantilevered Slab with Tl-2 Barrier of Length 1 m

\begin{tabular}{|c|c|c|c|c|c|c|}
\hline \multicolumn{7}{|c|}{ Cantilever length: 1 m } \\
\hline \multirow{2}{*}{$\begin{array}{c}\text { Barrier length } \\
(\mathrm{m})\end{array}$} & \multicolumn{2}{|c|}{ Slab thickness } & \multirow[t]{2}{*}{$\overline{t_{2} / \mathbf{t}_{1}}$} & \multirow{2}{*}{$\begin{array}{c}\Delta \\
(\mathbf{m m})\end{array}$} & \multirow{2}{*}{$\begin{array}{c}\mathbf{M}_{\mathbf{y}} \\
(\mathbf{k N} \cdot \mathbf{m m} / \mathbf{m m})\end{array}$} & \multirow{2}{*}{$\begin{array}{c}\mathbf{M}_{\mathbf{x}} \\
(\mathbf{k N} \cdot \mathbf{m m} / \mathbf{m m})\end{array}$} \\
\hline & $\mathbf{t}_{1}(\mathbf{m m})$ & $\mathrm{t}_{2}(\mathrm{~mm})$ & & & & \\
\hline \multirow{20}{*}{5} & 200 & 200 & 1 & -0.12 & -24.68 & -0.88 \\
\hline & & 240 & 1.2 & $\begin{array}{l}-0.09 \\
\end{array}$ & -26.41 & -0.98 \\
\hline & & 300 & 1.5 & $\begin{array}{l}-0.05 \\
\end{array}$ & -27.69 & -1.08 \\
\hline & & 400 & 2 & -0.03 & -29.12 & -1.20 \\
\hline & 225 & 225 & 1 & -0.09 & -25.22 & -0.90 \\
\hline & & 270 & 1.2 & -0.06 & -26.95 & -1.01 \\
\hline & & 337.5 & 1.5 & -0.04 & -28.18 & -1.11 \\
\hline & & 450 & 2 & -0.02 & -29.52 & -1.23 \\
\hline & 250 & 250 & 1 & -0.07 & -25.71 & -0.93 \\
\hline & & 300 & 1.2 & -0.05 & -27.42 & -1.04 \\
\hline & & 375 & 1.5 & -0.03 & -28.60 & -1.13 \\
\hline & & 500 & 2 & -0.01 & -29.84 & -1.25 \\
\hline & 300 & 300 & 1 & -0.04 & -26.51 & -0.97 \\
\hline & & 360 & 1.2 & -0.03 & -28.17 & -1.08 \\
\hline & & 450 & 1.5 & -0.02 & -29.23 & -1.17 \\
\hline & & 600 & 2 & -0.01 & -30.31 & -1.28 \\
\hline & 350 & 350 & 1 & -0.03 & -27.11 & -1.01 \\
\hline & & 420 & 1.2 & -0.02 & -28.72 & -1.11 \\
\hline & & 525 & 1.5 & -0.01 & -29.67 & -1.20 \\
\hline & & 700 & 2 & -0.01 & -30.62 & -1.30 \\
\hline \multirow{20}{*}{6} & 200 & 200 & 1 & -0.12 & -24.44 & -0.87 \\
\hline & & 240 & 1.2 & -0.08 & -26.23 & -0.98 \\
\hline & & 300 & 1.5 & -0.05 & -27.58 & -1.08 \\
\hline & & 400 & 2 & -0.03 & -29.07 & -1.20 \\
\hline & 225 & 225 & 1 & -0.09 & -25.05 & -0.90 \\
\hline & & 270 & 1.2 & -0.06 & -26.83 & -1.01 \\
\hline & & 337.5 & 1.5 & -0.04 & -28.11 & -1.11 \\
\hline & & 450 & 2 & -0.02 & -29.49 & -1.22 \\
\hline & 250 & 250 & 1 & -0.07 & -25.58 & -0.92 \\
\hline & & 300 & 1.2 & -0.05 & -27.33 & -1.03 \\
\hline & & 375 & 1.5 & -0.03 & -28.54 & -1.13 \\
\hline & & 500 & 2 & $\begin{array}{l}-0.01 \\
\end{array}$ & -29.82 & -1.25 \\
\hline & 300 & 300 & 1 & -0.04 & -26.43 & -0.97 \\
\hline & & 360 & 1.2 & -0.03 & -28.12 & -1.08 \\
\hline & & 450 & 1.5 & -0.02 & -29.20 & -1.17 \\
\hline & & 600 & 2 & -0.01 & -30.30 & -1.28 \\
\hline & 350 & 350 & 1 & -0.03 & -27.06 & -1.01 \\
\hline & & 420 & 1.2 & -0.02 & -28.68 & -1.11 \\
\hline & & 525 & 1.5 & -0.01 & -29.65 & -1.20 \\
\hline & & 700 & 2 & -0.01 & -30.61 & -1.30 \\
\hline
\end{tabular}




\begin{tabular}{|c|c|c|c|c|c|c|}
\hline \multicolumn{7}{|c|}{ "Cantilever length: 1 m } \\
\hline \multirow{2}{*}{$\begin{array}{c}\text { Barrier length } \\
(\mathbf{m})\end{array}$} & \multicolumn{2}{|c|}{ Slab thickness } & \multirow[t]{2}{*}{$\mathbf{t}_{2} / \mathbf{t}_{1}$} & \multirow{2}{*}{$\underset{(\mathbf{m m})}{\Delta}$} & \multirow{2}{*}{$\begin{array}{c}\mathbf{M}_{\mathbf{y}} \\
(\mathbf{k N} \cdot \mathbf{m m} / \mathbf{m m})\end{array}$} & \multirow{2}{*}{$\begin{array}{c}\mathbf{M}_{\mathbf{x}} \\
(\mathbf{k N} \cdot \mathbf{m m} / \mathbf{m m})\end{array}$} \\
\hline & $\mathbf{t}_{\mathbf{1}}(\mathbf{m m})$ & $\mathbf{t}_{2}(\mathbf{m m})$ & & & & \\
\hline \multirow{20}{*}{8} & 200 & 200 & 1 & -0.12 & -24.31 & -0.86 \\
\hline & & 240 & 1.2 & -0.08 & -26.14 & -0.97 \\
\hline & & 300 & 1.5 & -0.05 & -27.53 & -1.07 \\
\hline & & 400 & 2 & -0.03 & -29.05 & -1.20 \\
\hline & 225 & 225 & 1 & -0.09 & -24.96 & -0.89 \\
\hline & & 270 & 1.2 & -0.06 & -26.77 & -1.00 \\
\hline & & 337.5 & 1.5 & -0.04 & -28.08 & -1.10 \\
\hline & & 450 & 2 & -0.02 & -29.48 & -1.22 \\
\hline & 250 & 250 & 1 & -0.07 & -25.51 & -0.92 \\
\hline & & 300 & 1.2 & -0.05 & -27.29 & -1.03 \\
\hline & & 375 & 1.5 & -0.03 & -28.52 & -1.13 \\
\hline & & 500 & 2 & -0.01 & -29.81 & -1.25 \\
\hline & 300 & 300 & 1 & -0.04 & -26.40 & -0.97 \\
\hline & & 360 & 1.2 & -0.03 & -28.10 & -1.08 \\
\hline & & 450 & 1.5 & -0.02 & -29.19 & -1.17 \\
\hline & & 600 & 2 & -0.01 & -30.30 & -1.28 \\
\hline & 350 & 350 & 1 & -0.03 & -27.04 & -1.01 \\
\hline & & 420 & 1.2 & -0.02 & -28.67 & -1.11 \\
\hline & & 525 & 1.5 & -0.01 & -29.65 & -1.20 \\
\hline & & 700 & 2 & -0.01 & -30.61 & -1.30 \\
\hline \multirow{20}{*}{10} & 200 & 200 & 1 & -0.12 & -24.29 & -0.86 \\
\hline & & 240 & 1.2 & -0.08 & -26.13 & -0.97 \\
\hline & & 300 & 1.5 & -0.05 & -27.53 & -1.07 \\
\hline & & 400 & 2 & -0.03 & -29.05 & -1.20 \\
\hline & 225 & 225 & 1 & -0.09 & -24.95 & -0.89 \\
\hline & & 270 & 1.2 & -0.06 & -26.76 & -1.00 \\
\hline & & 337.5 & 1.5 & -0.04 & -28.08 & -1.10 \\
\hline & & 450 & 2 & -0.02 & -29.48 & -1.22 \\
\hline & 250 & 250 & 1 & -0.07 & -25.51 & -0.92 \\
\hline & & 300 & 1.2 & -0.05 & -27.28 & -1.03 \\
\hline & & 375 & 1.5 & -0.03 & -28.52 & -1.13 \\
\hline & & 500 & 2 & -0.01 & -29.81 & -1.25 \\
\hline & 300 & 300 & 1 & -0.04 & -26.39 & -0.97 \\
\hline & & 360 & 1.2 & -0.03 & -28.09 & -1.08 \\
\hline & & 450 & 1.5 & -0.02 & -29.19 & -1.17 \\
\hline & & 600 & 2 & -0.01 & -30.30 & -1.28 \\
\hline & 350 & 350 & 1 & -0.03 & -27.04 & -1.01 \\
\hline & & 420 & 1.2 & -0.02 & -28.67 & -1.11 \\
\hline & & 525 & 1.5 & -0.01 & -29.65 & -1.20 \\
\hline & & 700 & 2 & -0.01 & -30.61 & -1.30 \\
\hline
\end{tabular}




\begin{tabular}{|c|c|c|c|c|c|c|}
\hline \multicolumn{7}{|c|}{ Cantilever length: 1 m } \\
\hline \multirow{2}{*}{$\begin{array}{c}\text { Barrier length } \\
(\mathrm{m})\end{array}$} & \multicolumn{2}{|c|}{ Slab thickness } & \multirow{3}{*}{$\begin{array}{c}\mathbf{t}_{2} / \mathbf{t}_{1} \\
\\
1 \\
1\end{array}$} & \multirow{3}{*}{$\begin{array}{c}\begin{array}{c}\Delta \\
(\mathbf{m m})\end{array} \\
-0.12\end{array}$} & \multirow{3}{*}{$\begin{array}{c}\begin{array}{c}\mathbf{M}_{\mathbf{y}} \\
(\mathbf{k N} \cdot \mathbf{m m} / \mathbf{m m})\end{array} \\
-24.28\end{array}$} & \multirow{3}{*}{ 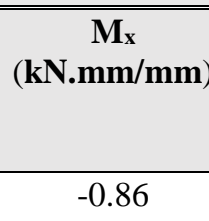 } \\
\hline & $\mathbf{t}_{1}(\mathbf{m m})$ & $\mathbf{t}_{2}(\mathrm{~mm})$ & & & & \\
\hline \multirow{20}{*}{12} & 200 & 200 & & & & \\
\hline & & 240 & 1.2 & -0.08 & -26.13 & -0.97 \\
\hline & & 300 & 1.5 & -0.05 & -27.53 & -1.07 \\
\hline & & 400 & 2 & -0.03 & -29.05 & -1.20 \\
\hline & 225 & 225 & 1 & -0.09 & -24.94 & -0.89 \\
\hline & & 270 & 1.2 & -0.06 & -26.76 & -1.00 \\
\hline & & 337.5 & 1.5 & -0.04 & -28.08 & -1.10 \\
\hline & & 450 & 2 & -0.02 & -29.48 & -1.22 \\
\hline & 250 & 250 & 1 & -0.07 & -25.51 & -0.92 \\
\hline & & 300 & 1.2 & -0.05 & -27.28 & -1.03 \\
\hline & & 375 & 1.5 & -0.03 & -28.52 & -1.13 \\
\hline & & 500 & 2 & -0.01 & -29.81 & -1.25 \\
\hline & 300 & 300 & 1 & -0.04 & -26.39 & -0.97 \\
\hline & & 360 & 1.2 & -0.03 & -28.09 & -1.08 \\
\hline & & 450 & 1.5 & -0.02 & -29.19 & -1.17 \\
\hline & & 600 & 2 & -0.01 & -30.30 & -1.28 \\
\hline & 350 & 350 & 1 & -0.03 & -27.04 & -1.01 \\
\hline & & 420 & 1.2 & -0.02 & -28.67 & -1.11 \\
\hline & & 525 & 1.5 & -0.01 & -29.65 & -1.20 \\
\hline & & 700 & 2 & -0.01 & -30.61 & -1.30 \\
\hline
\end{tabular}


Table A-10: Summary of Maximum deflection, Transverse Moment and Longitudinal Moment in Cantilevered Slab with Tl-2 Barrier of Length $1.5 \mathrm{~m}$

\begin{tabular}{|c|c|c|c|c|c|c|}
\hline \multicolumn{7}{|c|}{ Cantilever length: $1.5 \mathrm{~m}$} \\
\hline \multirow{2}{*}{$\begin{array}{c}\text { Barrier length } \\
\text { (m) }\end{array}$} & \multicolumn{2}{|c|}{ Slab thickness } & \multirow[t]{2}{*}{$\mathbf{t}_{2} / \mathbf{t}_{1}$} & \multirow{2}{*}{$\begin{array}{c}\Delta \\
(\mathbf{m m})\end{array}$} & \multirow{2}{*}{$\begin{array}{c}\mathbf{M}_{\mathbf{y}} \\
(\mathbf{k N} \cdot \mathbf{m m} / \mathbf{m m})\end{array}$} & \multirow{2}{*}{$\begin{array}{c}\mathbf{M}_{\mathbf{x}} \\
(\mathbf{k N} \cdot \mathbf{m m} / \mathbf{m m})\end{array}$} \\
\hline & $\mathbf{t}_{1}(\mathbf{m m})$ & $\mathbf{t}_{2}(\mathrm{~mm})$ & & & & \\
\hline \multirow{20}{*}{5} & 200 & 200 & 1 & -0.95 & -58.82 & -2.24 \\
\hline & & 240 & 1.2 & -0.66 & -62.82 & -2.54 \\
\hline & & 300 & 1.5 & -0.41 & -66.64 & -2.90 \\
\hline & & 400 & 2 & -0.21 & -71.29 & -3.33 \\
\hline & 225 & 225 & 1 & -0.69 & -60.07 & -2.36 \\
\hline & & 270 & 1.2 & -0.48 & -64.16 & -2.67 \\
\hline & & 337.5 & 1.5 & -0.30 & -68.01 & -3.03 \\
\hline & & 450 & 2 & -0.16 & -72.58 & -3.45 \\
\hline & 250 & 250 & 1 & -0.52 & -61.28 & -2.48 \\
\hline & & 300 & 1.2 & -0.37 & -65.41 & -2.80 \\
\hline & & 375 & 1.5 & -0.23 & -69.23 & -3.15 \\
\hline & & 500 & 2 & -0.12 & -73.69 & -3.57 \\
\hline & 300 & 300 & 1 & -0.32 & -63.43 & -2.71 \\
\hline & & 360 & 1.2 & -0.23 & -67.58 & -3.02 \\
\hline & & 450 & 1.5 & -0.14 & -71.26 & -3.36 \\
\hline & & 600 & 2 & -0.07 & -75.42 & -3.75 \\
\hline & 350 & 350 & 1 & -0.21 & -65.19 & -2.90 \\
\hline & & 420 & 1.2 & -0.15 & -69.36 & -3.22 \\
\hline & & 525 & 1.5 & -0.09 & -72.79 & -3.52 \\
\hline & & 700 & 2 & -0.05 & -76.64 & -3.89 \\
\hline \multirow{20}{*}{6} & 200 & 200 & 1 & -0.90 & -56.99 & -2.14 \\
\hline & & 240 & 1.2 & -0.63 & -61.28 & -2.46 \\
\hline & & 300 & 1.5 & -0.40 & -65.50 & -2.83 \\
\hline & & 400 & 2 & -0.21 & -70.58 & -3.29 \\
\hline & 225 & 225 & 1 & -0.67 & -58.59 & -2.28 \\
\hline & & 270 & 1.2 & -0.47 & -62.95 & -2.60 \\
\hline & & 337.5 & 1.5 & -0.29 & -67.14 & -2.98 \\
\hline & & 450 & 2 & -0.15 & -72.07 & -3.43 \\
\hline & 250 & 250 & 1 & -0.51 & -60.08 & -2.42 \\
\hline & & 300 & 1.2 & -0.36 & -64.46 & -2.74 \\
\hline & & 375 & 1.5 & -0.22 & -68.57 & -3.11 \\
\hline & & 500 & 2 & -0.12 & -73.31 & -3.55 \\
\hline & 300 & 300 & 1 & -0.32 & -62.64 & -2.66 \\
\hline & & 360 & 1.2 & -0.22 & -66.97 & -2.98 \\
\hline & & 450 & 1.5 & -0.14 & -70.85 & -3.33 \\
\hline & & 600 & 2 & -0.07 & -75.20 & -3.74 \\
\hline & 350 & 350 & 1 & -0.21 & -64.65 & -2.87 \\
\hline & & 420 & 1.2 & -0.15 & -68.95 & -3.19 \\
\hline & & 525 & 1.5 & -0.09 & -72.53 & -3.51 \\
\hline & & 700 & 2 & -0.05 & -76.51 & -3.89 \\
\hline
\end{tabular}




\begin{tabular}{|c|c|c|c|c|c|c|}
\hline \multicolumn{7}{|c|}{ Cantilever length: $1.5 \mathrm{~m}$} \\
\hline \multirow{2}{*}{$\begin{array}{l}\text { Barrier length } \\
(\mathbf{m})\end{array}$} & \multicolumn{2}{|c|}{ Slab thickness } & \multirow[t]{2}{*}{$\mathbf{t}_{2} / \mathbf{t}_{1}$} & \multirow{2}{*}{$\underset{(\mathbf{m m})}{\Delta}$} & \multirow{2}{*}{$\begin{array}{c}\mathbf{M}_{\mathbf{y}} \\
(\mathbf{k N} \cdot \mathbf{m m} / \mathbf{m m})\end{array}$} & \multirow{2}{*}{$\begin{array}{c}\mathbf{M}_{\mathbf{x}} \\
(\mathbf{k N} \cdot \mathbf{m m} / \mathbf{m m})\end{array}$} \\
\hline & $\mathbf{t}_{\mathbf{1}}(\mathbf{m m})$ & $\mathbf{t}_{2}(\mathrm{~mm})$ & & & & \\
\hline \multirow{20}{*}{8} & 200 & 200 & 1 & -0.86 & -55.41 & -2.06 \\
\hline & & 240 & 1.2 & -0.61 & -60.05 & -2.39 \\
\hline & & 300 & 1.5 & -0.39 & -64.67 & -2.79 \\
\hline & & 400 & 2 & -0.21 & -70.15 & -3.26 \\
\hline & 225 & 225 & 1 & -0.64 & -57.40 & -2.22 \\
\hline & & 270 & 1.2 & -0.46 & -62.04 & -2.56 \\
\hline & & 337.5 & 1.5 & -0.29 & -66.55 & -2.94 \\
\hline & & 450 & 2 & -0.15 & -71.77 & -3.41 \\
\hline & 250 & 250 & 1 & -0.49 & -58.95 & -2.35 \\
\hline & & 300 & 1.2 & -0.35 & -63.78 & -2.71 \\
\hline & & 375 & 1.5 & -0.22 & -68.14 & -3.09 \\
\hline & & 500 & 2 & -0.12 & -73.10 & -3.54 \\
\hline & 300 & 300 & 1 & -0.31 & -62.08 & -2.63 \\
\hline & & 360 & 1.2 & -0.22 & -66.56 & -2.96 \\
\hline & & 450 & 1.5 & -0.14 & -70.61 & -3.32 \\
\hline & & 600 & 2 & -0.07 & -75.10 & -3.74 \\
\hline & 350 & 350 & 1 & -0.21 & -64.30 & -2.85 \\
\hline & & 420 & 1.2 & -0.15 & -68.70 & -3.18 \\
\hline & & 525 & 1.5 & -0.09 & -72.39 & -3.50 \\
\hline & & 700 & 2 & -0.05 & -76.46 & -3.88 \\
\hline \multirow{20}{*}{10} & 200 & 200 & 1 & -0.84 & -54.98 & -2.04 \\
\hline & & 240 & 1.2 & -0.61 & -59.74 & -2.38 \\
\hline & & 300 & 1.5 & -0.38 & -64.50 & -2.78 \\
\hline & & 400 & 2 & -0.21 & -70.08 & -3.26 \\
\hline & 225 & 225 & 1 & -0.64 & -57.10 & -2.20 \\
\hline & & 270 & 1.2 & -0.45 & -61.84 & -2.55 \\
\hline & & 337.5 & 1.5 & -0.29 & -66.43 & -2.94 \\
\hline & & 450 & 2 & -0.15 & -71.73 & -3.41 \\
\hline & 250 & 250 & 1 & -0.49 & -58.95 & -2.35 \\
\hline & & 300 & 1.2 & -0.35 & -63.63 & -2.70 \\
\hline & & 375 & 1.5 & -0.22 & -68.06 & -3.08 \\
\hline & & 500 & 2 & -0.12 & -73.08 & -3.53 \\
\hline & 300 & 300 & 1 & -0.31 & -61.96 & -2.63 \\
\hline & & 360 & 1.2 & -0.22 & -66.49 & -2.96 \\
\hline & & 450 & 1.5 & -0.14 & -70.58 & -3.32 \\
\hline & & 600 & 2 & -0.07 & -75.09 & -3.74 \\
\hline & 350 & 350 & 1 & -0.21 & -64.23 & -2.85 \\
\hline & & 420 & 1.2 & -0.15 & -68.66 & -3.18 \\
\hline & & 525 & 1.5 & -0.09 & -72.37 & -3.50 \\
\hline & & 700 & 2 & -0.05 & -76.45 & -3.88 \\
\hline
\end{tabular}




\section{Cantilever length: $1.5 \mathrm{~m}$}

\begin{tabular}{|c|c|c|c|c|c|c|}
\hline \multirow{2}{*}{$\begin{array}{c}\text { Barrier length } \\
\text { (m) }\end{array}$} & \multicolumn{2}{|c|}{ Slab thickness } & \multirow{3}{*}{$\begin{array}{r}\mathbf{t}_{2} / \mathbf{t}_{1} \\
\\
1\end{array}$} & \multirow{3}{*}{$\begin{array}{c}\begin{array}{c}\Delta \\
(\mathbf{m m})\end{array} \\
-0.84\end{array}$} & \multirow{3}{*}{$\begin{array}{c}\begin{array}{c}\mathbf{M}_{\mathbf{y}} \\
(\mathbf{k N} . \mathbf{m m} / \mathbf{m m})\end{array} \\
-54.87 \\
\end{array}$} & \multirow{3}{*}{ 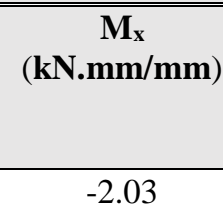 } \\
\hline & $\mathbf{t}_{\mathbf{1}}(\mathbf{m m})$ & $\mathrm{t}_{2}(\mathrm{~mm})$ & & & & \\
\hline \multirow{20}{*}{12} & 200 & 200 & & & & \\
\hline & & 240 & 1.2 & -0.60 & -59.68 & -2.38 \\
\hline & & 300 & 1.5 & -0.38 & -64.46 & -2.78 \\
\hline & & 400 & 2 & -0.21 & -70.07 & -3.26 \\
\hline & 225 & 225 & 1 & -0.63 & -57.03 & -2.20 \\
\hline & & 270 & 1.2 & -0.45 & -61.79 & -2.54 \\
\hline & & 337.5 & 1.5 & -0.29 & -66.41 & -2.94 \\
\hline & & 450 & 2 & -0.15 & -71.73 & -3.41 \\
\hline & 250 & 250 & 1 & -0.49 & -58.90 & -2.35 \\
\hline & & 300 & 1.2 & -0.35 & -63.61 & -2.70 \\
\hline & & 375 & 1.5 & -0.22 & -68.05 & -3.08 \\
\hline & & 500 & 2 & -0.12 & -73.08 & -3.53 \\
\hline & 300 & 300 & 1 & -0.31 & -61.94 & -2.62 \\
\hline & & 360 & 1.2 & -0.22 & -66.48 & -2.96 \\
\hline & & 450 & 1.5 & -0.14 & -70.57 & -3.32 \\
\hline & & 600 & 2 & -0.07 & -75.08 & -3.74 \\
\hline & 350 & 350 & 1 & -0.21 & -64.22 & -2.85 \\
\hline & & 420 & 1.2 & -0.15 & -68.65 & -3.18 \\
\hline & & 525 & 1.5 & -0.09 & -72.37 & -3.50 \\
\hline & & 700 & 2 & -0.05 & -76.45 & -3.88 \\
\hline
\end{tabular}


Table A-11: Summary of Maximum deflection, Transverse Moment and Longitudinal Moment in Cantilevered Slab with Tl-2 Barrier of Length 2 m

\begin{tabular}{|c|c|c|c|c|c|c|}
\hline \multicolumn{7}{|c|}{ Cantilever length: 2 m } \\
\hline \multirow{2}{*}{$\begin{array}{c}\text { Barrier length } \\
(\mathrm{m})\end{array}$} & \multicolumn{2}{|c|}{ Slab thickness } & \multirow[t]{2}{*}{$\overline{t_{2} / \mathbf{t}_{1}}$} & \multirow{2}{*}{$\begin{array}{c}\Delta \\
(\mathbf{m m})\end{array}$} & \multirow{2}{*}{$\begin{array}{c}\mathbf{M}_{\mathbf{y}} \\
(\mathbf{k N} \cdot \mathbf{m m} / \mathbf{m m})\end{array}$} & \multirow{2}{*}{$\begin{array}{c}\mathbf{M}_{\mathbf{x}} \\
(\mathbf{k N} \cdot \mathbf{m m} / \mathbf{m m})\end{array}$} \\
\hline & $\mathbf{t}_{1}(\mathbf{m m})$ & $\mathbf{t}_{2}(\mathrm{~mm})$ & & & & \\
\hline \multirow{20}{*}{5} & 200 & 200 & 1 & -2.94 & -81.38 & -5.09 \\
\hline & & 240 & 1.2 & -2.04 & -86.36 & -5.47 \\
\hline & & 300 & 1.5 & -1.27 & -91.53 & -5.92 \\
\hline & & 400 & 2 & -0.67 & -98.02 & -6.49 \\
\hline & 225 & 225 & 1 & -2.12 & -82.70 & -5.24 \\
\hline & & 270 & 1.2 & -1.48 & -87.84 & -5.64 \\
\hline & & 337.5 & 1.5 & -0.92 & -93.12 & -6.09 \\
\hline & & 450 & 2 & -0.49 & -99.68 & -6.67 \\
\hline & 250 & 250 & 1 & -1.59 & -84.03 & -5.40 \\
\hline & & 300 & 1.2 & -1.11 & -89.28 & -5.80 \\
\hline & & 375 & 1.5 & -0.69 & -94.63 & -6.26 \\
\hline & & 500 & 2 & -0.36 & -101.18 & -6.83 \\
\hline & 300 & 300 & 1 & -0.96 & -86.51 & -5.69 \\
\hline & & 360 & 1.2 & -0.67 & -91.90 & -6.10 \\
\hline & & 450 & 1.5 & -0.42 & -97.26 & -6.55 \\
\hline & & 600 & 2 & -0.22 & -103.66 & -7.10 \\
\hline & 350 & 350 & 1 & -0.63 & -88.66 & -5.94 \\
\hline & & 420 & 1.2 & -0.44 & -94.08 & -6.35 \\
\hline & & 525 & 1.5 & -0.27 & -99.36 & -6.80 \\
\hline & & 700 & 2 & -0.14 & -105.51 & -7.32 \\
\hline \multirow{20}{*}{6} & 200 & 200 & 1 & -2.74 & -77.41 & -4.83 \\
\hline & & 240 & 1.2 & -1.92 & -82.83 & -5.24 \\
\hline & & 300 & 1.5 & -1.21 & -88.63 & -5.74 \\
\hline & & 400 & 2 & -0.65 & -95.95 & -6.36 \\
\hline & 225 & 225 & 1 & -2.00 & -79.29 & -5.02 \\
\hline & & 270 & 1.2 & -1.41 & -84.87 & -5.44 \\
\hline & & 337.5 & 1.5 & -0.88 & -90.77 & -5.94 \\
\hline & & 450 & 2 & -0.47 & -98.08 & -6.57 \\
\hline & 250 & 250 & 1 & -1.51 & -81.11 & -5.20 \\
\hline & & 300 & 1.2 & -1.06 & -86.80 & -5.64 \\
\hline & & 375 & 1.5 & -0.67 & -92.72 & -6.14 \\
\hline & & 500 & 2 & -0.36 & -99.93 & -6.75 \\
\hline & 300 & 300 & 1 & -0.93 & -84.39 & -5.55 \\
\hline & & 360 & 1.2 & -0.65 & -90.16 & -5.98 \\
\hline & & 450 & 1.5 & -0.41 & -95.99 & -6.47 \\
\hline & & 600 & 2 & -0.22 & -102.88 & -7.06 \\
\hline & 350 & 350 & 1 & -0.61 & -87.09 & -5.84 \\
\hline & & 420 & 1.2 & -0.43 & -92.84 & -6.27 \\
\hline & & 525 & 1.5 & -0.27 & -98.49 & -6.74 \\
\hline & & 700 & 2 & -0.14 & -105.01 & -7.29 \\
\hline
\end{tabular}




\begin{tabular}{|c|c|c|c|c|c|c|}
\hline \multicolumn{7}{|c|}{ Cantilever length: $2 \mathrm{~m}$} \\
\hline \multirow{2}{*}{$\begin{array}{l}\text { Barrier length } \\
\text { (m) }\end{array}$} & \multicolumn{2}{|c|}{ Slab thickness } & \multirow[t]{2}{*}{$\mathbf{t}_{2} / \mathbf{t}_{1}$} & \multirow{2}{*}{$\begin{array}{c}\boldsymbol{\Delta} \\
(\mathbf{m m})\end{array}$} & \multirow{2}{*}{$\begin{array}{c}\mathbf{M}_{\mathbf{y}} \\
(\mathbf{k N} \cdot \mathbf{m m} / \mathbf{m m})\end{array}$} & \multirow{2}{*}{$\begin{array}{c}\mathbf{M}_{\mathbf{x}} \\
(\mathbf{k N} \cdot \mathbf{m m} / \mathbf{m m})\end{array}$} \\
\hline & $\mathbf{t}_{\mathbf{1}}(\mathbf{m m})$ & $\mathrm{t}_{2}(\mathrm{~mm})$ & & & & \\
\hline \multirow{20}{*}{8} & 200 & 200 & 1 & -2.53 & -73.14 & -4.56 \\
\hline & & 240 & 1.2 & -1.80 & -79.19 & -5.02 \\
\hline & & 300 & 1.5 & -1.15 & -85.85 & -5.57 \\
\hline & & 400 & 2 & -0.63 & -94.19 & -6.26 \\
\hline & 225 & 225 & 1 & -1.88 & -75.84 & -4.80 \\
\hline & & 270 & 1.2 & -1.34 & -82.00 & -5.27 \\
\hline & & 337.5 & 1.5 & -0.85 & -88.65 & -5.81 \\
\hline & & 450 & 2 & -0.46 & -96.80 & -6.49 \\
\hline & 250 & 250 & 1 & -1.44 & -78.31 & -5.03 \\
\hline & & 300 & 1.2 & -1.02 & -84.52 & -5.50 \\
\hline & & 375 & 1.5 & -0.65 & -91.09 & -6.04 \\
\hline & & 500 & 2 & -0.35 & -98.99 & -6.70 \\
\hline & 300 & 300 & 1 & -0.90 & -82.52 & -5.43 \\
\hline & & 360 & 1.2 & -0.64 & -88.70 & -5.89 \\
\hline & & 450 & 1.5 & -0.40 & -95.00 & -6.41 \\
\hline & & 600 & 2 & -0.22 & -102.35 & -7.03 \\
\hline & 350 & 350 & 1 & -0.60 & -85.82 & -5.76 \\
\hline & & 420 & 1.2 & -0.42 & -91.88 & -6.21 \\
\hline & & 525 & 1.5 & -0.27 & -97.88 & -6.71 \\
\hline & & 700 & 2 & -0.14 & -104.70 & -7.27 \\
\hline \multirow{20}{*}{10} & 200 & 200 & 1 & -2.44 & -71.45 & -4.47 \\
\hline & & 240 & 1.2 & -1.76 & -77.87 & -4.94 \\
\hline & & 300 & 1.5 & -1.13 & -84.96 & -5.52 \\
\hline & & 400 & 2 & -0.62 & -93.72 & -6.23 \\
\hline & 225 & 225 & 1 & -1.83 & -74.57 & -4.73 \\
\hline & & 270 & 1.2 & -1.31 & -81.04 & -5.21 \\
\hline & & 337.5 & 1.5 & -0.84 & -88.03 & -5.78 \\
\hline & & 450 & 2 & -0.46 & -96.49 & -6.47 \\
\hline & 250 & 250 & 1 & -1.41 & -77.35 & -4.97 \\
\hline & & 300 & 1.2 & -1.01 & -83.81 & -5.45 \\
\hline & & 375 & 1.5 & -0.64 & -90.64 & -6.01 \\
\hline & & 500 & 2 & -0.35 & -98.78 & -6.68 \\
\hline & 300 & 300 & 1 & -0.89 & -81.94 & -5.40 \\
\hline & & 360 & 1.2 & -0.63 & -88.29 & -5.87 \\
\hline & & 450 & 1.5 & -0.40 & -94.76 & -6.40 \\
\hline & & 600 & 2 & -0.22 & -102.25 & -7.02 \\
\hline & 350 & 350 & 1 & -0.60 & -85.47 & -5.74 \\
\hline & & 420 & 1.2 & -0.42 & -91.65 & -6.20 \\
\hline & & 525 & 1.5 & -0.27 & -97.75 & -6.70 \\
\hline & & 700 & 2 & -0.14 & -104.66 & -7.27 \\
\hline
\end{tabular}


Cantilever length: $\mathbf{2} \mathbf{m}$

\begin{tabular}{|c|c|c|c|c|c|c|}
\hline \multirow{2}{*}{$\begin{array}{c}\text { Barrier length } \\
\text { (m) }\end{array}$} & \multicolumn{2}{|c|}{ Slab thickness } & \multirow[t]{2}{*}{$\overline{\mathbf{t}_{2} / \mathbf{t}_{1}}$} & \multirow{2}{*}{$\begin{array}{c}\Delta \\
(\mathbf{m m})\end{array}$} & \multirow{2}{*}{$\begin{array}{c}\mathbf{M}_{\mathbf{y}} \\
(\mathbf{k N} \cdot \mathbf{m m} / \mathbf{m m})\end{array}$} & \multirow{2}{*}{$\begin{array}{c}\mathbf{M}_{\mathbf{x}} \\
(\mathbf{k N} \cdot \mathbf{m m} / \mathbf{m m})\end{array}$} \\
\hline & $\mathbf{t}_{1}(\mathrm{~mm})$ & $\mathrm{t}_{2}(\mathrm{~mm})$ & & & & \\
\hline \multirow{20}{*}{12} & 200 & 200 & 1 & -2.41 & -70.84 & -4.43 \\
\hline & & 240 & 1.2 & -1.74 & -77.43 & -4.92 \\
\hline & & 300 & 1.5 & -1.13 & -84.70 & -5.50 \\
\hline & & 400 & 2 & -0.62 & -93.62 & -6.22 \\
\hline & 225 & 225 & 1 & -1.81 & -74.14 & -4.70 \\
\hline & & 270 & 1.2 & -1.31 & -80.74 & -5.19 \\
\hline & & 337.5 & 1.5 & -0.84 & -87.86 & -5.77 \\
\hline & & 450 & 2 & -0.46 & -96.43 & -6.47 \\
\hline & 250 & 250 & 1 & -1.40 & -77.03 & -4.95 \\
\hline & & 300 & 1.2 & -1.01 & -83.60 & -5.44 \\
\hline & & 375 & 1.5 & -0.64 & -90.53 & -6.01 \\
\hline & & 500 & 2 & -0.35 & -98.74 & -6.68 \\
\hline & 300 & 300 & 1 & -0.89 & -81.77 & -5.39 \\
\hline & & 360 & 1.2 & -0.63 & -88.18 & -5.86 \\
\hline & & 450 & 1.5 & -0.40 & -94.71 & -6.40 \\
\hline & & 600 & 2 & -0.22 & -102.24 & -7.02 \\
\hline & 350 & 350 & 1 & -0.60 & -85.38 & -5.74 \\
\hline & & 420 & 1.2 & -0.42 & -91.59 & -6.20 \\
\hline & & 525 & 1.5 & -0.27 & -97.73 & -6.70 \\
\hline & & 700 & 2 & -0.14 & -104.65 & -7.27 \\
\hline
\end{tabular}


Table A-12: Summary of Maximum deflection, Transverse Moment and Longitudinal Moment in Cantilevered Slab with Tl-2 Barrier of Length $2.5 \mathrm{~m}$

\begin{tabular}{|c|c|c|c|c|c|c|}
\hline \multicolumn{7}{|c|}{ "Cantilever length: $2.5 \mathrm{~m}$} \\
\hline \multirow{2}{*}{$\begin{array}{c}\text { Barrier length } \\
(\mathrm{m})\end{array}$} & \multicolumn{2}{|c|}{ Slab thickness } & \multirow[t]{2}{*}{$\mathbf{t}_{2} / \mathbf{t}_{1}$} & \multirow{2}{*}{$\begin{array}{c}\Delta \\
(\mathbf{m m})\end{array}$} & \multirow{2}{*}{$\begin{array}{c}\mathbf{M}_{\mathbf{y}} \\
(\mathbf{k N} \cdot \mathbf{m m} / \mathbf{m m})\end{array}$} & \multirow{2}{*}{$\begin{array}{c}\mathbf{M}_{\mathbf{x}} \\
(\mathbf{k N} \cdot \mathbf{m m} / \mathbf{m m})\end{array}$} \\
\hline & $\mathbf{t}_{\mathbf{1}}(\mathbf{m m})$ & $\mathbf{t}_{2}(\mathbf{m m})$ & & & & \\
\hline \multirow{20}{*}{5} & 200 & 200 & 1 & -7.65 & -108.82 & -6.72 \\
\hline & & 240 & 1.2 & -5.22 & -113.17 & -6.95 \\
\hline & & 300 & 1.5 & -3.20 & -117.68 & -7.18 \\
\hline & & 400 & 2 & -1.67 & -123.24 & -7.44 \\
\hline & 225 & 225 & 1 & -5.45 & -109.60 & -6.81 \\
\hline & & 270 & 1.2 & -3.72 & -114.04 & -7.03 \\
\hline & & 337.5 & 1.5 & -2.28 & -118.67 & -7.27 \\
\hline & & 450 & 2 & -1.20 & -124.27 & -7.53 \\
\hline & 250 & 250 & 1 & -4.03 & -110.38 & -6.89 \\
\hline & & 300 & 1.2 & -2.76 & -114.90 & -7.12 \\
\hline & & 375 & 1.5 & -1.69 & -119.56 & -7.36 \\
\hline & & 500 & 2 & -0.89 & -125.23 & -7.62 \\
\hline & 300 & 300 & 1 & -2.39 & -111.88 & -7.05 \\
\hline & & 360 & 1.2 & -1.64 & -116.50 & -7.28 \\
\hline & & 450 & 1.5 & -1.01 & -121.23 & -7.51 \\
\hline & & 600 & 2 & -0.53 & -126.87 & -7.75 \\
\hline & 350 & 350 & 1 & -1.54 & -113.20 & -7.18 \\
\hline & & 420 & 1.2 & -1.06 & -117.87 & -7.41 \\
\hline & & 525 & 1.5 & -0.65 & -122.59 & -7.63 \\
\hline & & 700 & 2 & -0.34 & -128.15 & -7.85 \\
\hline \multirow{20}{*}{6} & 200 & 200 & 1 & -7.06 & -102.88 & -6.35 \\
\hline & & 240 & 1.2 & -4.87 & -95.50 & $\begin{array}{l}-6.62 \\
\end{array}$ \\
\hline & & 300 & 1.5 & -3.02 & -113.14 & -6.91 \\
\hline & & 400 & 2 & -1.60 & -119.75 & -7.24 \\
\hline & 225 & 225 & 1 & -5.07 & -104.24 & -6.48 \\
\hline & & 270 & 1.2 & -3.50 & -109.30 & -6.75 \\
\hline & & 337.5 & 1.5 & -2.18 & -114.75 & -7.04 \\
\hline & & 450 & 2 & -1.16 & -121.38 & -7.37 \\
\hline & 250 & 250 & 1 & -3.78 & -105.57 & -6.60 \\
\hline & & 300 & 1.2 & -2.61 & -110.72 & -6.88 \\
\hline & & 375 & 1.5 & -1.63 & -116.20 & -7.17 \\
\hline & & 500 & 2 & -0.86 & -122.83 & -7.48 \\
\hline & 300 & 300 & 1 & -2.27 & -108.01 & -6.83 \\
\hline & & 360 & 1.2 & -1.57 & -113.25 & -7.10 \\
\hline & & 450 & 1.5 & -0.98 & -118.72 & -7.38 \\
\hline & & 600 & 2 & -0.52 & -125.19 & -7.66 \\
\hline & 350 & 350 & 1 & -1.47 & -110.05 & -7.02 \\
\hline & & 420 & 1.2 & -1.02 & -115.30 & -7.28 \\
\hline & & 525 & 1.5 & -0.63 & -120.69 & -7.53 \\
\hline & & 700 & 2 & $\begin{array}{l}-0.34 \\
\end{array}$ & -126.94 & $\begin{array}{l}-7.79 \\
\end{array}$ \\
\hline
\end{tabular}




\begin{tabular}{|c|c|c|c|c|c|c|}
\hline \multicolumn{7}{|c|}{ Cantilever length: $2.5 \mathrm{~m}$} \\
\hline \multirow{2}{*}{$\begin{array}{l}\text { Barrier length } \\
(\mathbf{m})\end{array}$} & \multicolumn{2}{|c|}{ Slab thickness } & \multirow[t]{2}{*}{$\mathbf{t}_{2} / \mathbf{t}_{1}$} & \multirow{2}{*}{$\underset{(\mathbf{m m})}{\Delta}$} & \multirow{2}{*}{$\begin{array}{c}\mathbf{M}_{\mathbf{y}} \\
(\mathbf{k N} \cdot \mathbf{m m} / \mathbf{m m})\end{array}$} & \multirow{2}{*}{$\begin{array}{c}\mathbf{M}_{\mathbf{x}} \\
(\mathbf{k N} \cdot \mathbf{m m} / \mathbf{m m})\end{array}$} \\
\hline & $\mathbf{t}_{1}(\mathbf{m m})$ & $\mathbf{t}_{2}(\mathbf{m m})$ & & & & \\
\hline \multirow{20}{*}{8} & 200 & 200 & 1 & -6.37 & -95.36 & -5.88 \\
\hline & & 240 & 1.2 & -4.47 & -89.48 & -6.21 \\
\hline & & 300 & 1.5 & -2.83 & -107.75 & -6.59 \\
\hline & & 400 & 2 & -1.53 & -115.92 & -7.02 \\
\hline & 225 & 225 & 1 & -4.65 & -97.83 & -6.09 \\
\hline & & 270 & 1.2 & -3.27 & -103.80 & -6.42 \\
\hline & & 337.5 & 1.5 & -2.06 & -110.41 & -6.79 \\
\hline & & 450 & 2 & -1.12 & -118.42 & -7.20 \\
\hline & 250 & 250 & 1 & -3.52 & -100.13 & -6.28 \\
\hline & & 300 & 1.2 & -2.47 & -106.15 & -6.61 \\
\hline & & 375 & 1.5 & -1.56 & -112.69 & -6.96 \\
\hline & & 500 & 2 & -0.84 & -120.53 & -7.36 \\
\hline & 300 & 300 & 1 & -2.16 & -104.06 & -6.60 \\
\hline & & 360 & 1.2 & -1.51 & -110.05 & -6.92 \\
\hline & & 450 & 1.5 & -0.95 & -116.39 & -7.24 \\
\hline & & 600 & 2 & -0.51 & -123.77 & -7.59 \\
\hline & 350 & 350 & 1 & -1.42 & -107.14 & -6.85 \\
\hline & & 420 & 1.2 & -0.99 & -113.03 & -7.15 \\
\hline & & 525 & 1.5 & -0.62 & -119.11 & -7.45 \\
\hline & & 700 & 2 & -0.33 & -126.04 & -7.74 \\
\hline \multirow{20}{*}{10} & 200 & 200 & 1 & -6.04 & -91.54 & -5.65 \\
\hline & & 240 & 1.2 & -4.29 & -86.64 & -6.02 \\
\hline & & 300 & 1.5 & -2.74 & -105.36 & -6.45 \\
\hline & & 400 & 2 & -1.50 & -114.43 & -6.94 \\
\hline & 225 & 225 & 1 & -4.47 & -94.81 & -5.91 \\
\hline & & 270 & 1.2 & -3.17 & -101.34 & -6.27 \\
\hline & & 337.5 & 1.5 & -2.02 & -108.62 & -6.69 \\
\hline & & 450 & 2 & -1.10 & -117.37 & -7.15 \\
\hline & 250 & 250 & 1 & -3.40 & -97.72 & -6.13 \\
\hline & & 300 & 1.2 & -2.41 & -104.23 & -6.49 \\
\hline & & 375 & 1.5 & -1.53 & -111.33 & -6.89 \\
\hline & & 500 & 2 & $\begin{array}{l}-0.83 \\
\end{array}$ & -119.77 & $\begin{array}{l}-7.32 \\
\end{array}$ \\
\hline & 300 & 300 & 1 & -2.11 & -102.50 & -6.51 \\
\hline & & 360 & 1.2 & $\begin{array}{l}-1.49 \\
\end{array}$ & -108.86 & -6.85 \\
\hline & & 450 & 1.5 & -0.94 & -115.60 & -7.20 \\
\hline & & 600 & 2 & -0.51 & -123.37 & -7.57 \\
\hline & 350 & 350 & 1 & -1.40 & -106.11 & -6.80 \\
\hline & & 420 & 1.2 & -0.98 & -112.28 & -7.11 \\
\hline & & 525 & 1.5 & -0.62 & -118.64 & -7.42 \\
\hline & & 700 & 2 & -0.33 & -125.81 & -7.73 \\
\hline
\end{tabular}




\begin{tabular}{|c|c|c|c|c|c|c|}
\hline \multicolumn{7}{|c|}{ Cantilever length: $2.5 \mathrm{~m}$} \\
\hline \multirow{2}{*}{$\begin{array}{c}\text { Barrier length } \\
(\mathrm{m})\end{array}$} & \multicolumn{2}{|c|}{ Slab thickness } & \multirow{3}{*}{$\begin{array}{r}\mathbf{t}_{2} / \mathbf{t}_{1} \\
\\
1\end{array}$} & \multirow{3}{*}{$\begin{array}{c}\begin{array}{c}\Delta \\
(\mathbf{m m})\end{array} \\
-5.88\end{array}$} & \multirow{3}{*}{ 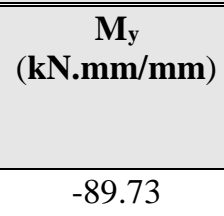 } & \multirow{3}{*}{$\begin{array}{c}\begin{array}{c}\mathbf{M}_{\mathbf{x}} \\
(\mathbf{k N} . \mathbf{m m} / \mathbf{m m}\end{array} \\
-5.55\end{array}$} \\
\hline & $\mathbf{t}_{1}(\mathbf{m m})$ & $\mathbf{t}_{2}(\mathrm{~mm})$ & & & & \\
\hline \multirow{20}{*}{12} & 200 & 200 & & & & \\
\hline & & 240 & 1.2 & -4.20 & -85.40 & -5.94 \\
\hline & & 300 & 1.5 & -2.71 & -104.40 & -6.40 \\
\hline & & 400 & 2 & $\begin{array}{l}-1.49 \\
\end{array}$ & -113.93 & -6.91 \\
\hline & 225 & 225 & 1 & -4.38 & -93.45 & -5.83 \\
\hline & & 270 & 1.2 & -3.12 & -100.31 & -6.22 \\
\hline & & 337.5 & 1.5 & -2.00 & -107.95 & -6.65 \\
\hline & & 450 & 2 & -1.10 & -117.04 & -7.13 \\
\hline & 250 & 250 & 1 & -3.35 & -96.70 & -6.07 \\
\hline & & 300 & 1.2 & -2.38 & -103.47 & -6.45 \\
\hline & & 375 & 1.5 & -1.52 & -110.86 & -6.86 \\
\hline & & 500 & 2 & -0.83 & -119.55 & -7.30 \\
\hline & 300 & 300 & 1 & -2.10 & -101.90 & -6.48 \\
\hline & & 360 & 1.2 & -1.48 & -108.44 & -6.83 \\
\hline & & 450 & 1.5 & -0.94 & -115.35 & -7.19 \\
\hline & & 600 & 2 & -0.51 & -123.27 & -7.56 \\
\hline & 350 & 350 & 1 & -1.39 & -105.76 & -6.78 \\
\hline & & 420 & 1.2 & -0.98 & -112.04 & -7.10 \\
\hline & & 525 & 1.5 & -0.62 & -118.51 & -7.42 \\
\hline & & 700 & 2 & -0.33 & -125.77 & -7.73 \\
\hline
\end{tabular}


Table A-13: Summary of Maximum deflection, Transverse Moment and Longitudinal Moment in Cantilevered Slab with Tl-4 Barrier of Length 1 m

\begin{tabular}{|c|c|c|c|c|c|c|}
\hline \multicolumn{7}{|c|}{ "Cantilever length: 1 m } \\
\hline \multirow{2}{*}{$\begin{array}{c}\text { Barrier length } \\
(\mathbf{m})\end{array}$} & \multicolumn{2}{|c|}{ Slab thickness } & \multirow[t]{2}{*}{$\overline{t_{2} / \mathbf{t}_{1}}$} & \multirow{2}{*}{$\begin{array}{c}\boldsymbol{\Delta} \\
(\mathbf{m m})\end{array}$} & \multirow{2}{*}{$\begin{array}{c}\mathbf{M}_{\mathbf{y}} \\
(\mathbf{k N} \cdot \mathbf{m m} / \mathbf{m m})\end{array}$} & \multirow{2}{*}{$\begin{array}{c}\mathbf{M}_{\mathbf{x}} \\
(\mathrm{kN} \cdot \mathrm{mm} / \mathbf{m m})\end{array}$} \\
\hline & $\mathbf{t}_{1}(\mathbf{m m})$ & $\mathrm{t}_{2}(\mathrm{~mm})$ & & & & \\
\hline \multirow{20}{*}{5} & 200 & 200 & 1 & -0.12 & -24.22 & -0.86 \\
\hline & & 240 & 1.2 & -0.08 & -25.91 & $\begin{array}{l}-0.97 \\
\end{array}$ \\
\hline & & 300 & 1.5 & -0.05 & -27.19 & -1.06 \\
\hline & & 400 & 2 & -0.03 & -28.67 & -1.18 \\
\hline & 225 & 225 & 1 & -0.09 & -24.74 & $\begin{array}{l}-0.89 \\
\end{array}$ \\
\hline & & 270 & 1.2 & -0.06 & -26.44 & $\begin{array}{l}-0.99 \\
\end{array}$ \\
\hline & & 337.5 & 1.5 & -0.04 & -27.70 & -1.09 \\
\hline & & 450 & 2 & -0.02 & -29.10 & -1.20 \\
\hline & 250 & 250 & 1 & -0.07 & -25.22 & -0.91 \\
\hline & & 300 & 1.2 & -0.05 & -26.92 & -1.02 \\
\hline & & 375 & 1.5 & -0.03 & -28.13 & -1.11 \\
\hline & & 500 & 2 & -0.01 & -29.46 & -1.23 \\
\hline & 300 & 300 & 1 & -0.04 & -26.04 & -0.96 \\
\hline & & 360 & 1.2 & -0.03 & $\begin{array}{l}-27.71 \\
\end{array}$ & -1.06 \\
\hline & & 450 & 1.5 & -0.02 & -28.83 & -1.15 \\
\hline & & 600 & 2 & -0.01 & -30.00 & -1.26 \\
\hline & 350 & 350 & 1 & -0.03 & -26.68 & $\begin{array}{l}-0.99 \\
\end{array}$ \\
\hline & & 420 & 1.2 & -0.02 & -28.31 & -1.09 \\
\hline & & 525 & 1.5 & -0.01 & -29.33 & -1.18 \\
\hline & & 700 & 2 & -0.01 & -30.37 & -1.29 \\
\hline \multirow{20}{*}{6} & 200 & 200 & 1 & -0.11 & -23.86 & -0.85 \\
\hline & & 240 & 1.2 & -0.08 & -25.63 & -0.96 \\
\hline & & 300 & 1.5 & -0.05 & -27.00 & -1.05 \\
\hline & & 400 & 2 & -0.03 & -28.57 & -1.17 \\
\hline & 225 & 225 & 1 & -0.08 & -24.46 & -0.88 \\
\hline & & 270 & 1.2 & -0.06 & -26.23 & -0.98 \\
\hline & & 337.5 & 1.5 & -0.04 & -27.56 & -1.08 \\
\hline & & 450 & 2 & -0.02 & -29.03 & -1.20 \\
\hline & 250 & 250 & 1 & -0.06 & -25.00 & -0.91 \\
\hline & & 300 & 1.2 & -0.05 & -26.76 & -1.01 \\
\hline & & 375 & 1.5 & -0.03 & -28.03 & -1.11 \\
\hline & & 500 & 2 & -0.01 & -29.41 & -1.22 \\
\hline & 300 & 300 & 1 & -0.04 & -25.90 & -0.95 \\
\hline & & 360 & 1.2 & -0.03 & -27.61 & -1.06 \\
\hline & & 450 & 1.5 & -0.02 & -28.76 & -1.15 \\
\hline & & 600 & 2 & -0.01 & -29.97 & -1.26 \\
\hline & 350 & 350 & 1 & -0.03 & -26.58 & -0.99 \\
\hline & & 420 & 1.2 & -0.02 & -28.24 & -1.09 \\
\hline & & 525 & 1.5 & -0.01 & -29.29 & -1.18 \\
\hline & & 700 & 2 & -0.01 & -30.36 & -1.29 \\
\hline
\end{tabular}




\begin{tabular}{|c|c|c|c|c|c|c|}
\hline \multicolumn{7}{|c|}{ Cantilever length: $1 \mathrm{~m}$} \\
\hline \multirow{2}{*}{$\begin{array}{l}\text { Barrier length } \\
(\mathbf{m})\end{array}$} & \multicolumn{2}{|c|}{ Slab thickness } & \multirow[t]{2}{*}{$\overline{\mathbf{t}_{2} / \mathbf{t}_{1}}$} & \multirow{2}{*}{$\begin{array}{c}\boldsymbol{\Delta} \\
(\mathbf{m m})\end{array}$} & \multirow{2}{*}{$\begin{array}{c}\mathbf{M}_{\mathbf{y}} \\
(\mathbf{k N} \cdot \mathbf{m m} / \mathbf{m m})\end{array}$} & \multirow{2}{*}{$\begin{array}{c}\mathbf{M}_{\mathbf{x}} \\
(\mathbf{k N} \cdot \mathbf{m m} / \mathbf{m m})\end{array}$} \\
\hline & $\mathbf{t}_{1}(\mathbf{m m})$ & $\mathbf{t}_{2}(\mathbf{m m})$ & & & & \\
\hline \multirow{20}{*}{8} & 200 & 200 & 1 & -0.11 & -23.62 & -0.84 \\
\hline & & 240 & 1.2 & -0.08 & -25.45 & -0.95 \\
\hline & & 300 & 1.5 & -0.05 & -26.90 & -1.05 \\
\hline & & 400 & 2 & -0.03 & -28.52 & -1.17 \\
\hline & 225 & 225 & 1 & -0.08 & -24.29 & -0.87 \\
\hline & & 270 & 1.2 & -0.06 & -26.11 & -0.98 \\
\hline & & 337.5 & 1.5 & -0.04 & -27.49 & -1.08 \\
\hline & & 450 & 2 & -0.02 & -29.00 & -1.20 \\
\hline & 250 & 250 & 1 & -0.06 & -24.87 & -0.90 \\
\hline & & 300 & 1.2 & -0.05 & -26.67 & -1.01 \\
\hline & & 375 & 1.5 & -0.03 & -27.98 & -1.10 \\
\hline & & 500 & 2 & -0.01 & -29.39 & -1.22 \\
\hline & 300 & 300 & 1 & -0.04 & -25.82 & -0.95 \\
\hline & & 360 & 1.2 & -0.03 & -27.56 & -1.05 \\
\hline & & 450 & 1.5 & -0.02 & -28.74 & -1.15 \\
\hline & & 600 & 2 & -0.01 & -29.97 & -1.26 \\
\hline & 350 & 350 & 1 & -0.03 & -26.53 & $\begin{array}{l}-0.99 \\
\end{array}$ \\
\hline & & 420 & 1.2 & -0.02 & -28.21 & -1.09 \\
\hline & & 525 & 1.5 & -0.01 & -29.28 & -1.18 \\
\hline & & 700 & 2 & -0.01 & -30.35 & -1.29 \\
\hline \multirow{20}{*}{10} & 200 & 200 & 1 & -0.11 & -23.57 & -0.84 \\
\hline & & 240 & 1.2 & -0.08 & -25.42 & -0.95 \\
\hline & & 300 & 1.5 & -0.05 & -26.88 & -1.05 \\
\hline & & 400 & 2 & -0.03 & -28.52 & -1.17 \\
\hline & 225 & 225 & 1 & -0.08 & -24.26 & -0.87 \\
\hline & & 270 & 1.2 & -0.06 & -26.09 & -0.98 \\
\hline & & 337.5 & 1.5 & -0.04 & -27.48 & -1.08 \\
\hline & & 450 & 2 & -0.02 & -29.00 & -1.20 \\
\hline & 250 & 250 & 1 & -0.06 & -24.85 & -0.90 \\
\hline & & 300 & 1.2 & -0.05 & -26.65 & -1.01 \\
\hline & & 375 & 1.5 & -0.03 & -27.97 & -1.10 \\
\hline & & 500 & 2 & -0.01 & -29.39 & -1.22 \\
\hline & 300 & 300 & 1 & -0.04 & -25.81 & -0.95 \\
\hline & & 360 & 1.2 & -0.03 & -27.55 & -1.05 \\
\hline & & 450 & 1.5 & -0.02 & -28.74 & -1.15 \\
\hline & & 600 & 2 & -0.01 & -29.97 & -1.26 \\
\hline & 350 & 350 & 1 & -0.03 & -26.53 & $\begin{array}{l}-0.99 \\
\end{array}$ \\
\hline & & 420 & 1.2 & -0.02 & -28.21 & $\begin{array}{l}-1.09 \\
\end{array}$ \\
\hline & & 525 & 1.5 & -0.01 & -29.28 & -1.18 \\
\hline & & 700 & 2 & -0.01 & -30.35 & -1.29 \\
\hline
\end{tabular}




\section{Cantilever length: $1 \mathrm{~m}$}

\begin{tabular}{|c|c|c|c|c|c|c|}
\hline \multirow{2}{*}{$\begin{array}{c}\text { Barrier length } \\
\text { (m) }\end{array}$} & \multicolumn{2}{|c|}{ Slab thickness } & \multirow[t]{2}{*}{$\overline{\mathbf{t}_{2} / \mathbf{t}_{1}}$} & \multirow{2}{*}{$\begin{array}{c}\Delta \\
(\mathbf{m m})\end{array}$} & \multirow{2}{*}{$\begin{array}{c}\mathbf{M}_{\mathbf{y}} \\
(\mathbf{k N} \cdot \mathbf{m m} / \mathbf{m m})\end{array}$} & \multirow{2}{*}{$\begin{array}{c}\mathbf{M}_{\mathbf{x}} \\
(\mathbf{k N} \cdot \mathbf{m m} / \mathbf{m m})\end{array}$} \\
\hline & $\mathbf{t}_{1}(\mathrm{~mm})$ & $\mathrm{t}_{2}(\mathrm{~mm})$ & & & & \\
\hline \multirow{20}{*}{12} & 200 & 200 & 1 & -0.11 & -23.57 & -0.84 \\
\hline & & 240 & 1.2 & -0.08 & -25.42 & -0.95 \\
\hline & & 300 & 1.5 & -0.05 & -26.88 & -1.05 \\
\hline & & 400 & 2 & -0.03 & -28.52 & -1.17 \\
\hline & 225 & 225 & 1 & -0.08 & -24.25 & -0.87 \\
\hline & & 270 & 1.2 & -0.06 & -26.08 & -0.98 \\
\hline & & 337.5 & 1.5 & -0.04 & -27.48 & -1.08 \\
\hline & & 450 & 2 & -0.02 & -29.00 & -1.20 \\
\hline & 250 & 250 & 1 & -0.06 & -24.85 & -0.90 \\
\hline & & 300 & 1.2 & -0.05 & -26.65 & -1.01 \\
\hline & & 375 & 1.5 & -0.03 & -27.97 & -1.10 \\
\hline & & 500 & 2 & -0.01 & -29.39 & -1.22 \\
\hline & 300 & 300 & 1 & -0.04 & -25.80 & -0.95 \\
\hline & & 360 & 1.2 & -0.03 & -27.55 & -1.05 \\
\hline & & 450 & 1.5 & -0.02 & -28.74 & -1.15 \\
\hline & & 600 & 2 & -0.01 & -29.97 & -1.26 \\
\hline & 350 & 350 & 1 & -0.03 & -26.53 & -0.99 \\
\hline & & 420 & 1.2 & -0.02 & -28.21 & -1.09 \\
\hline & & 525 & 1.5 & -0.01 & -29.28 & -1.18 \\
\hline & & 700 & 2 & -0.01 & -30.35 & -1.29 \\
\hline
\end{tabular}


Table A-14: Summary of Maximum deflection, Transverse Moment and Longitudinal Moment in Cantilevered Slab with Tl-4 Barrier of Length $1.5 \mathrm{~m}$

\begin{tabular}{|c|c|c|c|c|c|c|}
\hline \multicolumn{7}{|c|}{ Cantilever length: $1.5 \mathrm{~m}$} \\
\hline \multirow{2}{*}{$\begin{array}{l}\text { Barrier length } \\
(\mathbf{m})\end{array}$} & \multicolumn{2}{|c|}{ Slab thickness } & \multirow[t]{2}{*}{$\overline{\mathbf{t}_{2} / \mathbf{t}_{1}}$} & \multirow{2}{*}{$\begin{array}{c}\boldsymbol{\Delta} \\
(\mathbf{m m})\end{array}$} & \multirow{2}{*}{$\begin{array}{c}\mathbf{M}_{\mathbf{y}} \\
(\mathbf{k N} \cdot \mathbf{m m} / \mathbf{m m})\end{array}$} & \multirow{2}{*}{$\begin{array}{c}\mathbf{M}_{\mathbf{x}} \\
(\mathbf{k N} \cdot \mathbf{m m} / \mathbf{m m})\end{array}$} \\
\hline & $\mathbf{t}_{1}(\mathbf{m m})$ & $\mathbf{t}_{2}(\mathbf{m m})$ & & & & \\
\hline \multirow{20}{*}{5} & 200 & 200 & 1 & -0.93 & -57.97 & -2.16 \\
\hline & & 240 & 1.2 & -0.65 & -61.82 & -2.45 \\
\hline & & 300 & 1.5 & -0.40 & -65.51 & -2.79 \\
\hline & & 400 & 2 & -0.21 & -70.05 & -3.21 \\
\hline & 225 & 225 & 1 & -0.68 & -59.09 & -2.27 \\
\hline & & 270 & 1.2 & -0.47 & -63.05 & -2.57 \\
\hline & & 337.5 & 1.5 & -0.29 & -66.79 & -2.91 \\
\hline & & 450 & 2 & -0.15 & -71.32 & -3.34 \\
\hline & 250 & 250 & 1 & -0.51 & -60.20 & -2.38 \\
\hline & & 300 & 1.2 & -0.36 & -64.22 & -2.68 \\
\hline & & 375 & 1.5 & -0.22 & -67.98 & -3.03 \\
\hline & & 500 & 2 & -0.11 & -72.45 & -3.45 \\
\hline & 300 & 300 & 1 & -0.32 & -62.25 & -2.59 \\
\hline & & 360 & 1.2 & -0.22 & -66.33 & -2.89 \\
\hline & & 450 & 1.5 & -0.13 & -70.02 & -3.23 \\
\hline & & 600 & 2 & -0.07 & -74.29 & -3.64 \\
\hline & 350 & 350 & 1 & -0.21 & -64.00 & -2.78 \\
\hline & & 420 & 1.2 & -0.15 & -68.07 & -3.08 \\
\hline & & 525 & 1.5 & -0.09 & -71.63 & -3.40 \\
\hline & & 700 & 2 & -0.05 & -75.66 & -3.79 \\
\hline \multirow{20}{*}{6} & 200 & 200 & 1 & -0.87 & -55.74 & -2.04 \\
\hline & & 240 & 1.2 & -0.61 & -59.86 & -2.34 \\
\hline & & 300 & 1.5 & -0.38 & -63.95 & -2.70 \\
\hline & & 400 & 2 & -0.20 & -68.98 & -3.15 \\
\hline & 225 & 225 & 1 & -0.64 & -57.20 & -2.16 \\
\hline & & 270 & 1.2 & -0.45 & -61.42 & -2.47 \\
\hline & & 337.5 & 1.5 & -0.28 & -65.53 & -2.84 \\
\hline & & 450 & 2 & -0.15 & -70.50 & -3.29 \\
\hline & 250 & 250 & 1 & -0.49 & -58.61 & -2.28 \\
\hline & & 300 & 1.2 & -0.34 & -62.88 & -2.60 \\
\hline & & 375 & 1.5 & -0.21 & -66.96 & -2.97 \\
\hline & & 500 & 2 & -0.11 & -71.81 & -3.41 \\
\hline & 300 & 300 & 1 & -0.31 & -61.11 & -2.52 \\
\hline & & 360 & 1.2 & -0.21 & -65.39 & -2.84 \\
\hline & & 450 & 1.5 & -0.13 & -69.34 & -3.19 \\
\hline & & 600 & 2 & -0.07 & $\begin{array}{l}-73.89 \\
\end{array}$ & -3.62 \\
\hline & 350 & 350 & 1 & -0.20 & -63.16 & -2.72 \\
\hline & & 420 & 1.2 & -0.14 & -67.40 & -3.04 \\
\hline & & 525 & 1.5 & -0.09 & -71.17 & -3.38 \\
\hline & & 700 & 2 & -0.05 & -75.41 & -3.78 \\
\hline
\end{tabular}




\begin{tabular}{|c|c|c|c|c|c|c|}
\hline \multicolumn{7}{|c|}{ Cantilever length: $1.5 \mathrm{~m}$} \\
\hline \multirow{2}{*}{$\begin{array}{l}\text { Barrier length } \\
(\mathrm{m})\end{array}$} & \multicolumn{2}{|c|}{ Slab thickness } & \multirow[t]{2}{*}{$\mathbf{t}_{2} / \mathbf{t}_{1}$} & \multirow{2}{*}{$\begin{array}{c}\Delta \\
(\mathbf{m m})\end{array}$} & \multirow{2}{*}{$\begin{array}{c}\mathbf{M}_{\mathbf{y}} \\
(\mathbf{k N} \cdot \mathbf{m m} / \mathbf{m m})\end{array}$} & \multirow{2}{*}{$\begin{array}{c}\mathbf{M}_{\mathbf{x}} \\
(\mathbf{k N} \cdot \mathbf{m m} / \mathbf{m m})\end{array}$} \\
\hline & $\mathbf{t}_{1}(\mathbf{m m})$ & $\mathbf{t}_{2}(\mathbf{m m})$ & & & & \\
\hline \multirow{20}{*}{8} & 200 & 200 & 1 & -0.82 & -53.54 & -1.92 \\
\hline & & 240 & 1.2 & -0.58 & -58.02 & -2.24 \\
\hline & & 300 & 1.5 & -0.37 & -62.60 & -2.63 \\
\hline & & 400 & 2 & -0.20 & -68.18 & -3.11 \\
\hline & 225 & 225 & 1 & -0.61 & -55.44 & -2.06 \\
\hline & & 270 & 1.2 & -0.43 & -59.98 & -2.39 \\
\hline & & 337.5 & 1.5 & -0.27 & -64.51 & -2.78 \\
\hline & & 450 & 2 & -0.15 & -69.92 & -3.26 \\
\hline & 250 & 250 & 1 & -0.47 & -57.18 & -2.21 \\
\hline & & 300 & 1.2 & -0.33 & -61.73 & -2.54 \\
\hline & & 375 & 1.5 & -0.21 & -66.17 & -2.92 \\
\hline & & 500 & 2 & -0.11 & -71.39 & -3.39 \\
\hline & 300 & 300 & 1 & -0.30 & -60.15 & -2.46 \\
\hline & & 360 & 1.2 & -0.21 & -64.65 & -2.80 \\
\hline & & 450 & 1.5 & -0.13 & -68.86 & -3.17 \\
\hline & & 600 & 2 & -0.07 & -73.67 & -3.61 \\
\hline & 350 & 350 & 1 & -0.20 & -62.50 & -2.69 \\
\hline & & 420 & 1.2 & -0.14 & -66.91 & -3.01 \\
\hline & & 525 & 1.5 & -0.09 & -70.88 & -3.36 \\
\hline & & 700 & 2 & -0.05 & -75.29 & -3.77 \\
\hline \multirow{20}{*}{10} & 200 & 200 & 1 & -0.79 & -52.77 & -1.88 \\
\hline & & 240 & 1.2 & -0.57 & -57.45 & -2.21 \\
\hline & & 300 & 1.5 & -0.36 & -62.23 & -2.61 \\
\hline & & 400 & 2 & -0.20 & -68.01 & -3.10 \\
\hline & 225 & 225 & 1 & -0.60 & -54.87 & -2.04 \\
\hline & & 270 & 1.2 & -0.43 & -59.56 & -2.37 \\
\hline & & 337.5 & 1.5 & -0.27 & -64.26 & -2.77 \\
\hline & & 450 & 2 & -0.15 & -69.82 & -3.25 \\
\hline & 250 & 250 & 1 & -0.46 & -56.75 & -2.18 \\
\hline & & 300 & 1.2 & -0.33 & -61.42 & -2.52 \\
\hline & & 375 & 1.5 & -0.21 & -66.00 & -2.92 \\
\hline & & 500 & 2 & -0.11 & -71.32 & -3.39 \\
\hline & 300 & 300 & 1 & -0.30 & -59.88 & -2.45 \\
\hline & & 360 & 1.2 & -0.21 & -64.48 & -2.79 \\
\hline & & 450 & 1.5 & -0.13 & -68.78 & -3.16 \\
\hline & & 600 & 2 & -0.07 & -73.64 & -3.60 \\
\hline & 350 & 350 & 1 & -0.20 & -62.34 & -2.68 \\
\hline & & 420 & 1.2 & -0.14 & -66.82 & -3.01 \\
\hline & & 525 & 1.5 & -0.09 & -70.84 & -3.36 \\
\hline & & 700 & 2 & -0.05 & -75.27 & -3.77 \\
\hline
\end{tabular}




\section{Cantilever length: $1.5 \mathrm{~m}$}

\begin{tabular}{|c|c|c|c|c|c|c|}
\hline \multirow{2}{*}{$\begin{array}{c}\text { Barrier length } \\
(\mathrm{m})\end{array}$} & \multicolumn{2}{|c|}{ "Slab thickness } & \multirow[t]{2}{*}{$\overline{t_{2} / \mathbf{t}_{1}}$} & \multirow{2}{*}{$\begin{array}{c}\boldsymbol{\Delta} \\
(\mathbf{m m})\end{array}$} & \multirow{2}{*}{$\begin{array}{c}\mathbf{M}_{\mathbf{y}} \\
(\mathbf{k N} \cdot \mathbf{m m} / \mathbf{m m})\end{array}$} & \multirow{2}{*}{$\begin{array}{c}\mathbf{M}_{\mathbf{x}} \\
(\mathbf{k N} \cdot \mathbf{m m} / \mathbf{m m})\end{array}$} \\
\hline & $\mathbf{t}_{1}(\mathrm{~mm})$ & $\mathbf{t}_{2}-(\mathbf{m m})$ & & & & \\
\hline \multirow{20}{*}{12} & 200 & 200 & 1 & -0.79 & -52.53 & -1.87 \\
\hline & & 240 & 1.2 & -0.57 & -57.28 & -2.21 \\
\hline & & 300 & 1.5 & -0.36 & -62.15 & -2.61 \\
\hline & & 400 & 2 & -0.20 & -67.98 & -3.10 \\
\hline & 225 & 225 & 1 & -0.60 & -54.70 & -2.03 \\
\hline & & 270 & 1.2 & -0.43 & -59.45 & -2.37 \\
\hline & & 337.5 & 1.5 & -0.27 & -64.20 & -2.77 \\
\hline & & 450 & 2 & -0.15 & -69.80 & -3.25 \\
\hline & 250 & 250 & 1 & -0.46 & -56.63 & -2.18 \\
\hline & & 300 & 1.2 & -0.33 & -61.35 & -2.52 \\
\hline & & 375 & 1.5 & -0.21 & -65.96 & -2.91 \\
\hline & & 500 & 2 & -0.11 & -71.31 & -3.39 \\
\hline & 300 & 300 & 1 & -0.30 & -59.82 & -2.45 \\
\hline & & 360 & 1.2 & -0.21 & -64.44 & -2.79 \\
\hline & & 450 & 1.5 & -0.13 & -68.76 & -3.16 \\
\hline & & 600 & 2 & -0.07 & -73.63 & -3.60 \\
\hline & 350 & 350 & 1 & -0.20 & -62.31 & -2.68 \\
\hline & & 420 & 1.2 & -0.14 & -66.80 & -3.01 \\
\hline & & 525 & 1.5 & -0.09 & -70.83 & -3.36 \\
\hline & & 700 & 2 & -0.05 & -75.27 & -3.77 \\
\hline
\end{tabular}


Table A-15: Summary of Maximum deflection, Transverse Moment and Longitudinal Moment in Cantilevered Slab with Tl-4 Barrier of Length 2 m

\begin{tabular}{|c|c|c|c|c|c|c|}
\hline \multicolumn{7}{|c|}{ Cantilever length: $2 \mathrm{~m}$} \\
\hline \multirow{2}{*}{$\begin{array}{c}\text { Barrier length } \\
(\mathbf{m})\end{array}$} & \multicolumn{2}{|c|}{ Slab thickness } & \multirow[t]{2}{*}{$\mathbf{t}_{2} / \mathbf{t}_{1}$} & \multirow{2}{*}{$\begin{array}{c}\mathbf{\Delta} \\
(\mathbf{m m})\end{array}$} & \multirow{2}{*}{$\begin{array}{c}\mathbf{M}_{\mathbf{y}} \\
(\mathbf{k N} \cdot \mathbf{m m} / \mathbf{m m})\end{array}$} & \multirow{2}{*}{$\begin{array}{c}\mathbf{M}_{\mathbf{x}} \\
(\mathbf{k N} \cdot \mathbf{m m} / \mathbf{m m})\end{array}$} \\
\hline & $\mathbf{t}_{1}(\mathbf{m m})$ & $\mathbf{t}_{2}(\mathrm{~mm})$ & & & & \\
\hline \multirow{20}{*}{5} & 200 & 200 & 1 & -2.91 & -80.57 & -5.00 \\
\hline & & 240 & 1.2 & -2.02 & -85.40 & $\begin{array}{l}-5.37 \\
\end{array}$ \\
\hline & & 300 & 1.5 & -1.25 & -90.36 & -5.80 \\
\hline & & 400 & 2 & -0.66 & -96.61 & -6.34 \\
\hline & 225 & 225 & 1 & -2.10 & -81.74 & -5.13 \\
\hline & & 270 & 1.2 & -1.46 & -86.71 & -5.51 \\
\hline & & 337.5 & 1.5 & -0.90 & -91.80 & -5.95 \\
\hline & & 450 & 2 & -0.48 & -98.16 & -6.51 \\
\hline & 250 & 250 & 1 & -1.57 & -82.93 & -5.27 \\
\hline & & 300 & 1.2 & -1.09 & -88.01 & -5.65 \\
\hline & & 375 & 1.5 & -0.68 & -93.20 & -6.10 \\
\hline & & 500 & 2 & -0.36 & $\begin{array}{l}-99.61 \\
\end{array}$ & -6.66 \\
\hline & 300 & 300 & 1 & -0.95 & -85.23 & -5.53 \\
\hline & & 360 & 1.2 & -0.66 & -90.47 & -5.93 \\
\hline & & 450 & 1.5 & -0.41 & -95.72 & -6.38 \\
\hline & & 600 & 2 & -0.22 & -102.09 & -6.93 \\
\hline & 350 & 350 & 1 & -0.62 & -87.27 & -5.77 \\
\hline & & 420 & 1.2 & $\begin{array}{l}-0.43 \\
\end{array}$ & $\begin{array}{l}-92.59 \\
\end{array}$ & -6.17 \\
\hline & & 525 & 1.5 & -0.27 & -97.83 & $\begin{array}{l}-6.62 \\
\end{array}$ \\
\hline & & 700 & 2 & -0.14 & -104.06 & -7.15 \\
\hline \multirow{20}{*}{6} & 200 & 200 & 1 & -2.69 & -76.12 & -4.70 \\
\hline & & 240 & 1.2 & -1.88 & -81.30 & -5.09 \\
\hline & & 300 & 1.5 & -1.18 & -86.85 & -5.56 \\
\hline & & 400 & 2 & -0.63 & -93.90 & -6.17 \\
\hline & 225 & 225 & 1 & -1.96 & -77.80 & -4.87 \\
\hline & & 270 & 1.2 & -1.37 & -83.15 & -5.27 \\
\hline & & 337.5 & 1.5 & -0.86 & -88.82 & -5.75 \\
\hline & & 450 & 2 & -0.46 & -95.95 & -6.36 \\
\hline & 250 & 250 & 1 & -1.48 & -79.46 & -5.03 \\
\hline & & 300 & 1.2 & -1.04 & -84.93 & -5.45 \\
\hline & & 375 & 1.5 & -0.65 & -90.67 & -5.93 \\
\hline & & 500 & 2 & -0.35 & -97.79 & -6.54 \\
\hline & 300 & 300 & 1 & -0.91 & -82.53 & -5.35 \\
\hline & & 360 & 1.2 & -0.64 & -88.14 & -5.77 \\
\hline & & 450 & 1.5 & -0.40 & -93.90 & -6.26 \\
\hline & & 600 & 2 & -0.21 & -100.86 & -6.85 \\
\hline & 350 & 350 & 1 & -0.60 & -85.17 & -5.63 \\
\hline & & 420 & 1.2 & -0.42 & -90.83 & -6.06 \\
\hline & & 525 & 1.5 & -0.26 & -96.50 & -6.53 \\
\hline & & 700 & 2 & -0.14 & -103.22 & $\begin{array}{l}-7.10 \\
\end{array}$ \\
\hline
\end{tabular}




\begin{tabular}{|c|c|c|c|c|c|c|}
\hline \multicolumn{7}{|c|}{ Cantilever length: $2 \mathrm{~m}$} \\
\hline \multirow{2}{*}{$\begin{array}{l}\text { Barrier length } \\
\text { (m) }\end{array}$} & \multicolumn{2}{|c|}{ Slab thickness } & \multirow[t]{2}{*}{$\mathbf{t}_{2} / \mathbf{t}_{1}$} & \multirow{2}{*}{$\underset{(\mathbf{m m})}{\Delta}$} & \multirow{2}{*}{$\begin{array}{c}\mathbf{M}_{\mathbf{y}} \\
(\mathbf{k N} \cdot \mathbf{m m} / \mathbf{m m})\end{array}$} & \multirow{2}{*}{$\begin{array}{c}\mathbf{M}_{\mathbf{x}} \\
(\mathbf{k N . m m} / \mathbf{m m})\end{array}$} \\
\hline & $\overline{\mathbf{t}_{1}(\mathbf{m m})}$ & $\mathbf{t}_{2}(\mathbf{m m})$ & & & & \\
\hline \multirow{20}{*}{8} & 200 & 200 & 1 & -2.44 & -70.89 & -4.37 \\
\hline & & 240 & 1.2 & -1.73 & -76.64 & -4.80 \\
\hline & & 300 & 1.5 & -1.10 & -83.04 & -5.32 \\
\hline & & 400 & 2 & -0.60 & -91.22 & -6.00 \\
\hline & 225 & 225 & 1 & -1.81 & -73.37 & -4.58 \\
\hline & & 270 & 1.2 & -1.29 & -79.27 & -5.02 \\
\hline & & 337.5 & 1.5 & -0.82 & -85.74 & -5.56 \\
\hline & & 450 & 2 & -0.44 & -93.87 & -6.23 \\
\hline & 250 & 250 & 1 & -1.38 & -75.70 & -4.79 \\
\hline & & 300 & 1.2 & -0.98 & -81.70 & -5.24 \\
\hline & & 375 & 1.5 & -0.62 & -88.17 & -5.77 \\
\hline & & 500 & 2 & -0.34 & -96.18 & -6.44 \\
\hline & 300 & 300 & 1 & -0.87 & -79.80 & -5.17 \\
\hline & & 360 & 1.2 & -0.61 & -85.87 & -5.63 \\
\hline & & 450 & 1.5 & -0.39 & -92.23 & -6.15 \\
\hline & & 600 & 2 & -0.21 & -99.88 & -6.79 \\
\hline & 350 & 350 & 1 & -0.58 & -83.17 & -5.50 \\
\hline & & 420 & 1.2 & -0.41 & -89.22 & -5.95 \\
\hline & & 525 & 1.5 & -0.26 & -95.38 & -6.46 \\
\hline & & 700 & 2 & -0.14 & -102.61 & -7.06 \\
\hline \multirow{20}{*}{10} & 200 & 200 & 1 & -2.32 & -68.47 & -4.22 \\
\hline & & 240 & 1.2 & -1.67 & -74.61 & -4.68 \\
\hline & & 300 & 1.5 & -1.07 & -81.53 & -5.24 \\
\hline & & 400 & 2 & -0.59 & -90.32 & -5.95 \\
\hline & 225 & 225 & 1 & -1.74 & -71.43 & -4.46 \\
\hline & & 270 & 1.2 & -1.25 & -77.68 & -4.93 \\
\hline & & 337.5 & 1.5 & -0.80 & -84.60 & -5.49 \\
\hline & & 450 & 2 & -0.44 & -93.24 & -6.20 \\
\hline & 250 & 250 & 1 & -1.34 & -74.13 & -4.69 \\
\hline & & 300 & 1.2 & -0.96 & -80.44 & -5.16 \\
\hline & & 375 & 1.5 & -0.61 & -87.30 & -5.72 \\
\hline & & 500 & 2 & -0.33 & -95.73 & -6.42 \\
\hline & 300 & 300 & 1 & -0.85 & -78.76 & -5.11 \\
\hline & & 360 & 1.2 & -0.61 & -85.08 & -5.58 \\
\hline & & 450 & 1.5 & -0.38 & -91.73 & -6.12 \\
\hline & & 600 & 2 & -0.21 & -99.65 & -6.78 \\
\hline & 350 & 350 & 1 & -0.57 & -82.48 & -5.46 \\
\hline & & 420 & 1.2 & -0.41 & -88.72 & -5.92 \\
\hline & & 525 & 1.5 & -0.26 & -95.09 & -6.45 \\
\hline & & 700 & 2 & -0.14 & -102.49 & -7.06 \\
\hline
\end{tabular}




\begin{tabular}{|c|c|c|c|c|c|c|}
\hline \multicolumn{7}{|c|}{ Cantilever length: $2 \mathrm{~m}$} \\
\hline \multirow{2}{*}{$\begin{array}{c}\text { Barrier length } \\
(\mathrm{m})\end{array}$} & \multicolumn{2}{|c|}{ Slab thickness } & \multirow[t]{2}{*}{$\overline{\mathbf{t}_{2} / \mathbf{t}_{1}}$} & \multirow{2}{*}{$\begin{array}{c}\boldsymbol{\Delta} \\
(\mathbf{m m})\end{array}$} & \multirow{2}{*}{$\begin{array}{c}\mathbf{M}_{\mathbf{y}} \\
(\mathbf{k N} \cdot \mathbf{m m} / \mathbf{m m})\end{array}$} & \multirow{2}{*}{$\begin{array}{c}\mathbf{M}_{\mathbf{x}} \\
(\mathbf{k N} \cdot \mathbf{m m} / \mathbf{m m})\end{array}$} \\
\hline & $\mathbf{t}_{\mathbf{1}}(\mathbf{m m})$ & $t_{2}(\mathrm{~mm})$ & & & & \\
\hline \multirow{20}{*}{12} & 200 & 200 & 1 & -2.27 & -67.42 & -4.16 \\
\hline & & 240 & 1.2 & -1.64 & -73.79 & -4.63 \\
\hline & & 300 & 1.5 & -1.06 & -80.99 & -5.21 \\
\hline & & 400 & 2 & -0.59 & -90.07 & -5.94 \\
\hline & 225 & 225 & 1 & -1.71 & -70.62 & -4.42 \\
\hline & & 270 & 1.2 & -1.23 & -77.07 & -4.89 \\
\hline & & 337.5 & 1.5 & -0.79 & -84.23 & -5.47 \\
\hline & & 450 & 2 & -0.44 & -93.08 & -6.19 \\
\hline & 250 & 250 & 1 & -1.33 & -73.51 & -4.66 \\
\hline & & 300 & 1.2 & -0.95 & -79.99 & -5.14 \\
\hline & & 375 & 1.5 & -0.61 & -87.04 & -5.71 \\
\hline & & 500 & 2 & -0.33 & -95.63 & -6.41 \\
\hline & 300 & 300 & 1 & -0.84 & -78.39 & -5.08 \\
\hline & & 360 & 1.2 & -0.60 & -84.83 & -5.56 \\
\hline & & 450 & 1.5 & -0.38 & -91.60 & -6.12 \\
\hline & & 600 & 2 & -0.21 & -99.61 & -6.78 \\
\hline & 350 & 350 & 1 & -0.57 & -82.26 & -5.44 \\
\hline & & 420 & 1.2 & -0.41 & -88.59 & -5.92 \\
\hline & & 525 & 1.5 & -0.26 & -95.03 & -6.44 \\
\hline & & 700 & 2 & -0.14 & -102.47 & -7.06 \\
\hline
\end{tabular}


Table A-16: Summary of Maximum deflection, Transverse Moment and Longitudinal Moment in Cantilevered Slab with Tl-4 Barrier of Length $2.5 \mathrm{~m}$

\begin{tabular}{|c|c|c|c|c|c|c|}
\hline \multicolumn{7}{|c|}{ Cantilever length: $2.5 \mathrm{~m}$} \\
\hline \multirow{2}{*}{$\begin{array}{l}\text { Barrier length } \\
\text { (m) }\end{array}$} & \multicolumn{2}{|c|}{ Slab thickness } & \multirow[t]{2}{*}{$\overline{t_{2} / \mathbf{t}_{1}}$} & \multirow{2}{*}{$\begin{array}{c}\Delta \\
(\mathbf{m m})\end{array}$} & \multirow{2}{*}{$\begin{array}{c}\mathbf{M y}_{\mathbf{y}} \\
(\mathbf{k N} \cdot \mathbf{m m} / \mathbf{m m})\end{array}$} & \multirow{2}{*}{$\begin{array}{c}\mathbf{M}_{\mathbf{x}} \\
(\mathrm{kN} \cdot \mathbf{m m} / \mathbf{m m})\end{array}$} \\
\hline & $\mathbf{t}_{1}(\mathrm{~mm})$ & $\mathrm{t}_{2}(\mathrm{~mm})$ & & & & \\
\hline \multirow{20}{*}{5} & 200 & 200 & 1 & -7.62 & -108.46 & -6.68 \\
\hline & & 240 & 1.2 & -5.19 & -112.73 & -6.90 \\
\hline & & 300 & 1.5 & -3.18 & -117.14 & -7.13 \\
\hline & & 400 & 2 & -1.66 & -122.55 & -7.38 \\
\hline & 225 & 225 & 1 & -5.42 & -109.16 & -6.76 \\
\hline & & 270 & 1.2 & -3.70 & -113.51 & -6.98 \\
\hline & & 337.5 & 1.5 & -2.27 & -118.00 & -7.21 \\
\hline & & 450 & 2 & -1.19 & -123.50 & -7.46 \\
\hline & 250 & 250 & 1 & -4.00 & -109.87 & -6.84 \\
\hline & & 300 & 1.2 & -2.74 & -114.30 & -7.06 \\
\hline & & 375 & 1.5 & -1.68 & -118.86 & -7.29 \\
\hline & & 500 & 2 & -0.88 & -124.41 & -7.54 \\
\hline & 300 & 300 & 1 & -2.38 & -111.26 & -6.98 \\
\hline & & 360 & 1.2 & -1.63 & -115.80 & -7.21 \\
\hline & & 450 & 1.5 & -1.00 & -120.43 & -7.43 \\
\hline & & 600 & 2 & -0.52 & -126.00 & -7.67 \\
\hline & 350 & 350 & 1 & -1.53 & -112.51 & -7.11 \\
\hline & & 420 & 1.2 & -1.05 & -117.11 & -7.33 \\
\hline & & 525 & 1.5 & -0.64 & -121.77 & -7.55 \\
\hline & & 700 & 2 & -0.34 & -127.30 & -7.78 \\
\hline \multirow{20}{*}{6} & 200 & 200 & 1 & -7.00 & -102.14 & -6.28 \\
\hline & & 240 & 1.2 & -4.82 & -106.93 & -6.53 \\
\hline & & 300 & 1.5 & -2.99 & -112.07 & -6.81 \\
\hline & & 400 & 2 & -1.58 & -118.46 & -7.13 \\
\hline & 225 & 225 & 1 & -5.02 & -103.36 & -6.39 \\
\hline & & 270 & 1.2 & -3.47 & -108.27 & -6.65 \\
\hline & & 337.5 & 1.5 & -2.15 & -113.52 & -6.93 \\
\hline & & 450 & 2 & -1.14 & -119.99 & -7.25 \\
\hline & 250 & 250 & 1 & -3.74 & -104.58 & -6.51 \\
\hline & & 300 & 1.2 & -2.58 & -109.59 & -6.77 \\
\hline & & 375 & 1.5 & -1.60 & -114.90 & -7.05 \\
\hline & & 500 & 2 & -0.85 & -121.39 & -7.36 \\
\hline & 300 & 300 & 1 & -2.25 & -106.86 & -6.72 \\
\hline & & 360 & 1.2 & -1.55 & -111.98 & -6.98 \\
\hline & & 450 & 1.5 & -0.96 & -117.34 & -7.25 \\
\hline & & 600 & 2 & -0.51 & -123.77 & -7.55 \\
\hline & 350 & 350 & 1 & -1.46 & -108.82 & -6.90 \\
\hline & & 420 & 1.2 & -1.01 & -113.98 & -7.16 \\
\hline & & 525 & 1.5 & -0.63 & -119.32 & -7.41 \\
\hline & & 700 & 2 & -0.33 & -125.62 & -7.68 \\
\hline
\end{tabular}




\begin{tabular}{|c|c|c|c|c|c|c|}
\hline \multicolumn{7}{|c|}{ Cantilever length: $2.5 \mathrm{~m}$} \\
\hline \multirow{2}{*}{$\begin{array}{l}\text { Barrier length } \\
(\mathrm{m})\end{array}$} & \multicolumn{2}{|c|}{ Slab thickness } & \multirow[t]{2}{*}{$\overline{t_{2} / t_{1}}$} & \multirow{2}{*}{$\underset{(\mathbf{m m})}{\Delta}$} & \multirow{2}{*}{$\begin{array}{c}\mathbf{M}_{\mathbf{y}} \\
(\mathbf{k N} \cdot \mathbf{m m} / \mathbf{m m})\end{array}$} & \multirow{2}{*}{$\begin{array}{c}\mathbf{M}_{\mathbf{x}} \\
(\mathbf{k N} \cdot \mathbf{m m} / \mathbf{m m})\end{array}$} \\
\hline & $\mathbf{t}_{\mathbf{1}}(\mathbf{m m})$ & $\mathbf{t}_{2}(\mathrm{~mm})$ & & & & \\
\hline \multirow{20}{*}{8} & 200 & 200 & 1 & -6.25 & -93.65 & -5.74 \\
\hline & & 240 & 1.2 & -4.38 & -99.23 & -6.05 \\
\hline & & 300 & 1.5 & -2.76 & -105.49 & -6.41 \\
\hline & & 400 & 2 & -1.49 & -113.38 & -6.83 \\
\hline & 225 & 225 & 1 & -4.56 & -95.91 & -5.92 \\
\hline & & 270 & 1.2 & -3.19 & -101.63 & -6.24 \\
\hline & & 337.5 & 1.5 & -2.01 & -107.97 & -6.59 \\
\hline & & 450 & 2 & -1.09 & -115.86 & -7.01 \\
\hline & 250 & 250 & 1 & -3.44 & -98.06 & -6.10 \\
\hline & & 300 & 1.2 & -2.41 & -103.86 & -6.41 \\
\hline & & 375 & 1.5 & -1.52 & -110.22 & -6.77 \\
\hline & & 500 & 2 & -0.82 & -118.02 & -7.16 \\
\hline & 300 & 300 & 1 & -2.11 & -101.84 & -6.41 \\
\hline & & 360 & 1.2 & -1.48 & -107.70 & -6.72 \\
\hline & & 450 & 1.5 & -0.93 & -113.98 & -7.05 \\
\hline & & 600 & 2 & -0.50 & -121.50 & -7.42 \\
\hline & 350 & 350 & 1 & -1.39 & -104.92 & -6.66 \\
\hline & & 420 & 1.2 & -0.97 & -110.75 & -6.96 \\
\hline & & 525 & 1.5 & -0.61 & -116.89 & -7.27 \\
\hline & & 700 & 2 & -0.32 & -124.08 & -7.60 \\
\hline \multirow{20}{*}{10} & 200 & 200 & 1 & -5.86 & -88.85 & -5.44 \\
\hline & & 240 & 1.2 & -4.14 & -95.00 & -5.79 \\
\hline & & 300 & 1.5 & -2.64 & -102.06 & -6.20 \\
\hline & & 400 & 2 & -1.45 & -111.00 & -6.69 \\
\hline & 225 & 225 & 1 & -4.32 & -91.91 & -5.67 \\
\hline & & 270 & 1.2 & -3.06 & -98.17 & -6.03 \\
\hline & & 337.5 & 1.5 & -1.95 & -105.25 & -6.43 \\
\hline & & 450 & 2 & -1.06 & -114.05 & -6.90 \\
\hline & 250 & 250 & 1 & -3.29 & -94.70 & -5.89 \\
\hline & & 300 & 1.2 & -2.33 & -101.01 & -6.24 \\
\hline & & 375 & 1.5 & -1.48 & -108.04 & -6.64 \\
\hline & & 500 & 2 & -0.80 & -116.65 & -7.09 \\
\hline & 300 & 300 & 1 & -2.05 & -99.46 & -6.26 \\
\hline & & 360 & 1.2 & -1.44 & -105.75 & -6.60 \\
\hline & & 450 & 1.5 & -0.91 & -112.57 & -6.97 \\
\hline & & 600 & 2 & -0.49 & -120.70 & -7.37 \\
\hline & 350 & 350 & 1 & -1.36 & -103.22 & -6.56 \\
\hline & & 420 & 1.2 & -0.96 & -109.42 & -6.88 \\
\hline & & 525 & 1.5 & -0.60 & -115.98 & -7.22 \\
\hline & & 700 & 2 & -0.32 & -123.61 & -7.57 \\
\hline
\end{tabular}




\begin{tabular}{|c|c|c|c|c|c|c|}
\hline \multicolumn{7}{|c|}{ Cantilever length: $2.5 \mathrm{~m}$} \\
\hline \multirow{2}{*}{$\begin{array}{c}\text { Barrier length } \\
(\mathrm{m})\end{array}$} & \multicolumn{2}{|c|}{ Slab thickness } & \multirow{3}{*}{$\begin{array}{r}\mathbf{t}_{2} / \mathbf{t}_{1} \\
\\
1\end{array}$} & \multirow{3}{*}{$\begin{array}{c}\begin{array}{c}\Delta \\
(\mathbf{m m})\end{array} \\
-5.64\end{array}$} & \multirow{3}{*}{ 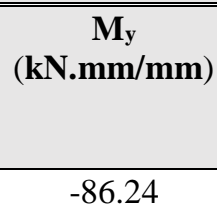 } & \multirow{3}{*}{$\begin{array}{c}\mathbf{M}_{\mathbf{x}} \\
(\mathbf{k N . m m} / \mathbf{m m}) \\
-5.28\end{array}$} \\
\hline & $\mathbf{t}_{1}(\mathbf{m m})$ & $\mathbf{t}_{2}(\mathrm{~mm})$ & & & & \\
\hline \multirow{20}{*}{12} & 200 & 200 & & & & \\
\hline & & 240 & 1.2 & -4.02 & -92.81 & -5.66 \\
\hline & & 300 & 1.5 & -2.59 & -100.41 & -6.11 \\
\hline & & 400 & 2 & -1.43 & -110.01 & -6.64 \\
\hline & 225 & 225 & 1 & -4.20 & -89.82 & -5.55 \\
\hline & & 270 & 1.2 & -2.99 & -96.46 & -5.93 \\
\hline & & 337.5 & 1.5 & -1.92 & -104.01 & -6.36 \\
\hline & & 450 & 2 & -1.05 & -113.37 & -6.87 \\
\hline & 250 & 250 & 1 & -3.22 & -93.01 & -5.79 \\
\hline & & 300 & 1.2 & -2.29 & -99.66 & -6.16 \\
\hline & & 375 & 1.5 & -1.46 & -107.10 & -6.58 \\
\hline & & 500 & 2 & -0.80 & -116.16 & -7.06 \\
\hline & 300 & 300 & 1 & -2.02 & -98.35 & -6.19 \\
\hline & & 360 & 1.2 & -1.43 & -104.91 & -6.55 \\
\hline & & 450 & 1.5 & -0.91 & -112.04 & -6.94 \\
\hline & & 600 & 2 & -0.49 & -120.46 & -7.36 \\
\hline & 350 & 350 & 1 & -1.35 & -102.50 & -6.52 \\
\hline & & 420 & 1.2 & -0.95 & -108.90 & -6.85 \\
\hline & & 525 & 1.5 & -0.60 & -115.69 & -7.21 \\
\hline & & 700 & 2 & -0.32 & -123.49 & -7.57 \\
\hline
\end{tabular}


Table A-17: Summary of Maximum deflection, Transverse Moment and Longitudinal Moment in Cantilevered Slab with Tl-4 Parapet of Length 1 m

\begin{tabular}{|c|c|c|c|c|c|c|}
\hline \multicolumn{7}{|c|}{ Cantilever length: 1 m } \\
\hline \multirow{2}{*}{$\begin{array}{c}\text { Barrier length } \\
(\mathrm{m})\end{array}$} & \multicolumn{2}{|c|}{ Slab thickness } & \multirow{3}{*}{$\begin{array}{c}\mathbf{t}_{2} / \mathbf{t}_{1} \\
\\
\\
1\end{array}$} & \multirow{3}{*}{$\begin{array}{c}\begin{array}{c}\Delta \\
(\mathbf{m m})\end{array} \\
-0.23\end{array}$} & \multirow{3}{*}{$\begin{array}{c}\begin{array}{c}\mathbf{M}_{\mathbf{y}} \\
(\mathbf{k N} \cdot \mathbf{m m} / \mathbf{m m})\end{array} \\
-36.19\end{array}$} & \multirow{3}{*}{ 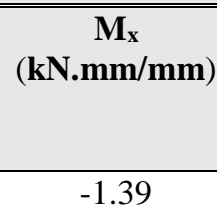 } \\
\hline & $\mathbf{t}_{1}(\mathbf{m m})$ & $\mathrm{t}_{2}(\mathrm{~mm})$ & & & & \\
\hline \multirow{20}{*}{5} & 200 & 200 & & & & \\
\hline & & 240 & 1.2 & $\begin{array}{l}-0.16 \\
\end{array}$ & -38.08 & -1.54 \\
\hline & & 300 & 1.5 & -0.10 & -40.33 & -1.72 \\
\hline & & 400 & 2 & -0.05 & -43.03 & -1.95 \\
\hline & 225 & 225 & 1 & $\begin{array}{l}-0.17 \\
\end{array}$ & -37.21 & -1.45 \\
\hline & & 270 & 1.2 & -0.12 & -39.11 & -1.60 \\
\hline & & 337.5 & 1.5 & -0.07 & -41.32 & -1.79 \\
\hline & & 450 & 2 & -0.04 & -43.92 & -2.02 \\
\hline & 250 & 250 & 1 & -0.13 & -38.14 & -1.51 \\
\hline & & 300 & 1.2 & -0.09 & -40.01 & -1.66 \\
\hline & & 375 & 1.5 & -0.05 & -42.17 & -1.84 \\
\hline & & 500 & 2 & -0.03 & -44.66 & -2.08 \\
\hline & 300 & 300 & 1 & -0.08 & -39.71 & -1.62 \\
\hline & & 360 & 1.2 & -0.05 & -41.52 & -1.76 \\
\hline & & 450 & 1.5 & -0.03 & -43.55 & -1.94 \\
\hline & & 600 & 2 & -0.02 & -45.81 & -2.17 \\
\hline & 350 & 350 & 1 & -0.05 & -40.97 & -1.70 \\
\hline & & 420 & 1.2 & -0.04 & -42.68 & -1.84 \\
\hline & & 525 & 1.5 & -0.02 & -44.58 & -2.01 \\
\hline & & 700 & 2 & -0.01 & -46.61 & -2.23 \\
\hline \multirow{20}{*}{6} & 200 & 200 & 1 & -0.22 & -35.39 & -1.36 \\
\hline & & 240 & 1.2 & -0.15 & -37.44 & -1.51 \\
\hline & & 300 & 1.5 & -0.09 & -39.86 & -1.70 \\
\hline & & 400 & 2 & -0.05 & -42.76 & -1.94 \\
\hline & 225 & 225 & 1 & -0.16 & -36.56 & -1.43 \\
\hline & & 270 & 1.2 & -0.11 & -38.59 & -1.58 \\
\hline & & 337.5 & 1.5 & -0.07 & -40.96 & -1.77 \\
\hline & & 450 & 2 & -0.04 & -43.73 & -2.01 \\
\hline & 250 & 250 & 1 & -0.13 & -37.60 & -1.49 \\
\hline & & 300 & 1.2 & -0.09 & -39.59 & -1.64 \\
\hline & & 375 & 1.5 & -0.05 & -41.89 & -1.83 \\
\hline & & 500 & 2 & -0.03 & -44.53 & -2.07 \\
\hline & 300 & 300 & 1 & -0.08 & -39.34 & -1.60 \\
\hline & & 360 & 1.2 & -0.05 & -41.24 & -1.75 \\
\hline & & 450 & 1.5 & -0.03 & -43.38 & -1.93 \\
\hline & & 600 & 2 & -0.02 & -45.74 & -2.16 \\
\hline & 350 & 350 & 1 & -0.05 & -40.71 & $\begin{array}{l}-1.69 \\
\end{array}$ \\
\hline & & 420 & 1.2 & -0.04 & -42.51 & -1.83 \\
\hline & & 525 & 1.5 & -0.02 & -44.48 & -2.01 \\
\hline & & 700 & 2 & -0.01 & -46.58 & -2.23 \\
\hline
\end{tabular}




\begin{tabular}{|c|c|c|c|c|c|c|}
\hline \multicolumn{7}{|c|}{ Cantilever length: 1 m } \\
\hline \multirow{2}{*}{$\begin{array}{l}\text { Barrier length } \\
(\mathrm{m})\end{array}$} & \multicolumn{2}{|c|}{ Slab thickness } & \multirow[t]{2}{*}{$\mathbf{t}_{2} / \mathbf{t}_{1}$} & \multirow{2}{*}{$\underset{(\mathbf{m m})}{\Delta}$} & \multirow{2}{*}{$\begin{array}{c}\mathbf{M}_{\mathbf{y}} \\
(\mathbf{k N} \cdot \mathbf{m m} / \mathbf{m m})\end{array}$} & \multirow{2}{*}{$\begin{array}{c}\mathbf{M}_{\mathbf{x}} \\
(\mathbf{k N} \cdot \mathbf{m m} / \mathbf{m m})\end{array}$} \\
\hline & $\mathbf{t}_{1}(\mathbf{m m})$ & $\mathbf{t}_{2}(\mathbf{m m})$ & & & & \\
\hline \multirow{20}{*}{8} & 200 & 200 & 1 & -0.21 & -34.78 & -1.34 \\
\hline & & 240 & 1.2 & -0.15 & -36.98 & $\begin{array}{l}-1.49 \\
\end{array}$ \\
\hline & & 300 & 1.5 & -0.09 & -39.58 & -1.68 \\
\hline & & 400 & 2 & -0.05 & -42.63 & -1.93 \\
\hline & 225 & 225 & 1 & -0.16 & -36.08 & -1.41 \\
\hline & & 270 & 1.2 & -0.11 & -38.25 & -1.56 \\
\hline & & 337.5 & 1.5 & -0.07 & -40.76 & -1.76 \\
\hline & & 450 & 2 & -0.04 & -43.64 & -2.00 \\
\hline & 250 & 250 & 1 & -0.12 & -37.23 & -1.47 \\
\hline & & 300 & 1.2 & -0.09 & -39.34 & -1.63 \\
\hline & & 375 & 1.5 & -0.05 & -41.75 & -1.83 \\
\hline & & 500 & 2 & -0.03 & -44.47 & -2.07 \\
\hline & 300 & 300 & 1 & -0.08 & -39.11 & -1.59 \\
\hline & & 360 & 1.2 & -0.05 & -41.10 & -1.75 \\
\hline & & 450 & 1.5 & -0.03 & -43.31 & -1.93 \\
\hline & & 600 & 2 & -0.02 & -45.72 & -2.16 \\
\hline & 350 & 350 & 1 & -0.05 & -40.57 & -1.68 \\
\hline & & 420 & 1.2 & -0.04 & -42.43 & -1.83 \\
\hline & & 525 & 1.5 & -0.02 & -44.45 & -2.01 \\
\hline & & 700 & 2 & -0.01 & -46.56 & -2.23 \\
\hline \multirow{20}{*}{10} & 200 & 200 & 1 & -0.21 & -34.64 & -1.33 \\
\hline & & 240 & 1.2 & -0.15 & -36.90 & -1.48 \\
\hline & & 300 & 1.5 & -0.09 & -39.54 & -1.68 \\
\hline & & 400 & 2 & -0.05 & -42.62 & -1.93 \\
\hline & 225 & 225 & 1 & -0.16 & -35.99 & -1.40 \\
\hline & & 270 & 1.2 & -0.11 & -38.19 & -1.56 \\
\hline & & 337.5 & 1.5 & -0.07 & -40.73 & -1.76 \\
\hline & & 450 & 2 & -0.04 & -43.64 & -2.00 \\
\hline & 250 & 250 & 1 & -0.12 & -37.16 & -1.47 \\
\hline & & 300 & 1.2 & -0.09 & -39.30 & -1.63 \\
\hline & & 375 & 1.5 & -0.05 & -41.74 & -1.82 \\
\hline & & 500 & 2 & -0.03 & -44.47 & -2.07 \\
\hline & 300 & 300 & 1 & -0.08 & -39.08 & -1.59 \\
\hline & & 360 & 1.2 & -0.05 & -41.09 & -1.74 \\
\hline & & 450 & 1.5 & -0.03 & -43.31 & -1.93 \\
\hline & & 600 & 2 & -0.02 & -45.71 & -2.16 \\
\hline & 350 & 350 & 1 & -0.05 & -40.56 & $\begin{array}{l}-1.68 \\
\end{array}$ \\
\hline & & 420 & 1.2 & -0.04 & -42.42 & -1.83 \\
\hline & & 525 & 1.5 & -0.02 & -44.45 & -2.01 \\
\hline & & 700 & 2 & -0.01 & -46.56 & -2.23 \\
\hline
\end{tabular}




\begin{tabular}{|c|c|c|c|c|c|c|}
\hline \multicolumn{7}{|c|}{ Cantilever length: $1 \mathrm{~m}$} \\
\hline \multirow{2}{*}{$\begin{array}{c}\text { Barrier length } \\
(\mathrm{m})\end{array}$} & \multicolumn{2}{|c|}{ Slab thickness } & \multirow[t]{2}{*}{$\overline{\mathbf{t}_{2} / \mathbf{t}_{1}}$} & \multirow{2}{*}{$\begin{array}{c}\boldsymbol{\Delta} \\
(\mathbf{m m})\end{array}$} & \multirow{2}{*}{$\begin{array}{c}\mathbf{M}_{\mathbf{y}} \\
(\mathbf{k N} \cdot \mathbf{m m} / \mathbf{m m})\end{array}$} & \multirow{2}{*}{$\begin{array}{c}\mathbf{M}_{\mathbf{x}} \\
(\mathbf{k N} \cdot \mathbf{m m} / \mathbf{m m})\end{array}$} \\
\hline & $\mathbf{t}_{\mathbf{1}}(\mathbf{m m})$ & $t_{2}(\mathrm{~mm})$ & & & & \\
\hline \multirow{20}{*}{12} & 200 & 200 & 1 & -0.21 & -34.61 & -1.33 \\
\hline & & 240 & 1.2 & -0.15 & -36.88 & -1.48 \\
\hline & & 300 & 1.5 & -0.09 & -39.53 & -1.68 \\
\hline & & 400 & 2 & -0.05 & -42.62 & -1.93 \\
\hline & 225 & 225 & 1 & -0.16 & -35.97 & -1.40 \\
\hline & & 270 & 1.2 & -0.11 & -38.18 & -1.56 \\
\hline & & 337.5 & 1.5 & -0.07 & -40.73 & -1.76 \\
\hline & & 450 & 2 & -0.04 & -43.64 & -2.00 \\
\hline & 250 & 250 & 1 & -0.12 & -37.15 & -1.47 \\
\hline & & 300 & 1.2 & -0.09 & -39.30 & -1.63 \\
\hline & & 375 & 1.5 & -0.05 & -41.74 & -1.82 \\
\hline & & 500 & 2 & -0.03 & -44.47 & -2.07 \\
\hline & 300 & 300 & 1 & -0.08 & -39.08 & -1.59 \\
\hline & & 360 & 1.2 & -0.05 & -41.09 & -1.74 \\
\hline & & 450 & 1.5 & -0.03 & -43.31 & -1.93 \\
\hline & & 600 & 2 & -0.02 & -45.71 & -2.16 \\
\hline & 350 & 350 & 1 & -0.05 & -40.56 & -1.68 \\
\hline & & 420 & 1.2 & -0.04 & -42.42 & -1.83 \\
\hline & & 525 & 1.5 & -0.02 & -44.45 & -2.01 \\
\hline & & 700 & 2 & -0.01 & -46.56 & -2.23 \\
\hline
\end{tabular}


Table A-18: Summary of Maximum deflection, Transverse Moment and Longitudinal Moment in Cantilevered Slab with Tl-4 Parapet of Length $1.5 \mathrm{~m}$

\begin{tabular}{|c|c|c|c|c|c|c|}
\hline \multicolumn{7}{|c|}{ Cantilever length: $1.5 \mathrm{~m}$} \\
\hline \multirow{2}{*}{$\begin{array}{l}\text { Barrier length } \\
(\mathrm{m})\end{array}$} & \multicolumn{2}{|c|}{ Slab thickness } & \multirow[t]{2}{*}{$\mathbf{t}_{2} / \mathbf{t}_{1}$} & \multirow{2}{*}{$\underset{(\mathbf{m m})}{\Delta}$} & \multirow{2}{*}{$\begin{array}{c}\mathbf{M}_{\mathbf{y}} \\
(\mathbf{k N} \cdot \mathbf{m m} / \mathbf{m m})\end{array}$} & \multirow{2}{*}{$\begin{array}{c}\mathbf{M}_{\mathbf{x}} \\
(\mathbf{k N} \cdot \mathbf{m m} / \mathbf{m m})\end{array}$} \\
\hline & $\mathbf{t}_{\mathbf{1}}(\mathbf{m m})$ & $\mathbf{t}_{2}(\mathbf{m m})$ & & & & \\
\hline \multirow{20}{*}{5} & 200 & 200 & 1 & -0.84 & -43.10 & -1.87 \\
\hline & & 240 & 1.2 & -0.87 & -68.58 & -3.13 \\
\hline & & 300 & 1.5 & -0.54 & -72.96 & -3.51 \\
\hline & & 400 & 2 & -0.29 & -78.46 & -4.02 \\
\hline & 225 & 225 & 1 & -0.62 & -44.15 & -1.97 \\
\hline & & 270 & 1.2 & -0.64 & -70.23 & -3.29 \\
\hline & & 337.5 & 1.5 & -0.40 & -74.67 & -3.68 \\
\hline & & 450 & 2 & -0.21 & -80.18 & -4.19 \\
\hline & 250 & 250 & 1 & -0.47 & -45.14 & -2.07 \\
\hline & & 300 & 1.2 & $\begin{array}{l}-0.48 \\
\end{array}$ & -71.77 & -3.45 \\
\hline & & 375 & 1.5 & -0.30 & -76.23 & -3.84 \\
\hline & & 500 & 2 & -0.16 & -81.71 & -4.35 \\
\hline & 300 & 300 & 1 & -0.29 & -46.90 & -2.26 \\
\hline & & 360 & 1.2 & -0.30 & -74.45 & -3.73 \\
\hline & & 450 & 1.5 & -0.18 & -78.88 & -4.13 \\
\hline & & 600 & 2 & -0.10 & -84.22 & -4.62 \\
\hline & 350 & 350 & 1 & -0.19 & -48.37 & -2.42 \\
\hline & & 420 & 1.2 & -0.20 & -76.65 & -3.97 \\
\hline & & 525 & 1.5 & -0.12 & -81.01 & -4.37 \\
\hline & & 700 & 2 & -0.06 & -86.16 & -4.84 \\
\hline \multirow{20}{*}{6} & 200 & 200 & 1 & -0.79 & -41.07 & -1.75 \\
\hline & & 240 & 1.2 & -0.83 & -65.84 & -2.96 \\
\hline & & 300 & 1.5 & -0.52 & -70.64 & -3.37 \\
\hline & & 400 & 2 & -0.28 & -76.74 & -3.91 \\
\hline & 225 & 225 & 1 & -0.59 & -42.38 & -1.87 \\
\hline & & 270 & 1.2 & -0.61 & -67.88 & -3.15 \\
\hline & & 337.5 & 1.5 & -0.38 & -72.72 & -3.56 \\
\hline & & 450 & 2 & -0.21 & -78.79 & -4.11 \\
\hline & 250 & 250 & 1 & -0.45 & -43.59 & -1.98 \\
\hline & & 300 & 1.2 & -0.46 & -69.74 & -3.32 \\
\hline & & 375 & 1.5 & -0.29 & -74.58 & -3.74 \\
\hline & & 500 & 2 & -0.16 & -80.59 & -4.28 \\
\hline & 300 & 300 & 1 & -0.28 & -45.70 & -2.19 \\
\hline & & 360 & 1.2 & -0.29 & -72.92 & -3.63 \\
\hline & & 450 & 1.5 & -0.18 & -77.71 & -4.05 \\
\hline & & 600 & 2 & -0.10 & -83.50 & -4.58 \\
\hline & 350 & 350 & 1 & -0.19 & -47.44 & -2.37 \\
\hline & & 420 & 1.2 & -0.19 & -75.51 & -3.90 \\
\hline & & 525 & 1.5 & -0.12 & -80.19 & -4.32 \\
\hline & & 700 & 2 & -0.06 & -85.70 & -4.81 \\
\hline
\end{tabular}


Cantilever length: $1.5 \mathrm{~m}$

\begin{tabular}{|c|c|c|c|c|c|c|}
\hline \multirow{2}{*}{$\begin{array}{l}\text { Barrier length } \\
(\mathbf{m})\end{array}$} & \multicolumn{2}{|c|}{ Slab thickness } & \multirow{2}{*}{$\overline{t_{2} / \mathbf{t}_{1}}$} & \multirow{2}{*}{$\begin{array}{c}\boldsymbol{\Delta} \\
(\mathbf{m m})\end{array}$} & \multirow{2}{*}{$\begin{array}{c}\mathbf{M}_{\mathbf{y}} \\
(\mathbf{k N} \cdot \mathbf{m m} / \mathbf{m m})\end{array}$} & \multirow{2}{*}{$\begin{array}{c}\mathbf{M}_{\mathbf{x}} \\
(\mathbf{k N} \cdot \mathbf{m m} / \mathbf{m m})\end{array}$} \\
\hline & $\mathbf{t}_{1}(\mathbf{m m})$ & $\mathbf{t}_{2}(\mathbf{m m})$ & & & & \\
\hline \multirow{20}{*}{8} & 200 & 200 & 1 & -0.74 & -38.92 & -1.63 \\
\hline & & 240 & 1.2 & $\begin{array}{l}-0.78 \\
\end{array}$ & -63.03 & -2.80 \\
\hline & & 300 & 1.5 & -0.50 & -68.42 & -3.25 \\
\hline & & 400 & 2 & -0.27 & -75.30 & -3.83 \\
\hline & 225 & 225 & 1 & -0.55 & -40.56 & -1.76 \\
\hline & & 270 & 1.2 & -0.58 & -65.55 & -3.01 \\
\hline & & 337.5 & 1.5 & -0.37 & -70.95 & -3.46 \\
\hline & & 450 & 2 & -0.20 & -77.73 & -4.05 \\
\hline & 250 & 250 & 1 & -0.42 & -42.04 & -1.89 \\
\hline & & 300 & 1.2 & -0.45 & -67.80 & -3.21 \\
\hline & & 375 & 1.5 & -0.28 & -73.17 & -3.66 \\
\hline & & 500 & 2 & -0.15 & -79.80 & -4.24 \\
\hline & 300 & 300 & 1 & -0.27 & -44.58 & -2.12 \\
\hline & & 360 & 1.2 & -0.28 & -71.60 & -3.56 \\
\hline & & 450 & 1.5 & -0.18 & -76.83 & -4.00 \\
\hline & & 600 & 2 & -0.09 & -83.07 & -4.56 \\
\hline & 350 & 350 & 1 & -0.18 & -46.64 & -2.32 \\
\hline & & 420 & 1.2 & -0.19 & -74.63 & -3.85 \\
\hline & & 525 & 1.5 & -0.12 & -79.65 & -4.28 \\
\hline & & 700 & 2 & -0.06 & -85.46 & -4.80 \\
\hline \multirow{20}{*}{10} & 200 & 200 & 1 & -0.71 & -38.05 & -1.58 \\
\hline & & 240 & 1.2 & -0.76 & -62.00 & -2.75 \\
\hline & & 300 & 1.5 & -0.49 & -67.72 & -3.21 \\
\hline & & 400 & 2 & -0.27 & -74.96 & -3.82 \\
\hline & 225 & 225 & 1 & -0.54 & -39.86 & -1.72 \\
\hline & & 270 & 1.2 & -0.57 & -64.75 & -2.97 \\
\hline & & 337.5 & 1.5 & -0.37 & -70.45 & -3.43 \\
\hline & & 450 & 2 & -0.20 & -77.51 & -4.04 \\
\hline & 250 & 250 & 1 & -0.42 & -41.48 & -1.86 \\
\hline & & 300 & 1.2 & -0.44 & -67.19 & -3.17 \\
\hline & & 375 & 1.5 & -0.28 & -72.81 & -3.64 \\
\hline & & 500 & 2 & -0.15 & -79.66 & -4.23 \\
\hline & 300 & 300 & 1 & -0.27 & -44.23 & -2.10 \\
\hline & & 360 & 1.2 & -0.28 & -71.26 & -3.54 \\
\hline & & 450 & 1.5 & -0.18 & -76.66 & -3.99 \\
\hline & & 600 & 2 & -0.09 & -83.02 & -4.55 \\
\hline & 350 & 350 & 1 & -0.18 & -46.43 & -2.31 \\
\hline & & 420 & 1.2 & -0.19 & -74.44 & -3.84 \\
\hline & & 525 & 1.5 & -0.12 & -79.57 & -4.28 \\
\hline & & 700 & 2 & -0.06 & -85.44 & -4.80 \\
\hline
\end{tabular}




\begin{tabular}{|c|c|c|c|c|c|c|}
\hline \multicolumn{7}{|c|}{ Cantilever length: $1.5 \mathrm{~m}$} \\
\hline \multirow{2}{*}{$\begin{array}{c}\text { Barrier length } \\
(\mathrm{m})\end{array}$} & \multicolumn{2}{|c|}{ Slab thickness } & \multirow[t]{2}{*}{$\mathbf{t}_{2} / \mathbf{t}_{1}$} & \multirow{2}{*}{$\begin{array}{c}\boldsymbol{\Delta} \\
(\mathbf{m m})\end{array}$} & \multirow{2}{*}{$\begin{array}{c}\mathbf{M}_{\mathbf{y}} \\
(\mathbf{k N} \cdot \mathbf{m m} / \mathbf{m m})\end{array}$} & \multirow{2}{*}{$\begin{array}{c}\mathbf{M}_{\mathbf{x}} \\
(\mathbf{k N} \cdot \mathbf{m m} / \mathbf{m m})\end{array}$} \\
\hline & $\mathbf{t}_{1}(\mathbf{m m})$ & $\mathbf{t}_{2}(\mathbf{m m})$ & & & & \\
\hline \multirow{20}{*}{12} & 200 & 200 & 1 & -0.70 & -37.73 & -1.56 \\
\hline & & 240 & 1.2 & -0.75 & -61.66 & -2.73 \\
\hline & & 300 & 1.5 & -0.49 & -67.54 & -3.20 \\
\hline & & 400 & 2 & -0.27 & -74.90 & -3.81 \\
\hline & 225 & 225 & 1 & -0.53 & -39.62 & -1.71 \\
\hline & & 270 & 1.2 & -0.57 & -64.52 & -2.96 \\
\hline & & 337.5 & 1.5 & -0.36 & -70.33 & -3.43 \\
\hline & & 450 & 2 & -0.20 & -77.48 & -4.04 \\
\hline & 250 & 250 & 1 & -0.41 & -41.31 & -1.85 \\
\hline & & 300 & 1.2 & -0.44 & -67.04 & -3.17 \\
\hline & & 375 & 1.5 & -0.28 & -72.75 & -3.63 \\
\hline & & 500 & 2 & -0.15 & -79.64 & -4.23 \\
\hline & 300 & 300 & 1 & -0.26 & -44.15 & -2.09 \\
\hline & & 360 & 1.2 & -0.28 & -71.20 & -3.53 \\
\hline & & 450 & 1.5 & -0.18 & -76.64 & -3.99 \\
\hline & & 600 & 2 & $\begin{array}{l}-0.09 \\
\end{array}$ & -83.01 & -4.55 \\
\hline & 350 & 350 & 1 & -0.18 & -46.39 & -2.30 \\
\hline & & 420 & 1.2 & $\begin{array}{l}-0.19 \\
\end{array}$ & -74.42 & -3.84 \\
\hline & & 525 & 1.5 & -0.12 & -79.56 & -4.28 \\
\hline & & 700 & 2 & $\begin{array}{l}-0.06 \\
\end{array}$ & -85.44 & -4.80 \\
\hline
\end{tabular}


Table A-19: Summary of Maximum deflection, Transverse Moment and Longitudinal Moment in Cantilevered Slab with Tl-4 Parapet of Length 2 m

\begin{tabular}{|c|c|c|c|c|c|c|}
\hline \multicolumn{7}{|c|}{ "Cantilever length: 2 m } \\
\hline \multirow{2}{*}{$\begin{array}{l}\text { Barrier length } \\
\text { (m) }\end{array}$} & \multicolumn{2}{|c|}{ Slab thickness } & \multirow[t]{2}{*}{$\mathbf{t}_{2} / \mathbf{t}_{1}$} & \multirow{2}{*}{$\begin{array}{c}\Delta \\
(\mathbf{m m})\end{array}$} & \multirow{2}{*}{$\begin{array}{c}\mathbf{M}_{\mathbf{y}} \\
(\mathbf{k N} \cdot \mathbf{m m} / \mathbf{m m})\end{array}$} & \multirow{2}{*}{$\begin{array}{c}\mathbf{M}_{\mathbf{x}} \\
(\mathbf{k N} \cdot \mathbf{m m} / \mathbf{m m})\end{array}$} \\
\hline & $\mathbf{t}_{\mathbf{1}}(\mathbf{m m})$ & $\mathrm{t}_{2}(\mathrm{~mm})$ & & & & \\
\hline \multirow{20}{*}{5} & 200 & 200 & 1 & -2.97 & -74.35 & -4.68 \\
\hline & & 240 & 1.2 & -2.09 & -79.61 & $\begin{array}{l}-5.09 \\
\end{array}$ \\
\hline & & 300 & 1.5 & -1.34 & -86.21 & -5.62 \\
\hline & & 400 & 2 & -0.74 & -94.90 & -6.32 \\
\hline & 225 & 225 & 1 & -2.20 & -77.19 & -4.93 \\
\hline & & 270 & 1.2 & -1.55 & -82.57 & -5.35 \\
\hline & & 337.5 & 1.5 & -0.99 & -89.29 & -5.89 \\
\hline & & 450 & 2 & -0.54 & -98.06 & $\begin{array}{l}-6.61 \\
\end{array}$ \\
\hline & 250 & 250 & 1 & -1.68 & -79.80 & -5.17 \\
\hline & & 300 & 1.2 & -1.18 & -85.27 & -5.60 \\
\hline & & 375 & 1.5 & -0.75 & -92.05 & -6.14 \\
\hline & & 500 & 2 & -0.41 & -100.80 & -6.86 \\
\hline & 300 & 300 & 1 & -1.05 & -84.34 & -5.60 \\
\hline & & 360 & 1.2 & -0.74 & -89.91 & -6.04 \\
\hline & & 450 & 1.5 & -0.47 & -96.75 & -6.59 \\
\hline & & 600 & 2 & -0.26 & -105.33 & -7.29 \\
\hline & 350 & 350 & 1 & -0.70 & -88.12 & -5.98 \\
\hline & & 420 & 1.2 & -0.49 & -93.73 & -6.42 \\
\hline & & 525 & 1.5 & -0.31 & -100.51 & -6.97 \\
\hline & & 700 & 2 & -0.17 & -108.78 & -7.64 \\
\hline \multirow{20}{*}{6} & 200 & 200 & 1 & -2.82 & -71.11 & -4.47 \\
\hline & & 240 & 1.2 & -2.00 & -76.76 & $\begin{array}{l}-4.91 \\
\end{array}$ \\
\hline & & 300 & 1.5 & -1.29 & -83.94 & $\begin{array}{l}-5.48 \\
\end{array}$ \\
\hline & & 400 & 2 & -0.72 & -93.43 & -6.23 \\
\hline & 225 & 225 & 1 & -2.11 & -74.43 & -4.75 \\
\hline & & 270 & 1.2 & -1.49 & -80.21 & -5.21 \\
\hline & & 337.5 & 1.5 & -0.96 & -87.49 & $\begin{array}{l}-5.78 \\
\end{array}$ \\
\hline & & 450 & 2 & $\begin{array}{l}-0.53 \\
\end{array}$ & -97.00 & -6.54 \\
\hline & 250 & 250 & 1 & -1.62 & -77.45 & $\begin{array}{l}-5.02 \\
\end{array}$ \\
\hline & & 300 & 1.2 & -1.15 & -83.32 & $\begin{array}{l}-5.48 \\
\end{array}$ \\
\hline & & 375 & 1.5 & -0.74 & -90.64 & -6.06 \\
\hline & & 500 & 2 & -0.41 & -100.03 & -6.82 \\
\hline & 300 & 300 & 1 & -1.03 & -82.67 & -5.49 \\
\hline & & 360 & 1.2 & $\begin{array}{l}-0.72 \\
\end{array}$ & -88.62 & -5.96 \\
\hline & & 450 & 1.5 & -0.46 & -95.90 & -6.54 \\
\hline & & 600 & 2 & -0.25 & -104.94 & -7.27 \\
\hline & 350 & 350 & 1 & -0.69 & -86.98 & -5.91 \\
\hline & & 420 & 1.2 & -0.48 & -92.91 & -6.37 \\
\hline & & 525 & 1.5 & -0.31 & -100.02 & -6.94 \\
\hline & & 700 & 2 & $\begin{array}{l}-0.17 \\
\end{array}$ & -108.58 & -7.63 \\
\hline
\end{tabular}




\begin{tabular}{|c|c|c|c|c|c|c|}
\hline \multicolumn{7}{|c|}{ Cantilever length: $2 \mathrm{~m}$} \\
\hline \multirow{2}{*}{$\begin{array}{c}\text { Barrier length } \\
(\mathrm{m})\end{array}$} & \multicolumn{2}{|c|}{ Slab thickness } & \multirow[t]{2}{*}{$\overline{\mathbf{t}_{2} / \mathbf{t}_{1}}$} & \multirow{2}{*}{$\begin{array}{c}\boldsymbol{\Delta} \\
(\mathbf{m m})\end{array}$} & \multirow{2}{*}{$\begin{array}{c}\mathbf{M}_{\mathbf{y}} \\
(\mathbf{k N} \cdot \mathbf{m m} / \mathbf{m m})\end{array}$} & \multirow{2}{*}{$\begin{array}{c}\mathbf{M}_{\mathbf{x}} \\
(\mathbf{k N} \cdot \mathbf{m m} / \mathbf{m m})\end{array}$} \\
\hline & $\mathbf{t}_{\mathbf{1}}(\mathbf{m m})$ & $\mathbf{t}_{2}(\mathbf{m m})$ & & & & \\
\hline \multirow{20}{*}{8} & 200 & 200 & 1 & -2.97 & -74.35 & -4.68 \\
\hline & & 240 & 1.2 & -2.09 & -79.61 & -5.09 \\
\hline & & 300 & 1.5 & -1.34 & -86.21 & -5.62 \\
\hline & & 400 & 2 & -0.74 & -94.90 & -6.32 \\
\hline & 225 & 225 & 1 & -2.20 & -77.19 & -4.93 \\
\hline & & 270 & 1.2 & -1.55 & -82.57 & -5.35 \\
\hline & & 337.5 & 1.5 & -0.99 & -89.29 & -5.89 \\
\hline & & 450 & 2 & -0.54 & -98.06 & -6.61 \\
\hline & 250 & 250 & 1 & -1.68 & -79.80 & -5.17 \\
\hline & & 300 & 1.2 & -1.18 & -85.27 & -5.60 \\
\hline & & 375 & 1.5 & -0.75 & -92.05 & -6.14 \\
\hline & & 500 & 2 & -0.41 & -100.80 & -6.86 \\
\hline & 300 & 300 & 1 & -1.05 & -84.34 & -5.60 \\
\hline & & 360 & 1.2 & -0.74 & -89.91 & -6.04 \\
\hline & & 450 & 1.5 & -0.47 & -96.75 & -6.59 \\
\hline & & 600 & 2 & -0.26 & -105.33 & -7.29 \\
\hline & 350 & 350 & 1 & -0.70 & -88.12 & -5.98 \\
\hline & & 420 & 1.2 & -0.49 & -93.73 & -6.42 \\
\hline & & 525 & 1.5 & -0.31 & -100.51 & -6.97 \\
\hline & & 700 & 2 & -0.17 & -108.78 & -7.64 \\
\hline \multirow{20}{*}{10} & 200 & 200 & 1 & -2.82 & -71.11 & $\begin{array}{l}-4.47 \\
\end{array}$ \\
\hline & & 240 & 1.2 & -2.00 & -76.76 & -4.91 \\
\hline & & 300 & 1.5 & -1.29 & -83.94 & -5.48 \\
\hline & & 400 & 2 & -0.72 & -93.43 & -6.23 \\
\hline & 225 & 225 & 1 & -2.11 & -74.43 & -4.75 \\
\hline & & 270 & 1.2 & -1.49 & -80.21 & -5.21 \\
\hline & & 337.5 & 1.5 & -0.96 & -87.49 & -5.78 \\
\hline & & 450 & 2 & -0.53 & -97.00 & -6.54 \\
\hline & 250 & 250 & 1 & -1.62 & -77.45 & -5.02 \\
\hline & & 300 & 1.2 & -1.15 & -83.32 & -5.48 \\
\hline & & 375 & 1.5 & -0.74 & -90.64 & -6.06 \\
\hline & & 500 & 2 & -0.41 & -100.03 & -6.82 \\
\hline & 300 & 300 & 1 & -1.03 & -82.67 & $\begin{array}{l}-5.49 \\
\end{array}$ \\
\hline & & 360 & 1.2 & -0.72 & -88.62 & -5.96 \\
\hline & & 450 & 1.5 & -0.46 & -95.90 & -6.54 \\
\hline & & 600 & 2 & -0.25 & -104.94 & -7.27 \\
\hline & 350 & 350 & 1 & -0.69 & -86.98 & -5.91 \\
\hline & & 420 & 1.2 & -0.48 & -92.91 & -6.37 \\
\hline & & 525 & 1.5 & -0.31 & -100.02 & -6.94 \\
\hline & & 700 & 2 & -0.17 & -108.58 & -7.63 \\
\hline
\end{tabular}




\begin{tabular}{|c|c|c|c|c|c|c|}
\hline \multicolumn{7}{|c|}{ Cantilever length: 2 m } \\
\hline \multirow{2}{*}{$\begin{array}{c}\text { Barrier length } \\
(\mathrm{m})\end{array}$} & \multicolumn{2}{|c|}{ Slab thickness } & \multirow{3}{*}{$\begin{array}{r}\mathbf{t}_{2} / \mathbf{t}_{1} \\
\\
1\end{array}$} & \multirow{3}{*}{$\begin{array}{c}\begin{array}{c}\Delta \\
(\mathbf{m m})\end{array} \\
-2.74 \\
\end{array}$} & \multirow{3}{*}{$\begin{array}{c}\begin{array}{c}\mathbf{M}_{\mathbf{y}} \\
(\mathbf{k N} \cdot \mathbf{m m} / \mathbf{m m})\end{array} \\
-69.49\end{array}$} & \multirow{3}{*}{$\begin{array}{c}\mathbf{M}_{\mathbf{x}} \\
(\mathbf{k N} \cdot \mathbf{m m} / \mathbf{m m}) \\
\\
-4.38\end{array}$} \\
\hline & $\mathbf{t}_{1}(\mathbf{m m})$ & $\mathbf{t}_{2}(\mathrm{~mm})$ & & & & \\
\hline \multirow{20}{*}{12} & 200 & 200 & & & & \\
\hline & & 240 & 1.2 & -1.95 & -75.45 & -4.83 \\
\hline & & 300 & 1.5 & -1.27 & -83.02 & -5.42 \\
\hline & & 400 & 2 & -0.72 & -92.97 & -6.21 \\
\hline & 225 & 225 & 1 & -2.06 & -73.12 & -4.67 \\
\hline & & 270 & 1.2 & -1.47 & -79.19 & -5.14 \\
\hline & & 337.5 & 1.5 & -0.95 & -86.82 & -5.74 \\
\hline & & 450 & 2 & -0.53 & -96.71 & -6.53 \\
\hline & 250 & 250 & 1 & -1.60 & -76.40 & -4.95 \\
\hline & & 300 & 1.2 & -1.13 & -82.53 & -5.43 \\
\hline & & 375 & 1.5 & -0.73 & -90.17 & -6.03 \\
\hline & & 500 & 2 & -0.41 & $\begin{array}{l}-99.84 \\
\end{array}$ & -6.81 \\
\hline & 300 & 300 & 1 & -1.01 & -82.02 & -5.45 \\
\hline & & 360 & 1.2 & -0.72 & -88.18 & -5.94 \\
\hline & & 450 & 1.5 & -0.46 & -95.68 & -6.53 \\
\hline & & 600 & 2 & -0.25 & -104.86 & -7.27 \\
\hline & 350 & 350 & 1 & -0.69 & -86.60 & -5.88 \\
\hline & & 420 & 1.2 & -0.48 & -92.67 & -6.36 \\
\hline & & 525 & 1.5 & -0.31 & -99.91 & -6.93 \\
\hline & & 700 & 2 & -0.17 & -108.55 & -7.63 \\
\hline
\end{tabular}


Table A-20: Summary of Maximum deflection, Transverse Moment and Longitudinal Moment in Cantilevered Slab with Tl-4 Parapet of Length $2.5 \mathrm{~m}$

\begin{tabular}{|c|c|c|c|c|c|c|}
\hline \multicolumn{7}{|c|}{ Cantilever length: $2.5 \mathrm{~m}$} \\
\hline \multirow{2}{*}{$\begin{array}{c}\text { Barrier length } \\
(\mathrm{m})\end{array}$} & \multicolumn{2}{|c|}{ Slab thickness } & \multirow{3}{*}{$\begin{array}{c}\mathbf{t}_{2} / \mathbf{t}_{1} \\
\\
1 \\
1\end{array}$} & \multirow{3}{*}{$\begin{array}{c}\begin{array}{c}\Delta \\
(\mathbf{m m})\end{array} \\
-8.70 \\
\end{array}$} & \multirow{3}{*}{$\begin{array}{c}\begin{array}{c}\mathbf{M}_{\mathbf{y}} \\
(\mathbf{k N} \cdot \mathbf{m m} / \mathbf{m m})\end{array} \\
-115.44\end{array}$} & \multirow{3}{*}{ 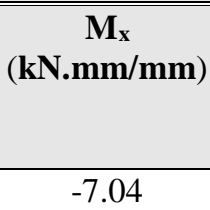 } \\
\hline & $\mathbf{t}_{\mathbf{1}}(\mathbf{m m})$ & $\mathbf{t}_{2}(\mathbf{m m})$ & & & & \\
\hline \multirow{20}{*}{5} & 200 & 200 & & & & \\
\hline & & 240 & 1.2 & -5.92 & -119.33 & -7.23 \\
\hline & & 300 & 1.5 & -3.66 & -124.02 & -7.45 \\
\hline & & 400 & 2 & -1.94 & -129.83 & -7.68 \\
\hline & 225 & 225 & 1 & -6.21 & -116.37 & -7.14 \\
\hline & & 270 & 1.2 & -4.23 & -120.34 & -7.34 \\
\hline & & 337.5 & 1.5 & -2.62 & -125.10 & -7.55 \\
\hline & & 450 & 2 & -1.39 & -130.97 & -7.78 \\
\hline & 250 & 250 & 1 & -4.60 & -117.26 & -7.23 \\
\hline & & 300 & 1.2 & -3.14 & -121.30 & -7.43 \\
\hline & & 375 & 1.5 & -1.95 & -126.12 & -7.64 \\
\hline & & 500 & 2 & -1.03 & -132.02 & -7.86 \\
\hline & 300 & 300 & 1 & -2.73 & -118.88 & -7.40 \\
\hline & & 360 & 1.2 & -1.87 & -123.00 & -7.60 \\
\hline & & 450 & 1.5 & -1.16 & -127.88 & -7.80 \\
\hline & & 600 & 2 & -0.61 & -133.79 & -8.01 \\
\hline & 350 & 350 & 1 & -1.76 & -120.23 & -7.54 \\
\hline & & 420 & 1.2 & -1.20 & -124.40 & -7.73 \\
\hline & & 525 & 1.5 & -0.74 & -129.31 & -7.92 \\
\hline & & 700 & 2 & -0.39 & -135.22 & -8.12 \\
\hline \multirow{20}{*}{6} & 200 & 200 & 1 & -8.04 & -108.50 & -6.60 \\
\hline & & 240 & 1.2 & -5.53 & -112.96 & -6.83 \\
\hline & & 300 & 1.5 & -3.46 & -118.35 & $\begin{array}{l}-7.09 \\
\end{array}$ \\
\hline & & 400 & 2 & -1.85 & -125.06 & $\begin{array}{l}-7.39 \\
\end{array}$ \\
\hline & 225 & 225 & 1 & -5.79 & -110.01 & -6.74 \\
\hline & & 270 & 1.2 & -3.98 & -114.56 & -6.97 \\
\hline & & 337.5 & 1.5 & -2.49 & -120.03 & -7.23 \\
\hline & & 450 & 2 & -1.34 & -126.79 & -7.52 \\
\hline & 250 & 250 & 1 & -4.32 & -111.43 & -6.87 \\
\hline & & 300 & 1.2 & -2.97 & -116.05 & -7.11 \\
\hline & & 375 & 1.5 & -1.86 & -121.57 & -7.36 \\
\hline & & 500 & 2 & -1.00 & -128.35 & -7.64 \\
\hline & 300 & 300 & 1 & -2.59 & -113.94 & -7.10 \\
\hline & & 360 & 1.2 & -1.79 & -118.64 & -7.33 \\
\hline & & 450 & 1.5 & -1.12 & -124.20 & -7.58 \\
\hline & & 600 & 2 & -0.60 & -130.95 & -7.84 \\
\hline & 350 & 350 & 1 & -1.68 & -116.00 & -7.29 \\
\hline & & 420 & 1.2 & -1.16 & -120.74 & -7.51 \\
\hline & & 525 & 1.5 & -0.72 & -126.31 & -7.75 \\
\hline & & 700 & 2 & -0.39 & -133.01 & -8.00 \\
\hline \multicolumn{7}{|c|}{ Cantilever length: $2.5 \mathrm{~m}$} \\
\hline
\end{tabular}




\begin{tabular}{|c|c|c|c|c|c|c|}
\hline \multirow{2}{*}{$\begin{array}{l}\text { Barrier length } \\
(\mathrm{m})\end{array}$} & \multicolumn{2}{|c|}{ Slab thickness } & \multirow{3}{*}{$\begin{array}{c}\mathbf{t}_{2} / \mathbf{t}_{\mathbf{1}} \\
\\
1\end{array}$} & \multirow{3}{*}{$\begin{array}{c}\begin{array}{c}\Delta \\
(\mathbf{m m})\end{array} \\
-7.24\end{array}$} & \multirow{3}{*}{ 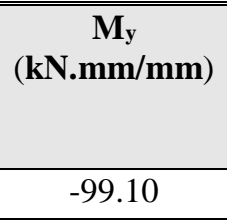 } & \multirow{3}{*}{ 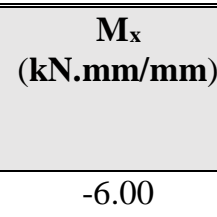 } \\
\hline & $\mathbf{t}_{1}(\mathbf{m m})$ & $\mathrm{t}_{2}(\mathrm{~mm})$ & & & & \\
\hline \multirow{20}{*}{8} & 200 & 200 & & & & \\
\hline & & 240 & 1.2 & -5.05 & -104.31 & -6.28 \\
\hline & & 300 & 1.5 & -3.20 & -110.67 & -6.61 \\
\hline & & 400 & 2 & -1.74 & -118.74 & -7.00 \\
\hline & 225 & 225 & 1 & -5.29 & -101.63 & -6.20 \\
\hline & & 270 & 1.2 & -3.68 & -106.94 & -6.49 \\
\hline & & 337.5 & 1.5 & -2.34 & -113.36 & -6.81 \\
\hline & & 450 & 2 & -1.27 & -121.46 & -7.19 \\
\hline & 250 & 250 & 1 & -3.99 & -103.95 & -6.39 \\
\hline & & 300 & 1.2 & -2.78 & -109.31 & -6.67 \\
\hline & & 375 & 1.5 & -1.76 & -115.76 & -6.99 \\
\hline & & 500 & 2 & -0.95 & -123.84 & -7.37 \\
\hline & 300 & 300 & 1 & -2.44 & -107.91 & -6.72 \\
\hline & & 360 & 1.2 & -1.70 & -113.33 & -6.99 \\
\hline & & 450 & 1.5 & -1.07 & -119.79 & -7.30 \\
\hline & & 600 & 2 & -0.58 & -127.77 & -7.65 \\
\hline & 350 & 350 & 1 & -1.60 & -111.12 & -6.98 \\
\hline & & 420 & 1.2 & -1.11 & -116.56 & -7.25 \\
\hline & & 525 & 1.5 & -0.70 & -123.00 & -7.54 \\
\hline & & 700 & 2 & -0.38 & -130.79 & -7.87 \\
\hline \multirow{20}{*}{10} & 200 & 200 & 1 & -6.80 & -93.48 & -5.64 \\
\hline & & 240 & 1.2 & -4.78 & -99.20 & -5.96 \\
\hline & & 300 & 1.5 & -3.06 & -106.26 & -6.34 \\
\hline & & 400 & 2 & -1.69 & -115.41 & -6.80 \\
\hline & 225 & 225 & 1 & -5.01 & -96.75 & $\begin{array}{l}-5.89 \\
\end{array}$ \\
\hline & & 270 & 1.2 & -3.52 & -102.55 & -6.21 \\
\hline & & 337.5 & 1.5 & -2.25 & -109.67 & -6.59 \\
\hline & & 450 & 2 & -1.24 & -118.82 & -7.04 \\
\hline & 250 & 250 & 1 & -3.81 & -99.69 & -6.12 \\
\hline & & 300 & 1.2 & -2.67 & -105.54 & -6.44 \\
\hline & & 375 & 1.5 & -1.70 & -112.69 & -6.81 \\
\hline & & 500 & 2 & -0.93 & -121.77 & -7.25 \\
\hline & 300 & 300 & 1 & -2.36 & -104.68 & -6.51 \\
\hline & & 360 & 1.2 & -1.65 & -110.58 & -6.82 \\
\hline & & 450 & 1.5 & -1.05 & -117.70 & -7.17 \\
\hline & & 600 & 2 & -0.57 & -126.51 & -7.58 \\
\hline & 350 & 350 & 1 & -1.56 & -108.71 & -6.83 \\
\hline & & 420 & 1.2 & -1.09 & -114.61 & -7.13 \\
\hline & & 525 & 1.5 & -0.69 & -121.62 & -7.46 \\
\hline & & 700 & 2 & -0.38 & -130.05 & -7.83 \\
\hline
\end{tabular}




\begin{tabular}{|c|c|c|c|c|c|c|}
\hline \multicolumn{7}{|c|}{ Cantilever length: $2.5 \mathrm{~m}$} \\
\hline \multirow{2}{*}{$\begin{array}{c}\text { Barrier length } \\
(\mathbf{m})\end{array}$} & \multicolumn{2}{|c|}{ Slab thickness } & \multirow[t]{2}{*}{$\mathbf{t}_{2} / \mathbf{t}_{1}$} & \multirow{2}{*}{$\begin{array}{c}\boldsymbol{\Delta} \\
(\mathbf{m m})\end{array}$} & \multirow{2}{*}{$\begin{array}{c}\mathbf{M}_{\mathbf{y}} \\
(\mathbf{k N} \cdot \mathbf{m m} / \mathbf{m m})\end{array}$} & \multirow{2}{*}{$\begin{array}{c}\mathbf{M}_{\mathbf{x}} \\
(\mathbf{k N} \cdot \mathbf{m m} / \mathbf{m m})\end{array}$} \\
\hline & $\mathbf{t}_{\mathbf{1}}(\mathbf{m m})$ & $\mathbf{t}_{2}(\mathbf{m m})$ & & & & \\
\hline \multirow{20}{*}{12} & 200 & 200 & 1 & -6.53 & -90.12 & -5.43 \\
\hline & & 240 & 1.2 & -4.62 & -96.24 & -5.78 \\
\hline & & 300 & 1.5 & -2.98 & -103.88 & -6.20 \\
\hline & & 400 & 2 & -1.66 & -113.87 & -6.72 \\
\hline & 225 & 225 & 1 & -4.85 & -93.91 & -5.71 \\
\hline & & 270 & 1.2 & -3.42 & -100.11 & -6.06 \\
\hline & & 337.5 & 1.5 & -2.20 & -107.80 & -6.48 \\
\hline & & 450 & 2 & -1.22 & -117.71 & -6.98 \\
\hline & 250 & 250 & 1 & -3.71 & -97.29 & -5.97 \\
\hline & & 300 & 1.2 & -2.61 & -103.54 & -6.31 \\
\hline & & 375 & 1.5 & -1.68 & -111.23 & -6.72 \\
\hline & & 500 & 2 & -0.93 & -120.98 & -7.21 \\
\hline & 300 & 300 & 1 & -2.31 & -103.00 & -6.40 \\
\hline & & 360 & 1.2 & -1.63 & -109.27 & -6.74 \\
\hline & & 450 & 1.5 & -1.04 & -116.85 & -7.13 \\
\hline & & 600 & 2 & -0.57 & -126.13 & -7.56 \\
\hline & 350 & 350 & 1 & -1.54 & -107.58 & -6.76 \\
\hline & & 420 & 1.2 & -1.08 & -113.80 & -7.08 \\
\hline & & 525 & 1.5 & -0.69 & -121.14 & -7.44 \\
\hline & & 700 & 2 & -0.37 & -129.85 & -7.82 \\
\hline
\end{tabular}


Table A-21: Summary of Maximum deflection, Transverse Moment and Longitudinal Moment in Cantilevered Slab with Tl-5 Barrier of Length 1 m

\begin{tabular}{|c|c|c|c|c|c|c|}
\hline \multicolumn{7}{|c|}{ 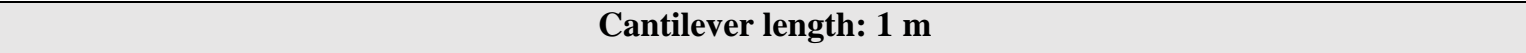 } \\
\hline \multirow{2}{*}{$\begin{array}{c}\text { Barrier length } \\
\text { (m) }\end{array}$} & \multicolumn{2}{|c|}{ Slab thickness } & \multirow[t]{2}{*}{$\overline{t_{2} / \mathbf{t}_{1}}$} & \multirow{2}{*}{$\begin{array}{c}\Delta \\
(\mathbf{m m})\end{array}$} & \multirow{2}{*}{$\begin{array}{c}\mathbf{M}_{\mathbf{y}} \\
(\mathbf{k N} \cdot \mathbf{m m} / \mathbf{m m})\end{array}$} & \multirow{2}{*}{$\begin{array}{c}\mathbf{M}_{\mathbf{x}} \\
(\mathbf{k N} \cdot \mathbf{m m} / \mathbf{m m})\end{array}$} \\
\hline & $\mathbf{t}_{\mathbf{1}}(\mathbf{m m})$ & $\mathbf{t}_{2}(\mathbf{m m})$ & & & & \\
\hline \multirow{20}{*}{5} & 200 & 200 & 1 & -0.11 & -23.72 & -0.85 \\
\hline & & 240 & 1.2 & -0.08 & -25.34 & -0.95 \\
\hline & & 300 & 1.5 & -0.05 & -26.59 & -1.04 \\
\hline & & 400 & 2 & -0.02 & -28.07 & -1.15 \\
\hline & 225 & 225 & 1 & -0.08 & -24.19 & -0.87 \\
\hline & & 270 & 1.2 & -0.06 & -25.84 & -0.97 \\
\hline & & 337.5 & 1.5 & -0.04 & -27.08 & -1.06 \\
\hline & & 450 & 2 & -0.02 & -28.53 & -1.18 \\
\hline & 250 & 250 & 1 & -0.06 & -24.63 & -0.90 \\
\hline & & 300 & 1.2 & -0.04 & -26.30 & -1.00 \\
\hline & & 375 & 1.5 & -0.03 & -27.52 & -1.08 \\
\hline & & 500 & 2 & -0.01 & -28.92 & -1.20 \\
\hline & 300 & 300 & 1 & -0.04 & -25.43 & -0.94 \\
\hline & & 360 & 1.2 & -0.03 & -27.10 & -1.04 \\
\hline & & 450 & 1.5 & -0.02 & -28.25 & -1.13 \\
\hline & & 600 & 2 & -0.01 & -29.53 & -1.24 \\
\hline & 350 & 350 & 1 & -0.03 & -26.09 & -0.97 \\
\hline & & 420 & 1.2 & -0.02 & -27.73 & -1.07 \\
\hline & & 525 & 1.5 & -0.01 & -28.82 & -1.16 \\
\hline & & 700 & 2 & -0.01 & -29.98 & -1.27 \\
\hline \multirow{20}{*}{6} & 200 & 200 & 1 & -0.11 & -23.18 & $\begin{array}{l}-0.84 \\
\end{array}$ \\
\hline & & 240 & 1.2 & -0.08 & -24.89 & -0.94 \\
\hline & & 300 & 1.5 & -0.05 & -26.26 & -1.02 \\
\hline & & 400 & 2 & -0.02 & -27.87 & -1.14 \\
\hline & 225 & 225 & 1 & -0.08 & -23.75 & -0.86 \\
\hline & & 270 & 1.2 & -0.06 & -25.47 & -0.96 \\
\hline & & 337.5 & 1.5 & -0.03 & -26.82 & -1.05 \\
\hline & & 450 & 2 & -0.02 & -28.37 & -1.17 \\
\hline & 250 & 250 & 1 & -0.06 & -24.27 & -0.88 \\
\hline & & 300 & 1.2 & -0.04 & -26.00 & \begin{tabular}{|c|}
-0.99 \\
\end{tabular} \\
\hline & & 375 & 1.5 & -0.03 & -27.31 & -1.08 \\
\hline & & 500 & 2 & -0.01 & -28.80 & -1.19 \\
\hline & 300 & 300 & 1 & -0.04 & -25.17 & -0.93 \\
\hline & & 360 & 1.2 & -0.03 & -26.89 & -1.03 \\
\hline & & 450 & 1.5 & -0.02 & -28.11 & -1.12 \\
\hline & & 600 & 2 & -0.01 & -29.46 & -1.23 \\
\hline & 350 & 350 & 1 & -0.03 & -25.89 & -0.97 \\
\hline & & 420 & 1.2 & -0.02 & -27.58 & -1.07 \\
\hline & & 525 & 1.5 & -0.01 & -28.72 & -1.16 \\
\hline & & 700 & 2 & -0.01 & -29.94 & -1.26 \\
\hline
\end{tabular}




\begin{tabular}{|c|c|c|c|c|c|c|}
\hline \multicolumn{7}{|c|}{ Cantilever length: $1 \mathrm{~m}$} \\
\hline \multirow{2}{*}{$\begin{array}{c}\text { Barrier length } \\
(\mathbf{m})\end{array}$} & \multicolumn{2}{|c|}{ Slab thickness } & \multirow[t]{2}{*}{$\overline{t_{2} / \mathbf{t}_{1}}$} & \multirow{2}{*}{$\begin{array}{c}\boldsymbol{\Delta} \\
(\mathbf{m m})\end{array}$} & \multirow{2}{*}{$\begin{array}{c}\mathbf{M}_{\mathbf{y}} \\
(\mathbf{k N} \cdot \mathbf{m m} / \mathbf{m m})\end{array}$} & \multirow{2}{*}{$\begin{array}{c}\mathbf{M}_{\mathbf{x}} \\
(\mathbf{k N} \cdot \mathbf{m m} / \mathbf{m m})\end{array}$} \\
\hline & $\mathbf{t}_{\mathbf{1}}(\mathrm{mm})$ & $\mathrm{t}_{2}(\mathrm{~mm})$ & & & & \\
\hline \multirow{20}{*}{8} & 200 & 200 & 1 & -0.10 & -22.74 & -0.82 \\
\hline & & 240 & 1.2 & -0.07 & -24.53 & -0.92 \\
\hline & & 300 & 1.5 & -0.04 & -26.02 & -1.01 \\
\hline & & 400 & 2 & -0.02 & -27.74 & -1.14 \\
\hline & 225 & 225 & 1 & -0.08 & -23.39 & -0.85 \\
\hline & & 270 & 1.2 & -0.05 & -25.20 & -0.95 \\
\hline & & 337.5 & 1.5 & -0.03 & -26.64 & -1.04 \\
\hline & & 450 & 2 & -0.02 & -28.29 & -1.17 \\
\hline & 250 & 250 & 1 & -0.06 & -23.98 & -0.87 \\
\hline & & 300 & 1.2 & -0.04 & -25.78 & -0.98 \\
\hline & & 375 & 1.5 & -0.03 & -27.18 & -1.07 \\
\hline & & 500 & 2 & -0.01 & -28.74 & -1.19 \\
\hline & 300 & 300 & 1 & -0.04 & -24.98 & -0.92 \\
\hline & & 360 & 1.2 & -0.03 & -26.75 & -1.03 \\
\hline & & 450 & 1.5 & -0.02 & -28.04 & -1.12 \\
\hline & & 600 & 2 & -0.01 & -29.43 & -1.23 \\
\hline & 350 & 350 & 1 & -0.03 & -25.77 & -0.96 \\
\hline & & 420 & 1.2 & -0.02 & -27.50 & -1.06 \\
\hline & & 525 & 1.5 & -0.01 & -28.68 & -1.15 \\
\hline & & 700 & 2 & -0.01 & -29.92 & -1.26 \\
\hline \multirow{20}{*}{10} & 200 & 200 & 1 & -0.10 & -22.62 & -0.82 \\
\hline & & 240 & 1.2 & -0.07 & -24.45 & -0.92 \\
\hline & & 300 & 1.5 & -0.04 & -25.97 & -1.01 \\
\hline & & 400 & 2 & -0.02 & -27.73 & -1.13 \\
\hline & 225 & 225 & 1 & -0.08 & -23.30 & -0.85 \\
\hline & & 270 & 1.2 & -0.05 & -25.14 & -0.95 \\
\hline & & 337.5 & 1.5 & -0.03 & -26.61 & -1.04 \\
\hline & & 450 & 2 & -0.02 & -28.27 & -1.17 \\
\hline & 250 & 250 & 1 & -0.06 & -23.92 & -0.87 \\
\hline & & 300 & 1.2 & -0.04 & -25.74 & -0.98 \\
\hline & & 375 & 1.5 & -0.03 & -27.16 & -1.07 \\
\hline & & 500 & 2 & -0.01 & -28.73 & -1.19 \\
\hline & 300 & 300 & 1 & -0.04 & -24.94 & -0.92 \\
\hline & & 360 & 1.2 & -0.03 & -26.73 & -1.02 \\
\hline & & 450 & 1.5 & -0.02 & -28.03 & -1.12 \\
\hline & & 600 & 2 & -0.01 & -29.43 & -1.23 \\
\hline & 350 & 350 & 1 & -0.03 & -25.75 & -0.96 \\
\hline & & 420 & 1.2 & -0.02 & -27.49 & -1.06 \\
\hline & & 525 & 1.5 & -0.01 & -28.68 & -1.15 \\
\hline & & 700 & 2 & -0.01 & -29.92 & -1.26 \\
\hline
\end{tabular}




\begin{tabular}{|c|c|c|c|c|c|c|}
\hline \multicolumn{7}{|c|}{ 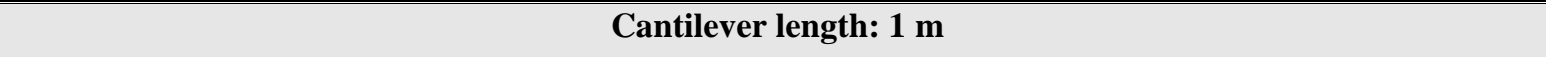 } \\
\hline \multirow{2}{*}{$\begin{array}{c}\text { Barrier length } \\
(\mathbf{m})\end{array}$} & \multicolumn{2}{|c|}{ Slab thickness } & \multirow[t]{2}{*}{$\mathbf{t}_{2} / \mathbf{t}_{1}$} & \multirow{2}{*}{$\begin{array}{c}\boldsymbol{\Delta} \\
(\mathbf{m m})\end{array}$} & \multirow{2}{*}{$\begin{array}{c}\mathbf{M}_{\mathbf{y}} \\
(\mathbf{k N} \cdot \mathbf{m m} / \mathbf{m m})\end{array}$} & \multirow{2}{*}{$\begin{array}{c}\mathbf{M}_{\mathbf{x}} \\
(\mathbf{k N} \cdot \mathbf{m m} / \mathbf{m m})\end{array}$} \\
\hline & $\mathbf{t}_{\mathbf{1}}(\mathbf{m m})$ & $\mathbf{t}_{2}(\mathrm{~mm})$ & & & & \\
\hline \multirow{20}{*}{12} & 200 & 200 & 1 & -0.10 & -22.58 & -0.82 \\
\hline & & 240 & 1.2 & -0.07 & -24.43 & -0.92 \\
\hline & & 300 & 1.5 & -0.04 & -25.96 & -1.01 \\
\hline & & 400 & 2 & -0.02 & -27.72 & -1.13 \\
\hline & 225 & 225 & 1 & -0.08 & -23.28 & -0.84 \\
\hline & & 270 & 1.2 & -0.05 & -25.13 & -0.95 \\
\hline & & 337.5 & 1.5 & -0.03 & -26.60 & -1.04 \\
\hline & & 450 & 2 & -0.02 & -28.27 & -1.17 \\
\hline & 250 & 250 & 1 & -0.06 & -23.90 & -0.87 \\
\hline & & 300 & 1.2 & -0.04 & -25.73 & -0.98 \\
\hline & & 375 & 1.5 & -0.03 & -27.15 & -1.07 \\
\hline & & 500 & 2 & -0.01 & -28.73 & -1.19 \\
\hline & 300 & 300 & 1 & -0.04 & -24.94 & -0.92 \\
\hline & & 360 & 1.2 & -0.03 & -26.73 & -1.02 \\
\hline & & 450 & 1.5 & -0.02 & -28.03 & -1.12 \\
\hline & & 600 & 2 & -0.01 & -29.43 & -1.23 \\
\hline & 350 & 350 & 1 & -0.03 & -25.74 & -0.96 \\
\hline & & 420 & 1.2 & -0.02 & -27.49 & -1.06 \\
\hline & & 525 & 1.5 & -0.01 & -28.68 & -1.15 \\
\hline & & 700 & 2 & -0.01 & -29.92 & -1.26 \\
\hline
\end{tabular}


Table A-22: Summary of Maximum deflection, Transverse Moment and Longitudinal Moment in Cantilevered Slab with Tl-5 Barrier of Length $1.5 \mathrm{~m}$

\begin{tabular}{|c|c|c|c|c|c|c|}
\hline \multicolumn{7}{|c|}{ "Cantilever length: $1.5 \mathrm{~m}$} \\
\hline \multirow{2}{*}{$\begin{array}{l}\text { Barrier length } \\
(\mathrm{m})\end{array}$} & \multicolumn{2}{|c|}{ Slab thickness } & \multirow[t]{2}{*}{$\mathbf{t}_{2} / \mathbf{t}_{1}$} & \multirow{2}{*}{$\begin{array}{c}\boldsymbol{\Delta} \\
(\mathbf{m m})\end{array}$} & \multirow{2}{*}{$\begin{array}{c}\mathbf{M}_{\mathbf{y}} \\
(\mathbf{k N} \cdot \mathbf{m m} / \mathbf{m m})\end{array}$} & \multirow{2}{*}{$\begin{array}{c}\mathbf{M}_{\mathbf{x}} \\
(\mathbf{k N} \cdot \mathbf{m m} / \mathbf{m m})\end{array}$} \\
\hline & $\mathbf{t}_{1}(\mathbf{m m})$ & $\mathbf{t}_{2}(\mathrm{~mm})$ & & & & \\
\hline \multirow{20}{*}{5} & 200 & 200 & 1 & -0.91 & -57.10 & -2.09 \\
\hline & & 240 & 1.2 & -0.63 & -60.80 & -2.36 \\
\hline & & 300 & 1.5 & -0.39 & -64.32 & -2.69 \\
\hline & & 400 & 2 & -0.20 & -68.66 & -3.10 \\
\hline & 225 & 225 & 1 & -0.66 & -58.06 & -2.18 \\
\hline & & 270 & 1.2 & -0.46 & -61.86 & -2.46 \\
\hline & & 337.5 & 1.5 & -0.28 & -65.45 & -2.79 \\
\hline & & 450 & 2 & -0.15 & -69.83 & -3.21 \\
\hline & 250 & 250 & 1 & -0.50 & -59.04 & -2.27 \\
\hline & & 300 & 1.2 & -0.35 & -62.91 & -2.56 \\
\hline & & 375 & 1.5 & -0.21 & -66.53 & -2.90 \\
\hline & & 500 & 2 & -0.11 & -70.91 & -3.31 \\
\hline & 300 & 300 & 1 & -0.31 & -60.91 & -2.46 \\
\hline & & 360 & 1.2 & -0.21 & -64.86 & -2.76 \\
\hline & & 450 & 1.5 & -0.13 & -68.48 & -3.09 \\
\hline & & 600 & 2 & -0.07 & -72.78 & -3.50 \\
\hline & 350 & 350 & 1 & -0.20 & -62.57 & -2.63 \\
\hline & & 420 & 1.2 & -0.14 & -66.55 & -2.93 \\
\hline & & 525 & 1.5 & -0.09 & -70.11 & -3.26 \\
\hline & & 700 & 2 & -0.04 & -74.26 & -3.66 \\
\hline \multirow{20}{*}{6} & 200 & 200 & 1 & -0.84 & -54.42 & -1.93 \\
\hline & & 240 & 1.2 & -0.59 & -58.33 & -2.22 \\
\hline & & 300 & 1.5 & -0.36 & -62.21 & -2.57 \\
\hline & & 400 & 2 & -0.19 & -67.05 & -3.00 \\
\hline & 225 & 225 & 1 & -0.62 & -55.69 & -2.04 \\
\hline & & 270 & 1.2 & -0.43 & -59.71 & -2.34 \\
\hline & & 337.5 & 1.5 & -0.27 & -63.65 & $\begin{array}{l}-2.69 \\
\end{array}$ \\
\hline & & 450 & 2 & -0.14 & -68.51 & -3.13 \\
\hline & 250 & 250 & 1 & -0.47 & -56.95 & -2.15 \\
\hline & & 300 & 1.2 & -0.33 & -61.03 & -2.45 \\
\hline & & 375 & 1.5 & -0.20 & -64.99 & -2.81 \\
\hline & & 500 & 2 & -0.11 & -69.82 & -3.25 \\
\hline & 300 & 300 & 1 & -0.29 & -59.27 & -2.36 \\
\hline & & 360 & 1.2 & -0.20 & -63.42 & -2.67 \\
\hline & & 450 & 1.5 & -0.13 & -67.34 & -3.02 \\
\hline & & 600 & 2 & -0.07 & -72.02 & -3.46 \\
\hline & 350 & 350 & 1 & -0.20 & -61.26 & -2.55 \\
\hline & & 420 & 1.2 & -0.14 & -65.42 & -2.86 \\
\hline & & 525 & 1.5 & -0.08 & -69.26 & -3.21 \\
\hline & & 700 & 2 & -0.04 & -73.74 & -3.63 \\
\hline
\end{tabular}




\begin{tabular}{|c|c|c|c|c|c|c|}
\hline \multicolumn{7}{|c|}{ Cantilever length: $1.5 \mathrm{~m}$} \\
\hline \multirow{2}{*}{$\begin{array}{l}\text { Barrier length } \\
\text { (m) }\end{array}$} & \multicolumn{2}{|c|}{ Slab thickness } & \multirow[t]{2}{*}{$\mathbf{t}_{2} / \mathbf{t}_{1}$} & \multirow{2}{*}{$\underset{(\mathbf{m m})}{\Delta}$} & \multirow{2}{*}{$\begin{array}{c}\mathbf{M}_{\mathbf{y}} \\
(\mathbf{k N} \cdot \mathbf{m m} / \mathbf{m m})\end{array}$} & \multirow{2}{*}{$\begin{array}{c}\mathbf{M}_{\mathbf{x}} \\
(\mathbf{k N} \cdot \mathbf{m m} / \mathbf{m m})\end{array}$} \\
\hline & $\mathbf{t}_{\mathbf{1}}(\mathbf{m m})$ & $\mathbf{t}_{2}(\mathbf{m m})$ & & & & \\
\hline \multirow{20}{*}{8} & 200 & 200 & 1 & -0.77 & -51.41 & -1.77 \\
\hline & & 240 & 1.2 & -0.54 & -55.64 & -2.08 \\
\hline & & 300 & 1.5 & -0.34 & -60.04 & -2.45 \\
\hline & & 400 & 2 & -0.18 & -65.57 & -2.92 \\
\hline & 225 & 225 & 1 & -0.57 & -53.13 & -1.90 \\
\hline & & 270 & 1.2 & -0.41 & -57.46 & -2.21 \\
\hline & & 337.5 & 1.5 & -0.25 & -61.88 & -2.59 \\
\hline & & 450 & 2 & -0.14 & -67.35 & -3.07 \\
\hline & 250 & 250 & 1 & -0.44 & -54.75 & -2.02 \\
\hline & & 300 & 1.2 & -0.31 & -59.13 & -2.34 \\
\hline & & 375 & 1.5 & -0.20 & -63.54 & -2.72 \\
\hline & & 500 & 2 & -0.10 & -68.92 & -3.20 \\
\hline & 300 & 300 & 1 & -0.28 & -57.61 & -2.26 \\
\hline & & 360 & 1.2 & -0.20 & -62.04 & -2.59 \\
\hline & & 450 & 1.5 & -0.12 & -66.35 & -2.97 \\
\hline & & 600 & 2 & -0.06 & -71.47 & -3.43 \\
\hline & 350 & 350 & 1 & -0.19 & -60.00 & -2.47 \\
\hline & & 420 & 1.2 & -0.13 & -64.42 & -2.80 \\
\hline & & 525 & 1.5 & -0.08 & -68.58 & -3.17 \\
\hline & & 700 & 2 & -0.04 & -73.40 & -3.61 \\
\hline \multirow{20}{*}{10} & 200 & 200 & 1 & -0.73 & -50.10 & -1.70 \\
\hline & & 240 & 1.2 & -0.52 & -54.55 & -2.02 \\
\hline & & 300 & 1.5 & -0.33 & -59.25 & -2.41 \\
\hline & & 400 & 2 & -0.18 & -65.13 & -2.90 \\
\hline & 225 & 225 & 1 & -0.55 & -52.06 & -1.84 \\
\hline & & 270 & 1.2 & -0.39 & -56.59 & -2.17 \\
\hline & & 337.5 & 1.5 & -0.25 & -61.28 & -2.56 \\
\hline & & 450 & 2 & -0.13 & -67.05 & -3.05 \\
\hline & 250 & 250 & 1 & -0.43 & -53.86 & -1.97 \\
\hline & & 300 & 1.2 & -0.31 & -58.43 & -2.31 \\
\hline & & 375 & 1.5 & -0.19 & -63.08 & -2.70 \\
\hline & & 500 & 2 & -0.10 & -68.70 & -3.19 \\
\hline & 300 & 300 & 1 & -0.27 & -57.00 & -2.23 \\
\hline & & 360 & 1.2 & -0.19 & -61.59 & -2.56 \\
\hline & & 450 & 1.5 & -0.12 & -66.09 & -2.95 \\
\hline & & 600 & 2 & -0.06 & -71.37 & -3.42 \\
\hline & 350 & 350 & 1 & -0.19 & -59.59 & -2.45 \\
\hline & & 420 & 1.2 & -0.13 & -64.14 & -2.79 \\
\hline & & 525 & 1.5 & $\begin{array}{l}-0.08 \\
\end{array}$ & -68.44 & -3.16 \\
\hline & & 700 & 2 & -0.04 & -73.35 & -3.61 \\
\hline
\end{tabular}




\begin{tabular}{|c|c|c|c|c|c|c|}
\hline \multicolumn{7}{|c|}{ Cantilever length: $1.5 \mathrm{~m}$} \\
\hline \multirow{2}{*}{$\begin{array}{c}\text { Barrier length } \\
(\mathrm{m})\end{array}$} & \multicolumn{2}{|c|}{ Slab thickness } & \multirow{3}{*}{$\begin{array}{r}\mathbf{t}_{2} / \mathbf{t}_{1} \\
\\
1\end{array}$} & \multirow{3}{*}{$\begin{array}{c}\begin{array}{c}\Delta \\
(\mathbf{m m})\end{array} \\
-0.72\end{array}$} & \multirow{3}{*}{$\begin{array}{c}\begin{array}{c}\mathbf{M}_{\mathbf{y}} \\
(\mathbf{k N} \cdot \mathbf{m m} / \mathbf{m m})\end{array} \\
-49.55\end{array}$} & \multirow{3}{*}{ 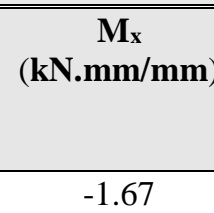 } \\
\hline & $\mathbf{t}_{1}(\mathbf{m m})$ & $\mathbf{t}_{2}(\mathrm{~mm})$ & & & & \\
\hline \multirow{20}{*}{12} & 200 & 200 & & & & \\
\hline & & 240 & 1.2 & -0.52 & -54.14 & -2.00 \\
\hline & & 300 & 1.5 & -0.33 & -59.00 & -2.39 \\
\hline & & 400 & 2 & -0.18 & -65.02 & -2.90 \\
\hline & 225 & 225 & 1 & -0.54 & -51.64 & -1.82 \\
\hline & & 270 & 1.2 & -0.39 & -56.28 & -2.15 \\
\hline & & 337.5 & 1.5 & -0.25 & -61.10 & -2.55 \\
\hline & & 450 & 2 & -0.13 & -66.98 & -3.05 \\
\hline & 250 & 250 & 1 & -0.42 & -53.54 & -1.96 \\
\hline & & 300 & 1.2 & -0.30 & -58.21 & -2.29 \\
\hline & & 375 & 1.5 & -0.19 & -62.96 & -2.69 \\
\hline & & 500 & 2 & -0.10 & -68.67 & -3.18 \\
\hline & 300 & 300 & 1 & -0.27 & -56.81 & -2.22 \\
\hline & & 360 & 1.2 & -0.19 & -61.47 & -2.56 \\
\hline & & 450 & 1.5 & -0.12 & -66.03 & -2.95 \\
\hline & & 600 & 2 & -0.06 & -71.35 & -3.42 \\
\hline & 350 & 350 & 1 & -0.19 & -59.48 & -2.45 \\
\hline & & 420 & 1.2 & -0.13 & -64.08 & -2.79 \\
\hline & & 525 & 1.5 & -0.08 & -68.42 & -3.16 \\
\hline & & 700 & 2 & -0.04 & -73.34 & -3.61 \\
\hline
\end{tabular}


Table A-23: Summary of Maximum deflection, Transverse Moment and Longitudinal Moment in Cantilevered Slab with Tl-5 Barrier of Length 2 m

\begin{tabular}{|c|c|c|c|c|c|c|}
\hline \multicolumn{7}{|c|}{ Cantilever length: $2 \mathrm{~m}$} \\
\hline \multirow{2}{*}{$\begin{array}{c}\text { Barrier length } \\
(\mathrm{m})\end{array}$} & \multicolumn{2}{|c|}{ Slab thickness } & \multirow[t]{2}{*}{$\overline{\mathbf{t}_{2} / \mathbf{t}_{1}}$} & \multirow{2}{*}{$\begin{array}{c}\Delta \\
(\mathbf{m m})\end{array}$} & \multirow{2}{*}{$\begin{array}{c}\mathbf{M}_{\mathbf{y}} \\
(\mathbf{k N} \cdot \mathbf{m m} / \mathbf{m m})\end{array}$} & \multirow{2}{*}{$\begin{array}{c}\mathbf{M}_{\mathbf{x}} \\
(\mathbf{k N} \cdot \mathbf{m m} / \mathbf{m m})\end{array}$} \\
\hline & $\mathbf{t}_{\mathbf{1}}(\mathbf{m m})$ & $\mathbf{t}_{\mathbf{2}}(\mathbf{m m})$ & & & & \\
\hline \multirow{20}{*}{5} & 200 & 200 & 1 & -2.88 & -79.78 & -4.91 \\
\hline & & 240 & 1.2 & -1.99 & -84.43 & -5.26 \\
\hline & & 300 & 1.5 & -1.22 & -89.19 & -5.67 \\
\hline & & 400 & 2 & -0.64 & -95.14 & -6.19 \\
\hline & 225 & 225 & 1 & -2.07 & -80.77 & -5.02 \\
\hline & & 270 & 1.2 & -1.43 & -85.55 & -5.38 \\
\hline & & 337.5 & 1.5 & -0.88 & -90.42 & -5.80 \\
\hline & & 450 & 2 & -0.46 & -96.51 & -6.33 \\
\hline & 250 & 250 & 1 & -1.54 & -81.80 & -5.14 \\
\hline & & 300 & 1.2 & -1.07 & -86.69 & -5.51 \\
\hline & & 375 & 1.5 & -0.66 & -91.65 & -5.93 \\
\hline & & 500 & 2 & -0.35 & -97.82 & -6.47 \\
\hline & 300 & 300 & 1 & -0.93 & -83.84 & -5.37 \\
\hline & & 360 & 1.2 & -0.65 & -88.89 & -5.75 \\
\hline & & 450 & 1.5 & -0.40 & -93.96 & -6.19 \\
\hline & & 600 & 2 & -0.21 & -100.18 & -6.73 \\
\hline & 350 & 350 & 1 & -0.61 & -85.72 & -5.59 \\
\hline & & 420 & 1.2 & -0.42 & -90.86 & -5.98 \\
\hline & & 525 & 1.5 & -0.26 & -95.97 & -6.41 \\
\hline & & 700 & 2 & -0.14 & -102.15 & -6.95 \\
\hline \multirow{20}{*}{6} & 200 & 200 & 1 & -2.64 & -74.81 & -4.57 \\
\hline & & 240 & 1.2 & -1.84 & -79.75 & -4.94 \\
\hline & & 300 & 1.5 & -1.14 & -84.98 & -5.39 \\
\hline & & 400 & 2 & -0.61 & -91.65 & -5.96 \\
\hline & 225 & 225 & 1 & -1.91 & -76.24 & -4.71 \\
\hline & & 270 & 1.2 & -1.34 & -81.33 & -5.09 \\
\hline & & 337.5 & 1.5 & -0.83 & -86.70 & -5.55 \\
\hline & & 450 & 2 & -0.44 & -93.49 & -6.13 \\
\hline & 250 & 250 & 1 & -1.44 & -77.69 & -4.86 \\
\hline & & 300 & 1.2 & -1.01 & -82.89 & -5.25 \\
\hline & & 375 & 1.5 & -0.63 & -88.36 & -5.71 \\
\hline & & 500 & 2 & -0.33 & -95.21 & -6.30 \\
\hline & 300 & 300 & 1 & -0.88 & -80.45 & -5.13 \\
\hline & & 360 & 1.2 & -0.62 & -85.82 & -5.54 \\
\hline & & 450 & 1.5 & $\begin{array}{l}-0.38 \\
\end{array}$ & -91.36 & -6.01 \\
\hline & & 600 & 2 & -0.20 & -98.22 & -6.60 \\
\hline & 350 & 350 & 1 & -0.58 & -82.90 & -5.39 \\
\hline & & 420 & 1.2 & -0.41 & -88.35 & -5.80 \\
\hline & & 525 & 1.5 & -0.25 & -93.91 & -6.27 \\
\hline & & 700 & 2 & -0.13 & -100.68 & -6.85 \\
\hline
\end{tabular}




\begin{tabular}{|c|c|c|c|c|c|c|}
\hline \multicolumn{7}{|c|}{ Cantilever length: $2 \mathrm{~m}$} \\
\hline \multirow{2}{*}{$\begin{array}{c}\text { Barrier length } \\
(\mathrm{m})\end{array}$} & \multicolumn{2}{|c|}{ Slab thickness } & \multirow[t]{2}{*}{$\overline{t_{2} / \mathbf{t}_{1}}$} & \multirow{2}{*}{$\begin{array}{c}\boldsymbol{\Delta} \\
(\mathbf{m m})\end{array}$} & \multirow{2}{*}{$\begin{array}{c}\mathbf{M}_{\mathbf{y}} \\
(\mathbf{k N} \cdot \mathbf{m m} / \mathbf{m m})\end{array}$} & \multirow{2}{*}{$\begin{array}{c}\mathbf{M}_{\mathbf{x}} \\
(\mathbf{k N} \cdot \mathbf{m m} / \mathbf{m m})\end{array}$} \\
\hline & $\mathbf{t}_{\mathbf{1}}(\mathbf{m m})$ & $\mathbf{t}_{2}(\mathrm{~mm})$ & & & & \\
\hline \multirow{20}{*}{8} & 200 & 200 & 1 & -2.34 & -68.51 & -4.17 \\
\hline & & 240 & 1.2 & -1.65 & -73.87 & -4.57 \\
\hline & & 300 & 1.5 & -1.05 & -79.85 & -5.06 \\
\hline & & 400 & 2 & -0.57 & -87.60 & -5.71 \\
\hline & 225 & 225 & 1 & -1.73 & -70.65 & -4.35 \\
\hline & & 270 & 1.2 & -1.22 & -76.18 & -4.76 \\
\hline & & 337.5 & 1.5 & -0.77 & -82.29 & -5.27 \\
\hline & & 450 & 2 & -0.42 & -90.13 & -5.92 \\
\hline & 250 & 250 & 1 & -1.32 & -72.73 & -4.53 \\
\hline & & 300 & 1.2 & -0.93 & -78.38 & -4.95 \\
\hline & & 375 & 1.5 & -0.59 & -84.55 & -5.46 \\
\hline & & 500 & 2 & -0.32 & -92.42 & -6.12 \\
\hline & 300 & 300 & 1 & -0.82 & -76.51 & -4.87 \\
\hline & & 360 & 1.2 & -0.58 & -82.31 & -5.30 \\
\hline & & 450 & 1.5 & -0.37 & -88.52 & -5.82 \\
\hline & & 600 & 2 & -0.20 & -96.29 & -6.48 \\
\hline & 350 & 350 & 1 & -0.55 & -79.74 & -5.18 \\
\hline & & 420 & 1.2 & -0.39 & -85.62 & -5.62 \\
\hline & & 525 & 1.5 & -0.24 & -91.80 & -6.13 \\
\hline & & 700 & 2 & -0.13 & -99.36 & -6.77 \\
\hline \multirow{20}{*}{10} & 200 & 200 & 1 & -2.18 & -65.13 & -3.96 \\
\hline & & 240 & 1.2 & -1.56 & -70.83 & -4.38 \\
\hline & & 300 & 1.5 & -1.00 & -77.34 & -4.91 \\
\hline & & 400 & 2 & -0.55 & -85.86 & -5.61 \\
\hline & 225 & 225 & 1 & -1.63 & -67.76 & -4.17 \\
\hline & & 270 & 1.2 & -1.16 & -73.62 & -4.60 \\
\hline & & 337.5 & 1.5 & -0.74 & -80.23 & -5.14 \\
\hline & & 450 & 2 & -0.41 & -88.79 & -5.84 \\
\hline & 250 & 250 & 1 & -1.26 & -70.23 & -4.37 \\
\hline & & 300 & 1.2 & -0.90 & -76.20 & -4.81 \\
\hline & & 375 & 1.5 & -0.57 & -82.87 & -5.36 \\
\hline & & 500 & 2 & -0.31 & -91.38 & -6.06 \\
\hline & 300 & 300 & 1 & -0.80 & -74.62 & -4.75 \\
\hline & & 360 & 1.2 & -0.57 & -80.73 & -5.21 \\
\hline & & 450 & 1.5 & -0.36 & -87.40 & -5.75 \\
\hline & & 600 & 2 & -0.19 & -95.69 & -6.44 \\
\hline & 350 & 350 & 1 & -0.54 & -78.33 & -5.09 \\
\hline & & 420 & 1.2 & -0.38 & -84.51 & -5.55 \\
\hline & & 525 & 1.5 & -0.24 & -91.07 & -6.09 \\
\hline & & 700 & 2 & -0.13 & -99.01 & -6.75 \\
\hline
\end{tabular}




\begin{tabular}{|c|c|c|c|c|c|c|}
\hline \multicolumn{7}{|c|}{ Cantilever length: $2 \mathrm{~m}$} \\
\hline \multirow{2}{*}{$\begin{array}{c}\text { Barrier length } \\
(\mathrm{m})\end{array}$} & \multicolumn{2}{|c|}{ Slab thickness } & \multirow[t]{2}{*}{$\overline{\mathbf{t}_{2} / \mathbf{t}_{1}}$} & \multirow{2}{*}{$\begin{array}{c}\boldsymbol{\Delta} \\
(\mathbf{m m})\end{array}$} & \multirow{2}{*}{$\begin{array}{c}\mathbf{M}_{\mathbf{y}} \\
(\mathbf{k N} \cdot \mathbf{m m} / \mathbf{m m})\end{array}$} & \multirow{2}{*}{$\begin{array}{c}\mathbf{M}_{\mathbf{x}} \\
(\mathbf{k N} \cdot \mathbf{m m} / \mathbf{m m})\end{array}$} \\
\hline & $\mathbf{t}_{\mathbf{1}}(\mathbf{m m})$ & $t_{2}(\mathrm{~mm})$ & & & & \\
\hline \multirow{20}{*}{12} & 200 & 200 & 1 & -2.10 & -63.36 & -3.86 \\
\hline & & 240 & 1.2 & -1.51 & -69.31 & -4.29 \\
\hline & & 300 & 1.5 & -0.97 & -76.20 & -4.84 \\
\hline & & 400 & 2 & -0.54 & -85.20 & -5.57 \\
\hline & 225 & 225 & 1 & -1.58 & -66.29 & -4.08 \\
\hline & & 270 & 1.2 & -1.13 & -72.39 & -4.53 \\
\hline & & 337.5 & 1.5 & -0.73 & -79.35 & -5.09 \\
\hline & & 450 & 2 & -0.40 & -88.32 & -5.82 \\
\hline & 250 & 250 & 1 & -1.22 & -69.00 & -4.30 \\
\hline & & 300 & 1.2 & -0.88 & -75.20 & -4.76 \\
\hline & & 375 & 1.5 & -0.56 & -82.19 & -5.32 \\
\hline & & 500 & 2 & -0.31 & -91.06 & -6.04 \\
\hline & 300 & 300 & 1 & -0.78 & -73.77 & -4.70 \\
\hline & & 360 & 1.2 & -0.56 & -80.10 & -5.17 \\
\hline & & 450 & 1.5 & -0.36 & -87.02 & -5.73 \\
\hline & & 600 & 2 & -0.19 & -95.54 & -6.43 \\
\hline & 350 & 350 & 1 & -0.53 & -77.76 & -5.05 \\
\hline & & 420 & 1.2 & -0.38 & -84.12 & -5.53 \\
\hline & & 525 & 1.5 & -0.24 & -90.87 & -6.08 \\
\hline & & 700 & 2 & -0.13 & -98.95 & -6.75 \\
\hline
\end{tabular}


Table A-24: Summary of Maximum deflection, Transverse Moment and Longitudinal Moment in Cantilevered Slab with Tl-5 Barrier of Length $2.5 \mathrm{~m}$

\begin{tabular}{|c|c|c|c|c|c|c|}
\hline \multicolumn{7}{|c|}{ Cantilever length: $2.5 \mathrm{~m}$} \\
\hline \multirow{2}{*}{$\begin{array}{c}\text { Barrier length } \\
\text { (m) }\end{array}$} & \multicolumn{2}{|c|}{ Slab thickness } & \multirow[t]{2}{*}{$\mathbf{t}_{2} / \mathbf{t}_{1}$} & \multirow{2}{*}{$\begin{array}{c}\boldsymbol{\Delta} \\
(\mathbf{m m})\end{array}$} & \multirow{2}{*}{$\begin{array}{c}\mathbf{M}_{\mathbf{y}} \\
(\mathbf{k N} \cdot \mathbf{m m} / \mathbf{m m})\end{array}$} & \multirow{2}{*}{$\begin{array}{c}\mathbf{M}_{\mathbf{x}} \\
(\mathbf{k N} \cdot \mathbf{m m} / \mathbf{m m})\end{array}$} \\
\hline & $\mathbf{t}_{\mathbf{1}}(\mathbf{m m})$ & $\mathbf{t}_{2}(\mathrm{~mm})$ & & & & \\
\hline \multirow{20}{*}{5} & 200 & 200 & 1 & -7.58 & -108.08 & -6.64 \\
\hline & & 240 & 1.2 & -5.16 & -112.27 & -6.85 \\
\hline & & 300 & 1.5 & -3.16 & -116.57 & -7.07 \\
\hline & & 400 & 2 & -1.65 & -121.84 & -7.31 \\
\hline & 225 & 225 & 1 & $\begin{array}{l}-5.39 \\
\end{array}$ & -108.69 & -6.71 \\
\hline & & 270 & 1.2 & -3.68 & -112.95 & -6.92 \\
\hline & & 337.5 & 1.5 & -2.25 & -117.33 & -7.14 \\
\hline & & 450 & 2 & -1.18 & -122.67 & -7.39 \\
\hline & 250 & 250 & 1 & -3.98 & -109.32 & -6.78 \\
\hline & & 300 & 1.2 & -2.72 & -113.65 & -6.99 \\
\hline & & 375 & 1.5 & -1.67 & -118.09 & $\begin{array}{l}-7.21 \\
\end{array}$ \\
\hline & & 500 & 2 & -0.87 & -123.49 & -7.46 \\
\hline & 300 & 300 & 1 & -2.36 & -110.58 & -6.91 \\
\hline & & 360 & 1.2 & -1.61 & -115.02 & $\begin{array}{l}-7.13 \\
\end{array}$ \\
\hline & & 450 & 1.5 & -0.99 & -119.54 & $\begin{array}{l}-7.35 \\
\end{array}$ \\
\hline & & 600 & 2 & -0.52 & -124.98 & -7.58 \\
\hline & 350 & 350 & 1 & -1.51 & -111.74 & $\begin{array}{l}-7.03 \\
\end{array}$ \\
\hline & & 420 & 1.2 & -1.04 & -116.24 & $\begin{array}{l}-7.24 \\
\end{array}$ \\
\hline & & 525 & 1.5 & -0.64 & -120.80 & -7.46 \\
\hline & & 700 & 2 & $\begin{array}{l}-0.33 \\
\end{array}$ & -126.24 & $\begin{array}{l}-7.68 \\
\end{array}$ \\
\hline \multirow{20}{*}{6} & 200 & 200 & 1 & $\begin{array}{l}-6.93 \\
\end{array}$ & -101.36 & -6.20 \\
\hline & & 240 & 1.2 & -4.77 & -106.00 & -6.45 \\
\hline & & 300 & 1.5 & -2.95 & -110.95 & -6.71 \\
\hline & & 400 & 2 & -1.56 & -117.06 & -7.01 \\
\hline & 225 & 225 & 1 & -4.97 & -102.43 & -6.30 \\
\hline & & 270 & 1.2 & -3.42 & -107.17 & -6.55 \\
\hline & & 337.5 & 1.5 & -2.12 & -112.22 & -6.82 \\
\hline & & 450 & 2 & -1.12 & -118.42 & $\begin{array}{l}-7.12 \\
\end{array}$ \\
\hline & 250 & 250 & 1 & -3.69 & -103.51 & -6.40 \\
\hline & & 300 & 1.2 & -2.55 & -108.34 & -6.65 \\
\hline & & 375 & 1.5 & -1.58 & -113.46 & $\begin{array}{l}-6.92 \\
\end{array}$ \\
\hline & & 500 & 2 & -0.83 & -119.71 & -7.22 \\
\hline & 300 & 300 & 1 & -2.21 & -105.58 & -6.60 \\
\hline & & 360 & 1.2 & $\begin{array}{l}-1.53 \\
\end{array}$ & -110.53 & -6.85 \\
\hline & & 450 & 1.5 & -0.95 & -115.71 & $\begin{array}{l}-7.11 \\
\end{array}$ \\
\hline & & 600 & 2 & -0.50 & -121.97 & -7.40 \\
\hline & 350 & 350 & 1 & $\begin{array}{l}-1.44 \\
\end{array}$ & -107.40 & -6.76 \\
\hline & & 420 & 1.2 & -0.99 & -112.41 & $\begin{array}{l}-7.01 \\
\end{array}$ \\
\hline & & 525 & 1.5 & -0.61 & -117.61 & -7.26 \\
\hline & & 700 & 2 & -0.32 & -123.83 & -7.54 \\
\hline
\end{tabular}




\begin{tabular}{|c|c|c|c|c|c|c|}
\hline \multicolumn{7}{|c|}{ Cantilever length: $2.5 \mathrm{~m}$} \\
\hline \multirow{2}{*}{$\begin{array}{c}\text { Barrier length } \\
(\mathrm{m})\end{array}$} & \multicolumn{2}{|c|}{ Slab thickness } & \multirow[t]{2}{*}{$\mathbf{t}_{2} / \mathbf{t}_{1}$} & \multirow{2}{*}{$\underset{(\mathbf{m m})}{\Delta}$} & \multirow{2}{*}{$\begin{array}{c}\mathbf{M}_{\mathbf{y}} \\
(\mathbf{k N} \cdot \mathbf{m m} / \mathbf{m m})\end{array}$} & \multirow{2}{*}{$\begin{array}{c}\mathbf{M}_{\mathbf{x}} \\
(\mathbf{k N} \cdot \mathbf{m m} / \mathbf{m m})\end{array}$} \\
\hline & $\mathbf{t}_{\mathbf{1}}(\mathbf{m m})$ & $\mathbf{t}_{2}(\mathrm{~mm})$ & & & & \\
\hline \multirow{20}{*}{8} & 200 & 200 & 1 & -6.12 & -91.83 & -5.58 \\
\hline & & 240 & 1.2 & -4.27 & -97.10 & -5.88 \\
\hline & & 300 & 1.5 & -2.68 & -102.98 & -6.21 \\
\hline & & 400 & 2 & -1.44 & -110.41 & -6.60 \\
\hline & 225 & 225 & 1 & -4.45 & -93.81 & -5.75 \\
\hline & & 270 & 1.2 & -3.11 & -99.22 & -6.04 \\
\hline & & 337.5 & 1.5 & -1.95 & -105.20 & -6.37 \\
\hline & & 450 & 2 & -1.05 & -112.70 & -6.77 \\
\hline & 250 & 250 & 1 & -3.35 & -95.73 & -5.90 \\
\hline & & 300 & 1.2 & -2.34 & -101.23 & -6.20 \\
\hline & & 375 & 1.5 & -1.47 & -107.27 & -6.53 \\
\hline & & 500 & 2 & -0.79 & -114.78 & -6.92 \\
\hline & 300 & 300 & 1 & -2.05 & -99.20 & -6.18 \\
\hline & & 360 & 1.2 & -1.43 & -104.80 & -6.48 \\
\hline & & 450 & 1.5 & -0.90 & -110.86 & -6.80 \\
\hline & & 600 & 2 & -0.48 & -118.30 & -7.17 \\
\hline & 350 & 350 & 1 & -1.35 & -102.12 & -6.42 \\
\hline & & 420 & 1.2 & -0.94 & -107.76 & -6.71 \\
\hline & & 525 & 1.5 & -0.59 & -113.79 & -7.02 \\
\hline & & 700 & 2 & -0.31 & -121.09 & -7.37 \\
\hline \multirow{19}{*}{10} & 200 & 200 & 1 & $\begin{array}{l}-5.64 \\
\end{array}$ & -85.88 & -5.21 \\
\hline & & 240 & 1.2 & -3.98 & -91.60 & -5.53 \\
\hline & & 300 & 1.5 & -2.53 & -98.17 & -5.91 \\
\hline & & 400 & 2 & -1.38 & -106.63 & -6.38 \\
\hline & 225 & 225 & 1 & -4.15 & -88.60 & -5.41 \\
\hline & & 270 & 1.2 & -2.93 & -94.45 & -5.74 \\
\hline & & 337.5 & 1.5 & -1.86 & -101.11 & -6.12 \\
\hline & & 450 & 2 & -1.01 & -109.61 & -6.58 \\
\hline & 250 & 250 & 1 & -3.16 & -91.14 & -5.61 \\
\hline & & 300 & 1.2 & -2.22 & -97.07 & -5.93 \\
\hline & & 375 & 1.5 & -1.41 & -103.77 & -6.31 \\
\hline & & 500 & 2 & -0.76 & -112.24 & -6.77 \\
\hline & 300 & 300 & 1 & -1.96 & -95.59 & -5.95 \\
\hline & & 360 & 1.2 & -1.38 & -101.61 & -6.28 \\
\hline & & 450 & 1.5 & -0.87 & -108.30 & -6.64 \\
\hline & & 600 & 2 & $\begin{array}{l}-0.47 \\
\end{array}$ & -116.60 & -7.07 \\
\hline & 350 & 350 & 1 & -1.30 & -99.27 & -6.24 \\
\hline & & 420 & 1.2 & -0.91 & -105.33 & -6.56 \\
\hline & & 525 & 1.5 & -0.58 & -111.94 & -6.91 \\
\hline
\end{tabular}




\begin{tabular}{|c|c|c|c|c|c|c|}
\hline & & 700 & 2 & -0.31 & -119.98 & -7.31 \\
\hline \multicolumn{7}{|c|}{ Cantilever length: $2.5 \mathrm{~m}$} \\
\hline \multirow{2}{*}{$\begin{array}{c}\text { Barrier length } \\
\text { (m) }\end{array}$} & \multicolumn{2}{|c|}{ Slab thickness } & \multirow[t]{2}{*}{$\mathbf{t}_{2} / \mathbf{t}_{1}$} & \multirow{2}{*}{$\begin{array}{c}\Delta \\
(\mathbf{m m})\end{array}$} & \multirow{2}{*}{$\begin{array}{c}\mathbf{M}_{\mathbf{y}} \\
(\mathbf{k N} \cdot \mathbf{m m} / \mathbf{m m})\end{array}$} & \multirow{2}{*}{$\begin{array}{c}\mathbf{M}_{\mathbf{x}} \\
(\mathbf{k N} \cdot \mathbf{m m} / \mathbf{m m})\end{array}$} \\
\hline & $\mathbf{t}_{1}(\mathbf{m m})$ & $\mathbf{t}_{2}(\mathbf{m m})$ & & & & \\
\hline \multirow{20}{*}{12} & 200 & 200 & 1 & -5.36 & -82.21 & -4.98 \\
\hline & & 240 & 1.2 & -3.80 & -88.28 & -5.33 \\
\hline & & 300 & 1.5 & -2.43 & -95.41 & -5.75 \\
\hline & & 400 & 2 & -1.34 & -104.68 & -6.27 \\
\hline & 225 & 225 & 1 & -3.98 & -85.45 & -5.22 \\
\hline & & 270 & 1.2 & -2.82 & -91.65 & -5.57 \\
\hline & & 337.5 & 1.5 & -1.80 & -98.84 & -5.99 \\
\hline & & 450 & 2 & -0.99 & -108.11 & -6.50 \\
\hline & 250 & 250 & 1 & -3.05 & -88.42 & -5.44 \\
\hline & & 300 & 1.2 & -2.16 & -94.69 & -5.79 \\
\hline & & 375 & 1.5 & -1.38 & -101.91 & -6.20 \\
\hline & & 500 & 2 & -0.75 & -111.09 & -6.70 \\
\hline & 300 & 300 & 1 & -1.91 & -93.55 & -5.82 \\
\hline & & 360 & 1.2 & -1.35 & -99.91 & -6.17 \\
\hline & & 450 & 1.5 & -0.86 & -107.08 & -6.57 \\
\hline & & 600 & 2 & -0.47 & -115.95 & -7.04 \\
\hline & 350 & 350 & 1 & -1.28 & -97.77 & -6.14 \\
\hline & & 420 & 1.2 & -0.90 & -104.14 & -6.49 \\
\hline & & 525 & 1.5 & -0.57 & -111.16 & -6.87 \\
\hline & & 700 & 2 & -0.31 & -119.62 & -7.29 \\
\hline
\end{tabular}


Appendix (B): $\quad$ Sample Code of SAP2000 API 
Sample code for obtaining maximum transverse and longitudinal moment and deflection for the unstiffened slab:

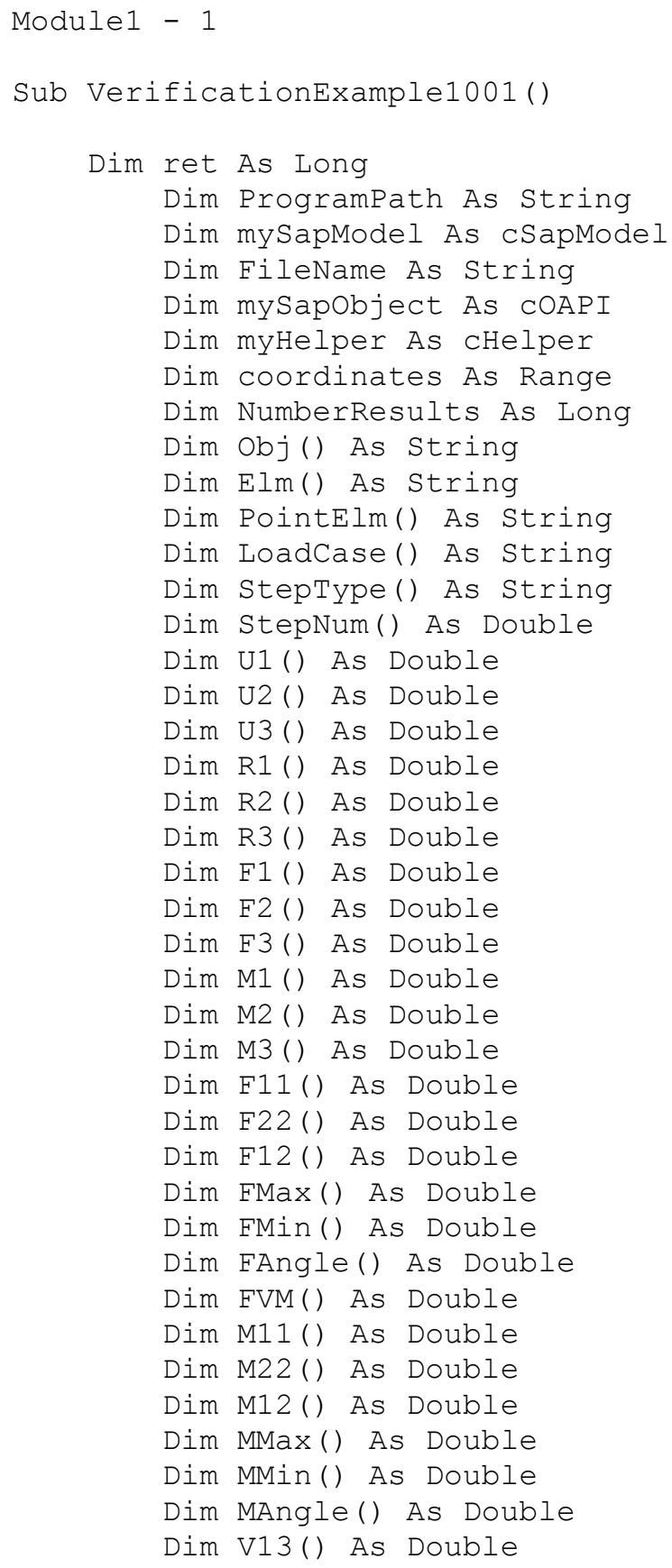




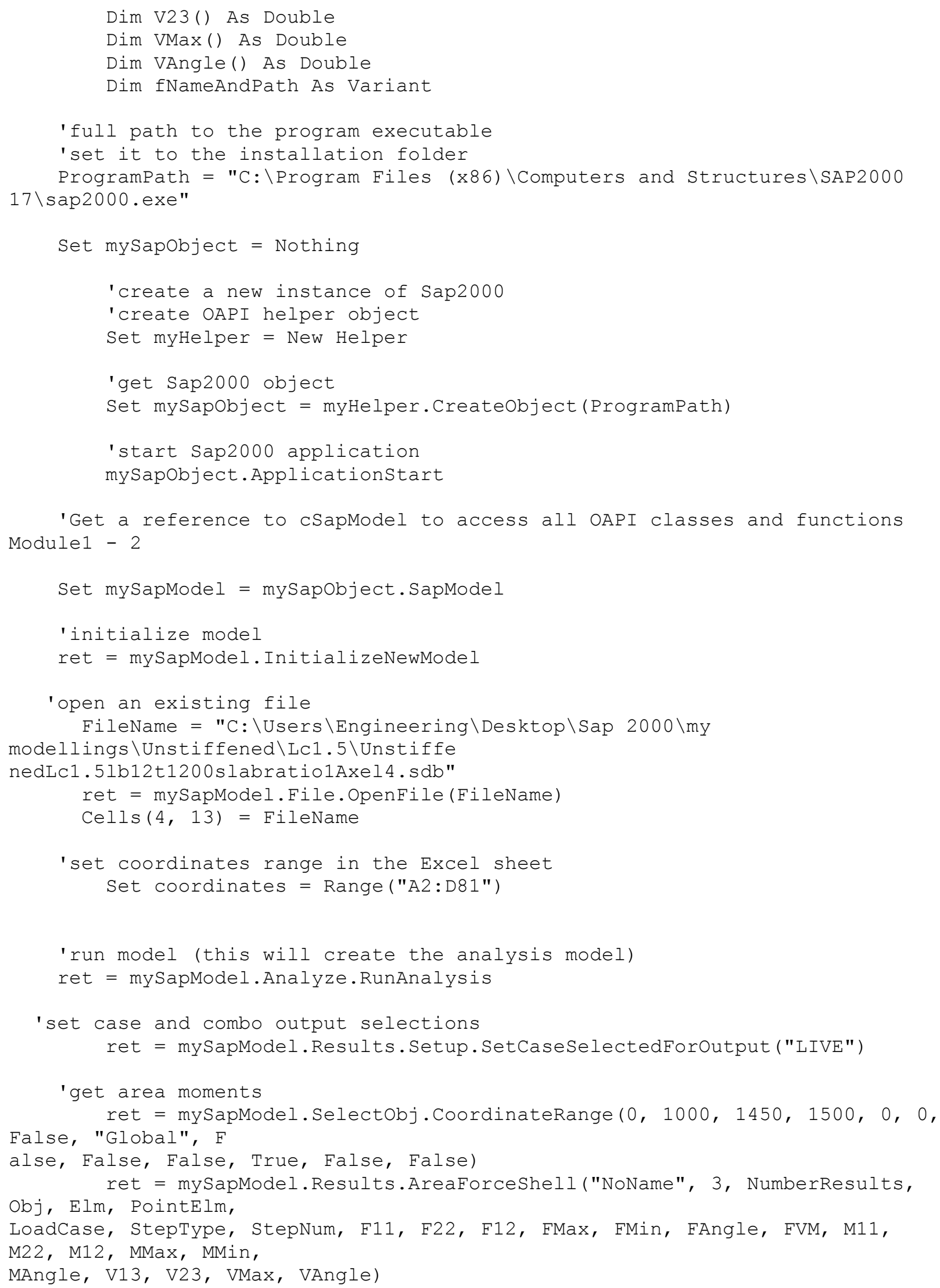


'write data to file; total of 4 M22 values per element, with 80 elements taken, $50 \times 50 \mathrm{~mm}$ e

a.

For $i=0$ To 79

coordinates $(i+1,2) \cdot$ Value $=$ M22(i)

Next i

'clear selection

ret $=$ mySapModel.Selectobj.ClearSelection

'get area moments

ret $=$ mySapModel.Selectobj.CoordinateRange $(50,100,500,1500,0,0$, False, "Global", Fa

lse, False, False, True, False, False)

ret = mySapModel.Results.AreaForceShell("NoName", 3, NumberResults,

Obj, Elm, PointElm,

LoadCase, Steptype, StepNum, F11, F22, F12, FMax, FMin, FAngle, FVM, M11, M22, M12, MMax, MMin,

MAngle, V13, V23, VMax, VAngle)

'write data to file; total of 4 M11 values per element, with 80 elements taken, 50 × $50 \mathrm{~mm}$ e

a.

For $i=0$ To 79

Next i

coordinates $(i+1,3)$. Value $=$ M11(i)

'clear selection

ret $=$ mySapModel.Selectobj.ClearSelection

'select joints to analyze and obtain their displacements; non-point boolean values irre

levant for range

ret $=$ mysapModel.Selectobj.CoordinateRange $(0,1000,0,0,0,0$,

False, "Global", False,

True, False, False, False, False)

ret = mySapModel.Results.JointDispl("NoName", 3, NumberResults, Obj,

Elm, LoadCase, Step

Type, StepNum, U1, U2, U3, R1, R2, R3)

'write joint displacements to Excel sheet; 21 points

For $i=0$ To 20

coordinates $(i+1,4)$. Value $=U 3(i)$

Module1 - 3

Next i

'clear selection

ret $=$ mySapModel.Selectobj.ClearSelection

'close SAP2000 


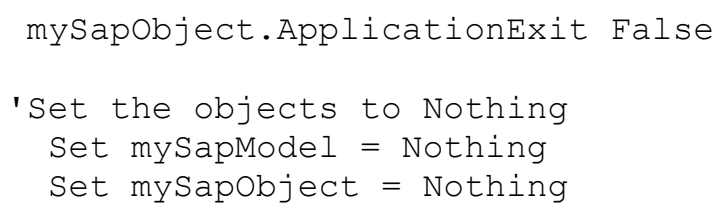

End Sub

\section{Sample code for obtaining maximum transverse and longitudinal moment and deflection}

\section{for the end-stiffened slab (TL-5):}

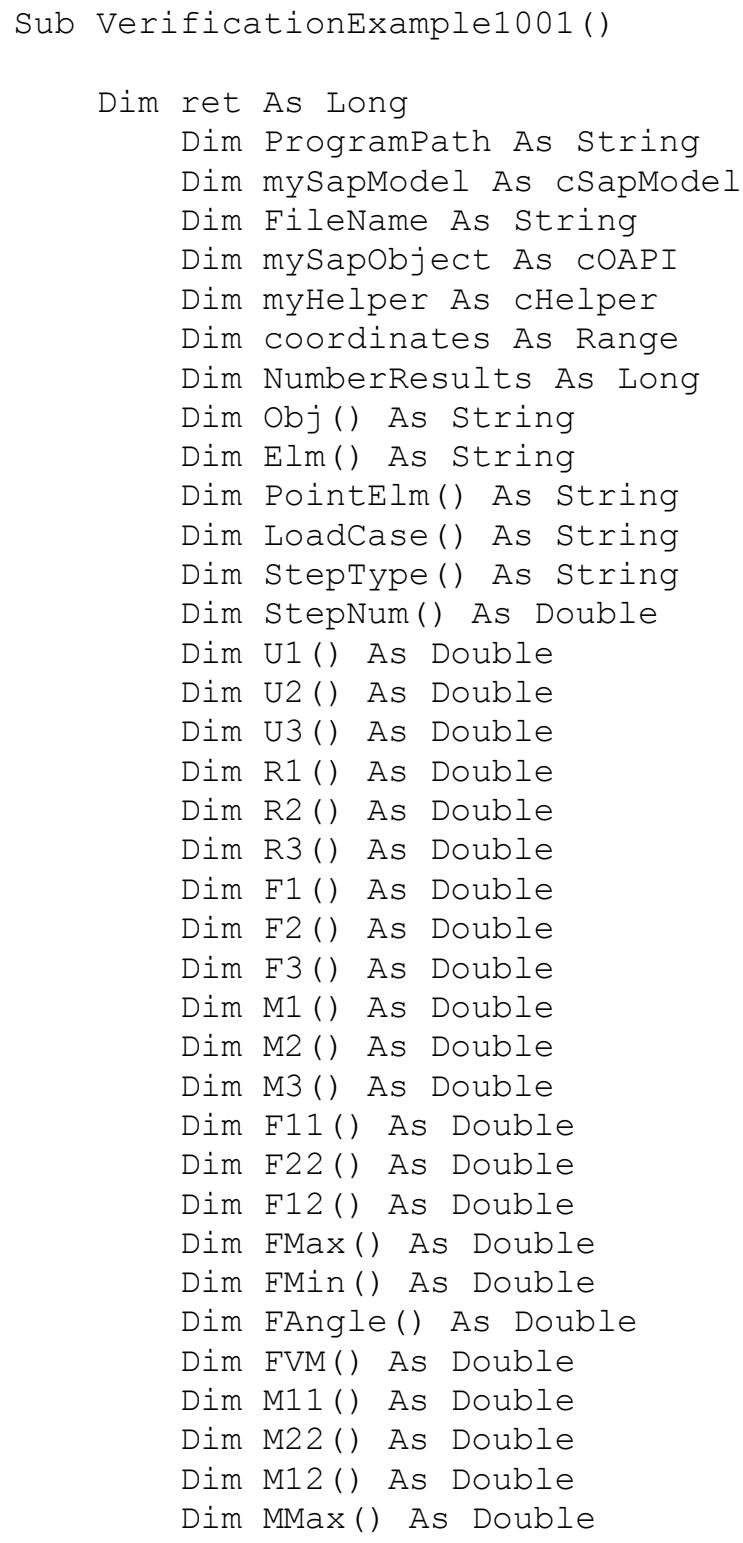




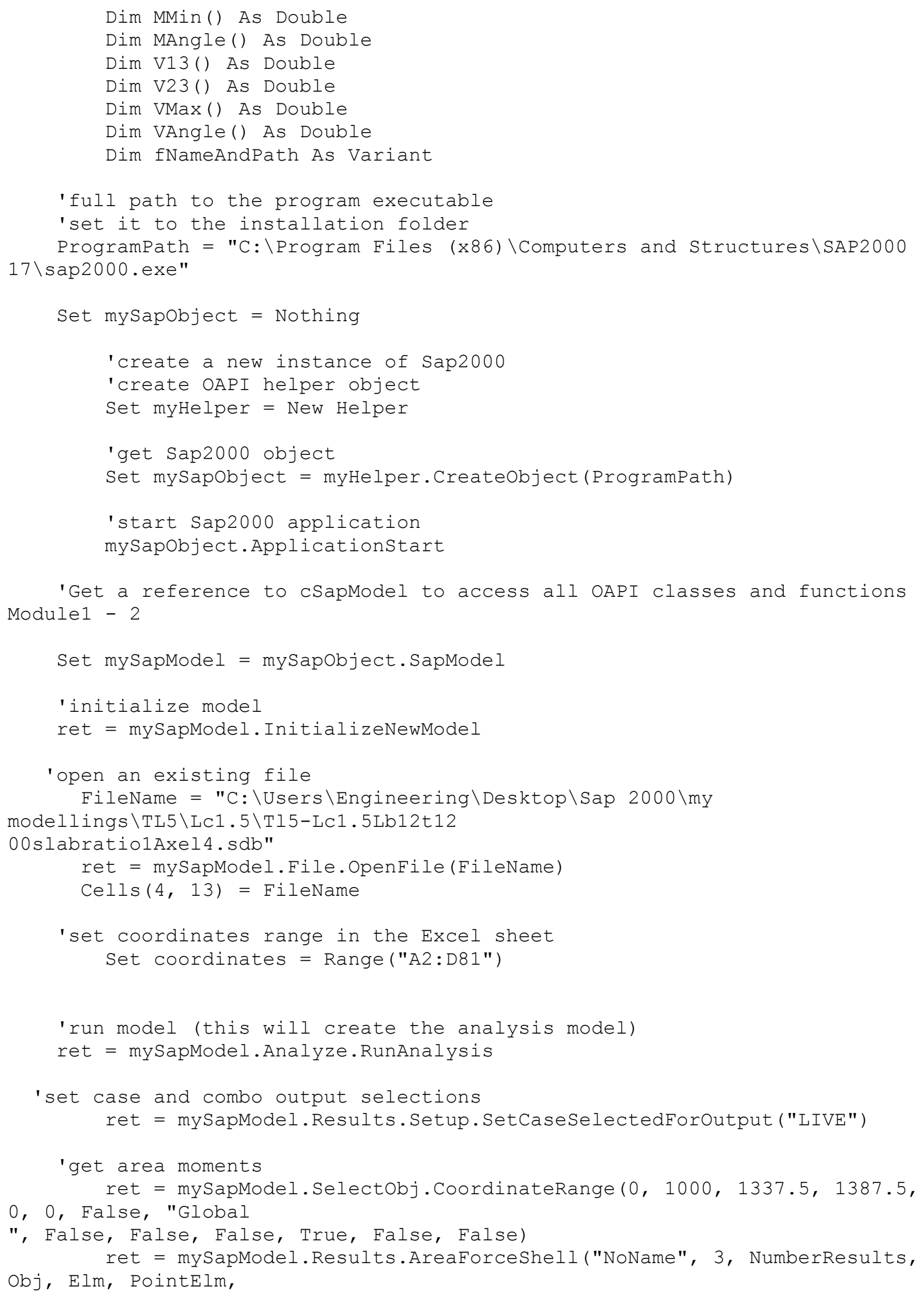




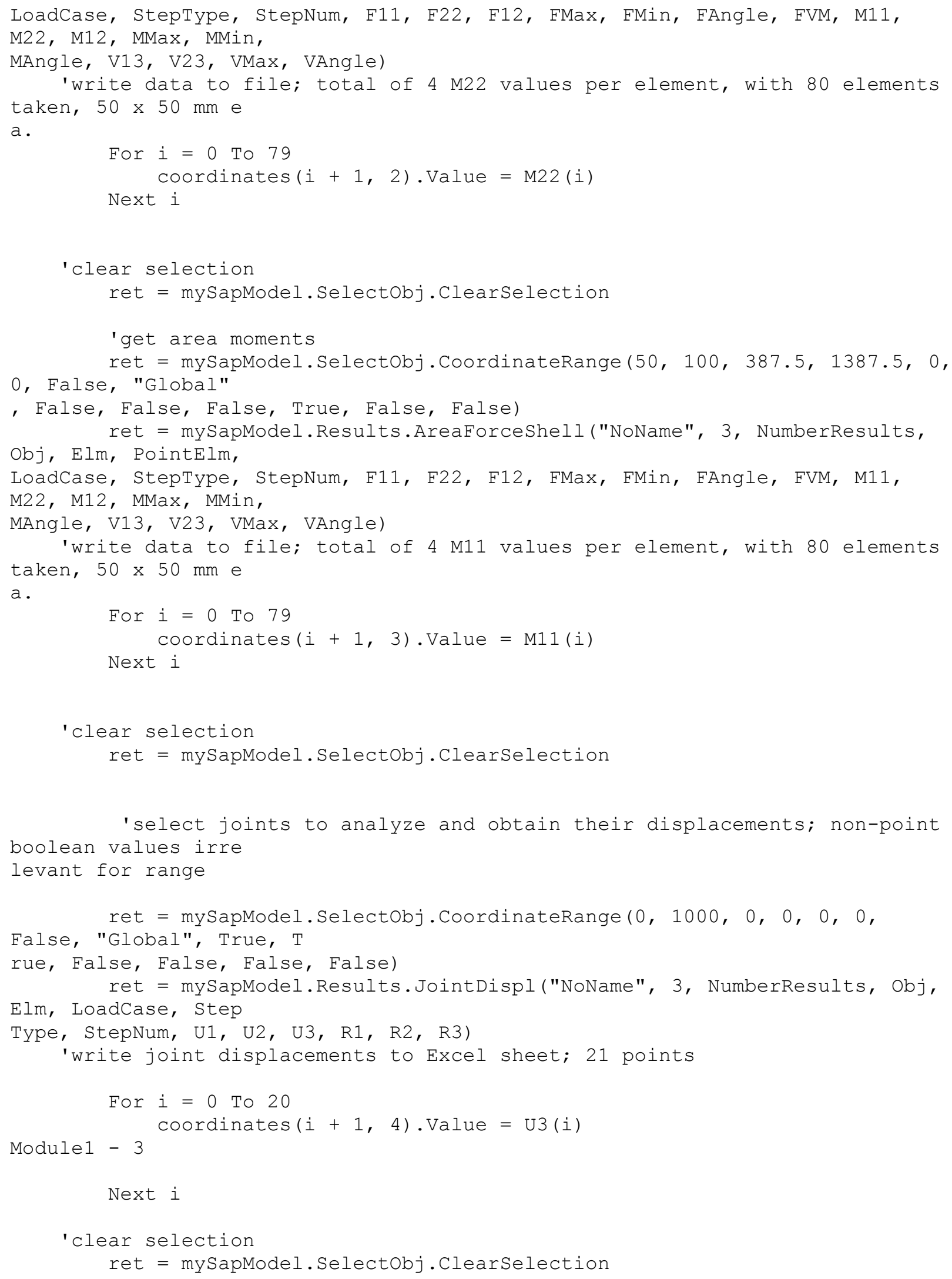




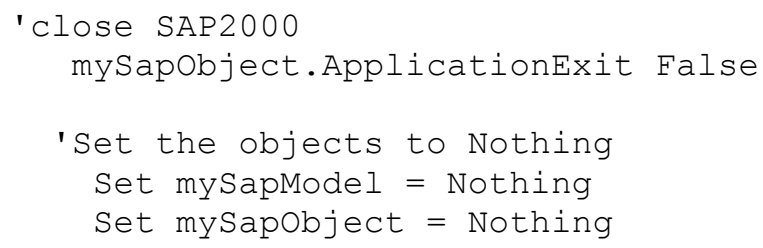




\section{REFERENCES}

Bakht, B. (1981). Simplified analysis of edge stiffened cantilever slabs. Journal of Structural Division, ASCE, 103(ST3), pp. 535-550.

Bakht, B., and Holland, D. (1976). A manual method for the elastic analysis of wide cantilever slabs of linearly varying thickness. Canadian journal of civil engineering, 3(4),

pp. 523-530.

Bakht, B., and Jaeger, L. G. (1985). Bridge analysis simplified. McGRAW-HILL BOOK COMPANY.

Bakht, B., Aziz, T. S., and Bartusevicius, K. F. (1979). Manual analysis of cantilever slabs of semi-infinite width, 6(2). Canadian journal of civil engineering, pp. 227-231.

CSA. (2014a). Canadian highway bridge design code (CHBDC), CAN/CSA-S6.1-14, Canadian Standard Association, Toronto, Ontario, Canada.

CSA. (2014b). Commentarries on the Canadian highway bridge design code (CHBDC), CAN/CSA-S6.1-14, Canadian Standard Association, Toronto, Ontario, Canada.

CSI. (2015). SAP2000 software, Integrated finite element analysis and design of structures, version 17. Computer and Structure Inc Berkeley, California, USA.

Dilger, W. H., Tadros, G., and Chebib, J. (1990). Bending moments in cantilever slabs. Development in short and medium span bridges. 90 (1), pp. 265-276.

https://wiki.csiamerica.com/display/kb/Shell. (n.d.).

Jaeger, L. G., and Bakht, B. (1990). Rationalization of simplified methods of analyzing cantilever slabs. Canadian Journal of Civil Engineering, 17(5), pp. 865-867.

Jajjawi, M. (2014). Simplified method of analysis for adjucent precast :"deck free" concrete box beams used in accelerated bridge construction ( MASc thesis) Ryerson University, Toronto, ON. 
Khederzadeh, H., and Sennah, K. (2014). Development of emprical expressions for the design transverse moment and tensile force in bridge cantilever deck slabs dueto horizontal railing loads. International Structural Specialty Conference CSCE 2014. Halifax, Nova Scotia pp. 1-10

Logan, D. L. (2012). A first course in the finite elemnet method, Fifth edition. Stamford, USA: Cengage learning.

Micovic, I. (2016). Development of empirical equations and tables for the design of bridge cantilever deck slab under CHBDC truck loading. Ryerson University, Toronto, Ontario, Canada.

Mufti, A. A., Bakht, B., and Jaeger, L. G. (1993). Moments in deck slabs due to cantilever loads. Journal of structural engineering New York, N.Y., 119(6), 1761-1777.

Munoz, J. V. (2016). Bridge edge beams LCCA and structural analysis for the evaluation of new concepts (Thesis). Stockholm, Sweden: KTH Royal Institute of Technology.

Parr, S. (1993). Analysis and Design of Deck Slab Overhangs of Girder Bridges MASc dissertation, University of Toronto, Totonto, Ontario, Canada.

Sawko, F., and Mills, J. (1971). Design of cantilever slabs for spine beam bridges. Proceeding of the Cardiff Conference. London: Crosby Lockwood and Son Ltd.

Xiao, Y. (1997). Analysis of Reinfirced Concrete Bridge Decksnunder the Live Truck Loads MASc dissertation, Technical University of Nova Scotia, Canada. 